*ak RMIS View/Frint Document Cover Sheet tow

This document was retrieved from the Documentation and Records Manaqement (DRM) ISEARCH System. It is intended for Information only and may not be the most recent or updated version. Contact a Document Service Center (see Hanford Info for locations) if you need additional retrieval information.

Accession \#: D196005891

Document \#: SD-MP-SRID-001

Title/Desc:

HLW STORAGE TANKS 242A EVAPORATOR STANDARDS REQUIREMENT IDENTIFICATION DOCUMENT

Pages: 635 


\section{(n)}

2. To: (Receiving Organization) Regmts Mgmt/Communications

5. Proj./Prog./Dept./Div.: Tank Farm Trans Proj / TWRS 8. Originator Remarks:

This TF S/RID was initially prepared as WHC-EP-750, Rev. 4 and is now being controlled as a supporting document. KEY WORDS: S/RID, WHC-EP-750.

\author{
3. From: (Originating Organization) \\ Reamts Mgmt/Communications \\ 6. Cog. Engr.: \\ E. Biebesheimer
}

4. Related EDT No.:
na
7. Purchase Order No.:
na

9. Equip./Component No.:

na

10. System/Bldg./Facility: na/na/TF Trans. Proj.

12. Major Assm. Dwg. No.:

na

This document is awaiting DOE-RL Approval. It is being released at this time to aid in maintaining configuration control. The Tank Farm S/RID is available electronically on the HLAN based Procedure Information.
13. Permit/Permit Application No.: na

14. Required Response Date:

na

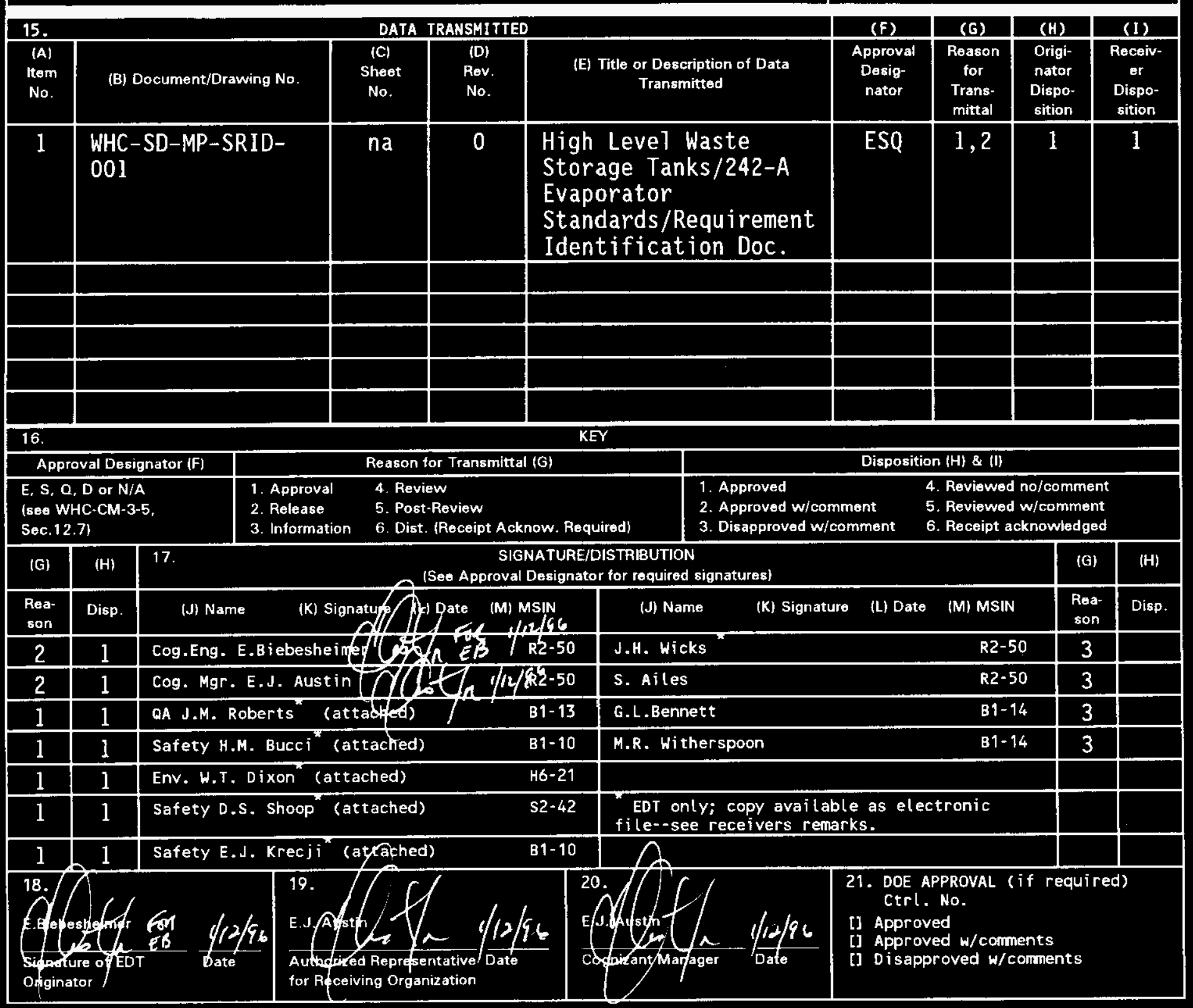




\section{WESTINGHOUSE HANFORD COMPANY}

\section{REQUIREMINIS}

\section{IDENIIAICAIION}

\section{DOCUMENT}

\section{EACILIT::}

High Level Wäste Storage Tank Farims/242-A Evaporator

\section{Functipn
SIGNATURES}

FACILITY FXPERT:

G. L. Greene $\quad S / 5 / 65$
RESPONSIBLE MNYCTONAC AREATRANAGER:

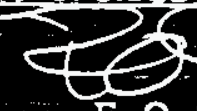

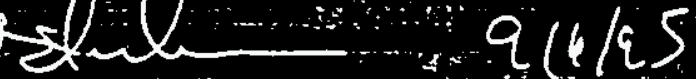

F. O. Strankman -................. Date

INTER PRETATTVE AUTHORITY CONCURR ENCE:

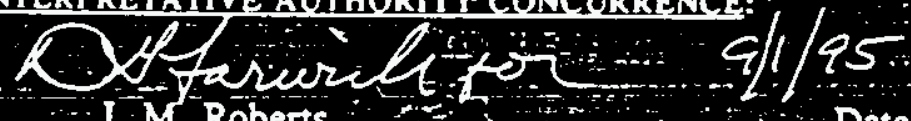
J. M. Roberts

EDT NO, 614254

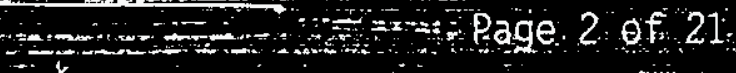




\section{STANDARDS}

\section{REQUIREMENTS}

\section{IDENTIFICATION}

\section{DOCUMENT}

FACILITY:

High Level Waste Storage Tank Farms/242-A Evaporator
EUNCTIONAL AREA:

Configuration Management
FACILITY EXPERT:

Richead R. Streboncy
RESPONSIBLE FUNCTIONAL AREA MANAGER:

w. c. Miller NTERPRETATYV AUTHORIT CONCURRENCE:

$9 / 33 / 95$

EDT No. 614254

$\therefore=8 \quad$ Page 4 of 21

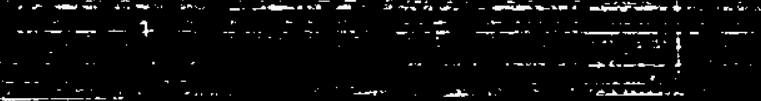




\section{WESTINGHOUSE HANFORD COMPANY}

\section{STANDARDS}

\section{REQUIREMENTS}

\section{IDENTIFICATION}

FACILITY:

High Level Waste Storage Tank Farms/242-A Evaporator

\section{DOCUMENT}

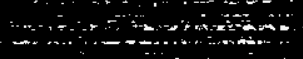

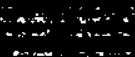

$=0$

$+2$
FUNCTIONAL AREA:

Training and Qualification

\section{SIGNATURES}

FACILITY EXPERT:

SSLating Ong 3i,1995

B. S. Darling

Date
RESPONSIBLE FUNCTIONAL AREA MANAGER:

$$
\text { T. Morton }
$$

ININXPRER ATIYE AOTHORITY CONCURRENCE:

\section{1}

NQSlow

R. G. STocum

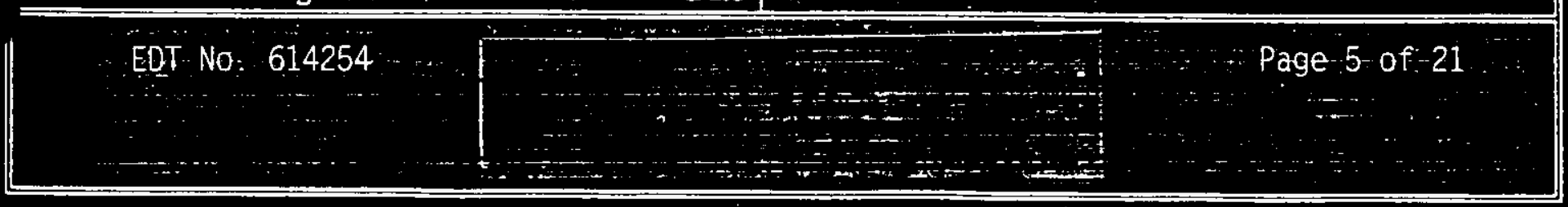




\section{WESTINGHOUSE HANFORD COMPANY}

\section{STANDARDS}

\section{REQUIREMENTS}

\section{IDENTIFICATION}

\section{DOCUMENT}

FACILITY:

High Level Waste Storage Tank Farms/242-A Evaporator
EUNCTIONAL AREA:

Emergency Management

\section{SIGNATURES}

\section{FACILITY EXPERT:}

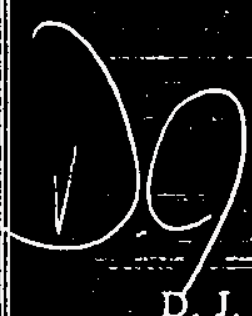

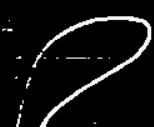

Guile 9-1-95
RESPONSIBLE FUNCTIONAL AREA MANAGER:

T. Morton

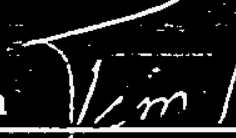

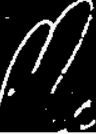

1.71 Date

INTERPRETATIVE AUTOORIO CONCURRENCE:

$7 \%$ M.E. hevan Date

EDT No.- 614254 


\section{WESTINGHOUSE HANFORD COMPANY}

\section{STANDARDS}

\section{REQUIREMENTS}

\section{IDENTIFICATION}

\section{DOCUMENT}

EACILITY:

High Level Waste Storage Tank Farms/242-A Evaporator

\section{SIGNATURES}

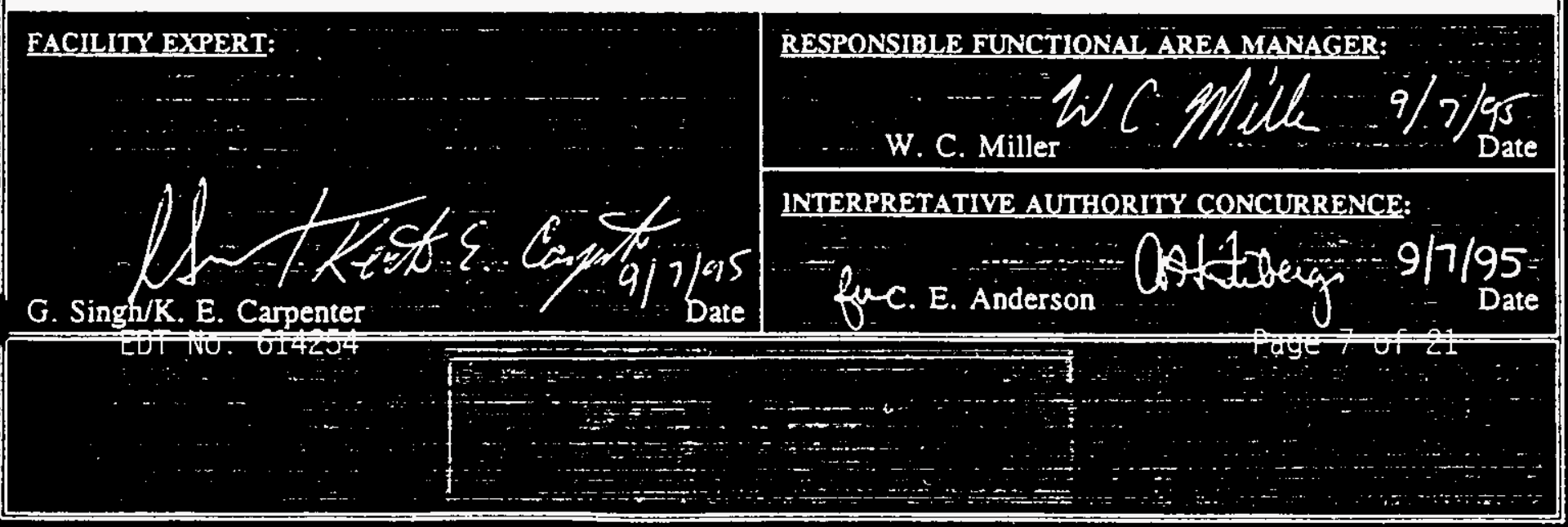




\section{WESTINGHOUSE HANFORD COMPANY}

\section{STANDARDS}

\section{REQUIREMENTS}

\section{IDENTIFICATION}

DOCUMENI

FACILITY: $:$

High Level Waste Storage Tank Farims/242-A Evaporator
FUNCTIONAL AREA:

Construction Program

SIGNATURES

FACILITY EXPERT:

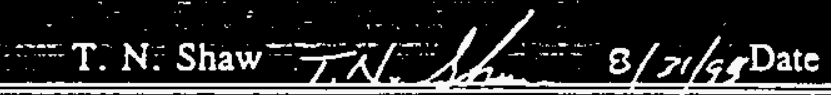

RESPONSIBLE FUNCTIONAL AREA MANAGER:

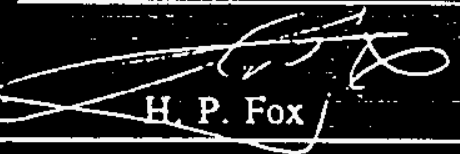

$8 \cdot 31.95$ Date INTERPRET AOTYE AUHHORIYY CONCURRENCE:

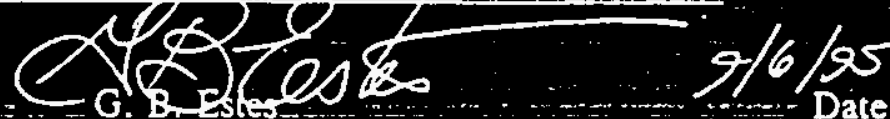

EDT NO 614254

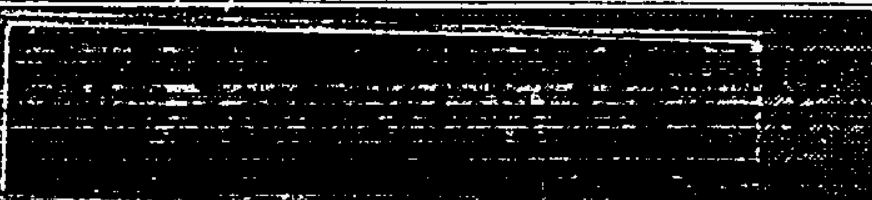




\section{WESTINGHOUSE HANFORD COMPANY}

\section{STANDARDS}

\section{REQUIREMENTS}

\section{IDENTIFICATION}

\begin{tabular}{c} 
FACHITY; \\
\hline HIGH LEVEL WASTE STORAGE \\
TANK FARMST242-A \\
EVAPORATOR
\end{tabular}

\section{DOCUMENT}

FUNCTIONAL AREA:

\section{Operations}

\section{SIGNATURES}

\section{AUTHOR:}

C. Widhalm

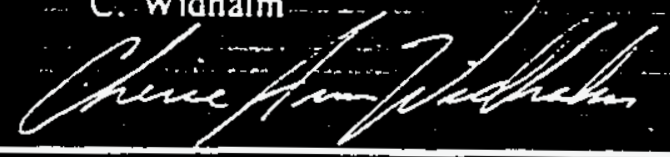

Date $3 / 30 / 9$

INTERPRETATIVE AUTHORITY CONCURRENCE:

M. D. Jackson /7 Q Zacken 9/Date FUCTONAL AREA OYWOS:

R. Ni

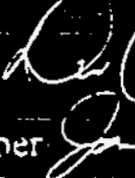

D. Reher

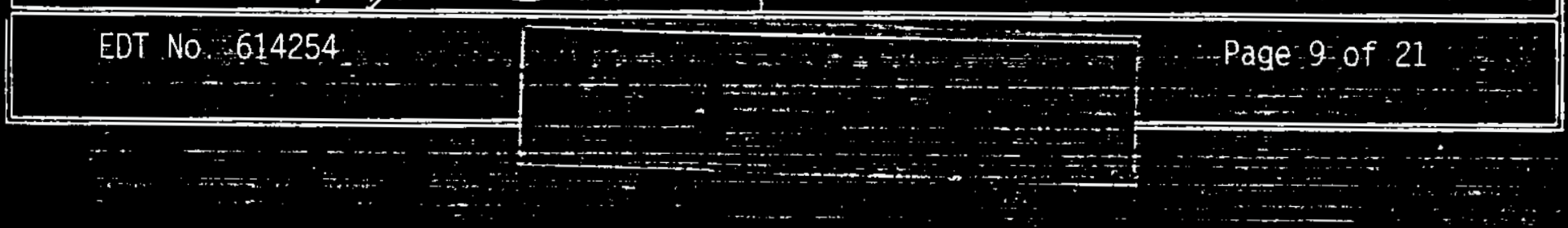




\section{WESTINGHOUSE HANFORD COMPANY}

\section{STANDARDS}

\section{REQUIREMENTS}

\section{IDENTIFICATION}

\section{DOCUMENT}

EACILITY:

High Level Waste Storage

Tank Farms/242-A Evaporator
FUNCTIONAL AREA:

Maintenance

\section{SIGNATURES}

FACILITY EXPERT:

WaOkerinch D. P. Kerwick EOT NO. 614254

$$
9 / 1 / 95
$$
. Date
RESPONSIBLE FUNCTIONAL AREA MANAGER:

9.4 .45 Date

H. P.Eex $>2$

INTERPRETATIVE AUTHOR TYY CONCURRENCE:

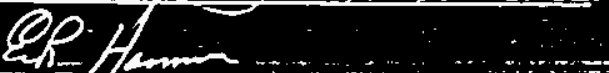

E. R. Hamm

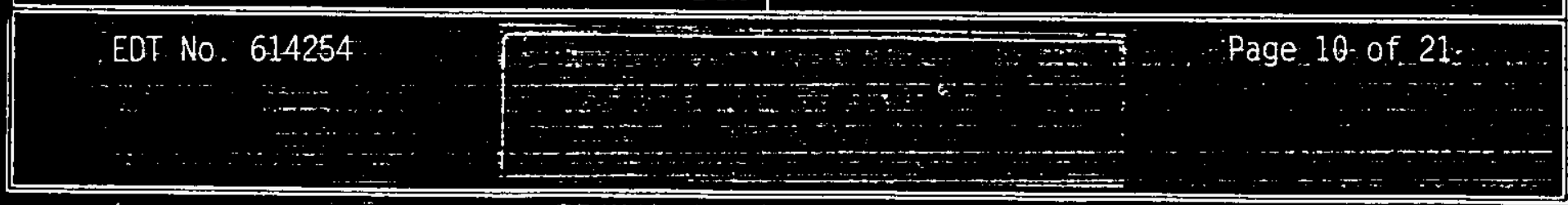




\section{WESTINGHOUSE HANFORD COMPANY}

\section{STANDARDS}

\section{REQUIREMENIS}

\section{IDENIIFICAIION}

\section{DOCUMENI}

FACILITY:

High Level Waste Storage Tank Farms/242-A Evaporator
DUNCTIONAL AREA:

Radiation Protection.

\section{SIGNATURES}

EACILITY EXPERT:

MGuimim $T_{5}$ 8-29-95

Antt medley s/29/15 D. J. Bracamontes/ D. W. Medley Date
RPSPONSIBLE FUNCTONAL AREA MANAGBR:

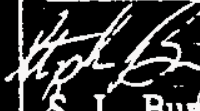

S. L. Buop/ C. L. Caldwell

INIERPRETATIVE AUTHOORITY CONCURRENCE:

$8 / 30 / 95$
$8-29-95$ Date

CDT No 614254 -




\section{WESTINGHOUSE HANFORD COMPANY}

\section{STANDARDS}

\section{REQUIREMENIS}

\section{IDENIIICATION}

\section{DOCUMENT}

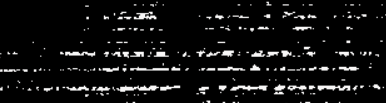

FACILITY:

FUNCTIONAL AREA:

High Level Waste-Storage

Tank Farms/242-A Evaporator $\therefore= \pm=$

SIGNATURES

\begin{tabular}{|c|c|}
\hline \multirow[t]{2}{*}{$\mathrm{FACIL}$} & RESPONSIBLS FUNCTIONAL AREA MANAGER: \\
\hline & $\begin{array}{l}\text { INTEkPRERATIVE AUTHORITY CONCURRENCE: } \\
\text { H/Y Gucec } \\
\text { H. M. Bucci }\end{array}$ \\
\hline ard & $=2$ page 12 of 21 \\
\hline
\end{tabular}




\section{WESTINGHOUSE HANFORD COMPANY}

\section{STANDARDS}

\section{REQUIREMENTS}

\section{IDENTIFICATION}

\section{DOCUMENT}

FACILITY:

HIGH LEVEL WASTE STORAGE

TANK FARMS/242-A EVAPORATOR

\section{FNCTIONAL AREA:}

Environmental Restoration

\section{SIGNATURES}

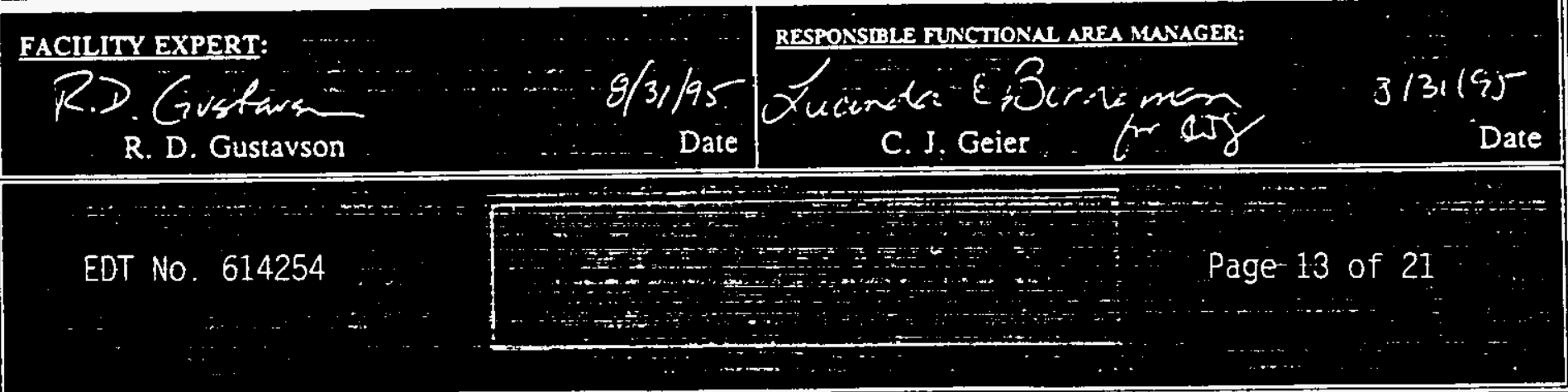




\section{WESTINGHOUSE HANFORD COMPANY}

\section{STANDARDS}

REQUIREMENTS

IDENTIFICATION

\section{DOCUMENT}

FACILITY:

HIGH LEVEL. WASTE STORAGE

TANK FARMS/242-A

EVAPORATOR
FUNCTIONAL ARSA:

Decontamination \& Decommissioning

\section{SIGNATURES}

\section{FACILITY EXPERT:}

R. D. Gusitur.

R. D. Gustavson

$9 / 31 / 95$

RESPOLSTRLE RXCTONAL AREA MUVAGER:

Xucunda 2$\}$ C. J. Geier

$e^{2}: \pi \cdot \pi$

$\pi / 3 i / 5 J$

Date

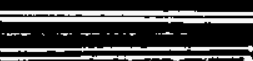

EDT. No. 614254

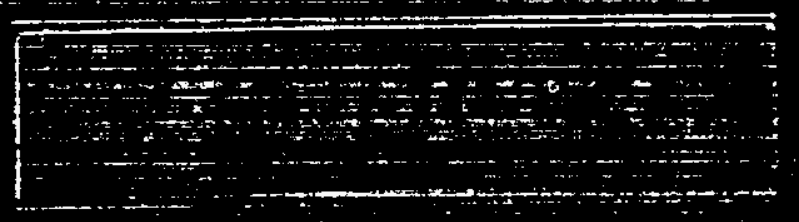

Page 14 of 21 


\section{WESTINGHOUSE HANFORD COMPANY}

\section{SIANDARDS}

\section{REQUIREMINIS}

\section{IDENTIFICAMON}

\section{DOCOMIATI:}

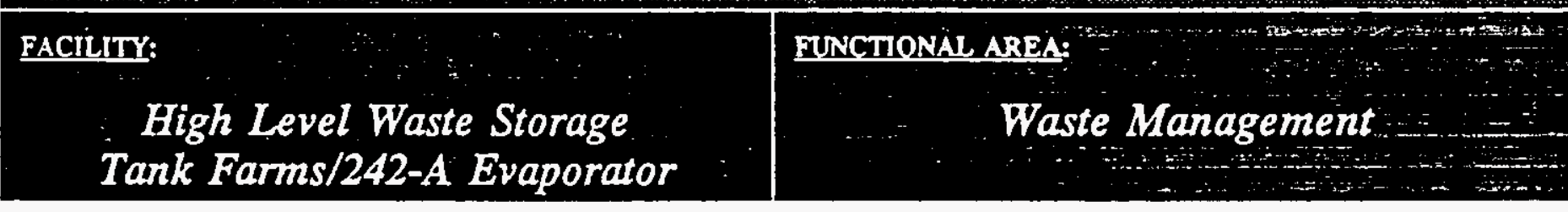

\section{SIGNATURES}

$$
+i=
$$

FACILITY EXPERT:

Q Eornemion $9 / 565$ gEs E. E. Borneman Date
RESPONSIBLE FUNCTIONAL AREA MANAGER:

c. J. Geier 7 - $915 / 95$ INTERPRETATIVS AUTIORITY CONCURRENCE:

Wuttamises
W. H. Hamilon, or 253 10. 614254 


\section{WESTINGHOUSE HANFORD COMPANY}

\section{STANDARDS}

\section{REQUIREMENTS}

\section{IDENTIFICATION}

\section{DOCUMENT}

FACILITY:

HIGH LEVEL WASTE STORAGE TANK FARMS/242-A EVAPORATOR
EUNCTIONAL AREA:

Research \& Development \& Experimental Activities

\section{SIGNATURES}

Facility Expert

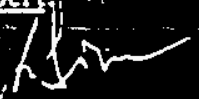

G. Singh $\therefore$

$-\cdots, \cdots$,

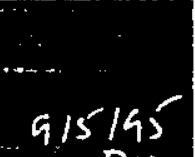

PSSPONSTBLE RUNCTIONAL, AREA MANAGSR:

$$
4 C \ddot{P} / \text { dh }
$$

W. C. Miller Dare

EDT No 614254

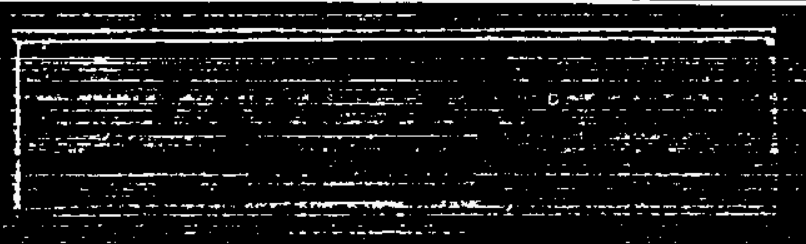




\section{WESTINGHOUSE HANFORD COMPANY}

\section{REQUIREMENTS}

\section{IDENTIFICATION}

\section{DOCUMENT}

FACILITY:

High Level Waste Storage Tank Farms/242-A Evaporator
FUNCTIONAL AREA:

Nuclear Safety

\section{SIGNATURES}

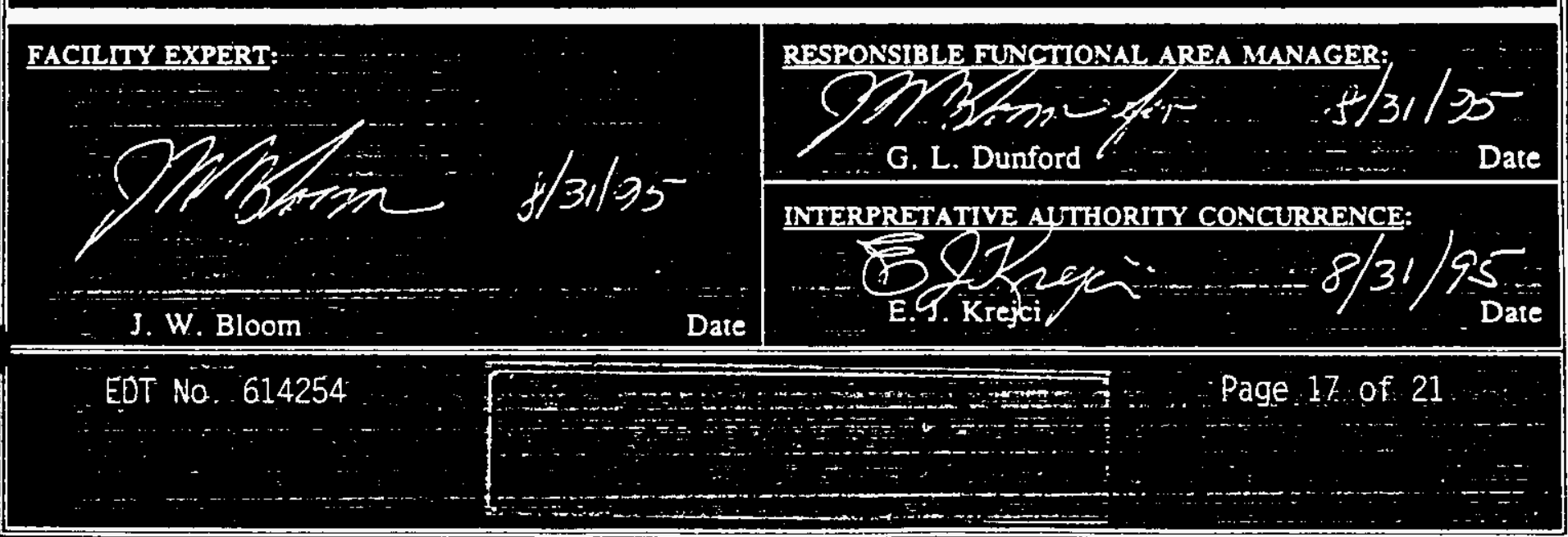




\section{WESTINGHOUSE HANFORD COMPANY}

\section{REOUTRIVINES}

\section{IDENTHACATON}

FACILITY:

High Level Waste Storage Tank Farms/242-A Evaporator

\section{- SIGNATURES}

FACILITY EXPERT:

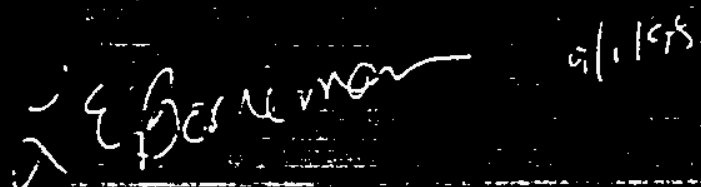

$\because$ L. E. Borneman
FUNCTIONAL AREA:

Environmental Protection

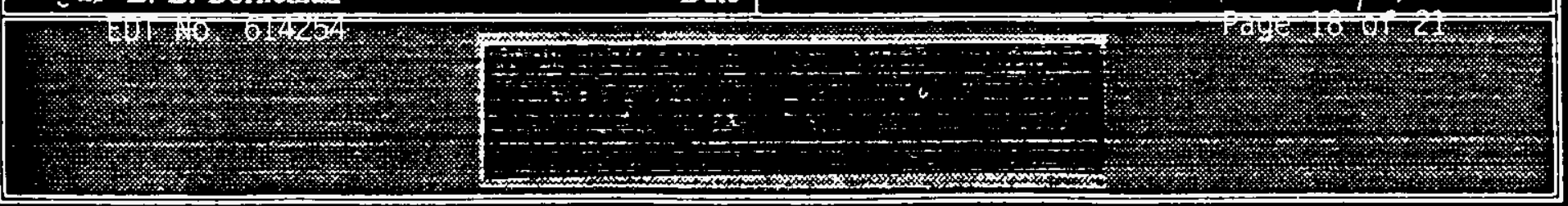




\section{WESTINGHOUSE HANFORD COMPANY}

\section{STANDARDS}

\section{REQUIREMENTS}

\section{IDENTIFICATION}

\section{DOCUMENT}

FACILITY:

High Level Waste Storage Tank Farms/242-A Evaporator
FUNCTIONAL AREA:

Occupational Safety

\& Health

\section{SIGNATURES}

FACILITY EXPERT:

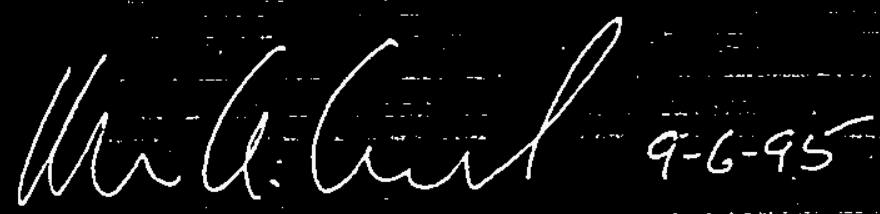

RESPONSIBLE FUNCTIONAL AREA MANAGER:

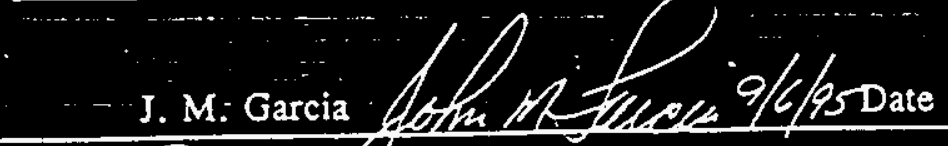
INTER RREAATTE AUIGERITY CONCURRENCE: Whape $9 / 6 / 95 \ldots$ Date X. Shoup $9 / 6 / 95$ Shape $9 / 6 / 95$ Date

E. R. Hewitt Date

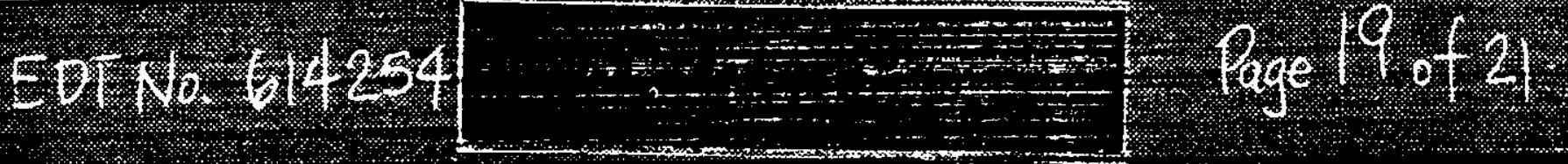




\section{WESTINGHOUSE HANFORD COMPANY}

\section{STANDARDS}

\section{REQUIREMTENTS}

\section{IDENTIFICATION}

DOCUMENT

FACILITY:

High Level Waste Storage

Tank Farms/242-A Evaporator
EINCIONAL AREA:

Packaging \& Transportation

\section{SIGNATURES}

\section{FACILITY EXPERT:}

Bail G Hapum 9/5/95 P. A. Gagnon
RESPONSIBLE FUNCTIONAL AREA MANAGER:

c. J. Geier (12/4ha: $9 / 5 / 95$ Date INTERPRETATIVE AUTHÓRITY CONCURRENCE: 


\section{WESTINGHOUSE HANFORD COMPANY}

\section{STLAVDARDS}

\section{REQUIREMTENES}

\section{IDENTHICAMON}

\section{DOCUMTENT}

\section{FAcility:}

High Level Waste Storage Tank Farms/242-A Evaporator
DUNCIIONAL AREA:

Safeguards and Security

\section{SIGNATURES}

$$
=
$$

FACILITY DXPPRT:
G. L. Greene

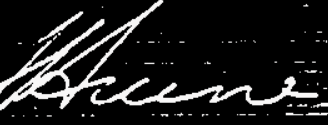

07110.614254

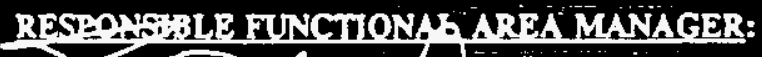

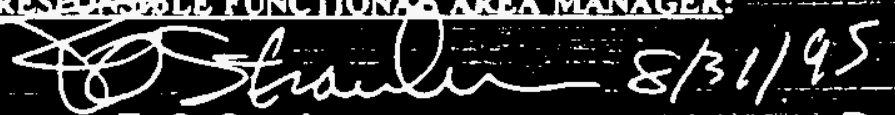

F. O. Strankman

Date

WIIPPRETATOL AIMHORITY CONCURRSNCF:

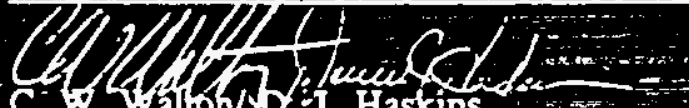

Date $8 x$ is Date

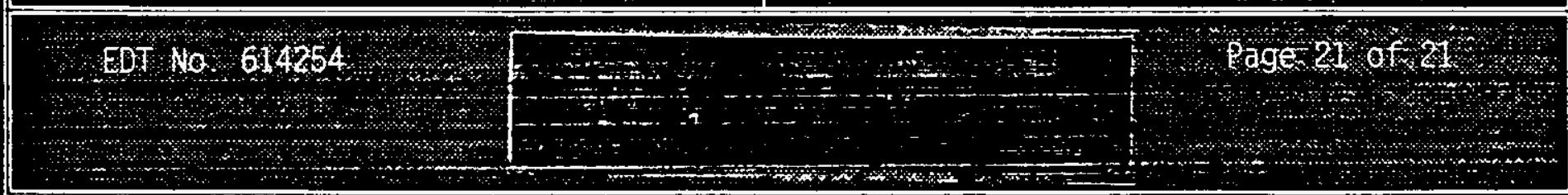




\title{
High Level Waste Storage Tanks/242-A Evaporator Standards/Requirement Identification Document
}

\author{
E. Biebesheimer \\ Westinghouse Hanford Company, Richland, WA 99352 \\ U.S. Department of Energy Contract DE-AC06-87RL10930
}

$\begin{array}{llll}\text { EDT/ECN: } & 614254 & \text { UC: } 2030 \\ \text { Org Code: } & 77830 & \text { Charge Code: } & \text { N1561 } \\ \text { B\&R Code: } & \text { EW3120071 } & \text { Tota1 Pages: } & 609\end{array}$

Key Words: WHC-EP-750, S/RID, Standards/Requirement Identification Document.

Abstract: This document, the Standards/Requirements Identification Document (S/RID) for the subject facility, represents the necessary and sufficient requirements to provide an adequate level of protection of the worker, public health and safety, and the environment. It lists those source documents from which requirements were extracted, and those requirements documents considered, but from which no requirements were taken. Documents considered as source documents included State and Federal Regulations, DOE Orders, and DOE Standards.

TRADEMARK DISCLAIMER. Reference herein to any specific comercial product, process, or service by trade name, trademark, manufacturer, or otherwise, does not necessarily constitute or imply its endorsement, recommendation, or favoring by the United States Government or any agency thereof or its contractors or subcontractors.

Printed in the United States of America. To obtain copies of this document, contact: WHC/BCS Document Control Services, P.O. Box 1970, Mailstop H6-08, Richland WA 99352, Phone (509) 372-2420; Fax (509) 376-4989.
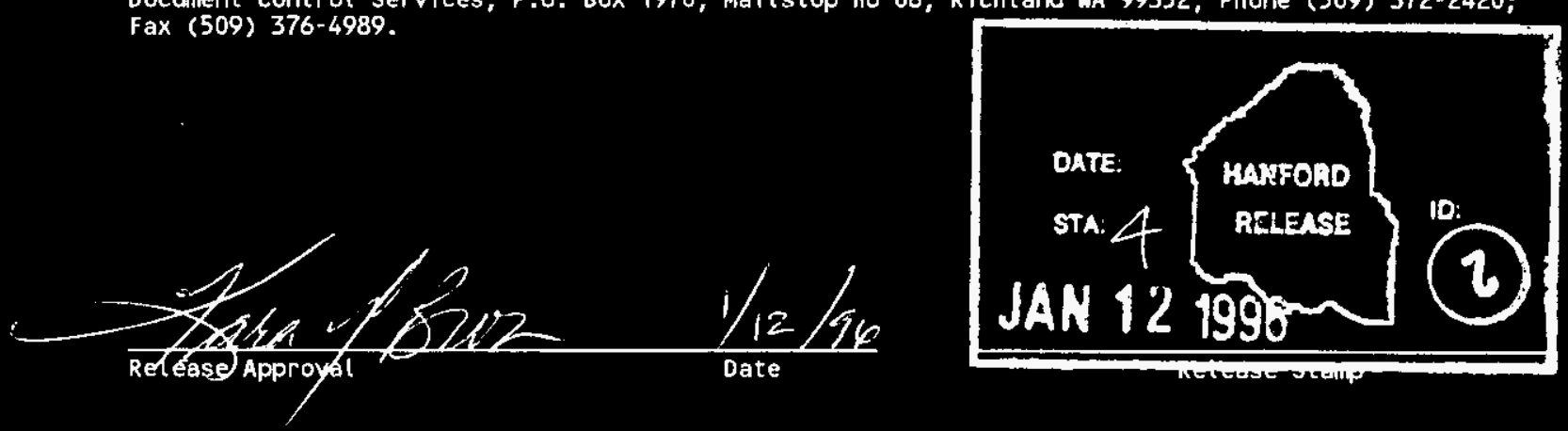

Approved for Public Release 
WHC-SD-MP-SRID-001, Rev. 0

Page $i \mathrm{i}$ of $i \mathrm{i}$

\section{CONTENTS}

The High-Level Waste Storage Tank Farms/242-A Evaporator Standards/Requirements Identification Document (S/RID) is comprised of twenty functional areas. Three of the twenty functional areas were evaluated as having functional area nonapplicability. Each functional area follows as a separate chapter, either containing the S/RID or a justification for nonapplicability.

This S/RID was initially prepared as an external procedure, (WHC-EP-750, Rev 4). Prior to DOE-RL approval, the document including DOE-RL comments, is being released as a supporting document to aid in configuration control.

The twenty functional areas listed below follow as chapters.

\begin{tabular}{|c|c|}
\hline $\begin{array}{l}\text { Chapter } \\
1 . \\
2 . \\
3 . \\
4 . \\
5 . \\
6 . \\
7 . \\
8 . \\
9 . \\
10 . \\
11 . \\
12 . \\
13 . \\
14 . \\
15 . \\
16 . \\
17 . \\
18 . \\
19 . \\
20 .\end{array}$ & $\begin{array}{l}\text { Functional Area } \\
\text { Management Systems } \\
\text { Quality Assurance } \\
\text { Configuration Management } \\
\text { Training and Qual ification } \\
\text { Emergency Preparedness } \\
\text { Safeguards \& Security } \\
\text { Engineering Design } \\
\text { Construction } \\
\text { Operations } \\
\text { Maintenance } \\
\text { Radiation Protection } \\
\text { Fire Protection } \\
\text { Packaging \& Transportation } \\
\text { Environmental Restoration } \\
\text { Decontamination \& Decommissioning } \\
\text { Waste Management } \\
\text { R\&D/Experimenttal Activities } \\
\text { Nuclear Safety } \\
\text { Occupational Safety and Health } \\
\text { Environmental Protection }\end{array}$ \\
\hline
\end{tabular}




\section{TABLE OF CONTENTS}

1.1 .1

1.1 .2

1.1 .3

1.1 .4

1.2

1.2.1

1.2 .2

1.2.3

1.3

1.3.1

1.3.2

1.3.3

1.3.4

1.4

1.5

1.6

1.6.1

1.6 .2

1.6 .3

1.6 .4

Policies, Plans, and Procedures ................. 3

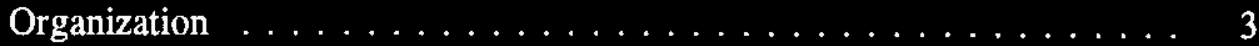

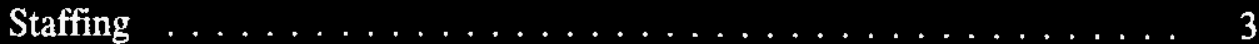

Training and Qualification $\ldots \ldots \ldots \ldots \ldots \ldots$

POLICY AND PROCEDURES

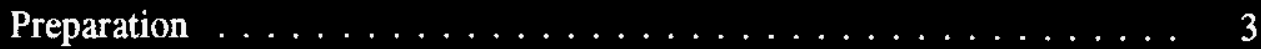

Review and Approval ................. 6

Control and Maintenance . . . . . . . . . . . . . 7

ISSUES MANAGEMENT $\ldots \ldots \ldots \ldots \ldots \ldots \ldots \ldots$

Issue Identification $\ldots \ldots \ldots \ldots \ldots \ldots \ldots$

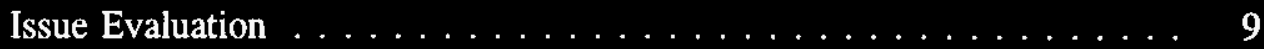

Root Cause and Corrective Action Analysis . . . . . . . . . . . 10

Tracking and Trending ................... 10

COMPLIANCE MANAGEMENT .................. 11

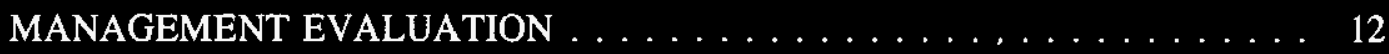

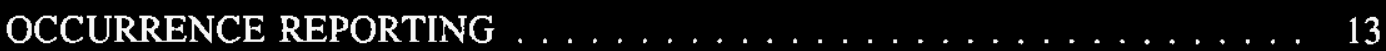

Identification and Categorization $\ldots \ldots \ldots \ldots \ldots$

Notification and Reporting . . . . . . . . . . . . . . . . . 14

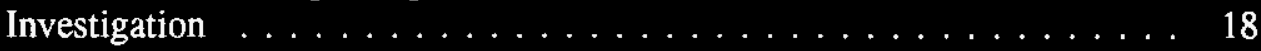

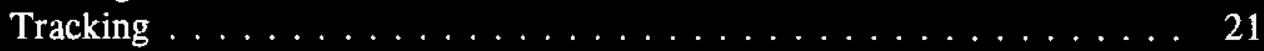

OPERATIONAL READINESS REVIEWS $\ldots \ldots \ldots \ldots \ldots \ldots \ldots$

Approach and Organization $\ldots \ldots \ldots \ldots \ldots \ldots \ldots \ldots \ldots \ldots \ldots$

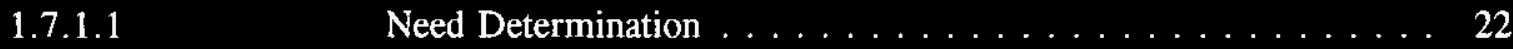

1.7.1.2 Team Organization and Responsibilities . . . . . . . . . . 24

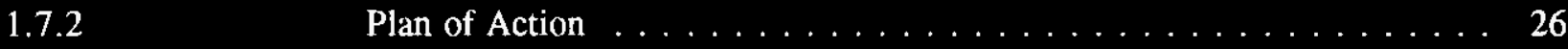

1.7.2.1 Operational Readiness Reviews $\ldots \ldots \ldots \ldots$

1.7.2.1.1 Implementation Plan . . . . . . . . . . 30

1.7.2.1.2 Implementation $\ldots \ldots \ldots \ldots \ldots \ldots \ldots \ldots \ldots$

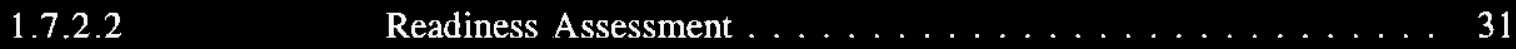


1.7 .3

1.7 .4

1.8

1.8 .1

1.8.1.1

1.8.1.2

1.8.1.3

1.8.2

1.8.2.1

1.8.2.2
Tracking and Closure of Findings $\ldots \ldots \ldots \ldots \ldots \ldots \ldots \ldots$

Documentation ............................. 34

DOCUMENT AND DATABASE CONTROL - RECORDS MANAGEMENT . 35

Control ........................... 35

Document Control Systems $\ldots \ldots \ldots \ldots \ldots \ldots \ldots$

Computer Use $\ldots \ldots \ldots \ldots \ldots \ldots \ldots \ldots \ldots \ldots \ldots$

Records Management Planning $\ldots \ldots \ldots \ldots \ldots$

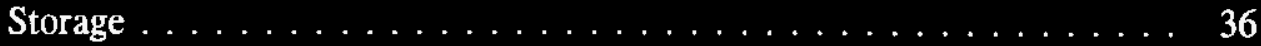

Controls and Facilities for Records Storage . . . . . . . . . . 36

Controls for Records Retrieval . . . . . . . . . . . . 38

Retention and Disposal $\ldots \ldots \ldots \ldots \ldots \ldots \ldots$

Quality Assurance ... . . . . . . . . . . . . . . . . . . 41

1.10 .2

Configuration Management $\ldots \ldots \ldots \ldots \ldots \ldots \ldots$

1.10 .3

Training and Qualification ...................... 41

1.10 .4

Emergency Management . . . . . . . . . . . . . . . . . . . 42

1.10 .5

1.10 .6

Operations . . . . . . . . . . . . . . . . . . . . 42

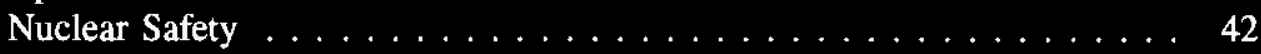




\subsection{MANAGEMENT SYSTEMS}

\section{INTRODUCTION}

A Standards/Requirements Identification Document (S/RID) sets forth the Environmental Safety and Health (ES\&H) standards/requirements. This S/RID is applicable to the appropriate life cycle phases of design, construction, operation, and preparation for decommissioning for each of the categories of facilities addressed in Revision 5 of the Department of Energy Implementation Plan for the Defense Nuclear Facilities Safety Board (DNFSB) Recommendation 90-2. This Recommendation calls for the strengthening of DOE weapons complex activities through the identification and application of relevant DOE Orders, regulations, industry codes/standards, industry guidance documents and, as appropriate, good industry practices. These standards/requirements are adequate to ensure protection of the health and safety of workers, the public, and the environment.

The Tank Farms S/RID contains standards/requirements that are necessary for safe operation of the Tank Farms and its associated facilities, and that are the direct responsibility of the specific facility manager. The Management Systems Program defined in this document is described in general accordance with the Environment, Safety, and Health Configuration Guide, Revision 0, dated July 30, 1993, and is presented in program elements and subelements. The specific DOE Orders, regulations, industry codes/standards, guidance documents and good industry practices that serve as the basis for each element/subelement are identified and aligned with each subelement. Additional subelements and sub-subelements were added to the basic format for further clarification and definition. A subelement was added to address Issue Evaluation and was assigned subelement number 1.3.2. The existing subelements, Root Cause and Corrective Action Analysis and Tracking and Trending were renumbered 1.3.3 and 1.3.4 respectively. Subelement 1.7.1, Approach and Organization, was further enhanced with the addition of the following subelements: Need Determination (1.7.1.1), and Team Organization and Responsibilities (1.7.1.2). Subelement 1.7.2, Plan of Action, was further clarified with the addition of the following subelements: Operational Readiness Reviews (1.7.2.1), and Readiness Assessment (1.7.2.2). Subelement 1.8.1, Control, was further enhanced with the addition of the following sub-subelements: Document Control Systems (1.8.1.1), Computer Use (1.8.1.2), and Records Management Planning (1.8.1.3). Subelement 1.8.2, Storage was further clarified with the addition of the following sub-subelements: Controls and Facilities for Records Storage (1.8.2.1), and Controls for Records Retrieval (1.8.2.2). Subelement 1.8.3, Retention and Disposal, was further enhanced with the addition of the following sub-subelements: Controls for Record Retention and Storage Media (1.8.3.1), and Controls for Authorized Records Disposal (1.8.3.2). A new subelement addressing Lessons Learned was added as number 1.9. Key interfaces was renumbered as 1.10. A reference section was added as Element 1.11.

This S/RID contains only those requirements that Tank Farms personnel are clearly responsible to satisfy. Other requirements that are applicable to Tank Farms, but are satisfied by others, are defined in the Westinghouse Hanford Company (WHC) Level S/RID. For application in this S/RID, the words "shall" and "should" in requirements statements both indicate mandatory compliance. The Key interface information contained in the Functional Area documents is provided for general recognition and understanding and is not considered to contain prescriptive requirements. Additionally, some of the requirements cited in this document are intentionally duplicated in the corresponding WHC S/RID. This was necessary to address required implementation responsibilities occurring at both the company and facility levels. 
- Some source documents developed for a specific functional area, such as Operations, contain requirements that can be usefully applied to other functional areas for which corresponding requirements are not available or as well defined. Where requirements are cited in this S/RID from such source documents, application is intended for all other functional areas unless superseded by a program specific requirement or unless the topic being addressed is inappropriate. Those requirements which apply strictly to a given functional area, such as Operations or Maintenance will be cited in the appropriate functional area.' This approach permits broad application of useful requirements and enhances the level of consistency between functional areas.

\section{SCOPE}

This S/RID applies to the Tank Waste Remediation Systems (TWRS) Organization which includes the following:

- East Tank Farm Transition Project

- West Tank Farm Transition Project

Evaporator Project

- Interim Stabilization Project

- Characterization Sampling Project (Excluding the Labs)

The near-term mission of TWRS is to store, treat, and immobilize the highly radioactive Hanford Site Waste.

The scope of this functional area is the collection of those requirements to be followed by site organization management to develop a program of commitment to ES\&H in a formal, controlled manner. 
1.1

$\underline{1.1 .1}$

$\underline{1.1 .2}$

$\underline{1.1 .3}$

$\underline{1.1 .4}$

1.2

$\underline{1.2 .1}$

MANAGEMENT AND ADMINISTRATION

Policies, Plans, and Procedures

REQUIREMENT SOURCE: 10CFR830 Part 120(c)(2)(i)

"Work Processes. Work shall be performed to established technical standards and administrative controls using approved instructions, procedures, or other appropriate means. Items shall be identified and controlled to ensure their proper use. Items shall be maintained to prevent their damage, loss, or deterioration. Equipment used for process monitoring or data collection shall be calibrated and maintained."

\section{Organization}

\section{REQUIREMENT SOURCE: 10CFR830 Part 120(c)(1)(i)}

"Program. A written QAP shall be developed, implemented, and maintained. The QAP shall describe the organizational structure, functional responsibilities, levels of authority, and interfaces for those managing, performing, and assessing the work. The QAP shall describe management processes, including planning, scheduling, and resource considerations."

\section{REQUIREMENT SOURCE: DOE5480.19(920518) Chapter I, Section C.4}

"Workers and their supervisors should be held accountable for operating performance. Personnel involved in significant or frequent violations of operating practices should be counseled, retrained, and disciplined, as appropriate. Supervisor performance appraisals and promotions should include an assessment of operating performance."

\section{Staffing}

The primary requirement source document for the qualification aspects of personnel selection, including background, experience, and education, is DOE Order $5480.20 \mathrm{~A}$, Personnel Selection, Qualification, Training, and Staffing Requirements at DOE Reactor and Non-Reactor Nuclear Facilities. General and detailed requirements from this and other source document applicable to personnel selection and staffing are identified in the Training and Qualification (T\&Q) Functional Area.

\section{Training and Oualification}

The Requirements for this subelement are included in the Training and Qualification Functional Area.

POLICY AND PROCEDURES

\section{Preparation}

\section{REQUIREMENT SOURCE: 10CFR830 Part 120(c)(1)(iv)}

"Documents and Records.

Documents shall be prepared, reviewed, approved, issued, used, and revised to prescribe processes, specify requirements, or establish design. Records shall be specified, prepared, reviewed, approved, and maintained." 


\section{REQUIREMENT SOURCE: DOE4330.4B Chapter II, Section 6.3.6, Paragraph 1}

Author's Note: Only Sentence 6 applies.

"Responsibilities for procedure program administration should be clearly defined. Procedures should be controlled in accordance with facility administrative requirements. All procedures should be periodically reviewed (e.g., every 2 years or prior to use for infrequently used procedures) for changes affecting content (such as reference material revisions, permanent incorporation of changes, incorporation of industry and in-house experience) and for philosophy and format enhancements and human-factors considerations. Checklists for the review should be utilized to ensure the scope and depth of the review is consistent and adequate. Procedure revisions should receive the same review and approval as new procedures as described in Paragraphs 6.3.2 through 6.3.4 above, with the extent of these reviews varying dependent upon the extent of the revision. A method should exist to ensure that technical specification and other commitments are not inadvertently changed or deleted in the process of revising procedures."

\section{REQUIREMENT SOURCE: DOE5480.19 Chapter XVI, Section C.2.b}

"Procedures should incorporate appropriate information from applicable source documents, such as the facility design documents, safety analysis documents, and vendor technical manuals."

\section{REQUIREMENT SOURCE: DOE5480.19(920518) Chapter XVI, Section C.1,Para 1 and 2 , Sent 1 thru 3}

"To ensure consistency among operations procedures, the methods for developing new procedures, including procedure formats, should be clearly defined. Administrative procedures and/or writers' guides should direct the development and review process for procedures.

Procedures should be developed for all anticipated operations, evolutions, tests, and abnormal or emergency situations. Annunciator/alarm response procedures that guide the operator in verifying abnormal conditions or changes in plant status and provide the appropriate corrective action should be developed for all alarm panels. All procedures should provide administrative and technical direction to conduct the intent of the procedure effectively."

REQUIREMENT SOURCE: DOE5480.19(920518) Chapter XVI, Section C.2.a, Sentence 1

"The scope and applicability of individual procedures should be readily apparent."

\section{REQUIREMENT SOURCE: DOE5480.19(920518) Chapter XVI, Section C.2.a,} Sentence 3

"In addition, to enhance rapid retrieval, emergency procedures should be distinguishable from other procedures."

REQUIREMENT SOURCE: DOE5480.19(920518) Chapter XVI, Section C.2.c, Sentence 1

"Prerequisites and initial conditions should be detailed." 
REQUREMIENT SOURCE: DOE5480.19(920518) Chapter XVI, Section C.2.c, Sentence 3 thru 5

"In addition, any hoses, tools, or other temporary testing equipment should be verified operable, calibrated, or inspected and in good condition where possible, before implementing any test procedure, to ensure that they function as expected during the test. These verifications should be identified in the prerequisite section, with completion sign-offs required. "Hold" points (requiring independent verification and/or approval) should be clearly delineated."

\section{REQUIREMENT SOURCE: DOE5480.19(920518) Chapter XVI, Section C.2.d}

"Definitions used in the procedure should be explained."

REQUIREMENT SOURCE: DOE5480.19(920518) Chapter XVI, Section C.2.e

"Procedures should be easily understood, and actions should be clearly stated."

REQUIREMINT SOURCE: DOE5480.19(920518) Chapter XVI, Section C.2.f

"Procedures should contain only one action per step."

REQUIREMENT SOURCE: DOE5480.19(920518) Chapter XVI, Section C.2.h, Sentence 1

"Warnings, notes, and cautions should be easily identifiable and should not contain action statements."

REQUIREMENT SOURCE: DOE5480.19(920518) Chapter XVI, Section C.2.i, Sentence 1 and 2

"Warnings and cautions should precede the step to which they apply. Warnings, notes, and cautions should appear on the same page as the step to which they apply."

REQUIREMINT SOURCE: DOE5480.19(920518) Chapter XVI, Section C.2.j, First seven words

"Procedures should be technically and administratively accurate"

\section{REQUIREMENT SOURCE: DOE5480.19(920518) Chapter XVI, Section C.2.k}

"Individual sign-offs should be provided for selected critical steps. One sign-off should not be applied to more than one action."

\section{REQUIREMENT SOURCE: DOE5480.19(920518) Chapter XVI, Section C.2.I}

"Limits and/or tolerances for operating parameters should be specified and should be consistent with the readable accuracy of instrumentation. Operators should not be required to perform mental arithmetic to determine if a specified parameter is acceptable." 


\section{REQUIREMENT SOURCE: DOE5480.19(920518) Chapter XVI, Section C.2.m}

"Acceptance criteria for surveillance or test procedures should be easily discerned, including tolerances and units. If calculations are needed to compare data to acceptance criteria, the calculations should be clearly explained."

\section{REQUIREMENT SOURCE: DOE5480.19(920518) Chapter XVI, Section C.2.n,} Sentence 1

"Sequence of procedural steps should conform to the normal or expected operational sequence."

\section{REQUIREMENT SOURCE: DOE5480.19(920518) Chapter XVI, Section C.2.0,} Sentence 1

"Procedures should be developed with consideration for the human-factor aspects of their intended use."

\section{REQUIREMENT SOURCE: DOE5480.19(920518) Chapter XVI, Section C.2.p}

"Emergency operating procedures should provide guidance in responding to single and multiple casualties."

\section{REQUIREMENT SOURCE: DOE5480.19(920518) Chapter XVI, Section C.2.q}

"Portions or steps of other procedures that are used or referred to when performing a procedure should be specifically identified within the procedure so that operators will not be confused when transferring between procedures."

\section{REQUIREMENT SOURCE: DOE5480.19(920518) Chapter XVI, Section C.2.r}

"Component or system shutdown and restoration requirements following shutdown or a surveillance or test activity should be specific and controlled by the procedure."

Review and Approval

REQUIREMENT SOURCE: DOE4330.4B Chapter Il, Section 6.3.2, Paragraph 1, Sentence 1 thru 3

"Verification is a review to ensure the proper format and technical accuracy of a new or revised procedure. This review should ensure that the format incorporates human-factors principles and other appropriate administrative policies. The technical accuracy review should also include a review of the procedure against the design requirement for that system or component."

\section{REQUIREMENT SOURCE: DOE4330.4B Chapter II, Section 6.3.2, Paragraph 2}

"Verification should be conducted by one or more reviewers who were not involved in writing the procedure. Other disciplines such as health physics and operations should be considered for the review process." 


\section{REQUIREMENT SOURCE: DOE4330.4B Chapter II, Section 6.3.4}

"Approval should be consistent with facility technical specifications or their equivalent and administrative procedures. As a minimum, the maintenance manager or designee should approve maintenance procedures."

\section{REQUIREMIENT SOURCE: DOE5480.19(920518) Chapter XVI, Section C.4, Paragraph 1 and 2, Sent 1}

"Operating procedures should be approved by the operations supervisor. In addition, procedures that affect safety-related equipment and emergency procedures should be reviewed by the facility safety review committee or by another appropriate review mechanism.

Procedure revisions should receive the same depth of review and level of approval as the initial versions. New and revised procedures should be approved prior to use.

Changes in Operations procedure that do not affect the intent of operations procedure should be approved by two individuals; one should be a qualified operator, and the other should be a member of facility management."

\section{REQUIREMENT SOURCE: DOE5480.19(920518) Chapter XVI, Section C.5}

"New and revised operations procedures should be reviewed prior to issuance and at periodic intervals to ensure that the information and instructions are technically accurate and that appropriate human-factor considerations have been included. The frequency of subsequent reviews should be specified; it may vary with the type and complexity of the activity involved and with time as a given plant reaches operational maturity. Applicable procedures should be reviewed after an unusual incident (such as an accident, an unexpected transient, significant operator error, or equipment malfunction). During reviews, procedures should be compared to source documents to verify their accuracy. In addition, new procedures should be validated by walk-throughs in the facility or by operation on a facility-specific simulator to ensure workability."

\section{REQUIREMINT SOURCE: DOE5480.21 Preamble, Section 10.b}

"A safety evaluation shall be performed for:

(1) Temporary or permanent changes in the facility as described in the existing safety analyses;

(2) Temporary or permanent changes in the procedures as described in existing safety analyses; or

(3) Test or experiments not described in existing safety analyses. "

\section{Control and Maintenance}

\section{REQUIREMENT SOURCE: DOE5480.19(920518) Chapter XVI, Section C.3, Sentence 2}

"The review and approval process for each procedure change or revision should be documented." 


\section{REQUIREMENT SOURCE: DOE5480.19(920518) Chapter XVI, Section C.3,} Sentence 6

"Procedure changes do not involve retyping or reissuing a procedure. "Procedure revisions" constitute a new, retyped edition of the procedure. Procedure changes and revisions should conform to the following practices:

a. Procedure changes intended for use more than one time should be documented in a location readily available for operator reference. To avoid the possibility of error, these changes should also be referenced in procedure copies used by operators.

b. Appropriate procedure changes and revisions should be initiated when procedure inadequacies or errors are noted.

c. Procedure revisions should be initiated when a change has been outstanding for an extended period (e.g., greater than 6 months) or when a procedure has been affected by several changes (e.g., more than five). All currently effective procedure changes should normally be incorporated when the procedure is revised.

d. Procedure revisions should be implemented concurrently with modifications. Procedure updates required by temporary modifications should be handled as procedure "change" and implemented concurrently with the temporary modification installation.

e. Important information regarding changed or revised procedures should be communicated to appropriate operations personnel via the required reading system (Chapter XIV), a pre-shift briefing, or a similar method.

f. Documentation of the reason for key procedure steps should be maintained and reviewed when implementing changes or revisions that alter these steps. This practice is important to ensure that the reason for any step is not overlooked.

g. The review process should involve verification and validation of the procedure using walkthroughs or similar methods."

\section{REQUIREMENT SOURCE: DOE5480.19(920518) Chapter XVI, Section C.4, Paragraph 2, Sent 3 and 4}

"Within 2 weeks, these procedure changes should be concurred with by the individuals who would normally approve a revision or the Initial version of the procedure. Changes that alter the intent of a procedure should receive the same approval as a new or revised procedure."

\section{REQUIREMENT SOURCE: DOE5480.19(920518) Chapter XVI, Section C.7}

"Facility operation should be conducted in accordance with applicable procedures that reflect the facility design basis. The requirements for use of procedures should be clearly defined and understood by all operators. If procedures are deficient, a procedure change should be initiated. In exception to this policy, operators may take whatever action is necessary during emergency conditions to place the facility in a safe condition, and to protect equipment, personnel, and public safety without first initiating a procedure change.

Operators should have procedures with them and follow them in a step-by-step manner when the procedures contain sign-offs for the various activities. In addition, procedures should be referenced during infrequent or unusual evolutions when the operator is not intimately familiar with the procedure requirements or when errors could cause significant adverse impact to the facility. Operators need not reference emergency procedures during the performance of 
immediate actions since these actions, are committed to memory; however, the emergency procedure immediate action instructions should be reviewed after the actions are performed, thus, verifying, that all required actions have been taken."

\section{$\underline{1.3 .1}$}

\section{ISSUES MANAGEMENT}

\section{Issue Identification}

The potential sources for issues include Occurrence reports; review, audit, and assessment reports; deficiencies; nonconformances; noncompliances with requirements/standards; lessons learned from other facilities; and employee concerns. This element therefore interfaces with all other functional areas and programs.

\section{REQUIREMENT SOURCE: 10CFR830 Part 120(c)(1)(iii)}

"Quality Improvement.

Processes to detect and prevent quality problems shall be established and implemented. Items, services, and processes that do not meet established requirements shall be identified, controlled, and corrected according to the importance of the problem and the work affected. Correction shall include identifying the causes of problems and working to prevent recurrence. Item characteristics, process implementation, and other quality-related information shall be reviewed and the data analyzed to identify items, services, and processes needing improvement."

\section{REQUIREMENT SOURCE: DOE5480.29 Preamble, Section 3, Sentence 3, and 3.a thru 3.d}

"Situations by which a DOE, contractor, or subcontractor employee may choose to file an employee concern include:

a. The need to express an ES\&H concern through a nonroutine reporting pathway because the employee is dissatisfied with the effectiveness of existing employee concerns program procedures (for the purpose of this order, unless otherwise specified, employee is to mean DOE, contractor, and subcontractor employees);

b. Fear of potential reprimand, retaliation, or duress as a result of filing a concern within the routine management chain or other existing reporting systems;

c. Belief that corrective actions for previously identified concerns are not being implemented; or

d. The lack of an employee concerns program within a DOE contractor or subcontractor organization."

1.3.2 Issue Evaluation

\section{REQUIREMENT SOURCE: DOE5480.29 Preamble, Section 9.d}

"The following are intended to be illustrative, but not all inclusive, of criteria which should be utilized to assess the significance of the concern. Immediate significance is judged by determining whether the concern involves: 
(1) Initiation of work in the face of identified environment, safety, or health concerns which could result in an immediate or nearterm threat to the safety of the public or workers;

(2) Continuation of operations in the face of inoperable or deficient ES\&H equipment, monitoring instrumentation, or systems;

(3) Any violations of PAAA enforcement authority criminal acts involving nuclear safety matters (e.g., falsification of plant logs and records), other willful violations of DOE nules, Orders, and regulations; operational procedures, specification limits, or criminal acts;

(4) Deficiencies observed in the normal reporting system (i.e., lack of notification of ES\&H issues and events of significance to proper authorities as required by DOE Orders, procedures, and Federal and State environmental laws);

(5) The collection, dissemination, and recording of inaccurate or falsified ES\&H related data; or

(6) Material misrepresentations to inspectors, auditors, or reviewers when performing official duties."

\section{$\underline{1.3 .3}$}

Root Cause and Corrective Action Analysis

\section{REQUIREMINT SOURCE: DOE4330.4B Chapter II, Section 17.3.3, Paragraph 1, Sentence 1 and 2}

"The above actual or probable causes of a problem should be evaluated by one or more techniques or methodologies to establish a final root cause. An acceptable root cause should meet three criteria: (a) its correction should prevent recurrence of the unplanned occurrence; (b) its correction should be feasible; and (c) its correction should not adversely impact safety, reliability, or operational goals."

\section{REQUIREMIENT SOURCE: DOE4330.4B Chapter II, Section 17.3.3, Paragraph 1, Sentence 2}

"An acceptable root cause should meet three criteria: (a) its correction should prevent recurrence of the unplanned occurrence; (b) its correction should be feasible; and (c) its correction should not adversely impact safety, reliability, or operational goals."

REQUIREMENT SOURCE: DOE5480.19(920518) Chapter VI, Section C.5.d, Sentence 1

"Appropriate corrective action should be established for each event investigation, and specific personnel should be assigned responsibilities for the corrective action."

REQUIREMENT SOURCE: DOE5480.19(920518) Chapter VI, Section C.5.d, Sentence 3

"The final approval for corrective action should be made by the facility manager."

Tracking and Trending

\section{REQUIREMENT SOURCE: BMP-10CFR20 Appendix A}

"Tracking systems shall be established to provide for: 
(1) Timely self-identification of nuclear safety deficiencies,

(2) Prompt and complete reporting of such deficiencies to DOE,

(3) Root cause analysis of nuclear safety deficiencies,

(4) Prompt correction of nuclear safety deficiencies in a manner which precludes recurrence, and

(5) Identification of modifications in practices or facilities that can improve public or worker radiological health and safety."

\section{COMPLIANCE MANAGEMENT}

Author's Note: This S/RID is being developed as part of the implementation of DNFSB recommendation 90-2. It provides a primary tool of the compliance management program.

\section{REQUIREMINT SOURCE: DOE5480.23 Attachment I, Section 4.d.(1), Sentences 1 and 2}

"This Order requires that contractors carry out their responsibilities in accordance with the assumptions and commitments set forth in pertinent DOE-approved SARs. In other words, contractors are required to adhere to commitments made in SARs and to conduct operations in such a way that the assumptions made in the SAR are valid."

\section{REQUIREMENT SOURCE: DOE5480.23 Attachment I, Section 4.d.(2), Sentences 1 and 2}

"All material associated with accident analyses or institution safety programs appearing in an SAR, including such assumptions, are to be taken as commitments to which the operating contractor proposes to adhere. The set of commitments must include facility-specific implementation of nuclear safety requirements."

\section{REQUIREMENT SOURCE: DOE5480.23 Section 8}

"A contractor, as designated in writing by the PSO, who is responsible for the design, construction, or operation of DOE nuclear facilities shall be required to perform a safety analysis that develops and evaluates the adequacy of the safety basis for each such facility. The safety basis to be analyzed shall include management, design, construction, operation, and engineering characteristics necessary to protect the public, workers, and the environment from the safety and health hazards posed by the nuclear facility or non-facility nuclear operations. All contractors shall be held responsible for adhering to assumptions and commitments set forth in the safety analysis. Contractors shall be required to prepare, and shall submit to DOE for its approval, SARs documenting safety analyses for each DOE nuclear facility under their cognizance. Contractors responsible for conducting one or more non-facility nuclear operations are required to maintain up to date analyses of the safety of such operations and analyses documented in a form that is auditable by DOE."

\section{REQUTREMENT SOURCE: DOE5480.23(940310) Section 9.c.}

"Periodic Updates of Safety Analysis Reports. Contractors shall be required to review and update as necessary, SARs annually, pursuant to this Order to ensure that the information in each SAR is current and remains applicable. Revisions shall be submitted to the PSO at least annually and shall reflect all changes implemented up to 6 months prior to the filing of the 
updated SAR. The DOE approval of any Unreviewed Safety Question Pursuant to DOE 5480.21 , amendments to the TSR's, and the material submitted by the contractor to the PSO in support of these approvals shall be considered and addendum to the SAR until the information is incorporated into the SAR as part of the next annual update."

\section{MANAGEMENT EVALUATION}

Author's Note: Additional Requirements relevant to this area are included in the QA Functional Area.

\section{REQUIREMENT SOURCE: DOE5480.19(920518) Chapter VI, Section C.8}

"Patterns of deficiencies such as operator errors or inadequate procedures should be trended. A periodic summary report of events, causes, and trends should be submitted to department heads, the facility manager, and appropriate managers. Department heads should ensure training programs include appropriate material from the summary report."

\section{REQUIREMIENT SOURCE: DOE5480.26 Section 6.f Introduction, and 6.f.(1)}

"Facility Managers. As defined in paragraph 4 of this Order shall:

(1) Assess facility Performance Indicators and other operations information, such as reportable occurrences, for trends in improving or deterioration conditions; and"

\section{REQUIREMENT SOURCE: DOE5480.26 Section 7.a.(1)}

"For all DOE facilities included in the DOE PI program, contractors shall provide their PI report addressing the specified list of Performance Indicators, provided in subparagraph $\mathrm{c}$ below, to the cognizant Field Organization, on a quarterly basis. For those facilities identified in Appendix 1 of DOE-STD-1048-92, which do not report to a Field Office, their quarterly report should be sent directly to the cognizant PSO."

\section{REQUIREMINT SOURCE: DOE5480.26 Section 7.a.(3)}

"Performance Indicators are designed to be reportable as numerical values on a consistent basis so that they are readily usable in trending analysis. For each facility included in the DOE PI program, the contractor shall gather, analyze and report the Performance Indicators data, to include narrative data, according to the requirements of this Order and the guidance provided in DOE-STD-1048-92."

\section{REQUIREMENT SOURCE: DOE5480.26 Section 7.b.(1), Sentence 2}

"Facility Managers shall assess their facility operating information for trends and indications of deteriorating/improving conditions and identify lessons-learned and good practices that should be used in their facility to prevent occurrences or to improve safety and/or operations."

\section{REQUIREMENT SOURCE: DOE5482.1B Section 9.d(1)}

"Internal appraisals shall be conducted at the operating level by persons not directly responsible for performance of the activities being appraised." 


\section{REQUIREMENT SOURCE: DOE5482.1B Section 9.d(2), (a) thru (f)}

"The internal appraisal system shall:

a) Function primarily in an advisory capacity to a designated position or management authority so that corrective actions can be taken.

b) Be clearly defined in writing.

c) Be auditable.

d) Be reviewed by management for adequacy of performance every 3 years, or more often, as required.

e) Review the overall operation of each facility with sufficient frequency to assure adequate ES\&H coverage.

f) Provide multidisciplinary reviews with in-depth technical competence in the areas being reviewed."

\section{REQUIREMENT SOURCE: RLIP5484.1A Section 4.i}

"(1) Ensure compliance with DOE Order 5484.1 and this RLIP.

(2) Ensure investigations of Type A, B, and C incidences are in accordance with the methods as instructed by the Safety System Development Center, EG\&G, Idaho.

(3) Ensure accident coding includes the organization cost code of the worker and the RL Division having program overview responsibility.

(4) Ensure the use of the Bureau of Labor Statistics (BLS), 29 CFR 1904, criteria to support the recordability of injuries and illnesses.

(5) Ensure the use of the System Safety Development Center document 7B to support the recordability of vehicle accidents, fire, or other property losses.

(6) Review and analyze incident data to determine the start of adverse trends affecting program operations, and establish goals and objectives for reducing or eliminating the causes of the adverse trends.

(7) Review reports of contractor investigation boards and order additional investigation, if necessary."

1.6

$\underline{1.6 .1}$

\section{OCCURRENCE REPORTING}

Emergency classification requirements are found in the Emergency Management Functional Area.

\section{Identification and Categorization}

\section{REQUIREMENT SOURCE: DOE5000.3B Section 7.a. Introduction, Sentence 1}

"Categorization of Reportable Occurrences shall be made as soon as practical and, in all cases, within 2 hours of identification." 


\section{REQUIREMENT SOURCE: DOE5000.3B Section 8.a.(1)}

"The facility staff and operators shall identify and promptly notify the Facility Manager of abnormal events and conditions and record and archive all information pertaining to such occurrences."

\section{REQUIREMENT SOURCE: DOE5000.3B Section 8.a.(3)}

"The Facility Manager shall categorize the occurrence as required in Paragraph 7a of this Order utilizing the facility specific procedures developed in accordance with Paragraph $8 \mathrm{~d}(2)$ of this Order. For occurrences resulting from and directly related to a previously identified cause which is currently documented in a nonfinalized Occurrence Report, the Facility Manager, with concurrence from the Facility Representative and Program Manager, may submit a 10-Day Update Report in lieu of a new Occurrence Report."

\section{REQUIREMENT SOURCE: DOE5000.3B Section 8.a.(4)}

"The Facility Manager shall be available at all times to carry out the requirements of this Order."

\section{$\underline{1.6 .2}$}

Notification and Reporting

\section{REQUIREMENT SOURCE: DOE5000.3B Section 7.b.(1), Paragraph 1, Sentence 1}

"Oral notification to DOE and offsite authorities of emergencies shall be made within 15 minutes or less of categorization."

\section{REQUIREMENT SOURCE: DOE5000.3B Section 7.b.(1), Paragraph 2, Sentence 4}

"A Notification Report shall be prepared and submitted as soon as practical but, in all cases, before the close of the next business day from the time of categorization (not to exceed 80 hours)."

\section{REQUIREMENT SOURCE: DOE5000.3B Section 7.b.(2), Sentence 1}

"Oral notification to DOE of unusual occurrences shall be as soon as sufficient information is obtained to indicate the general nature and extent of the occurrence but, in all cases, within 2 hours of categorization."

\section{REQUIREMENT SOURCE: DOE5000.3B Section 7.b.(4)}

"Any changes in categorization shall be documented in a 10-Day Occurrence Report and submitted before the close of the next business day from the time of recategorization (not to exceed 80 hours). A justification for the new categorization shall be included in the report."

\section{REQUIREMENT SOURCE: DOE5000.3B Section 7.c.}

"In addition to the initial oral notifications required in Paragraph $7 \mathrm{~b}$, follow-up oral notification shall also be made to DOE for any of the following:

(1) Any further degradation in the level of safety of the facility or other worsening conditions, including those that require the declaration of any emergency class as defined by DOE Order $5500.2 B$, if such a declaration has not been previously made; 
(2) Any change from one emergency class (as defined in DOE Order 5500.2B) or category (as defined by this Order) to another; or

(3) Termination of an emergency."

\section{REQUIREMENT SOURCE: DOE5000.3B Section 7.d}

"An Occurrence Report shall be prepared for all Reportable Occurrences..."

\section{REQUIREMENT SOURCE: DOE5000.3B Section 7.d.(2)}

"Within 10 working days of categorization, the contractor shall submit a 10-Day Occurrence Report utilizing the information available at that time;"

\section{REQUIREMENT SOURCE: DOE5000.3B Section 7.d.(3)}

"The 10-Day Occurrence Report shall be updated when significant new information is available and submitted as a 10-Day Update Report;"

\section{REQUIREMENT SOURCE: DOE5000.3B Section 7.e.(1)}

"At facilities where classified operations are not conducted and classified information is not generated, authorized classifier (AC) reviews of Occurrence Reports are not required. Similarly, at facilities where UCNI operations are not conducted and UCNI is not generated, review of the Occurrence Reports by a Reviewing Official is not required."

\section{REQUIREMENT SOURCE: DOE5000.3B Section 8.a.(5)}

"For oral notification, the Facility Manager shall simultaneously contact the DOE Facility Representative and the Headquarters (HQ) Emergency Operations Center (EOC) through which the DOE Program Manager and any other necessary program staff can be located and direct communications links with the Facility Manager established. The HQ EOC function here is to facilitate communications within line organizations and to record and archive conversations. To facilitate this archival function, the oral notification shall include as many of the required report fields [see discussion in Attachment II, Section 1, regarding Fields 1-18 identified with an asterisk $(*)$ ] as known at the time of the oral notification with particular emphasis on clear and succinct descriptions of the occurrence (Field 15); brief, concise descriptions of the operating conditions of the facility at the time of the occurrence (Field 16); and immediate actions taken, including results, if known (Field 18). The Facility Manager may use the local Field/Site EOC to expedite establishing the direct communication link required above. To promote common understanding, the use of jargon should be avoided and uncommon or facility/site-specific abbreviations and acronyms should be fully described in oral notifications and spelled out in subsequent written reports."

\section{REQUIREMENT SOURCE: DOE5000.3B Section 8.a.(10)}

"The Facility Manager shall prepare and submit the Notification Report (fields 1 through 18 of the Occurrence Report), and distribute it to the DOE Facility Representative and Program Manager before the close of the next business day from the time of categorization (not to exceed 80 hours). When an unclassified Notification Report is submitted using the computerized DOE ORPS data base, Paragraph $8 \mathrm{c}(1)$ below, the distribution requirement is automatically satisfied." 


\section{REQUTREMINT SOURCE: DOE5000.3B Section 8.b.(1)}

"For every Reportable Occurrence, the Facility Manager shall determine and document in the Occurrence Report as soon as practical:

(a) The significance, nature and extent of the event or condition;

(b) The cause(s) of the event or condition, including the root cause, as appropriate; and

(c) The corrective actions to be taken to correct the condition and prevent recurrence."

\section{REQUIREMENT SOURCE: DOE5000.3B Section 8.b.(4)}

"The Final Occurrence Report shall be prepared by the Facility Manager and submitted when the analysis of the occurrence has been completed, root cause(s) and contributing cause(s) finalized, corrective actions(s) determined and scheduled, and lessons-learned identified. This report shall be submitted to the DOE Facility Representative within $\mathbf{4 5}$ days of categorization of the occurrence. If the required analysis cannot be completed within $\mathbf{4 5}$ days, an update to the 10-Day Occurrence Report shall be submitted within the $\mathbf{4 5}$ days and shall include a detailed explanation of the delay and an estimated date for submittal of the Final Occurrence Report."

\section{REQUIREMENT SOURCE: DOE5000.3B Section 8.b.(5)}

"The Final Occurrence Report shall then be reviewed and approved by the DOE Facility Representative within 7 working days of receipt and forwarded to the Program Manager for approval when the information required in subparagraph (4) above is provided. The Program Manager shall review and approve the Occurrence Report within 14 days of receipt. The Program Manager should provide any comments on the final report at this time. If the computerized DOE ORPS data base is being used, the Program Manager's comments should be provided via the data base. The Program Manager's comments are not mandatory. If the Final Occurrence Report is not approved, then the report shall be returned to the Facility Manager with an explanation for the disapproval. The revised Final Occurrence Report shall be resubmitted within 21 days of disapproval. If it cannot be resubmitted within this time period, then an update to the 10-Day Occurrence Report shall be submitted within the 21 days and shall include a detailed explanation of the delay and an estimated date for resubmittal of the final report."

\section{REQUIREMENT SOURCE: DOE5000.3B Section 8.b.(6)}

"The Occurrence Reports (10-Day and Final) shall be prepared by the Facility Manager and distributed to the Program Manager, the affected program self-assessment group, PSOs, the Heads of all Field Organizations, the DOE Facility Representative, Office of Nuclear Safety (NS-1), Office of Environment, Safety and Health (EH-1), all DOE Management and Operations (M\&O) contractors, and the Office of Nuclear Safety Policy and Standards (NE-70). For those occurrences involving safeguards and security issues, copies of the Occurrence Reports should be provided to the Office of Security Affairs (SA-1). When unclassified Occurrence Reports (10-Day and final) are entered onto the DOE ORPS data base, Paragraph $8 \mathrm{c}(1)$ below, by the Facility Manager, the distribution requirement is automatically satisfied. Distribution of written classified reports shall be defined by the cognizant PSO based on a "need to know." " 


\title{
REQUIREMENT SOURCE: DOE5000.3B Section 8.c(2), Paragraph 1
}

\author{
"Utilization.
}

Contractors for each facility or group of facilities shall collect and disseminate to their personnel the operations information obtained from their facilities, other similar DOE facilities, and the lessons to be learned from this information. Each Facility Manager should adopt the use of trending and analysis of this information for early indication of deteriorating conditions. Corrective action should be taken for any identified deteriorating conditions. The Facility Manager, DOE Facility Representative, and DOE Program Manager should review the DOE ORPS data base to identify good practices and lessons learned from other facilities that can be used in his/her facility."

\section{REQUIREMENT SOURCE: DOE5480.19(920518) Chapter VI, Section C.5.c, Sentence 1}

"The root cause of the event should be determined."

\section{REQUIREMENT SOURCE: DOE5480.19(920518) Chapter VI, Section C.5.d, Sentence 1}

\begin{abstract}
"Appropriate corrective action should be established for each event investigation, and specific personnel should be assigned responsibilities for the corrective action."
\end{abstract}

\section{REQUIREMENT SOURCE: DOE5480.19(920518) Chapter VI, Section C.5.d, Sentence 3}

"The final approval for corrective action should be made by the facility manager. "

\section{REQUIREMENT SOURCE: DOE5480.19(920518) Chapter VI, Section C.6, Paragraph 1}

"An investigative report should be prepared in a timeframe determined by the responsible authority. The report should include a description of the event (including pertinent conditions), a discussion of the impact of the event, root cause, the lessons learned, and the proposed corrective action(s). The report should include positive aspects of the event (such as particularly effective personnel responses). The investigative report should be approved by the facility manager and reviewed by appropriate supervisors, managers, and the safety review committee."

\section{REQUIREMENT SOURCE: DOE5480.19(920518) Chapter VI, Section C.8}

"Patterns of deficiencies such as operator errors or inadequate procedures should be trended. A periodic summary report of events, causes, and trends should be submitted to department heads, the facility manager, and appropriate managers. Department heads should ensure training programs include appropriate material from the summary report."

\section{REQUIREMIENT SOURCE: DOE5480.19(920518) Chapter VI, Section C.9,} Sentence 2

"If an act of sabotage is discovered or suspected, it is important to begin an investigation immediately and to accomplish the following:

a. Determine the condition of the affected system(s) and ensure the operability of all safety-related systems; 
b. Decide if continued operation is justified or if systems are available to support safe facility shutdown; and

c. Minimize the impact of discovered acts of sabotage and deter future acts of sabotage."

\section{REQUIREMENT SOURCE: DOE5480.19(920518) Chapter VII, Section C. 1}

"Procedures should be developed to address appropriate notifications and should include the following elements:

a. Specific responsibilities for notifications;

b. Identification of events and conditions requiring notifications;

c. Identification of primary and alternate personnel to be notified for various situations;

d. Establishment of time requirements for notifications that are consistent with the facility emergency plan; and

e. Definition of recordkeeping requirements that documents the reason for notifications, the time, of notifications, and the person notified."

\section{REQUIREMENT SOURCE: DOE5480.19(920518) Chapter VII, Section C. 2, Sentence 1}

"The operations supervisor should ensure that all appropriate personnel receive notification when required."

\section{REQUIREMENT SOURCE: DOE5480.19(920518) Chapter VII, Section C. 3}

"Names of primary and alternate contacts and current phone numbers and page codes should be readily available to the person assigned to make the notifications."

\section{REQUIREMENT SOURCE: DOE5480.19(920518) Chapter VII, Section C. 4, Sentence 1}

"All notifications should be documented. "

REQUIREMENT SOURCE: DOE5480.19(920518) Chapter VII, Section C. 5

"Adequate communication equipment should be maintained in the main control area to meet the objectives of this chapter."

$\underline{\text { Investigation }}$

\section{REQUIREMIENT SOURCE: DOE5000.3B Section 8.c(2), Paragraph 1}

"Utilization.

Contractors for each facility or group of facilities shall collect and disseminate to their personnel the operations information obtained from their facilities, other similar DOE facilities, and the lessons to be learned from this information. Each Facility Manager should adopt the use of trending and analysis of this information for early indication of deteriorating conditions. Corrective action should be taken for any identified deteriorating conditions. The Facility Manager, DOE Facility Representative, and DOE Program Manager should review the DOE 
ORPS data base to identify good practices and lessons learned from other facilities that can be used in his/her facility."

\section{REQUIREMENT SOURCE: DOE5480.19(920518) Chapter VI, Section C.1, Sentence 1 thru 3}

"Events that occur in the facility and adversely affect operations, personnel safety, or DOE requirements (DOE 5000.3A) should receive a thorough investigation. The criteria for when to perform an event investigation should be clearly established. Specific events requiring investigation should be listed for supervisory use, along with criteria for use in deciding what "near miss" situations should receive review."

\section{REQUIREMENT SOURCE: DOE5480.19(920518) Chapter VI, Section C.2, Sentence 1}

"The operations supervisor or another manager should be responsible for event investigations."

\section{REQUIREMENT SOURCE: DOE5480.19(920518) Chapter VI, Section C.3, Sentence 4 and 5}

"Investigators should be trained in facility systems and operations and other major disciplines appropriate for the event under investigation. Additionally, investigators should be trained in techniques for conducting an investigation. "

\section{REQUIREMENT SOURCE: DOE5480.19(920518) Chapter VI, Section C.4, Paragraph 1, Sent 1 thru 3}

"Sufficient data must be collected to allow the event investigators to perform a reconstruction and analysis of the event. An individual should be assigned responsibility for collecting the required information and assembling the information for review. It is important to collect the necessary information as soon as possible after the event."

\section{REQUIREMENT SOURCE: DOE5480.19(920518) Chapter VI, Section C.4, Paragraph 1, Sentence 5}

"Information should be gathered in the following areas:

a. Initial facility conditions.

b. Statements of operators and personnel involved in the event (this should be permanently recorded).

c. Pertinent computed printouts (post-trip log sequence of events) and strip charts.

d. Pertinent documentation (such as operator logs, radiation work permits, chemistry logs, and radiological surveys) as required to establish conditions prior to and during the event."

\section{REQUIREMENT SOURCE: DOE5480.19(920518) Chapter VI, Section C.4, Paragraph 2, Sentence 3}

"Methods for collecting this information can vary; however, the event investigation containing relevant information should be permanently recorded for future reference." 
REQUIREMENT SOURCE: DOE5480.19(920518) Chapter VI, Section C.4, Paragraph 3, Sent 2 and 3

"The collection of data should not interfere with the continued operation of the facility. Temporary interference should occur only if necessary to understand the event."

\section{REQUIREMINT SOURCE: DOE5480.19(920518) Chapter VI, Section C.5, Sentence 1}

"Upon completion of the data collection, a structured review of the abnormal event should occur."

\section{REQUIREMINT SOURCE: DOE5480.19(920518) Chapter VI, Section C.5, Sentence 3}

"Each event investigation should include the following steps, with emphasis placed on each individual step depending upon the severity or potential consequences of the event."

\section{REQUIREMENT SOURCE: DOE5480.19(920518) Chapter VI, Section C.5.a, Sentence 1}

"The abnormal event should be reconstructed using the collected information."

\section{REQUIREMENT SOURCE: DOE5480.19(920518) Chapter VI, Section C.5.b, Sentence 1 thru 4}

"Once the facts of the event have been established, the event should be analyzed to determine the response of equipment and involved personnel. During the analysis, emphasis should be placed on determining the proper response of systems, comparison of actual and expected response, adequacy of procedures, and factors affecting human performance. When available, the event should be compared with previous event investigations of similar events or transients. During the analysis, a safety evaluation should be performed to ascertain the proper response of equipment and to identify detrimental effects on facility equipment."

\section{REQUIREMENT SOURCE: DOE5480.19(920518) Chapter VI, Section C.5.c,} Sentence 1

"The root cause of the event should be determined."

REQUIREMENT SOURCE: DOE5480.19(920518) Chapter VI, Section C.5.d, Sentence 1

"Appropriate corrective action should be established for each event investigation, and specific personnel should be assigned responsibilities for the corrective action."

REQUIREMENT SOURCE: DOE5480.19(920518) Chapter VI, Section C.5.d, Sentence 3

"The final approval for corrective action should be made by the facility manager." 


\section{REQUIREMENT SOURCE: DOE5480.19(920518) Chapter VI, Section C.8}

"Patterns of deficiencies such as operator errors or inadequate procedures should be trended. A periodic summary report of events, causes, and trends should be submitted to department heads, the facility manager, and appropriate managers. Department heads should ensure training programs include appropriate material from the summary report."

\section{REQUIREMENT SOURCE: DOE5480.19(920518) Chapter VI, Section C.9, Sentence 2}

"If an act of sabotage is discovered or suspected, it is important to begin an investigation immediately and to accomplish the following:

a. Determine the condition of the affected system(s) and ensure the operability of all safety-related systems;

b. Decide if continued operation is justified or if systems are available to support safe facility shutdown; and

c. Minimize the impact of discovered acts of sabotage and deter future acts of sabotage."

Tracking

\section{REQUIREMENT SOURCE: DOE5000.3B Section 8.b.(9)}

"Contractors shall maintain the ORPS data base (Paragraph $8 \mathrm{c}(1)$ below) up-to-date on the status of Final Occurrence Report corrective actions. Status reports of all incomplete Occurrence Reports (not final) and incomplete corrective actions shall be available at any time from the ORPS data base."

\section{OPERATIONAL READINESS REVIEWS}

Operational Readiness reviews (ORRs) provides a structured methodology for determining that a facility, project, process, or activity is ready to be occupied and/or operated in a safe and controlled manner. For the remainder of this section the term "facility" will be used to include a facility, project, process, or activity.

It is DOE policy that no new hazardous or nuclear facilities be started, nor should such existing facilities be restarted, without a documented and approved review or readiness. The process is applied on a graded approach, which addresses all key elements of ORR, ranging from short, simple, low-level efforts to comprehensive efforts covering all hardware, personnel, and procedures depending on the complexity of, and hazards posed by, the subject facility. The ORR process includes, among other things, a determination of the level of compliance with ES\&H Orders and OSHA regulations.

DOE 5480.31 establishes the actions to be taken, and assigns responsibility for authorizing the restart of nuclear facilities. RLID 5480.31 in turn implements the requirements of the order at the Hanford site.

This element identifies specific requirements to be addressed in determining the need for and conducting WHC ORRs at the Hanford site. DOE or other approvals necessary to proceed with an ORR or facility restart are identified; however, requirements for conduct of DOE ORRs are not included. Interfaces and coordination with oversight organizations necessary for WHC ORRs are identified if specified in the requirement documents. 
This element interfaces with all programs and functional area involved in the start, restart, operation, or support of a given facility.

$\underline{1.7 .1}$

\section{Approach and Orqanization}

\section{REQUIREMENT SOURCE: RLID5480.31 Section 6.e(1)}

"RL contractors with responsibilities for performance of ORRs and RAs shall be required to:

(1) Prepare an implementing procedure for use in performing startup and restart activities in accordance with this Implementing Directive."

$\underline{\text { Need Determination }}$

REQUIREMINT SOURCE: RLID5480.31 Section 8.0

Author's Note: Only Paragraphs one and two apply.

"REQUIREMENTS. Quarterly, each responsible contractor shall identify to RL Line Management all facility new start and restart activities planned for the next two years. The responsible contractor shall provide a basic description of the facility/activity, identify the anticipated AA, for both the contractor and DOE, for each new start or restart action in accordance with this Implementing Directive requirements. (If the anticipated AA is not the same as required by this directive, the contractor shall provide justification as to why they believe this is acceptable.) This report will identify the hazard classification of the activity or facility in accordance with reference $f$ (or existing hazard category and provide justification to the existing hazard category as to its comparison to hazard class), if the new start or restart is an ORR or RA (if the contractor anticipates that neither an ORR or RA is applicable to the startup or restart, they will justify this assumption), and the expected date of operation.

Where an unplanned shutdown occurs and an ORR or RA is required for restart, the responsible contractor shall notify RL line management verbally and in writing, as soon as practical.

RL line management will review the responsible contractor's proposal and, as necessary, recommend approval or modifications to DOE-HQ who will approve, or modify and approve, the contractor's proposal."

\section{REQUIREMENT SOURCE: RLID5480.31 Section 8.1.c}

"Determination of when an ORR is performed is based on the hazard category, as defined in references $f$ and $g$. The contractor shall conduct an ORR in accordance with this Implementing Directive when any of the following conditions occur:

(1) Initial start-ups of new hazard category 1,2, and 3 facilities.

(2) Restart after an unplanned shutdown of a facility directed by a DOE management official for safety or other appropriate reasons.

(3) Restart after an extended shutdown for hazard category 1 and 2 facilities. Extended shutdown for a category 1 facility is 6 months. Extended shutdown for a category 2 facility is 12 months. 
(4) Restart of hazard category 1 and 2 facilities after major plant or facility modifications required for future program work and/or for enhanced safety, which require changes in the safety basis previously approved by DOE.

(5) Restart after a facility shutdown because of operations outside the safety basis.

(6) When deemed appropriate for less than hazard category 3 facilities by DOE management officials, or deemed appropriate for restarts of hazard category 3 facilities."

\section{REQUTREMENT SOURCE: RLID5480.31 Section 8.1.d}

"Start-ups and restarts of facilities or activities not requiring an ORR shall be evaluated in accordance with Section 8.2."

\section{REQUIREMENT SOURCE: RLID5480.31 Section 8.2.a}

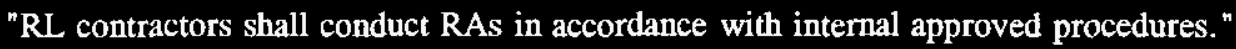

\section{REQUIREMINT SOURCE: RLID5480.31 Section 8.2.b}

"Requirements applicable to restarts of facilities/activities that do not involve RAs.

(1) A MOU will be developed between the contractor and RL line management and approved by the RL AA that defines which facilities/activities may be restarted without a RA. Normally these will be where:

(a) A pre-approved procedure is in place; or

(b) For short duration (less than 12 months), shutdowns with minor modifications to the facility or procedures.

The pre-approved procedures will be part of the MOU. Additionally, any time this means is used, the contractor shall inform RL line management verbally within one working day and in writing within one week.

For short duration shutdowns, the contractor shall provide adequate justification in the MOU to substantiate their rationale that a RA is not required."

\section{REQUIREMINT SOURCE: RLID5480.31 Section 8.2.c, Paragraph 1}

"Where an unplanned shutdown occurs and a RA is required for restart, the responsible contractor shall notify RL line management in writing, as soon as practical."

\section{REQUIREMENT SOURCE: RLID5480.31 Section 8.2.d}

"Contractor management shall determine if a RA is required for startup of new facilities or restart of a facility, as well as recommend the level of involvement by RL using the requirements given below. If the recommendation for $\mathrm{RL}$ involvement does not meet these requirements the contractor shall provide a written justification for the appropriateness of this recommendation." 


\section{REQUIREMENT SOURCE: RLID5480.31 Section 8.2.e}

"Determination of when a RA is performed is based on the hazard category as defined in reference $f$ and $g$. The contractor shall conduct a RAs in accordance with this Implementing Directive, when any of the following conditions occur:

(1) Initial start-ups of new, less than hazard category 3 facilities.

(2) Restart after an extended shutdown for less than hazard category 2 facilities. Extended shutdown is $\mathbf{1 2}$ months or greater.

(3) Restart of less than hazard category 2 facilities after substantial plant or facility modifications required for future program work.

(4) Restarts from routine shutdowns for all facilities. "

\subsubsection{Team Organization and Responsibilities}

\section{REQUIREMINT SOURCE: RLID5480.31 Section 6.f}

"ORR Team Leader shall:

(1) Coordinate the preparation and approve an IP using the requirements of the approved POA and this Implementing Directive.

(2) Select the ORR team members that are technically qualified, thoroughly familiar with the activity being reviewed, and have experience or training in performance-based review techniques.

(3) Establish training and orientation requirements for the team members, including visits to the facility and/or review appropriate facility documentation prior to the start of the ORR, to gain familiarization with the facility and any proposed changes.

(4) Assure that the ORR team does not include, as senior members, individuals who are responsible for accomplishing the work being reviewed.

(5) Assure that no Team Member reviews work for which he or she is directly responsible.

(6) Provide a copy of the IP through approved channels within RL.

(7) Prepare a final report documenting the results of the ORR, including a conclusion of the facility's ability to operate safely.

(8) Remain available and have team members available in the closeout verification of ORR findings requiring ORR team closure or to participate, as requested, by line management."

\section{REQUIREMENT SOURCE: RLID5480.31 Section 6.g}

"RA Team Leaders shall:

(1) Select the RA team members that are technically qualified, thoroughly familiar with the activity being reviewed, and have experience or training in performance-based review techniques. 
(2) Establish training and orientation requirements for the team members, including visits to the facility and/or review appropriate facility documentation prior to the start of the RA, to gain familiarization with the facility and any proposed changes.

(3) Assure that the RA team does not include, as senior members, individuals who are responsible for accomplishing the work being reviewed for new starts, or as required in the MOU for all other RAs.

(4) No RA team member should review work for which he or she is directly responsible for new starts, or as required in the MOU for all other RAs.

(5) Prepare a final report documenting the results of the RA, including a conclusion of the facility's ability to operate safely.

(6) Remain available and have team members available in the closeout verification of RA findings requiring RA team closure, or to participate as requested by line management."

\section{REQUIREMENT SOURCE: RLID5480.31 Section 8.2.j}

"RL line management shall appoint and ensure that contractor management appoints RA teams in accordance with the following requirements.

(1) RAs sball be conducted by personnel qualified in the technical activities involved.

(2) The RL and contractor RA team leaders will determine and document qualifications of the respective team members.

(3) Team Members shall be technically qualified, thoroughly familiar with the activity being reviewed and have experience or training in performance-based review techniques.

(4) The training requirements should indicate that the RA team members visit the facility and/or review appropriate facility documentation, prior to the start of the RA, to gain familiarization with the facility and any proposed changes, as applicable.

(5) No RA team member should review work for which he or she is directly responsible for new starts of less than hazard class 3 facilities, or as required in the MOU for all other RAs."

\section{REQUIREMENT SOURCE: RLID5480.31 Section 8.2.k}

"The RA Team Leader is a senior individual (for RL RAs the team leader will be a DOE person) with the necessary qualifications for managing and conducting the RA. The basis of the qualifications should include:

- Technical familiarity with the activities and functional areas being reviewed

- Previous performance-based review experience or training

- Demonstrated leadership and managerial skills.

The RA team leader is responsible for overseeing the RA process, including:

- Defining RA team membership

Planning, scheduling, coordinating, and conducting the RA 
- Compiling or acquiring access to all necessary background information (e.g., description of process equipment and control measures)

- Acting as the team interface with management.

A key responsibility of the team leader is selection and qualification of the team members. Each team member should have the following qualifications, as defined and verified by the team leader:

- Technical knowledge of the area assigned for evaluation. The knowledge shall include working experience in the technical area.

- Knowledge of performance-based assessment processes and methods. This knowledge may be gained through experience as an auditor or inspector, or it may be gained through training and evaluated as acceptable by the team leader.

- Facility specific information, which may be gained through a combination of required reading and facility tours and presentations."

$\underline{1.7 .2}$

1.7 .2 .1

Plan of Action

Operational Readiness Reviews

\section{REQUIREMENT SOURCE: RLID5480.31 Attachment 10.9}

"Each of the core requirements listed below, as a minimum, must be addressed when developing the breadth of an ORR. Justification must be provided in the POA, if it is determined that a particular core requirement is not applicable or will not be reviewed. The POA may reference a timely, independent review which addressed the requirements in a technically sound manner, to justify not performing further evaluation of a core requirement during conduct of an ORR. A graded approach, defined in Attachment 10.8, will be used to determine the level of analysis, documentation, and/or actions necessary to evaluate the core requirements listed below, or other core requirements in the defined breadth of the ORR. The minimum core requirements are as follows:

1. There are adequate and correct procedures and safety limits for operating the process systems and utility systems.

2. Training and qualification programs for operations and operations support personnel have been established, documented, and implemented (the training and qualification program encompasses the range of duties and activities required to be performed).

3. Level of knowledge of operations and operations support personnel is adequate based on reviews of examinations and examination results, and selected interviews of operating and operations support personnel.

4. Facility safety documentation is in place that describes the "safety envelope" of the facility. The safety documentation should characterize the hazards/risks associated with the facility, and should identify mitigating measures (systems, procedures, administrative controls, etc.) that protect workers and the public from those hazards/risks. Safety systems and systems essential to worker and public safety are defined, and a system to maintain control over the design and modification of facilities and safety-related utility systems is established.

5. A program is in place to confirm and periodically reconfirm the condition and operability of safety systems, including safety related process systems and safety related utility systems. 
This includes examinations of records of tests and calibration of safety system and other instruments which monitor limiting conditions of operation, or that satisfy TSRs. All systems are currently operable and in a satisfactory condition.

6. A process has been established to identify, evaluate, and resolve deficiencies and recommendations made by oversight groups, official review teams, audit organizations, and the operating contractor.

7. A systematic review of the facility's conformance to applicable DOE Orders has been performed, any nonconformances have been identified, and schedules for gaining compliance have been justified in writing and formally approved.

8. Management programs are established, sufficient numbers of qualified personnel are provided, and adequate facilities and equipment are available to ensure operational support services (e.g., training, maintenance, waste management, environmental protection, industrial safety and hygiene, radiological protection and health physics, emergency preparedness, fire protection, quality assurance, criticality safety, and engineering) are adequate for operations.

9. A routine and emergency operations drill program, including program records, has been established and implemented.

10. An adequate startup or restart test program has been developed, that includes adequate plans for graded operations testing to simultaneously confirm operability of equipment, the viability of procedures, and the training of operators.

11. Functions, assignments, responsibilities, and reporting relationships are clearly defined, understood, and effectively implemented with line management responsible for control of safety.

12. The implementation status for DOE 5480.19, CONDUCT OF OPERATIONS REQUIREMENTS FOR DOE FACILITIES, is adequate for operations.

13. There are sufficient numbers of qualified personnel to support safe operations.

14. A program is established to promote a sitewide culture in which personnel exhibit an awareness of public and worker safety, health, and environmental protection requirements and, through their actions, demonstrate a high priority commitment to comply with these requirements.

15. The facility systems and procedures, as affected by facility modifications, are consistent with the description of the facility, procedures, and accident analysis included in the safety basis.

16. Modifications to the facility have been reviewed for potential impacts on procedures and training and qualification. Procedures have been revised to reflect these modifications, and training has been performed to these revised procedures.

17. The technical and management qualifications of contractor personnel, responsible for facility operations, are adequate.

18. The technical and managerial qualifications of those personnel at the field organization and at DOE-HQ, who have been assigned responsibilities for providing direction and guidance to the contractor, including the Facility Representatives, are adequate (DOE ORR only). 
19. The results of the responsible contractor $O R R$ are adequate to verify the readiness of hardware, personnel, and management programs for operations (DOE ORR only).

20. Operations Office Oversight Programs, such as Occurrence Reporting, Facility Representative, Corrective Action, and Quality Assurance Programs, are adequate (DOE ORR only)."

\section{REQUIREMINT SOURCE: RLID5480.31 Section 6.e(2)}

"For ORRs, prepare POA for all contractor ORRs and submit them to the cognizant RL Line Management for review and approval prior to conduct of the ORRs. POAs will be submitted for review and approval a minimum of five months prior to the anticipated start date of the contractor ORR."

\section{REQUIREMENT SOURCE: RLID5480.31 Section 8.1.f}

"Requirements applicable to start-ups or restarts of facilities/activities involving ORRs.

(1) A formal POA, IP, and final report including closure of prestart findings shall be prepared. The resolution of all findings from the ORR shall be documented and maintained with the POA, IP, and the final report. A copy of the contractor POA, IP, and final report shall be included in the DOE final report.

(2) The ORR is a verification of line management having achieved readiness to startup or restart the facility. Therefore, the prerequisite for starting the ORR is that line management certifies that readiness has been achieved. It may be appropriate to conduct ORRs at more than one point in the startup of a facility (e.g., energizing plant electric power system, introduction of hazardous materials, introduction of fissionable materials to the site, initiation of nuclear operations, or initiation of decontamination and decommissioning). The POA approved by RL shall specify the prerequisites for starting the responsible contractor's ORR; the prerequisites shall address each core requirement determined to be applicable when developing the scope of the ORR. For the DOE ORR, as a minimum, the responsible contractor must have certified by formal correspondence that readiness to startup or restart the facility has been achieved, as documented by the responsible contractor ORR. In addition, the DOE POA shall specify additional prerequisites, such as certification of readiness to oversee facility operations by RL and DOE-HQ management."

\section{REQUIREMENT SOURCE: RLID5480.31 Section 8.1.g}

"Line management will develop the breadth of the ORR and document it in the POA. The minimum set of core requirements (see Attachment 10.9) shall be addressed. If a core requirement is determined to be not applicable when developing the breadth of the ORR, the basis for the non-applicability determination shall be documented. The breadth may be expanded at a later time by the ORR team, if appropriate. The graded approach (see Attachment 10.10) shall be applied to develop the depth of evaluation of the core requirements."

\section{REQUIREMENT SOURCE: RLID5480.31 Section 8.1.h}

"The contractor and DOE ORR POA shall be approved by the startup or restart authorities. RL line management shall provide the contractor POA to the appropriate levels of DOE management, as required by reference $h$ and for RL ORR to the OSA and the HQ EH representative. RL line management shall also submit the DOE POA to the AA, through normal channels, who will follow the above for the DOE POA." 


\section{REQUIREMENT SOURCE: RLID5480.31 Section 8.1.i}

"DOE line management shall appoint and ensure that contractor management appoints ORR teams in accordance with the following requirements.

(1) ORRs shall be conducted by personnel qualified in the technical activities involved.

(2) The DOE and contractor ORR team leaders will determine and document qualifications of the respective ORR team members.

(3) Team Members shall be technically qualified, thoroughly familiar with the activity being reviewed and have experience or training in performance-based review techniques.

(4) The training requirements shall indicate that the ORR team members visit the facility and/or review appropriate facility documentation, prior to the start of the ORR, to gain familiarization with the facility and any proposed changes, as applicable.

(5) The ORR teams shall not include, as senior members, individuals who are responsible for accomplishing the work being reviewed.

(6) Additionally, no ORR team member shall review work for which he or she is directly responsible."

\section{REQUIREMENT SOURCE: RLID5480.31 Section 8.1.j}

"The ORR Team Leader is a senior individual (for RL the individual shall be a senior DOE person) with the necessary qualifications for managing and conducting the ORR. The basis of the qualifications should include:

- Technical familiarity with the activities and functional areas being reviewed

- Previous performance-based review experience or training

- Demonstrated leadership and managerial skills

- ORR experience or formal training

- Be an independent person, as defined by reference $\mathbf{j}$.

NOTE: In accordance with reference $\mathrm{j}$, the definition of independent person is a condition characterizing an individual or group of individuals qualified to analyze, review, inspect, test, audit, or otherwise evaluate activities and work results because:

(a) They have no direct responsibility or involvement in performing the activity or work;

(b) They are not accountable for the activity or work results; and

(c) They do not report directly to the immediate supervisor who are responsible for performing the activity or work being evaluated.

The ORR team leader is responsible for overseeing the ORR process, including:

- Defining ORR team membership

- Preparing and approving the ORR IP 
- Planning, scheduling, coordinating, and conducting the ORR

- Estimating the Man-Hours required to implement the plan

- Establishing ORR objectives and milestones

- Compiling or acquiring access to all necessary background information (e.g., description of process equipment and control measures)

- Acting as the team interface with management

- Manage the preparation and disbursement of the ORR report

- Remain available and assure team members are available for closure verification of findings

- For contractor ORRs where a PRP is used, approve the Plan.

A key responsibility of the team leader is selection and qualification of the team members. Team member qualification must be defined by the team leader. Each team member shall have the following qualifications, as defined and verified by the team leader:

- Technical knowledge of the area assigned for evaluation. The knowledge shall include working experience in the technical area

- Knowledge of performance-based assessment processes and methods. This knowledge may be gained through experience as an auditor or inspector, or it may be gained through training and evaluated as acceptable by the team leader

- Facility specific information which may be gained through a combination of required reading and facility tours and presentations."

\section{REQUIREMINT SOURCE: RLID5480.31 Section 8.1.I}

"When an ORR is deemed necessary, for a less than hazard class 3 facility or activity, the contractor shall prepare a MOU to define the means to be used by the team in determining the approach to be used by the ORR team in documenting the facility's capability for safe startup or restart. The MOU shall be approved by the RL AA."

Implementation Plan

\section{REQUIREMENT SOURCE: RLID5480.31 Attachment 10.4, Section 1.0}

"The ORR IP is developed by the team responsible for conducting the ORR. The IP is approved by the team leader designated in the ORR POA. This ORR IP documents not only the process by which the team conducts the review, but also defines the rationale for that process. A "Graded Approach" shall by used in the determination of the scope of the IP (see Attachment 10.10). The documentation includes the selection of CRAs, the review and assessment methodology, and the procedures by which the team will develop findings and conclusions, and the criteria to be applied to categorize findings as prestart and poststart. The ORR IP is the document that provides for the depth of evaluation of the ORR breadth and execution of other details in the approved ORR POA.

The ORR IP shall provide sufficient detail to serve as both information to management and guidance to the ORR team members. The ORR IP details the objectives and sub-objectives of 
the review. The team preparing the ORR IP requires a thorough understanding of the facility and its associated issues. Pre-development onsite facility visits and interviews may be required before the ORR IP can be adequately developed.

The ORR IP shall be provided by the team leader through proper channels, to appropriate oversight and higher-level DOE management prior to commencement of the RL ORR.

The following outline provides a preferred format for the ORR IP. "

\section{REQUIREMENT SOURCE: RLID5480.31 Section 8.1.m}

"The ORR IP is approved by the ORR team leader and used by the ORR team leader to execute the ORR. The team leader will provide the ORR IP through normal channels to the appropriate oversight organizations."

\section{Implementation}

\section{REQUIREMENT SOURCE: RLID5480.31 Section 8.1.p}

"The contractor will be required to satisfy all prestart findings of the DOE ORR prior to startup or restart of the facility."

1.7.2.2 Readiness Assessment

\section{REQUIREMENT SOURCE: RLID5480.31 Section 6.e(3)}

"For RAs, prepare Readiness Plans for new starts, or as required by MOU for restarts, and submit it to the cognizant RL Line Management for review and approval a minimum of three months prior to the anticipated start date of the contractors RA."

\section{REQUIREMENT SOURCE: RLID5480.31 Section 8.2.g}

"Requirements applicable to start-ups or restarts of facilities/activities involving RAs.

(1) A MOU between the contractor and RL AAs defining the means to be used by the team in determining the approach to be used by the RA team in documenting the facility's capability for safe startup or restart.

The MOU is the agreement between the contractor and the RL AA as to the level of review for an RA. The MOU shall contain the technical justification for doing an RA, the means of accomplishing the RA, and the AA for the RA. It shall also contain the scope of the RA and the prerequisites for the RA.

The means for performing the RA may be a pre-approved procedure, check list, lines of inquiry, or CRA based. The means is to be based on the graded approach of Attachment 10.10 and shall be documented in the MOU.

(2) A formal Readiness Plan and tinal report shall be prepared. The resolution of all findings from the RA shall be documented and maintained in the final report.

(3) For new starts of less than hazard category 3 facilities, the RA is a verification of line management having achieved readiness to startup the facility. Therefore, for new starts of less than hazard category 3 facilities, the prerequisite for starting the RA is that line management certifies that readiness has been achieved. The Readiness Plan approved by RL shall specify 
the prerequisites for starting the responsible contractor's RA. For the RL RA, as a minimum, the responsible contractor must have certified by formal correspondence that readiness to startup or restart the facility has been achieved, as documented by the responsible contractor RA.

(4) For restarts of facilities, both extended and routine, the RA is a verification of line management having achieved readiness to restart the facility. However, the extent of the verification by line management for both the contractor and RL shall be specified in the MOU.

(5) A graded approach shall be used and documented in the MOU for the determination of both contractor and RL involvement in the RA."

\section{REQUIREMINT SOURCE: RLID5480.31 Section 8.2.1}

"The contractor will be required to perform its RA after its line management certifies that the facility is ready to operate."

\section{REQUIREMENT SOURCE: RLID5480.31 Section 8.2.n}

"The contractor will be required to satisfy all prestart findings of the DOE RA prior to startup or restart of the facility."

\section{Tracking and Closure of Findings}

Requirements which specify the process for tracking and closure of review findings, including independent verification of closure, are specified in this subelement

\section{REQUIREMENT SOURCE: RLID5480.31 Attachment 10.7, Section 3}

"The contractor and RL management must prepare corrective action plans for the correction of all findings assigned to each element. The action plan shall be discussed in the closeout meeting, and should contain the following elements:

a. The finding, as written in the report submitted by the ORR team, and whether the finding is a prestart or poststart finding.

b. A detailed proposed action plan for addressing the deficiencies identified in that finding. The proposed action plan shall provide evaluation of any overall programmatic deficiencies or root causes related to a specific finding, which may lead to further similar occurrences, and include actions addressing such deficiencies or root causes. For prestart findings in the DOE ORR, DOE must approve the contractor's proposed corrective action plan.

c. The proposed dates by which the action elements will be completed. If the corrective actions for a finding are phased, then the dates for each phase shall be detailed.

d. If it is a poststart finding, a description of the risks and mitigating actions, if any, to be taken during the interim, which will reduce the risks associated with the finding to an acceptable level before final correction. Include justification that the activity can proceed with acceptable risk. DOE line management shall verify that the corrective action plan has been entered into the appropriate quality program issue management system." 


\section{REQUIREMENT SOURCE: RLID5480.31 Attachment 10.7, Section 4}

"Monitoring and verification of satisfactory closure of prestart findings is defined in the ORR report as either closure by the ORR team, or is a line management responsibility. The ORR team leader and team members may be required to assist in the verification or adequate resolution of prestart findings. This is accomplished by development of a closure package that is reviewed and certified by the facility management, and further reviewed by the requirements of the RL ORR final report. The Team Leader and Team Member, who identify a prestart item, will make the determination on closure of the prestart item. Normally, for the more complex and/or critical items, the reviews will be by the ORR team. For the remainder of the prestart and all poststart items, closure is by RL line management. These procedures shall be documented either in a facility wide requirement, or within the individual ORR IP. Closure packages shall contain the following information:

a. The finding, written verbatim from the original report, and identifying the finding as a prestart or poststart finding;

b. The actions proposed in the action plan developed, submitted, and approved with the original completion schedule.

c. A brief description of the actual corrective actions taken, and reasons for concluding that closure has been achieved and how referenced documents support closure. The referenced documents, or excerpted objective evidence from these documents illustrating the corrective actions, and the dates of the actions, shall also be included.

d. Signatures of appropriate facility management, as defined by the site procedures, or within the ORR IP.

e. RL Verification ( $R L$ ORR prestart findings, as a minimum)."

\section{REQUIREMENT SOURCE: RLID5480.31 Section 8.1.r}

"The mechanism for closure of RL ORR prestart findings is defined in this Implementing Directive (see Attachment 10.7). This process includes:

(1) Development of action plans, approved by DOE, to correct the findings

(2) Documenting completion of response actions corresponding to the findings in a closure package

(3) DOE verification of closure of prestart findings. The Team Leader and Team Member who identify a prestart item will make the determination on closure of the prestart item. Normally, for the more complex and/or critical items, the reviews will be by the ORR team. For the remainder of the prestart and all poststart items closure is by RL line management."

\section{REQUIREMENT SOURCE: RLID5480.31 Section 8.2.p}

"The mechanism for closure of RL RA prestart findings is defined in this Implementing Directive (see Attachment 10.7). This process includes:

(1) Development of action plans, approved by DOE, to correct the findings.

(2) Documenting completion of response actions corresponding to the findings in a closure package. 
(3) DOE verification of closure of prestart findings. The organization verifying the closure will be designated by the Approval Authority."

\section{Documentation}

Requirements identified in this subelement specify documentation of the ORR, including the final ORR Report and the Readiness to Proceed Memorandum submitted for DOE approval and initiation of the DOE ORR process. Requirements pertaining to maintenance of records and documents is addressed in section 1.8 of this S/RID.

\section{REQUIREMENT SOURCE: RLID5480.31 Section 8.1.q}

"Upon completion of the contractor or RL ORR, a final report shall be prepared and approved by the ORR team leader. The final report will document the results of the ORR and the conclusion of the ORR team as to whether startup or restart of the facility can proceed safely. There shall be a statement in each ORR final report as to whether any identified nonconformances or schedules for gaining compliance with applicable DOE Orders, Secretary of Energy Notices, and Standards/Requirements Identification Documents (SRID) have been justified in writing, have been formally approved, and in the opinion of the ORR team, maintain adequate protection of the public health and safety, worker safety, or the environment. This conclusion will be based on:

(1) Review of the program to document conformance with applicable DOE requirements, including a process to address new requirements. This type of program may be a compliance review program, safety basis development program, or any other appropriate program documenting conformance with applicable requirements.

(2) Extensive use of references to DOE requirements in the ORR documentation.

Additionally, there shall be a "Lessons Learned" section of the final report which may be applied to future ORR efforts. This section may be completed subsequent to facility startup or restart."

\section{REQUIREMENT SOURCE: RLID5480.31 Section 8.1.s}

"The final report will be submitted to the AA and used by the AA as a basis to grant approval for the start or restart of the facility."

\section{REQUIREMENT SOURCE: RLID5480.31 Section 8.2.0}

"Upon completion of the contractor or RL RA, a final report shall be prepared and approved by the RA team leader. The final report will document the results of the RA and make a conclusion as to whether startup or restart can proceed safely. There shall be a statement in each new start RA final report as to whether any identified nonconformances or schedules for gaining compliance with applicable DOE Orders, Secretary of Energy Notices, and SRID have been justified in writing, have been formally approved, and in the opinion of the RA team, maintain adequate protection of the public health and safety, worker safety, or the environment.

Additionally, there shall be a "Lessons Learned" section of the final report, which may be applied to future RA efforts. This section may be completed subsequent to facility startup or restart." 


\section{REQUIREMENT SOURCE: RLID5480.31 Section 8.2.q}

"The final report will be submitted to the $\mathrm{AA}$ and used by the $\mathrm{AA}$ as a basis to grant approval for the start or restart of the facility."

\section{REQUIREMINT SOURCE: RLID5480.31 Section 8.2.r}

"A copy of the final report will be provided to the appropriate oversight organizations through normal channels for review and comment."

1.8

\section{$\underline{1.8 .1}$}

\section{$\underline{1.8 .1 .1}$}

\section{DOCUMENT AND DATABASE CONTROL - RECORDS MANAGEMENT}

In the context of this element, the term "document" will be used to include policies, procedures, engineering drawings, databases, and other documents or information requiring control and retention.

\section{Control}

\section{Document Control Systems}

Author's Note: Additional Requirements for this subelement are included in the Operations Functional Area.

\section{REQUIREMENT SOURCE: DOE-STD-1073-93 Chapter 2, Section 2.3.2.3,} Paragraph 6

"Notification of Pending Changes. Pending changes are those for which conceptual design has been approved and the design change is in process, those changes that have been implemented in the field, but for which the document revision has not been completed. The document control organization should provide notice of pending changes to the persons on the controlled distribution list for the document involved. A notice of the pending change should also be attached to, or appropriately referenced on, the affected master document, in order to alert anyone requesting a copy of the document."

\section{REQUIREMENT SOURCE: DOE5000.3B Section $8 . \mathrm{g}$}

"All supporting information pertaining to each Occurrence Report (e.g., graphs, analyses, etc.) shall be retained in accordance with DOE Order 1324.2A."

\section{Computer Use}

\section{REQUIREMENT SOURCE: DOE1330.1D Section 8.g}

"Each site will have procedures in place which discourage the abuse or misuse of the software operated at the site or any of the data associated with that software. Custom-developed software will have safeguards against abuse or misuse identified and incorporated into the software as early in the development process as possible. " 
Records Management Planning

\section{REQUIREMENT SOURCE: DOE1324.2A Preamble, Section 9.b}

"Identify and plan for the preservation of records documenting the organization, functions, policies, decisions, procedures, and essential transactions, including records containing evidence or information necessary for the protection of the rights of the Government and individuals."

\section{REQUIREMENT SOURCE: DOE1324.2A Chapter I, Section 3}

"IDENTIFY OR OBTAIN DISPOSITION AUTHORITY. The completed inventory is reviewed to determine the proper disposition authority for each filing series. The files described will fall into one of the following categories:

a. Nonrecord material. This is disposed of when no longer needed.

b. Record material covered by the GRS or Department of Energy Records Schedule (DOERS). Filing series descriptions are compared to the item descriptions in the schedules. Where they match closely enough to determine coverage, the schedule and item number, are indicated in block 7 of DOE F 1324.10.

c. Record material not covered by existing schedules.

(1) Two situations are possible:

(a) The filing series description simply cannot be matched against any of the descriptions in the schedules, or

(b) They can be matched but the creator or holder of the records does not agree with the authorized disposition of those schedules.

(2) In either case, DOE F 1324.5, "Request for Records Disposition Authorization," must be completed and submitted through the appropriate records officers to AD-242."

\section{REQUIREMENT SOURCE: DOE1324.6 Section 12.b}

"Determine whether or not an electronic document is a record in sufficient time to prevent unauthorized erasure or change."

Storage

\section{Controls and Facilities for Records Storage}

\section{REQUIREMENT SOURCE: DOE1324.3 Chapter I, Section 5.a}

"Decentralization of Files.

(1) Departmental policy provides for the maximum feasible decentralization of file stations.

This policy provides for placing file stations where they will be readily accessible to those who use them most often. This keeps as many records as practicable in small, usable collections. In small files the difficulty of finding a particular document is reduced because there are fewer papers to search through. 
(2) Duplicate file stations consisting of extra copies or other nonrecord material should be established only when official stations are not readily accessible to another group which needs frequent reference to the records."

\section{REQUIREMINT SOURCE: DOE1324.3 Chapter I, Section 5.b}

\section{"Centralization of Files.}

(1) Types of Files Best Suited to Centralization. Centralizing records often results in duplicate recordkeeping and less efficient use of space, personnel, and filing equipment. The practice, therefore, of centralizing files should be limited to those instances where there is a realistic need to centralize. Examples of realistic needs to centralize for documentation and control purposes are: certain regulatory files, official personnel files, construction project files, personnel security files, and contract files. Centralization also may be desirable when several organizational units require frequent reference to the same records.

(2) Location of Users. Records (file stations) should be reasonably close to regular users. Records located in the same room or in the general vicinity of the majority of users normally will provide convenient access. Users located in separate buildings or a considerable distance from the filing station they use will require duplicate files. These additional file stations should be authorized."

\section{REQUIREMENT SOURCE: DOE1324.6 Section 15}

\section{"RECORDS PROTECTION, PRESERVATION, AND ACCESS RESTRICTION.}

Special precautions may need to be taken to ensure the safekeeping of electronically stored data. Before establishing safeguards, the sensitivity of the data should be determined, vulnerabilities identified, and the degree of risk considered. A primary method for identifying and determining the most cost-effective means of protecting such data is through risk assessment, i.e., an orderly process through which potential adverse events can be identified, evaluated, and controlled so as to minimize loss or harm to informational assets. Also, the following items need to be considered:

a. The desirability of retaining a duplicate copy of data (records) as a backup in the event that a recovery should be necessary. Backup copies should be stored in a different area to prevent possible destruction by the same source that destroyed the originals. The organization that supplies software (e.g.,application packages) must be consulted to ensure compliance with copyright provisions before any software can be copied.

b. The necessity for requiring physical security, i.e., limiting physical access to the hardware, assuring fire protection, maintaining an inventory, prohibiting smoking, drinking, or eating near the hardware.

c. Procedures for using the equipment and records may need to be examined to ensure that only authorized persons have access. Provisions of the Privacy Act require the protection of sensitive information. The use of passwords is one technical method of minimizing the possibility of unauthorized access. However, passwords must be adequately protected.

d. Further protection may be afforded the data by using encryption equipment or software that can either transmit or store data in encoded form.

e. Unclassified, sensitive electronic records shall not be processed without the express written approval of the Computer Protection Program Manager in accordance with DOE 1360.2, page 5 , paragraph $6 \mathrm{c}(1)$, which states: "For new or significantly changed sensitive computer 
applications, protection specifications must be reviewed and approved in writing by the Computer Protection Program Manager prior to commencing acquisition or programming action." Consult him or her also for any specific requirements for processing unclassified data applications, e.g., color coded or specifically marked diskettes. In the Computer Protection Program Manager must certify "That new or significantly changed sensitive computer applications are designed reviewed and system tested prior to operational use... Upon successful completion of the system test, the Computer Protection Program Manager shall certify that the system meets the documented and approved system protection specifications; related applicable Federal policies, regulations, and standards; and that the results of the test demonstrate that the protection provisions are adequate to safeguard the sensitive data processed." "

\title{
REQUIREMENT SOURCE: DOE1324.6 Section 11.a
}

\author{
"RETRIEVING ELECTRONICALLY STORED RECORDS.
}

Personnel should be able to easily retrieve electronically stored records until their authorized disposition. This requirement is important when an automated system is upgraded or replaced with a new one. Records stored on the old system should be converted or the new system should be designed so that the records continue to be usable until their authorized disposition date. One possibility is to design systems that are compatible with a variety of other systems. An alternative is to contract with a commercial service that will convert records from one format to another."

\section{REQUIREMENT SOURCE: DOE5500.7B Section 11.b}

"Manner of Storage. Records will be stored at the site in such a manner as to ensure ease of access, retrieval, and control. The site will have the necessary capability to make the records immediately available. Classified records shall be handled in accordance with DOE 5632.5 and DOE 5635.1A; UCNI records will be controlled in accordance with DOE 5635.4."

Retention and Disposal

\section{Controls for Records Retention and Storage Media}

\section{REQUIREMENT SOURCE: DOE1324.2A Preamble, Section 9.c}

"Develop a planned approach to retire or transfer records no longer required for current activities to lower cost storage with a preference for use of Federal Records Centers over local records holding areas."

\section{REQUIREMINT SOURCE: DOE1324.2A Chapter II, Section 2.a(2)}

\author{
"Organizational Unit Designation.
}

(a) Separate RIDS are prepared for each file station. For example, in an office services branch consisting of a mail section, a word processing section, a records management section, and a graphics section, each section has its own set of files constituting four separate file stations which require four separate RIDS, one for each file station.

(b) Responsibility for files maintenance and disposition actions must be assigned to an appropriate staff member." 


\title{
REQUIREMENT SOURCE: DOE1324.2A Chapter I, Section 6
}

\author{
"OTHER CONSIDERATIONS.
}

a. Automatic Data Processing (ADP)/Electronic Records. ADP/electronic, machine-readable information is included in the statutory definition of records. Such records are described separately from hard copy records. This is done by entering a separate subitem on the DOE F 1324.10 to show the filing series is also in an electronic media (e.g., tape or disc). As long as they generally duplicate hard copy records, they have the same disposition. However, they are inventoried separately and their disposition is to be shown.

b. Micrographics. This includes those means of reducing the size of hard copy records, such as microfiche and microfilm. There are instances when reducing records by these means is a sound course of action. Each such project of significant size requires a cost-benefit study to assure the project is clearly to the advantage of the Government when purchase of a micrographic system is contemplated. These copies have to be adequate substitutes for the hard copies they are replacing, and be readable and usable for the approved retention period of those hard copy records. Note that approval of NARA is required if the project involves microfilming of permanent records. Local approval is permitted for temporary records. Once quality control checks are completed on the films, the hard copy records should be disposed of.

c. Classified Records Disposal. Classified documents (records) are scheduled just like unclassified records. While accountability for Secret and Top Secret records is required, the protection of all classified records (including Confidential records) involves high costs in manpower, space, and filing equipment. The disposition of accountable documents involves special effort because of security requirements. Vigorous efforts are to be made to assure compliance with disposition authorities. Nonrecord and extra copies of classified documents are promptly disposed of when no longer needed. DOE 5635.1A, CONTROL OF CLASSIFIED DOCUMENTS AND INFORMATION, of 2-12-88, contains the security requirements and procedures for these documents. Classification of the records is to be indicated on the DOE F 1324.10 to aid in complying with the procedures in DOE 5635.1A.

d. Unclassified, Sensitive Information. This category of records includes Unclassified Controlled Nuclear Information (UCNI) Naval Nuclear Propulsion Information (under the cognizance of NE-60), Export Controlled Information, Official Use Only Information, and a variety of other sensitive information on which controls are placed by organizations. No attempt will be made to comply with the numerous requirements for the handling, including special markings, of these records in records holding areas or in Federal Records Centers. However, where these types of records are recalled by their custodial office or organization it is incumbent on that office to comply with the requirements in Departmental regulations or directives, such as DOE 5635.4, PROTECTION OF UNCLASSIFIED INFORMATION, of 2-3-88. No action on these records will be taken by records personnel."

\section{REQUIREMENT SOURCE: DOE1324.2A Chapter II, Section 2.d}

"Using RIDS.

(1) The approved RIDS is the basic document in the management plan. They are to be reviewed, analyzed, and compiled at records officer level, i.e., each Departmental and M\&O contractor records officer will have a plan for their records management activities, based on the RIDS. 
(2) Some considerations in using RIDS are as follows:

(a) Records are to be disposed of no later than 1 year from their authorized disposal dates (records material disposal dates are stated as the minimum periods of time which records must be retained).

(b) Nonrecord material should be disposed of prior to but no later than the scheduled disposal date (nonrecord material disposal dates are construed as maximum, rather than minimum, periods).

(c) Disposal and transfer of inactive records are accomplished on a regular basis; coordination with the servicing FRC is required prior to transfers of such records;

(d) An expedited timetable is necessary if records accumulate rapidly; and

(e) Given careful planning, actions under the management plan are scheduled as much as possible so as not to interfere with current operations."

\section{REQUIREMENT SOURCE: DOE5500.7B Section 11.c}

"Disposition of Records. Emergency Operating Records shall be maintained until they are superseded or replaced. Once superseded, these records revert to standard records disposition requirements."

\section{LESSONS LEARNED}

\section{REQUIREMENT SOURCE: DOE5480.19(920518) Chapter VI, Section C.8}

"Patterns of deficiencies such as operator errors or inadequate procedures should be trended. A periodic summary report of events, causes, and trends should be submitted to department heads, the facility manager, and appropriate managers. Department heads should ensure training programs include appropriate material from the summary report."

\section{KEY INTERFACES}

The Management Systems Functional Area is a collection of systems and processes which service all other functional areas. Interfaces with the various Management Systems elements are identified by the other functional areas.

All the other functional areas interface with Management Systems for requirements/standards related to:

r Aspects of functional area management and administration regarding the need for policies and procedures, definition of an organizational structure, stafing, training, and qualification;

ค Policy and procedure preparation, review, approval, control, and maintenance.

Issue management systems for the identification, evaluation, and prioritization of issues, determination of root causes, and the development, tracking, and completion of appropriate corrective action;

- Compliance management processes for the identification and implementation of new and changed requirements/standards; 
- Management assessments for the evaluation of Tank Farms activities to determine the degree of compliance with applicable requirements/standards;

Identification, categorization, notification, reporting, investigation, and tracking of occurrences;

^ Operational readiness reviews and readiness assessments;

- Document control systems to ensure current documents are available to and used by Tank Farms personnel;

- Records storage provisions to ensure records generated at Tank Farms are available for future reference;

- Records disposition measures to ensure records generated at Tank Farms are retained only until their specified retentions; and

ح Lessons learned processes for the identification and dissemination of information regarding Tank Farms activities and events to permit continuation of those that are desirable and prevention of those that are not.

Specific interfaces between Tank Farms functional areas are discussed in the following sections.

\section{Quality Assurance}

Interface with the Quality Assurance Functional Area for requirements/standards related to the need for:

- Procedures, instructions, and other appropriate means to perform work at Tank Farms;

- An organizational structure, functional responsibilities, levels of authority, and interfaces for the managing, performing, and assessing work at Tank Farms.

\section{Configuration Management}

Interface exists with the Configuration Management Functional Area for requirements/standards related to measures for the protection of master copies of Tank Farms documents.

\section{$\underline{\text { 1.10.3 }} \quad$ Training and Qualification}

The primary requirement source document for personnel training is DOE Order $5480.20 \mathrm{~A}$, Personnel Selection, Qualification, Training, and Staffing Requirements at DOE Reactor and Non-Reactor Nuclear Facilities. General and detailed requirements from this and other source document applicable to personnel training are identified in the T\&Q Functional Area.

Responsible authorities of the various programs should interface closely with the T\&Q Functional Area to coordinate development of training modules and determine the most effective way to accomplish the various types of training, e.g., what type of training would be most effective and which organization should develop and deliver the training. 
$\underline{1.10 .4}$

$\underline{1.10 .5}$

1.10 .6

1.11

$\underline{1.11 .1}$

\section{Emergency Management}

Requirements for the identification, categorization, notification, and reporting of emergencies are detailed in the Emergency Management Functional Area.

\section{Operations}

Interface exists with the Operations Functional Area for Tank Farms for requirements/standards related to definition of:

- The need for policies and procedures to support operations at Tank Farms;

- The general content of polices governing Tank Farms operations.

Compliance and implementation is an Operations Function.

\section{Nuclear Safety}

Review and approval of policies and procedures requires interface with the Nuclear Safety Functional Area for Tank Farms for requirements/standards related to safety evaluations for Unreviewed Questions.

\section{REFERENCES}

\section{Requirement Source Documents}

The following documents were used as requirement sources in the development of this S/RID:

10 CFR 830, Nuclear Safety Management, Part 120, Quality Assurance Requirements, 5/5/94.

DOE 1324.2A, Records Disposition, 9/13/88; Change 1, 4/9/92.

DOE 1324.3, Files Management, 3/2/81; Change 1, 4/9/92.

DOE 1324.6, Automated Office Electronic Recordkeeping, 7/8/87; Change 1, 6/12/92.

DOE 1330.1D, Computer Software Management, 5/18/92.

DOE 4330.4B, Maintenance Management Program, 2/10/94.

DOE 5000.3B, Occurrence Reporting and Processing of Operations Information, 1/19/93;

Change $1,7 / 2 / 93$.

DOE 5480.19, Conduct of Operations Requirements for DOE Facilities, 7/9/90; Change 1, $5 / 18 / 92$.

DOE 5480.21, Unreviewed Safety Questions, 12/24/91.

DOE 5480.26, Trending and Analysis of Operations Information Using Performance Indicators, $1 / 15 / 93$.

DOE 5480.29, Employee Concerns Management System, 1/15/93. 
DOE 5482.1B, Environmental, Safety, and Health Appraisal Program, 9/23/86; Change 1, $11 / 18 / 91$.

DOE 5500.7B, Emergency Operating Records Protection Program, 10/23/91.

DOE-STD-1073-93, Guide for Operational Configuration Management Program, 11/93.

RLID 5480.31, Startup and Restart of Facilities Operational Readiness Review and Readiness Assessments, 09/26/94.

RLIP 5484.1A, Environmental Protection, Safety, and Health Protection Information Reporting Requirements, 02/26/93.

Reviewed Documents Not Used as Requirement Sources

The following documents were reviewed as requirement sources but were not used in the development of this S/RID:

10 CFR 50 Appendix B, Quality Assurance Criteria for Nuclear Power Plants and Fuel Reprocessing Plants, 3/25/94.

DOE 1300.2A, DOE Technical Standards Program, 5/19/92.

DOE 1324.4A, Micrographics Management, 5/18/92.

DOE 1324.5A, Records Management Program, 4/30/92.

DOE 1340.1B, Management of Public Communications Publications and Scientific, Technical, and Engineering Publications, 1/7/93.

DOE 1360.1B, Acquisition and Management of Computing Resources, 1/7/93.

DOE 1360.6A, ADP Equipment/Data Systems, 11/12/92.

DOE 1430.1D, Scientific and Technical Information Management, 6/30/94.

DOE 1430.2B, Scientific and Technical Information Management Program, 2/25/93.

DOE 1430.4A, Library Services, 5/18/92.

DOE 2300.1B, Audit Resolution and Followup, 6/8/92.

DOE 2320.1C, Cooperation with the Inspector General, 5/18/92.

DOE 2320.2B, Establishment of Departmental Position on Inspector General Reports, 5/18/92.

DOE 3220.1 A, Management of Contractor Personnel Policies and Programs, 5/14/92.

DOE 3220.3A, Human Resource Development for M\&O Contractors, 5/18/92.

DOE 3410.1B, Training Management Plan; Change 2, 5/18/92.

DOE 4320.2A, Capital Assessment Management Process, 2/10/94.

DOE 4700.1, Project Management System, 3/6/87; Change 1, 6/2/92. 
DOE 5480.20A, Personnel Selection, Qualification, Training, and Staffing Requirements at DOE Reactor and Non-Reactor Nuclear Facilities; Change 1, 11/15/94.

DOE 5480.22, Technical Safety Requirements, 2/25/92; Change 1, 9/15/92.

DOE 5480.23, Nuclear Safety Analysis Reports, 4/03/92; Change 1, 3/10/94.

DOE 5480.31, Startup and Restart of Nuclear Facilities, 9/15/93.

DOE 5484.1, Environmental Protection, Safety, and Health Protection Information Reporting Requirements, 2/24/81; Change 7, 10/17/90.

DOE 5500.1B, Emergency Management System, 4/30/91; Change 1, 2/27/92.

DOE 5500.2B, Emergency Categories, Classes, and Notification and Reporting Requirements, 4/30/91; Change 1, 2/27/92.

DOE 5500.3A, Planning and Preparedness for Operational Emergencies, 4/30/91; Change 1, $2 / 27 / 92$.

DOE 5632.5, Physical Protection of Classified Matter, 12/3/88; Change 1, 7/30/93.

DOE 5635.1A, Control of Classified Documents and Information, 2/12/88.

DOE 5639.1, Information Security Program, 10/19/92.

DOE 5650.2B, Identification of Classified Information, 12/31/90; Change 2, 4/28/93.

DOE 5650.3A, Identification of Unclassified Controlled Nuclear Information, 6/8/92.

DOE/EH 0135, Criteria for Technical Safety Appraisals, 4/90.

DOE NE/SP-000IT, Writer's Guide for Technical Procedures, 9/91.

DOE-SAGD, Self Assessment Guidance Document, 12/92.

DOE-STD-1073-93, Guide to Operational Configuration Management Program, 11/93.

DOE-STD-3006-93, Planning and Conduct of Operational Readiness Reviews, 11/93.

ANSI/ANS-3.2-88, Administrative Controls and Quality Assurance for the Operational Phase of Nuclear Power Plants, 4/6/89.

EMCA-202, Order Compliance Self-Assessment Instruction, 8/3/92.

RL 5482.1B, ES\&H QA Appraisal and Surveillance Program, 3/4/87.

S/RIAI, Standards/Requirements Implementation Assessment Inspection, 9/1/94.

S/RID-DAI, Standards/Requirements Identification Document Development and Approval Instruction, 9/1/94.

NUREG-0899, Guidelines for Preparation of Emergency Operating Procedures, 8/82. 
ASME-NQA-1-1994, Quality Assurance Program Requirements for Nuclear Facility Applications, 1994.

BMP-86-024, Software Controls for Plant Computers, 12/91.

BMP-85-026, Writing Guidelines for Maintenance, Test, and Calibration Procedures, 6/85.

BMP-90-015, Performance Objectives and Criteria for Operating and Near Term Operating License Plants, 8/90. 
TABLE OF CONTENTS

2.0 QUALITY ASSURANCE

2.1

2.6

2.12 .1

2.12.2

2.12 .3

2.12 .4

2.12 .5

2.12 .6

2.13
MANAGEMENT AND ADMINISTRATION $\ldots \ldots \ldots \ldots \ldots \ldots$

QUALITY ASSURANCE PROGRAM ................ 3

TRAINING AND QUALIFICATION OF PERSONNEL . . . . . . . . 3

QUALITY IMPROVEMENT $\ldots \ldots \ldots \ldots \ldots \ldots \ldots \ldots$

DOCUMENTS AND RECORDS $\ldots \ldots \ldots \ldots \ldots \ldots \ldots$

WORK PROCESSES $\ldots \ldots \ldots \ldots \ldots \ldots \ldots \ldots \ldots$

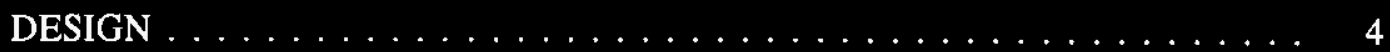

PROCUREMENT $\ldots \ldots \ldots \ldots \ldots \ldots \ldots \ldots \ldots \ldots$

INSPECTION AND ACCEPTANCE TESTING $\ldots \ldots \ldots \ldots \ldots \ldots$

MANAGEMENT ASSESSMENT $\ldots \ldots \ldots \ldots \ldots \ldots \ldots \ldots$

INDEPENDENT ASSESSMENT $\ldots \ldots \ldots \ldots \ldots \ldots \ldots$

KEY INTERFACES $\ldots \ldots \ldots \ldots \ldots \ldots \ldots \ldots \ldots \ldots \ldots \ldots$

Training and Qualification $\ldots \ldots \ldots \ldots \ldots \ldots$

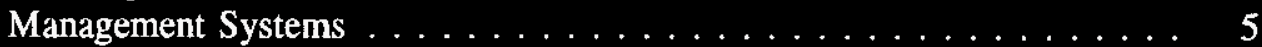

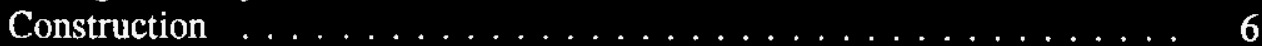

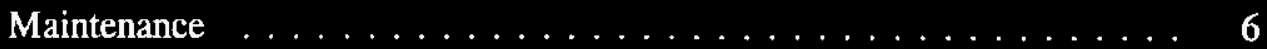

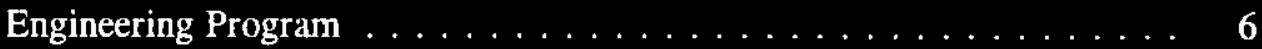

Environmental Protection $\ldots \ldots \ldots \ldots \ldots$

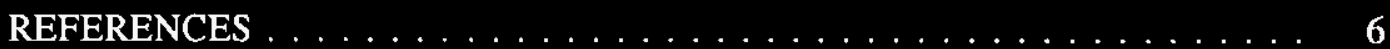

2.13.1

2.13 .2 


\subsection{QUALITY ASSURANCE}

\section{INTRODUCTION}

A Standards/Requirements Identification Document (S/RID) sets forth the Environmental Safety and Health (ES\&H) standards/requirements. This S/RID is applicable to the appropriate life cycle phases of design, construction, operation, and preparation for decommissioning for each of the categories of facilities addressed in Revision 5 of the Department of Energy Implementation Plan for the Defense Nuclear Facilities Safety Board (DNFSB) Recommendation 90-2. This Recommendation calls for the strengthening of U.S. Department of Energy (DOE) weapons complex activities through the identification and application of relevant DOE Orders, regulations, industry codes/standards, industry guidance documents and, as appropriate, good industry practices. These standards/requirements are adequate to ensure protection of the health and safety of workers, the public, and the environment.

The Tank Farms S/RID contains standards/requirements that are necessary for safe operation of the Tank Farms and its associated facilities, and that are the direct responsibility of the specific facility manager. The Quality Assurance Program defined in this document is described in general accordance with the Environment, Safety, and Health Configuration Guide, Revision 0, dated July 30, 1993, and is presented in program elements. The Tank Farms is considered a nuclear facility, therefore, requirements included are citations directly extracted from 10 CFR 830.120, "Quality Assurance Requirements."

This S/RID contains only those requirements that Tank Farms personnel are clearly responsible to satisfy. Other requirements that are applicable to Tank Farms, but are satisfied by others, are defined in the Westinghouse Hanford Company (WHC) S/RID. For application in this S/RID, the words "shall and "should" in requirements statements both indicate mandatory compliance. The Key interface information contained in the Functional Area documents is provided for general recognition and understanding and is not considered to contain prescriptive requirements.

The company-level Quality Assurance (QA) Functional Area Document addresses QA requirements which are implemented at a company level. These company-level QA requirements apply to Management and Administration of the WHC QA Program, Standards Laboratory control of Measurement and Test Equipment (M\&TE), independent assessment, and corrective action tracking activities.

\section{SCOPE}

This S/RID applies to the Tank Waste Remediation Systems (TWRS) Organization which includes the following:

- East Tank Farm Transition Project

- West Tank Farm Transition Project

- Evaporator Project

- Interim Stabilization Project 
- Characterization Sampling Project (Excluding the Labs)

The near-term mission of TWRS is to store, treat, and immobilize the highly radioactive Hanford Site Waste. 


\section{MANAGEMENT AND ADMINISTRATION}

Author's Note: The requirements for Management and Administration of the WHC QA Program are included in the company-level Quality Assurance Functional Area Document for implementation.

\section{QUALITY ASSURANCE PROGRAM}

\section{REQUIREMENT SOURCE: 10CFR830 Part 120(c)(1)(i)}

"Program. A written QAP shall be developed, implemented, and maintained. The QAP shall describe the organizational structure, functional responsibilities, levels of authority, and interfaces for those managing, performing, and assessing the work. The QAP shall describe management processes, including planning, scheduling, and resource considerations."

\section{TRAINING AND QUALIFICATION OF PERSONNEL}

Author's Note: The training requirements for the administration of general and specialized training within QA are deferred to the TWRS Training and Qualification Functional Area Document. Requirements which have been identified for implementation by the company-level Training Organization are included in the company-level Training and Qualification Functional Area Document.

\section{REQUIREMENT SOURCE: 10CFR830 Part 120(c)(1)(ii)}

"Personnel Training and Qualification. Personnel shall be trained and qualified to ensure they are capable of performing their assigned work. Personnel shall be provided continuing training to ensure that job proficiency is maintained."

\section{QUALITY IMPROVEMENT}

Author's Note: The company corrective action management system [Hanford Action Tracking System (HATS)] is implemented at the company level and requires use by the facilities.

\section{REQUIREMENT SOURCE: 10CFR830 Part 120(c)(1)(iii)}

"Quality Improvement.

Processes to detect and prevent quality problems shall be established and implemented. Items, services, and processes that do not meet established requirements shall be identified, controlled, and corrected according to the importance of the problem and the work affected. Correction shall include identifying the causes of problems and working to prevent recurrence. Item characteristics, process implementation, and other quality-related information shall be reviewed and the data analyzed to identify items, services, and processes needing improvement. "

\section{DOCUMENTS AND RECORDS}

Author's Note: The document control and records storage and retrieval processes have been deferred to the TWRS Management Systems Functional Area Document. 


\section{REQUIREMENT SOURCE: 10CFR830 Part 120(c)(1)(iv)}

"Documents and Records.

Documents shall be prepared, reviewed, approved, issued, used, and revised to prescribe processes, specify requirements, or establish design. Records shall be specified, prepared, reviewed, approved, and maintained. ${ }^{n}$

\section{WORK PROCESSES}

Author's Note: As discussed in the ES\&H Configuration Guide, requirements for monitoring surveillance and inspection activities which, upon implementation, prevent, detect, and mitigate the release of harmful materials into the environment by providing for the collection, preparation, analysis, validation, verification, and documentation of environmental data are addressed in the TWRS Environmental Protection (EP) Functional Area Document. Specifically, requirements have been extracted from the following source documents and included in Element 20.3 (Environmental Monitoring, Surveillance, and Inspections) of the TWRS EP Functional Area Document:

- WAC 246-247 (Section 075), "Radioactive Air Emissions"

- $\quad 40$ CFR 61 (Subpart 93), "National Emission Standards for Hazardous Air Pollutants (NESHAPS)"

- TPA (Attachment 2, Section 6.5), "Hanford Federal Facility Agreement and Consent Order [Tri-Party Agreement (TPA)]"

\section{REQUIREMENT SOURCE: 10CFR830 Part 120(c)(2)(i)}

"Work Processes. Work shall be performed to established technical standards and administrative controls using approved instructions, procedures, or other appropriate means. Items shall be identified and controlled to ensure their proper use. Items shall be maintained to prevent their damage, loss, or deterioration. Equipment used for process monitoring or data collection shall be calibrated and maintained."

\section{DESIGN}

Author's Note: Specific requirements for design have been deferred to the TWRS Engineering Program Functional Area Document.

\section{REQUIREMENT SOURCE: 10CFR830 Part 120(c)(2)(ii)}

"Design. Items and processes shall be designed using sound engineering/scientific principles and appropriate standards. Design work, including changes, shall incorporate applicable requirements and design bases. Design interfaces shall be identified and controlled. The adequacy of design products shall be verified or validated by individuals or groups other than those who performed the work. Verification and validation work shall be completed before approval and implementation of the design." 


\section{REQUIREMENT SOURCE: 10 CFR830 Part 120(c)(2)(iii)}

"Procurement. Procured items and services shall meet established requirements and perform as specified. Prospective suppliers shall be evaluated and selected on the basis of specified criteria. Processes to ensure that approved suppliers continue to provide acceptable items and services shall be established and implemented. "

INSPECTION AND ACCEPTANCE TESTING

Author's Note: Calibration requirements for the Standards Lab Control of Measurement and Test Equipment (M\&TE) are addressed in the company-level QA Functional Area Document.

\section{REQUIREMENT SOURCE: 10CFR830 Part 120(c)(2)(iv)}

"Inspection and Acceptance Testing. Inspection and testing of specified items, services, and processes shall be conducted using established acceptance and performance criteria. Equipment used for inspections and tests shall be calibrated and maintained."

MANAGEMENT ASSESSMENT

\section{REQUIREMENT SOURCE: 10CFR830 Part 120(c)(3)(i)}

"Management Assessment.

Managers shall assess their management processes. Problems that hinder the organization from achieving its objectives shall be identified and corrected."

\subsection{1}

INDEPENDENT ASSESSMENT

Author's Note: The area of audits and assessments is a major interface with all organizations in the dissemination of audit and assessment results and follow-up and closure of audit findings and assessment deficiencies or recommendations. Requirements for this element are addressed in the company-level QA Functional Area Document. TWRS is committed to having independent assessments conducted in accordance with the company-level QA Functional Area Document.

\section{KEY INTERFACES}

\section{$\underline{2.12 .1}$}

\section{Training and Qualification}

The QA Functional Area must provide input to and utilize the output from the Training and Qualification Functional Area for general and specialized training within QA, such as, general employee training for QA and corrective action, and the development of training modules.

\section{$\underline{2.12 .2}$}

\section{Management Systems}

Requirements for Tracking and Trending Analysis of identified QA issues are addressed in the TWRS Management Systems Functional Area Document. Document Control and records management processes established in the TWRS Management Systems Functional Area Document apply to QA records. 
$\underline{\underline{2.12 .3}}$

$\underline{2.12 .4}$

$\underline{2.12 .5}$

$\underline{2.12 .6}$

2.13

$\underline{2.13 .1}$

$\underline{2.13 .2}$

\section{Construction}

The TWRS Construction Functional Area Document incorporates QA requirements for construction program controls which are imposed by incorporation of appropriate quality assurance clauses in construction management and construction contracts, and implemented through procedures and instructions.

\section{Maintenance}

The TWRS QA Functional Area Document provides oversight and inspection requirements. The TWRS Maintenance Functional AREA incorporates into its processes the QA controls for ensuring inspections are complete, quality problems are detected and prevented, and quality improvement measures are imposed.

\section{Engineering Program}

The TWRS Engineering Program Functional Area Document has incorporated QA requirements to ensure that appropriate QA controls are imposed for design processes and related activities.

\section{Environmental Protection}

The QA Functional Area addresses control of work processes which would include requirements pertaining to monitoring, surveillance, and testing activities. Per the ES\&H Configuration Guide, the TWRS EP Functional Area Document discusses these activities and has included QA requirements that provide programmatic controls and describe methods of implementation.

\section{REFERENCES}

\section{Requirement Source Documents}

The following documents were used as requirement sources in the development of this S/RID:

10 CFR Part 830, Nuclear Safety Management, 04/05/94.

\section{Reviewed Documents Not Used as Requirement Sources}

The following documents were reviewed as requirement sources but were not used in the development of this S/RID:

10 CFR 50 Appendix A, General Design Criteria for Nuclear Power Plants

10 CFR 50 Appendix B, Quality Assurance Criteria for Nuclear Power Plants and Fuel Reprocessing Plants

40 CFR 61, "National Emission Standards for Hazardous Air Pollutants (NESHAPS), EPA, Amendments as of 07/01/94

DOE Order 4700.1, Project Management System, 06/22/92

DOE Order 5700.6C, Quality Assurance, 08/21/91 
DOE/RW/0333P, QA Requirements and Description for the Civilian Radioactive Waste Management Program, 12/18/92

ANSI/ASME N45.2-1977, Quality Assurance Program Requirements for Nuclear Facilities ASME-NQA-1-1994, Quality Assurance Requirements for Nuclear Facility Applications, 94 ASME-NQA-3-1989, Quality Assurance Program Requirements for the Collection of Scientific and Technical Information for Site Characterization of High-Level Nuclear Waste Repositories

International Organization for Standardization (ISO) 9000, Quality Management and Quality Assurance Standards-Guidelines for Selection and Use

International Organization for Standardization (ISO) 9004-1987, Quality Management and Quality System Elements-Guidelines

International Atomic Energy Agency (IAEA) International Nuclear Safety Advisory Group's Safety Series No. 75-INSAG-3, Basic Safety Principles for Nuclear Power Plants Use

U.S. EPA, Interim Guidelines and Specifications for Preparing Quality Assurance Project Plans (QAMS-005/80), 12/29/80

NUREG 1293 Rev. 1, Quality Assurance Guidance for a Low-Level Radioactive Waste Disposal Facility

"DRAFT" ANSI/ASQC E4-19xx, Specifications and Guidelines for Quality Systems for Environmental Data Collection and Environmental Technology Programs, Draft 09/91

WAC 246-247, "Radioactive Air Emissions," DOH Amendment as of 01/31/94

SNT-TC-1A, American Society for Nondestructive Testing, 1984 Edition

TPA, "Hanford Federal Facility Agreement and Consent Order [Tri-Party Agreement (TPA)]," 03/01/94 



\section{TABLE OF CONTENTS}

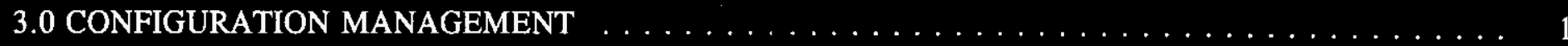

3.1

3.1 .1

3.1 .2

3.1 .3

3.1 .4

3.1 .5

3.2
MANAGEMENT AND ADMINISTRATION . . . . . . . . . 2

Program Boundary Definition $\ldots \ldots \ldots \ldots \ldots$

Program Assessment $\ldots \ldots \ldots \ldots \ldots \ldots \ldots \ldots \ldots \ldots \ldots$

Document and Database Control ................ 5

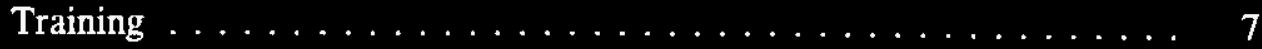

Graded Approach $\ldots \ldots \ldots \ldots \ldots \ldots \ldots \ldots \ldots \ldots$

TECHNICAL BASELINE $\ldots \ldots \ldots \ldots \ldots \ldots \ldots \ldots$

Establishing The Technical Baseline $\ldots \ldots \ldots \ldots \ldots$

Reconstitution of the Technical Baseline $\ldots \ldots \ldots 8$

CHANGE CONTROL $\ldots \ldots \ldots \ldots \ldots \ldots$

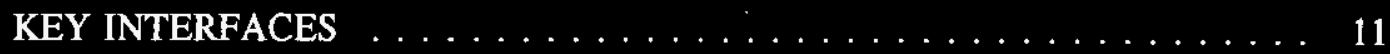

Management Systems . . . . . . . . . . . . . . . 11

Engineering Program $\ldots \ldots \ldots \ldots \ldots \ldots \ldots \ldots \ldots \ldots \ldots$

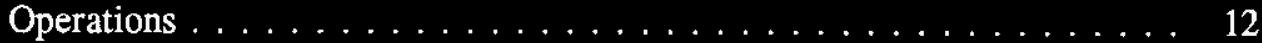

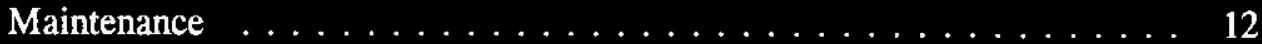

Nuclear Safety . . . . . . . . . . . . . . . . . 12

Training and Qualification $\ldots \ldots \ldots \ldots \ldots \ldots \ldots$

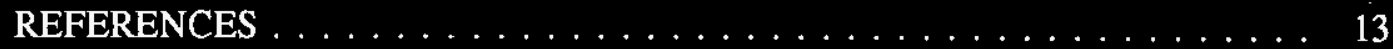

Requirement Source Documents . . . . . . . . . . . . . . . 13

Reviewed Documents Not Used as Requirement Sources . . . . . . . . . . 13 


\subsection{CONFIGURATION MANAGEMENT}

\section{INTRODUCTION}

A Standards/Requirements Identification Document (S/RID) sets forth the Environmental Safety and Health (ES\&H) standards/requirements. This S/RID is applicable to the appropriate life cycle phases of design, construction, operation, and preparation for decommissioning for each of the categories of facilities addressed in Revision 5 of the Department of Energy Implementation Plan for the Defense Nuclear Facilities Safety Board (DNFSB) Recommendation 90-2. This Recommendation calls for the strengthening of DOE weapons complex activities through the identification and application of relevant DOE Orders, regulations, industry codes/standards, industry guidance documents and, as appropriate, good industry practices. These standards/requirements are adequate to ensure protection of the health and safety of workers, the public, and the environment.

The Tank Farms S/RID contains standards/requirements that are necessary for safe operation of the Tank Farms and its associated facilities, and that are the direct responsibility of the specific facility manager. The Configuration Management Program defined in this document is described in general accordance with the Environment, Safety, and Health Configuration Guide, Revision 0, dated July 30, 1993, and is presented in program elements and subelements. The specific DOE Orders, regulations, industry codes/standards, guidance documents and good industry practices that serve as the basis for each element/subelement are identified and aligned with each subelement.

This S/RID contains only those requirements that Tank Farms personnel are clearly responsible to satisfy. Other requirements that are applicable to Tank Farms, but are satisfied by others, are defined in the Westinghouse Hanford Company (WHC) Level S/RID. For application in this S/RID, the words "shall" and "should" in requirements statements both indicate mandatory compliance. The Key interface information contained in the Functional Area documents is provided for general recognition and understanding and is not considered to contain prescriptive requirements.

\section{SCOPE}

This S/RID applies to the Tank Waste Remediation Systems (TWRS) Organization which includes the following:

$\begin{array}{ll}- & \text { East Tank Farm Transition Project } \\ \text { - } & \text { West Tank Farm Transition Project } \\ \text { - } & \text { Evaporator Project } \\ \text { - } & \text { Interim Stabilization Project } \\ & \text { Characterization Sampling Project (Excluding the Labs) }\end{array}$

The near-term mission of TWRS is to store, treat, and immobilize the highly radioactive Hanford Site Waste. 
Author's Note: Additional requirements are included in the Engineering Functional Area.

\section{REQUIREMENT SOURCE: 10CFR830 Part 120(c)(2)(i)}

"Performance

Work Processes. Work shall be performed to established technical standards and administrative controls using approved instructions, procedures, or other appropriate means. Items shall be identified and controlled to ensure their proper use. Items shall be maintained to prevent their damage, loss, or deterioration. Equipment used for process monitoring or data collection shall be calibrated and maintained."

\section{REQUIREMENT SOURCE: DOE-STD-1073-93 Chapter 2, Section 2.1.2, Paragraph 6, Sent. 2 thru 4}

"The CM program should provide for the review and approval of vendor procedures prior to the commencement of work or impose the use of facility procedures in all work performed at the facility... acceptance criteria should be established... and vendor information... should be incorporated directly into the facility document control program..."

REQUIREMENT SOURCE: DOE-STD-1073-93 Chapter 2, Section 2.1.4.1, Paragraph 3, Sent. 1 thru 3

"Action plans should... identify how CM development activities and results will be communicated throughout the organization... Action plans should also establish methods for measuring and controlling progress, ... management accountabilities,... status reports, and periodic management reviews..."

REQUIREMENT SOURCE: DOE-STD-1073-93 Chapter 2, Section 2.1.4.2, Paragraph 1, Sent. 1 and 3

"Configuration management governing procedures should... support the action plan... The CM program plan should identify the CM governing procedures that will be developed."

REQUIREMENT SOURCE: DOE-STD-1073-93 Chapter 2, Section 2.1.4.2, Paragraph 2, Sent. 1 and 2

"The CM governing procedures... should indicate how the CM functions are carried out in the various implementing procedures, and thus, how those functions conform with the $\mathrm{CM}$ program plan."

\section{REQUIREMENT SOURCE: DOE-STD-1073-93 Chapter 2, Section 2.1.4.3,} Paragraph 1

\footnotetext{
"The program management element should also ensure that appropriate implementing procedures prepared for each $\mathrm{CM}$ program function. In contrast with governing procedures, the implementing procedures provide the detailed instructions for carrying out CM program functions. Implementing procedures are developed for individual program elements as needed. The size of the operating organization influences the need to proceduralize CM activities; the larger the organization and the more numerous the interfaces, the greater the need for procedural controls."
} 
REQUIREMENT SOURCE: DOE-STD-1073-93 Chapter 2, Section 2.2.1.5, Paragraph 1

"The CM equipment database should be established to cross-reference the CM program SSC's with their design requirements, design basis, and associated documents. It should use the BEST Available Design Information to fill the database fields. The Best Available Design Information comes from three basic sources:

(1) existing design information,

(2) new or revised design information, and

(3) reconstituted design information."

Program Boundary Definition

Author's Note: Requirements are included in the Engineering Program Functional Area.

Program Assessment

REQUIREMENT SOURCE: DOE-STD-1073-93 Chapter 1, Section 1.3.5.1, Paragraph a, Sent. 1 thru 5

"Initial assessments, [include] two vertical slice assessments... One of these should be on a safety system related to the principal facility hazard... Two horizontal slice assessments... one of these should be on change control and the other on a technical topical area... [should also be performed.]"

\section{REQUIREMENT SOURCE: DOE-STD-1073-93 Chapter 1, Section 1.3.5.1, Paragraph b}

"Post-implementation assessments. After the CM program upgrades are implemented, a horizontal slice assessment should be performed for each CM program element to determine if that element addresses identified weaknesses and is effective in accomplishing the CM functions. For each system design information summary (DIS) developed by the DR adjunct program, a field validation should be performed to ensure that the design requirements are accurately reflected in the physical configuration and the associated facility documentation. After the MCA adjunct program is developed, a technical quality review should be performed of its assumptions, methods, and products."

\section{REQUIREMENT SOURCE: DOE-STD-1073-93 Chapter 1, Section 1.3.5.1, Paragraph c}

"Periodic effectiveness assessments. After the CM program and its adjunct programs have been implemented, a combination of vertical and horizontal slice assessments should be performed periodically to measure the overall $\mathrm{CM}$ program effectiveness and to determine if CM controls are adequate and appropriate. The results of these assessments should establish the basis for revisions to the CM program plan, either increasing or decreasing controls."

\section{REQUIREMENT SOURCE: DOE-STD-1073-93 Chapter 1, Section 1.3.5.2}

"Physical configuration assessments, or walkdowns, should be performed for representative sample SSCs to determine the degree of agreement between the physical configuration and the configuration depicted in the facility documentation. Physical walkdowns should be included as part of the programmatic assessments conducted during the initial assessments, post-implementation assessments, and periodic effectiveness assessments. If substantive 
discrepancies (either in number or type) are discovered, appropriate immediate corrective actions should be developed to establish agreement between the physical configuration and the documentation. The corrective actions should include additional walkdowns to characterize the problem and to determine the extent of the problem. They should also include technical evaluations to determine whether the physical configuration or the documentation should be changed."

\section{REQUREMENT SOURCE: DOE-STD-1073-93 Chapter 1, Section 1.3.5.3}

"Structures, systems, and components within the CM program should be tested periodically to determine if they are still capable of meeting their design requirements. This monitoring should also address surveillance actions, periodic in-service inspections and tests, and other monitoring of SSCs to ensure safe and reliable operation of the facility. Monitoring should also include measurements and trending of data related to the actual aging degradation of equipment, to the extent identified by the MCA adjunct program and approved by the design authority."

\section{REQUIREMENT SOURCE: DOE-STD-1073-93 Chapter 1, Section 1.3.5.4}

"An SSC within the CM program should be tested after modification (and before being turned over for service) to determine if it is capable of meeting its design requirements (i.e., the post-implementation acceptance criteria). If a changed SSC fails to meet its post-implementation acceptance criteria, turnover for operation should be postponed until either a technical review has been completed and any follow-up actions are completed or until the SSC is returned to its original condition and tested satisfactorily."

\section{REQUIREMENT SOURCE: DOE-STD-1073-93 Chapter 2, Section 2.3.1.1, Paragraph 2}

"First, a complete survey of document types in use should be conducted with support of the various organizations at the facility. Each organization should identify the document types it prepares and the important document types it uses. Document types identified during the initial assessments should also be addressed."

\section{REQUIREMINT SOURCE: DOE-STD-1073-93 Chapter 2, Section 2.3.1.2,} Paragraph 1, Sentences $1 \& 2$

"For each document type to be included in the CM program, the adequacy of the existing document control process should be evaluated against each of the basic document control functions. A survey of existing document control processes should be conducted to identify the process that either identifies, stores, controls, tracks, or retrieves the included document types."

\section{REQUIREMINT SOURCE: DOE-STD-1073-93 Chapter 2, Section 2.5.3.1, Sentences 1 thru 4}

"These assessments periodically examine existing functions and processes related to the $\mathrm{CM}$ program to ensure their continued effectiveness and to identify improvements and enhancements, if needed. Similar to the initial assessments, periodic program effectiveness assessments use a combination of vertical slice and horizontal slice assessment methods. Objective measures and criteria to assess effectiveness should be defined and used. These periodic assessments should be used as the technical basis for adjusting the $\mathrm{CM}$ program by increasing or decreasing the controls." 
REQUIREMENT SOURCE: DOE-STD-1073-93 Chapter 2, Section 2.5.3.3, Paragraph 3, Sent. 1 and 4

"Performance monitoring programs should be implemented to routinely monitor,... trend, and analyze performance data... for SSC's within the CM program... This responsibility should include the establishment of performance goals and acceptance criteria consistent with the associated SSC design requirements. "

\section{Document and Database Control}

Author's Note: Additional requirements are included in the Management Systems Functional Area.

\section{REQUIREMENT SOURCE: 10CFR830 Part 120(c)(1)(iv)}

"Documents and Records.

Documents shall be prepared, reviewed, approved, issued, used, and revised to prescribe processes, specify requirements, or establish design. Records shall be specified, prepared, reviewed, approved, and maintained."

\section{REQUIREMENT SOURCE: DOE-STD-1073-93 Chapter 1, Section 1.3.1.5}

"Databases for use in the identification, storage, control and retrieval of information important to configuration management should be established, and policy and criteria for their use should be defined."

\section{REQUIREMENT SOURCE: DOE-STD-1073-93 Chapter 2, Section 2.1.3, Paragraph 2}

"Well coordinated and controlled databases become primary focal points of effective CM programs. There are two general types of CM databases that need to be established and controlled: equipment databases and document databases. Equipment databases contain and correlate information about the SSC's within the CM program, while document databases convey information about the documents, including their status. Both databases provide information useful for the evaluation of changes. Properly designed and well-managed equipment and document databases are essential configuration management tools; they support many functions important to safe facility operation. Such databases are included in the scope of the CM program because they contain and correlate vital configuration management information."

\section{REQUIREMENT SOURCE: DOE-STD-1073-93 Chapter 2, Section 2.1.3, Paragraph 3}

"Because of the importance of these databases to the CM program, the program management element should define policies and procedures for establishing and controlling them. A site/division CM directive could be used to define general policy and criteria for $\mathrm{CM}$ equipment and document databases. The CM program plans should discuss the steps necessary for developing (or validating) and controlling these databases." 
REQUIREMENT SOURCE: DOE-STD-1073-93 Chapter 2, Section 2.1.3, Paragraph 5

"The steps to develop effective CM databases should include the identification of those databases that contain CM-related information, the consolidation of related information into a few key databases, and the establishment of control mechanisms to ensure data quality and accuracy. An initial study should be conducted to identify existing equipment and document databases, their contents and uses, responsible organizations, and locations. This initial study should reflect the results of, and may be performed in conjunction with, other initial assessments."

\section{REQUIREMENT SOURCE: DOE-STD-1073-93 Chapter 2, Section 2.1.3, Paragraph 7, Sentence 2}

"Special controls should be instituted to ensure that any database used for configuration management purposes will be protected to prevent inadvertent or unauthorized changes of the data."

\section{REQUIREMINT SOURCE: DOE-STD-1073-93 Chapter 2, Section 2.1.3, Paragraph 8}

"Equipment databases should specify equipment classifications, contain or reference equipment design requirements, and cross-reference supporting $\mathrm{CM}$ information. These databases should provide current information on facility SSC's and associated documents within the CM program, with emphasis on design documents. An approach that has proven successful elsewhere is the development of a computerized CM master equipment database that includes every facility component. Each component is assigned a unique identifier based on system, component type, and component function before it is included in the database. This database can serve as the primary source of descriptive, testing, and operational data on hardware and instrumentation. Equipment databases are discussed further in the implementation guidance for the design requirements program element. "

\section{REQUIREMENT SOURCE: DOE-STD-1073-93 Chapter 2, Section 2.3.2.4, Paragraph 3}

"As defined in the program criteria, the document database should have the capability to identify documents within the CM program on the basis of their relationship to particular SSC's (such as a particular pump), types of SSC's (such as motor-operated valves), technical topics (such as fire protection), and other relational data (such as the specific vendor) necessary for the identification of documents. This information should be integrated with the types of information discussed above (e.g., information regarding pending changes) for document control and tracking. Consideration should be given to assigning key words or using fully searchable text files for the most important documents."

\section{REQUIREMENT SOURCE: DOE-STD-1073-93 Chapter 2, Section 2.3.2.4, Paragraph 4, Sent. 1 and 6}

"Availability and retrieval times should be based on the needs of document owners and users. This should be followed by periodic monitoring to ensure that document retrieval requirements continue to be adequate." 


\section{$\underline{3.1 .4}$}

$\underline{\mathbf{3 . 1 . 5}}$

3.2

\section{Training}

Training requirements are addressed in the Training and Qualification Functional Area Document.

\section{Graded Approach}

\section{REQUIREMENT SOURCE: DOE-STD-1073-93 Chapter 1, Section 1.4.2.5, Paragraph 1}

"The graded approach involves both the assignment of grades and the subsequent application of those grades in determining the degree of implementation. The importance and priorities of SSCs within a facility need to be considered within the context of the overall importance of the facility. The objective is to ensure that the highest level of attention and resources is applied to the most important SSCs at the most important facilities. Grading should focus on avoiding the cost of applying high levels of attention where such attention is not warranted. It is important that the grading system include consideration of both the overall facility importance grade and the importance grades for the SSCs within the facility."

\section{TECHNICAL BASELINE}

Author's Note: Additional Requirements are included in the Engineering Functional Area.

\section{REQUIREMENT SOURCE: DOE-STD-1073-93 Chapter 1, Section 1.3.2.1,} Paragraph c

"The design requirements should be incorporated into an equipment database that correlates each SSC with the SSC grade, the design requirements, technical topics involved, and associated documentation."

REQUIREMENT SOURCE: DOE-STD-1073-93 Chapter 1, Section 1.3.2.1, Paragraph d

"The design requirements for new facilities and modifications to existing facilities should be established, categorized, and documented as they are developed, in a form amenable to review and addition to the equipment database."

\section{REQUIREMENT SOURCE: DOE-STD-1073-93 Chapter 1, Section 1.3.2.2}

"The boundaries for each system and process should be established in such a manner as to contain the components necessary to satisfy the design requirements for that system or process."

\section{REQUIREMENT SOURCE: DOE-STD-1073-93 Chapter 1, Section 1.3.2.3}

"Each SSC should be assigned a grade based on the most important type of design requirements applicable to it. The SSC grade should be used as the basis for the degree of control on all activities associated with the SSC."

\section{REQUIREMENT SOURCE: DOE-STD-1073-93 Chapter 1, Section 1.3.2.4}

"On the basis of the equipment scope criteria and the assignment of SSC grades, the specific SSCs included in the CM program should be identified. " 


\section{REQUIREMIENT SOURCE: DOE-STD-1073-93 Chapter 1, Section 1.3.2.5, Paragraph b}

"The design basis for new or modified design requirements should be established and documented as these requirements are developed."

\section{REQUIREMENT SOURCE: DOE-STD-1073-93 Chapter 2, Section 2.2.1, Paragraph 2}

"Configuration management program criterion 1.3.2.1 states that the design requirements and design basis should be formally established, documented, and maintained. The CM program should identify the various processes and procedures used to establish the design requirements and design basis. For new facilities and physical changes to existing facilities, the program should ensure that procedures are in place that adequately establish the associated design requirements and their design basis, and that document them in a form suitable for use in the CM program. Documentation of the design requirements includes their correlation with associated SSC's and their categorization by type (i.e., safety, environmental, mission, and other). Documentation of the design basis involves its correlation with associated design requirements. Once the design requirements and design basis are established and documented, the CM program should ensure that processes and procedures are in place to maintain them so that they are complete and accurate. "

\section{REQUIREMENT SOURCE: DOE-STD-1073-93 Chapter 2, Section 2.2.1.2, Paragraph 2}

"To ensure a format suitable for use in the operational CM program, the design requirements and design basis should be differentiated, the design requirements should be correlated with the associated SSC's, the design basis should be correlated with the design requirements, the design requirements should be categorized (i.e., safety, environmental, mission, or other), and accurate as-built drawings should be provided. Timely recognition of these interfaces and appropriate coordination will save time and avoid additional costs after turnover."

Reconstitution of the Technical Baseline

\section{REQUIREMENT SOURCE: DOE-STD-1073-93 Chapter 1, Section 1.3.6.1}

\section{Author's Note: Criterion 1.3.1.1.c is not included in this document.}

"A program plan, an action plan, and implementing procedures should be developed for the DR adjunct program. The DR program plan should be based on the initial assessments and the graded approach. The DR adjunct program should be implemented in stages to provide a timely initial set of design information and more information as it becomes available. It should include prioritization of the development and issuance of DISs. Design information summaries for systems or technical topics necessary to support the facility accident analysis and TSRs should receive the highest priority. The DR program plan should address the same topics identified for the CM program plan (described in criterion 1.3.1.1.c)."

\section{REQUIREMENT SOURCE: DOE-STD-1073-93 Chapter 1, Section 1.3.6.2, Paragraph a}

"Identification and Retrieval of Source Documents. The objective and scope of source documents to be reviewed should be defined for each document identification and retrieval 
stage. The recommended stages are the formal review, the smart search, and the comprehensive search. The formal review should address those on-hand documents, such as the facility safety analysis and TSRs, that contain summary-type design information; the smart search should identify and retrieve those types of documents that can be identified as most likely to contain design requirements; and the comprehensive search should identify and retrieve any remaining documents that might contain design information, including DOE correspondence and vendor correspondence."

\section{REQUIREMENT SOURCE: DOE-STD-1073-93 Chapter 1, Section 1.3.6.2, Paragraph b}

"Extraction of Design Information. Technical review and identification of design information from each source document should include both design requirements and design basis information. Extracted design information should be identified as to the applicable facility SSC, type of SSC, technical topic area, and whether it is a design requirement or design basis. The technical review and identification of design information from each source document should be complete, such that the document does not have to be reconsidered during subsequent searches and reviews."

\section{REQUIREMINT SOURCE: DOE-STD-1073-93 Chapter 1, Section 1.3.6.3}

"Extracted design information should be verified by a second party to ensure that the design information was extracted completely and accurately from the source documents. Extracted design information should be technically validated to ensure that it is reasonable, that it is applicable to the current facility mission and configuration, and that the analytical methods and technical assumptions used in the design process are valid and appropriate. Design basis information should be correlated with the design requirements. Extracted design information should also be evaluated to identify any missing design requirements or design basis information. Design Information Summaries should be field validated to ensure that design requirements are properly reflected in the physical configuration and in the associated facility documentation."

\section{REQUIREMENT SOURCE: DOE-STD-1073-93 Chapter 1, Section 1.3.6.4, Sentences 2 and 3}

"...open items should be dispositioned by a formal resolution process and should be tracked to completion and closeout, including documentation of their resolution. Safety-significant open items (i.e., discrepancies) should be promptly addressed by existing programs for determining operability and reportability and resolved by those programs."

\section{REQUIREMENT SOURCE: DOE-STD-1073-93 Chapter 1, Section 1.3.6.5}

"Missing design information should be evaluated to determine which part needs to be regenerated. Missing design information that is critical, including that necessary to support the facility accident analysis and TSRs, should be regenerated in order of priority."

\section{REQUIREMENT SOURCE: DOE-STD-1073-93 Chapter 1, Section 1.3.6.6, Paragraph 1}

"Extracted design requirements should be entered into the CM equipment database promptly after verification and technical validation. Design information summaries should include a system description (including systems interface information), system operability requirements, system-level design requirements, component-level design requirements, the design basis, and related design topical information. They also should identify design requirements by type; 
attributes of the design that were not mandatory for the designer should be distinguished from other types of design requirements. The authorization basis should be clearly distinguished from other aspects of the design basis. The DISs should be written for easy use by individuals at all levels of experience. ${ }^{n}$

\section{CHANGE CONTROL}

\section{REQUIREMENT SOURCE: DOE-GUIDE-10CFR830 Section 6.6}

"Design Changes. Design changes, including field changes and nonconforming items dispositioned "use-as-is" or "repair," should be controlled by measures commensurate with those applied to the original design. Temporary modifications should receive the same levels of control as the designs of permanent modifications."

\section{REQUIREMENT SOURCE: DOE-STD-1073-93 Chapter 1, Section 1.3.4.1}

"All mechanisms that can lead to temporary or permanent changes in the design requirements, facility configuration, or facility documentation within the CM program should be identified. Such mechanisms might include hardware modifications not controlled as projects, hardware modifications controlled as projects, maintenance changes, operational changes, procurement changes, document changes, and computer software changes. Change mechanisms should be evaluated to determine which are adequate as is, and which need to be improved, consolidated, or terminated. The resulting change mechanisms should be integrated with the CM program. Within approved CM change mechanisms, each proposed change, including temporary changes and partially implemented changes, should be described sufficiently to support technical reviews, management reviews, and approvals. "

\section{REQUIREMENT SOURCE: DOE-STD-1073-93 Chapter 1, Section 1.3.4.2}

"Each specific proposed change should be reviewed to determine if it is within the bounds of the design requirements. Changes to the design requirements should be evaluated and approved by design authority prior to implementation. The technical reviews should evaluate safety, environmental, and mission impacts; determine appropriate post-implementation acceptance criteria; and identify the affected SSCs and facility documentation."

\section{REQUIREMENT SOURCE: DOE-STD-1073-93 Chapter 1, Section 1.3.4.3}

"Before implementation, management should review proposed changes (including those that do not involve a change to design requirements) to verify that the technical reviews have been performed adequately, that the change package is complete and ready for implementation, and that any external approvals necessary prior to implementation have been obtained. On the basis of these reviews, management should take approval action."

\section{REQUIREMENT SOURCE: DOE-STD-1073-93 Chapter 1, Section 1.3.4.4}

Author's Note: Criterion 1.3.5.4 is in section 3.1.2 of this document.

"Each change should be implemented in accordance with its approved change package. The change process should include mechanisms for field change requests, and technical reviews and approvals of field changes should be commensurate with those of the original change package. The change process should generate accurate as-built information. After the physical implementation of changes, post-modification testing should be conducted (see criterion 1.3.5.4)." 


\section{REQUTREMENT SOURCE: DOE-STD-1073-93 Chapter 1, Section 1.3.4.5}

"Each change should be documented and that documentation should include a description of the change, as well as an account of the technical reviews, management approvals, as-built information, and post-modification test results. Documents that are included in the CM program and are affected by a change, either directly or indirectly, should be revised."

\section{REQUIREMENT SOURCE: DOE-STD-1073-93 Chapter 2, Section 2.4.1.1, Paragraph 2, Sentence 4}

"Mechanisms for temporary physical changes and temporary document changes should be identified for formal change control."

\section{REQUIREMENT SOURCE: DOE-STD-1073-93 Chapter 2, Section 2.4.1.2, Paragraph 1}

"After the various sources of change have been identified, a determination should be made regarding which of those processes alter the configuration and therefore need formal controls. Formal control measures should be provided for any change process that affects either (1) the physical configuration, as defined by the SSC's included in the CM program or (2) the facility documents included in the $\mathrm{CM}$ program. An example of a change mechanism that might be out of scope is the control of scaffolding that cannot affect an SSC within the CM program (i.e., no system interaction through falling, etc.) or its associated documentation."

\section{REQUIREMENT SOURCE: DOE-STD-1073-93 Chapter 2, Section 2.4.2.1}

"Specific changes should be identified only within established change processes. The need for a potential change may be identified by anyone within the facility and should be documented by the requester to support the processing of the change request. As defined by the $\mathrm{CM}$ program criteria, each proposed change should be described adequately to support technical and management reviews prior to approval. Change initiation should include the name of the requester, a description of the proposed change, the affected SSCs and associated SSC grade, the reason for the change, alternative solutions, due date, and constraints. It should also include any other information needed for review, tracking, approval and further processing."

\section{KEY INTERFACES}

\section{Management Systems}

The CM Functional Area interfaces with several elements of Management Systems. Issue Management should provide a process for the handling of possible discrepancies between a reconstituted technical baseline and the existing configuration. Compliance Assessment should be used to verify CM Program conformance to requirements.

CM policies and procedures and supporting requirements for Document Control Records Management are elements of the Management Systems Functional Area. Management Systems provides the necessary infrastructure and ensures that positive administrative controls are in place to support CM Program development, implementation, and maintenance. CM policies and procedures must be developed and promulgated by management in accordance with requirements identified in the Management Systems Functional Area. 


\section{$\underline{3.4 .2}$}

The Engineering Program Functional Area should provide for the establishment and maintenance of the engineering related technical requirements and should include technical review of changes within the scope of the CM Program. Material Condition and Aging is covered in the Engineering Program Functional Area.

The design process is established in accordance with requirements specified in the Engineering Program Functional Area. The CM Program must effectively control the data and information that is used as design input and created as design output by the Engineering Program function.

\section{Operations}

Operational activities can contribute to inadvertent and undocumented changes that may deviate from the established technical baseline. The Operations Functional Area should provide requirements to ensure that the proper technical reviews to guard against these kinds of changes are conducted.

The CM Program ensures the adequacy, accuracy, and currency of the drawings, procedures, and data/information used to operate the facility. The technical requirements identified and controlled by the CM Program are used by procedure developers and operators to control equipment and systems within safe operating envelopes. Changes to either the design or the equipment installed are translated to effective operations via the $\mathrm{CM}$ process.

\section{$\underline{3.4 .4}$}

\section{Maintenance}

Configuration Management ensures that safety-related drawings, flow control diagrams, electrical one-lines, I\&C schematics, etc., of critical structures, systems and components are controlled and reflect the current approved configuration/operational status. Maintenance should ensure that any activities that change the design of the facility are treated as design changes and are implemented using applicable design control and configuration management guidelines. Maintenance work request should be periodically reviewed to ensure that they are not used to implement facility design and configuration changes.

The requirements documents effecting configuration control are identified in the Engineering Functional Area of this S/RID.

\section{Nuclear Safety}

The Nuclear Safety Functional Area should include the appropriate safety requirements which are included in the technical baseline which forms the foundation of the CM Program and that technical reviews conducted on changes incorporate the needed nuclear safety attributes.

The CM Program helps ensure that the information used for Nuclear Safety analyses is accurate, complete, and up-to-date. The CM process should ensure that the impact of design and facility changes will be identified and addressed to ensure that the SSCs are operated and maintained within the maximum safe limits. The Nuclear Safety Functional Area should also ensure that appropriate safety requirements are included in the CM controlled technical baseline of Tank Farms. 


\section{Training and Oualification}

Training is required for personnel to perform certain CM Program specific activities. Additional training is required for a broader spectrum of the Tank Farms staff to provide awareness of the CM Program, its elements, and functions.

\section{REFERENCES}

\section{Requirement Source Documents}

10 Code of Federal Regulations Part 830, Nuclear Safety Management, 04/05/94

DOE-STD-1073-93 DOE Standard, Guide for Operational Configuration Management Program, Parts I and II, November 1993

DOE Implementation Guide for 10 CFR $830.120,08 / 94$

\section{Reviewed Documents Not Used as Requirement Sources}

DOE 4330.4B, Maintenance Management Program, February 10, 1994.

DOE 4700.1, Project Management System, Change 1, June 2, 1992.

DOE 5480.19,Conduct of Operations Requirements for DOE Facilities, Change 1, May 18, 1992.

DOE 5700.6C, Quality Assurance, August 21, 1991.

DOE 6430.1A, General Design Criteria, April 6, 1989.

DOE/EH0135, Criteria for Technical Safety Appraisal, June 1990.

ASME-NQA-1-1994, Quality Assurance Program Requirements for Nuclear Facility Applications, 1994.

NUREG/CR-4640, Handbook of Software Quality Assurance Techniques Applicable to the Nuclear Industry.

NUREG/CR-5147, Fundamental Attributes of a Configuration Management Program.

EPRI NP-5640, Modification and Design Control Guidelines for Generic Problem Prevention (NCIG-06), Volumes 1 and 2, March 1988.

NUMARC 90-12, Design Basis Guidelines.

BMP 87-006, Report on Configuration Management in the Nuclear Industry, July 1987.

NIRMA-PP02-1989, Position Paper on Configuration Management. 



\section{TABLE OF CONTENTS}

\subsection{TRAINING AND QUALIFICATION}

4.1.1

4.1 .2

4.2

4.2 .1

4.2.2

4.2 .3

4.2 .4

4.2 .5

4.2 .6

4.2 .7

4.2.8

4.2.8.1

4.2.8.2

4.2 .9

4. 2.10

Program Policy $\ldots \ldots \ldots \ldots \ldots \ldots \ldots \ldots \ldots \ldots \ldots \ldots \ldots \ldots$

Training Organization Staffing and Training $\ldots \ldots \ldots \ldots$

ADMINISTRATION OF TRAINING $\ldots \ldots \ldots \ldots \ldots \ldots$

Selection and Qualification $\ldots \ldots \ldots \ldots \ldots$

Training Needs Assessment $\ldots \ldots \ldots \ldots \ldots$

Design and Development . . . . . . . . . . . . . . 9

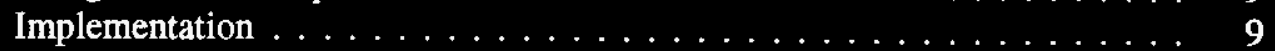

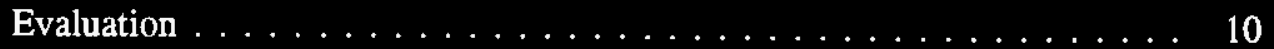

Facilities and Equipment $\ldots \ldots \ldots \ldots \ldots \ldots \ldots$

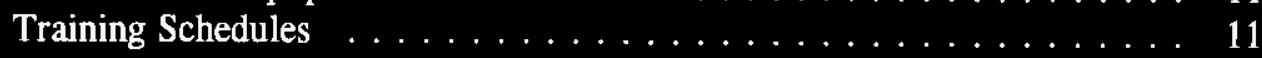

Testing, Qualification, Certification .............. 11

Testing ................................. 11

Qualification and Requalification .............. 12

Revision and Update of Training . . . . . . . . . . . . . . . 14

Extension, Exceptions and Alterations $\ldots \ldots \ldots \ldots \ldots$

TRAINING CATEGORIES AND SUBJECTS $\ldots \ldots \ldots \ldots \ldots \ldots$

General Employee Training $\ldots \ldots \ldots \ldots \ldots \ldots$

Lockout and Tagout Training $\ldots \ldots \ldots \ldots \ldots$

Hazard Communication Training $\ldots \ldots \ldots \ldots \ldots$

Maintenance Training Program . . . . . . . . . . . . . . . . 18

Management and Supervisory Training .............. 19

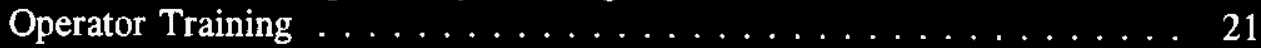

Continuing Training $\ldots \ldots \ldots \ldots \ldots \ldots \ldots \ldots \ldots \ldots \ldots \ldots$

Technical Support Personnel Training . . . . . . . . . . . . . . . 23

TRAINING RECORDS AND DOCUMENTATION $\ldots \ldots \ldots \ldots \ldots \ldots$

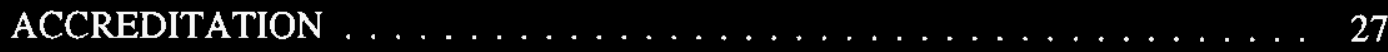

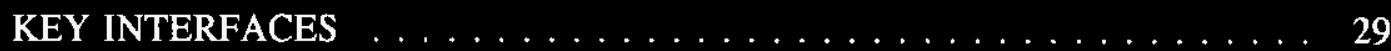

Management Systems . . . . . . . . . . . . . . . . . . . . 29

Quality Assurance . . . . . . . . . . . . . . . . . . . . 29

Configuration Management $\ldots \ldots \ldots \ldots . \ldots \ldots$

Emergency Management $\ldots \ldots \ldots \ldots \ldots \ldots$

Safeguards and Security $\ldots \ldots \ldots \ldots \ldots \ldots \ldots \ldots \ldots \ldots$

Engineering Program $\ldots \ldots \ldots \ldots \ldots \ldots \ldots$ 
4.6.7

4.6.8

4.6 .9

4.6.10

4.6.11

4.6 .12

4.6 .13

4.6 .14

4.6 .15

4.6 .16

4.6 .17

4.6 .18

4.6.19

4.7
Construction Program . . . . . . . . . . . . . . 30

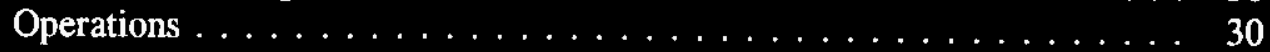

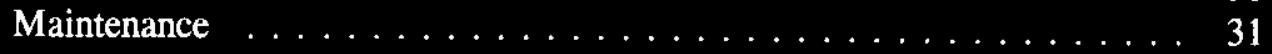

Radiation Protection .................... 31

Fire Protection $\ldots \ldots \ldots \ldots \ldots \ldots \ldots \ldots \ldots \ldots \ldots \ldots \ldots \ldots$

Packaging and Transportation . . . . . . . . . . . . 32

Environmental Restoration . . . . . . . . . . . . . . . 32

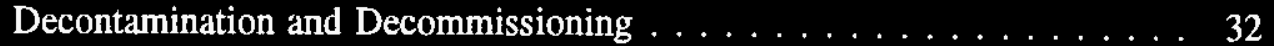

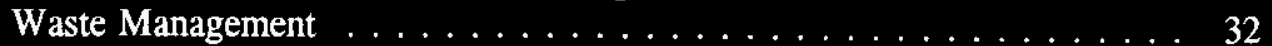

Research and Development and Experimental Activities . . . . . . . . . 32

Nuclear Safety . . . . . . . . . . . . . . . . . . 32

Occupational Safety and Health . . . . . . . . . . . . . 32

Environmental Protection $\ldots \ldots \ldots \ldots \ldots \ldots \ldots \ldots$

REFERENCES ......................... 33

Requirement Source Documents $\ldots \ldots \ldots$. . . . . . . . . . 33

Reviewed Documents Not Used as Requirement Sources . . . . . . . . . 34 


\subsection{TRAINING AND QUALIFICATION}

\section{INTRODUCTION}

A Standards/Requirements Identification Document (S/RID) sets forth the Environmental Safety and Health (ES\&H) standards/requirements. This S/RID is applicable to the appropriate life cycle phases of design, construction, operation, and preparation for decommissioning for each of the categories of facilities addressed in Revision 5 of the Department of Energy Implementation Plan for the Defense Nuclear Facilities Safety Board (DNFSB) Recommendation 90-2. This Recommendation calls for the strengthening of DOE weapons complex activities through the identification and application of relevant DOE Orders, regulations, industry codes/standards, industry guidance documents and, as appropriate, good industry practices. These standards/requirements are adequate to ensure protection of the health and safety of workers, the public, and the environment. The Tank Farms S/RID contains standards/requirements that are necessary for safe operation of the Tank Farms and its associated facilities, and that are the direct responsibility of the specific facility manager.

The Training and Qualification Program defined in this document is described in general accordance with the Environment, Safety, and Health Configuration Guide, Revision 0, dated July 30, 1993, and is presented in program elements and subelements. The specific DOE Orders, regulations, industry codes/standards, guidance documents and good industry practices that serve as the basis for each element/subelement are identified and aligned with each subelement. Several additional subelements have been included in this S/RID that are not specifically identified in the ES\&H Configuration Guide. This has been done to improve the readability and usability of the S/RID. Some subelements have been divided in order to allow readers to focus on requirements in logical groups. additionally, subelements have been added to accommodate the transfer of training related requirements from other functional area S/RIDs, thus allowing all training requirements to be contained in the Training and Qualification S/RID. Subelements added for these reasons include: Program Policy (4.1.1), Training Organization and Staffing (4.1.2), Testing (4.2.8.1), Qualification and Requalification (4.2.8.2), Extension, Exceptions and Alterations (4.2.10), General Employee Training (4.3.1), Lockout and Tagout Training (4.3.1.1), Hazard Communication Training (4.3.1.2), Maintenance Training Program (4.3.2), Management and Supervisory Training (4.3.3), Operator Training (4.3.4), Continuing Training (4.3.5), Technical Support Personnel Training (4.3.6). Subelements 4.6.1 thru 4.6.19 were added to provide further key interface definition. Element 4.7 was added to address document references.

This S/RID contains only those requirements that Tank Farms personnel are clearly responsible to satisfy. Other requirements that are applicable to Tank Farms, but are satisfied by others, are defined in the Westinghouse Hanford Company (WHC) Level S/RID. For application in this S/RID, the words "shall" and "should" in requirement statements both indicate mandatory compliance. The key interface information contained in the Functional Area documents is provided for general recognition and understanding and is not considered to contain prescriptive requirements. Additionally, some of the requirements cited int his document are intentionally duplicated in the corresponding Company Level S/RID. This was necessary to address required implementation responsibilities occurring at both the company and facility levels. 


\section{SCOPE}

This S/RID applies to the Tank Waste Remediation Systems (TWRS) Organization which includes the following:

\section{East Tank Farm Transition Project}

- West Tank Farm Transition Project

- Evaporator Project

- Interim Stabilization Project

Characterization Sampling Project (Excluding the Labs)

The near-term mission of the TWRS is to store, treat, and immobilize the highly radioactive Hanford Site Waste. 


\section{1}

$\underline{4.1 .1}$

\section{MANAGEMENT AND ADMINISTRATION}

\section{Program Policy}

\section{REQUIREMENT SOURCE: 10CFR830 Part 120(c)(3)(i)}

"Management Assessment.

Managers shall assess their management processes. Problems that hinder the organization from achieving its objectives shall be identified and corrècted."

\section{REQUIREMINT SOURCE: WAC-173-303 Section 330(1)}

"Training program. The facility owner or operator shall provide a program of classroom instruction or on-the-job training for facility personnel. This program must teach personnel to perform their duties in a way that ensures the facility's compliance with this chapter 173-303 WAC, must teach facility personnel dangerous waste management procedures (including contingency plan implementation) relevant to the positions in which they are employed, must ensure that facility personnel are able to respond effectively to emergencies, and shall include those elements set forth in the training plan required in subsection (2) of this section. In addition: (a) The training program shall be directed by a person knowledgeable in dangerous waste management procedures, and must include training relevant to the positions in which the facility personnel are employed;

(b) Facility personnel must participate in an annual review of the training provided in the training program;

(c) This program must be successfully completed by the facility personnel: (i) Within six months after these regulations become effective; or

(ii) Within six months after their employment at or assignment to the facility, or to a new position at the facility, whichever is later. Employees hired after the effective date of these regulations must be supervised until they complete the training program; and

(d) At a minimum, the training program shall familiarize facility personnel with emergency equipment and systems, and emergency procedures. The program shall include other parameters as set forth by the department, but at a minimum shall include, where applicable:

(i) Procedures for using, inspecting, repairing, and replacing facility emergency and monitoring equipment;

(ii) Key parameters for automatic waste feed cut-off systems;

(iii) Communications or alarm systems;

(iv) Response to fires or explosions;

(v) Response to ground-water contamination incidents; and

(vi) Shutdown of operations."

\section{REQUIREMENT SOURCE: WAC-173-303 Section 330(2)}

"Written training plan. The owner or operator shall develop a written training plan which must be kept at the facility and which must include the following documents and records:

(a) For each position related to dangerous waste management at the facility, the job title, the job description, and the name of the employee filling each job. The job description must include the requisite skills, education, other qualifications, and duties for each position; 
(b) A written description of the type and amount of both introductory and continuing training required for each position; and

(c) Records documenting that facility personnel have received and completed the training required by this section."

Training Organization Staffing and Training

\section{REQUIREMENT SOURCE: DOE5480.20A Chapter I, Section 2}

"TRAINING ORGANIZATION REQUIREMENTS. The operating contractor shall establish one or more organizations to be responsible for the training of operating organization personnel. This organization(s) shall be held accountable for providing facility line management with the support necessary to ensure that personnel in the operating organization are qualified to safely and effectively meet job requirements. In some cases (e.g., Category B reactors, low-hazard (category 3 ) non-reactor nuclear facilities, or less complex, small facilities) this function may be integrated into the operating organization and may not necessarily be officially designated as a training organization. The responsibilities, qualifications, and authority of training organization personnel shall be documented, and managerial responsibilities and authority clearly defined. This organization may include subcontracted personnel who conduct training activities. At sites where a central training organization is used, this organization may be separate from the facility operating organization for support in areas of regulatory training. For example, central training organizations that provide support to line operating organizations may conduct training for the operating organization in regulatory compliance issues (e.g., OSHA training, Radiation Worker training, supervisory/management training, etc.) that have site-wide application, and which have content that is defined from other sources."

\section{REQUIREMENT SOURCE: DOE5480.20A Chapter I, Section 3}

"SUBCONTRACTOR PERSONNEL QUALIFICATION REQUIREMENTS. Subcontractor personnel shall meet the qualification requirements for the job function to be performed. In addition, the operating organization shall ensure that subcontractor and temporary personnel who perform specialized activities (e.g., radiation protection, maintenance, in-service inspection, radiography, and welding) are qualified to perform their assigned tasks. Personnel shall be considered adequately qualified with proper documentation of at least one of the following:

a. The satisfactory result of an audit of subcontractor records which relate to qualification of the subcontractor personnel being considered for assignment by the operating organization, or;

b. The operating organization's previous verification (within 2 years) of the ability of the subcontractor employee to perform assigned tasks safely and efficiently, or;

c. Successful completion by the subcontractor employee of those segments of the operating organization's qualification program which are considered pertinent to accomplishment of the task to be performed.

For subcontractor personnel who do not meet the requirements, work activities on engineered safety features as identified in the facility Safety Analysis Report shall be supervised by a person who meets the qualification criteria established by the operating organization for conduct of the activities." 


\section{REQUIREMENT SOURCE: DOE5480.20A Chapter I, Section 4.a}

"The operating contractor shall establish a process for selection and assignment of personnel into the operating organization. This process should consider factors such as background, experience, and education and should be based on the ability of the person to meet job performance requirements. Selection of operating organization personnel may involve a selection test."

\section{REQUIREMENT SOURCE: DOE5480.20A Chapter I, Section 4.b}

"If an individual does not meet the experience requirements of this Order, consideration may be given to the collective experience of the operating organization. Individuals who do not meet the experience requirements for a position may be assigned to that position provided the overall operating organization is considered balanced and strong and that DOE approval is obtained on a case-by-case basis."

\section{ADMINISTRATION OF TRAINING}

\section{REQUIREMENT SOURCE: 10CFR830 Part 120(c)(1)(ii)}

This citation is included for completeness. It is recognized that DOE5480.20A Paragraph 5 states that "Implementation of the requirements of this Order will meet 10CFR830.120, Criteria 2 - Personnel Training and Qualification."

"Personnel Training and Qualifications. Personnel shall be trained and qualified to ensure they are capable of performing their assigned work. Personnel shall be provided continuing training to ensure that job proficiency is maintained."

\section{REQUIREMENT SOURCE: DOE5480.20A Preamble, Attachment 1}

\section{"DOE 5480.20A, PERSONNEL SELECTION, QUALIFICATION, AND TRAINING} REQUIREMENTS FOR DOE NUCLEAR FACILITIES, of (date), requires that the following requirements be applied to contractors awarded DOE procurement management[sic spelling error] and operating contracts for operable DOE nuclear facilities. Management and operating contractors shall:

1. Implement the requirements of DOE $5480.20 \mathrm{~A}$ as they apply to the facility and the position;

2. Prepare and submit a Training Implementation Matrix to the Operations Office Manager for review and approval;

3. Prepare and submit procedures which establish the requirements for granting exceptions to specific training or qualification requirements for an individual to the Operations Office Manager for review and approval;

4. Provide written requests for certification extensions to the Operations Office Manager for approval; and

5. Prepare and submit an assessment of the need for a simulator to the Operations Office Manager for review and approval (Category $\mathrm{A}$ test and research reactors only).

6. Perform periodic systematic evaluations of training and qualification programs." 


\section{REQUIREMENT SOURCE: DOE5480.20A Preamble, Section 8.a}

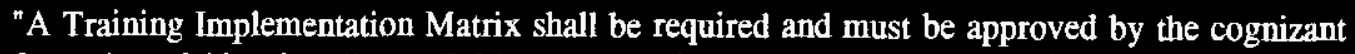
Operations Office for all new DOE reactor and non-reactor nuclear facilities prior to operations. The operating contractor shall meet the requirement of this Order to the extent possible prior to operation. The matrix shall be based on the status of existing compliance and shall include the time-frame for incremental implementation and full implementation of the requirements that are not being met at the time the facility begins to operate."

\section{REQUIREMINT SOURCE: DOE5480.20A Preamble, Section 8.b}

"Contractors with an approved Training Implementation Matrix previously submitted in accordance with the 2-20-91 issuance of this Order shall be required to submit (as necessary) either an addendum or page changes to the Training Implementation Matrix to reflect the changes made as a result of the revision to this Order. Changes shall be submitted to the cognizant Operations Office for approval within 90 days from the issue date of this Order."

\section{REQUIREMENT SOURCE: DOE5480.20A Chapter I, Section 7 Introduction, Sentence 1 and 2}

"TRAINING REQUIREMENTS. Training to support qualification and certification programs shall be based on a systematic approach to training. A graded approach shall be used to establish the systematic approach to training for operations personnel, maintenance personnel, technicians, and the technical staff."

\section{REQUIREMENT SOURCE: DOE5480.20A Chapter I, Section 7.a.(1) Introduction}

"A Training Implementation Matrix which defines and describes the application of the selection, qualification, certification, and training requirements of this Order shall be prepared by the contractor operating organization. The Matrix shall clearly define the organization, planning, and administration of the qualification program and set forth the responsibility, authority, and methods for conducting training. Suitable justification for exceptions shall be included in the Matrix for any requirement not implemented. At some sites with several facilities, a combined Training Implementation Matrix may be submitted."

\section{REQUIREMENT SOURCE: DOE5480.20A Chapter I, Section 7.a.(1)(a)}

"Personnel who are appointed to positions in the operating organization subsequent to approval of the Training Implementation Matrix required by DOE 5480.20 of 2-20-91 shall meet the education and experience requirements of this Order. This excludes personnel who held positions prior to the approval of the Training Implementation Matrix from meeting the education and experience requirements stated for these positions."

\section{REQUIREMENT SOURCE: DOE5480.20A Chapter I, Section 7.a.(1)(b)}

"The Training Implementation Matrix should identify whether future persons selected for these positions will meet the education and experience requirements or include a request for an exception from the requirements for all future appointees if the requirement is deemed inappropriate on the basis of the hazard involved, the complexity of the operation, or the risk involved. This relief from the education and experience requirements does not, however, exclude these personnel from the training requirements identified in this Order for their job positions. Participation is required in job-specific training and qualification/certification programs and subsequent continuing training programs." 


\section{REQUIREMINT SOURCE: DOE5480.20A Chapter I, Section 7.a.(2)}

"The training and qualification program for nuclear facilities should be developed on the basis of the hazards involved and risk associated with the operation of the facility or activity. Accordingly, the level of detail of and content of the Training Implementation Matrix and content of the training programs should reflect the training and qualification needs of these facilities to assure personnel are qualified to carry out their assigned responsibilities (i.e., a graded approach should be applied)."

\section{REQUIREMENT SOURCE: DOE5480.20A Chapter I, Section 7.a.(4)}

"This Order establishes personnel selection, qualification, and training requirements for operable nuclear facilities. There are other training requirements (e.g., other DOE orders and regulations such as those of the Environmental Protection Agency (EPA), Occupational Safety and Health Administration (OSHA), Department of Transportation (DOT), etc.) that may be applicable and need to be implemented. Implementation of such training requirements need not conform to the requirements, methods, and standards established by this Order."

\section{REQUIREMENT SOURCE: DOE5480.20A Chapter I, Section 7.c, Sentences 1-3}

"Initial Training Requirements. An initial training program shall be established for operating organization personnel at operable nuclear facilities to develop or enhance their knowledge and skills to perform job assignments. These programs should be structured commensurate with specific position needs. Examinations (written, oral, operational evaluations, performance demonstrations) on material included in the training programs shall be administered and documented as appropriate. ${ }^{n}$

\section{REQUIREMENT SOURCE: DOE5480.20A Chapter I, Section 7.c, Sentences 4-5}

"Personnel who are in-training shall not independently make decisions or take actions that could affect facility safety, nor shall personnel who are in-training be placed in such positions. However, they may independently perform specific tasks or job assignments for which they are qualified."

Selection and Qualification

\section{REQUIREMENT SOURCE: DOE/EH0256T(940431) Chapter 6, Part 1, Article 616.3}

"Instructors-in-training shall be monitored by a qualified instructor."

\section{REQUIREMIENT SOURCE: DOE/EH0256T(940431) Chapter 6, Part 1, Article 616.4}

"Subject matter experts without instructor qualification may provide training in their areas of expertise. However, these subject matter experts should be trained as instructors when this occurs routinely." 
"The concept of training personnel as a team, stressing team communications and interaction, shall be used where job functions require team solutions and activities. For example, many facility normal and abnormal operations require interaction and coordination of duties among the operating personnel. In cases such as these, team training is necessary."

\section{REQURREMENT SOURCE: DOE5480.20A Chapter I, Section 7.b Introduction, Sentences 1 and 2}

"Training Process. Initial and continuing training programs shall be established to ensure that operating organization personnel are qualified to perform job requirements. This shall be achieved by using a systematic approach to training."

\section{REQUIREMENT SOURCE: DOE5480.20A Chapter I, Section 7.b.(1)}

"A systematic analysis of the jobs to be performed.

Analysis typically involves the conduct of job analysis, needs analysis, or both; job analysis to determine tasks for training, and needs analysis to distinguish between actual and desired performance and to propose workable solutions. The analysis should include both normal and emergency duties. Program goals are then established and the scope of training program content is defined.

A graded approach should be used when analyzing jobs. For example, experience with the conduct of job and task analysis has shown that detailed methods such as those described in industry task analysis procedures or in the DOE Guidelines for Job and Task Analysis for Department of Energy Nuclear Facilities, DOE/EP-0095, are rarely needed. Rather, using qualified trainers and subject matter experts, more simplified methods can produce equivalent results as effectively and more efficiently. One method that can be used to conduct a job analysis is the table-top job analysis method.

This is a method where a team of trainers, subject matter experts (e.g., qualified employees), and supervisors meet to identify duty areas involved in a specific job, tasks performed within each duty area, and tasks that should be included in the training program. The resulting task list typically ranges from the teens to approximately 250 tasks with the average being 125 150 for an operator or maintenance program. At non-reactor nuclear facilities where operator positions are sometimes more narrowly defined than a reactor operator job, the average is less. The verification and modification of task lists from similar facilities and jobs has also been found to be an effective method of job analysis. Similarly, table-top methods can also be used to derive learning objectives from task lists. These methods are less time consuming, more cost effective, and are usually self-validating.

Because of varied complexity and scope of job functions, the degree of analysis (needs analysis, job analysis, task analysis) necessary to define training program content will vary. For example, a job and needs analysis may be appropriate for operations and maintenance personnel, whereas a less formal broad-based assessment of training needs is appropriate for technical staff personnel. Job analyses need not be conducted for technical staff personnel. Consensus-based content guides should be used to assist with the determination of technical staff training program content. This method may also be sufficient to determine training program content for operating organization positions at many category 3 hazard nuclear facilities."

\section{REQUIREMENT SOURCE: DOE5480.20A Chapter I, Section 7.b.(2)}

"Learning objectives derived from the analysis of the job that describe desired performance after training. 
Learning objectives define the content of the training program. They are derived from task statements and represent the knowledge and skills necessary to perform the job. The objectives are organized into instructional units and sequenced to aid in the learning process. The objectives form the "blueprint" which guides the development of all training materials, tests, and strategies. Objectives are determined using one or more content analysis techniques. The most common techniques include verification analysis, document analysis, templating, detailed task analysis, or group brainstorming. In most cases the learning objectives, which address the knowledge and skills necessary to perform the task, can be developed directly from the task list and do not require additional analysis. A graded approach should be used to select the most effective technique for determining the learning objectives. For example, experience has shown that detailed task analysis is not necessary when good operating procedures exist or if improper performance of the task is of low consequence. Group brainstorming or a joint review of the procedure by a trainer and a subject matter expert (SME) can produce acceptable results."

\section{Design and Development}

\section{REQUIREMINT SOURCE: DOE5480.20A Chapter I, Section 7.a Introduction}

"General. Training programs shall consist of a combination of classroom-type and on-the-job training, and include simulator and laboratory training as it applies to the position. Classroom-type training may include lectures, seminars, computer-based training, and structured self-study activities."

\section{REQUIREMENT SOURCE: DOE5480.20A Chapter I, Section 7.b.(3)}

"Training design, development, and implementation based on the learning objectives.

Materials (e.g., lesson plans and OJT guides, training aids, and student materials) are developed to conduct training. The materials should reflect good instructional design and incorporate methods and activities that maximize knowledge and skill retention. Development of additional learning objectives, and in some cases, rewording of objectives also occurs. A graded approach should be used to develop training materials. For example, the training materials used to guide discussions with technical staff trainees could include a one-page outline of the lesson content that includes the key points and a student handout to distribute. The level of detail should take into account the job position and experience of the designated instructor. This approach may also be sufficient for much of the training that is conducted at category 3 hazard nuclear facilities. Training/Evaluation standards are also developed to provide guidance for on-the-job training. Additional activities include development of test items and examinations. Technical and instructional reviews of the products that are developed should be conducted. Recommendations resulting from these reviews should be incorporated as necessary to assure that program content is both technically and educationally sound.

Program implementation consists of activities related to the actual conduct of training, as well as resource allocation, planning, and scheduling. Implementation requires assigning instructors and support staff, scheduling training and facilities, and conducting training."

\section{$\underline{4.2 .4}$}

\section{Implementation}

\section{REQUIREMENT SOURCE: DOE5480.20A Chapter I, Section 7.b.(4)}

"Evaluation of trainee mastery of the objectives during training. 
Mastery of the learning objectives by the trainees should be evaluated periodically during the training. Evaluation methods include oral questioning, written examinations, performance of related tasks by the use of evaluation instruments (e.g., qualification standards, checklists, performance tests, job performance measures (JPM), or other similar methods). Evaluations should be content valid, administered consistently, controlled, and documented as appropriate to the level of assurance needed. Content valid examinations are examinations that accurately and consistently measure the associated learning objectives. A graded approach should be used during evaluation. For example, structured on-the-job familiarization can be used in lieu of formal on-the-job evaluation for managers, non-certified supervisors, and technical staff personnel. Much of the training for managers, non-certified supervisors, and technical staff personnel occurs in nontraditional settings such as discussions with individual managers. In addition, learning objectives for managers, non-certified supervisors, and technical staff personnel may not be readily adaptable to prescribed standards or quantitative testing. In such instances, qualitative evaluations are acceptable. For example, trainee mastery could be assessed from responses during discussions, behavior during role-playing, or material developed during training exercises. Qualitative evaluations may also be used to assess trainee mastery of learning at category 3 hazard nuclear facilities."

Evaluation

\section{REQUIREMENT SOURCE: DOE-STD-1070-94 Section 8, Paragraph 3}

"Tracking Evaluation Results.

Contractor management should submit a written corrective action plan to the DOE line organization representative responsible for the training program that was evaluated. This corrective action plan should address the schedule and actions that will be taken to resolve recommendations."

\section{REQUIREMENT SOURCE: DOE5480.20A Preamble, Section 6.b}

"Evaluations of training and qualification programs shall be conducted using DOE-STD-1070-94."

\section{REQUIREMENT SOURCE: DOE5480.20A Chapter I, Section 7.a.(3), Sentence 1}

"Qualification and certification programs shall be reviewed by contractor facility management and shall be kept up to date to reflect changes to the facility, Safety Analysis Reports, Technical Safety Requirements, procedures, regulations, and applicable industry operating experience."

\section{REQUIREMENT SOURCE: DOE5480.20A Chapter I, Section 7.b.(5)}

"Evaluation and revision of the training based on the performance of trained personnel in the job setting.

Evaluation provides the critical feedback loop to ensure the training is up to date and reflects the requirements of the job. Specifically, training programs are evaluated for program and lesson content adequacy, test adequacy, presentation adequacy, documentation adequacy, and post-training job performance. In addition, the operating performance of job incumbents should be monitored to determine individual strengths and weaknesses. The feedback received from the evaluation process is used to modify and improve program content and delivery. Program content should be periodically monitored and revisions should be made (as appropriate) to include changes in areas such as policies and/or procedures, system or component design, job requirements, regulatory requirements, and industry guidelines or 
4.2.6

$\underline{4.2 .7}$

$\underline{4.2 .8}$

$\underline{4.2 .8 .1}$ commitments. Adjustments should also be made as a result of reviews of operating experience information such as Occurrence Reports, inspection reports, information notices, and bulletins. Feedback obtained from instructors, students, and supervisors is also reviewed for its potential impact on future training programs. The results are translated into action items or recommendations which are factored into program content."

\section{Facilities and Equipment}

DOE 5480.20A Preamble, Section 6.b which is in 4.2 .5 of this document contains requirements applicable to this subelement.

\section{Training Schedules}

\section{REQUIREMENT SOURCE: DOE/EH0135 TC.1.15}

"Training and retraining schedules are maintained to keep all personnel adequately qualified and/or certified. "

Testing, Qualification, Certification

\section{Testing}

\section{REQUTREMENT SOURCE: DOE5480.20A Chapter I, Section 7.d.(4)}

"Personnel who are responsible for developing and delivering training may be excused from continuing training for the area of primary administrative responsibility. For example, an individual who prepares, administers, and grades a written examination need not take the examination."

\section{REQUIREMINT SOURCE: DOE5480.20A Chapter I, Section 8 Introduction}

"OPERATOR AND SUPERVISOR EXAMINATION REQUIREMENTS. Comprehensive written and oral examinations and operational evaluations shall be prepared and administered to demonstrate that certified operator and certified supervisor candidates possess the required knowledge and skills. Comprehensive written examinations and individual performance demonstrations shall be administered to ascertain the qualification of other operator and supervisor candidates that include duties that are important to engineered safety features as identified in the Safety Analysis Report. For Category A reactor facility certified personnel, the oral examination shall be separate from the operational evaluation. Operational evaluations and oral examinations may be combined for Category B reactor and non-reactor nuclear facility certified personnel. These examinations shall contain a representative sampling of the knowledge and skills identified in and derived from the learning objectives resulting from the systematic analysis of the position. Examinations should include questions from sources such as Safety Analysis Reports, Technical Safety Requirements, system description manuals, operating procedures, Occurrence Reports, and other applicable sources."

\section{REQUIREMENT SOURCE: DOE5480.20A Chapter I, Section 8.a}

"Written procedures that establish requirements for examinations shall be developed and implemented. These procedures shall address, at a minimum, examination/evaluation development, approval, security, administration, remediation, and maintenance of examination question banks." 


\section{REQUIREMENT SOURCE: DOE5480.20A Chapter I, Section 8.b}

"Oral examinations may be conducted as a one-on-one walkthrough or by an oral board or committee consisting of personnel identified by contractor facility management. The oral examination content shall be tailored to evaluate the candidate's operational knowledge (initial/continuing training program subjects) and organizational awareness (e.g., operating philosophy, use of procedures, shift and relief turnovers, verification of system/equipment status) to determine how the individual will function in an operating environment."

Qualification and Requalification

\section{REQUIREMENT SOURCE: DOE5480.20A Chapter I, Section 5 Introduction}

"QUALIFICATION PROCESS REQUIREMENTS. Qualification is defined in terms of education, experience, training, examination, and any special requirements necessary for performance of assigned responsibilities. The requirements in this Order are based on industry standards and are intended to provide reasonable assurance that personnel at DOE nuclear facilities possess qualifications to operate and maintain the facility safely and reliably under all conditions."

\section{REQUIREMINT SOURCE: DOE5480.20A Chapter I, Section 5.a}

"Operating organizations shall define qualification requirements for personnel in each functional level based on the criteria contained in this Order. The relative importance of managerial and technical competence should be considered by management in establishing these requirements. Specific knowledge and skills differ for each level in the organization. At the higher functional level, managerial competence is the dominant need, whereas technical competence is the dominant need at other functional levels."

\section{REQUIREMENT SOURCE: DOE5480.20A Chapter I, Section 5.b}

"Even though applied broadly to personnel in the operating organization, the term qualification has a different application for different positions. For example, managers and technical staff personnel may be considered qualified by virtue of meeting the entry-level requirements associated with the position and by completing applicable position-specific training (see paragraph $7 \mathrm{~h}$ and $7 \mathrm{i}$ ). A comprehensive examination need not be administered to determine their qualification. Continuing training and professional development programs should be established to meet the needs of the individual and the position. Chapter I, paragraph $7 \mathrm{~d}(1)$ contains requirements that shall be included in the continuing training program to the extent to which they apply to the position. Satisfactory performance of their assigned duties and assessment of individual performance such as that which is typically included in personal performance appraisals may be used to document contimued satisfactory performance."

\section{REQUIREMIENT SOURCE: DOE5480.20A Chapter I, Section 5.c}

"Technician and maintenance personnel qualification shall include demonstrated performance capabilities (performance demonstrations) to ascertain their ability to adequately perform assigned tasks. Written examinations should also be administered to personnel in these positions. However, a comprehensive final examination need not be administered to ascertain formal qualification of technicians and maintenance personnel (with the exception of radiological control technicians, who shall comply with the requirements of the DOE Radiological Control Manual). Participation in continuing training programs is required to maintain and improve their abilities to continue to function safely in the operating organization. The requirements that are described in Chapter I, paragraph 7d, shall be implemented to the 
extent to which they apply to the position. Their continued satisfactory performance of assigned duties and their satisfactory participation in the continuing training program (classroom, OJT, laboratory, etc.) serves as sufficient evidence of maintenance of their qualification."

\section{REQUIREMENT SOURCE: DOE5480.20A Chapter I, Section 5.d, Sentences 1 and 4}

"Qualification of operators and their immediate supervisors shall include examinations (written, oral, operational evaluations, performance demonstrations) as applicable to the position. Written examinations and performance demonstrations shall be administered to qualified operators and supervisors. Written and oral examinations and operational evaluations shall be administered to certified operators and supervisors. Initial qualification/certification for a position shall include a comprehensive examination to ascertain the person's suitability to perform assigned duties."

\section{REQUIREMENT SOURCE: DOE5480.20A Chapter I, Section 5.d, Sentences 5 and 7}

"Participation in the continuing training program described in Chapter I, paragraph $7 \mathrm{~d}$ shall be required following initial qualification to the extent to which it applies to the position. Upon completion of the continuing training program requalification may be achieved by either administering a comprehensive requalification examination, including any operational evaluations or performance demonstrations that may be specified, or by administering periodic examinations (e.g., quarterly) during the requalification cycle. Whether a comprehensive examination or periodic examinations are administered, after completing the continuing training program, the operating organization shall indicate by signature that the person has successfully completed the requalification program and is formally requalified."

\section{REQUIREMENT SOURCE: DOE5480.20A Chapter I, Section 5.e}

"Qualification may be granted only after assuring that all requirements (including training and examinations as required) and other specified requirements (e.g., medical examination) have been satisfactorily completed."

\section{REQUIREMENT SOURCE: DOE5480.20A Chapter I, Section 5.f}

"Qualification of operators and their immediate supervisors in the operating organization is valid for a period not to exceed two years unless revoked for cause (e.g., medical disqualitication, performance deficiencies)."

\section{REQUIREMENT SOURCE: DOE5480.20A Chapter I, Section 9}

"OPERATOR AND SUPERVISOR REEXAMINATION REQUIREMENTS. Reexaminations for certified and qualified operators and supervisors shall include subjects in which the person is expected to be knowledgeable and emphasize those subjects covered by the continuing training program. The contractor shall administer comprehensive biennial examinations, or administer periodic (e.g., quarterly) examinations throughout the continuing training cycle. Written examinations and performance demonstrations shall be administered to qualified operators and supervisors. Written and oral examinations and operational evaluations shall be administered to certified operators and supervisors.

For Category A reactor facility certified personnel, the oral examination shall be separate from the operational evaluation. Operational evaluations and oral examinations may be combined 
for Category B reactor and non-reactor nuclear facility certified personnel. Written examinations for certified operators and certified supervisors shall include a representative sampling of the topics specified in Chapters II, III, and IV to the extent applicable to the position and the facility. Operational evaluations shall require certified operators and certified supervisors to demonstrate an understanding of and the ability to perform a representative sampling of the control manipulations specified in Chapters II, III, and IV to the extent applicable to the position and the facility."

\section{REQUIREMENT SOURCE: DOE5480.20A Chapter I, Section 10 Introduction}

"REQUALIFICATION REQUIREMENTS. Operators and their immediate supervisors shall not be allowed to continue to function in qualified or certified positions if they have not completed all of the requalification or recertification program elements within the two year continuing training cycle. The program elements consist of the continuing training program and the associated reexaminations. If a qualified or certified operator or supervisor fails a requalification or recertification examination, or shows serious job performance deficiencies which indicate that he or she may perform in an unsafe manner, the person shall be removed from activities requiring qualification or certification."

\section{REQUIREMENT SOURCE: DOE5480.20A Chapter I, Section 10.a}

"Qualification or certification may be regained after completing remedial training designed to correct the deficiency(s) and satisfactorily completing a reexamination. In addition, recertification shall be based on the following:

(1) A review of individual operating performance during the past certification period by either line management, by a committee, or by a person designated by management; and

(2) A current medical examination as required by Chapter II paragraph 3, Chapter III paragraph 3, or Chapter IV paragraph 3."

$\underline{4.2 .9}$

\section{Revision and Update of Training}

Requirements applicable to this subelement are included in 4.2, Administration of Training.

\section{Extension, Exceptions and Alterations}

\section{REQUIREMENT SOURCE: DOE5480.20A Chapter I, Section 11 Introduction}

"EXCEPTIONS TO TRAINING REQUIREMENTS. The initial training programs that are described in this Order were developed for persons assumed to have the entry-level knowledge and skills required of the position for which they are to fill, on the basis of meeting the education and experience requirements contained in this Order. Some candidates may already possess the knowledge and skills necessary for certain of their job requirements, and may be excepted from certain areas of training programs on the basis of prior education, experience, training, and/or testing. Testing (i.e., performance demonstrations, written examinations, oral examinations) is the preferred method for excepting persons from specific areas of training. In all cases, the requisite examinations (as described in paragraph 8 ) to establish qualification/certification shall be completed. "

\section{REQUIREMENT SOURCE: DOE5480.20A Chapter I, Section 11.a}

"The operating organization shall establish an administrative procedure that describes the methods used to administer and document exceptions to initial training program requirements. 
The name of the person and the specific subject for which the exception is requested, along with justification for the exception, shall be included as part of the documentation. In all cases, the operating organization shall ensure that sufficient facility-specific instruction is provided to enable the candidate to perform job requirements. The operating organization shall submit the procedure for granting exceptions to the Operations Office Manager for approval."

\section{REQUIREMENT SOURCE: DOE5480.20A Chapter I, Section 11.b}

"Personnel placed in the training program who have satisfactorily completed training programs comparable in content and in performance standards may be released (excepted) from portions of training on an individual case basis. Exception from training should be based on a review of previous training records (i.e., transcripts), personal interviews, and on examinations that are based on the objectives stated for the training program."

\section{REQUIREMENT SOURCE: DOE5480.20A Chapter I, Section 11.c}

"Exceptions from qualification or certification requirements may be approved by contractor management after approval of the exception procedure by the Operations Office Manager."

\section{REQUIREMENT SOURCE: DOE5480.20A Chapter I, Section 11.d}

"Persons who believe that they have knowledge or skills equivalent to that which is addressed by the training may challenge the requirement to attend individual portions of the training program. In situations such as these, examinations (written or performance) may be administered by the operating contractor. If challenge examinations are administered, they shall be sufficiently comprehensive to adequately test the learning objective(s) that are stated in the training program. The use of challenge tests is not considered taking an exception to the training and, as such, challenge tests are excluded from the requirements for exceptions contained in preceding portions of this section. Accordingly, they do not need to be approved on a case-by-case basis."

\section{REQUIREMENT SOURCE: DOE5480.20A Chapter I, Section 12 Introduction}

"EXTENSION REQUIREMENTS. An extension of qualification or certification may be granted to persons on a case-by-case basis in order to support operational and schedular commitments."

\section{REQUIREMENT SOURCE: DOE5480.20A Chapter I, Section 12.a}

"The operating organization shall establish an administrative procedure for granting extensions to qualification or certification. At a minimum, the documentation to support the extension should include:

(1) Responsibility for approval of the extension;

(2) Length of the extension; and

(3) Explanation of the circumstances that prevented the person from completing the requirements." 


\section{REQUIREMENT SOURCE: DOE5480.20A Chapter I, Section 12.b}

"Extensions of certification of operators and supervisors may be approved only by the Operations Office Manager. Extensions of qualification of operators and supervisors may be approved by contractor facility management."

\section{REQUIREMENT SOURCE: DOE5480.20A Chapter I, Section 13 Introduction}

"ALTERNATIVES TO EDUCATION AND EXPERIENCE REQUIREMENTS. The purpose of establishing education and experience requirements is to help ensure that personnel have the ability to perform their job safely and reliably. Education and experience requirements of this Order are consistent with nuclear industry standards for similar positions. As a result of the considerable variation in the operations of DOE nuclear facilities, it is reasonable to consider and allow substitutions and alternatives to the education and experience requirements contained herein. Work experience may be substituted for education and education and training may be substituted for experience in specific cases. Using alternatives to education and experience requirements is intended to allow individuals who do not meet the literal education and experience requirements of this Order, but who are otherwise qualified or capable, to fill positions in the operating organization."

\section{REQUIREMENT SOURCE: DOE5480.20A Chapter I, Section 13.a}

"Alternatives to Education. Educational requirements are described as either baccalaureate or associate degree, or high school diploma. In each case, the type of degree/diploma required is a function of the person's responsibilities. Persons who do not possess the formal educational requirements specified shall not be automatically eliminated where other factors provide sufficient assurance of their abilities to fulfill the duties of a specific position. These factors shall be evaluated on a case-by-case basis and approved and documented by the operating organization. The following are examples that may be considered in making the evaluation of an acceptable alternative to the educational requirements:

(1) General Education Development (GED) test for a high school diploma;

(2) Professional engineers license or completion of Engineer in Training (EIT) examination for a baccalaureate or associate degree requirement;

(3) Completion of technical portions of an engineering, engineering technology, or related science program may substitute for the baccalaureate or associate degree. Successful completion shall be determined by a transcript or other certification by an accredited institution. For example, completion of 80 semester credit hours may be substituted for the baccalaureate requirement and 43 semester credit hours for the associate degree. The courses shall be in appropriate technical subjects relevant to the position to be filled; and

(4) Related experience may substitute for education at the rate of six semester credit hours for each year of experience up to a maximum of 60 credit hours."

\section{REQUIREMENT SOURCE: DOE5480.20A Chapter I, Section 13.b}

"Alternatives to Experience. Experience in design, construction, and operational training may be considered applicable nuclear experience and should be evaluated on a case-by-case basis.

(1) Where course work is related to job assignments, post-secondary education may be substituted. Formal education shall not be allowed to substitute for more than 50 percent of the experience requirement unless otherwise stated in Chapters II, III, or IV. 
(2) Job-related training in the position sought may qualify as equivalent to nuclear experience on a one-for-one basis for up to a maximum of two years."

4.3

4.3.1

4.3.1.1

4.3.1.2

\section{TRAINING CATEGORIES AND SUBJECTS}

\section{General Emplovee Training}

\section{REQUIREMENT SOURCE: DOE5480.20A Chapter I, Section 7.e Introduction}

"General Employee Training (GET) Requirements. All persons employed either full- or part-time in DOE nuclear facilities shall be trained commensurate with their job duties"

\section{REQUIREMINT SOURCE: DOE5480.20A Chapter I, Section 7.e.(2)}

\begin{abstract}
"Visitors, contracted personnel, and temporary personnel shall be under continuous escort while at the facility unless they have been trained in appropriate areas from the above list to the extent necessary to ensure safe execution of their duties. For example, short-term visitors should be given instruction in items (a), (c), (d), (e), and (g), while contracted and temporarily assigned personnel may need training in additional topics as related to their assignments."
\end{abstract}

\section{REQUIREMENT SOURCE: DOE5500.3A Section 11.c.(11)(b)}

Author's Note: Facility specific emergency training is provided to Operations, Maintenance, and Health Physics personnel.

"A formal training program must be in place for the instruction and qualification of all personnel (i.e., primary and alternate) comprising the facility emergency response organization to include initial training and annual retraining for both onsite and offsite incidents, including transportation incidents."

\section{Lockout and Tagout Training}

Author's Note: Additional requirements are included in the WHC Company S/RID.

\section{REQUIREMENT SOURCE: 29CFR1910 Part 332(b)(3)}

"Training. Additional requirements for qualified persons. Qualified persons (i.e., those permitted to work on or near exposed energized parts) shall, at a minimum, be trained in and familiar with the following:(i)The skills and techniques necessary to distinguish exposed live parts from other parts of electric equipment, (ii) The skills and techniques necessary to determine the nominal voltage of exposed live parts, and (iii) The clearance distances specified in 29 CFR 1910.333(c) and the corresponding voltages to which the qualified person will be exposed. Note 1: for the purpose of 29 CFR 1910.331 through 1910.335 , a person must have the training required by paragraph (b)(3) of this section in order to be considered a qualified person. Note 2: Qualified persons whose work on energized equipment involves either direct contact by means of tools or materials must be also have the training needed to meet 29 CFR $1910.333(c)(2) . "$

Hazard Communication Training

REQUIREMENT SOURCE: 29CFR1910 Part 1200(h)

"Hazard Communication 
Employee information and training. Employers shall provide employees with information and training on hazardous chemicals in their work area at the time of their initial assignment, and whenever a new hazard is introduced into their work area."

\section{REQUIREMENT SOURCE: 29CFR1910 Part 1200(h)(1)}

"Hazard Communication

Employee information and training.

Information. Employees shall be informed of:

(i) The requirements of this section;

(ii) Any operations in their work area where hazardous chemicals are present; and,

(iii) The location and availability of the written hazard communication program, including the required list(s) of hazardous chemicals, and material safety data sheets required by this section."

\section{REQUIREMINT SOURCE: 29CFR1910 Part 1200(h)(2)}

"Hazard Communication

Employee information and training

Training. Employee training shall include at least:

(i) Methods and observations that may be used to detect the presence or release of a hazardous chemical in the work area (such as monitoring conducted by the employer, continuous monitoring devices, visual appearance or odor of hazardous chemicals when being released, etc.);

(ii) The physical and health hazards of the chemicals in the work area;

(iii) The measures employees can take to protect themselves from these hazards, including specific procedures the employer has implemented to protect employees from exposure to hazardous chemicals, such as appropriate work practices, emergency procedures, and personal protective equipment to be used; and,

(iv) The details of the hazard communication program developed by the employer, including an explanation of the labeling system and the material safety data sheet, and how employees can obtain and use the appropriate hazard information."

Maintenance Training Program

\section{REQUIREMENT SOURCE: DOE4330.4B Chapter II, Section 3.3.6, Sentence 1}

"In addition to training in technical maintenance functions as described in the preceding, a select group or team should be schooled in principles and methods of root-cause analysis."

\section{REQUIREMENT SOURCE: DOE5480.20A Chapter I, Section 7.g.(1)}

"All technicians and maintenance personnel shall be qualified to perform the tasks associated with their specialty, or work under the direct supervision of personnel qualified to perform the activity or task." 


\section{REQUIREMENT SOURCE: DOE5480.20A Chapter I, Section 7.g.(2)}

"Training on engineered safety features as identified in the facility Safety Analysis Report shall be conducted for personnel who perform work on those systems/components. Included in this category are systems having a direct impact on the safe operation of the facility. Examples of engineered safety feature systems are emergency core cooling systems, instrumentation systems that provide protective functions, emergency electrical power distribution systems, and other systems whose failure could have an adverse affect to the environment or the health and safety of the public. System training shall, at a minimum, include the following elements:

(a) Purpose of the system;

(b) General description of the system including major components, relationship to other systems, and all safety implications associated with working on the system; and

(c) Related industry and facility-specific experience."

\section{REQUIREMENT SOURCE: DOE5480.20A Chapter IV, Section 2.d}

"Technicians. Technicians are principally involved in calibration, inspection, troubleshooting, testing, maintenance, and radiation protection activities at the facility. Examples are laboratory technicians, instrument technicians, and radiological control technicians.

(1) Experience:

Job related

1 year"

\section{REQUIREMENT SOURCE: DOE5480.20A Chapter IV, Section 2.e}

"Maintenance Personnel. Maintenance personnel are responsible for the maintenance and repair of mechanical and electrical equipment.

(1) Experience:

Maintenance related 1 year"

Management and Supervisory Training

\section{REQUIREMENT SOURCE: DOE/EH0256T(940431) Chapter 6, Part 5, Article 651}

"Other Radiological Training

Management Training

Line Managers (DOE and contractors) who manage, supervise or provide oversight of Radiological Control Programs shall be trained in the principles of this Manual. Such training should be based on DOE standardized core course training materials supplemented by site-specific procedures and be completed by new personnel prior to formally assuming line supervision and management responsibilities. Incumbents should participate in continuing training. The continuing training should emphasize self-assessment and external evaluations including performance indicators, root causes and lessons learned based on operational experience."

\section{REQUIREMINT SOURCE: DOE5480.20A Chapter I, Section 7.i Introduction}

"Management and Supervisory Training Requirements. The topics listed in paragraph $7 \mathrm{~h}$ shall be considered for applicability when developing manager and supervisor training programs. If training related to those topics is applicable to the position, that training shall be included in 
addition to the topics listed below, as appropriate to their job responsibilities. Supervisory skills and management training need not be subject to examination as part of initial training, nor is it necessary to include training on these topics in the continuing training program. It may, however, be appropriate to include additional topics such as these as part of the ongoing professional development program for managers and supervisors."

\section{REQUIREMENT SOURCE: DOE5480.20A Chapter I, Section 7.i.(1)}

"Supervisory Skills Training. The supervisory skills training program shall include the following (or equivalent):

(a) Leadership;

(b) Interpersonal communication;

(c) Responsibilities and authority;

(d) Motivation of personnel;

(e) Problem analysis and decision making;

(f) Fitness for duty procedures; and

(g) Administrative policies and procedures."

\section{REQUIREMENT SOURCE: DOE5480.20A Chapter I, Section 7.i.(2)}

"Management Training. The management training program should include:

(a) Supervisory skills training;

(b) Quality assurance and quality control;

(c) Facility security and emergency plans;

(d) Purchasing;

(e) Material storage;

(f) Facility modifications (configuration control);

(g) Nuclear, industrial, and radiation safety;

(h) Environmental issues; and

(i) Budgeting."

\section{REQUIREMENT SOURCE: DOE5480.20A Chapter IV, Section 2.a}

"Managers. The term "Manager" refers to a person whose assigned responsibilities include ensuring that a plant or facility is safely and reliably operated, and that supporting operational and administrative activities are properly controlled. Managers are responsible for nuclear safety, operational efficiency and reliability, control of onsite emergencies, and any other activities necessary to safeguard the health and safety of the workforce, the general public, and the environment. Operational responsibilities include prioritizing and assessing facility 
activities including modifications, and overseeing the operating organization. Administrative responsibilities include maintenance of a qualified staff, budgets, maintaining employee performance, administering disciplinary actions consistent with company policies, public information, and coordination with corporate offices. This functional level typically includes the Plant/Facility Manager or Director, the Operations Manager, the Maintenance Manager, the Training Manager, and the Technical Manager. Prior to assuming the duties of the assigned position, persons at the manager level shall meet the following requirements:

(1) Education: Baccalaureate in engineering or related science

(2) Experience:

Nuclear

4 years

(3) Special Requirements:

(a) Education or experience that is job-related may be substituted for a degree on a case-by-case basis. The degree may fulfill 3 of the 4 years of nuclear experience required on a one-for-one time basis;

(b) Managers shall receive facility-specific training based upon a comparison of the individual's background and abilities with the responsibilities and duties of the position; and

(c) The Training Manager shall have a baccalaureate including courses in education and technical subjects (baccalaureate need not be in engineering or related science)."

\section{REQUIREMENT SOURCE: DOE5480.20A Chapter IV, Section 2.b}

"Supervisors. This functional level consists of those individuals who are responsible for the quantity and quality of work performed and who direct the actions of operators, technicians, or maintenance personnel. Their duties include ensuring that work is performed in compliance with procedures, policies, and industrial safety practices. Prior to assuming the duties of the assigned position, supervisors shall meet the following requirements:

(1) Education: High School Diploma

(2) Experience:

Nuclear

3 years

(3) Special Requirement: Full-time academic training (i.e., degree programs, trade schools, vocational programs, etc.) may be substituted on a one-for-one basis for 2 of the 3 years of required nuclear experience."

\section{Operator Training}

\section{REQUIREMENT SOURCE: DOE5480.19 Chapter V, Section C.3, Paragraph 3}

"When trainees record equipment parameters on official round sheets (as opposed to practice round sheets) or logs, the on-shift instructor should verify that the recorded information is correct. In addition, the trainee and on-shift instructor should discuss any out-of-specification readings and the consequences of allowing such trend to continue." 


\section{REQUIREMENT SOURCE: DOE5480.19(920518) Chapter X, Section C.3, Sentence 1 and 2}

"Operators should be trained in the appropriate techniques for verifying the positions of all facility components. In addition, a reference document should be provided explaining what an operator should do when verifying a component position."

\section{REQUIREMENT SOURCE: DOE5480.20A Chapter IV, Section 2.c}

"Operators. Operators are persons responsible for performing operations associated with engineered safety features as identified in the Safety Analysis Report, operating support systems which could affect engineered safety features, or conducting activities with radioactive materials. Duties may include manipulating facility controls, monitoring parameters, and operating equipment in facility safety systems. Operators include fissionable material handlers, tritium facility operators, chemical process operators, waste tank operators, and enrichment facility operators.

(1) Education: High School Diploma"

\section{REQUIREMENT SOURCE: DOE5480.20A Chapter IV, Section 4 Introduction}

"SPECIFIC TRAINING REQUIREMENTS. The depth and scope of training and qualification programs for operating organization personnel at non-reactor nuclear facilities shall be commensurate with the hazard level and complexity of the operations (i.e., a graded approach should be used to develop and implement the training programs). This section provides specific training requirements for operators, fissionable material handlers, and supervisors."

\section{REQUIREMENT SOURCE: DOE5480.20A Chapter IV, Section 4.a}

"Operators. Operator training shall be sufficiently comprehensive to cover areas which are fundamental to the candidate's assigned tasks to ensure that personnel are capable of safely performing their job duties. The training program shall include the following:

(1) A core of subjects such as industrial safety, instrumentation and control, basic physics, chemistry, industry operating experience, and major facility systems, as applicable to the position and the facility.

(2) On-the-job and classroom-type training to ensure that personnel are familiar with all aspects of their positions. Such training shall include but not be limited to:

(a) Normal and emergency procedures;

(b) Administrative procedures;

(c) Radiation control practices;

(d) Location and functions of pertinent safety systems and equipment;

(e) Procedures for making changes or alterations in operations and operating procedures; and

(f) Technical Safety Requirements." 


\section{$\underline{4.3 .5}$}

REQUIREMINT SOURCE: DOE5480.20A Chapter IV, Section 4.c

"Supervisors. The supervisor training program shall include the categories and on-the-job training specified for operators and fissionable material handlers to the extent to which they are applicable. This training shall be of increased depth to reflect the added responsibility of the supervisor position."

\section{Continuing Training}

\section{REQUIREMINT SOURCE: DOE5480.20A Chapter I, Section 7.d Introduction}

"Continuing Training Requirements. Continuing training programs shall be established to maintain and enhance the knowledge and skills of operating organization personnel who perform functions associated with engineered safety features as identified in the facility Safety Analysis Report. The guidance in DOE-STD-1060-93, Guide to Good Practices for Continuing Training, should be used to develop continuing training programs that improve the knowledge and skills of operating organization personnel."

\section{REQUTREMENT SOURCE: DOE5480.20A Chapter I, Section 7.d.(1)}

"These programs shall be structured commensurate with specific position needs, and shall be administered on a cycle not to exceed two years. Continuing training shall include, at a minimum, training in significant facility system and component changes, applicable procedure changes, applicable industry operating experience, selected fundamentals with emphasis on seldom used knowledge and skills necessary to assure safety, and other training as needed to correct identified performance problems."

\section{REQUIREMENT SOURCE: DOE5480.20A Chapter I, Section 7.d.(2)}

"Periodic examinations (written, oral, operational evaluations, performance demonstrations, as applicable to the position) shall be administered and documented throughout the cycle on material included in the operator (operators and their immediate supervisors) training programs. Periodic examinations (written and/or performance demonstrations) of other members of the operating organization (i.e., maintenance personnel, technicians, technical staff) is also appropriate in some areas during the continuing training program."

\section{$\underline{4.3 .6}$}

\section{Technical Support Personnel Training}

REQUIREMINT SOURCE: DOE-STD-1073-93 Chapter 1, Section 1.3.1.6, Paragraph 1, Sentence 3

"The CM program should include training on CM concepts, terminology, definitions, and procedures."

\section{REQUIREMIENT SOURCE: DOE/EH0256T(940431) Chapter 6, Part 5, Article 654.3}

"Radiological support personnel should have:

a. Applicable training on standardized core course topics from Radiological Worker I and II and Radiological Control Technician training and additional job-specific topics,

b. Training appropriate to the tasks to be performed;

c. Continuing training to provide continued improvement in knowledge and skills." 
REQUIREMENT SOURCE: DOE5480.20A Chapter I, Section 7.g.(3)

"Training program content for radiological control technicians (RCT) shall be in accordance with the requirements contained in 10 CFR 835, Occupational Radiation Protection, and DOE/EH-0256T, DOE Radiological Control Manual. RCT training program elements (i.e., selection, training process, continuing training, qualification) shall be in accordance with the requirements of this Order."

\section{REQUIREMENT SOURCE: DOE5480.20A Chapter I, Section 7.h.(1)}

"The contractor shall develop a list of specific technical staff positions that have a direct impact on employee, facility, or public safety."

\section{REQUIREMENT SOURCE: DOE5480.20A Chapter I, Section 7.h.(2)}

"Training shall be provided to entry-level technical staff personnel who provide technical support to the operating organization. Training in the following facility-specific subject areas shall be included as appropriate to the position:

(a) Facility organization;

(b) Facility fundamentals;

1 Heat transfer, fluid flow, and thermodynamics

$\underline{2}$ Electrical science

3 Nuclear physics

4 Chemistry/chemistry controls

5 Process controls

(c) Facility systems, components, and operations;

(d) Simulator training;

(e) Environment, Safety, and Health Orders;

(f) Codes and standards overview;

(g) Facility document system;

(h) Safety Analysis Reports and Technical Safety Requirements;

(i) Nuclear criticality control;

(j) Material, maintenance, and modification control;

(k) ALARA and radwaste reduction program; and

(l) Quality Assurance/Quality Control practices."

\section{REQUIREMENT SOURCE: DOE5480.20A Chapter IV, Section 2.f}

"Technical Staff. Personnel in these positions are responsible for supervision and performance of technical support functions for the operating organization. Personnel involved in surveillance, testing, analyzing facility data, planning modifications, program review, and technical problem resolution in their area of expertise are also included. They have expertise in mechanical, electrical, instrumentation and control, chemistry, radiation protection, safety, or quality assurance/independent assessment. For personnel assigned to equivalent positions, non-reactor nuclear facilities should use the education and experience requirements contained in Chapter II, Category A Reactor Personnel, paragraph 2c. For positions for which there is no equivalent, the education and experience requirements are as listed below. The education and experience requirements listed below apply to supervisory positions or positions with authority to make independent decisions or to review and concur, and not to entry-level positions. 
(2) Experience:

Job related

2 years

Nuclear

1 year"

\section{REQUIREMENT SOURCE: DOE5480.20A Chapter IV, Section 2.g Introduction}

"Training Organization Personnel. Training organization personnel are responsible for working with the line organization to identify and meet personnel and organization needs. Training organization personnel assist line organizations in determining training program content, developing training materials, scheduling training, and delivering training programs for the operating organization."

\section{REQUIREMINT SOURCE: DOE5480.20A Chapter IV, Section 2.g.(1)}

"Training Coordinators.

(a) Education: High School Diploma

(b) Experience:

Nuclear

2 years

Onsite

6 months"

\section{REQUIREMENT SOURCE: DOE5480.20A Chapter IV, Section 2.g.(2)}

"Training Instructors.

(a) Education: High School Diploma

(b) Experience: Consistent with the material being presented.

(c) Special Requirements:

1 Instructors who are responsible for instruction on subjects such as Technical Safety Requirements shall have received training on facility operating characteristics and principles, and operating limits (Safety Limits, Limiting Control Settings, and Limiting Conditions for Operation) and their bases; and

$\underline{2}$ Instructors shall have demonstrated knowledge of instructional techniques through training or experience and be qualified by the Training Manager (or equivalent) for the material being presented."

\section{REQUIREMENT SOURCE: SNT-TC-1A Section 5.1}

Author's Note: WHC personnel involved in nondestructive examinations are trained in accordance with American Society for Nondestructive Testing, SNT-TC-1A, "Personnel Qualification and Certification in Nondestructive Testing, 1984 edition".

"The employer shall establish a written practice for the control and administration of NDT personnel training, examination, and certification." 


\section{REQUIREMENT SOURCE: SNT-TC-1A Section $\mathbf{5 . 2}$}

"The employer's written practice shall describe the responsibility of each level of certification for determining the acceptability of materials or components in accordance with the applicable codes, standards, specifications, and procedures."

\section{TRAINING RECORDS AND DOCUMENTATION}

\section{REQUIREMENT SOURCE: 10CFR835 Part 704(a)}

Author's Note: This citation applies to Tank Farms only for training records developed to demonstrate compliance with the facility responsibilities of the requirements of 10CFR835 Part 901 (a) and 10CFR835 Part 901(b). The requirements of 10CFR835 Part 902 and 10CFR835 Part 903 are a Site level responsibility.

"Training records shall be maintained, as necessary, to demonstrate compliance with $\$ \S$ 835.901, 835.902, and 835.903."

\section{REQUIREMENT SOURCE: DOE/EH0256T(940431) Chapter 7, Part 2, Article 725.5}

"The following instructional materials shall be maintained:

a. Course name, with revision and approval date;

b. Instructor's manuals, course content, or lesson plans containing topical outlines;

c. Video and audio instructional materials, including the dates and lessons for which they were used;

d. Handouts or other materials retained with the master copy of the course;

e. Job-specific training documents, such as instrument use, radiological procedures, Radiological Work Permit special training requirements, pre-job briefings and mock-up training."

\section{REQUIREMENT SOURCE: DOE5480.11 Section 9.m(5)}

"Training Records. Training Records of plant employees, radiation workers, and radiation safety personnel shall be retained to document the level of understanding and proficiency of personnel who work with radioactive materials. Certification of successful completion of training programs and performance records should also be retained."

\section{REQUIREMENT SOURCE: DOE5480.20A Chapter I, Section 15 Introduction}

"RECORD REQUIREMENTS. Contractors shall develop and implement administrative procedures that specify requirements for the maintenance of training, qualification, and certification records for operating organization personnel. The guidance in the Nuclear Information and Records Management Association Guidelines for Management of Nuclear Related Training Records, TG-17 should be used to help standardize identification, handling, and storage of training records."

\section{REQUIREMENT SOURCE: DOE5480.20A Chapter I, Section 15.a}

"Qualification and certification of personnel shall be documented in an easily auditable format. Individual record documentation shall include the following at a minimum:

(1) Education, experience, and employment history and most recent health evaluation summary (e.g., similar to NRC Form 396); 
(2) Training programs completed and qualification/certification achieved;

(3) Latest completed checklists, graded written examinations (with answers corrected as necessary or examination keys), simulator examinations (where applicable), and operational evaluations used for certification (this requires controlling access to training records to maintain examination security). The record should include an evaluation of knowledge and performance during operational evaluations;

(4) Lists of questions asked and the examiner's overall evaluation of the responses on oral examinations;

(5) Correspondence relating to exceptions to training requirements and extensions of qualification/certification;

(6) Records of qualification for one-time-only special tests or operations; and

(7) Attendance records for required training courses or sessions."

\section{REQUIREMENT SOURCE: DOE5480.20A Chapter I, Section 15.b}

"A historical record that documents initial qualification or certification, and applicable information from the above list that verifies the most recent qualification or certification shall be retained in individual records. Superseded information should be handled in accordance with DOE 1324.2A, RECORDS DISPOSITION. "

\section{ACCREDITATION}

Author's Note: Training program accreditation is a DOE requirement levied on the Hanford training organization. The Tank Farm facility is responsible for compliance with the accreditation program requirement to the degree that it fulfills its training and qualification requirements to qualify, certify, and requalify/recertify assigned personnel using approved training materials and procedures.

\section{REQUIREMENT SOURCE: DOE5480.18B Section 8.a.(1)}

"The contractor shall determine which facility training programs require accreditation by using the functional descriptions contained in DOE-STD-1077-94, "Training Accreditation Program Standard: Requirements and Guidelines." "

\section{REQUIREMENT SOURCE: DOE5480.18B Section 8.a.(2)}

"The contractor shall conduct an initial self-evaluation by comparing current training programs to the accreditation objectives and criteria. Guidelines for the conduct of the self-evaluation are contained in DOE-STD-1077-94, "Training Accreditation Program Standard: Requirements and Guidelines." "

\section{REQUIREMENT SOURCE: DOE5480.18B Section 8.a.(3)}

"The contractor shall determine necessary improvements to the existing training program to meet the accreditation objectives and criteria, based on the results of the initial self-evaluation. A Training Program Accreditation Plan should be prepared In accordance with the guidelines of DOE-STD-1077-94, "Training Accreditation Program Standard: Requirements and Guidelines." The Training Program Accreditation Plan shall identify and prioritize the programs to be accredited and shall address all training program implementation schedules, 
upgrade needs and scope, personnel needs, and facility needs. Specific training programs for which an exception to this Order is deemed appropriate shall be identified, with justification for the exception, in the Plan. The Training Program Accreditation Plan shall be approved by the Operations Office Manager and the appropriate Secretarial Officer, with Environment, Safety and Health concurrence."

\section{REQUIREMENT SOURCE: DOE5480.18B Section 8.a.(4)}

"A second self-evaluation is performed by the contractor following completion of necessary improvements to the training program, as identified in the Training Program Accreditation Plan. A Contractor Self-Evaluation Report shall be written for the training program(s) to be accredited in accordance with the guidelines of DOE-STD-1077-94, "Training Accreditation Program Standard: Requirements and Guidelines." The Contractor Self-Evaluation Report may contain more than one program provided that all of the programs are directly related to each other (e.g., Operator, Shift Supervisor, and Shift Manager would be acceptable whereas Operator, Mechanical Maintenance Technician, and Chemistry Technician would not) and respective program strengths and weaknesses are clearly differentiated. The Contractor Self-Evaluation Report shall describe how the current training program(s) meets the accreditation objectives and criteria, document program weaknesses, and describe any corrective actions being implemented."

\section{REQUIREMENT SOURCE: DOE5480.18B Section 8.b.(1)}

"Accreditation shall be maintained during the 4-year period by submitting an Accreditation Maintenance Report, which includes all accredited programs, 2 years after accreditation or renewal of accreditation. The report shall provide specific information with appropriate documentation regarding actions taken during the 2-year period. The report should be brief but shall include the following:

(a) A description of any major changes to accredited training programs since the last accreditation;

(b) A description of any other activities that have had a bearing on the effectiveness of the accredited training programs;

(c) A report on organizational changes that may affect the accredited training programs (including an updated training staff roster);

(d) A description of the principal strengths and/or weaknesses of the accredited training programs determined through self-assessments;

(e) An assessment of the benefits and/or disadvantages derived from training modifications made in connection with accreditation; and

(f) Recommendations for changes in the accreditation process."

\section{REQUIREMENT SOURCE: DOE5480.18B Section 8.c. Introduction}

"Renewal of accreditation shall be submitted no later than 4 years from the initial accreditation and each 4 years thereafter. The contractor shall attempt to maximize the number of programs submitted for renewal to reduce costs and impact on operations. Renewal of accreditation consists of the following activities: " 


\section{REQUIREMENT SOURCE: DOE5480.18B Section 8.c.(1)}

"The contractor shall submit a Contractor Self-Evaluation Report which includes all accredited programs prior to a request for renewal. Review, approval, and submittal of the Contractor Self-Evaluation Report shall be performed as described in paragraph $8 \mathrm{a}(4){ }^{n}$

\section{6}

4.6.1

$\underline{4.6 .2}$

\section{KEY INTERFACES}

The Training and Qualification Functional Area interfaces with all other Functional Areas through the provision of general Tank Farms training programs and support of other Functional Area specific training needs as identified and defined by the managers of each Functional Area. Key interfaces include: Management Systems, Quality Assurance (QA), Emergency Management, Engineering, Operations, Maintenance, Radiation Protection, and Occupational Safety and Health, and others to a lesser extent.

\section{Management Systems}

Training and Qualification programs support the consistent and effective performance of the vital information processes governed by Tank Farms Management Systems. Generally, training provides an established mechanism for staff selection (through minimum qualification criteria), definition of initial and continuing training content, etc. Training in each management system area transfers understanding in program processes, responsibilities, knowledge of requirements, and the importance of compliance, safety, and accountability and will be provided as identified by management.

\section{Ouality Assurance}

Formal training for personnel assigned to Quality Assurance (QA)/Quality Control (QC)/Nondestructive Examination (NDE) tasks is provided to ensure consistent and effective accomplishment of their job functions. Training needs and requirements should be identified by the management of the QA Functional Area at the site level and at each facility and should include both education in work related principles and should contribute to the enhancement of skills and practices. Training should provide an understanding of: processes and tools being used, the extent of variability of those processes, or tools, and the degree of control available over those variables, quality standards, potential consequences of improper work, special skills, and proficiency criteria. QA/QC/NDE personnel should be provided with continuing training, including re-certification where required, to ensure professional proficiency is maintained. Training should provide both general and specialized training (i.e., inspection and audit personnel) to meet the Quality Assurance organizations' performance needs. QA related training should also be provided for personnel in specific categories of jobs, such as; operators, designers, managers, supervisors, crafts, inspectors, and others.

\section{Configuration Management}

Formal training in Configuration Management provides improved operations and enhanced understanding in the integrated management of technical information. The Manager of the Configuration Management Functional Area should identify training needs and requirements to address training to ensure the consistent utilization of vital site and facility information pertaining to: design, maintenance, engineering, construction, operations, safety, and information management (document control and records management). 


\subsection{4}

$\underline{4.6 .5}$

$\underline{4.6 .6}$

$\underline{4.6 .7}$

$\underline{4.6 .8}$

\section{Emergency Management}

Formal training for Emergency Management is required as defined by the management of the Emergency Management functional area to support three distinct audiences; general employee training, the Hanford emergency response organization (ERO), and off-site response organizations. Detailed ERO (and off-site team) training should address: chain of command, E-Plan execution, procedural adherence, equipment utilization, emergency operations center, special precautions and limitations, identification and assessment of job related hazards, scheduling and execution of drills, public interface issues, radiological and hazardous material properties, emergency response skills, and emergency controls, lessons learned from previous drills, among other related topics. General employee training should include: alarm recognition and response, response actions, and other Tank Farms specific information.

\section{Safequards and Security}

Formal training for the Safeguards and Security Functional Area promotes understanding and performance in the key areas of personnel access and material protection. training needs and requirements should be identified by the management of the Safeguards and Security Functional Area and should address: personnel security, proper badging, visitor control, site wide security education, and select security procedures such as computer security and classified automated data processing and inventory control systems. This S/RID contains the requirements for general employee training; training requirements specific to Safeguards and Security and/or for the training of Safeguards and Security personnel are detailed in the Safeguards and Security S/RID.

\section{Engineering Program}

The technical tasks associated with engineering, design, and safety analysis require the formal training and qualification processes reflected by professional engineering standards. Formal training develops and maintains technical competence in the areas of: system, facility, and site design, facility and site assessment, design control process, field change modifications, construction, design basis development, configuration change evaluations, safety and non-safety class systems, hazards assessment, among others. Formal training establishes training criteria, proficiency requirements, and qualifications, as needed, for review and approvals of engineering documents. Engineering Management and Supervision should identify training needs and requirements, review lesson plans, monitor training effectiveness, and provide periodic evaluations to promote self improvement.

\section{Construction Program}

Construction Program Functional Area management identify training needs and requirements to ensure construction supervisors and staff involved in new construction and modification activities are qualified and/or certified to the job positions assigned. This S/RID contains the requirements for general employee training; training requirements specific to Construction and/or for the training of Construction personnel are detailed in the Westinghouse Hanford Company Site Construction Program S/RID Functional Area.

\section{Operations}

Formal training for the Operations Functional Area consists of various formats. Effective training should include classroom training for fundamentals and general training topics. Advanced syllabus items may involve simulator, laboratory, hands on, and on-the-job field applications of classroom knowledge through the demonstration of practical factor performance and on shift experience. The management of the Operations Functional Area should identify 
training needs and requirements for training that should include: conduct of operations, As-Low-As-Reasonably-Achievable (ALARA), key elements as defined in DOE Order 5480.19, professional development, medical and fitness for duty requirements, procedural adherence, and continuous compliance with analyzed safety parameters.

\section{Maintenance}

Formal training of Maintenance personnel is determined by the Tank Farms Maintenance Manager (See the Maintenance Functional Area document) and includes comprehensive lesson plans and curriculum for the initial and continued training of key maintenance positions. Close teaming with the training organization in course development, training plans and schedules, qualification and certification programs, and identification of continued proficiency requirements commensurate with designated job descriptions is essential. Training syllabi should include: maintenance work practices, ALARA, personal safety techniques, tool and equipment control, decontamination, maintenance records, work package development and tracking, configuration controls, modifications, and field changes, among others. This S/RID contains the general training requirements for employee training; training requirements specific to Maintenance and/or for the training of Maintenance personnel are detailed in the Maintenance S/RID.

\section{Radiation Protection}

Formal training provides both general and specific training curricula in the area of radiation protection. Training needs and requirements are identified by the management of the Radiation Protection functional area and should include: technician specific training and qualification, supervisor discipline training, radiological monitoring, personnel exposure control, entry and exit controls, contamination control techniques, radioactive materials handling, radiological barriers, QA records, ALARA and radiological control curriculum, radiological hazards, worker awareness, Radiation Protection certifications, examinations, normal and emergency responses to radiological situations, lessons learned from Operations, Occurrence Reporting across the site and the DOE complex, and other related Radiation Protection topics. This S/RID contains requirements for Radiological General Employee Training; training requirements specific to Radiation Protection and/or for all other radiological protection training such as Radiation Worker Training and Radiological Control Technician Training, etc., are detailed in the Radiation Protection S/RID.

\section{Fire Protection}

Formal training in the Fire Protection Functional Area is essential to ensure the personnel safety and high performance of any individual assigned within the fire protection organization, the fire department brigade, apparatus drivers, fire test and inspection personnel, and any other persons with responsibilities for fire safety. Training program content and needs should be identified by Fire Protection management to reflect the applicable criteria contained in the identified mandatory Fire Protection Functional Area codes and standards and should consider facility specific characteristics. Training programs should emphasize fire hazards, fire alarms and response, fire prevention, communications, general safety, and other related topics. Qualification and certification programs should be identified for facility operators, fire investigators, emergency medical personnel, fire officers, and fire service inspectors, among others. This S/RID contains the requirements for general employee training; training requirements specific to Fire Protection and/or for the training of Fire Protection personnel are detailed in the Fire Protection S/RID. 


\section{$\underline{4.6 .12}$}

$\underline{4.6 .13}$

$\underline{4.6 .14}$

$\underline{4.6 .15}$

$\underline{4.6 .16}$

$\underline{4.6 .17}$

$\underline{4.6 .18}$

\section{Packaging and Transportation}

Formal training for the Packaging and Transportation Functional Area provides appropriate personnel with a detailed understanding of hazardous materials, safety precautions, applicable Federal, State and local regulations as well as pertinent DOE Orders. Training syllabi developed in accordance with the needs and requirements identified by Packaging and Transportation management should include, among others: regulations governing the packaging, labeling, container requirements, security, and allowed forms of transportation, etc.

\section{Environmental Restoration}

This functional area is not applicable to Tank Farms.

\section{Decontamination and Decommissioning}

This functional area is not applicable to Tank Farms.

\section{Waste Management}

Formal training for the Waste Management area provides the transfer mechanism for understanding and ensuring consistent and continuous compliance to regulatory statutes regarding waste management. Key training topics as identified by the management of the Waste Management Functional Area may include: waste system operations, waste stream management, emergency response, hazardous waste safety, waste handling procedures, procedural adherence, waste minimization methods and practices, communications, and other related training topics.

\section{Research and Development and Experimental Activities}

This functional area is not applicable to Tank Farms.

\section{Nuclear Safety}

Formal training for Nuclear Safety personnel provides general and specialized training as defined by the management of the nuclear Safety Functional Area insupporting professional development and qualification in specific job functions. Nuclear safety training should include: risks associated with facility operations, location, design basis, and operations of pertinent safety systems, configuration change control procedures, safety analysis of technical issues, operational safety requirements, response to nuclear criticality among others. Training should promote technical competence, professional skills, and practical application of theoretical knowledge commensurate with job positions.

\section{Occupational Safety and Health}

Formal training in Occupational Safety and Health, as defined by the management of the functional area ensures consistent and thorough understanding of fundamentals for general employees, managers/supervisors, and ensures visitors and contractors are adequately trained prior to performing work. Essential safety topics include: health and safety issues, medical and fitness for duty requirements, among others. The Occupational Safety and Health Act (OSHA) training program also facilitates the continued professional development of the safety and health staff through training courses, seminars, conferences, laboratory experience, field studies and other learning activities. 
Formal training in the area of Environmental Protection is defined by the management of the Environmental Protection Functional Area. Key areas should include: monitoring and surveillance systems, inspection requirements, permit management, pollution control, records and reports, pollution prevention techniques, waste minimization, quality of records, procedural adherence, safety, ALARA, emergency response, contingency planning, and other related topics.

4.7

$\underline{4.7 .1}$

\section{REFERENCES}

\section{Requirement Source Documents}

The following documents were used as requirement sources in the development o this S/RID: 10CFR830, Code of Federal Regulations, Nuclear Safety Management, 5/5/94.

10CFR835, Occupational Radiation Protection, 12/13/93.

29CFR1910, Code of Federal Regulations, Occupational Safety and Health Standards, May 1994.

WAC-173-303, Dangerous Waste Regulations, 1993.

DOE 4330.4B, Maintenance Management Program, 2/10/94.

DOE 5480.11, Radiation Protection for Occupational Workers, Change 3, 6/17/92.

DOE 5480.18B, Nuclear Facility Accreditation Training Program, 8/31/94.

DOE 5480.19, Conduct of Operations Requirements For DOE Facilities, Change 1, 5/18/92.

DOE 5480.20A, Personnel Selection, Qualification, Training, and Staffing Requirements at DOE Reactor and Non-Reactor Nuclear Facilities, 11/15/94.

DOE 5480.21, Unreviewed Safety Questions, 12/24/91.

DOE 5500.3A, Planning and Preparedness For Operational Emergencies, Change 1, 2/27/92.

DOE/EH0135, Performance Objectives and Criteria for Technical Safety Appraisals at Department of Energy Facilities and Sites, 6/28/90.

DOE/EH0256T(940431), DOE Radiological Control Manual, April 1994.

DOE-STD-1070-94, DOE Standard For Evaluation of Nuclear Facility Training Programs, $6 / 1 / 94$

DOE-STD-1073-93, DOE Standard Guide for Operational Configuration Management Program, Rev. 0, 1/17/94.

SNT-TC-1A, American Society for Nondestructive Testing, 08/84. 
The following documents were reviewed as requirements sources but were not used in the development of this S/RID:

49CFR172, Hazardous Materials Table, Special Provisions, Hazardous Material Communications Requirements and Emergency Response Information Requirements 10/1/92.

WAC-296-155, Safety Standards: Construction Work, 1993

DOE 5400.1, General Environmental Protection Program, 11/9/88.

DOE 5480.1B, Environment, Safety and Health Program for Department of Energy Operations, 9/23/86.

DOE 5480.4, Environmental Protection, Safety, and Health Protection Standards, Change 4, $1 / 7 / 93$.

DOE 5480.7A, Fire Protection, 2/17/93.

DOE 5480.9A, Construction Project Safety and Health Management, 4/13/94.

DOE 5480.10, Contractor Industrial Hygiene Program, 6/26/85.

DOE 5483.1A, Occupational Safety and Health Program For DOE Contractor Employees at Government-Owned Contractor-Operated Facilities, 6/22/83.

DOE 5700.6C, Quality Assurance, 8/21/91.

DOE 5820.2A, Radioactive Waste Management, 9/26/88.

DOE-RL-92-36, Hanford Site Hoisting and Rigging Manual, 1/15/93.

RLID 5480.7, Fire Protection, Rev. 0, 1/17/94.

NIRMA-PP02-1989, Position Paper on Configuration Management, Rev. 0, 1/1/89.

ANSI/ANS-8.20, Nuclear Criticality Safety Training, 1991.

ANSI-Z88.2-1992, Respiratory Protection, Rev. 3, 8/6/92.

ASME-NQA-1-1994, Quality Assurance Program Requirements for Nuclear Facilities Applications, 7/29/94.

BMP-87-006, Report on Configuration Management in the Nuclear Utility Industry, Rev. 0, $7 / 1 / 87$.

BMP-90-009-1992-R1, Guidelines for the Conduct of Design Engineering, Rev. 1, 2/1/92.

54FR3904, Federal Register: Safety and Health Program Management Guidelines; Issuance of Voluntary Guidelines, 1/26/89. 


\section{TABLE OF CONTENTS}

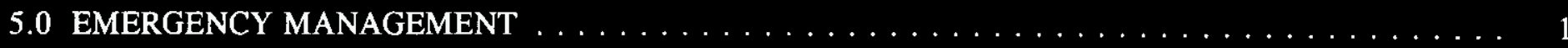

Program Policy $\ldots \ldots \ldots \ldots . \ldots \ldots$

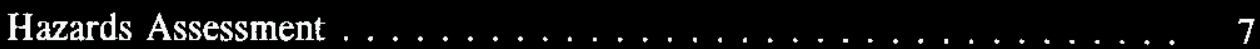

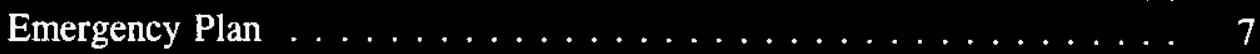

5.3 .3

Emergency Implementing Procedures $\ldots \ldots \ldots \ldots \ldots$

Notifications and Staff Augmentations . . . . . . . . . . . . . . . 22

Reporting and Event Investigations $\ldots \ldots \ldots \ldots \ldots \ldots$ 
5.10 .1

5.10 .2

5.10 .3

5.10 .4
Drill and Exercise Program . . . . . . . . . . . . . . . 29

Reviews, Audits and Evaluations . . . . . . . . . . . . . . 30

Emergency Readiness Assurance Program $\ldots \ldots \ldots \ldots \ldots \ldots$

Deficiency Identification and Correction $\ldots \ldots \ldots \ldots \ldots \ldots$

Safeguards and Security $\ldots \ldots \ldots \ldots \ldots \ldots \ldots \ldots \ldots \ldots \ldots$

Operations . . . . . . . . . . . . . . . . . . 31

Training and Qualification $\ldots \ldots \ldots \ldots \ldots \ldots \ldots \ldots \ldots \ldots \ldots$

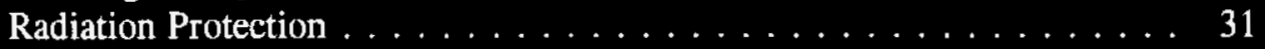

Waste Management $\ldots \ldots \ldots \ldots \ldots \ldots \ldots \ldots \ldots \ldots \ldots \ldots, 31$

Occupational, Health and Safety $\ldots \ldots \ldots \ldots \ldots \ldots \ldots \ldots . \ldots . \ldots . \ldots$

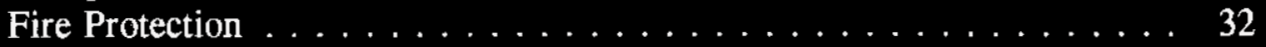

Medical . . . . . . . . . . . . . . . . . . . . 32

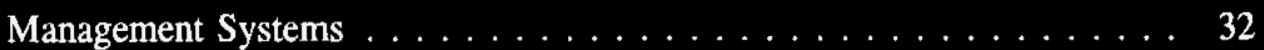

Nuclear Safety . . . . . . . . . . . . . . . . . . . 32

Packaging and Transportation $\ldots \ldots \ldots \ldots \ldots \ldots \ldots \ldots \ldots \ldots \ldots$

Quality Assurance $\ldots \ldots \ldots \ldots \ldots \ldots \ldots \ldots \ldots \ldots \ldots \ldots \ldots$

Environmental Protection $\ldots \ldots \ldots \ldots \ldots \ldots \ldots \ldots \ldots \ldots . \ldots \ldots$

Emergency Management $\ldots \ldots \ldots \ldots \ldots \ldots \ldots \ldots \ldots \ldots$

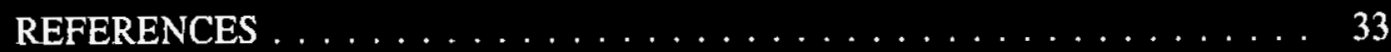

Requirement Source Documents $\ldots \ldots \ldots \ldots \ldots \ldots \ldots \ldots . . \ldots 33$

Reviewed Documents Not Used as Requirement Sources . . . . . . . 33 


\subsection{EMIERGENCY MANAGEMIENT}

\section{INTRODUCTION}

A Standards/Requirements Identification Document (S/RID) sets forth the Environmental Safety and Health (ES\&H) standards/requirements. This S/RID is applicable to the appropriate life cycle phases of design, construction, operation, and preparation for decommissioning for each of the categories of facilities addressed in Revision 5 of the Department of Energy Implementation Plan for the Defense Nuclear Facilities Safety Board (DNFSB) Recommendation 90-2. This Recommendation calls for the strengthening of DOE weapons complex activities through the identification and application of relevant DOE Orders, regulations, industry codes/standards, industry guidance documents and, as appropriate, good industry practices. These standards/requirements are adequate to ensure protection of the health and safety of workers, the public, and the environment.

The Tank Farms S/RID, contains standards/requirements that are necessary for safe operation of the Tank Farms and its associated facilities, and that are the direct responsibility of the specific facility manager. The Emergency Management (EM) Program defined in this document is described in general accordance with the Environment, Safety, and Health Configuration Guide, Revision 0, dated July 30, 1993, and is presented in program elements and subelements. The specific DOE Orders, regulations, industry codes/standards, guidance documents and good industry practices that serve as the basis for each element/subelement are identified and aligned with each subelement.

Sections 5.3 was changed to Planning Documents to additionally include the areas of Emergency Plan (subsection 5.3.2), and Emergency Implementing Procedures (subsection 5.3.3). Section 5.6 was renamed and expanded to include Event Containment and Consequence Assessment. (subsection 5.6.1). Additional elements and subelements were added to the basic format for further clarification and definition. Element 5.1, Management and Administration was further clarified by the addition of the following subelements: Program Policy (5.1.1), Duties, Responsibilities, and Authorities for Program Management (5.1.2), and Duties, Responsibilities and Authorities for ERO (5.1.3). Element 5.5, Classification, Notification and Reporting, was further enhanced by the addition of the following subelements: Event Classification and Emergency Action Levels (EALs) (5.5.1), Notifications and Staff Augmentation (5.5.2), and Reporting and Event Investigations (5.5.3). Element 5.7, Recovery and Reentry, was further defined by the addition of the following subelements: Recovery (5.7.1) and Reentry (5.7.2). Element 5. 11, Key Interfaces, was further enhanced by the addition of the following subelements: Management Systems (5.11.9), Nuclear Safety (5.11.10), Packaging and Transportation (5.11.11), Quality Assurance (5.11.12), and Environmental Protection (5.11.13). Element 5.12, References, was added to define applied and considered reference documents.

This S/RID contains only those requirements that Tank Farms personnel are clearly responsible to satisfy. Other requirements that are applicable to Tank Farms, but are satisfied by others, are defined in the Westinghouse Hanford Company (WHC) Level S/RID. For application in this S/RID, the words "shall" and "should" in requirement statements both indicate mandatory compliance. The key interface information contained in the Functional Area documents is provided for general recognition and understanding and is not considered to contain prescriptive requirements. Additionally, some of the requirements cited in this document are intentionally duplicated in the corresponding Company Level S/RID. This was necessary to address required implementation responsibilities occurring at both the company and facility levels. 


\title{
SCOPE
}

This S/RID applies to the Tank Waste Remediation Systems (TWRS) Organization which includes the following:

\author{
- $\quad$ East Tank Farm Transition Project \\ - West Tank Farm Transition Project \\ - Evaporator Project \\ - Interim Stabilization Project \\ - Characterization Sampling Project (Excluding the Labs)
}

The near-term mission of TWRS is to store, treat, and immobilize the highly radioactive Hanford Site Waste. 
5.1

$\underline{5.1 .1}$

$\underline{5.1 .2}$

\section{$\underline{5.1 .3}$}

\section{MANAGEMIENT AND ADMINISTRATION}

\section{Program Policy}

EM program policy is determined by senior management and demonstrated throughout emergency planning, preparedness and response programs. Policy is addressed at the company level on behalf of the Tank Farms.

\section{Duties, Responsibilities, and Authorities for Program Management}

\section{REQUIREMENT SOURCE: DOE5500.3A Section 11.a}

Author's Note: The following statements in this requirement are not applicable to Tank Farms: Offsite Response Interface; Medical Support; Public Information, Exercises. Medical Support is a Hanford Fire Department requirement. Others are site requirements.

"As part of the EMS, DOE elements and DOE contractors shall establish and maintain emergency management programs consisting of plans and procedures for response to Operational Emergencies involving or affecting DOE facilities, including DOE transportation activities. These emergency management programs must be commensurate with the assessment of potential hazards and targets and must include the following elements:Emergency Response Organization, Offsite Response Interfaces, Operational Emergency Event Classes, Notification, Consequence Assessment, Protective Actions, Medical Support, Recovery and Reentry, Public Information, Emergency Facilities and Equipment, Training, Drills and Exercises, and Program Administration."

\section{REQUIREMENT SOURCE: DOE5500.3A Section 11.c.(13)(a)}

Author's Note: The Tank Farms emergency Management administrator is not responsible for development of the Emergency Readiness Assurance Plan (ERAP) and annual updates, or development of exercise programs. These are site requirements.

"Program Administration. Provisions must be in place for the continued administration of the emergency management program as follows:

Each PSO, each Head of Field Element, and each contractor facility subject to this Order shall designate an individual to administer the emergency management program for their program, Field Element, or facility. This individual's responsibilities shall include development and maintenance of the emergency plan, development of the Emergency Readiness Assurance Plan (ERAP) and annual updates, development and conduct of training and exercise programs, coordination of assessment activities, development of related documentation, and coordination of emergency resources. ${ }^{n}$

Duties, Responsibilities and Authorities for ERO

\section{REQUIREMENT SOURCE: DOE5000.3B Section 8.a.(2)}

"(2) Appropriate immediate response(s) shall be taken by contractor operations personnel to stabilize or return the facility/operation to a safe condition."

\section{REQUIREMENT SOURCE: DOE5500.1B Section 10.w(26)(a)2}

"Ensure immediate mitigative and corrective emergency response actions and appropriate protective action recommendations to minimize the consequences of the emergency, protect 
worker and public health and safety, provide security, and ensure the continuance of such actions until the emergency is resolved;"

REQUIREMENT SOURCE: DOE5500.2B Section 10.c(5)(d)

"Directs and takes appropriate emergency response actions within the site boundary under its control and at the scene of the emergency."

\section{REQUIREMENT SOURCE: DOE5500.3A Section 11.c.( 1)}

Author's Note: Tank Farms is not responsible for the following statements in (a): medical support, public information, coordination and liaison with offsite support and response organizations. Medical support is a Hanford Fire Department requirement. Other statements are site requirements.

"Emergency Response Organization. An element with clearly specified authorities and responsibilities for emergency response and mitigation have overall responsibility for the initial and ongoing response to, and mitigation of, an emergency, and must:

(a) Perform, but not be limited to, the following functions: event categorization, determination of the emergency class, notification, provision of protective action recommendations, management and decision making, control of onsite emergency activities, consequence assessment, protective actions, medical support, public information, activation and coordination of onsite response resources, security, communications, administrative support, and coordination and liaison with offsite support and response organizations;

(b) Consist of an adequate number of experienced and trained personnel, including designated alternates, for timely performance of the functions identified above;

(c) Assign emergency response responsibilities and tasks to specific individuals identified by name, title, or position; and

(d) Integrate local agencies and organizations which would be relied upon to provide onsite response services and include those contractor and private organizations that may be relied upon to provide specialized expertise and assistance to all emergency planning, preparedness, and readiness assurance activities."

\section{REQUIREMENT SOURCE: WAC-173-303 Section 360(1)}

"Emergency coordinator.

At all times, there must be at least one employee either on the facility premises or on call with the responsibility for coordinating all emergency response measures. This emergency coordinator must be thoroughly familiar with all aspects of the facility's contingency plan, required by WAC 173-303-350(2), all operations and activities at the facility, the location and properties of all wastes handled, the location of all records within the facility, and the facility layout. In addition, this person must have the authority to commit the resources needed to carry out the contingency plan." 


\section{REQUIREMENT SOURCE: 29CFR1910 Part 120(p)(7)(i)}

"New employees. The employer shall develop and implement a training program, which is part of the employer's safety and health program, for employees exposed to health hazards or hazardous substances at TSD operations to enable the employees to perform their assigned duties and functions in a safe and healthful manner so as not endanger themselves or other employees. The initial training shall be for 24 hours and refresher training shall be for eight hours annually. Employees who have received the initial training required by this paragraph shall be given a written certificate attesting that they have successfully completed the necessary training."

\section{REQUIREMENT SOURCE: 29CFR1910 Part 120(p)(7)(ii)}

"Current employees. Employers who can show by an employee's previous work experience and/or training that the employee has had training equivalent to the initial training required by this paragraph, shall be considered as meeting the initial training requirements of this paragraph as to that employee. Equivalent training includes the training that existing employees might have already received from actual site work experience. Current employees shall receive eight hours of refresher training annually."

\section{REQUIREMENT SOURCE: 29CFR1910 Part 120(p)(8)(iii)(A)}

"Training for emergency response employees shall be completed before they are called upon to perform in real emergencies. Such training shall include the elements of the emergency response plan, standard operating procedures the employer has established for the job, the personal protective equipment to be worn and procedures for handling emergency incidents.

Exceptions \#1: An employer need not train all employees to the degree specified if the employer divides the work force in a manner such that a sufficient number of employees who have responsibility to control emergencies have the training specified, and all other employees, who may first respond to an emergency incident, have sufficient awareness training to recognize that an emergency response situation exists and that they are instructed in that case to summon the fully trained employees and not attempt control activities for which they are not trained.

Exception \#2: An employer need not train all employees to the degree specified if arrangements have been made in advance for an outside fully-trained emergency response team to respond in a reasonable period and all employees, who may come to the incident first, have sufficient awareness training to recognize that an emergency response situation exists and they have been instructed to call the designated outside fully trained emergency response team for assistance."

\section{REQUIREMENT SOURCE: 29CFR1910 Part 120(p)(8)(iii)(B)}

"Employee members of TSD facility emergency response organizations shall be trained to a level of competence in the recognition of health and safety hazards to protect themselves and other employees. This would include training in the methods used to minimize the risk of safety and health hazards; in the safe use of control equipment; in the selection and use of appropriate personal protective equipment; in the safe operating procedures to be used at the incident scene; in the appropriate response to over exposure from health hazards or injury to themselves and other employees; and in the recognition of subsequent symptoms which may result from over exposures." 
REQUIREMENT SOURCE: 29CFR1910 Part 120(p)(8)(iii)(C)

"The employer shall certify that each covered employee has attended and successfully completed the training required in paragraph (p)(8)(iii) of this section, or shall certify the employee's competency at least yearly. The method used to demonstrate competency for certification of training shall be recorded and maintained by the employer."

\section{REQUIREMENT SOURCE: 29CFR1910 Part 120(q)(11)}

"(i) Meet all the requirements of paragraphs (b) through (o) of this section; or

(ii) Where the clean-up is done on plant property using plant or workplace employees, such employees shall have completed the training requirements of the following: 29 CFR $1910.38(a) ; 1910.134 ; 1910.1200$, and other appropriate safety and health training made necessary by the tasks that they are expected to be performed such as personal protective equipment and decontamination procedures. All equipment to be used in the performance of the clean-up work shall be in serviceable condition and shall have been inspected prior to use."

\section{REQUIREMINT SOURCE: 40CFR265 Part 56(a)}

Author's Note: (2) not applicable to Tank Farms. Tank Farms provide notifications to the Occurrence Notifications Center (ONC). The ONC provides notifications to state and local agencies.

"Emergency procedures. Whenever there is an imminent or actual emergency situation, the emergency coordinator (or his designee when the emergency coordinator is on call) must immediately:

(1) Activate internal facility alarms or communication systems, where applicable, to notify all facility personnel; and

(2) Notify appropriate State or local agencies with designated response roles if their help is needed."

\section{REQUIREMENT SOURCE: DOE5500.3A Section 11.c.(11)(b) Introduction}

"A formal training program must be in place for the instruction and qualification of all personnel (i.e., primary and alternate) comprising the facility emergency response organization to include initial training and annual retraining for both onsite and offsite incidents, including transportation incidents."

\section{REQUIREMENT SOURCE: DOE5500.3A Section 11.c.(11)(b)(1)}

"All training must be systematic and performance based, i.e., based on an analysis of tasks to be performed during an emergency, and developed with performance objectives, emphasis on team training, and facility-specific emergency response scenarios."

\section{REQUIREMENT SOURCE: DOE5500.3A Section 11.c.(11)(b)(2)}

"Annual retraining shall include training on weaknesses detected during drills and exercises, changes to plans, procedures, and lessons learned from emergencies at DOE and other industrial facilities." 


\section{REQUIREMENT SOURCE: DOE5500.3A Section 11.c.(13)(b)}

"Program Administration. Provisions must be in place for the contimued administration of the emergency management program as follows:

The emergency plan and implementing procedures shall be controlled distribution documents and shall be annually reviewed and updated. "

\section{Hazards Assessment}

Author's Note: WHC Emergency Management is the lead for Hazard Assessment.

\section{REQUIREMENT SOURCE: DOE5500.3A Section 11.b.( 1)}

"Hazards Assessment.

A hazards assessment shall be prepared and maintained for each facility and shall be used for emergency planning purposes. This hazards assessment provides the technical basis for the emergency management program and shall include information sufficient to determine the scope and extent of the program elements comprising the emergency management program for the respective facility. This hazards assessment shall be derived from information provided by the assessment of the potential DOE requirements. The use of vulnerability and target analyses may include sensitive or classified information which will need special handling."

\section{Emergency Plan}

\section{REQUIREMINT SOURCE: 29CFR1910 Part 38(a)(1)}

"Employee emergency plans and fire preventions. Emergency action plan -- Scope and application. This paragraph (a) applies to all emergency action plans required by a particular OSHA standard. The emergency action plan shall be in writing (except as provided in the last sentence of paragraph (a)(5)(iii) of this section) and shall cover those designated actions employers and employees must take to ensure employee safety from fire and other emergencies."

\section{REQUIREMENT SOURCE: 29CFR1910 Part 38(a)(2)}

"Elements. The following elements, at a minimum, shall be included in the plan:

(i) Emergency escape procedures and emergency escape route assignments;

(ii) Procedures to be followed by employees who remain to operate critical plant operations before they evacuate;

(iii) Procedures to account for all employees after emergency evacuation has been completed;

(iv) Rescue and medical duties for those employees who are to perform them;

(v) The preferred means of reporting fires and other emergencies; and

(vi) Names or regular job titles of persons or departments who can be contacted for further information or explanation of duties under the plan. " 


\section{REQUIREMINT SOURCE: 29CFR1910 Part 38(a)(4)}

"Employee emergency plans and fire preventions. Emergency action plan. Evacuation. The employer shall establish in the emergency action plan the types of evacuation to be used in emergency circumstances."

\section{REQUIREMENT SOURCE: 29CFR1910 Part 120(q)(6)}

Author's Note: Subparts (ii), (iii), and (iv) are applicable to Tank Farms for radiological releases only. Hazardous materials releases requirements are applicable to the Hanford Fire Department HAZMAT organization. In this context, first responders are titled discovering individuals, however these individuals are trained to fulfill this requirement.

"Training. Training shall be based on the duties and function to be performed by each responder of an emergency response organization. The skill and knowledge levels required for all new responders, those hired after the effective date of this standard, shall be conveyed to them through training before they are permitted to take part in actual emergency operations on an incident. Employees who participate, or are expected to participate, in emergency response, shall be given training in accordance with the following paragraphs:

(i) First responder awareness level. First responders at the awareness level are individuals who are likely to witness or discover a hazardous substance release and who have been trained to initiate an emergency response sequence by notifying the authorities of the release. First responders at the awareness level shall have sufficient training or have had sufficient experience to objectively demonstrate competency in the following areas:

(A) An understanding of what hazardous substances are, and the risks associated with them in an incident.

(B) An understanding of the potential outcomes associated with an emergency created when hazardous substances are present.

(C) The ability to recognize the presence of hazardous substances in an emergency.

(D) The ability to identify the hazardous substances, if possible.

(E) An understanding of the role of the first responder awareness individual in the employer's emergency response plan including site security and control and the U.S. Department of Transportation's Emergency Response Guidebook.

(F) The ability to realize the need for additional resources, and to make appropriate notifications to the communication center.

(ii) First responder operations level. First responders at the operations level are individuals who respond to releases or potential releases of hazardous substances as part of the initial response to the site for the purpose of protecting nearby persons, property, or the environment from the effects of the release. They are trained to respond in a defensive fashion without actually trying to stop the release. Their function is to contain the release from a safe distance, keep it from spreading, and prevent exposures. First responders at the operational level shall have received at least eight hours of training or have had sufficient experience to objectively demonstrate competency in the following areas in addition to those listed for the awareness level and the employer shall so certify:

(A) Knowledge of the basic hazard and risk assessment techniques. 
(B) Know how to select and use proper personal protective equipment provided to the first responder operational level.

(C) An understanding of basic hazardous materials terms.

(D) Know how to perform basic control, containment and/or confinement operations within the capabilities of the resources and personal protective equipment available with their unit.

(E) Know how to implement basic decontamination procedures.

(F) An understanding of the relevant standard operating procedures and termination procedures.

(iii) Hazardous materials technician. Hazardous materials technicians are individuals who respond to releases or potential releases for the purpose of stopping the release. They assume a more aggressive role than a first responder at the operations level in that they will approach the point of release in order to plug, patch or otherwise stop the release of a hazardous substance. Hazardous materials technicians shall have received at least 24 hours of training equal to the first responder operations level and in addition have competency in the following areas and the employer shall so certify:

(A) Know how to implement the employer's emergency response plan.

(B) Know the classification, identification and verification of known and unknown materials by using field survey instruments and equipment.

(C) Be able to function within an assigned role in the Incident Command System.

(D) Know how to select and use proper specialized chemical personal protective equipment provided to the hazardous materials technician.

(E) Understand hazard and risk assessment techniques.

(F) Be able to perform advance control, containment, and/or confinement operations within the capabilities of the resources and personal protective equipment available with the unit.

(G) Understand and implement decontamination procedures.

(H) Understand termination procedures.

(I) Understand basic chemical and toxicological terminology and behavior.

(iv) Hazardous materials specialist. Hazardous materials specialists are individuals who respond with and provide support to hazardous materials technicians. Their duties parallel those of the hazardous materials technician, however, those duties require a more directed or specific knowledge of the various substances they may be called upon to contain. The hazardous materials specialist would also act as the site liaison with Federal, state, local and other government authorities in regards to site activities. Hazardous materials specialists shall have competency in the following areas and the employer shall so certify:

(A) Know how to implement the local emergency response plan.

(B) Understand classification, identification and verification of known and unknown materials by using advanced survey instruments and equipment. 
(C) Know the state emergency response plan.

(D) Be able to select and use proper specialized chemical personal protective equipment provided to the hazardous materials specialist.

(E) Understand in-depth hazard and risk techniques.

(F) Be able to perform specialized control, containment, and/or confinement operations within the capabilities of the resources and personal protective equipment available.

(G) Be able to determine and implement decontamination procedures.

(H) Have the ability to develop a site safety and control plan.

(I) Understand chemical, radiological and toxicological terminology and behavior.

(v) On scene incident commander. Incident commanders, who will assume control of the incident scene beyond the first responder awareness level, shall receive at least 24 hours of training equal to the first responder operations level and in addition have competency in the following areas and the employer shall so certify:

(A) Know and be able to implement the employer's incident command system.

(B) Know how to implement the employer's emergency response plan.

(C) Know and understand the hazards and risks associated with employees working in chemical protective clothing.

(D) Know how to implement the local emergency response plan.

(E) Know of the state emergency response plan and of the Federal Regional Response Team.

(F) Know and understand the importance of decontamination procedures."

\section{REQUIREMENT SOURCE: 29CFR1910 Part 120(q)( 8)}

Author's Note: Subparts $i$ and ii are applicable to Tank Farms for radiological releases only. Hazardous materials releases requirements are applicable to the Hanford Fire Department HAZMAT organization. In this context, first responders are titled discovering individuals, however these individuals are trained to fulfill this requirement.

"Refresher training.

(i) Those employees who are trained in accordance with paragraph (q)(6) of this section shall receive annual refresher training of sufficient content and duration to maintain their competencies, or shall demonstrate competency in those areas at least yearly.

(ii) A statement shall be made of the training or competency, and if a statement of competency is made, the employer shall keep a record of the methodology used to demonstrate competency." 


\section{REQUIREMIENT SOURCE: 40CFR265 Part 51}

"Purpose and implementation of contingency plan.

(a) Each owner or operator must have a contingency plan for his facility. The contingency plan must be designed to minimize hazards to human health or the environment from fires, explosions, or any unplanned sudden or non-sudden release of hazardous waste or hazardous waste constituents to air, soil, or surface water.

(b) The provisions of the plan must be carried out immediately whenever there is a fire, explosion, or release of hazardous waste constituents which could threaten human health or the environment. "

\section{REQUIREMINT SOURCE: 40CFR265 Part 52(a)}

"Content of contingency plan. The contingency plan must describe the actions facility personnel must take to comply with 265.51 and 265.56 in response to fires, explosions, or any unplanned sudden or non-sudden release of hazardous waste or hazardous waste constituents to air, soil, or surface water at the facility."

\section{REQUIREMENT SOURCE: 40CFR265 Part 52(i)}

"Content of contingency plan. The plan must include an evacuation plan for facility personnel where there is a possibility that evacuation could be necessary. This plan must describe signal(s) to be used to begin evacuation, evacuation routes, and alternate evacuation routes (in cases where the primary routes could be blocked by releases of hazardous waste or fires). "

\section{REQUIREMIENT SOURCE: 40CFR265 Part 53(a)}

"Copies of contingency plan. Maintained at the facility;"

\section{REQUIREMENT SOURCE: DOE5500.3A Section 11.d.( 1)}

Author's Note: Tank Farms meets subsection (c) by meeting the requirements of WHC emergency plan contents and format. WHC Emergency Management is responsible for ensuring their contents and format requirements are compatible with applicable DOE, Federal, state, tribal, and local emergency plans. Copies are required to be maintained at the facility.

"Documentation. PSOs, Heads of Field Elements, and all managers/administrators of a DOEor contractor-operated facility shall develop and maintain an emergency plan and associated procedures to document their emergency management program. These documents must be controlled distribution documents. The documentation shall include:

An emergency plan which describes the provisions for response to an operational emergency.

(a) The plan must contain information to describe each element of the emergency management program, describe the overall picture of emergency response capabilities, and include material necessary for the understanding of the plans (e.g., diagrams, illustrations, maps, and transportation routes). The emergency plan must reference procedures and supporting material (i.e., PRAs, MSSAs, EAs, EISs, etc.) which may be used by emergency response personnel.

(b) The emergency plan must describe the EPZs applicable to the facility to include topographical features, demographic information, transportation routes, land use, major industrial facilities, public facilities, and jurisdictional boundaries. 
(c) The emergency plan must be consistent with other plans for similar DOE facilities and coordinated and compatible with other applicable DOE, Federal, state, tribal, and local emergency plans. The emergency plan must integrate the response plans for specific incidents (e.g., fire medical, security, and natural phenomena)."

\section{REQUIREMINT SOURCE: WAC-173-303 Section 350(2)}

"Contingency plan. Each owner or operator must have a contingency plan at his facility for use in emergencies or sudden or nonsudden releases which threaten the public health and the environment. If the owner or operator has already prepared a spill prevention control and countermeasures (SPCC) plan in accordance with Part 112 of Title 40 CFR or Part 1510 of chapter V, or some other emergency or contingency plan, he need only amend that plan to incorporate dangerous waste management provisions that are sufficient to comply with the requirements of this section and WAC 173-303-360."

\section{REQUIREMENT SOURCE: WAC-173-303 Section 350(3)(d)}

Author's Note: Tank Farms emergency organization listing is issued to site personnel and locations. The home phone numbers of the emergency coordinators (building emergency directors) is not on the listing due to confidential information policies. The home phone numbers are listed in the controlled Emergency On-Call Listing issued by WHC Emergency Management.

"A current list of names, addresses, and phone numbers (office and home) of all persons qualified to act as the emergency coordinator required under WAC 173-303-360(1). Where more than one person is listed, one must be named as primary emergency coordinator, and others must be listed in the order in which they will assume responsibility as alternates. For new facilities only, this list may be provided to the department at the time of facility certification (as required by WAC 173-303-810(14)(a)(i)), rather than as part of the permit application;"

\section{REQUIREMENT SOURCE: WAC-173-303 Section 350(3)(e)}

"(e) A list of all emergency equipment at the facility (such as fire extinguishing systems, spill control equipment, communications and alarm systems, and decontamination equipment), where this equipment is required. This list must be kept up to date. In addition, the plan must include the location and a physical description of each item on the list, and a brief outline of its capabilities; and"

\section{REQUIREMENT SOURCE: WAC-173-303 Section 350(3)(f)}

"(f) An evacuation plan for facility personnel where there is a possibility that evacuation could be necessary. This plan must describe the signal(s) to be used to begin evacuation, evacuation routes, and alternate evacuation routes."

\section{REQUIREMENT SOURCE: WAC-173-303 Section 350(4)}

Author's Note: Item (b) does not apply.

"Copies of contingency plan. A copy of the contingency plan and all revisions to the plan shall be:

(a) Maintained at the facility; and 
(b) Submitted to all local police departments, fire departments, hospitals, and state and local emergency response teams that may be called upon to provide emergency services."

\section{REQUIREMINT SOURCE: WAC-173-303 Section 350(5)}

"Amendments. The owner or operator shall review and immediately amend the contingency plan, if necessary, whenever:

(a) Applicable regulations or the facility permit are revised;

(b) The plan fails in an emergency;

(c) The facility changes (in its design, construction, operation, maintenance, or other circumstances) in a way that materially increases the potential for fires, explosions, or releases of dangerous waste or dangerous waste constituents, or in a way that changes the response necessary in an emergency;

(d) The list of emergency coordinators changes; or

(e) The list of emergency equipment changes."

\section{REQUIREMENT SOURCE: WAC-296-62 Section 3140(8)(a)(b)}

"Emergency response program.

(a) Emergency response plan. An emergency response plan shall be developed and implemented by all employers. Such plans need not duplicate any of the subjects fully addressed in the employer's contingency planning required by permits, such as those issued by the United States Environmental Protection Agency, provided that the contingency plan is made part of the emergency response plan. The emergency response plan shall be a written portion of the employer's safety and health program required in this section. Employers who will evacuate their employees from the worksite location when an emergency occurs and who do not permit any of their employees to assist in handling the emergency are exempt from the requirements of WAC 296-62-3140(8) if they provide an emergency action plan complying with WAC 296-24-567.

(b) Elements of an emergency response plan. The employer shall develop an emergency response plan for emergencies which shall address, as a minimum, the following areas to the extent that they are not addressed in any specific program required in this section:

(i) Preemergency planning and coordination with outside parties.

(ii) Personnel roles, lines of authority, and communication.

(iii) Emergency recognition and prevention.

(iv) Safe distances and places of refuge.

(v) Site security and control.

(vi) Evacuation routes and procedures.

(vii) Decontamination procedures.

(viii) Emergency medical treatment and first aid. 
(ix) Emergency alerting and response procedures.

(x) Critique of response and follow-up.

(xi) PE and emergency equipment. "

\section{$\underline{\mathbf{5 . 3 . 3}}$}

Emergency Implementing Procedures

\section{REQUIREMENT SOURCE: 29CFR1910 Part 120(p)(8)(iv)}

"Procedures for handling emergency incidents.

(A) In addition to the elements for the emergency response plan required in paragraph (p)(8)(ii) of this section, the following elements shall be included for emergency response plans to the extent that they do not repeat any information already contained in the emergency response plan:

(1) Site topography, layout, and prevailing weather conditions.

(2) Procedures for reporting incidents to local, state, and federal governmental agencies.

(B) The emergency response plan shall be compatible and integrated with the disaster, fire and/or emergency response plans of local, state, and federal agencies.

(C) The emergency response plan shall be rehearsed regularly as part of the overall training program for site operations.

(D) the site emergency response plan shall be reviewed periodically and, as necessary, be amended to keep it current with new or changing site conditions or information.

(E) An employee alarm system shall be installed in accordance with 29CFR 1910.165 to notify employees of an emergency situation; to stop work activities if necessary; to lower background noise in order to speed communication; and to begin emergency procedures.

(F) Based upon the information available at time of the emergency, the employer shall evaluate the incident and the site response capabilities and proceed with the site emergency response plan."

\section{REQUIREMENT SOURCE: DOE5480.10 Section 9.c(4)(f)}

"Procedures shall be established for emergency actions involving chemical carcinogens (e.g., cleanup of spills or accidental releases). Occurrences which could result in exposure of personnel or release to the environment shall be investigated and, if appropriate, reported (refer to DOE 5484.1)."

\section{REQUIREMENT SOURCE: DOE5500.3A Section 11.d, Paragraph 1}

"Documentation. PSOs, Heads of Field Elements, and all managers/administrators of a DOEor contractor-operated facility shall develop and maintain an emergency plan and associated procedures to document their emergency management program. These documents must be controlled distribution documents." 


\section{REQUIREMENT SOURCE: DOE5500.3A Section 11.d.( 2)}

"Procedures which describe how the emergency plan shall be implemented.

(a) Procedures must consist of special emergency plan implementing procedures (e.g., EALs, event categorization, notification, EOC operation) as well as other procedures currently in use (e.g., equipment operation, chemistry controls, radiological monitoring, and maintenance) which would be utilized in, or associated with, emergency response activities.

(b) Procedures must be consistent and compatible with the emergency plan. Emergency procedures must contain the detailed information and the specific instructions needed to carry out the emergency plan during a drill, exercise, or actual emergency. Procedures must clearly and concisely identify the individual(s) responsible for performance of response activities and delineate the specific actions steps to be performed. Procedures must identify the relevant prerequisites (i.e., conditions which must exist prior to specific actions being performed) and precautions (regarding personnel safety and equipment operation) associated with the response actions."

\section{REQUIREMENT SOURCE: WAC-173-303 Section 350(3)(b)}

"(b) A description of the actions which shall be taken in the event that a dangerous waste shipment, which is damaged or otherwise presents a hazard to the public health and the environment, arrives at the facility, and is not acceptable to the owner or operator, but cannot be transported, pursuant to the requirements of WAC 173-303-370(5), Manifest system, reasons for not accepting dangerous waste shipments;"

\section{REQUIREMENT SOURCE: WAC-173-303 Section 360(2)(a)}

Author's Note: Subsection (ii) is not applicable. Tank Farms notifies the Occurrence Notification Center (ONC). The ONC notifies offsite agencies.

"Whenever there is an imminent or actual emergency situation, the emergency coordinator (or his designee when the emergency coordinator is on call) must immediately:

(i) Activate internal facility alarms or communication systems, where applicable, to notify all facility personnel; and

(ii) Notify appropriate state or local agencies with designated response roles if their help is needed."

\section{REQUIREMENT SOURCE: WAC-173-303 Section 360(2)(b)}

"Whenever there is a release, fire, or explosion, the emergency coordinator must immediately identify the character, exact source, amount, and areal extent of any released materials."

\section{REQUIREMENT SOURCE: WAC-173-303 Section 360(2)(c)}

"Concurrently, the emergency coordinator shall assess possible hazards to human health and the environment (considering direct, indirect, immediate, and long-term effects) that may result from the release, fire, or explosion." 


\section{REQUIREMENT SOURCE: WAC-173-303 Section 360(2)(i)}

"During an emergency, the emergency coordinator must take all reasonable measures necessary to ensure that fires, explosions, and releases do not occur, recur, or spread to other dangerous waste at the facility. These measures must include, where applicable, stopping processes and operations, collecting and containing released waste, and removing or isolating containers."

\section{REQUIREMINT SOURCE: WAC-173-303 Section 360(2)(g)}

"If the facility stops operations in response to a fire, explosion, or release, the emergency coordinator must monitor for leaks, pressure buildup, gas generation, or ruptures in valves, pipes, or other equipment, wherever this is appropriate."

\section{REQUIREMENT SOURCE: WAC-173-303 Section 360(2)(h)}

"Immediately after an emergency, the emergency coordinator must provide for treating, storing, or disposing of recovered waste, contaminated soil or surface water, or any other material that results from a release, fire, or explosion at the facility."

\section{REQUIREMENT SOURCE: WAC-173-303 Section 360(2)(i)}

"The emergency coordinator must ensure that, in the affected area(s) of the facility:

(i) No waste that may be incompatible with the released material is treated, stored, or disposed of until cleanup procedures are completed; and

(ii) All emergency equipment listed in the contingency plan is cleaned and fit for its intended use before operations are resumed."

\section{REQUIREMENT SOURCE: WAC-296-62 Section 3140(8)(d)}

Author's Note: Subsection (B) is not applicable to Tank Farms. Tank Farms reports incidents to the Occurrence Notifications Center (ONC).

Subsection (B)(ii). Tank Farms emergency plans are compatible with site emergency plans. WHC emergency management is responsible for ensuring the emergency plans format and contents are compatible with local, state and federal agencies.

Subsection (iv). The site emergency plan is the responsibility of WHC emergency management organization.

Subsection (vi) is applicable, but Tank Farms implements their emergency plans for the facility, not the site emergency plan.

In this requirement site equals facility.

"Procedures for handling emergency incidents.

(i) In addition to the elements for the emergency response plan required in

(b) of this subsection, the following elements shall be included for emergency response plans to the extent that they do not repeat any information already contained in the emergency

response plan: 
(A) Site topography, layout, and prevailing weather conditions.

(B) Procedures for reporting incidents to local, state, and federal governmental agencies.

(ii) The emergency response plan shall be compatible and integrated with the disaster, fire, and/or emergency response plans of local, state, and federal agencies.

(iii) The emergency response plan shall be rehearsed regularly as part of the overall training program for site operations.

(iv) The site emergency response plan shall be reviewed periodically and, as necessary, be amended to keep it current with new or changing site conditions or information.

(v) An employee alarm system shall be installed in accordance with WAC 296-24-631 to notify employees of an emergency situation; to stop work activities if necessary; to lower background noise in order to speed communication; and to begin emergency procedures.

(vi) Based upon the information available at time of the emergency, the employer shall evaluate the incident and the site response capabilities and proceed with the appropriate steps to implement the site emergency response plan."

5.4

$\underline{5.4 .1}$

$\underline{5.4 .2}$

\section{FACILITIES, EQUIPMENT AND RESOURCES}

\section{Emergency Response Facilities}

Author's Note: Requirements for the subelement are included in the WHC S/RID.

\section{Emergency Equipment and Supplies}

\section{REQUIREMENT SOURCE: 29CFR1910 Part 134(a)(7), Last Sentence}

"Respiratory protection. Permissible practice. Respirators for emergency use such as self-contained devices shall be thoroughly inspected at least once a month and after each use."

\section{REQUIREMENT SOURCE: 29CFR1910 Part 134(f)(2)(iv)}

"Maintenance and care of respirators. A record shall be kept of inspection dates and findings for respirators maintained for emergency use."

\section{REQUIREMENT SOURCE: 29CFR1910 Part 134(1)(5)(iii)}

"Maintenance and care of respirators. Instructions for proper storage of emergency respirators, such as gas masks and self-contained breathing apparatus, are found in "use and care" instructions usually mounted inside the carrying case lid."

\section{REQUIREMINT SOURCE: 40CFR265 Part 52(e)}

"Content of contingency plan. The plan must include a list of all emergency equipment at the facility (such as fire extinguishing systems, spill control equipment, communications and alarm systems (internal and external), and decontamination equipment), where this equipment is required. This list must be kept up to date. In addition, the plan must include the location and a physical description of each item on the list, and a brief outline of its capabilities." 


\section{REQUIREMINT SOURCE: DOE5500.3A Section 11.c.(10)(d)}

"Adequate equipment and supplies must be available and operable for emergency response personnel to carry out their respective duties and responsibilities."

\section{Communications Equipment}

\section{REQUIREMENT SOURCE: 29CFR1910 Part 38(a)(3)}

"Employee emergency plans and fire preventions. Emergency action plan. Alarm System.

(i) The employer shall establish an employee alarm system which complies with 1910.165.

(ii) If the employee alarm system is used for alerting fire brigade members, or for other purposes, a distinctive signal for each purpose shall be used."

\section{REQUIREMENT SOURCE: 29CFR1910 Part 165(b)(1)}

"Employee alarm systems. General requirements. The employee alarm system shall provide warning for necessary emergency action as called for in the emergency action plan, or for reaction time for safe escape of employees from the workplace or the immediate work area, or both."

\section{REQUIREMINT SOURCE: 29CFR1910 Part 165(b)(2)}

"The employee alarm shall be capable of being perceived above ambient noise or light levels by all employees in the affected portions of the workplace. Tactile devices may be used to alert those employees who would not otherwise be able to recognize the audibile[SIC] or visual alarm."

\section{REQUIREMENT SOURCE: 29CFR1910 Part 165(b)(3)}

"Employee Alarm systems. General requirements. The employee alarm shall be distinctive and recognizable as a signal to evacuate the work area or to perform actions designated under the emergency action plan."

\section{REQUIREMENT SOURCE: 29CFR1910 Part 165(b)(4)}

"Employee Alarm systems. General requirements. The employer shall explain to each employee the preferred means of reporting emergencies, such as manual pull box alarms, public address systems, radio or telephones. The employer shall post emergency telephone numbers near telephones, or employee notice boards, and other conspicuous locations when telephones serve as a means of reporting emergencies. Where a communication system also serves as the employee alarm system, all emergency messages shall have priority over all non-emergency messages."

\section{REQUIREMENT SOURCE: 29CFR1910 Part 165(b)(5)}

"Employee Alarm systems. General requirements. The employer shall establish procedures for sounding emergency alarms in the workplace. For those employers with 10 or fewer employees in a particular workplace, direct voice communication is an acceptable procedure for sounding the alarm provided all employees can hear the alarm. Such workplaces need not have a back-up system." 


\section{REQUIREMENT SOURCE: WAC-173-303 Section 340(1)}

Author's Note: Subsection (b) statement pertaining to summoning local police departments pertains to the Hanford Patrol for Tank Farms. Subsection (b) statement concerning summoning emergency assistance from state or local emergency response teams is not applicable to Tank Farms. Tank Farms does not request offsite assistance.

Subsection (d) statement pertaining to "Water a adequate volume and pressure supply water hose streams, foam producing equipment, automatic sprinklers, or water spray systems " is not a Tank Farms responsibility. These requirements are Fire Protection and/or the hanford Fire Department.

"Required equipment. All facilities must be equipped with the following, unless it can be demonstrated to the department that none of the hazards posed by waste handled at the facility could require a particular kind of equipment specified below:

(a) An internal communications or alarm system capable of providing immediate emergency instruction to facility personnel;

(b) A device, such as a telephone or a hand-held, two-way radio, capable of summoning emergency assistance from local police departments, fire departments, or state or local emergency response teams;

(c) Portable fire extinguishers, fire control equipment, spill control equipment, and decontamination equipment; and

(d) Water at adequate volume and pressure to supply water hose streams, foam producing equipment, automatic sprinklers, or water spray systems. All facility communications or alarm systems, fire protection equipment, spill control equipment, and decontamination equipment, where required, must be tested and maintained as necessary to assure its proper operation in time of emergency."

\section{REQUIREMENT SOURCE: WAC-173-303 Section 340(2)}

"Access to communications or alarms. Personnel must have immediate access to the signalling devices described in the situations below:

(a) Whenever dangerous waste is being poured, mixed, spread, or otherwise handled, all personnel involved must have immediate access to an internal alarm or emergency communication device, either directly or through visual or voice contact with another employee, unless such a device is not required in subsection (1) of this section;

(b) If there is ever just one employee on the premises while the facility is operating, he must have immediate access to a device, such as a telephone or a hand-held, two-way radio, capable of summoning external emergency assistance, unless such a device is not required in subsection (1) of this section."

\section{REQUIREMENT SOURCE: DOE5500.1B Section 10.w(26)(a)1}


"Ensure the proper identification, categorization, and notification of emergencies or other reportable occurrences to line management and the HQ EOC, in accordance with applicable DOE policies and requirements;"

\section{Event Classification and Emergency Action Levels (EALs)}

\section{REQUIREMENT SOURCE: 40CFR265 Part 56(b)}

"Emergency procedures. Whenever there is a release, fire, or explosion, the emergency coordinator must immediately identify the character, exact source, amount and a real extent of any released materials. He may do this by observation or review of facility records or manifests and, if necessary, by chemical analysis."

\section{REQUIREMENT SOURCE: DOE5500.2B Section 11.a.2(a)4b}

Author's Note: Special Nuclear Material is not applicable to Tank Farms.

"Non-reactor Facilities. An Alert shall be declared when events are in progress or have occurred which involve an actual or potential substantial degradation of the level of safety of the facility. Any release of hazardous materials (radiological or non-radiological) is expected to be limited to small fractions of the appropriate PAG or ERPG exposure limits."

\section{REQUIREMENT SOURCE: DOE5500.2B Section 11.a.2(a)4d}

Author's Note: DOE 5000.3A superseded by DOE 5000.3B.

"Safeguards and Security. An Alert shall be declared when events are in progress, have occurred, or are anticipated which could involve an actual or potential substantial degradation in the level of protection of the facility or the loss or possible loss of Special Nuclear Material (SNM). Pre-emergency conditions which warrant increased safeguards and security measures shall be reported in accordance with DOE 5000.3A, Attachment 2 Group 5, procedures for non-emergency occurrences."

\section{REQUIREMENT SOURCE: DOE5500.2B Section 11.a.2(a)4e}

"Transportation. An Alert shall be declared when events are in progress or have occurred which involve an actual or potential substantial degradation of the safety of the shipment. Any release of hazardous materials (radiological or non-radiological) is expected to be limited to small fractions of the appropriate PAG or ERPG exposure levels. "

\section{REQUIREMENT SOURCE: DOE5500.2B Section 11.a.2(b)7.b}

"Non-reactor Facilities. A Site Area Emergency shall be declared when events are in progress or have occurred which involve actual or likely major failures of facility functions needed for protection of workers and the public. Any release of hazardous materials (radiological or non-radiological) is expected to exceed appropriate PAG or ERPG exposure levels onsite but is not expected to exceed the appropriate PAGs or ERPGs offsite."

\section{REQUIREMENT SOURCE: DOE5500.2B Section 11.a.2(b)7.d}

"Safeguards and Security. A Site Area Emergency shall be declared when events are in progress or have occurred which involve actual malevolent acts resulting in major failures of protective systems." 


\section{REQUIREMENT SOURCE: DOE5500.2B Section 11.a.2(b)7.e}

"Transportation. A Site Area Emergency shall be declared when events are in progress or have occurred which involve an actual or potential major reduction in the safety of the shipment. Any release of hazardous materials (radiological or non-radiological) is expected to exceed appropriate PAG or ERPG exposure levels in the immediate vicinity of the accident or incident but is not expected to exceed the appropriate PAGs or ERPGs in a general public area."

\section{REQUIREMENT SOURCE: DOE5500.2B Section 11.a.2(c)7.b}

"Non-reactor Facilities. A General Emergency shall be declared when events are in progress or have occurred which involve actual or imminent catastrophic reduction of facility safety systems with potential for loss of containment or confinement integrity, (e.g., release of large quantities of hazardous materials to the environs) and/or release of hazardous materials (radiological or non-radiological) that can reasonably be expected to exceed appropriate PAG or ERPG exposure levels offsite."

\section{REQUIREMENT SOURCE: DOE5500.2B Section 11.a.2(c)7.d}

"Safeguards and Security. A General Emergency shall be declared when events are in progress or have occurred which involve malevolent action resulting in catastrophic degradation of protection systems that could lead to substantial offsite impacts."

\section{REQUIREMENT SOURCE: DOE5500.2B Section 11.a.2(c)7.e}

"Transportation. A General Emergency shall be declared when events have occurred which involve an actual or imminent catastrophic reduction in the safety of the shipment. Any release of hazardous materials (radiological or non-radiological) is expected to exceed appropriate PAG or ERPG exposure levels in a general public area. If the event has occurred on a DOE site, the release is expected to exceed appropriate PAG or ERPG exposure levels offsite" $^{\text {" }}$

\section{REQUIREMENT SOURCE: DOE5500.3A Section 11.c.( 3)}

Author's Note: Last sentence is not a facility requirement.

"Operational Emergency Event Classes. Operational Emergencies involving or affecting DOE facilities must be characterized as one of the Operational Emergency classes (e.g., Alert, Site Area Emergency, or General Emergency) in accordance with DOE 5500.2B. EALs, the specific criteria used to recognize and categorize events, must be developed for the spectrum of potential Operational Emergencies identified by the hazards assessment. EALs form the basis for notification and participation of offsite organizations and for determining what and when protective measures will be implemented. EAL initiating conditions (i.e., individual instrument readings, equipment status, valve positions, parameter values, onsite and/or offsite monitor readings, etc.) must be specifically identified in procedures and must be observable and recognizable in a timely manner by responsible personnel. The EALs and related information must be consistent and integrated with the emergency plans and procedures of offsite Federal, state, tribal, and local organizations, and should be reviewed annually, as appropriate, by all parties involved in response activities." 


\section{Notifications and Staff Augmentations}

Author's Note: For DOE 5000.3B requirement see TWRS Management Systems.

\section{REQUIREMENT SOURCE: 40CFR355 Part 40(b)(2)}

"Emergency release notification. Notice requirements. The notice required under this section shall include the following to the extent known at the time of notice and so long as no delay in notice or emergency response results:

(i) The chemical name or identity of any substance involved in the release.

(ii) An indication of whether the substance is an extremely hazardous substance.

(iii) An estimate of the quantity of any such substance that was released into the environment.

(iv) The time and duration of the release.

(v) The medium or media into which the release occurred.

(vi) Any known or anticipated acute or chronic health risks associated with the emergency and, where appropriate, advice regarding medical attention necessary for exposed individuals.

(vii) Proper precautions to take as a result of the release, including evacuation (unless such information is readily available to the community emergency coordination pursuant to the emergency plan).

(viii) The names and telephone number of the person or persons to be contacted for further information."

\section{REQUIREMENT SOURCE: DOE5000.3B Section 8.a.(5)}

Author's Note: Tank Farms is responsible for notifying the Occurrence Notification Center (ONC). The ONC is responsible for notifying DOE HQ Emergency Operations Center (EOC).

"For oral notification, the Facility Manager shall simultaneously contact the DOE Facility Representative and the Headquarters (HQ) Emergency Operations Center (EOC) through which the DOE Program Manager and any other necessary program staff can be located and direct communications links with the Facility Manager established. The HQ EOC function here is to facilitate communications within line organizations and to record and archive conversations. To facilitate this archival function, the oral notification shall include as many of the required report fields [see discussion in Attachment II, Section 1, regarding Fields 1-18 identified with an asterisk $\left(^{*}\right)$ ] as known at the time of the oral notification with particular emphasis on clear and succinct descriptions of the occurrence (Field 15); brief, concise descriptions of the operating conditions of the facility at the time of the occurrence (Field 16); and immediate actions taken, including results, if known (Field 18). The Facility Manager may use the local Field/Site EOC to expedite establishing the direct communication link required above. To promote common understanding, the use of jargon should be avoided and uncommon or facility/ site-specific abbreviations and acronyms should be fully described in oral notifications and spelled out in subsequent written reports."

\section{REQUIREMENT SOURCE: DOE5500.2B Section 12.b(2)(a)}

Author's Note: Tank Farms provides timely notification through the Occurrence Notification Center. 
"The Manager/Administrator of each DOE- or contractor-operated facility shall:

Concurrently notify the HQ EOC and the Field Element of the emergency as soon as crucial information is available but no later than 15 minutes after categorization of the event as an Emergency;"

\section{REQUIREMENT SOURCE: DOE5500.3A Section 11.c.(4)}

Author's Note: Tank Farms is responsible for notifying the Occurrence Notification Center $(O N C)$. The ONC is responsible for notifying and providing continued communications with DOE elements, Federal, state, tribal, and local organizations. DOE 5000.3A is superseded by DOE 5000.3B.

"Notification. Notification and communication of emergency information must be consistent with the requirements of DOE 5000.3A and 5500.2B. Provisions must be in place for prompt initial notification of appropriate DOE elements and other Federal, state, tribal, and local organizations, and for continuing effective communication among the response organizations throughout an emergency. The content and format of the initial notification and follow-up messages must be prearranged and standardized in the emergency plan. The handling of classified and/or controlled information during an emergency must be in accordance with established procedures and DOE requirements."

\section{REQUIREMENT SOURCE: WAC-173-303 Section 360(2)(d)}

Author's Note: Tank Farms is responsible for notifying the Occurrence Notification Center (ONC). The ONC is responsible for notifying the National Response Center.

"If the emergency coordinator determines that the facility has had a release, fire, or explosion which could threaten human health or the environment, he must report his findings as follows:

(i) If his assessment indicates that evacuation of local areas may be advisable, he must immediately notify appropriate local authorities. He must be available to help appropriate officials decide whether local areas should be evacuated; and

(ii) He must immediately notify the department and either the government official designated as the on-scene coordinator, or the National Response Center (using their 24-hour toll free number (800) 424-8802)."

\section{REQUIREMENT SOURCE: WAC-173-303 Section 360(2)(e)}

Author's Note: Applies to the facility Emergency Coordinator.

"His assessment report must include:

(i) Name and telephone number of reporter;

(ii) Name and address of facility;

(iii) Time and type of incident (e.g., release, fire);

(iv) Name and quantity of material(s) involved, to the extent known;

(v) The extent of injuries, if any; and

(vi) The possible hazards to human health or the environment outside the facility." 
Reporting and Event Investiqations

\title{
REQUIREMENT SOURCE: DOE5500.1B Section 10.w(26)(a)5
}

"Provide for investigation of root cause(s) and corrective actions to prevent recurrence;"

\section{REQUIREMENT SOURCE: DOE5500.2B Section 12.h(2)(d)}

"Provide written reports concerning the emergency event as soon as practical but within 24 hours of event categorization; and"

\section{REQUIREMENT SOURCE: WAC-173-303 Section 360(2)(k)}

"The owner or operator must note in the operating record the time, date, and details of any incident that requires implementing the contingency plan. Within fifteen days after the incident, he must submit a written report on the incident to the department. The report must include:

(i) Name, address, and telephone number of the owner or operator;

(ii) Name, address, and telephone number of the facility;

(iii) Date, time, and type of incident (e.g., fire, explosion);

(iv) Name and quantity of material(s) involved;

(v) The extent of injuries, if any;

(vi) An assessment of actual or potential hazards to human health or the environment, where this is applicable;

(vii) Estimated quantity and disposition of recovered material that resulted from the incident;

(viii) Cause of incident; and

(ix) Description of corrective action taken to prevent reoccurrence of the incident."

\section{EVENT CONTAINMENT AND PERSONNEL PROTECTION}

\author{
Event Containment and Conseruence Assessment
}

\section{REQUIREMINT SOURCE: 29CFR1910 Part 120(q)(3)(ii)}

"Emergency response to hazardous substance release. Procedures for handling emergency response. The individual in charge of the ICS shall identify, to the extent possible, all hazardous substances or conditions present and shall address as appropriate site analysis, use of engineering controls, maximum exposure limits, hazardous substance handling procedures, and use of any new technologies."

\section{REQUIREMENT SOURCE: DOE5500.2B Section 11.a(2)(a)}

"Alert. Declaration of an Operational Alert requires the availability of personnel and resources to: 
1 Provide continuous assessment of pertinent information for DOE decision makers, offsite authorities, the public, and other appropriate entities;

2 Conduct appropriate assessments, investigations, or preliminary or confirmatory sampling and monitoring;

3 Mitigate the severity of the occurrence or its consequences; and

4 Prepare for other response actions should the situation become more serious, requiring emergency response organizations to mobilize or activate resources.

\section{REQUIREMENT SOURCE: DOE5500.2B Section 11.a.2(b)}

Author's Note: Items 2 and 3 below is performed at the company level and do not apply to Tank Farms.

"Site Area Emergency. Declaration of an Operational Site Area Emergency requires initiation of predetermined protective actions for onsite personnel and the notification and assembly of emergency response personnel and equipment to activate response centers to provide:

1 Continuous assessment of pertinent information for DOE decision makers, offsite authorities, and other appropriate entities;

2 Establish communications, consultation, and liaison with offsite authorities;

3 Provide information to the public through offsite authorities and the media;

4 Conduct or assist in any evacuations and sheltering;

5 Conduct appropriate assessments, investigations, or sampling and monitoring;

6 Mitigate the severity of the actual or potential consequences; and

7 Mobilize appropriate emergency response groups or security forces for immediate dispatch should the situation become more serious."

\section{REQUIREMINT SOURCE: DOE5500.2B Section 11.a.2(c)}

Author's Note: Items 2 and 3 below is performed at the company level and do not apply to Tank Farms.

"General Emergency. Declaration of an Operational General Emergency requires the notification, mobilization, and dispatch of all appropriate emergency response personnel and equipment including appropriate DOE national response assets to:

1 Activate the response centers and other emergency assets to provide continuous assessment of information;

2 Establish communications, consultation, and liaison with offsite authorities and recommend predetermined protective actions for the public;

3 Provide information to the public through offsite authorities and the media;

4 Conduct or assist in any evacuations;

5 Conduct appropriate assessments, investigations, or sampling and monitoring;

6 Mitigate the severity of the actual or potential consequences; and

7 Mobilize and dispatch appropriate emergency response groups or security forces."

\section{REQUIREMENT SOURCE: DOE5500.3A Section 11.c.( 5)}

Author's Note: Item (d) is performed at the company level and does not apply to Tank Farms.

"Consequence Assessment. Provisions must be in place to adequately assess the actual or potential onsite and offsite consequences of an emergency and must include:

(a) Timely initial assessment of the actual or potential consequences of an emergency and continuous, in-depth assessment of events throughout an emergency; 
(b) Integration of the consequence assessment process with the process for categorization of an event as an emergency, determination of the appropriate emergency class, and protective action decision making, including projections of onsite and offsite consequences;

(c) Monitoring and evaluation of the specific indicators necessary to continually assess the consequences of emergency events and to monitor safety, health, environmental, and security conditions which may affect or exacerbate the emergency; and

(d) Coordinate with Federal, state, tribal, and local organizations to locate and track hazardous materials released to the environment; estimate the integrated impact of such release on the public and the environment; and locate and recover materials, especially those with national security implications."

\section{REQUIREMENT SOURCE: DOE5500.3A Section 11.c.( ๑)(e)}

Author's Note: Provisions must be in place for specific pre-determined actions to be taken in response to emergency conditions to protect onsite personnel and the public and must include the following:

"Determination of the area surrounding the specific facility actually affected by an Operation Emergency, and"

\section{Protective Actions}

\section{REQUIREMENT SOURCE: DOE5480.11 Section 9.p(3)(a)3}

"The potential amount of exposure to rescue personnel for each specific Type 1 emergency action shall be evaluated by the person onsite having the emergency action responsibility. The emergency situation should be immediately evaluated and an exposure objective should be established for the rescue mission. The evaluation of the inherent risks should consider:

a The reliability of the prediction of radiation injury from measured/estimated dose rates. In this context, consideration should be given to the uncertainties associated with the specific instruments and techniques used to estimate the dose rate. This is especially crucial when the estimated dose approximates 100 rad (1 gray) or more.

b The effects of acute external and/or internal exposure.

c The capability to reduce risk through physical mechanisms such as the use of protective equipment, remote manipulation equipment, or similar means.

d The probability of success of the rescue action."

\section{REQUIREMENT SOURCE: DOE5500.3A Section 11.c.( ๑)(b)}

"Control, monitoring, and maintenance of records of onsite personnel exposures to hazardous materials;" 


\section{$\underline{5.6 .3}$}

$\underline{5.6 .4}$

Personnel Accountability and Evacuation

REQUIREMENT SOURCE: DOE5500.3A Section 11.c.( ๑)(c)

"Accountability for all facility personnel, within 30 minutes (not to exceed 45 minutes) of emergency determination, and timely sheltering and/or evacuation of workers, to include predetermined criteria, procedures, assembly areas, transportation methods, and routes;"

\section{Medical Response}

\section{REQUIREMENT SOURCE: 29CFR1910 Part 120(q)(9)(ii)}

"Any emergency response employees who exhibits signs or symptoms which may have resulted from exposure to hazardous substances during the course of an emergency incident, either immediately or subsequently, shall be provided with medical consultation as required in paragraph (f)(3)(ii) of this section."

\section{RECOVERY AND REENTRY}

\section{REQUIREMENT SOURCE: 10CFR835 Part 1301(c)}

"When the conditions under which the emergency or accident exposures were received have been eliminated, operating management shall notify the Head of the responsible DOE field organization."

\section{REQUIREMENT SOURCE: 10CFR835 Part 1301(d)}

"Operations after an emergency or accidental exposure in excess of the limits specified in $\S \S$ 835.202 or 835.205 may be resumed only with the approval of the DOE."

\section{REQUIREMENT SOURCE: 10CFR835 Part 1301(e)}

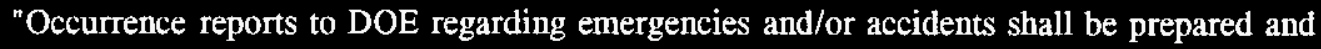
submitted in accordance with Departmental requirements for occurrence reporting and processing."

\section{REQUIREMENT SOURCE: 10CFR835 Part 1302(a)}

"The risk of injury to those individuals involved in rescue and recovery operations shall be minimized."

\section{REQUIREMENT SOURCE: 10CFR835 Part 1302(b)}

"Operating management shall weigh actual and potential risks to rescue and recover individuals against the benefits to be gained."

\section{REQUIREMENT SOURCE: 10CFR835 Part 1302(d)}

"The dose limits (Whole Body) for individuals performing these operations are as follows:

5 rems-All Activities

10 rems-Protecting major property (Where lower dose limit not practicable) 
25 rems-Lifesaving or protection of large populations (Where lower dose limit not practicable)

$>25$ rems-Lifesaving or protection of large populations (Only on a voluntary basis to personnel fully aware of the risks involved)

NOTE: The lens of the eye dose limit is three times the listed values. The shallow dose limit to the skin of the whole body and the extremities is ten times the listed values. These doses are in addition to and accounted for separately from the doses received under the limits in $\S \S$ 835.202 and $835.205 . "$

\section{REQUIREMENT SOURCE: 10CFR835 Part 1302(e)}

"Each individual selected shall be trained in accordance with $\$ 835.902$ and briefed beforehand of the known or anticipated hazards to which the individual will be subjected."

\section{REQUIREMENT SOURCE: DOE5480.11 Section 9.p(3)(b)1}

"Recovery of Deceased Victim.

1 The recovery of deceased victims should be well planned. Except as provided in subparagraph 3 below, the amount of radiation exposure received by persons in recovery operations shall be controlled within existing occupational exposure limits."

\section{REQUIREMINT SOURCE: DOE5500.3A Section 11.c.( 8)}

Author's Note: While the majority of this activity is performed at the site level, participation is required by Tank Farms personnel.

"Recovery and Reentry. Provisions must be made for recovery from an Operational Emergency and reentry into the affected facility.

(a) The approach and general procedures for recovery include: decision making and communications associated with termination of an emergency; dissemination of information to Federal, state, tribal, and local organizations regarding the emergency and relaxation of public protective actions; establishment of a recovery organization; and establishment of general criteria for resumption of normal operations.

(b) The means must exist for estimating dosage and for protecting workers and the general public from hazardous exposure during recovery and reentry activities."

\section{REQUIREMENT SOURCE: WAC-173-303(940523) Section 360(2)(h)}

"Immediately after an emergency, the emergency coordinator must provide for treating, storing, or disposing of recovered waste, contaminated soil or surface water, or any other material that results from a release, fire, or explosion at the facility."

\section{REQUIREMENT SOURCE: WAC-173-303(940523) Section 360(2)(i)}

"The emergency coordinator must ensure that, in the affected area(s) of the facility:

(i) No waste that may be incompatible with the released material is treated, stored, or disposed of until cleanup procedures are completed; and

(ii) All emergency equipment listed in the contingency plan is cleaned and fit for its intended use before operations are resumed." 
REQUIREMIENT SOURCE: WAC-173-303(940523) Section 360(2)(j)

5.8

$\underline{5.8 .1}$

$\underline{5.8 .2}$

5.9

$\underline{5.9 .1}$

$\underline{5.9 .2}$

5.10

$\underline{5.10 .1}$

"The owner or operator muist notify the department, and appropriate local authorities, that the facility is in compliance with (i) of this subsection before operations are resumed in the affected area(s) of the facility."

\section{PUBLIC INFORMATION}

Public and Media Education

This is done at the site level by DOE-RL on behalf of the Tank Farms.

\section{Emergency Public Information Response}

This is done at the site level by DOE-RL on behalf of the Tank Farms.

COORDINATION WITH OFFSITE AGENCIES

These requirements are met at the site level by DOE-RL on behalf of the Tank Farms.

\section{Management Coordination}

These requirements are met at the site level on behalf of the Tank Farms.

Response Coordination

Author's Note: These requirements are met at the site level on behalf of the Tank Farms.

DEMONSTRATING, MONITORING AND IMPROVING PERFORMANCE

Drill and Exercise Program

Author's Note: Only training and drills pertaining to Tank Farms Personnel apply to Tank Farms.

\section{REQUIREMENT SOURCE: DOE5500.1B Section 10.w(26)(a)3}

Author's Note: Tank Farms is not responsible for providing participation with state, tribal, and local authorities. This is a responsibility for the company emergency management through the exercise program.

"Ensure a continuing program of training, drills, and exercises for facility personnel, and provide for participation by state, tribal, and local authorities;"

\section{REQUIREMENT SOURCE: DOE5500.3A Section 11.c.(12)(a)}

Author's Note: Tank Farms is not responsible for conducting at least one drill per year to train in notifications and emergency communication with regional Federal, state, tribal, and local authorities and DOE HQ. This communications/notifications is the responsibility of the Occurrence Notification Center.

"Drills must be used to develop and maintain personnel skills, expertise, and response capability. Drills must be of sufficient scope and frequency to ensure adequate response 
capability in all applicable areas. Drills must include emergency response activities such as notification, emergency communication, fire, medical emergencies, hazardous material detection and monitoring, environmental sampling and analyses, security, personnel accountability, evacuation, emergency categorization, weapons handling, decontamination, facility activation, public information, and health physics. There must be at least one drill per year to train in notification and emergency communications with regional Federal, state, tribal, and local authorities and DOE HQ."

\section{REQUIREMENT SOURCE: DOE5500.3A Section 11.c.(12)(c)}

"Drills and Exercises. A coordinated program of drills and exercises must be an integral part of the emergency management program as follows:

Drills and exercises must be conducted in a manner which emphasizes facility-specific emergency events and response activities and which minimizes the use of generic, nonspecific simulations."

\section{REQUIREMENT SOURCE: DOE5500.3A Section 11.c.(12)(d)}

"Drills and Exercises. A coordinated program of drills and exercises must be an integral part of the emergency management program as follows:

Each member of the emergency response organization shall participate in a drill or exercise at least annually to demonstrate proficiency in assigned response duties and responsibilities."

\section{REQUIREMINT SOURCE: DOE5500.3A Section 11.c.(12)(e)}

"Drills and Exercises. A coordinated program of drills and exercises must be an integral part of the emergency management program as follows:

Emergency management improvements and corrective actions identified during actual emergencies or during drills and exercises must be incorporated into the emergency management program."

\section{Reviews, Audits and Evaluations}

Requirements for this subelement are included in the WHC Company Emergency Management Functional Area.

\section{Emergency Readiness Assurance Program}

Emergency Readiness Assurance Program requirements are met at the Company level on behalf of Tank Farms.

\section{Deficiency Identification and Correction}

\section{REQUIREMINT SOURCE: DOE5482.1B PREAMBLE Section 9.a(5)}

"The appraised organization shall respond to appraisal reports within 30 days of receipt and indicate what corrective action will be taken." 


\section{REQUIREMENT SOURCE: DOE5482.1B PREAMBLE Section 9.a(7)}

\subsection{1}

$\underline{\mathbf{5 . 1 1 . 1}}$

$\underline{5.11 .2}$

$\underline{5.11 .3}$

$\underline{5.11 .4}$

\section{$\underline{5.11 .5}$}

"Follow up visits by a management representative may be required for the purpose of discussing the adequacy of corrective action and whether additional action is necessary. These discussions shall be confirmed in writing and, where no additional action is necessary, shall constitute formal closeout of the appraisal."

\section{KEY INTERFACES}

These interfaces are primarily in place at the site level. Tank Farms does not interface with offsite agencies (i.e., Federal, State, local, tribal, etc.).

Author's Note: All interfaces at the DOE/HQ, DOE/RL, and offsite agencies (i.e., Federal, State, tribal, local, etc.) are the responsibility of site emergency management.

\section{Safequards and Security}

Tank Farms EM interfaces with Safeguards and Security to develop security scenarios for facility emergency drills, and development of emergency implementing procedure pertaining to security events.

\section{Operations}

Tank Farms EM interfaces with Operations to develop credible operational scenarios for facility emergency drills; development of emergency implementing procedures and emergency plans; to ensure coordination between emergency implementing procedures and emergency plans; and to ensure coordination with facility and site emergency implementing procedures for emergency events.

\section{Training and Qualification}

Tank Farms EM interfaces with site emergency management training and qualifications to ensure coordination with emergency response organization training.

Tank Farms EM interfaces with Tank Farms training and qualification to ensure coordination with emergency implementing procedures, plans, and facility response personnel, and the general employee (GET).

\section{Radiation Protection}

Tank Farms EM interfaces with facility radiation protection for technical support to assist with quality onsite monitoring and radiological dose assessment programs; for input for facility emergency drill scenarios; and for personnel protection procedure development.

\section{Waste Management}

Tank Farms EM interfaces with facility waste management to ensure coordination between emergency planning and facility emergency plans and implementing procedures. 


\section{$\underline{\mathbf{5 . 1 1 . 6}}$}

$\underline{\mathbf{5 . 1 1 . 7}}$

$\underline{\mathbf{5 . 1 1 . 8}}$

$\underline{5.11 .9}$

$\underline{5.11 .10}$

$\underline{5.11 .11}$

$\underline{5.11 .12}$

$\underline{\mathbf{5 . 1 1 . 1 3}}$

\section{Occupational, Health and Safety}

Tank Farms EM interfaces with Occupational, Health and Safety (OSH) to coordinate compliance with OSH requirements for hazardous materials emergency response; for industrial hygiene input for facility drill scenario development; development of personnel protection emergency implementing procedures, and to ensure sufficient respiratory equipment and supplies are available for emergency response.

\section{Fire Protection}

Tank Farms EM interfaces with Fire Protection during development of emergency plans and implementing procedures, development of facility emergency drills scenarios, and training of the Tank Farms emergency response organization.

\section{Medical}

Tank Farms EM interfaces with Medical to ensure immediate response capabilities for onsite medical emergencies, development of emergency response implementing procedures, and development of facility emergency drill scenarios.

\section{Management Systems}

Tank Farms EM interfaces with Management Systems to ensure that Management and Administration, Document Control and Records Management, Policy and Procedure Systems, Compliance Management, Corrective Actions, Lessons Learned, and Self-Assessment activities correctly integrate site standards. Particularly close coordination with Occurrence Reporting during emergency events is crucial to a successful EM effort.

\section{Nuclear Safety}

Tank Farms EM interfaces with Nuclear Safety to access technical information necessary for the development of emergency response plans and emergency implementing procedures.

\section{Packaging and Transportation}

Tank Farms EM interfaces with Site and Facility Packing and Transportation to provide appropriate emergency response information and carrier information, including organizations and authorities to be notified in the event of a release of materials. Coordination between the Transportation Program and Tank Farms EM ensures that commonly handled hazardous materials are known and included in emergency plans and procedures for the facility, and that special equipment and vehicles for transportation are known and available for emergency situations.

\section{Quality Assurance}

Tank Farms EM interfaces with Quality Assurance (QA) to ensure that independent assessments, audits, and corrective actions meet site QA standards. QA may perform independent assessments of the EM program.

\section{Environmental Protection}

Tank Farms EM interfaces with Environmental Protection to ensure hazardous material accident response and spill control, be it small or large, is effectively addressed. The 
$\underline{\mathbf{5 . 1 1 . 1 4}}$

\subsection{2}

\section{$\underline{5.12 .1}$}

interfaces involves development of hazardous materials information in the emergency plans and procedures, and spill reporting process.

\section{Emergency Management}

Tank Farms EM interfaces with Company Emergency Management to ensure coordination during development of emergency plans and procedures, and facility emergency drills. This coordination to ensure EM addresses applicable site EM requirements and policies. Tank Farms EM interface also includes coordination during site exercises and training of building emergency directors.

\section{REFERENCES}

\section{Requirement Source Documents}

The following documents were used as requirement sources in the development of this EM Functional Area Document.

29 CFR 1910, Occupational Safety and Health Standards; OSHA/Labor, 07/01/93 Edition

40 CFR 265, Interim Status Standards for Owners and Operators of Hazardous Waste Treatment, Storage, and Disposal Facilities; EPA/Solid Wastes, 07/01/92 Edition

40 CFR 302, Designation Reportable Quantities, and Notification; EPA/Superfund, Emergency Planning, and Community Right-to-Know Programs, 07/01/93 Edition

40 CFR 355, Emergency Planning and Notification; EPA/Superfund, Emergency Planning, and Community Right-to-Know Programs, 07/01/93 Edition

WAC-173-303, Dangerous Waste Regulations; Washington State Department of Ecology, 1992 Edition

WAC-296-62, Occupational Health Standards - Safety Standards for Carcinogens; Washington Department of Labor and Industries, 1990 Edition

DOE 5000.3B, Occurrence Reporting and Processing of Operations Information, 01/19/93, Page Change 1: 07/02/93

DOE 5480.10, Contractor Industrial Hygiene Program, 06/26/85

DOE 5480.11, Radiation Protection for Occupational Workers, change 3, 12/21/88.

DOE 5482.1B, Environment, Safety, and Health Appraisal Program, 09/23/86, Change 1, $11 / 18 / 91$

DOE 5500.1B, Emergency Management System, 04/30/91, Page Change 1: 02/27/92

DOE 5500.2B, Emergency Categories, Classes, and Notification and Reporting Requirements, 04/30/91, Page Change 1: 02/27/92

DOE 5500.3A, Planning and Preparedness for Operational Emergencies, 04/30/91, Page Change 1: $02 / 27 / 92$ 
The following documents were reviewed as requirement sources but were not used in the development of this EM Functional Area document. These documents were not used because the requirements contained in the above list were more prescriptive.

DOE 5480.19, Conduct of Operations Requirements for DOE Facilities, 07/09/90, Change 1: $05 / 18 / 92$

DOE 5500.4, Public Affairs Policy and Planning Requirements for Emergencies, 06/08/92

DOE 5500.10, Emergency Readiness Assurance Program, 04/30/91, Page Change 1: 02/27/92

DOE 5632.8, Protection Program Operations: System Performance Tests, 02/04/ 88.

DOE EMG-ADM, Program Administration, 12/11/91

DOE EMG-CA, Guidance for Consequence Assessment, 07/28/92

DOE EMG-EC, Guidance for Event Classification and Emergency Action Levels, 06/26/92

DOE EMG-EMS, Interim Guidance for Emergency Medical Support, 06/26/92

DOE EMG-ERO, Interim Guidance for Emergency Response Organization, 07/30/93

DOE EMG-FAC/EQ, Interim Guidance for Emergency Facilities and Equipment, 07/30/93

DOE EMG-HAZ, Guidance for Hazards Assessment, 06/26/92

DOE EMG-N, Interim Guidance for Notification, 07/28/92

DOE EMG-PA, Interim Guidance for Protective Actions, 06/01/93

DOE EMG-R/R, Interim Guidance for Reentry and Recovery, 06/01/93

DOE EMG-TRNG, Interim Guidance for Emergency Management Training, 07/28/92

DOE/RL-91-28, Hanford Facility Dangerous Waste Permit Application, General Information, Rev 1, May 1993

DOE/RL-91-28, Hanford Facility Contingency Plan, 05/28/93 Appendix 7A

DOE/EH 0135, Performance Objectives and Criteria for Technical Safety Appraisals at Department of Energy Facilities and Sites, 06/28/90

BMP 85-014, Generic Guidance for Emergency Preparedness Program Review, Rev 1, April 1991

BMP 87-019, Maintaining Emergency Preparedness Manual, Rev 0, November 1987

BMP 90-015, Performance Objectives and Criteria for Operating and Near-term Operating License Plants, August 1990

BMP 90-020, Performance Objectives and Criteria for Corporate Evaluations, November 1990 


\section{TABLE OF CONTENTS}

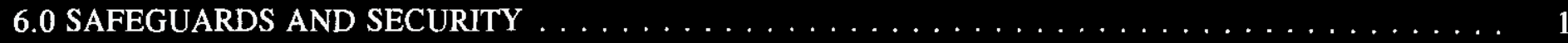

6.1

6.2

6.3

6.3 .1

6.3 .2

6.3 .3

6.3 .4

6.3.5

6.3 .6

6.4

6.4 .1

6.4 .2

6.5

6.6

6.6 .1

6.6 .2

6.6 .3

6.6 .4

6.6 .5

6.7

6.8

6.9

6.10
6.4 .3

MANAGEMENT AND ADMINISTRATION . 3

PERSONNEL SECURITY $\ldots \ldots \ldots \ldots \ldots \ldots \ldots \ldots$

PROTECTION PROGRAM OPERATIONS .............. 3

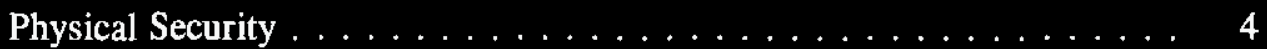

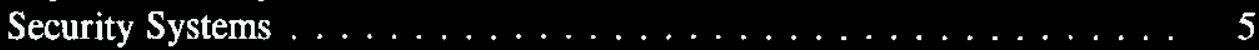

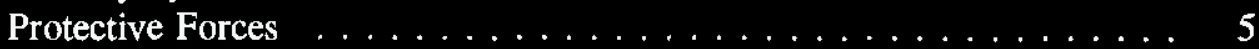

Security Identification Badges and Passes . . . . . . . . . . . 5

Incident Response and Management . . . . . . . . . . . . 5

Transportation Security . . . . . . . . . . . . . . 5

MATERIAL CONTROL AND ACCOUNTABILITY FOR SPECIAL

NUCLEAR MATERIAL $\ldots \ldots \ldots \ldots \ldots \ldots \ldots \ldots$

Material Control and Accountability Plan $\ldots \ldots \ldots \ldots$

Special Nuclear Material Accountability System . . . . . . . . . 6

Material Control System . . . . . . . . . . . . . . . 6

FACILITY APPROVALS, SECURITY AND NUCLEAR MATERIAL

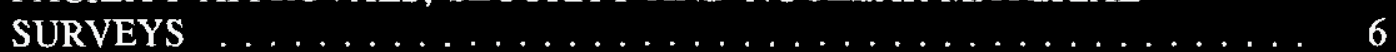

INFORMATION SECURITY PROGRAM $\ldots \ldots \ldots \ldots \ldots \ldots$

Classified Matter Protection and Control (CMPC) $\ldots \ldots \ldots 7$

Technical Surveillance Countermeasures (TSCM) $\ldots \ldots \ldots \ldots$

Automated Information Systems Security Program (Classified

Computer Security) ...................... 7

Unclassified Computer and Sensitive Automated Data Processing

Systems . . . . . . . . . . . . . . . . . 7

Communications Security $\ldots \ldots \ldots \ldots 7$

OPERATIONS SECURITY $($ OPSEC) $\ldots \ldots \ldots \ldots \ldots \ldots$

FOREIGN OWNERSHIP, CONTROL OR INFLUENCE (FOCI) $\ldots \ldots \ldots \ldots$

EVALUATION OF RADIOLOGICAL AND TOXICOLOGICAL AND

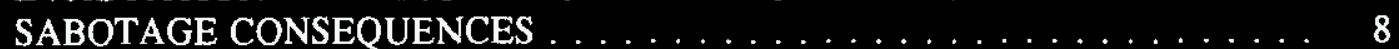

KEY INTERFACES $\ldots \ldots \ldots \ldots \ldots \ldots \ldots \ldots \ldots$

6.10 .1

6.10 .2

Emergency Management

8

Packaging and Transportation $\ldots \ldots \ldots \ldots \ldots \ldots$ 
High Level Waste Storage

WHC-SD-MP-SRID-001

Tank Farms/242-A Evaporator

January 10,1996

Standards/Requirements Identification Document

Rev. 0

6.0 Safeguards and Security

Page ii of ii

6.11

REFERENCES

9

6.11 .1

Requirement Source Documents $\ldots . \ldots \ldots \ldots \ldots \ldots . \ldots . .9$

6.11 .2

Reviewed Documents Not Used as Requirement Sources

9 


\subsection{SAFEGUARDS AND SECURITY}

\section{INTRODUCTION}

A Standards/Requirements Identification Document (S/RID) sets forth the Environmental Safety and Health (ES\&H) standards/requirements. This S/RID is applicable to the appropriate life cycle phases of design, construction, operation, and preparation for decommissioning for each of the categories of facilities addressed in Revision 5 of the Department of Energy Implementation Plan for the Defense Nuclear Facilities Safety Board (DNFSB) Recommendation 90-2. This Recommendation calls for the strengthening of DOE weapons complex activities through the identification and application of relevant DOE Orders, regulations, industry codes/standards, industry guidance documents and, as appropriate, good industry practices. These standards/requirements are adequate to ensure protection of the health and safety of workers, the public, and the environment.

The Tank Farms S/RID contains standards/requirements that are necessary for safe operation of the Tank Farms and its associated facilities, and that are the direct responsibility of the specific facility manager. The Safeguards and Security (SAS) Program defined in this document is described in general accordance with the Environment, Safety, and Health Configuration Guide, Revision 0, dated July 30, 1993, and is presented in program elements and subelements. The specific DOE Orders, regulations, industry codes/standards, guidance documents and good industry practices that serve as the basis for each element/subelement are identified and aligned with each subelement.

This S/RID contains only those requirements that Tank Farms personnel are clearly responsible to satisfy. Other requirements that are applicable to Tank Farms, but are satisfied by others, are defined in the Westinghouse Hanford Company (WHC) Level S/RID. For application in this S/RID, the words "shall" and "should" in requirements statements both indicate mandatory compliance. The Key interface information contained in the Functional Area documents is provided for general recognition and understanding and is not considered to contain prescriptive requirements. Additionally, some of the requirements cited in this document are intentionally duplicated in the corresponding Company Level S/RID. This was necessary to address required implementation responsibilities occurring at both the company and facility levels.

\section{SCOPE}

This S/RID applies to the Tank Waste Remediation Systems (TWRS) Organization which includes the following:

- East Tank Farm Transition Project

- West Tank Farm Transition Project

- Evaporator Project

- Interim Stabilization Project

- Characterization Sampling Project (Excluding the Labs) 
The near-term mission of TWRS is to store, treat, and immobilize the highly radioactive Hanford Site Waste.

The main body of SAS requirements applicable to TWRS used in this document are from RLID 5632.1B, "Asset Protection Requirements". These requirements cover health and safety issues, as well as, protection of government property. More traditional SAS requirements were reviewed, but considered nonapplicable due to the following reasons:

1. The nuclear material involved has been previously declared waste, has been written off the MC\&A books, and is currently under the control of a waste management organization. (Reference DOE Order 5633.3B)

2. The nuclear material in the identified Material Balance Area (MBA) involved is Category IV, Attractiveness Level E or lesser. (Reference DOE 5633.3B)

3. The following are not present in the Tank Farm Facility:

a. Vital equipment (Per DOE Order 5632.1C and Manual 5632.1C-1)

b. $\quad$ Classified computer systems (Per DOE Order 5639.6)

c. Security alarm systems

d. Personnel Security Assurance Program (PSAP) positions (Per DOE Order 5632.1C and Manual 5632.1C-1

Classified Documents are not stored in Tank Farm facilities. However, the "Radiological Sabotage Risk Evaluation of the Hanford Tank Farms Final Technical Report, May 27, 1994" is a classified document containing Tank Farms information. 


\section{REQUIREMENT SOURCE: RLID5632.1B Section 6.c}

"Asset owners or designee shall appoint security focal point(s) who will be responsible for coordinating all security concerns, relative to the facility, with their Security Organization. Additional responsibilities shall include:

(1) Ensuring adequate access control measures are instituted and maintained

(2) Posting required signs

(3) Managing facility lock and key program

(4) Ensuring all security requirements/procedures are met as outlined in their contractor Security Manual

(5) Ensure that all facility occupants are knowledgeable of their security responsibilities

(6) Maintaining necessary security reference materials

(7) Providing adequate visitor control measures

(8) Complete an Asset Protection Review with the assistance of their Security Organization."

Author's Note: Requirements associated with Personnel Security are applicable to the TWRS organization, but are not cited in the Facility S/RID as implementation occurs through company level programs. Funding is provided by the TWRS organization, via the company wide support pool, for the company level support necessary to maintain compliance with requirements relative to personnel security.

\section{REQUIREMENT SOURCE: RLID5632.1B Section 7.1.c}

"To Arrive at an asset protection strategy, the asset owner, in conjunction with his/her Security Organization, shall perform an Asset Protection Review using Attachments 8.1 and 8.2. The review (as documented on the Asset Protection Agreement, Attachment 8.2) shall identify threat(s) to the asset, asset value, strategic business impact(s), any unacceptable risks involved with the protection strategy, concurrence of the appropriate Security Organization, and signature of the person responsible for the Asset Protection Strategy (asset owner)."

\section{REQUIREMENT SOURCE: RLID5632.1B Section 7.1.d}

"If it is determined after completion of the asset protection review, that administrative controls are adequate for access control, the asset owner shall consider protection of certain assets by locking internal office doors, use of PC lockdown devices, storing assets in a storage container, etc. Administrative controls may only apply during the day shift, Monday through Friday. Day shift is defined as the working hours of the majority of the facility occupants. All facilities shall be locked between 6:00 p.m. and 6:00 a.m., unless pre-approved by asset owners in conjunction with the affected contractor security organization, or in consideration of 
special operational requirements (24-hour manned facility) as documented in an approved Asset Protection Agreement. All unoccupied facilities shall be locked.

(1) Specific Facility check procedures shall be established (e.g., end of shift lock up).

(2) A sign shall be installed at the main entrance indicating entry/access requirements and/or instructions. The asset owner should consider installing a telephone at the main entrance so visitors can call the person they are visiting, if necessary.

(3) When administrative controls are used as an access control measure, certain types of low-level assets (Category IV D SNM, precious metals, explosives, drugs) shall be secured as required in applicable directives. Examples are precious metals as required by Property Management directives and Category IV D, as required by DOE Order 5632.2A."

\section{REQUIREMENT SOURCE: RLID5632.1B Section 7.1.g}

"The completed "Asset Protection Agreement," Attachment 8.2 to this directive, shall be used as the approved security plan for those facilities meeting the Asset Protection Requirements. For those facilities which do not meet the minimum protection requirements identified in the Asset Protection Template (Attachment 8.1), the Asset Protection Agreement (Attachment 8.2) must be approved by RL SAS with the concurrence of the appropriate RL Program Office. Unresolvable disagreements between the asset owner and Contractor Security Organization as to the appropriate protection strategy to apply, shall be resolved by RL SAS and the appropriate RL Program Office. Additionally, appropriate justification shall be completed and approved by the funding source in those situations where management or the client chooses to exceed the minimum protection criteria. This justification shall include the incremental cost of the added protection and which program/funding source will bear the cost. "

\section{Physical Security}

\section{REQUIREMENT SOURCE: RLID5632.1B Section 7.3.b}

"Access control shall be provided according to the Asset Protection Template (Attachment 8.1). The number of frequently used entrances to a facility shall be limited. It is the host's responsibility to assist visitors requiring entry into the facility."

\section{REQUIREMENT SOURCE: RLID5632.1B Section 7.4.a}

"The designated security focal point shall ensure the minimum physical security requirements are met for each facility. Minimum requirements will be established, per the Asset Protection Template (Attachment 8.1) and applicable DOE Orders/Directives. Generic requirements for all levels of physical protection include:

(1) Signs shall be posted around the perimeter and at the main entrances to each facility, as stated in the Asset Protection Agreement, which prohibit trespassing, list prohibited articles, and advise personnel that vehicles and their hand carried items are subject to search. At government-owned facilities, the standard DOE "Atomic Energy Act, No Trespassing" sign will be used. At government-leased facilities, contractor security organizations shall consult with their Office of Legal Counsel for the posting of locally developed "No Trespassing" signs. These signs will contain language which complies with the required DOE wording. When access points and the perimeter of fenced areas are sufficiently posted with signs, then facilities within the area do not require signs unless the access requirements are more restrictive than the area itself. 
In addition to the signs above, Prohibited Article signs shall be posted in accordance with RLID 5632.PA, PROHIBITED ARTICLE POLICY.

(2) Unoccupied/abandoned facilities shall be locked.

(3) There is no requirement to install door locks on interior offices requiring only low-level security protection. However, at the discretion of facility management, in conjunction with their Security Organization, interior locks may be installed. If interior locks are installed, issuance and records management of the keys/combinations will be the responsibility of facility management."

\section{REQUIREMENT SOURCE: RLID5632.1B Section 7.4.b}

"When determining the physical security requirements of assets the following shall be considered:

(1) Value of the asset(s)

(2) Portability

(3) Attractiveness

(4) The applicable/credible threat (against the matter located in the area)

(5) A review of any property losses and/or adverse security trends associated with the assets."

$\underline{6.3 .2}$

\section{Security Systems}

Author's Note: Refer to subelement 6.3.1 for associated requirements.

\section{$\underline{6.3 .3}$}

$\underline{6.3 .4}$

$\underline{6.3 .5}$

\section{Protective Forces}

Author's Note: Requirements associated with Protective Forces are applicable to the TWRS organization, but are not cited in the Facility S/RID as implementation occurs through a company level program by Hanford Patrol. Funding is provided by the TWRS organization, via the company wide support pool, to acquire the Protective Forces support required for its operations.

\section{Security Identification Badges and Passes}

Author's Note: Requirements associated with Security Identification Badges and Passes are applicable to the TWRS organization, but are not cited in the Facility S/RID as implementation occurs through company level programs. Funding is provided by the TWRS organization, via the company wide support pool, for the company level support necessary to maintain compliance with requirements relative to security badges.

\section{Incident Response and Management}

Author's Note: The TWRS personnel response and management to any security emergency situation is to call Hanford Patrol via the 911 system.

\section{Transportation Security}

Author's Note: The TWRS organization does not transport any nuclear materials requiring a security escort. 

MATERIAL

\section{REQUIREMENT SOURCE: DOE5633.3B Chapter I, Section 6.a}

"Facility materials control and accountability procedures shall be reviewed and approved (prior to implementation) by facility operations management at a level of authority sufficient to ensure compliance by operations personnel. Procedures shall be consistent with the approved facility Materials Control and Accountability Plan, and procedures shall be distributed to all applicable organizations and individuals in the facility having materials control and accountability responsibilities."

$\underline{6.4 .1}$

\section{Material Control and Accountability Plan}

Author's Note: The company level Safeguards organization prepares and maintains the Material Control and Accountability Plan.

Special Nuclear Material Accountability System

Author's Note: Requirements associated with this section are not applicable to the TWRS organization.

\section{Material Control System}

Author's Note: Requirements associated with this section are not applicable to the TWRS organization.

FACILITY APPROVALS, SECURITY AND NUCLEAR MATERIAL SURVEYS

\section{REQUIREMENT SOURCE: DOE5634.1B Chapter IV, Section 7}

Author's Note: The TWRS organization is only responsible for participation in performance evaluations relative to any TWRS security interests when requested by the company level SAS organization.

"PERFORMANCE SEGMENT. Surveys of facilities shall include a performance evaluation to assess the capability of the safeguards and security system to meet performance objectives. The performance evaluation shall determine system performance against scenarios for applicable threats/targets."

\section{INFORMATION SECURITY PROGRAM}

Author's Note: The following subelements, as identified in the ES\&H Configuration Guide, are not applicable to the TWRS organization, or the facility is not directly responsible for implementation:

1) 6.6.2 - Technical Surveillance and Countermeasures (TSCM). WHC has no qualifying facilities.

2) 6.6.3 - Automated Information Systems Security (Classified Computers). The TWRS organization does not utilize classified computer systems. 
3) 6.6.4 - Unclassified Computer and Sensitive Data Processing Systems. (Facility has no direct responsibility for implementation). This program is developed and implemented by Information Resources Management.

4) 6.6.5 - Communications Security (COMSEC). The TWRS organization does not utilize any communications equipment that involves COMSEC requirements.

\section{Classified Matter Protection and Control (CMPC)}

Author's Note: These requirements are applicable to the TWRS organization, but the limited training TWRS personnel must receive for these requirements is obtained through the Hanford General Employee Training program.

\section{REQUIREMENT SOURCE: DOE-M-5632.1C-1 Chapter III, Section 1.b}

"Access to classified matter shall be limited to persons who possess appropriate access authorization and who require such access (need-to-know) in the performance of official duties. Controls shall be established to detect and deter unauthorized access to classified matter."

\section{REQUIREMENT SOURCE: DOE-M-5632.1C-1 Chapter III, Section 1.c}

"Custodians and authorized users of classified matter are responsible for the protection and control of such matter."

\section{REQUIREMENT SOURCE: DOE-M-5632.1C-1 Chapter III, Section 2, Sentence 1}

"IN USE. Classified matter in use shall be constantly attended by or under the control of a person or persons having the proper access authorization and a need-to-know, who are responsible for its protection."

\section{REQUIREMENT SOURCE: DOE-M-5632.1C-1 Chapter III, Section 3.a}

"General. Classified matter shall be stored in a manner to prevent unauthorized persons from gaining access."

\section{$\underline{6.6 .2}$}

$\underline{6.6 .3}$

$\underline{6.6 .4}$

$\underline{6.6 .5}$

\section{Technical Surveillance Countermeasures (TSCM)}

Author's Note: Refer to element 6.6 for nonapplicability statement.

Automated Information Systems Security Program (Classified Computer Security)

Author's Note: Refer to element 6.6 for nonapplicability statement.

Unclassified Computer and Sensitive Automated Data Processing Systems

Author's Note: Refer to element 6.6 for nonapplicability statement.

\section{Communications Security}

Author's Note: Refer to element 6.6 for nonapplicability statement. 
Author's Note: The TWRS organization is not directly responsible for implementation of requirements relative to the (OPSEC) program. Most of the OPSEC requirements are implemented through company level programs. Facility requirements relative to the OPSEC program are adequately addressed in other element and subelements of this functional area such as Protection Program Operations and Classified Matter Protection and Control.

\section{FOREIGN OWNERSHIP, CONTROL OR INFLUENCE (FOCI)}

Author's Note: The TWRS organization is not responsible for implementation of the (FOCI) program. The required (FOCI) submissions by a contractor will be addressed in company level correspondence.

\section{EVALUATION OF RADIOLOGICAL AND TOXICOLOGICAL AND SABOTAGE CONSEQUENCES}

Author's Note: The company level SAS organization performs the evaluation of radiological and toxicological sabotage consequences with facility participation on the committee. The TWRS organization is responsible for identifying facility personnel to participate, providing the project funding, and implementing the identified protection strategies.

\section{REQUIREMENT SOURCE: DOE5632.1C Preamble, Section 5.b}

"Protection and control shall be provided in a graded, cost-effective fashion, in accordance with the potential risks to the national security and/or the health and safety of DOE and contractor employees, the public, and the environment."

\section{REQUIREMENT SOURCE: DOE5632.1C Preamble, Section 7.b}

"Threat. The "Design Basis Threat Policy for the Department of Energy Programs and Facilities (U)" shall be used to identify and characterize the range of potential adversary threats to Departmental programs and facilities. Field Elements should review and develop, as appropriate, supplementary local threat policy to take into account site-specific and regional-specific threat considerations."

\section{REQUIREMENT SOURCE: RLID5630.3A Section 7.0, Paragraph 1}

"All RL contractors possessing hazardous materials in use or storage, including that contained in waste, shall perform graded assessments of the risk, due to radiological/toxicological sabotage consistent with the levels of hazards present within the facility. Graded assessments are performed by determining the amounts of radioactive and non-radioactive (toxicological) materials."

6.10

$\underline{6.10 .1}$

$\underline{6.10 .2}$

\section{KEY INTERFACES}

\section{Emergency Management}

The TWRS emergency management personnel develop facility specific emergency drills relative to security incidents.

\section{Packaging and Transportation}

No key interfaces were identified in this area specific to the TWRS organization. 


\section{Requirement Source Documents}

The following documents were used as requirement sources in the development of this S/RID:

DOE 5632.1C, Protection and Control of Safeguards and Security Interests, 07/15/94.

DOE 5633.3B, Control and Accountability of Nuclear Materials, 09/07/94.

DOE 5634.1B, Facility Approvals, Security Surveys , and Nuclear Materials Surveys, 09/15/92.

DOE M 5632.1C-1, Manual for Protection and Control of Safeguards and Security Interests, 07/15/94.

RLID 5632.1B, Asset Protection Requirements, 08/22/94.

\section{$\underline{6.11 .2}$}

\section{Reviewed Documents Not Used as Requirement Sources}

The following documents were reviewed as requirement sources but were not used in the development of this S/RID:

DOE 1240.2B, Unclassified Visits and Assignments by Foreign Nationals, 08/21/92.

DOE 1360.2B, Unclassified Computer Security Program, 05/18/92.

DOE 5630.3A, Protection of Departmental Facilities Against Radiological and Toxicological Sabotage, 06/28/93.

DOE 5630.11B, Safeguards and Security Program, 08/02/94.

DOE 5630.13A, Master Safeguards and Security Agreements, 06/08/92.

DOE 5630.14A, Safeguards and Security Program Planning, 06/09/92.

DOE 5631.1C, Safeguards and Security Awareness Program, 05/04/94.

DOE 5631.2C, Personnel Security Program, 02/17/94.

DOE 5631.6A, Personnel Security Assurance Program, 09/15/92.

DOE 5632.7A, Protective Force Program, 04/13/94.

DOE 5634.3, Foreign Ownership, Control, or Influence Program, 06/14/93.

DOE 5639.1, Information Security Program, 10/19/92.

DOE 5639.3, Violation of Laws, Losses, and Incidents of Security Concern, 09/15/92.

DOE 5639.5, Technical Surveillance Countermeasures Program, 08/03/92.

DOE 5639.7, Operational Security Program, 04/30/92.

DOE 6430.1A, General Design Criteria, 04/06/89. 
DOE M 5639.6A-1, Manual of Security Requirements for the Classified Automated Information System Security Program, 07/15/94. 


\section{TABLE OF CONTENTS}

\subsection{ENGINEERING PROGRAM}

7.1 .1

7.1 .2

7.1 .3

7.1 .4

7.1 .5

7.1 .6

7.1 .7

7.1 .8

7.1 .9

7.1 .10

7.1 .11

7.1 .12

Program Policy and Procedures $\ldots \ldots \ldots \ldots \ldots$

Authority and Responsibility $\ldots \ldots \ldots \ldots \ldots$

Staffing and Training $\ldots \ldots \ldots \ldots \ldots \ldots$

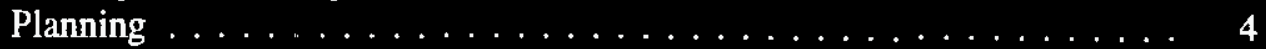

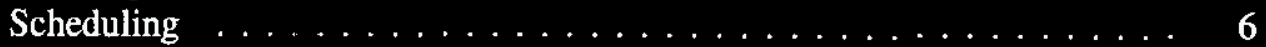

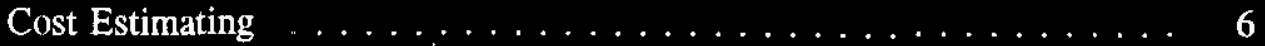

Standards and Guides . . . . . . . . . . . . . . 6

Engineering Assistance Request Process $\ldots \ldots \ldots \ldots 7$

Testing Program $\ldots \ldots \ldots \ldots \ldots$

Construction Inspection $\ldots \ldots \ldots \ldots \ldots$

Engineering Documentation $\ldots \ldots \ldots \ldots \ldots$

Organizational and Programmatic Interfaces $\ldots \ldots \ldots \ldots$

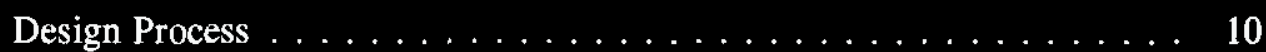

7.2 .2

Design Criteria $\ldots \ldots \ldots \ldots \ldots \ldots$

Design Products $\ldots \ldots \ldots \ldots \ldots \ldots$

Design Review and Verification $\ldots \ldots \ldots \ldots \ldots$

Design Change Controls $\ldots \ldots \ldots \ldots \ldots \ldots \ldots$

Design Life . . . . . . . . . . . . . . . . . . . 11

Management Systems $\ldots \ldots \ldots \ldots \ldots \ldots$

7.3.3

7.3.4

7.3 .5

7.3.6

7.3.7

7.3 .8

7.3 .9

7.3 .10

7.3 .11

7.3 .12

7.3 .13

7.3 .14

7.3.15

Quality Assurance ....................... 12

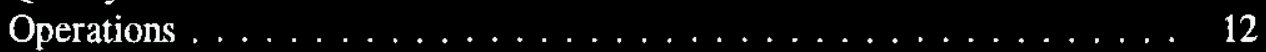

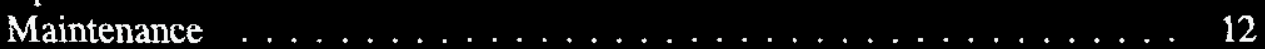

Construction Program . . . . . . . . . . . . . . . 12

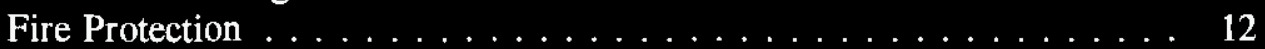

Nuclear Safety . . . . . . . . . . . . . . . . . 12

Research and Development and Experimental Activities . . . . . . . . 13

Occupational Safety and Health . . . . . . . . . . . . . . 13

Waste Management $\ldots \ldots \ldots \ldots \ldots \ldots \ldots$

Environmental Protection $\ldots \ldots \ldots \ldots \ldots \ldots$

Configuration Management $\ldots \ldots \ldots \ldots \ldots$

Emergency Preparedness and Management . . . . . . . . . 13

Radiation Protection ....................... 13

Training and Qualification $\ldots \ldots \ldots \ldots \ldots$ 


\subsection{ENGINEERING PROGRAM}

\section{INTRODUCTION}

A Standards/Requirements Identification Document (S/RID) sets forth the Environmental Safety and Health (ES\&H) standards/requirements. This S/RID is applicable to the appropriate life cycle phases of design, construction, operation, and preparation for decommissioning for each of the categories of facilities addressed in Revision 5 of the Department of Energy Implementation Plan for the Defense Nuclear Facilities Safety Board (DNFSB) Recommendation 90-2. This Recommendation calls for the strengthening of DOE weapons complex activities through the identification and application of relevant DOE Orders, regulations, industry codes/standards, industry guidance documents and, as appropriate, good industry practices. These standards/requirements are adequate to ensure protection of the health and safety of workers, the public, and the environment.

The Tank Farms S/RID contains standards/requirements that are necessary for safe operation of the Tank Farms and its associated facilities, and that are the direct responsibility of the specific facility manager. The Engineering Program defined in this document is described in general accordance with the Environment, Safety, and Health Configuration Guide, Revision 0, dated July 30, 1993, and is presented in program elements and subelements. The specific DOE Orders, regulations, industry codes/standards, guidance documents and good industry practices that serve as the basis for each element/subelement are identified and aligned with each subelement.

This S/RID contains only those requirements that Tank Farms personnel are clearly responsible to satisfy. Other requirements that are applicable to Tank Farms, but are satisfied by others, are defined in the Westinghouse Hanford Company (WHC) Level S/RID. For application in this S/RID, the words "shall" and "should" in requirements statements both indicate mandatory compliance. The Key interface information contained in the Functional Area documents is provided for general recognition and understanding and is not considered to contain prescriptive requirements.

\section{SCOPE}

This S/RID applies to the Tank Waste Remediation Systems (TWRS) Organization which includes the following:

- $\quad$ East Tank Farm Transition Project

- West Tank Farm Transition Project

- Evaporator Project

- Interim Stabilization Project

- Characterization Sampling Project (Excluding the Labs)

The near-term mission of TWRS is to store, treat, and immobilize the highly radioactive Hanford Site Waste. 
The Engineering Program Functional Area establishes and monitors the design bases interfaces for safe operation of TWRS facilities. The design bases for Tank Farms are documented in:

ISB (Vol. I \& II) - Doc. \# WHC-SD-WM-ISB-001, Rev. 0-G,

- TWRS Functions and Requirements Document (Draft) - Doc. \# DOE/RL-92-60, 09/94. 


\section{Program Policy and Procedures}

The requirements for program policies and procedures that are generally applicable to DOE facilities are covered in the Management Systems S/RID. Requirements for program policies and procedures specifically applicable to the Engineering Design functional area are contained in this subelement.

\section{REQUIREMENT SOURCE: DOE-GUIDE-10CFR830 Section 1.1}

"The principle factor reflecting the performance of an organization is the quality of its products and services. Criterion 1 requires that an organization develop and maintain an effective management system with the goal of ensuring safe, reliable products and services that meet or exceed the customer's requirements, needs, and expectations. The management system should include the methods for managing, performing, and assessing the adequacy of work, including work assigned to parties outside the organization.

The management system should focus on accomplishing the mission as outlined in the organization's strategic plan. The management system applies to every component and employee of the organization, and includes the organizational structure, functional responsibilities, levels of authority, and interfaces.

DOE Orders and other requirements documents prescribe a variety of management systems to assist DOE offices and contractors in achieving their missions and goals. If a formal management system has been established for a facility or activity, its attributes should be compared to the criteria of 10 CFR Part 830.120 to ensure that all requirements have been adequately addressed."

\section{REQUIREMENT SOURCE: DOE-GUIDE-10CFR830 Section 1.2}

"Management retains the primary responsibility and is accountable for the scope and implementation of the management system. However, every individual in the organization is responsible for achieving quality in his or her activities. Management should promote effective achievement of performance objectives through the:

- establishment of task assignments;

- identification of lines of communication; and

- determination and provision of the necessary resources and environment to accomplish the required activities.

Management should ensure that all personnel understand and implement the management system."

\section{REQUIREMENT SOURCE: DOE-GUIDE-10CFR830 Section 1.3}

"The scope and depth of the management system's application of requirements to a specific activity should be determined by the use of a grading process. The grading process provides the flexibility to design controls that best suit the facility or activity. The graded approach process should determine the appropriate level of effort necessary to attain and document the requirements established through the consideration of prescribed factors. This process-is based on a prescribed facility-specific or activity-specific factors such as the:

- level of risk;

- age, status, and condition of a facility or process;

- history of problems at a site or facility; 
The graded approach process should not be used to obtain relief from the requirements of 10 CFR Part 830.120."

\section{REQUIREMENT SOURCE: DOE-GUIDE-10CFR830 Section 5.2, Paragraph 2}

"The manager is responsible for planning and designing the work process. The required goals should be known in order to plan for the work processes. Work should be performed to prescribed-standards, procedures, or instructions of a detail commensurate with the complexity and importance of the work. When possible, administrative controls should be simplified to minimize the impact of controls on the worker. Personnel performing a process should be included in process improvement activities. The work process should be designed to produce the desired quantity and quality of output."

\section{REQUIREMENT SOURCE: DOE-GUIDE-10CFR830 Section 5.2, Paragraph 3}

"The manager is responsible for placing qualified personnel in positions to accomplish work and training them in the requirements of the job. Workers should be trained to new conditions if the work process is changed."

\section{REQUIREMENT SOURCE: DOE-GUIDE-10CFR830 Section 5.3, Paragraph 1}

"Workers are responsible for the quality of their own work. Workers should set goals for doing the work correctly the first time and contribute to improved work processes."

\section{REQUIREMENT SOURCE: DOE-GUIDE-10CFR830 Section 5.4, Paragraph 1}

"The manager should clearly identify authorities, responsibilities, and interfaces, both internal and external regarding the work process in appropriate work process documents. Policies, procedures, goals, plans, and any other information affecting a process should be clearly communicated to the personnel working within that process."

Staffing and Training

For the training and qualification requirements applicable to the Engineering Program Functional Area, see the Training and Qualification Functional Area Document.

\section{Planning}

Author's Note: All requirements from source document DOE Order 4700.1 are applicable only to project activities.

\section{REQUIREMENT SOURCE: DOE-GUIDE-10CFR830 Section 5.1}

"A work process includes all activities involved in performing defined tasks to achieve an objective. Work processes may include such activities as planning, scheduling, accounting, project management, design, analysis, fabrication, procurement, construction, installation, testing, operation, modification, maintenance, and decommissioning. The work process is a planned mix of people, equipment, environmental conditions, supply, management support, resources, and requirements. Any one of these elements has the potential for not allowing process goals to be met. " 


\section{REQUIREMENT SOURCE: DOE-GUIDE-10CFR830 Section 5.2, Paragraph 1}

"Managers should routinely be involved in work processes to ensure that criteria for acceptable work performance are clearly defined. The manager is responsible for setting requirements and policies which control the conditions under which the work process is required to function. These conditions should be considered as an element affecting product and service output and quality."

\section{REQUIREMENT SOURCE: DOE-GUIDE-10CFR830 Section 5.3, Paragraph 2}

"Workers should be considered as prime resources concerning the various aspects of their process. They understand how the process works and how metrics can best be applied. They are first line contact with both customers and suppliers and possess first hand knowledge of the products and services being supplied to and by their process."

\section{REQUIREMENT SOURCE: DOE-GUIDE-10CFR830 Section 5.4, Paragraph 2}

"Applicable work process documents should be readily accessible to the worker. Work process documents should be based on the skills of the workers using them and on the complexity and importance of the work. Work process documents should include any requirements for special processes which are highly dependent on the control of the process or the skill of the operator, and for which the quality of the product cannot be readily determined by inspection or test."

\section{REQUIREMENT SOURCE: DOE-GUIDE-10CFR830 Section 5.4, Paragraph 3}

"Work process documents should address such process elements as methods to prevent the use of incorrect or defective items and to ensure items requiring traceability are identified and controlled. Documents should describe methods controlling packaging, shipping, receiving, storage, handling, cleaning, and preservation of items to prevent damage, loss, or deterioration."

\section{REQUTREMENT SOURCE: DOE4700.1 Chapter III.B.2.c.(1)(a)}

"Technical objectives for each project should be established so that relationships among project needs, urgency, risks, and value can be established."

\section{REQUIREMENT SOURCE: DOE4700.1 Chapter III.B.2.c.(2)(a)}

"The design should be complete from a total system viewpoint to include facilities, utilities, hardware, software, personnel, and procedures."

\section{REQUIREMENT SOURCE: DOE4700.1 Chapter III.B.2.c.(2)(b)[1]}

"Requirements regarding design compatibility of engineering interfaces should be defined in appropriate specifications."

\section{REQUIREMENT SOURCE: DOE4700.1 Chapter III.B.2.c.(2)(b)[2]}

"Interface requirements related to major system elements, facilities, utilities, hardware, software, and procedures should be established, coordinated, and maintained."

\section{REQUIREMENT SOURCE: DOE4700.1 Chapter III.B.2.c.(2)(b)[3]}

"Clear lines of communications and timely dissemination of changes to these interface documents should be maintained." 
Scheduling

Author's Note: All requirements from source document DOE Order 4700.1 are applicable only to project activities.

Additional requirements are included in section 7.1.4.

\section{REQUIREMIENT SOURCE: DOE4700.1 Chapter III.F. 9.a.(2)[2]}

"All the contractually authorized work shall be planned, scheduled, budgeted, and authorized by the contractor."

\section{REQUIREMENT SOURCE: DOE4700.1 Chapter III.F. 9.a.(2)[3]}

"Although no specific scheduling techniques are required by the criteria, all authorized work shall be formally scheduled in a manner which shall permit the evaluation of actual progress against contract milestones, and the contract master schedule shall be clearly supported by lower-level schedules."

\section{REQUIREMENT SOURCE: DOE4700.1 Chapter III.F. 9.a.(3)[2]}

"The accounting criteria require that contract costs and performance measurement data elements be accumulated and summarized from the bottom up as directly as possible, without allocations."

\section{REQUIREMENT SOURCE: DOE4700.1 Chapter III.F. 9.a.(3)[3]}

"The contractor's system must be able to provide material price and usage variances, cost accumulation for materials on a basis consistent with the budgets, and full accountability for all contract materials ordered, received and used. "

\section{REQUIREMENT SOURCE: DOE4700.1 Chapter III.F. 9.a.(3)[4]}

"Indirect costs shall be controlled and procedures are required for identifying management control of overhead costs."

\section{REQUIREMENT SOURCE: DOE4700.1 Chapter III.F. 9.a.(4)[2]}

"Comparisons of actual versus planned performance are required by the analysis criteria."

\section{Cost Estimating}

Requirements for this subelement are included in 7.1.4.

\section{Standards and Guides}

Author's Note: The requirements from source document DOE Order 6430.1A are applicable only where dictated by Controlled Manuals. For all other design tasks, source document DOE Order 6430.1A should be used only as a basis for design decisions and the application of new design criteria. Meaningful operational, environmental protection, or safety benefits should be achieved before automatically implementing the DOE Order 6430.1A criteria, and probabilistic risk methods may be used to assist in this evaluation. 


\section{REQUIREMENT SOURCE: DOE6430.1A Section 0109, Sentences 1 and 2}

"Reference Standards and Guides. This section lists the reference standards and guides cited in these criteria. The latest edition of standards and guides shall be used."

\section{REQUIREMENT SOURCE: DOE6430.1A Section 0140[09]}

"Deviations from specified standards shall be identified and procedures established to ensure their control."

\section{Engineering Assistance Request Process}

Requirements for this subelement are included in section 7.1.4.

\section{Testing Program}

\section{REQUIREMENT SOURCE: DOE-GUIDE-10CFR830 Section 8.1}

"Inspections/tests are accomplished to verify that physical characteristics and functions of systems, structures, and components are acceptable to the organization that will use the systems, structures, and components. Systems, structures, and components requiring inspection/test should be identified early in the design phase.

Inspections and tests should be conducted according to a graded approach. Acceptance parameters and other requirements such as inspection/test equipment or qualified inspection/test personnel should be specified in design documentation.

Systems, structures, and components should be ready for service at the conclusion of the inspection or test process. The types of systems, structures, and components and the length of time they are to remain in storage should be considered when generating the inspection or test plan.

The inspection/test process should identify the status of systems, structures, and components requiring examination to ensure that failed or untested systems, structures, and components are not used. A method should be developed which controls reinspection and retesting for previously failed systems, structures, or components. The method should provide for review and documentation of changed inspection/test parameters.

Inspections/tests should be performed by technically qualified personnel that have the freedom of access and communication to report inspection/test results. Final acceptance of systems, structures, or components should be verified and documented by organization having the final responsibility for the system, structure, or component.

All personnel should check items supplied to their work process to ascertain that the items are correct and suitable for use. All personnel should check their process output to verify that it meets or exceeds requirements."

\section{REQUIREMENT SOURCE: DOE-GUIDE-10CFR830 Section 8.2}

"Inspection/test methods should be established that define the requirements for activities that verify conformance of systems, structures, or components with specified requirements. Results of these activities should be documented and retained as project records. Inspection/test activities should be performed by persons other than those who performed or directly supervised the work being examined. 
Inspections/tests should be performed to written directives. Appropriate sections of approved codes or standards may be used for acceptance requirements and inspection/test methods in lieu of specially written test procedures. Inspection/test documentation should contain provisions for at least the following:

- identification of characteristics to be examined;

- required qualifications of individuals who perform the examination;

- a description of the examination methods including equipment and calibration requirements;

- acceptance and rejection criteria;

- $\quad$ suitable environmental conditions;

- $\quad$ required safety measures; and

- mandatory hold points, when required.

Inspection/test results should be evaluated and verified by authorized personnel to document that all requirements have been satisfied. Records should, at a minimum, identify:

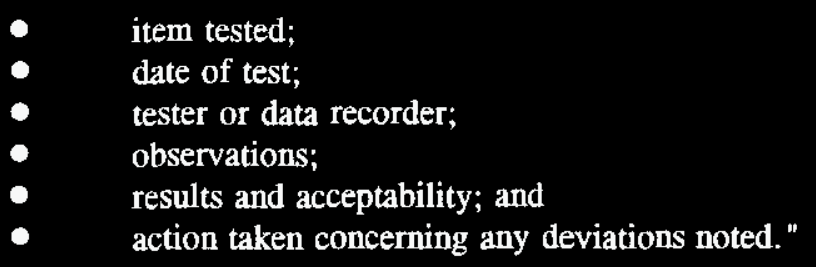

\section{REQUIREMENT SOURCE: DOE-GUIDE-10CFR830 Section 8.3}

"The inspection and acceptance testing methods should establish requirements for a calibration system to ensure that measuring and test equipment (M\&TE) used to verify conformance to design requirements are of the proper type, range, accuracy, and are uniquely identified and traceable to their calibration data.

The method should ensure that adequate procedures for testing, retesting, adjusting, and re-calibration of M\&TE are maintained and documented by organizations performing inspection and testing functions. When applicable, M\&TE should be calibrated to standards traceable to the National Institute of Standards and Technology,"

\section{Construction Inspection}

Requirements for this subelement are included in section 7.1.9.

\section{$\underline{7.1 .11}$}

\section{Engineering Documentation}

\section{REQUIREMENT SOURCE: DOE-GUIDE-10CFR830 Section 4.1}

"Documents and records are required to manage, perform, and assess work. Management should identify any documents which must be controlled and records which must be generated, and should commit the resources necessary to accomplish the document and record requirements."

\section{REQUIREMENT SOURCE: DOE-GUIDE-10CFR830 Section 4.2}

"Documents may be required by organizations, projects, or programs to control policy, administrative, or technical information. A document may describe work to be done, data to be used at different locations or by different people, or, in changing situations, data that is controlled from time to time for reference purposes. A document control process should establish requirements to release documents 
for distribution, identify recipients, specify actions to be taken with existing documents when revisions are released for distribution or documents are canceled, and identify unique revisions and copies.

Document control requirements should be defined by each organizational unit. Although the actual process may be supplied internally or externally, the organizational unit is responsible for ensuring that their requirements are being met."

\section{REQUIREMENT SOURCE: DOE-GUIDE-10CFR830 Section 4.3}

"A record contains information that is retained for its expected future value. Records should be sufficient to support technical and regulatory decisions. Records and documents may be electronically stored, written or printed, microfilm, photographs, radiographs, or laser disks.

Records are compiled into a records management system that ensures appropriate records are maintained. The records system should include provisions for retention, protection, preservation, changing, traceability, accountability, and retrievability of records. While in storage, records should be protected from damage, loss, and deterioration. Evidentiary records should have appropriate procedures controlling media type, chain of custody, and confidentiality.

For records that require electronic processing and control, the hardware and software required to maintain and access the records should be maintained and controlled to ensure that the records remain usable. These records include information recorded on magnetic media and optical disks.

The National Archives and Records Administration (NARA) has final authority for approving the disposition of Government records. NARA publishes the General Records Schedule (GRS), and approves DOE unique records schedules. All records management systems should have schedules for records retention and disposition in accordance with the requirements of NARA and DOE 1324.2 (latest issue), "Records Disposition. " Records management systems should address the requirements of DOE 1324.5 (latest issue), Records Management Program." Applicable standards may differ in records management terminology from the NARA requirements. Care should be taken to ensure that the requirements of NARA, applicable standards, and any additional statutory requirements are met. Records retention times may also be included in contractual requirements."

Requirements for this subelement are included in 7.2.

\section{REQUIREMENT SOURCE: DOE-GUIDE-10CFR830 Section 6.1}

"Definition, control, and verification of design is necessary to ensure that systems, structures, and components fulfill contractual requirements and customer expectations. Design work should be based on sound engineering and scientific principles. A formal design process should be established which provides control of design inputs, outputs, verification, configuration and design changes, documentation, records, and technical and administrative interfaces.

Systems, structures, and components important to safety should be subject to more stringent operational criteria and verification requirements than those not important to safety. DOE 6430.1 (latest issue), "General Design Criteria," provides a definition of safety class and examples of systems, structures, and components that are normally designated as safety class in DOE facilities. Safety Analysis Reports should exist for each DOE nuclear facility which define that facility's systems, structures, and components important to safety. 
Designs should provide for appropriate inspection, testing, and maintenance to ensure continuing reliability and safety of the system, structure, or component. The design should consider the expected use and life expectancy of the system, structure, or component in order to address appropriate disassembly and disposal requirements.

Design records may include design input, calculations and analyses, engineering reports, design output documentation, design verification documentation, design change documentation, and design revisions."

\section{REQUIREMENT SOURCE: DOE-GUIDE-10CFR830 Section 6.3, Paragraph 1}

"The design process should translate design input into design output documents that are technically correct and meet the end-user's requirements. Aspects critical to the safety or reliability of the designed system, structure, or component should be identified during the design phase. Design output documents should be useable by other project processes such as: manufacturing, assembly, construction, testing, inspection, maintenance, and decommissioning."

\section{REQUIREMENT SOURCE: DOE-GUIDE-10CFR830 Section 6.3, Paragraph 2}

"Computer software used to originate or verify design solutions during the design process should be validated or the status of code validation should be identified and documented prior to use."

\section{REQUIREMENT SOURCE: DOE-GUIDE-10CFR830 Section 6.3, Paragraph 3}

"The agency accomplishing the design should verify that design output documents meet design input requirements and that any deviations have been approved and documented."

\section{REQUIREMENT SOURCE: DOE-GUIDE-10CFR830 Section 6.2, Paragraph 1}

"Design inputs should be technically correct and complete. These inputs may include such information as design bases, health and safety considerations, expected life cycle, performance parameters, codes and standards requirements, and reliability requirements. Technical design interfaces should be identified in the input documents and methods should be established for their control."

7.2.3 Design Products

\section{REQUIREMENT SOURCE: DOE-GUIDE-10CFR830 Section 6.4}

"The completed design should be recorded in design output documents such as drawings, specifications, test/inspection plans, maintenance requirements, and reports. As-built drawings and shop drawings should be maintained after production or construction to show actual configuration. The administrative interface process should clearly indicate responsibilities for design output document activities including as-built mark-up and up-dating during project construction/production phases, media use and transmission, document control, and records management."

\section{REQUIREMENT SOURCE: DOE-GUIDE-10CFR830 Section 6.5, Paragraph 2}

"Design verification should be performed by technically knowledgeable persons separate from those who performed the design. Interim verifications may be made at predetermined stages of design 
development. The extent and number of design verifications should be based on a graded approach and should depend on the designed product's complexity and importance to project success."

\section{REQUIREMENT SOURCE: DOE-GUIDE-10CFR830 Section 6.5, Paragraph 3}

"Design verification should be completed before design output is used by other organizations or to support other work such as procurement, manufacture, construction, or experiment. When this timing cannot be achieved, the unverified portion of the design should be identified and controlled. In all cases, design verifications should be completed before relying on the system, structure, or component to perform its function and before installation becomes irreversible."

\section{REQUIREMENT SOURCE: DOE6430.1A Section 0140[10]}

"To the extent practicable, and particularly in the case of innovative design, the design should be independently reviewed by competent consultants in construction or manufacturing techniques to confirm the practicability of construction or manufacture."

\section{Design Change Controls}

\section{REQUIREMENT SOURCE: DOE-GUIDE-10CFR830 Section 6.6}

"Design Changes. Design changes, including field changes and nonconforming items dispositioned "use-as-is" or "repair," should be controlled by measures commensurate with those applied to the original design. Temporary modifications should receive the same levels of control as the designs of permanent modifications."

\subsubsection{Design Life}

\section{REQUIREMENT SOURCE: DOE-STD-1073-93 Chapter 1, Section 1.3.7.2}

"Components in the facility, including passive components (e.g., structures), should be screened to identify those that are potentially life-limiting for the facility."

\section{REQUIREMENT SOURCE: DOE-STD-1073-93 Chapter 1, Section 1.3.7.3}

"The remaining lifetime for each potentially life-limiting component should be evaluated. Major aging degrading mechanisms that could affect potentially life-limiting components should be identified. The present material condition of each such component should be determined."

\section{KEY INTERFACES}

\section{INTERFACE BOUNDARIES}

The Engineering Design Functional Area applies to all design activities at a facility. This Functional Area interfaces essentially with all other functional areas to some degree, in both programmatic and technical functional areas.

The following functional areas have a major interface with the Engineering Program Functional Area:

\section{Management Systems}

The Engineering Program uses applicable higher tier policies and procedures developed outside this functional area. Policies and procedures applicable solely to the Engineering Program Functional Area should exist within this functional area, but should be subject to general controls from the Management 
Systems Functional Area. Design-related needs for document control and records management should be contained in the Engineering Program Functional Area.

\section{Quality Assurance}

The QA Functional Area provides oversight of the conduct of the Engineering Program Functional Area. The Engineering Program should ensure that appropriate QA controls are imposed on subcontractors and vendors. The Engineering Program Functional Area should incorporate into its processes a means of timely dispositioning of deficiencies whether identified by the QA function or through design verification and self-assessment activities. The Engineering Program Functional Area should also specify quality control inspection requirements for physical attributes important to design.

\section{Operations}

The Operations Functional Area should provide operational mission and needs and capabilities to engineering for new design efforts. The Engineering Program provides information necessary to permit the Operations Functional Area to ensure operation of the facility within the limits imposed by the design. For example, the engineering design function must provide information on safety limits for equipment operation, information to develop operating procedures, and inputs for use in operational activities such as instrument calibration and establishment of instrument setpoints. The system engineering function is within the scope of the Operations S/RID; however the Engineering Program S/RID includes requirements for obtaining system engineer's input for design changes.

\section{$\underline{7.3 .4}$}

\section{Maintenance}

The interface between Engineering and Maintenance Program Functional Areas should be defined so that maintenance activities that change design features of facility components are treated as design changes and are subject to applicable design control requirements. Maintenance activities that maintain or restore the facility to its as-designed condition are solely within the Maintenance Functional Area. The Engineering Program Functional Area should provide post-maintenance testing requirements for work affecting the design and should develop technical requirements for materials and services used in maintenance activities that potentially affect the design. The Engineering Program should also provide maintenance with vendor instructions and recommendations obtained during the project construction phase.

\section{$\underline{7.3 .5}$}

\section{Construction Program}

Engineering interfaces with the Construction Program in the areas of scheduling, estimating, design reviews, and construction inspection. Engineering design contract documents are used by construction to provide required facilities.

\subsubsection{Fire Protection}

The interface between Engineering Program and Fire Protection Functional Areas is necessary because the Fire Protection Functional Area evaluates the fire hazards and defines the design features that are necessary to mitigate those hazards. The Engineering Program Functional Area ensures that those design features are incorporated into the design and provides the necessary support services (power, water, etc.) required by fire protection systems.

The Nuclear Safety Functional Area contains the controls and requirements for SAR preparation, definition and analysis of credible accidents, and performing dose calculations needed for the SAR. The Engineering Program Functional Area recognizes the need for engineering support to this process 
and the need to ensure that designs are consistent with the SAR and other technical safety requirements and commitments.

\section{Research and Development and Experimental Activities}

Research and Development activities aren't currently a part of the mission of Tank Farms and accordingly no interface exists.

\section{Occupational Safety and Health}

Public Law requires that this functional area be integrated into the design of facilities to ensure a safe working environment for operating personnel.

\section{Waste Management}

There is a series of Public Laws that affect design relating to this functional area. Their primary purpose is to manage and remediate waste to assure that the health of workers and the public is not compromised.

\subsubsection{1}

$\underline{7.3 .12}$

$\underline{7.3 .13}$

7.3.14

\section{Environmental Protection}

The Environmental Protection Functional Area interfaces with the Engineering Program in the areas of developing data necessary to the preparation of National Environmental Policy Act documents, licenses, and permits, as well as consideration of other agency requirements in facility engineering activities.

\section{Configuration Management}

The Engineering Program Functional Area provides information to the Configuration Management Functional Area and uses the design and configuration baselines maintained within that functional area.

\section{Emergency Preparedness and Management}

The Engineering Program Functional Area incorporates into its designs the requirements necessary to support emergency preparedness and management functions. Such requirements include those necessary to perform safety-related functions under emergency conditions, as well as the capability to monitor facility conditions, and provide communications and other necessary support.

\section{Radiation Protection}

The Radiation Protection Functional Area provides design input regarding the radiation hazards associated with the processes being conducted within the facility. The Engineering Program Functional Area contains requirements for ensuring that appropriate design measures are taken to ensure compliance with radiation protection standards and requirements. The Radiation Protection Functional Area provides timely input to the design process by providing reviews of designs for compliance with radiation protection standards and requirements.

\section{Training and Qualification}

The Engineering Program Functional Area contains requirements for defining the training needs of personnel assigned to carry out the requirements contained therein. The Engineering Program is responsible for implementing the appropriate engineering-specific training and qualifications requirements. The Training and Qualification Functional Area defines the requirements for general employee training, security training, and instructor training and qualification. 


\section{Requirement Source Documents}

10 CFR Part 830, Nuclear Safety Management, 4/5/94

DOE 4700.1, Project Management System, Change 1, 06/02/92

DOE 6430.1A, General Design Criteria, 04/06/89

DOE Implementation Guide for 10 CFR $830.120,08 / 94$

DOE-STD-1073-93, Guide for Operational Configuration Management Program, 11/93

\section{Reviewed Documents Not Used as Requirement Sources}

DOE 5400.1, General Environmental Protection Program, Change 1, 06/29/90.

DOE 5400.5, Radiation Protection of the Public and the Environment, Change 2, 01/07/93.

DOE 5480.1B, Environment, Safety and Health Program for Department of Energy Operations, Change 5, 05/10/93.

DOE 5480.4, Environmental Protection, Safety, and Health Protection Standards, 05/15/84.

DOE 5480.9, Construction Safety and Health Program, 12/18/80.

DOE 5480.11, Radiation Protection for Occupational Workers, Change 3, 06/17/92.

DOE 5480.19, Conduct of Operations for DOE Facilities, Change 1, 05/18/92.

DOE 5481.1B, Safety Analysis and Review System, Change 1, 05/19/87.

DOE 5700.6C, Quality Assurance, 08/21/91

DOE 5820.2A, Radioactive Waste Management, 09/26/88.

ANSI N45.2.11 1974, Quality Assurance Requirements for Design of Nuclear Power Plants. ASME-NQA-1-1994, Quality Assurance Requirements for Nuclear Facility Applications, 1994. BMP 85 013, Plant Modification Control Program, 05/85.

BMP 84 026, Setpoint Change Control Program, Revision 1, 06/86.

BMP 90 009, Guidelines for the Conduct of Design Engineering, Revision 1, 02/92 


\section{TABLE OF CONTENTS}

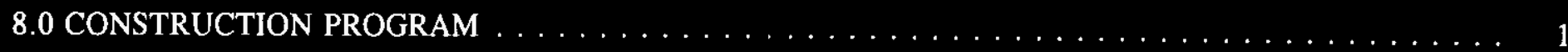

Policies and Procedures $\ldots \ldots \ldots \ldots 2$

8.1 .3

Authority and Responsibility $\ldots \ldots \ldots \ldots \ldots$

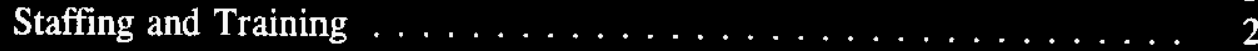

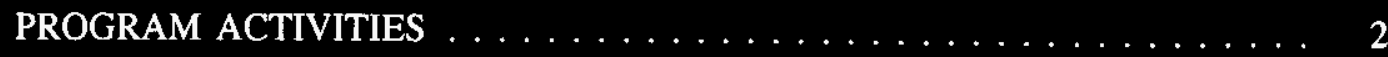

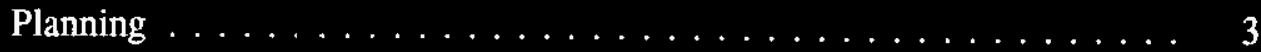

8.2 .3

8.2 .4

8.2 .5

8.2 .6

8.2 .7

8.2 .8

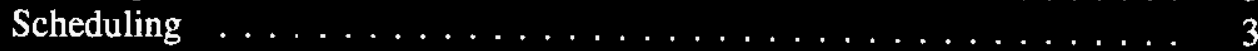

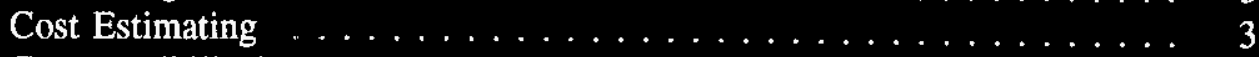

Constructibility/Maintainability/Value Engineering . . . . . . . . . 4

Material and Equipment Storage . . . . . . . . . . . . . . 4

Contract Selection . . . . . . . . . . . . . . . . 4

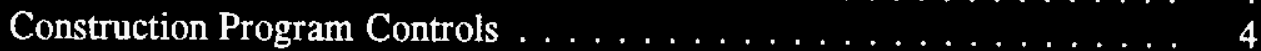

Walkthroughs of Construction Sites $\ldots \ldots \ldots \ldots$

Management Systems . . . . . . . . . . . . . . . 7

Quality Assurance . . . . . . . . . . . . . . . . . 7

Configuration Management $\ldots \ldots \ldots \ldots \ldots$

Training and Qualification ................. 7

Safeguards and Security $\ldots \ldots \ldots \ldots \ldots$

Engineering Program $\ldots \ldots \ldots \ldots \ldots \ldots \ldots$

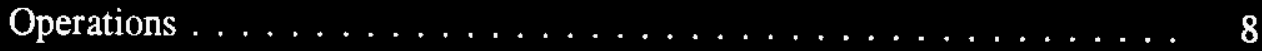

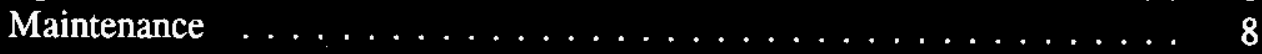

Radiation Protection .................... 9

Fire Protection . . . . . . . . . . . . . . . . . 9

Research and Development and Experimental Activities . . . . . . . . . 9

Occupational Safety and Health . . . . . . . . . . . . . . . 9

Environmental Protection $\ldots \ldots \ldots \ldots \ldots$

$8.4 \quad$ REFERENCES $\ldots \ldots \ldots \ldots \ldots \ldots \ldots \ldots \ldots \ldots \ldots \ldots \ldots \ldots \ldots$

8.4.1 Requirement Source Documents $\ldots \ldots \ldots \ldots \ldots \ldots$

8.4.2 Reviewed Documents Not Used as Requirement Sources . . . . . . . . 10 


\subsection{CONSTRUCTION PROGRAM}

\section{INTRODUCTION}

A Standards/Requirements Identification Document (S/RID) sets forth the Environmental Safety and Health (ES\&H) standards/requirements. This S/RID is applicable to the appropriate life cycle phases of design, construction, operation, and preparation for decommissioning for each of the categories of facilities addressed in Revision 5 of the Department of Energy Implementation Plan for the Defense Nuclear Facilities Safety Board (DNFSB) Recommendation 90-2. This Recommendation calls for the strengthening of DOE weapons complex activities through the identification and application of relevant DOE Orders, regulations, industry codes/standards, industry guidance documents and, as appropriate, good industry practices. These standards/requirements are adequate to ensure protection of the health and safety of workers, the public, and the environment.

The Tank Farms S/RID contains standards/requirements that are necessary for safe operation of the Tank Farms and its associated facilities, and that are the direct responsibility of the specific facility manager. The Construction Program defined in this document is described in general accordance with the Environment, Safety, and Health Configuration Guide, Revision 0, dated July 30, 1993, and is presented in program elements and subelements. The specific DOE Orders, regulations, industry codes/standards, guidance documents and good industry practices that serve as the basis for each element/subelement are identified and aligned with each subelement.

This S/RID contains only those requirements that Tank Farms personnel are clearly responsible to satisfy. Other requirements that are applicable to Tank Farms, but are satisfied by others, are defined in the Westinghouse Hanford Company (WHC) Level S/RID. For application in this S/RID, the words "shall" and "should" in requirements statements both indicate mandatory compliance. The Key interface information contained in the Functional Area documents is provided for general recognition and understanding and is not considered to contain prescriptive requirements.

\section{SCOPE}

This S/RID applies to the Tank Waste Remediation Systems (TWRS) Organization which includes the following:

- $\quad$ East Tank Farm Transition Project

- West Tank Farm Transition Project

- Evaporator Project

- Interim Stabilization Project

Characterization Sampling Project (Excluding the Labs)

The near-term mission of TWRS is to store, treat, and immobilize the highly radioactive Hanford Site Waste. 
8.1

$\underline{8.1 .1}$

$\underline{8.1 .2}$

$\underline{\mathbf{8 . 1 . 3}}$

\section{MANAGEMIENT AND ADMINISTRATION}

\section{Policies and Procedures}

Author's Note: Additional requirements are contained in the Quality Assurance Functional Area.

\section{REQUIREMENT SOURCE: DOE4700.1 Attachment III-7.2.a.(1)}

"The contractor's management control systems shall include policies, procedures, and methods which are designed to ensure that they will accomplish the following: Define all authorized work and related resources to meet the requirements of the contract, using the framework of the contract work breakdown structure."

\section{Authority and Responsibility}

\section{REQUIREMINT SOURCE: 10CFR830 Part 120(c)(2)(i)}

"Performance

Work Processes. Work shall be performed to established technical standards and administrative controls using approved instructions, procedures, or other appropriate means. Items shall be identified and controlled to ensure their proper use. Items shall be maintained to prevent their damage, loss, or deterioration. Equipment used for process monitoring or data collection shall be calibrated and maintained."

\section{Staffing and Training}

The comprehensive requirements for Training and Qualification programs are contained within that functional area element.

\section{PROGRAM ACTIVITIES}

\section{REQUIREMENT SOURCE: DOE4700.1 Attachment III-7.2.a.(2)}

"The contractor's management control systems shall include policies, procedures, and methods which are designed to ensure that they will accomplish the following: Identify the internal organizational elements and the major subcontractors responsible for accomplishing the authorized work."

\section{REQUIREMENT SOURCE: DOE4700.1 Attachment III-7.2.a.(4)}

"The contractor's management control systems shall include policies, procedures, and methods which are designed to ensure that they will accomplish the following: Identify the managerial positions responsible for controlling overhead (indirect costs)."

\section{REQUIREMENT SOURCE: DOE4700.1 Attachment III-7.2.a.(5)}

"The contractor's management control systems shall include policies, procedures, and methods which are designed to ensure that they will accomplish the following: Provide for integration of the contract work breakdown structure with the contractor's functional organizational structure in a manner that permits cost and schedule performance measurement for contractor work breakdown structure and organizational elements. " 
Planning

REQUIREMENT SOURCE: DOE4700.1 Chapter V.A.2.c.(1) [1]

"Specific project management plans shall be prepared for each major system acquisition and major project per Chapter II."

REQUIREMENT SOURCE: DOE4700.1 Chapter V.A.2.c.(2)

"General project management plans shall be prepared for categories or types of projects which are to be managed similarly, encompassing the same areas that the specific management plans address."

\section{REQUIREMENT SOURCE: DOE4700.1 Chapter V.A.2.c.(3) [1]}

"Projects managed by general management plans shall have a specific document containing scope, estimate, schedule, and designated individuals assigned authorities and responsibilities."

\section{REQUIREMENT SOURCE: DOEN4700.5 Attachment 2, Section 2.a.(4)(b)1}

"Ensure that a process is established and is in operation throughout the project life to identify programmatic, operational, legislative, institutional, and other requirements or constraints, which may affect technical, cost, or schedule baselines and ensure that such baselines properly reflect such potential impacts."

Scheduling

\section{REQUIREMENT SOURCE: DOEN4700.5 Attachment 2, Section 2.a.(4)(b)2}

"Develop schedules that integrate with the WBS and cost estimate, and represent all work scope regardless of funding source. Use activity logic to depict all work scope, constraints, and decision points. Estimate and assign durations to activities representing work accomplishment."

\section{REQUIREMENT SOURCE: DOEN4700.5 Attachment 2, Section 2.a.(4)(b)3}

"Establish an approved schedule baseline which clearly depicts critical path activities and milestones from which actual performance for all activities and milestones can be compared, and from which forecast data can be generated. Resource-load activities, as required and at the appropriate level, to develop time phased budgets that are integrated with the schedule. Permit only authorized changes to the schedule baseline."

\section{$\underline{8.2 .3} \quad$ Cost Estimating}

\section{REQUIREMENT SOURCE: DOE5700.2D PREAMBLE: Section 8.c.}

"All sequential cost estimates shall be reconciled and kept on file with previous estimates until the project is completed, thereby ensuring traceability from project start to completion. Each estimate documentation file shall also include the basis for the estimate, show how the estimate was performed, and contain a contingency analysis. All estimates shall be performed in constant-year dollars and then escalated into year-of-expenditure (generally fiscal year) dollars. Both the estimates and the escalation rates used will be kept on file until the project is completed." 


\section{REQUTREMENT SOURCE: DOE5700.2D PREAMBLE: Section 8.d.}

"Check estimates are recommended for validating project estimates. Check estimates can be made by the project engineer/manager or by any qualified DOE or support contractor personnel. It is highly desirable that the check estimate be made by someone other than those who performed the original estimate. The check estimate may utilize any of the estimating methods shown in Attachment 1."

\section{REQUIREMENT SOURCE: DOEN4700.5 Attachment 2, Section 2.a.(3)(b)1}

"Prepare cost estimates using appropriate estimating methodologies that are integrated with the WBS, and the DOE cost structure as specified by the DOE, for all contract work. Ensure that all estimates are consistent with DOE 5700.2D and in accordance with FAR 15.804, "Cost and Price Data Analysis, as applicable."

REQUIREMENT SOURCE: DOE4700.1 Chapter V.A.2.q.(2)

"Maintainability considerations shall include: Ease of replacement or installed equipment;"

\section{REQUIREMENT SOURCE: DOE4700.1 Chapter V.A.2.q.(3)}

"Maintainability considerations shall include: Accessibility of installed equipment and building systems for performance of maintenance;

\section{REQUIREMENT SOURCE: DOE4700.1 Chapter V.A.2.q.(5)}

"Maintainability considerations shall include: Provisions of maintenance instructions and as-built drawings, especially the location of underground and otherwise concealed utility lines, process chemical and coolant piping."

\section{REQUIREMENT SOURCE: DOE4700.1 Chapter V.C.2.h.(2)(a) [4]}

"In adopting any new techniques or methods, care should be exercised to assure that the design criteria are satisfied, and that the results will be achieved without any decrease in desired quality and without any sacrifice in essential requirements."

\section{Material and Equipment Storage}

Requirements for this subelement are included in Section 8.1.2 and the Packaging and Transportation Functional Area.

\subsubsection{Contract Selection}

Author's Note: Requirements for this section are included in the Engineering Functional Area.

\section{Construction Program Controls}

Author's Note: The following four requirements from DOE 1324.2A provide direction for the maintenance and disposition of construction records. 


\section{REQUIREMENT SOURCE: DOE1324.2A Chapter V, Attachment V-14, Item 2.a}

"Working drawings and construction specifications, "as-built" drawings, shop drawings, standard drawings, repair and alteration drawings, equipment specifications, operating and maintenance manuals, equipment warranty data, final inspection and acceptance reports, construction cost and schedule data, space assignment plans, and other essential information to document the construction process.

(1) For completed projects. Until dismantlement or disposal of facility, equipment, system or process; or when superseded or obsolete, whichever is earlier (see item d., below, for exceptions).

(2) For projects terminated prior to construction completion. 5 years after construction is terminated."

\section{REQUIREMENT SOURCE: DOE1324.2A Chapter V, Attachment V-14, Item 2.b}

"Construction Completion Reports (Documented summary of the project, from design through construction completion.)

(1) For unique or special-interest by projects. 20 years, unless covered exception in d., below.

(2) For other projects. Until dismantlement or disposal of the facility, equipment, or process; or when superseded or obsolete, whichever is earlier."

\section{REQUIREMENT SOURCE: DOE1324.2A Chapter V, Attachment V-14, Item 2.c}

"Miscellaneous Construction Records. Information correspondence, and other records developed during the construction process, essential to performance of the process but not essential for project record purposes following project completion. Until project completion."

\section{REQUIREMENT SOURCE: DOE1324.2A Chapter V, Attachment V-14, Item 2.d}

"Records selected for architectural, historical, and technological significance (see notes at end of schedule for selection criteria). Permanent. Offer to NARA when file is inactive. (See first paragraph of introduction to this schedule).

(1) Project description, location, construction costs and performance schedules.

(2) "As built" architectural and engineering drawings (selected to adequately depict the principal architectural and engineering features).

(3) Photographs of completed project.

(4) Construction Completion Reports."

\section{REQUIREMENT SOURCE: DOE4700.1 Chapter V.C.2.h.(2)(d)1 [5]}

"Standard change controls procedures shall be established for projects not having specific project management plans." 


\section{REQUIREMENT SOURCE: DOE4700.1 Chapter V.C.2.h.(2)(d)1 [6]}

"These procedures shall include authorities and responsibilities for changes during both design and construction."

\section{REQUIREMENT SOURCE: DOE6430.1A Section 0150-4.1}

\section{"General}

Pollution and soil erosion controls shall be implemented during construction activities to mitigate impacts on air, water, and other environmental resources and to assure compliance with Federal, State and local laws and regulations. Site-specific industrial waste problems shall be considered prior to construction. Special construction permit and environmental protection requirements shall be addressed at a pre-bid conference and shall be clearly stated within the contract documents."

\section{REQUIREMENT SOURCE: DOE6430.1A Section 0150-5, Sentences 1 thru 4}

\section{"TEMPORARY SECURITY FENCING}

Prior to construction the following conditions and requirements for temporary security fencing shall be implemented:

o Exclusion of unauthorized vehicular and pedestrian traffic from the construction site o Restriction of authorized vehicular traffic to designated access roads

o Protection of construction materials and installed work

Temporary security fencing shall be installed, as required, at unsecured construction sites to prevent vandalism or theft.

Temporary security fencing shall provide a level of integrity and a clear zone to suit site-specific conditions.

Temporary security fencing shall be consistent with site-specific security and protection goals and operational requirements. "

\section{Walkthroughs of Construction Sites}

\section{REQUIREMENT SOURCE: DOE4700.1 Chapter III, Section D.2.j}

"Inspection. Inspection methods of activities affecting quality should be established and executed by or for the organization performing the activity. The inspection should validate conformance with the prescribed documented instructions, procedures, and drawings. Examinations, measurements, or tests of material or products processed should be performed for each work operation, where necessary, to assure quality. If inspection of processed material or products is impossible or not advantageous, indirect control by monitoring processing methods, equipment, and personnel should be provided. Both inspection and process monitoring should be provided when control is inadequate without both. If mandatory inspection points which require witnessing or inspection by the contractor's designated representative, and if work cannot proceed beyond these points without the consent of its designated representative, the specific points should be indicated in appropriate documents."

\section{REQUIREMENT SOURCE: DOE4700.1 Chapter V, Section A.2.1}

"Construction Health and Safety. A comprehensive health and safety program must be established and utilized for all Departmental construction projects. The goals of this program 
are to protect DOE employees, contractor employees, and the general public from hazards; to protect property from damage, and to prevent delay or internuption in the Department's programs caused by accidents and fires in connection with construction activities. The authorities, responsibilities, and standards for construction safety are contained in DOE 5480.1A, DOE 5481.1A, and DOE 6430.1, Chapter 10. Consideration of safety requirements must begin early in the planning phase of a project to ensure that they are included in all plans, studies, schedules, and cost estimates. An example of a safety requirement which must begin early is the case in which additional real estate may be required to achieve fire separations necessary to meet the improved risk criteria of DOE 5480.1A."

\section{KEY INTERFACES}

The Construction Program Functional Area interfaces to some degree with most other Functional Areas. Key interface areas are identified below.

$\underline{\mathbf{8 . 3 . 1}}$

$\underline{\mathbf{8 . 3 . 2}}$

$\underline{\mathbf{8 . 3 . 3}}$

\section{Management Systems}

The Construction Program interfaces with Management Systems primarily in the areas of policy and procedures development, organizational structure, assignment of authorities and responsibilities, and project control and reporting systems. DOE 4700.1 provides the major management requirements that interface and overlap between Management Systems and Construction Program management activities.

Requirements for Operational Readiness Reviews (ORR) are contained in the Management Systems Functional Area.

\section{Ouality Assurance}

The Construction Program, working with the procurement staff, should implement the Quality Assurance Program through incorporation of appropriate quality assurance clauses in construction management and construction contracts, and monitoring construction operations to ensure performance in accordance with the contracts. A detailed description of the Quality Assurance requirements that interface with construction is found within the Quality Assurance Program Functional Area.

\section{Configuration Management}

The Construction Management Program interfaces with both this functional area and the Engineering Program to implement Configuration Management requirements for control of changes to the baseline technical scopes, schedules and estimates. A shared interface for overall document control exists among Construction, Quality Assurance, and Configuration Management.

\section{Training and Qualification}

The interface with this functional area is primarily in two areas: ensuring training of the Construction Program staff in the areas of construction management, government contracting including contract administration, and occupational safety and health; and in establishing and scheduling specific training and accrediting programs to ensure availability of adequate qualified construction craft personnel.

Due to a wide variety of special processes that may be part of a construction project, varying degrees of training and qualification may be required. Several of these areas have been included in this document, and provide examples of areas of interface. 
$\underline{\mathbf{8 . 3 . 5}}$

\section{$\underline{8.3 .6}$}

\section{$\underline{\mathbf{8 . 3 . 7}}$}

\section{$\underline{\mathbf{8 . 3 . 8}}$}

\section{Safequards and Security}

The interfaces in this area are in the areas of physical protection of construction materials and equipment, and prevention of construction contractor personnel intrusion into operating areas.

\section{Engineering Program}

The Construction Program is responsible for implementing the Engineering Program's design drawings and specifications. Extensive interfacing should occur between the two, particularly for the following:

- Establishing cost estimates and schedules;

- Constructibility reviews;

- Establishing work packages for procurement;

- Control of scope, estimates and schedules;

- Permitting and licensing efforts;

- Review and approval of vendor drawings;

- Identifying laydown space and temporary utility needs;

- Construction inspection activities;

- Planning and execution of startup; and,

- Record maintenance, distribution and retention.

A principal interface occurs among engineering, construction, and Quality Assurance, wherein construction's nonconformances with engineering direction are identified, processed, and resolved.

\section{Operations}

The operations staff of the facility become the in-situ owners of the construction project on behalf of DOE. Therefore, the major interface is the operability testing and final acceptance of the constructed project.

\section{Maintenance}

The interface between Construction and Maintenance Programs may exist on many levels depending on the size and complexity of the project. Normal interfaces are in the areas of scheduling, temporary utilities, startup, and records maintenance, distribution and retention. Additionally, construction forces may be required to adopt and implement many of the Maintenance Program's functions in order to preserve and maintain systems, structures, components, tools, vehicles, and equipment either constructed or used in construction. Other interfaces may develop as systems, structures, or components are accepted by operations and maintenance from construction on an individual basis.

For construction items that are turned over, the interface is the transfer of responsibility and documentation for the particular item. 
$\underline{8.3 .9}$

$\underline{\mathbf{8 . 3 . 1 0}}$

$\underline{8.3 .11}$

$\underline{8.3 .12}$

$\underline{\mathbf{8 . 3 . 1 3}}$

8.4

$\underline{8.4 .1}$

\section{Radiation Protection}

Interfacing with this functional area is primarily for personnel protection. For most new facility projects no interface will be required.

\section{Fire Protection}

Interfacing with this functional area is primarily for planning, installation and test of temporary and permanent fire protection systems. In all cases the fire protection requirements prescribed by the Fire Protection Program will be implemented by the Construction Program, as applicable.

\section{Research and Development and Experimental Activities}

This Functional Area is not applicable to Tank Farms.

\section{Occupational Safety and Health}

The Construction Program, working with the procurement staff, should implement OSHA through incorporation of appropriate clauses in construction management and construction contracts and, working with the construction inspector, should monitor construction operations to ensure contractor conformance to OSHA. The Construction Program also interfaces with $\mathrm{OS} \& \mathrm{H}$ in the area of personnel training.

Many of the requirements (and standards therein) specified within OS\&H are also applicable to ensure the safety and quality of systems, structures, and components as described in Section 8.2.7.5.

\section{Environmental Protection}

The Construction Program interfaces with this functional area for permitting, licensing and pollution control activities.

\section{REFERENCES}

Documents referenced as requirements in this document are summarized below in Section 8.4.1. Additional documents reviewed, but not included are summarized in Section 8.4.2.

\section{Requirement Source Documents}

The following references have provided requirements used in this document.

10 Code of Federal Regulations Part 830, Nuclear Safety Management, 04/05/94.

DOE Order 1324.2A, Records Disposition, U.S. Department of Energy, Change 1, 04/09/92.

DOE Order 4700.1, Project Management System, U.S. Department of Energy, Change 1, $06 / 02 / 92$.

DOE Order 5700.2D, Cost Estimating, Analysis, and Standardization, U.S. Department of Energy, 06/12/92.

DOE Order 6430.1A, General Design Criteria, U.S. Department of Energy, 04/06/89. 
DOE Notice 4700.5, Project Control System Guidelines, U.S. Department of Energy, 08/21/92.

\section{Reviewed Documents Not Used as Requirement Sources}

Numerous documents were reviewed for applicability and inclusion into this functional area. These were not included because they were higher level requirements that had been integrated into referenced requirements, they were lower level requirements used during implementation, or they were found to be not applicable to this functional area. The documents reviewed are as follows:

29 CFR 1926, Safety and Health Regulation for Construction, Occupational Safety and Health Administration, U.S. Department of Labor, 07/01/93.

ACI SP-4-89, Formwork for Concrete, American Concrete Institute, Fifth Edition, 1989.

AISI WR 120, Wire Rope User's Manual, American Iron and Steel Institute, Second Edition, 1985.

ANSI/ASQC-C1-85, Specification of General Requirements for a Quality Assurance Program, American Society of Quality Control, 1985.

ASME B30 series, "Safety Standards for Cableways, Cranes, Derricks, Hoists, Hooks, Jacks, and Slings", American Society of Mechanical Engineers.

DOE Order 1300.2A, U.S. Department of Energy Technical Standards Program, U.S. Department of Energy, 05/19/92.

DOE Order 1324.5A, Records Management Program, U.S. Department of Energy, 04/30/92.

DOE Order 2030.3, Federalism Guidelines, U.S. Department of Energy, Change 1, 05/14/92.

DOE Order 2200.6A, Financial Accounting, U.S. Department of Energy, Change 1, 04/13/93.

DOE Order 4010.1A, Value Engineering, U.S. Department of Energy, 05/14/92.

DOE Order 4200.1C, Competition in Contracting, U.S. Department of Energy, 01/09/87.

DOE Order 4300.1C, Real Property Management, U.S. Department of Energy, 06/28/92.

DOE Order 4320.1B, Development Planning, U.S. Department of Energy, 01/07/91.

DOE Order 4700.3, General Plant Projects, U.S. Department of Energy, Change 1, 11/16/92.

DOE Notice 4700.6, Extension of DOE N 4700.5, U.S. Department of Energy, 06/07/93.

DOE Order 5480.4, Environmental Protection, Safety, and Health Protection Standards, U.S. Department of Energy, 05/15/84.

DOE Order 5480.6, Safety of Department of Energy-Owned Nuclear Reactors, U.S.

Department of Energy, 09/23/86.

DOE Order 5632.6, Physical Protection of DOE Property and Unclassified Facilities, U.S.

Department of Energy, 02/09/88. 
DOE Order 5700.5A, Policy and Management Procedures for Financial Incentives Programs, U.S. Department of Energy, 06/08/92.

DOE Order 5700.6C, Quality Assurance, U.S. Deparment of Energy, 08/21/91.

DOE Order 5700.7C, Work Authorization System, U.S. Department of Energy, 05/18/92.

DOE/EH-0135, Performance Objectives and Criteria for Technical Safety Appraisals at Department of Energy s, U.S. Department of Energy, 06/90.

DOE/MA-0040, Cost \& Schedule Control Systems Criteria for Contract Performance Measurement Work Breakdown Schedule Guide, U.S. Department of Energy, 10/81.

DOE/MA-0046, Cost Estimating Manual, U.S. Department of Energy, 01/82.

DOE/MA-0063, Volume 1, Cost Guide (Economic Analysis), U.S. Department of Energy, $01 / 82$.

DOE/MA-0063, Volume 2, Cost Guide (Standard Procedures for Determining Revenue Requirements), U.S. Department of Energy, 06/82.

DOE/MA-0063, Volume 3, Cost Guide (Cost Factors), U.S. Department of Energy, 04/82.

DOE/MA-0063, Volume 4, Cost Guide (Cost Data and Cost Estimating Relationships--CER), U.S. Department of Energy, 05/82.

DOE/MA-0063, Volume 5, Cost Guide (Construction of Economic Escalation Indices), U.S. Department of Energy, 05/82.

DOE/MA-0154, Acquisition Regulators Handbook - Source Evaluation, U.S. Department of Energy, 02/86.

DOE/MA-0295, Work Breakdown Structure Guide, U.S. Department of Energy, 02/06/87.

FAR Part 48, Value Engineering, 04/01/84.

FAR Part 52.248, Value Engineering - Construction, 03/89.

Hanford Federal Facilities Agreement and Consent Order (Tri-Party Agreement), U.S. Department of Energy, Washington Department of Ecology, U.S. Environmental Protection Agency, 03/01/94.

ASME-NQA-1-1994, Quality Assurance Program Requirements for Nuclear Facilities, American Society of Mechanical Engineers, 07/24/94.

BMP 85-031, Guidelines for the Conduct of Technical Support Activities at Nuclear Power Stations, Institute of Nuclear Power Operations, Revision 2, 03/92.

BMP 86-023, Guidelines for Nuclear Power Plant Construction Projects, Institute of Nuclear Power Operations, 10/86.

NFPA 204M, Smoke and Heat Venting, National Fire Protection Association, 1991.

NFPA 241, Safeguarding Construction, Alteration, and Demolition Operations, National Fire Protection Association, 1993. 
OMB Circular A-34, Instructions on Budget Execution, .

OMB Circular A-109, Major System Acquisitions, 04/05/76.

OMB A-119, Use of Voluntary Standards, 01/17/80.

P.L. 95-507, Small Business Investment Act of 1977.

DOE-RL Order 4330.1, Maintenance of Property, U.S. Department of Energy, Richland, Change 1, 01/25/88.

RLIP 4330.4, Automotive and Construction Equipment Maintenance Management, U.S. Department of Energy, Richland, 04/23/93.

RLID 5700.3, Project Cost Estimating, Analysis, and Standardization, U.S. Department of Energy, Richland, 04/25/94.

RLIP 4700.1A, Project Management System, U.S. Department of Energy, Richland, Change $3,02 / 16 / 93$.

RLIPP 4010.1, Value Engineering, U.S. Department of Energy, Richland, 11/20/90.

WAC 296-24, General Safety and Health Standards, Washington Department of Labor and Industries, 12/31/92.

WAC 296-155, Construction Safety, Washington Department of Labor and Industries, $12 / 31 / 92$ 


\section{TABLE OF CONTENTS}

9.1 .1

9.1 .2

9.1 .3

9.1 .4

9.2

9.2 .2

9.3

9.3.1

9.3 .2

9.3 .3

9.3.4

9.3.5

9.4

\section{REFERENCES}

Requirement Source Documents
Conduct of Operations $\ldots \ldots \ldots \ldots \ldots \ldots$

Operating Performance $\ldots \ldots \ldots \ldots \ldots \ldots$

Dissemination of Operating Documents ............. 3

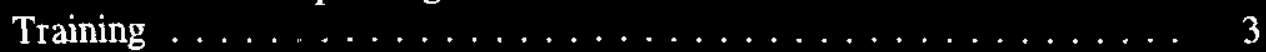

TECHNICAL BASES FOR OPERATION $\ldots \ldots \ldots \ldots \ldots$

Operational Basis Documents $\ldots \ldots \ldots \ldots \ldots \ldots$

Abnormal Events $\ldots \ldots \ldots \ldots \ldots \ldots$

OPERATIONAL PROCEDURES $\ldots \ldots \ldots \ldots \ldots \ldots$

Operating Procedures $\ldots \ldots \ldots \ldots \ldots$

Emergency Procedures $\ldots \ldots \ldots \ldots \ldots$

Operational Readiness $\ldots \ldots \ldots \ldots \ldots$

Safety Practices ........................ 4

Sensitive System Identification $\ldots \ldots \ldots \ldots \ldots$

OPERATIONAL RECORDS $\ldots \ldots \ldots \ldots \ldots \ldots \ldots \ldots \ldots$

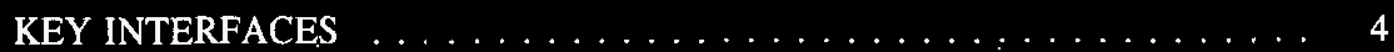

Management Systems $\ldots \ldots \ldots \ldots \ldots \ldots \ldots$

Quality Assurance . . . . . . . . . . . . . . . . 4

Configuration Management $\ldots \ldots \ldots \ldots \ldots$

Training and Qualification $\ldots \ldots \ldots \ldots \ldots \ldots$

Emergency Management $\ldots \ldots \ldots \ldots \ldots \ldots$

Engineering Program $\ldots \ldots \ldots \ldots \ldots \ldots$

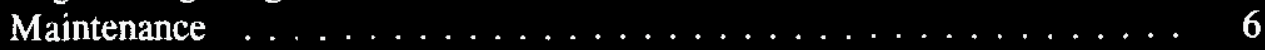

Radiation Protection . . . . . . . . . . . . . . . . 6

Research and Development and Experimental Activities . . . . . . . 6

Nuclear Safety . . . . . . . . . . . . . . . . . 6

Occupational Safety and Health . . . . . . . . . . . . 7

Environmental Protection $\ldots \ldots \ldots \ldots \ldots \ldots$

Fire Protection $\ldots \ldots \ldots \ldots \ldots \ldots$

Safeguards and Security $\ldots \ldots \ldots \ldots \ldots$

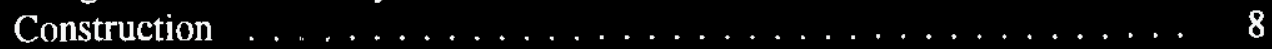

Packaging and Transportation $\ldots \ldots \ldots \ldots \ldots$

Reviewed Documents Not Used as Requirement Sources . . . . . . . . . . 8 


\subsection{OPERATIONS}

\section{INTRODUCTION}

This Standards/Requirements Identification Document (S/RID) sets forth the Environmental Safety and Health (ES\&H) standards/requirements. This S/RID is applicable to the appropriate life cycle phases of design, construction, operation, and decommissioning for each of the categories of facilities addressed in Revision 5 of the Department of Energy Implementation Plan for Defense Nuclear Facilities Safety Board (DNFSB) Recommendation 90-2. This Recommendation calls for the strengthening of DOE weapons complex activities through the identification and application of relevant DOE Orders, regulations, industry codes/standards, industry guidance documents and, as appropriate, good industry practices. These standards/requirements are adequate to ensure protection of the health and safety of workers, the public, and the environment.

The Tank Farms S/RID, as defined in Revision 5 of the Department of Energy Implementation Plan for DNFSB Recommendation 90-2, contains standards/requirements that are necessary for safe operation of the Tank Farms and its associated facilities, and that are the direct responsibility of the specific facility manager.

The Operations Program defined in this document is described in general accordance with the Environment, Safety, and Health Configuration Guide, Revision 0, dated July 30, 1993, and is presented in program elements and subelements. The specific DOE Orders, regulations, industry codes/standards, guidance documents and good industry practices that serve as the basis for each element/subelement are identified and aligned with each subelement.

Requirements for the development, review, approval, and use of procedures (subelement 9.3.1 and 9.3.2) are identified in the Training and Procedures S/RID. Additional interface definition was included in subelement 9.5 for Fire Protection (9.5.13), Safeguards and Security (9.5.14), Construction (9.5.15), and Packaging and Transportation (9.5.16).

This S/RID contains only those requirements that Tank Farms personnel are clearly responsible to satisfy. Other requirements that are applicable to Tank Farms, but are satisfied by others, are defined in the WHC Site S/RID. For application in this S/RID, the words "shall" and "should" in requirement statement both indicate mandatory compliance. The key interface information contained in the Functional Area documents is provided for general recognition and understanding and is not considered to contain prescriptive requirements. Additionally, some of the requirements cited in this document are intentionally duplicated in the corresponding WHC S/RID. This was necessary to address required implementation responsibilities occurring at both the company and facility levels.

\section{SCOPE}

This S/RID applies to the Tank Waste Remediation Systems (TWRS) Organization in its entirety which includes the following:

r East Tank Farm Transition Project

r West Tank Farm Transition Project 
- Evaporator Project

- Interim Stabilization Project

- Characterization Sampling Project (Excluding the Labs)

The near-term mission of TWRS is to store, treat, and immobilize the highly radioactive Hanford Site Waste. 
9.1

9.1.1

9.1 .2

9.1 .3

$\underline{9.1 .4}$

9.2

9.2 .1

\section{$\underline{9.2 .2}$}

9.3

9.3.1

$\underline{9.3 .2}$

\section{$\underline{9.3 .3}$}

\section{MANAGEMENT}

\section{Conduct of Operations}

Requirements for this subelement are identified in the Tank Farms Transition Projects Conduct of Operations Applicability Matrix.

\section{Operating Performance}

Requirements for this subelement are identified in the Tank Farms Transition Projects Conduct of Operations Applicability Matrix in chapter 2.

\section{Dissemination of Operating Documents}

Requirements for this subelement are identified in the Tank Farms Transition Projects Conduct of Operations Applicability Matrix in chapters 8, 14, and 15.

\section{Training}

Requirements for this subelement are identified in the Tank Farms Transition Projects Conduct of Operations Applicability Matrix in chapter 5 and the Training and Qualification S/RID.

\section{TECHNICAL BASES FOR OPERATION}

\section{Operational Basis Documents}

Requirements for this subelement are identified in the Tank Farms Transition Projects Conduct of Operations Applicability Matrix in chapter 8.

\section{Abnormal Events}

Requirements for this subelement are identified in the Tank Farms Transition Projects Conduct of Operations Applicability Matrix in chapter 4.

\section{OPERATIONAL PROCEDURES}

\section{Operating Procedures}

Requirements for this subelement are identified in the Tank Farms Transition Projects Conduct of Operations Applicability Matrix in chapter 16.

\section{Emergency Procedures}

Requirements for this subelement are identified in the Tank Farms Transition Projects Conduct of Operations Applicability Matrix in chapter 16.

\section{Operational Readiness}

Requirements for this subelement are identified in the Tank Farms Transition Projects Conduct of Operations Applicability Matrix in chapters 8, and 10. 
2.3.4

$\underline{9.3 .5}$

9.4

9.5

$\underline{9.5 .1}$

9.5.2

\section{Safety Practices}

Requirements for this subelement are identified in the Tank Farms Transition Projects Conduct of Operations Applicability Matrix in chapters 1, 2, and 9.

\section{Sensitive Svstem Identification}

Requirements for this subelement are identified in the Tank Farms Transition Projects Conduct of Operations Applicability Matrix in chapter 13, and 18.

\section{OPERATIONAL RECORDS}

Requirements for this subelement are identified in the Tank Farms Transition Projects Conduct of Operations Applicability Matrix in chapter 11.

\section{KEY INTERFACES}

Because of the unique nature of operations, interfaces exist to some extent with each of the other Functional Areas. The proper management of these interfaces is critical to the success of Operations. The interfaces identified should be verified to have been adequately addressed.

\section{Management Systems}

Management Systems interface with Operations to provide the administrative programs and procedures that control the following:

- Policies and their related administrative procedures to provide the framework for promulgation of site and facility management controls.

- Operating and emergency procedures to ensure consistency in format content and use at all facilities.

- Operational records retention and storage requirements to incorporate federal, state, and company regulations for the types of records maintained.

- Occurrence investigation and reporting procedures to include DOE, state, and company requirements for identification, reporting, and investigating events.

- Goals and operating performance expected.

- Operational Readiness Review Program to include requirements for readiness reviews of systems, components, and processes

- Human and material resources programs to include requirements for position descriptions, periodic performance reviews, disciplinary procedures, and fitness for duty policies.

\section{Quality Assurance}

Quality Assurance interfaces with Operations to:

- Provide the requirements to be applied to activities that are important to quality as described in the Operations Quality Assurance Plan. 
- Perform independent audits and surveillance of Operations activities, including Quality Control inspections.

\section{Configuration Management}

Configuration management interfaces with Operations to:

- Define, maintain, and distribute drawings and vendor material required to operate the facilities within ES\&H guidelines.

- Establish a change control process to ensure normal and emergency procedures are maintained to current configuration and requirements.

- Provide verification and control of vendor related material required for Operations.

- Maintain and distribute safety analysis, including technical specifications and/or operational safety requirements.

\section{Training and Qualification}

Training and Qualification interfaces with Operations to:

- Establish the procedures and qualification requirements that control the training and/or selection of operations personnel.

- Develop and implement the training curricula and programs for Operations.

- Conduct management and supervisory training.

- Conduct personnel protection and safety training, including independent verification and lockout/tagout.

- Provide for a Systematic Approach to Training to ensure the training programs adequately prepare operations personnel to perform their assigned tasks.

\subsubsection{Emergency Management}

Emergency Management interfaces with Operations to:

- Develop the facility Emergency Plans.

- Develop emergency response procedures for Operations.

- Participate in emergency drills as part of team training.

- Ensure communications systems are adequate.

\subsubsection{Engineering Program}

Engineering interfaces with Operations to:

- Provide safety analysis, technical requirements, limiting conditions for operations, and operational safety requirements to define the safety envelope. 
- Ensure modifications are accomplished within an approved Change Control Program that provides for an Operational Readiness Review if required, as-built drawings and procedures, and approved vendor material.

- $\quad$ Provide direct day-to-day Engineering support.

\section{Maintenance}

Maintenance interfaces with Operations to:

- Provide a priority system for maintenance response to equipment problems affecting operations.

- Provide operations input to maintenance tasks to ensure personnel are aware of potential hazards.

- Obtain access to equipment in accordance with maintenance schedules.

- Ensure equipment Lockout/Tagout as required to protect the health and safety of workers.

- Provide post maintenance tests requirements.

\section{Radiation Protection}

Radiation Protection interfaces with Operations to:

- Develop and implement programs and procedures for monitoring the radiation levels in the work place and in facility effluents.

- Develop and implement the operational procedures necessary to protect Operations personnel and the environment from exposure and uncontrolled releases.

- Define responsibility of Operations personnel to implement elements of the Radiation Protection Program, e.g., placement of step-off pads, conduct surveys, etc.

- Establish qualification or training requirements for operators conducting radiation program activities.

\section{Research and Development and Experimental Activities}

Presently, no interface needs exist with Operations.

\section{$\underline{9.5 .10}$}

\section{Nuclear Safety}

Nuclear Safety interfaces with Operations to:

- Ensure Operations are conducted within the prescribed safety envelope through an established Unreviewed Safety Question Program applied to evolutions and procedure changes.

- Ensure appropriate nuclear safety requirements are incorporated into operating documents. 


\section{Fire Protection}

Fire Protection interfaces with Operations to:

- Establish the requirements for surveillance of fire protection equipment, such as fire extinguishers.

- Establish the requirements for fire prevention activities, such as proper storage and handling of flammable materials.

- Test emergency communication systems.

- Establish requirements for qualification and training of operations personnel for activities assigned under the Fire Protection Functional Area.

\section{5 .14}

\section{Safequards and Security}

Safeguards and Security interfaces with Operations to:

- Determine operations specific responsibility for Safeguards and Security.

- Establish qualification and training requirements to carry out assigned responsibility. 
9.5.15

9.5 .16

9.6

9.6.1

\section{$\underline{9.6 .2}$}

\section{Construction}

Construction interfaces with Operations to:

$\uparrow \quad$ Establish procedures for testing and turnover of facilities and equipment

\section{Packaging and Transportation}

- Define responsibility of Operations personnel to implement elements of the Packaging and Transportation Program.

- Establish qualification or training requirements for operators conducting program activities.

\section{REFERENCES}

\section{Requirement Source Documents}

The following documents were used as requirements sources in the development of this S/RID: 29CFR1910, Code of Federal Regulations, Occupational Safety and Health Standards, May 1994.

49CFR172, Hazardous Materials Table, Special Provisions, Hazardous Material Communications Requirements and Emergency Response Information Requirements, 10/1/92.

ANSI/ANS-8.19-1984, Administrative Practices for Nuclear Criticality Safety, 10/1/84.

DOE 5480.19, Conduct Of Operations Requirements for DOE Facilities, Chg 1, 5/18/92.

WAC 173-303-340, Department of Ecology, 1993.

\section{Reviewed Documents Not Used as Requirement Sources}

The following documents were reviewed as requirement sources but were not used in the development of this S/RID. These documents were not used because the requirements contained in DOE Order 5480.19, "Conduct of Operations Requirements for DOE Facilities," are more prescriptive.

DOE 5480.20A, Personnel Selection, Qualification, and Training Requirements for DOE Nuclear Facilities, 11/15/94.

DOE 5480.24, Nuclear Criticality Safety, 8/12/92.

DOE-STD-1030-92, Guide to Good Practices for Lockouts and Tagouts.

DOE-STD-1031-92, Guide to Good Practices for Communications.

DOE-STD-1032-92, Guide to Good Practices for Operations Organization and Administration, December 1992.

DOE-STD-1033-92, Guide to Good Practices for Operations and Administration Updates Through Required Reading, December 1992. 
DOE-STD-1034-93, Guide to Good Practices for Timely Orders to Operators, March 1993.

DOE-STD-1035-93, Guide to Good Practices for Logkeeping, March 1993.

DOE-STD-1036-93, Guide to Good Practices for Independent Verification, June 1993.

DOE-STD-1037-93, Guide to Good Practices for Operations Aspects of Unique Processes, June 1993.

DOE-STD-1038-93, Guide to Good Practices for Operations Turnover, June 1993.

DOE-STD-1039-93, Guide to Good Practices for Control of Equipment and System Status, March 1993.

DOE-STD-1040-93, Guide to Good Practices for Control of On-Shift-Training.

DOE-STD-1041-93, Guide to Good Practices for Shift Routines and Operating Practices, June 1993.

DOE-STD-1042-93, Guide to Good Practices for Control Area Activities, June 1993.

DOE-STD-1043-93, Guide to Good Practices for Operator Aids Postings, June 1993.

DOE-STD-1044-93, Guide to Good Practices for Equipment and Piping Labeling.

DOE-STD-1045-93, Guide to Good Practices for Notifications and Identification of Abnormal Events.

ANSI/ANS-8.1-1983, Nuclear Criticality Safety with Fissionable Materials Outside Reactors, $10 / 7 / 83$.

ANSI/ANS-8.20-1991, Nuclear Criticality Safety Training. 


\section{TABLE OF CONTENTS}

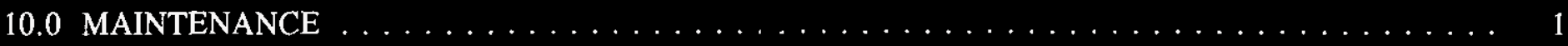

10.1

10.2

10.2 .1

10.2 .2

10.2 .3

10.2 .4

10.2 .5

10.2 .6

10.2 .7

10.3

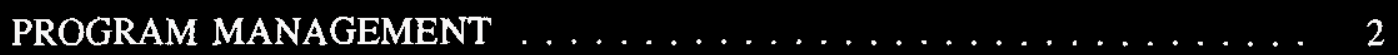

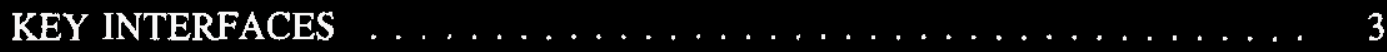

Configuration Management $\ldots \ldots \ldots \ldots \ldots \ldots$

Engineering Program $\ldots \ldots \ldots \ldots \ldots \ldots \ldots \ldots \ldots \ldots \ldots \ldots$

Operations . . . . . . . . . . . . . . . . . 4

Quality Assurance . . . . . . . . . . . . . . . . . 4

Radiation Protection . . . . . . . . . . . . . . . 4

Training and Qualification ................ 5

Occupational, Health and Safety $\ldots \ldots \ldots \ldots \ldots$

10.3.1 Requirement Source Documents $\ldots \ldots \ldots \ldots \ldots$

10.3.2 Reviewed Documents Not Used as Requirement Sources . . . . . . . . 6 


\subsection{MAINTENANCE}

\section{INTRODUCTION}

A Standards/Requirements Identification Document (S/RID) sets forth the Environmental Safety and Health (ES\&H) standards/requirements. This S/RID is applicable to the appropriate life cycle phases of design, construction, operation, and preparation for decommissioning for each of the categories of facilities addressed in Revision 5 of the Department of Energy Implementation Plan for the Defense Nuclear Facilities Safety Board (DNFSB) Recommendation 90-2. This Recommendation calls for the strengthening of DOE weapons complex activities through the identification and application of relevant DOE Orders, regulations, industry codes/standards, industry guidance documents and, as appropriate, good industry practices. These standards/requirements are adequate to ensure protection of the health and safety of workers, the public, and the environment.

The Tank Farms S/RID contains standards/requirements that are necessary for safe operation of the Tank Farms and its associated facilities, and that are the direct responsibility of the specific facility manager. The Tank Farms Maintenance Implementation Plan (MIP) defines the maintenance program as described in the Environment, Safety, and Health Configuration Guide, Revision 0, dated July 30, 1993.

This S/RID contains only those requirements that Tank Farms personnel are clearly responsible to satisfy. Other requirements that are applicable to Tank Farms, but are satisfied by others, are defined in the Westinghouse Hanford Company (WHC) Level S/RID. For application in this S/RID, the words "shall and "should" in requirements statements both indicate mandatory compliance. The Key interface information contained in the Functional Area documents is provided for general recognition and understanding and is not considered to contain prescriptive requirements.

\section{SCOPE}

This S/RID applies to the Tank Waste Remediation Systems (TWRS) Organization which includes the following:

\section{- $\quad$ East Tank Farm Transition Project}

- West Tank Farm Transition Project

- Evaporator Project

- Interim Stabilization Project

$\neg \quad$ Characterization Sampling Project (Excluding the Labs)

The near-term of TWRS is to store, treat, and immobilize the highly radioactive Hanford Site Waste. 


\section{REQUIREMENT SOURCE: DOE4330.4B Preamble, Section 10.a}

"Each DOE contractor in coordination with the appropriate field element shall develop, implement, and document a program in conformance with the policy and objectives of this Order in a Site Maintenance Plan (SMP) and/or a Maintenance Implementation Plan. An approved Maintenance Implementation Plan and the Program Implementation and Baseline Activities part of the SMP constitute agreements between the field element and the contractor on the implementation of the requirements of this Order. The program shall clearly define:

(1) The structures, systems, and components included, using a graded approach and the requirements derived from Technical Safety Requirements.

(2) The management systems used to control maintenance activities, including the means for monitoring and measuring the effectiveness of the program and the management of maintenance backlog.

(3) The assignment of responsibilities and authority for all levels of the maintenance organization.

(4) Mechanisms for feedback of relevant information, such as trend analysis and instrumentation performance/reliability data, to identify necessary program modifications.

(5) Provisions for identification, evaluation, and correction of possible component, system design, quality assurance, or other relevant problems.

(6) Performance indicators and criteria to be utilized to measure equipment, systems, and personnel effectiveness in maintenance activities.

(7) Interfaces between maintenance and other organizations (i.e., operations, engineering, quality, training, environment, safety, and health).

(8) A self-assessment program to monitor the effectiveness and efficiency of the maintenance program.

(9) Provisions for planning, scheduling, and coordination of maintenance activities."

\section{REQUIREMENT SOURCE: DOE4330.4B Preamble, Section 10.b, Sentence 1}

"Periodic inspections of structures, systems, components, and equipment, particularly those important to the safe and reliable operation of a facility, shall be performed to determine whether deterioration is taking place and to identify and address technical obsolescence that threatens performance, safety, or facility preservation."

\section{REQUIREMIENT SOURCE: DOE4330.4B Preamble, Section 10.d, Sentence 1}

"For DOE nuclear facilities, a graded approach shall be used to determine the depth of detail required and magnitude of resources expended for each maintenance program element described in Chapter II."

\section{REQUIREMIENT SOURCE: DOE4330.4B Preamble, Section 10.d, Sentence 3}

"For each DOE nuclear facility, the maintenance program shall be described in a Maintenance Implementation Plan, which addresses the 18 elements (excluding the introduction) in the sequence and format of Chapter II." 


\section{REQUIREMENT SOURCE: DOE4330.4B Preamble, Section 10.d, Sentence 5}

"For those DOE nuclear facilities where deviations from the maintenance program elements are considered necessary and appropriate (or not applicable), such deviations (or nonapplicable elements) shall be identified in the Maintenance Implementation Plan with supporting rationale."

\section{REQUIREMENT SOURCE: DOE4330.4B Preamble, Section 10.e}

"Maintenance Implementation Plans for nuclear facilities shall be submitted to the Managers of field elements for approval. For new nuclear facilities, Maintenance Implementation Plans shall be submitted 90 days prior to startup. Changes to Maintenance Implementation Plans shall be submitted and approved prior to implementation."

\section{REQUIREMENT SOURCE: DOE4330.4B Chapter II, Paragraph 8, Sentence 2 and 3}

Author's Note: The Tank Farms MIP addresses the objectives identified in Chapter 2 of DOE 4330.4B.

"The Introduction subsection briefly describes the objective to be achieved. Addressing each of the objectives is a requirement for an adequate maintenance program."

10.2

$\underline{10.2 .1}$

$\underline{10.2 .2}$

\section{KEY INTERFACES}

\section{Configuration Management}

Configuration Management ensures that safety-related drawings, flow control diagrams, electrical one-lines, I\&C schematics, etc., of critical structures, systems and components are controlled and reflect the current approved configuration/operational status. Maintenance should ensure that any activities that change the design of the facility are treated as design changes and are implemented using applicable design control and configuration management guidelines. Maintenance work request should be periodically reviewed to ensure that they are not used to implement facility design and configuration changes.

The requirements documents effecting configuration control are identified in the Engineering Functional Area of this S/RID.

\section{Engineering Program}

Engineering provides the basis for maintenance of the facility through the issuance of equipment design/purchase specifications, drawings, change control documents and operational limits. Specific maintenance related guidance, recommended spare parts lists and preventive maintenance criteria are typically provided by equipment vendors. The design output and vendor supplied information and subsequently used to develop the facility specific maintenance, inspection, surveillance and testing procedures.

Maintenance and Engineering have a critical interface on Post-Maintenance testing. Equipment testing requirements are normally issued as part of the original facility basis and subsequently modification work control packages. Feedback must be provided to Engineering on the adequacy of inadequacy of testing requirements. Maintenance must also have a continuous interface with Engineering and technical support functions in determining the cause of repetitive equipment failures and to investigate the root cause of unplanned events.

Requirements documents not covered by this Functional Area are addressed in the Engineering Functional Area of this S/RID. 


\section{Operations}

All Maintenance activities on equipment that is important to safety, that affects operation or that changes control indications or alarms must be authorized by Operations. This authorization should be in writing on the document controlling the work. Maintenance is responsible for ensuring that documentation on the status of work in progress is available in the control area for review by Operations personnel.

Operations interface with Maintenance on Post-Maintenance and Post-Modification testing is also an important link to safe operation of the facility. Testing by maintenance personnel should include performance of all functions that may have been affected by the work. The testing should also verify the maintenance or modification performed served to correct the original problem and that no new problems were introduced. Any testing following maintenance should be specified on the maintenance work order other work authorizing document. The Operations supervisor ensures that testing appropriately proves equipment operability.

Interface actions not directly addressed in the Maintenance Functional Area are addressed in the Operations Functional Area of the S/RID.

\section{$\underline{10.2 .4}$}

\section{Ouality Assurance}

The Maintenance Organization is responsible for establishing and implementing a process to detect and prevent quality problems and to ensure quality improvement. Data on equipment reliability and performance, maintenance work process, personnel training and qualifications should be reviewed and analyzed to identify items and processes needing improvement. The elements of this quality improvement process are used as input to the facility QAP so that a method exists for providing continuous feedback on potential areas of improvement.

The Maintenance organization will also closely interface with Quality Assurance on procurement, inspection and testing to ensure that approved suppliers continue to provide acceptable parts and services, that processes are conducted using established acceptance and performance criteria and that equipment used for inspections and tests are properly calibrated and maintained. These interfaces should be defined in policy and facility level guidelines and procedures that control these activities.

\subsubsection{Radiation Protection}

The Radiation Protection Functional Area provides input into the Work Control portion of the Maintenance Functional Area regarding the requirements necessary to perform the maintenance task ALARA. The Maintenance Functional Area should establish controls to ensure that maintenance planning and the maintenance craft are integrated with the Radiation Protection activity to ensure that the maintenance task can be performed as planned and within the ALARA guidelines.

The primary personnel safety concerns affecting Maintenance activities are to ensure that radiation exposure levels are maintained in accordance with ALARA criteria. Maintenance interfaces with the Radiation Protection functional areas through the use of Radiation Work Permits and facility specific Radiation Protection training. Both of these areas incorporate ALARA criteria and guidelines but require feedback from Maintenance in order to be effective. Maintenance should interface with the Health Physics organization during facility condition inspections to assist in determining levels of radiation and determining areas and levels of surface and airborne contamination. Health Physics provides supporting services to Maintenance organization by measuring radiation exposures, incorporating ALARA criteria into work control documents and processes, and by specifying temporary shielding, protective clothing and respiratory protection required for maintenance activities in controlled areas. 
The Maintenance manager is responsible and accountable for determining the training and qualification needs of each individual in the maintenance organization. The Maintenance manager and supervisors should closely interface with the Training organization to establish and maintain course content, determine and support training schedules, accomplish on-the-job training (OJT) and provide feedback to adjust course content and emphasis. The Maintenance manager is also responsible for developing and maintaining appropriate personnel job descriptions.

The Training organization maintains existing programs, develops new training programs and presents the training using in-house personnel or vendor supplied personnel when appropriate. The Training organization should maintain maintenance training programs that meet the intent of established industrial guidelines and address specific facility needs. These training programs should be supported and guided by the Maintenance organization via periodic reviews. The Training organization is also responsible for developing and implementing performance-based training.

\section{Occupational, Health and Safety}

The Maintenance organization interfaces with the Occupational Health and Safety (OSHA) functional areas by using and following industry accepted guidelines and practices covering a wide spectrum of personnel and equipment $\backslash$ safety issues. These interfaces should be defined in the policy and facility level guidance and procedures that control the safety issues.

A shared responsibility exists between the Maintenance and Safety organizations to insure that work documents and activities are developed and conducted in accordance with OSHA criteria and guidelines. The areas that most affect the conduct of Maintenance are as follows:

1. Toxic and Hazardous Materials

2. Personal Protection Equipment

3. Materials Handling and Storage

4. Hand Held Equipment and Tools

5. Welding and Brazing

6. Hoisting and Rigging

7. Carcinogen Control

8. Medical and First Aid

9. Confined Space Entry

10. Powered Platforms and Lifts

11. Electrical Safety

12. Health and Safety Training

\section{REFERENCES}

\section{Requirement Source Documents}

In the S/RID development process several documents were reviewed (see the documents listed in Section 10.14.2). In the course of this review it was determined the DOE Order 4330.4B, "Maintenance Management Program" dated February 10, 1994, contained the necessary and sufficient requirements for the Maintenance Programs at Hanford Site. This document is current and is familiar to DOE facility personnel. Therefore this DOE Order has been used as the source of requirements for the Tank Farms Maintenance S/RID. Specific references to other standards and requirements are referenced in the Functional Area document that has primary responsibility for implementation. 


\section{Reviewed Documents Not Used as Requirement Sources}

The following documents were reviewed during the development of this S/RID. It was determined that DOE $4330.4 \mathrm{~B}$ referenced in Section 10.14.1 adequately addressed the maintenance issues and that the documents listed below didn't offer any significant additional coverage of maintenance requirements. These documents do offer additional insights and guidance for implementation. DOE Order 5480.20A provides the qualification requirements for Maintenance Personnel. These requirements have been addressed in the Operations S/RID and have not been duplicated in this S/RID.

10 CFR 830.120, Quality Assurance, 5/4/94

29 CFR 1910, OSHA, General Industry

29 CFR 1926, OSHA, Construction

WAC 173-303, Dangerous Waste Regulations

DOE 5480.20A, Personnel Selection, Qualification, Training, and Staffing Requirements at DOE Nuclear Facilities, 11/15/94.

DOE 5483.1A, Occupational Safety and Health Program, 6/22/83

DOE 6430.1A, Design Criteria, 4/6/89

BMP 83-025, MA-308 Unscheduled Outage Planning, 6/84.

BMP 85-032, Rev. 01, MA-30, Preventive Maintenance, 12/88.

BMP 90-008, Maintenance Programs in the Nuclear Power Industry, 3/90.

BMP 92-001, Guidelines for the Conduct of Maintenance at Nuclear Power Stations, 4/92.

BMP TQ-501, Development and Implementation of On-The-Job Training Programs, 10/82.

DOE-STD-1050-93, Guidelines to Good Practices for Planning, Scheduling, and Control of Maintenance at DOE Nuclear Facilities, $3 / 93$.

DOE-STD-1051-93, Guidelines to Good Practices for Maintenance Organization and Administration at DOE Nuclear Facilities, 3/93.

DOE-STD-1052-93, Guidelines to Good Practices for Types of Maintenance at DOE Nuclear Facilities, $3 / 93$.

DOE-STD-1053-93, Guidelines to Good Practices for the Control of Maintenance Activities at DOE Nuclear Facilities, $3 / 93$.

DOE-STD-1054-93, Guidelines to Good Practices for the Control and Calibration of Measurement and Test Equipment (M\&TE) at DOE Nuclear Facilities, $3 / 93$.

DOE-STD-1055-93, Guidelines to Good Practices for Maintenance Management Involvement at DOE Nuclear Facilities, 3/93.

DOE-RL-92-36, Hanford Site Hoisting and Rigging Manual, 1/93. 


\section{TABLE OF CONTENTS}

11.0 RADIATION PROTECTION

11.1.1.1

11.1.1.2

11.1.1.3

11.1.1.4

11.1 .1 .5

11.1.1.6

11.1 .2

11.1 .3

11.1 .4

11.1 .5

11.1.6

11.1.7

11.1.7.1

11.1 .7 .2

11.1.7.3
Exposure Controls . . . . . . . . . . . . . . . . 4

Radiological Work Planning $\ldots \ldots \ldots \ldots \ldots$

ALARA Reviews $\ldots \ldots \ldots \ldots \ldots \ldots \ldots \ldots$

ALARA Performance and Training Requirements $\ldots \ldots \ldots$

ALARA Committee and Staffing . . . . . . . . . . 8

Dose Tracking and Trending $\ldots \ldots \ldots \ldots$ g

Radiation Protection Training $\ldots \ldots \ldots \ldots . \ldots \ldots$

RP Selection and Qualification $\ldots \ldots \ldots \ldots$

Radiological Program Performance Goals . . . . . . . . . . . . . 9

Program Policy and Procedures $\ldots \ldots \ldots \ldots$

Policy for Response to Abnormal Situations . . . . . . . . . . . . 10

Records Management . . . . . . . . . . . . . . . 11

Survey Records/Radiological Work Control Records . . . . . . . . 12

ALARA Review/Program Records . . . . . . . . . . . . . 13

Miscellaneous Radiation Protection Records . . . . . . . . . 14
11.2 .1

11.2 .2

11.2 .3

11.2 .4

11.4 .1 .1

11.4.1.2
Radiation Monitors, Alarms and Surveys . . . . . . . . . . . . . . . . 14

Airborne Radioactivity Monitors, Alarms and Surveys . . . . . . . . 15

Contamination Monitoring and Surveys . . . . . . . . . . . . 15

Dose Rate Surveys $\ldots \ldots \ldots \ldots \ldots$

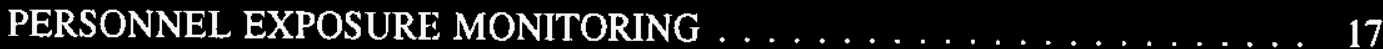

Personnel Exposure Monitoring $\ldots \ldots \ldots \ldots \ldots$

Exposure Limits $\ldots \ldots \ldots \ldots \ldots \ldots$

Dosimetry Program $\ldots \ldots \ldots \ldots \ldots$

Calculation Methods/Models $\ldots \ldots \ldots \ldots 21$

RADIATION AREA ACCESS CONTROL . . . . . . . . . . . . . . 21

Access Restrictions and Posting $\ldots \ldots \ldots \ldots \ldots \ldots \ldots \ldots \ldots$

Access Restrictions $\ldots \ldots \ldots \ldots \ldots \ldots \ldots \ldots \ldots \ldots \ldots$

Posting ....................... 24

Radiation Work Permits $\ldots \ldots \ldots \ldots \ldots$

RADIOACTIVE MATERIALS MANAGEMENT $\ldots \ldots \ldots \ldots \ldots \ldots$ 
11.5 .1

11.5 .2

11.5 .3

11.5 .4

11.6

11.6 .1

11.6.1.1

11.6.1.2

11.6.1.3

11.6.2

11.6 .3

11.6 .4

11.8.1

11.8 .2

11.8 .3

11.8 .4

11.10.1

11.10 .2

11.10 .3

11.10 .4

11.10 .5

11.10 .6

11.10.7

11.10 .8

11.10 .9

11.10 .10

11.10 .11

11.10 .12

11.10 .13

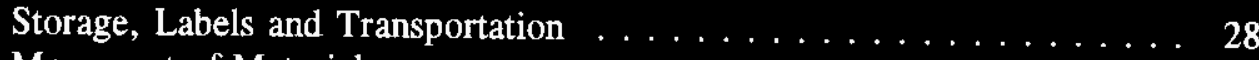

Movement of Material . . . . . . . . . . . . . . . . . . . . . 29

Specific Nuclide Control . . . . . . . . . . . . . . . . . 32

Sealed Source Management $\ldots \ldots \ldots \ldots \ldots \ldots \ldots \ldots \ldots . \ldots . \ldots$

CONTAMINATION CONTROL $\ldots \ldots \ldots \ldots \ldots \ldots \ldots \ldots \ldots, \ldots \ldots$

Personnel, Equipment and Area Contamination Control . . . . . . . . . 34

Personnel Contamination Monitoring $\ldots \ldots \ldots \ldots \ldots$. . . . 34

Personnel Contamination Control . . . . . . . . . . . . . . 35

Equipment and Area Contamination Control . . . . . . . . . 36

Personnel, Equipment and Area Decontamination . . . . . . . . . . . 39

Respiratory Protection Program . . . . . . . . . . . . . . . . 40

Source Containment, Confinement, and Ventilation Control . . . . . . 40

LABORATORY ANALYSIS $\ldots \ldots \ldots \ldots \ldots \ldots \ldots \ldots \ldots \ldots$

RADIOLOGICAL PROTECTION EQUIPMENT AND SUPPLIES $\ldots \ldots \ldots 41$

Monitoring and Survey Instrumentation . . . . . . . . . . . . . 41

Respiratory Equipment and Supplies . . . . . . . . . . . . . . . . . 41

Protective Clothing $\ldots \ldots \ldots \ldots \ldots \ldots \ldots \ldots \ldots \ldots \ldots$

Equipment Maintenance and Calibration $\ldots \ldots \ldots \ldots \ldots \ldots \ldots 42$

RADIATION PROTECTION OF THE PUBLIC AND ENVIRONMENT $\ldots \ldots 43$

Dose Limits . . . . . . . . . . . . . . . . . . . . . 43

Liquid Waste Discharges . . . . . . . . . . . . . . . . . 43

Solid Waste Disposal . . . . . . . . . . . . . . . . . . 43

Demonstration of Compliance . . . . . . . . . . . . . 43

KEY INTERFACES $\ldots \ldots \ldots \ldots \ldots \ldots \ldots \ldots \ldots \ldots \ldots$

Management Systems . . . . . . . . . . . . . . . . . 44

Quality Assurance . . . . . . . . . . . . . . . . . . . . 44

Configuration Management $\ldots \ldots \ldots \ldots \ldots \ldots \ldots \ldots \ldots . \ldots . \ldots 44$

Training and Qualifications $\ldots \ldots \ldots \ldots \ldots \ldots \ldots \ldots \ldots$

Emergency Planning $\ldots \ldots \ldots \ldots \ldots \ldots \ldots \ldots \ldots \ldots$

Engineering Program $\ldots \ldots \ldots \ldots \ldots \ldots \ldots \ldots \ldots \ldots$

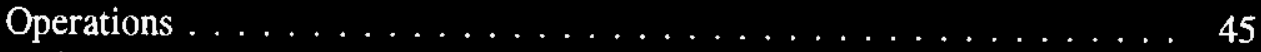

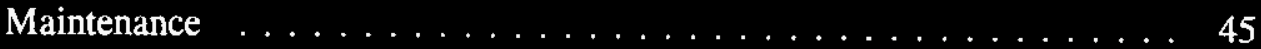

Packaging and Transportation ................ 45

Research and Development and Experimental Activities . . . . . . . . . 45

Nuclear Safety $\ldots \ldots \ldots \ldots \ldots \ldots \ldots \ldots \ldots \ldots \ldots \ldots \ldots$

Environmental Protection $\ldots \ldots \ldots \ldots \ldots \ldots \ldots \ldots \ldots \ldots . \ldots 45$

Occupational Safety and Health . . . . . . . . . . . . 45 
High Level Waste Storage

Tank Farms/242-A Evaporator

Standards/Requirements Identification Document

11.0 Radiation Protection
WHC-SD-MP-SRID-001

January 10, 1996

Rev. 0

Page iii of iii

11.11

REFERENCES

11.11 .1

Requirement Source Documents . . . . . . . . . . . . . . . 45

11.11 .2

Reviewed Documents Not Used as Requirement Sources

46 


\subsection{RADIATION PROTECTION}

\section{INTRODUCTION}

A Standards/Requirements Identification Document (S/RID) sets forth the Environmental Safety and Health (ES\&H) standards/requirements. This S/RID is applicable to the appropriate life cycle phases of design, construction, operation, and preparation for decommissioning for each of the categories of facilities addressed in Revision 5 of the Department of Energy Implementation Plan for the Defense Nuclear Facilities Safety Board (DNFSB) Recommendation 90-2. This Recommendation calls for the strengthening of DOE weapons complex activities through the identification and application of relevant DOE Orders, regulations, industry codes/standards, industry guidance documents and, as appropriate, good industry practices. These standards/requirements are adequate to ensure protection of the health and safety of workers, the public, and the environment.

The Tank Farms S/RID contains standards/requirements that are necessary for safe operation of the Tank Farms and its associated facilities, and that are the direct responsibility of the specific facility manager. The Radiation Protection (RP) Program defined in this document is described in general accordance with the Environment, Safety, and Health Configuration Guide, Revision 0, dated July 30, 1993, and is presented in program elements and subelements. The specific DOE Orders, regulations, industry codes/standards, guidance documents and good industry practices that serve as the basis for each element/subelement are identified and aligned with each subelement. Several additional subelements have been included in this S/RID that are not specifically identified in the ES\&H Configuration Guide. This has been done to improve the readability and usability of the S/RID. Some subelements have been divided in order to allow readers to focus on requirements in logical groups. An additional element and various subelements sub-subelements were added to the basic for further clarification and definition. Subelement 11.1.1, Exposure Reduction and ALARA, was further clarified by the addition of the following subelements: Exposure Controls (11.1.1.1), Radiological Work Planning (11.1.1.2), ALARA Reviews (11.1.1.3), ALARA Performance and Training Requirements (11.1.1.4), ALARA Committee and Staffing (11.1.1.5, and Dose Tracking and Trending (11.1.1.6). Element 11.1, Management, was further defined by the addition of the following subelements: RP Selection and Qualification (11.1.3), Management Requirements and Commitments (11.1.4), Radiological Program Performance Goals (11.1.5), Program Policy and Procedures (11.1.6), Policy for Response to Abnormal Situations (11.1.7), and Records Management (11.1.8). Element 11.2, Monitoring and Surveys, was embellished with the addition of subelement 11.2. 4, Dose Rate Surveys. Subelement 11.4.1, Access Restrictions, was further defined by the addition of subelement 11.4.1.1, Access Restrictions, and 11.4. 1.2, Posting. Subelement 11.5.4, Sealed Source Management, was added to address that topic. Subelement 11.6.1, Personnel, Equipment, and Area Contamination Control, was further clarified by the addition of the following sub-subelements: Personnel Contamination Monitoring (11.6.1.1), Personnel Contamination Control (11.6.1.2), and Equipment and Area Contamination Control (11.6.1.3). Subelements 11.6.3, Respiratory Protection Program, 11.6.4, Source Containment, Confinement, and Ventilation Control, and 11.8.4, Equipment Maintenance and Calibration, were added to address those topics. Element 11.11, References, was added to define applied and considered reference documents.

This S/RID contains only those requirements that Tank Farms personnel are clearly responsible to satisfy. Other requirements that are applicable to Tank Farms, but are satisfied by others, are defined in the Westinghouse Hanford Company (WHC) Level S/RID. For application in this S/RID, the words 
"shall" and "should" in requirement statements both indicate mandatory compliance. The key interface information contained in the Functional Area documents is provided for general recognition and understanding and is not considered to contain prescriptive requirements. Additionally, some of the requirements cited in this document are intentionally duplicated in the corresponding Company Level S/RID. This was necessary to address required implementation responsibilities occurring at both the company and facility levels.

\section{SCOPE}

This S/RID applies to the Tank Waste Remediation Systems (TWRS) Organization which includes the following:
-
East Tank Farm Transition Project
$\bullet$
West Tank Farm Transition Project
Evaporator Project
Interim Stabilization Project
Characterization Sampling Project (Excluding the Labs)

The near-term mission of TWRS is to store, treat, and immobilize the highly radioactive Hanford Site Waste. 


\section{1}

\section{PROGRAM MANAGEMENT}

Author's Note: Tank Farms will conduct radiological activities in accordance with the requirements of 10 CFR 835 by implementation of the DOE-approved WHC Radiological Control Manual, and the WHC Radiological Control Manual Implementation Plan.

\section{REQUIREMENT SOURCE: 10CFR835 Part 102}

"Internal audits. Internal audits of all functional elements of the radiation protection program shall be conducted no less frequently than every 3 years and shall include program content and implementation."

\section{Exposure Reduction and ALARA}

Although limiting contamination (Section 11.6, Contamination Control), the monitoring of radiation (Section 11.2, Facility Monitoring and Surveys) and Entry and Exit Control (Section 11.4, Access Controls) are also integral parts of the overall As-Low-As-Reasonably-Achievable (ALARA) program. Requirements relating to these specific subjects are included in the individual sections of the Tank Farms Radiation Protection Functional Area.

\section{REQUIREMENT SOURCE: 10CFR835 Part 1001(a)}

"Measures shall be taken to maintain radiation exposure in controlled areas as low as is reasonably achievable through facility and equipment design and administrative control. The primary methods used shall be physical design features (e.g., confinement, ventilation, remote handling, and shielding). Administrative controls and procedural requirements shall be employed only as supplemental methods to control radiation exposure."

\section{REQUIREMENT SOURCE: 10CFR835 Part 1001(b)}

"For specific activities where use of physical design features are demonstrated to be impractical, administrative controls and procedural requirements shall be used to maintain radiation exposures ALARA."

\section{REQUIREMENT SOURCE: 10CFR835 Part 1003(a)}

"During routine operations, the combination of design features and administrative control procedures shall provide that:

(1) The anticipated magnitude of the total effective dose equivalent shall not exceed 5 rems ( 0.05 sievert) in a year;

(2) The anticipated magnitude of the committed dose equivalent to any organ or tissue, plus any deep dose equivalent from external exposure, shall not exceed 50 rems $(0.5$ sievert $)$ in a year; and

(3) Exposure levels are as low as reasonably achievable."

\section{REQUIREMENT SOURCE: DOE/EH0256T(940431) Chapter 3, Part 1, Article 311}

"Planning Radiological Work

Requirements

Technical requirements for the conduct of work, including construction, modifications, operations, maintenance and decommissioning, shall incorporate radiological criteria to ensure 
safety and maintain radiation exposures ALARA. The primary methods used to maintain exposures ALARA shall be facility and equipment design features. These features may be augmented by administrative and procedural requirements. To accomplish this, the design and planning processes should incorporate radiological considerations in the early planning stages. The checklist in Appendix 3A is helpful in reducing occupational radiation exposure."

\subsubsection{Exposure Controls}

\section{REQUIREMENT SOURCE: DOE/EH0256T(940431) Chapter 3, Part 1, Article 314.1}

"Temporary Shielding

The installation, use and removal of temporary shielding should be controlled by procedure. ${ }^{\text {" }}$

\section{REQUIREMENT SOURCE: DOE/EH0256T(940431) Chapter 3, Part 1, Article} 314.2

"The effects of the additional weight of temporary shielding on systems and components should be evaluated and established to be within the design basis prior to installation."

\section{REQUIREMENT SOURCE: DOE/EH0256T(940431) Chapter 3, Part 1, Article 314.3}

"Installed temporary shielding should be periodically inspected and surveyed to verify effectiveness and integrity."

\section{REQUIREMENT SOURCE: DOE/EH0256T(940431) Chapter 3, Part 1, Article 314.4}

"Radiation surveys should be performed during the alteration or removal of installed temporary shielding."

\section{REQUIREMENT SOURCE: DOE/EH0256T(940431) Chapter 3, Part 1, Article 314.5}

"Installed temporary shielding should be visibly marked or labeled with the following or equivalent wording: "Temporary Shielding - Do Not Remove Without Permission from Radiological Control." "

\section{REQUIREMENT SOURCE: DOE/EH0256T(940431) Chapter 3, Part 1, Article 314.6}

"Installed temporary shielding should be periodically evaluated to assess the need for its removal or replacement with permanent shielding."

\section{REQUIREMENT SOURCE: DOE/EH0256T(940431) Chapter 3, Part 4, Article} 342. 8

"Where practicable, parts and components should be removed to areas with low dose rates to perform work." 
REQUIREMINT SOURCE: DOE/EH0256T(940431) Chapter 3, Part 4, Article 343.1

"Logs and Communications

Radiological Control personnel should maintain logs to document radiological occurrences, status of work activities and other relevant information."

REQUIREMENT SOURCE: DOE/EH0256T(940431) Chapter 3, Part 4, Article 343.3

"Communication systems required by the Radiological Work Permit or technical work document should be checked for operability before being brought into the work area and periodically during work."

\section{REQUIREMENT SOURCE: DOE/EH0256T(940431) Chapter 3, Part 4, Article 343.4}

"Workers should keep Radiological Control personnel informed of the status of work activities that affect radiological conditions."

11.1.1.2 Radiological Work Planning

\section{REQUIREMENT SOURCE: DOE/EH0256T(940431) Chapter 3, Part 1, Article 312.1}

"Planning for Maintenance, Operations and Modifications Maintenance and modification plans and procedures shall be reviewed to identify and incorporate radiological requirements, such as engineering controls and dose and contamination reduction considerations. Performance of this review is the responsibility of line management, with support and concurrence from the Radiological Control Organization."

\section{REQUIREMINT SOURCE: DOE/EH0256T(940431) Chapter 3, Part 1, Article 312.2}

"For routine tasks, such as surveillance, tours and minor non-radiological maintenance, performance of the above review and documentation of identified radiological requirements may be conducted as part of the Radiological Work Permit process (see Article 321)."

\section{REQUIREMENT SOURCE: DOE/EH0256T(940431) Chapter 3, Part 1, Article 315.1}

"Technical Work Documents

Technical work documents, such as procedures, work packages, or job or research plans, should be used to control hands-on work with radioactive materials. Technical work documents are not required for incidental or routine work activities that involve a low potential of worker exposure or workplace contamination, such as the collection of trash or used protective clothing."

\section{REQUIREMENT SOURCE: DOE/EH0256T(940431) Chapter 3, Part 1, Article 315.2}

"Technical work documents used to control radiological work activities should be reviewed and approved by the Radiological Control Organization." 
REQUIREMENT SOURCE: DOE/EH0256T(940431) Chapter 3, Part 1, Article 315.3

"Radiological Control Hold Points should be incorporated into technical work documents for steps that require action by the Radiological Control Organization to prevent radiation exposures in excess of Administrative Control Levels, high airborne radioactivity concentrations, or the release of radioactivity to the environment. "

\section{REQUIREMIENT SOURCE: DOE/EH0256T(940431) Chapter 3, Part 2, Article 324.1}

"Pre-Job Briefings

At a minimum, pre-job briefings should be held prior to the conduct of work anticipated to exceed the trigger levels identified in Article 312.3."

\section{REQUIREMENT SOURCE: DOE/EH0256T(940431) Chapter 3, Part 2, Article 324.2}

"At a minimum, the pre-job briefing should include:

a. Scope of work to be performed;

b. Radiological conditions of the workplace;

c. Procedural and RWP requirements;

d. Special radiological control requirements;

e. Radiologically limiting conditions, such as contamination or radiation levels that may void the RWP;

f. Radiological Control Hold Points;

g. Communications and coordination with other groups;

h. Provisions for housekeeping and final cleanup;

i. Emergency response provisions."

\section{REQUIREMENT SOURCE: DOE/EH0256T(940431) Chapter 3, Part 2, Article} 324.3

"Pre-job briefings should be conducted by the cognizant work supervisor."

\section{REQUIREMENT SOURCE: DOE/EH0256T(940431) Chapter 3, Part 2, Article 324.4}

"Workers and supervisors directly participating in the job, cognizant Radiological Control personnel, and representatives from involved support organizations should attend the briefing. " 
REQUIREMENT SOURCE: DOE/EH0256T(940431) Chapter 3, Part 2, Article 324.5

"A summary of topics discussed and attendance at the pre-job briefing should be documented. This documentation should be maintained with the technical work document."

\section{REQUIREMINT SOURCE: DOE/EH0256T(940431) Chapter 3, Part 4, Article} 341.1

"Radiological Work Controls

Requirements

Radiological work activities shall be conducted as specified by the controlling technical work document and Radiological Work Permit."

\section{REQUIREMINT SOURCE: DOE/EH0256T(940431) Chapter 3, Part 4, Article 342. 6}

"The identity of components and systems should be verified prior to work."

\section{REQUIREMINT SOURCE: DOE/EH0256T(940431) Chapter 3, Part 4, Article} 342. 7

"Work activities and shift changes should be scheduled to prevent idle time in radiation areas."

ALARA Reviews

\section{REQUIREMENT SOURCE: DOE/EH0256T(940431) Chapter 3, Part 1, Article 312.4}

"Tasks with the potential to exceed the above trigger levels shall undergo a formal, documented radiological or ALARA review. At a minimum, this review should consider the following:
a. Inclusion of Radiological Control Hold Points in the technical work documents;
b. Elimination or reduction of radioactivity through line flushing and decontamination;
c. Use of work processes and special tooling to reduce time in the work area;
d. Use of engineered controls to minimize the spread of contamination and generation of airborne radioactivity;
e. Specification of special radiological training or monitoring requirements;
f. Use of mock-ups for high exposure or complex tasks;
g. Engineering, design and use of temporary shielding to reduce radiation levels;
h. Walkdown or dry-run of the activity using applicable procedures;
i. Staging and preparation of necessary materials and special tools;
j. Maximization of prefabrication and shop work; 
k. Review of abnormal and emergency procedures and plans;

1. Identification of points where signatures and second party or independent verifications are required;

$\mathrm{m}$. Establishment of success or completion criteria, with contingency plans to anticipate difficulties;

n. Development of a pre-job estimate of collective dose to be incurred for the job;

o. Provisions for waste minimization and disposal."

\section{REQUIREMENT SOURCE: DOE/EH0256T(940431) Chapter 3, Part 1, Article 312.5}

"Radiological requirements identified as part of the above radiological review should be documented in the job plans, procedures or work packages. "

Requirements for this subelement are found in the Training and Qualification Functional Area.

ALARA Committee and Staffing

\section{REQUIREMENT SOURCE: DOE/EH0256T(940431) Chapter 1, Part 3, Article 138}

\section{"ALARA Committee}

An ALARA Committee should be established. The membership should include managers and workers from the line, the technical support organization and the Radiological Control Organization. It is more effective if a line manager, such as Director of Operations, Research, or Maintenance serves as the Chair. This Committee may be part of a general safety or radiation safety committee whose functions include ALARA activities and possibly be combined with the Radiological Awareness Committee (see Article 132) for smaller facilities.

The ALARA Committee should make recommendations to management to improve progress toward minimizing radiation exposure and radiological releases. The Committee should evaluate items such as construction and design of facilities and systems, planned major modifications or work activities, as well as experimental test plans for exposure, waste and release minimization. The Committee should also receive, as a minimum, the results of all reviews and audits, both internal and external, and should review the overall conduct of the Radiological Control Program.

The As-Low-As-Reasonably-Achievable (ALARA) process of reducing radiation exposures is a fundamental requirement of every radiological control program. There is considerable leeway in determining how far is reasonable. Reducing exposure is desirable because of the direct relation to the health and safety of workers and the public. Reducing radiation exposure improves the quality of the workplace and in the long nun saves resources."

\section{REQUIREMENT SOURCE: DOE/EH0256T(940431) Chapter 3, Part 1, Article 312.6}

"Radiological work anticipated to exceed individual or collective dose criteria established in the Site-Specific Radiological Control Manual should be reviewed and approved by the ALARA Committee." 


\section{$\underline{11.1 .1 .6}$}

$\underline{11.1 .2}$

$\underline{11.1 .3}$

$\underline{11.1 .4}$

Dose Tracking and Trending

\section{REQUIREMENT SOURCE: DOE/EH0256T(940431) Chapter 3, Part 4, Article 344.3}

"During the performance of jobs for which a pre-job dose estimate was made, the Radiological Control Organization, in cooperation with line periodically monitor collective dose accumulation and management, should periodically monitor collective dose accumulation and compare it with the pre-job dose estimate. Differences should be reviewed to identify causes and assess the need for corrective actions."

\section{Radiation Protection Training}

Refer to the Training and Qualification Functional Area document for other training requirements.

\section{RP Selection and Oualification}

\section{REQUIREMENT SOURCE: DOE/EH0256T(940431) Chapter 6, Part 4, Article 641}

"Radiological Control Technician Qualification

Requirements

Training and qualification of Radiological Control Technicians and their immediate supervisors shall address routine operations and also focus on recognizing and handling situations in both normal and changing radiological conditions. Newly qualified technicians and those still in training should be given the opportunity to work with qualified, experienced technicians to foster development."

\section{REQUIREMENT SOURCE: DOE/EH0256T(940431) Chapter 6, Part 4, Article 642.1}

"Radiological Control Technician

Radiological Control Technician qualification consists of the standardized core course training material, on-the-job training per the Qualification Standards, and passing both a final comprehensive written examination and final Oral Examination Board."

\section{REQUIREMINT SOURCE: DOE/EH0256T(940431) Chapter 6, Part 4, Article 644.2}

"Radiological Control Technician Supervisors should have supervisory and leadership capabilities to direct the work of technicians; effectively interact with crafts, line supervisors, professional staff and other managers; and be able to respond and direct others in emergency and abnormal situations."

\section{Radiological Program Performance Goals}

\section{REQUIREMENT SOURCE: DOE/EH0256T(940431) Chapter 1, Part 2, Article 121. 9}

"A performance indicator program for measuring and trending the effectiveness of the Radiological Control Program against predetermined goals should be established and maintained." 


\section{REQUIREMENT SOURCE: DOE/EH0256T(940431) Chapter 1, Part 3, Article} 132.4

"Radiological performance goals should be reviewed at least annually and revised as appropriate. Normally, more stringent goals should be set annually to reflect the improved radiological performance at the facility. Occasionally, a goal may be made less stringent to accommodate changes in work load or mission."

\section{REQUIREMENT SOURCE: DOE/EH0256T(940431) Chapter 1, Part 3, Article} 133.2

"The Radiological Control Manager should provide radiation exposure information, such as supplemental dosimeter-readings or volume of waste generated, to supervisors and managers on a frequent enough basis to permit priority management of exposure control. The frequency should be consistent with the nature of the workload and the radiation exposure potential."

\section{Program Policy and Procedures}

\section{REQUIREMENT SOURCE: 10CFR835 Part 501(d)}

"Administrative procedures shall be written as necessary to demonstrate compliance with the provisions of this section. These administrative procedures shall include actions essential to ensure the effectiveness and operability of barricades, devices, alarms, and locks. Authorizations shall be required to perform specific work within the area and shall include specific radiation protection measures."

\section{REQUIREMENT SOURCE: DOE/EH0256T(940431) Chapter 1, Part 2, Article 125.5}

"Managers, supervisors and workers should be involved in the development of accurate, clear, written procedures for performing radiological work. If during the use of procedures a written requirement cannot be responsibly followed, the work should be stopped and guidance obtained."

\section{Policy for Response to Abnormal Situations}

\section{REQUIREMENT SOURCE: DOE/EH0256T(940431) Chapter 3, Part 4, Article 345.1}

"Stop Radiological Work Authority

Radiological Control Technicians and their supervisors, line supervision, and any worker through their supervisor has the authority and responsibility to stop radiological work activities for any of the following reasons:

a. Inadequate radiological controls;

b. Radiological controls not being implemented;

c. Radiological Control Hold Point not being satisfied." 
REQUIREMENT SOURCE: DOE/EH0256T(940431) Chapter 3, Part 4, Article 345.3

"Once radiological work has been stopped, it shall not be resumed until proper radiological control has been reestablished. "

\section{REQUIREMENT SOURCE: DOE/EH0256T(940431) Chapter 3, Part 4, Article 345.4}

"Resumption of radiological work requires the approval of the line manager responsible for the work and the Radiological Control Manager."

\section{Records Management}

The Records Management element includes requirements which are specific for the maintenance of Tank Farms Radiation Protection records and for generating required Radiation Protection Reports. The Document Control and Records Management Functional Area under Management Systems provides overall requirements for maintaining records and the Document Control Organization will take responsibility for the long term handling and control of Radiation Protection records using the requirements contained in the Management Systems Functional Area. Additionally, there are Document Control and Records Management requirements from the Management Systems Functional Area which Radiation Protection (and other functional areas) are responsible for complying with.

\section{REQUTREMENT SOURCE: 10CFR835 Part 701(a)}

"Records shall be maintained to document compliance with this part and with radiation protection programs required by $\S 835.101$."

\section{REQUIREMENT SOURCE: DOE/EH0256T(940431) Chapter 7, Part 1, Article 713.1}

"Recordkeeping Standards

Radiological control records shall be accurate and legible. The records should include the following:

a. Identification of the facility, specific location, function and process;

b. Signature or other identifying code of the preparer and date;

c. Legible entries in black ink;

d. Corrections identified by a single line-out, initialed and dated;

e. Supervisory signature to ensure review and proper completion of forms."

\section{REQUIREMENT SOURCE: DOE/EH0256T(940431) Chapter 7, Part 1, Article $\mathbf{7 1 3 . 3}$}

"Radiological control records should not include:

a. Opaque substances for corrections;

b. Shorthand or other nonstandardized terms. " 
Survey Records/Radiological Work Control Records

\section{REQUIREMENT SOURCE: 10CFR835 Part 703}

Author's Note: Item (d) below is performed by a sitewide organization.

"The following information shall be documented and maintained:

(a) Results of surveys for radiation and radioactive material in the workplace as required by $\$ \$$ $835.401,835.403$, and 835.404;

(b) Results of surveys, measurements, and calculations used to determine individual occupational exposure from external and internal sources;

(c) Results of surveys for the release of material and equipment as required by $\$ 835.1101(d)$; and

(d) Results of maintenance and calibration performed on:

(1) Instruments used for area monitoring and contamination control as required by $\$ 835.401$; and

(2) Devices used for individual monitoring as required by $\$ \$ 835.401$ and $835.402 . "$

\section{REQUIREMIENT SOURCE: 10CFR835 Part 704(e)}

"Changes in equipment, techniques, and procedures used for monitoring in the workplace shall be documented."

\section{REQUIREMENT SOURCE: DOE/EH0256T(940431) Chapter 7, Part 5, Article 751.1}

"Radiological Surveys

Requirements

Radiological Control Programs require the performance of radiation, airborne radioactivity and contamination surveys to determine existing conditions in a given location. Maps with sufficient detail to permit identification of original survey and sampling locations should be maintained. Records shall contain sufficient detail to be meaningful even after the originator is no longer available. Radiological surveys should be recorded on appropriate standard forms and include the following common elements:

1. Date, time and purpose of the survey.

2. General and specific location of the survey.

3. Name and signature of the surveyor and analyst.

4. Pertinent information needed to interpret the survey results.

5. Reference to a specific Radiological Work Permit if the survey is performed to support the permit." 


\section{REQUIREMENT SOURCE: DOE/EH0256T(940431) Chapter 7, Part 5, Article 753}

\section{"Airborne Radioactivity}

In addition to the elements provided in Article 751, records of airborne radioactivity shall include, at a minimum, the following information:

a. Model and serial number of the sampler and laboratory counting instrument when available or unique identifier of each sampler and instrument.

b. Location of fixed air samplers

c. Location of portable air samplers used for a survey

d. Air concentrations in general airborne areas and breathing zones

e. Supporting parameters, including collection efficiency, flow rate, duration of sampling, correction factors and filter medium."

\section{REQUIREMENT SOURCE: DOE/EH0256T(940431) Chapter 7, Part 5, Article 754}

\section{"Contamination Surveys}

In addition to the elements required by Article 751, records of contamination surveys shall include, at a minimum, the following information:

a. Model and serial number of counting equipment.

b. Contamination levels (using appropriate units) and appropriate supporting parameters including counting efficiency, counting time, correction factors, type of radiation and whether the contamination was fixed or removable.

c. Location of areas found to contain hot particles or high concentrations of localized contamination.

d. Follow-up survey results for decontamination processes cross-referenced to the original survey."

\section{ALARA Review/Program Records}

\section{REQUIREMENT SOURCE: 10CFR835 Part 704(b)}

"Actions taken to maintain occupational exposures as low as reasonably achievable, including the actions required for this purpose by $\S 835.101$, as well as facility design and control actions required by $\S \S 835.1001,835.1002$, and 835.1003 , shall be documented."

REQUIREMENT SOURCE: DOE/EH0256T(940431) Chapter 7, Part 4, Article 742

"ALARA Records

Records of As-Low-As-Reasonably-Achievable (ALARA) plans and goals shall be maintained to demonstrate the adequacy of the ALARA Program. These records should include the minutes of ALARA committees and other committees where radiological safety issues are formally discussed." 
Miscellaneous Radiation Protection Records

\section{REQUIREMENT SOURCE: 10CFR835 Part 704(c)}

"Records shall be maintained to document the results of internal audits and other reviews of program content and implementation."

\section{REQUIREMINT SOURCE: 10CFR835 Part 704(d)}

"Written declarations of pregnancy shall be maintained."

\section{2}

\section{MONITORING AND SURVEYS}

\section{REQUIREMINT SOURCE: 10CFR835 Part 401(a)}

"Monitoring of individuals and areas shall be performed to:

(1) Demonstrate compliance with the regulations in this part;

(2) Document radiological conditions in the workplace;

(3) Detect changes in radiological conditions;

(4) Detect the gradual buildup of radioactive material in the workplace; and

(5) Verify the effectiveness of engineering and process controls in containing radioactive material and reducing radiation exposure."

\section{REQUIREMENT SOURCE: 10CFR835 Part 401(b)}

"Area monitoring in the workplace shall be routinely performed, as necessary, to identify and control potential sources of personnel exposure to radiation and/or radioactive material."

\section{REQUIREMENT SOURCE: 10CFR835 Part 401(c)}

"Instruments used for monitoring and contamination control shall be:

(1) Periodically maintained and calibrated on an established frequency of at least once per year;

(2) Appropriate for the type(s), levels, and energies of the radiation(s) encountered;

(3) Appropriate for existing environmental conditions; and

(4) Routinely tested for operability."

\section{$\underline{11.2 .1}$}

\section{Radiation Monitors, Alarms and Surveys}

Author's Note: Requirements applicable to this subelement are contained in section 11.2.2 and 11.2.4. 


\section{REQUIREMENT SOURCE: 10CFR835 Part 403(a)}

"Measurements of radioactivity concentrations in the ambient air of the workplace shall be performed as follows:

(1) Air sampling shall be performed in occupied areas where, under typical conditions, an individual is likely to receive an annual intake of 2 percent or more of the specified ALI values. For a given radionuclide and lung retention class, the ALI is the product of the DAC listed in appendix A of this part and the constant $2.4 \times 10^{\circ} \mathrm{ml}$. Samples shall be taken as necessary to detect and evaluate the level or concentration of airborne radioactive material at work locations.

(2) Real-time air monitoring, using continuous air monitors as defined in $\S 835.2$, shall be performed in normally occupied areas where an individual is likely to be exposed to a concentration of airborne radioactivity exceeding $1 \mathrm{DAC}$ as specified in appendix $\mathrm{A}$ of this part or where there is a need to alert potentially exposed individuals to unexpected increases in airborme radioactivity levels.

(3) For the airborne radioactive material that could be encountered, real-time air monitors shall have alarm capability and sufficient sensitivity to alert potentially exposed individuals that immediate action is necessary in order to minimize or terminate inhalation exposures."

\section{Contamination Monitoring and Surveys}

\section{REQUIREMENT SOURCE: 10CFR835 Part 404(a)}

"Instruments and techniques used for radioactive contamination monitoring and control shall be adequate to ensure compliance with the requirements specified in this section."

\section{REQUIREMENT SOURCE: DOE/EH0256T(940431) Chapter 5, Part 5, Article 554.1}

"Contamination Surveys

In addition to the requirements of Article 551, routine contamination surveys should be conducted in Radiological Buffer Areas established for the control of contamination and other areas with the potential for spread of contamination as follows:

a. Prior to transfer of equipment and material from one Radiological Buffer Area to another;

b. Prior to transfer of equipment and material from highly contaminated areas within Radiological Buffer Areas unless precautions such as bagging or wrapping are taken prior to transfer;

c. Only, at contamination area control points, change areas, or step-off pads when in use, or per shift in high use situations;

d. Daily, in office space located in Radiological Buffer Areas;

e. Daily, in lunch rooms or eating areas near Radiological Buffer Areas;

f. Weekly, in routinely occupied Radiological Buffer Areas; 
g. Weekly, or upon entry if entries are less frequent, in areas where radioactive materials are handled or stored;

h. Weekly, or upon entry if entries are less frequent, where contamination boundaries or postings are located;

i. During initial entry into a known or suspected contamination area, periodically during work, at completion of job, or as specified in a Radiological Work Permit;

j. After a leak or spill of radioactive materials. "

\section{REQUIREMENT SOURCE: DOE/EH0256T(940431) Chapter 5, Part 5, Article 554.3}

"Contamination surveys should incorporate techniques to detect both removable and fixed. contamination."

\section{REQUIREMENT SOURCE: DOE/EH0256T(940431) Chapter 5, Part 5, Article 554.6}

"Swipe surveys for removable contamination shall be reported in units of disintegrations per minute per $100 \mathrm{~cm} 2(\mathrm{dpm} / 100 \mathrm{~cm} 2)$. For swipe surveys of small items covering less than 100 $\mathrm{cm} 2$, the results shall be reported in units of dpm per area swiped."

\section{REQUIREMINT SOURCE: DOE/EH0256T(940431) Chapter 5, Part 5, Article 554.7}

"Large area wipes are encouraged and should be used to supplement standard swipe techniques in areas generally assumed not to be contaminated, such as entrances to Radiological Buffer Areas. If an evaluation indicates that an area wiped is contaminated, a thorough contamination swipe survey should be performed."

Dose Rate Surveys

\section{REQUIREMENT SOURCE: 10CFR835 Part 403(b)}

"Monitoring of radiation in the workplace shall be performed using stationary (area) or portable radiation instruments, or a combination thereof. The instruments shall be readily available and shall be capable of measuring ambient radiation dose rates for the purpose of controlling radiation exposures."

\section{REQUIREMENT SOURCE: DOE/EH0256T(940431) Chapter 5, Part 5, Article 552.1}

"Radiation Exposure Surveys In addition to the requirements of Article 551, routine radiation surveys should be performed in accordance with the following minimum frequencies:

a. Daily, in office space located in Radiological Buffer Areas where the potential exists for external radiation exposure;

b. Weekly, in routinely occupied Radiological Buffer Areas and Radiation Areas; 
c. Upon initial entry, weekly during continuing operations, and when levels are expected to change in High Radiation Areas;

d. Weekly, for operating HEPA-filtered ventilation units;

e. Weekly, for temporary Radiation Area boundaries to ensure that radiation areas do not extend beyond posted boundaries;

f. Monthly, or upon entry, if entries are less frequent than monthly for Radioactive Material Areas;

g. Montbly, for potentially contaminated ducts, piping and hoses in use outside radiological facilities. "

\section{REQUIREMENT SOURCE: DOE/EH0256T(940431) Chapter 5, Part 5, Article 552.2}

"Performance of radiation surveys should include dose rate measurements of the general area, dose rates at a distance of 30 centimeters from a source or surface of interest to evaluate potential whole body exposures, and dose rates on contact with potential sources of radiation where there is a potential for hands-on work."

\section{REQUIREMENT SOURCE: DOE/EH0256T(940431) Chapter 5, Part 5, Article 552.3}

"Surveys should be conducted whenever operations are being performed that might result in personnel being exposed to small intense beams of radiation, such as those generated by shielded $\mathrm{x}$-ray devices or due to removal or alteration of shielding. "

PERSONNEL EXPOSURE MONITORING

Personnel Exposure Monitoring

\section{REQUIREMENT SOURCE: 10CFR835 Part 402(a)}

"For the purpose of monitoring individual exposures to external radiation, personnel dosimetry shall be provided to and used by:

(1) Radiological workers who, under typical conditions, are likely to receive one or more of the following:

(i) An effective dose equivalent to the whole body of 0.1 rem ( 0.001 sievert) or more in a year;

(ii) A shallow dose equivalent to the skin or to any extremity of 5 rems $(0.05$ sievert) or more in a year;

(iii) A lens of the eye dose equivalent of 1.5 rems ( 0.015 sievert) or more in a year;

(iv) A deep dose equivalent from external exposures to any organ or tissue other than the lens of the eye of 5 rems $(0.05$ sievert);

(2) Declared pregnant workers who are likely to receive from external sources a dose equivalent to the embryo/fetus in excess of 10 percent of the applicable limit in $\S 835.206$; 
(3) Minors and members of the public likely to receive, in 1 year, from external sources, a dose in excess of 50 percent of the applicable limits in $\S 835.207$ or $\$ 835.208$, respectively; or

(4) Individuals entering a high or very high radiation area."

\section{REQUIREMENT SOURCE: 10CFR835 Part 402(c)}

"For the purpose of monitoring individual exposures to internal radiation, internal dose evaluation programs (including routine bioassay programs) shall be conducted for:

(1) Radiological workers who, under typical conditions, are likely to receive 0.1 rem $(0.001$ sievert) or more committed effective dose equivalent, and/or 5 rems ( 0.05 sievert) or more committed dose equivalent to any organ or tissue, from all occupational radionuclide intakes in a year;

(2) Declared pregnant workers likely to receive an intake resulting in a dose equivalent to the embryo/fetus in excess of 10 percent of the limit stated in $\$ 835.206$; or

(3) Minors and members of the public who are likely to receive, in 1 year, an intake resulting in a committed effective dose equivalent in excess of 50 percent of the limits stated in $\S$ 835.207 or $\$ 835.208$, respectively."

11.3.2 Exposure Limits

\section{REQUIREMENT SOURCE: 10CFR835 Part 202(a)}

"The occupational exposure to general employees resulting from DOE activities, other than planned special exposures under $\S 835.204$ and emergency exposure situations under $\S$ 835.1302, shall be controlled so the following annual limits are not exceeded:

(1) A total effective dose equivalent of 5 rems ( 0.05 sievert);

(2) The sum of the deep dose equivalent for external exposures and the committed dose equivalent to any organ or tissue other than the lens of the eye of 50 rems ( 0.5 sievert);

(3) A lens of the eye dose equivalent of 15 rems ( 0.15 sievert); and

(4) A shallow dose equivalent of 50 rems ( 0.5 sievert) to the skin or to any extremity."

\section{REQUIREMENT SOURCE: 10CFR835 Part 204(a)}

"A planned special exposure may be authorized for a radiological worker to receive doses in addition to and accounted for separately from the doses received under the limits specified in $\S$ 835.202(a), provided that each of the following conditions is satisfied:

(1) The planned special exposure is considered only in an exceptional situation when alternatives that might prevent a radiological worker from exceeding the limit in $\S$ 835.202(a)(1) are unavailable or impractical;

(2) The contractor management (and employer, if the employer is not the contractor) specifically requests the planned special exposure, in writing; and

(3) Joint written approval from the appropriate DOE Headquarters program office and the Assistant Secretary for Environment, Safety and Health is received." 


\section{REQUIREMENT SOURCE: 10CFR835 Part 204(b)}

"Prior to requesting an individual to participate in an authorized planned special exposure, the individual's dose from all previous planned special exposures and all doses in excess of the occupational dose limits shall be determined."

\section{REQUIREMENT SOURCE: 10CFR835 Part 204(c)}

"An individual shall not receive a planned special exposure that, in addition to the doses determined in $\$ 835.204(\mathrm{~b})$, would result in a dose exceeding the following:

(1) A total effective dose equivalent of 5 rems ( 0.05 sievert) in the current year; and

(2) A cumulative total effective dose equivalent of 25 rems ( 0.25 sievert)."

\section{REQUIREMENT SOURCE: 10CFR835 Part 204(d)}

"Prior to a planned special exposure, written consent shall be obtained from each individual involved. Each individual shall be:

(1) Informed of the purpose of the planned operations and procedures to be used;

(2) Informed of the estimated doses and associated potential risks and specific radiological conditions and other hazards which might be involved in performing the task; and

(3) Instructed in the measures to be taken to keep the dose ALARA considering other risks that may be present."

\section{REQUIREMENT SOURCE: 10CFR835 Part 206(a)}

"The dose equivalent limit for the embryo/fetus from the period of conception to birth, as a result of occupational exposure of a declared pregnant worker, is 0.5 rem ( 0.005 sievert)."

\section{REQUIREMENT SOURCE: 10CFR835 Part 206(b)}

"Substantial variation above a uniform exposure rate that would satisfy the limits provided in $\S$ 835.206(a) shall be avoided."

\section{REQUIREMENT SOURCE: 10CFR835 Part 206(c)}

"If the dose equivalent to the embryo/fetus is determined to have already exceeded $0.5 \mathrm{rem}$ ( 0.005 sievert) by the time a worker declares her pregnancy, the declared pregnant worker shall not be assigned to tasks where additional occupational exposure is likely during the remaining gestation period."

\section{REQUIREMINT SOURCE: 10CFR835 Part 207}

"Any minor exposed to radiation and/or radioactive material during direct on-site access at a DOE site or facility shall not exceed 0.1 rem (0.001 sievert) total effective dose equivalent in a year." 


\section{REQUIREMINT SOURCE: 10CFR835 Part 208}

"Any member of the public exposed to radiation and/or radioactive material during direct on-site access at a DOE site or facility shall not exceed 0.1 rem (0.001 sievert) total effective dose equivalent in a year."

\section{REQUIREMENT SOURCE: 10CFR835 Part 209(a)}

"The derived air concentration (DAC) values given in appendices $\mathrm{A}$ and $\mathrm{C}$ to this part shall be used in the control of occupational exposures to airborne radioactive material."

\section{REQUIREMENT SOURCE: DOE/EH0256T(940431) Chapter 2, Part 1, Article 213.5}

"The radiological worker dose limits provided in Table 2-1 also apply to general employees. However, general employees who have not completed Radiological Worker I or II Training are not permitted unescorted access to any area in which they are expected to receive doses in excess of 100 mrem in one year. General employees who have not received Radiological Worker I or II training are not normally expected to exceed 100 mrem in a year."

\section{REQUIREMENT SOURCE: DOE/EH0256T(940431) Chapter 2, Part 1, Article 215.1}

"The employer shall provide the option of a mutually agreeable assignment of work tasks, without loss of pay or promotional opportunity, such that further occupational radiation exposure is unlikely."

\section{Dosimetry Program}

\section{REQUIREMINT SOURCE: 10CFR835 Part 205(a)}

"Non-uniform exposures of the skin from X-rays, beta radiation, and/or radioactive material on the skin are to be assessed as specified in this section."

\section{REQUIREMENT SOURCE: 10CFR835 Part 205(b)}

"For purposes of demonstrating compliance with $\S 835.202(a)(4)$, assessments shall be conducted as follows:

(1) Area of skin irradiated is $100 \mathrm{~cm} 2$ or more. The non-uniform dose equivalent received during the year shall be averaged over the $100 \mathrm{~cm} 2$ of the skin receiving the maximum dose, added to any uniform dose equivalent also received by the skin, and recorded as the shallow dose equivalent to any extremity or skin for the year.

(2) Area of skin irradiated is $10 \mathrm{~cm} 2$ or more, but is less than $100 \mathrm{~cm} 2$. The non-uniform dose equivalent $(\mathrm{H})$ to the irradiated area received during the year shall be added to any uniform dose equivalent also received by the skin and recorded as the shallow dose equivalent to any extremity or skin for the year. $\mathrm{H}$ is the dose equivalent averaged over the $1 \mathrm{~cm} 2$ of skin receiving the maximum absorbed dose, $D$, reduced by the fraction $f$, which is the irradiated area in $\mathrm{cm} 2$ divided by $100 \mathrm{~cm} 2$ (i.e., $H=\mathrm{tD}$ ). In no case shall a value of $\mathrm{f}$ less than 0.1 be used.

(3) Area of skin irradiated is less than $10 \mathrm{~cm} 2$. The non-uniform dose equivalent shall be averaged over the $1 \mathrm{~cm} 2$ of skin receiving the maximum dose. This dose equivalent shall: 
(i) Be recorded in the individual's occupational exposure history as a special entry; and

(ii) Not be added to any other shallow dose equivalent to any extremity or skin recorded as the dose equivalent for the year."

\section{Calculation Methods/Models}

\section{REQUIREMENT SOURCE: 10CFR835 Part 4}

"Radiological units. Unless otherwise specified the quantities used in the records required by this part shall be clearly indicated in special units of curie rad, or rem, including multiples and subdivisions of these units. The SI units becquerel (Bq), gray (Gy), and sievert (Sv) are only provided parenthetically in this part for reference with scientific standards. These SI units are not authorized for use in records required under this part."

\subsection{RADIATION AREA ACCESS CONTROL}

\subsubsection{Access Restrictions and Posting}

11.4.1.1 $\quad$ Access Restrictions

\section{REQUIREMENT SOURCE: 10CFR835 Part 501(a)}

"Personnel entry control shall be maintained for each radiological area."

\section{REQUIREMENT SOURCE: 10CFR835 Part 501(b)}

"The degree of control shall be commensurate with existing and potential radiological hazards within the area."

\section{REQUIREMENT SOURCE: 10CFR835 Part 501(c)}

"One or more of the following methods shall be used to ensure control:

(1) Signs and barricades;

(2) Control devices on entrances;

(3) Conspicuous visual and/or audible alarms;

(4) Locked entrance ways; or

(5) Administrative controls."

\section{REQUIREMENT SOURCE: 10CFR835 Part 501(e)}

"No control(s) shall be installed at any radiological area exit that would prevent rapid evacuation of personnel under emergency conditions."

\section{REQUIREMENT SOURCE: 10CFR835 Part 502(a)}

"High radiation areas. One or more of the following features shall be used for each entrance or access point to a high radiation area where radiation levels exist such that an individual could exceed a deep dose equivalent to the whole body of $1 \mathrm{rem}(0.01$ sievert) in any one hour at 30 centimeters from the source or from any surface that the radiation penetrates:

(1) A control device that prevents entry to the area when high radiation levels exist or upon entry causes the radiation level to be reduced below that level defining a high radiation area; 
(2) A device that functions automatically to prevent use or operation of the radiation source or field while personnel are in the area;

(3) A control device that energizes a conspicuous visible or audible alarm signal so that the individual entering the high radiation area and the supervisor of the activity are made aware of the entry;

(4) Entryways that are locked. During periods when access to the area is required, positive control over each entry is maintained;

(5) Continuous direct or electronic surveillance that is capable of preventing unauthorized entry;

(6) A control device that will automatically generate audible and visual alarm signals to alert personnel in the area before use or operation of the radiation source and in sufficient time to permit evacuation of the area or activation of a secondary control device that will prevent use or operation of the source."

\section{REQUIREMENT SOURCE: 10CFR835 Part 502(b)}

"Very high radiation areas. In addition to the above requirements, additional measures shall be implemented to ensure individuals are not able to gain access to very high radiation areas when dose rates are in excess of the posting requirements of $\S 835.603(\mathrm{c}) .^{n}$

\section{REQUIREMENT SOURCE: 10CFR835 Part 502(c)}

"No control(s) shall be established in a high or very high radiation area that would prevent rapid evacuation of personnel."

\section{REQUIREMENT SOURCE: DOE/EH0256T(940431) Chapter 2, Part 3, Article 233.1}

"The size of the Radiological Buffer Area should be commensurate with the potential for the spread of contamination outside Contamination, High Contamination and Airborne Radioactivity Areas. At a minimum, the Radiological Buffer Area should include the area adjacent to any exit from and entrance to Contamination, High Contamination and Airborne Radioactivity Areas."

\section{REQUIREMENT SOURCE: DOE/EH0256T(940431) Chapter 2, Part 3, Article} 233.2

"A Radiological Buffer Area is not required for High Contamination Areas or Airborne Radioactivity Areas that are completely within Contamination Areas."

\section{REQUIREMENT SOURCE: DOE/EH0256T(940431) Chapter 2, Part 3, Article} 233.3

"A Radiological Buffer Area established to limit exposure to external radiation should surround Radiation, High Radiation and Very High Radiation Areas. The boundary for the Radiological Buffer Area should be established to limit radiation doses to general employees to less than 100 mrem per year. Radiological Buffer Areas need not be posted for external exposure control if other posted boundaries provide equivalent employee protection." 


\section{REQUIREMINT SOURCE: DOE/EH0256T(940431) Chapter 3, Part 3, Article} 334. 2

"Physical controls to prevent inadvertent or unauthorized access to High and Very High Radiation Areas shall be maintained in accordance with Appendix 3B."

\section{REQUIREMENT SOURCE: DOE/EH0256T(940431) Chapter 3, Part 3, Article 334. 3}

"Minimum requirements for unescorted entry into High Radiation Areas shall include the following:

a. Radiological Worker II training (or Radiological Worker I with High/Very High Radiation Area access training in accordance with Article 632.5) and training in the use of a survey meter (or dose rate indicating device), as described in Article 126

b. Worker's signature on the RWP;

c. Personnel and supplemental dosimeters;

d. Survey meter or dose rate indicating device available at the work area. "

\section{REQUIREMIENT SOURCE: DOE/EH0256T(940431) Chapter 3, Part 3, Article 334. 4}

"Minimum requirements for unescorted entry into High Radiation Areas where dose rates exist such that a worker could exceed a whole body dose of 1 rem in one hour shall include those items listed in Article 334.3 and the following:

a. A determination of the worker's current exposure, based on primary and supplemental dosimeter readings;

b. Pre-job briefing, as applicable;

c. Review and determination by the Radiological Control Organization regarding the required level of Radiological Control Technician coverage."

\section{REQUIREMENT SOURCE: DOE/EH0256T(940431) Chapter 3, Part 3, Article 334. 5}

"Workers shall be prevented from entry to Very High Radiation Areas when the radiation source is exposed and very high radiation fields are present. In addition to the controls required in Articles 334.2 and 334.3, a survey shall be made prior to the first entry to the area after the source has been secured or shielded to verify the very high radiation field has been terminated."

\section{REQUIREMIENT SOURCE: DOE/EH0256T(940431) Chapter 3, Part 3, Article 334. 6}

"Facility operations personnel should be notified prior to personnel entry to areas where operational or system changes made by operations personnel could result in significantly increased area dose rates." 
REQUIREMENT SOURCE: DOE/EH0256T(940431) Chapter 3, Part 3, Article 334. 7

"The number, issue and use of keys shall be strictly controlled where locked entryways are used to control access to High and Very High Radiation Areas."

\section{REQUIREMENT SOURCE: DOE/EH0256T(940431) Chapter 3, Part 3, Article} 334.8

"The Radiological Control Organization should maintain an inventory of High and Very High Radiation Areas."

\section{REQUIREMENT SOURCE: DOE/EH0256T(940431) Chapter 3, Part 3, Article 334. 9}

"Weekly inspections of the physical access controls to High and Very High Radiation Areas should be made to verify controls are adequate to prevent unauthorized entry."

Posting

Author's Note: Requirement DOE/EH0256T(940431), Chapter 2, Part 2, Article 223.1, as located in subelement 11.6.3, is also applicable to this subelement.

\section{REQUREMENT SOURCE: 10CFR835 Part 404(e)}

"Entry control pursuant to $\S 835.501$ and posting pursuant to $\S 835.603$ are not required for areas with fixed contamination meeting the conditions of $\$ 835.404(\mathrm{~d})$."

\section{REQUIREMENT SOURCE: 10CFR835 Part 601(a)}

"Working areas that require posting because of the presence, or potential presence, of radiation and/or radioactive material are delineated in the subsequent paragraphs of this section. Radioactive items or containers of radioactive materials, shall be individually labeled if adequate warning is not provided by control measures and required posting."

\section{REQUIREMENT SOURCE: 10CFR835 Part 601(b)}

"DOE approved signs, labels, and radiation symbols shall be used to identify areas specified in this subpart."

\section{REQUIREMINT SOURCE: 10CFR835 Part 601(c)}

"Required signs and labels shall have a yellow background. The radiation symbol shall be black or magenta."

\section{REQUIREMENT SOURCE: 10CFR835 Part 601(d)}

"Signs required by this subpart shall be clear and conspicuously posted and may include radiological protection instructions." 


\section{REQUIREMENT SOURCE: 10CFR835 Part 602(a)}

"Each access point to a controlled area (as defined in $\S 835.2$ ) shall be posted, identifying it as a controlled area, whenever radioactive material and/or radiation fields which would require posting under $\$ 835.603$ may be present in the area."

\section{REQUIREMENT SOURCE: 10CFR835 Part 603}

"Each access point to a radiological area (as defined in $\$ 835.2$ ) shall be posted with conspicuous signs bearing the wording provided in this section.

(a) Radiation Area. The words "Caution, Radiation Area" shall be posted at any area accessible to individuals in which radiation levels could result in an individual receiving a deep dose equivalent in excess of 0.005 rem ( 0.05 millisievert) in 1 hour at 30 centimeters from the source or from any surface that the radiation penetrates.

(b) High Radiation Area. The words "Danger, High Radiation Area" shall be posted at any area accessible to individuals in which radiation levels could result in an individual receiving a deep dose equivalent in excess of 0.1 rem ( 0.001 sievert) in 1 hour at 30 centimeters from the radiation source or from any surface that the radiation penetrates.

(c) Very High Radiation Area. The words "Grave Danger, Very High Radiation Area" shall be posted at any area accessible to individuals in which radiation levels could result in an individual receiving an absorbed dose in excess of 500 rads ( 5 grays) in one hour at 1 meter from the radiation source or from any surface that the radiation penetrates.

(d) Airborne Radioactivity Area. The words "Caution, Airborne Radioactivity Area" shall be posted for any occupied area in which airborne radioactivity levels exceed, or are likely to exceed, 10 percent of the DAC value listed in appendix $\mathrm{A}$ or appendix $\mathrm{C}$ of this part.

(e) Contamination Area. The words "Caution, Contamination Area" shall be posted where contamination levels exceed values listed in appendix D of this part, but are less than or equal to 100 times those values.

(f) High Contamination Area. The words "Danger, High Contamination Area" shall be posted where contamination levels are greater than 100 times the values listed in appendix D of this part."

\section{REQUIREMENT SOURCE: DOE/EH0256T(940431) Chapter 2, Part 3, Article 233, Introduction}

"Posting Radiological Buffer Areas

A Radiological Buffer Area shall be established within the Controlled Area to provide secondary boundaries to minimize the spread of contamination and to limit doses to general employees who have not been trained as radiological workers. It is not expected that Radiological Buffer Areas will be established around inactive or secured Contamination Areas. The need for Radiological Buffer Areas in conjunction with Radioactive Material Areas should be evaluated."

REQUIREMENT SOURCE: DOE/EH0256T(940431) Chapter 2, Part 3, Article 233.4 
REQUIREMIENT SOURCE: DOE/EH0256T(940431) Chapter 2, Part 3, Article 236.1

"Posting Radioactive Material Areas

Areas where radioactive materials are used, handled or stored should be posted "CAUTION, RADIOACTIVE MATERIAL." The posting shall meet the requirements in Article 231."

REQUIREMENT SOURCE: DOE/EH0256T(940431) Chapter 2, Part 3, Article 236.2

"Radioactive Material Areas should be located within Controlled Areas."

\section{REQUIREMENT SOURCE: DOE/EH0256T(940431) Chapter 2, Part 3, Article} 236.3

"Radioactive Material Areas are not required when the radioactive material in any one location:

a. Consists of ten or less sealed sources with half-lives less than 30 days or activities less than those specified in Table 1 of DOE N5400.9 (Extended by DOE N5400.10)

b. Is inside a Contamination, High Contamination, or Airborne Radioactivity Area."

\section{REQUIREMENT SOURCE: DOE/EH0256T(940431) Chapter 2, Part 3, Article 237.1}

"Posting Underground Radioactive Material Areas

Underground Radioactive Material Areas shall be established to indicate the presence of underground items that contain radioactive materials such as pipelines, radioactive cribs, covered ponds, covered ditches, catch tanks, inactive burial grounds, and sites of known, covered, unplanned releases (spills)."

\section{REQUIREMENT SOURCE: DOE/EH0256T(940431) Chapter 2, Part 3, Article 237.2}

"Underground Radioactive Material Area shall be posted "UNDERGROUND RADIOACTIVE MATERIAL." Posting should include instnuctions or special warnings to workers such as "Consult With Radiological Control Organization Before Digging" or "Subsurface Contamination Exists." The posting shall meet the applicable requirements of Article 231."

REQUIREMINT SOURCE: DOE/EH0256T(940431) Chapter 2, Part 3, Article 237.3

"Underground Radioactive Material Areas may be located outside Controlled Areas unless access is likely to result in individual doses greater than 100 mrem/year in a year from underground radioactive material."

11.4.2 Radiation Work Permits

REQUIREMENT SOURCE: DOE/EH0256T(940431) Chapter 3, Part 2, Article 322.2

"RWPs should be used to control the following activities: 
a. Entry into Radiation Areas;

b. Entry into Contamination Areas;

c. Handling of materials with removable contamination that exceed the values of Table 2-2."

\section{REQUIREMENT SOURCE: DOE/EH0256T(940431) Chapter 3, Part 2, Article 322.3}

"Job-specific RWPs shall be used to control non-routine operations or work in areas with changing radiological conditions. The job-specific RWP shall remain in effect only for the duration of the job."

\section{REQUIREMENT SOURCE: DOE/EH0256T(940431) Chapter 3, Part 2, Article 322.4}

"General RWPs may be used to control routine or repetitive activities, such as tours and inspections or minor work activities, in areas with well-characterized and stable radiological conditions. General RWPs should not be approved for periods longer than 1 year."

\section{REQUIREMIENT SOURCE: DOE/EH0256T(940431) Chapter 3, Part 2, Article 322.5}

"Radiological surveys shall be routinely reviewed to evaluate adequacy of RWP requirements. RWPs shall be updated if radiological conditions change to the extent that protective requirements need modification."

\section{REQUIREMENT SOURCE: DOE/EH0256T(940431) Chapter 3, Part 2, Article 322.6}

"RWPs should be posted at the access point to the applicable radiological work area."

\section{REQUIREMENT SOURCE: DOE/EH0256T(940431) Chapter 3, Part 2, Article} 322.7

"Workers shall acknowledge by signature or through electronic means where automated access systems are in place that they have read, understand and will comply with the RWP prior to initial entry to the area and after any revisions to the RWP."

\section{REQUIREMENT SOURCE: DOE/EH0256T(940431) Chapter 3, Part 2, Article 322.8}

"Worker pocket or electronic dosimeter readings should be recorded in a format that identifies and provides linkage to the applicable RWP."

\section{REQUIREMENT SOURCE: DOE/EH0256T(940431) Chapter 3, Part 2, Article 322.9}

"An alternative formal mechanism, such as written procedures or experiment authorizations, may be used in lieu of an RWP as the administrative control over radiological work activities. If an alternative mechanism is used, it should meet the requirements of this Article and Articles 321 and 323." 
REQUIREMENT SOURCE: DOE/EH0256T(940431) Chapter 3, Part 2, Article 323.1

"Radiological Work Permit Preparation

The responsibility for ensuring adequate planning and control of work activities resides with line management. The lead work group responsible for the planned activity or for the area should initiate the preparation of the RWP."

\section{ReQUIREMINT SOURCE: DOE/EH0256T(940431) Chapter 3, Part 2, Article} 323.2

"RWPs shall be reviewed and approved by the Radiological Control Organization."

REQUIREMENT SOURCE: DOE/EH0256T(940431) Chapter 3, Part 2, Article 323.3

"The RWP shall be based on current radiological surveys and anticipated radiological conditions."

\section{REQUIREMENT SOURCE: DOE/EH0256T(940431) Chapter 3, Part 2, Article 323.4}

"The RWP shall be approved by the supervisor responsible for the work or area and the appropriate Radiological Control supervisor. Revisions or extensions to RWPs shall be subject to the same approval process."

RADIOACTIVE MATERIALS MANAGEMENT

Storage, Labels and Transportation

\section{REQUTREMENT SOURCE: DOE/EH0256T(940431) Chapter 4, Part 1, Article 414. 1 \\ "Radioactive Material Storage \\ Radioactive material should be stored in a designated Radioactive Material Area." \\ REQUIREMENT SOURCE: DOE/EH0256T(940431) Chapter 4, Part 1, Article 414. 2}

"Long-term (more than 60 days) storage of radioactive material should be in a specially designated Radioactive Material Area."

\section{ReQUIREMENT SOURCE: DOE/EH0256T(940431) Chapter 4, Part 1, Article 414. 4}

"Each Radioactive Material Area should be approved by the Radiological Control Manager."

REQUIREMENT SOURCE: DOE/EH0256T(940431) Chapter 4, Part 1, Article 414. 5

"A custodian should be assigned responsibility for each Radioactive Material Area. A custodian may have responsibility for more than one storage area." 
ReQUIREMENT SOURCE: DOE/EH0256T(940431) Chapter 4, Part 1, Article 414. 6

"The custodian should conduct walkthroughs of Radioactive Material Areas to check container integrity."

\section{REQUIREMIENT SOURCE: DOE/EH0256T(940431) Chapter 4, Part 1, Article} 414. 7

"The custodian should conduct annual or more frequent reviews of each Radioactive Material Area, with emphasis on decontamination, movement of material to long-term storage locations and disposal of unneeded material."

REQUIREMENT SOURCE: DOE/EH0256T(940431) Chapter 4, Part 1, Article 414. 8

"Storage of nonradioactive material in a Radioactive Material Area is discouraged."

\section{REQUIREMENT SOURCE: DOE/EH0256T(940431) Chapter 4, Part 1, Article} 414. 9

"Outdoor storage of radioactive material is discouraged. In cases where outdoor storage is necessary, the integrity of containers used shall be ensured to prevent degradation from weathering and subsequent release of radioactive material. The custodian should check container integrity monthly at outdoor Radioactive Material Areas."

\section{REQUIREMENT SOURCE: DOE/EH0256T(940431) Chapter 4, Part 1, Article} 414.10

"Radioactive material should be stored in a manner that reduces combustible loading. The use of cardboard containers for storage is discouraged."

\section{REQUIREMENT SOURCE: DOE/EH0256T(940431) Chapter 4, Part 1, Article} 414.11

"Flammable or combustible materials should not be stored adjacent to Radioactive Material Areas."

\section{REQUIREMENT SOURCE: DOE/EH0256T(940431) Chapter 4, Part 1, Article 414.12}

"Fire protection measures, such as smoke detectors, water sprinklers and fire extinguishers, should be considered when establishing a Radioactive Material Area."

\section{Movement of Material}

Author's Note: Requirements DOE/EH0256T(940431), Chapter 5, Part 5, Article 554.3 and DOE/EH0256T(940431), Chapter 5, Part 5, Article 554.6, as located in subelement 11.2.3 are also applicable to this subelement. 


\section{REQUIREMINT SOURCE: 10CFR835 Part 1101}

"The following requirements apply for the release of materials and equipment from radiological areas for use in controlled areas:

(a) In radiological areas established to control surface or airborne radioactive material, material and equipment shall be treated as radioactive material and shall not be released from radiological areas to controlled areas if either of the following conditions exist:

(1) Measurements of accessible surfaces show that either the total or removable contamination levels exceed the values specified in appendix D to this part; or

(2) Prior use suggests that the contamination levels on inaccessible surfaces are likely to exceed the values specified in appendix $\mathrm{D}$ to this part.

(b) Material and equipment exceeding the total or removable contamination levels specified in appendix $\mathrm{D}$ to this part may be conditionally released for movement on-site from one radiological area for immediate placement in another radiological area only if appropriate monitoring and control procedures are established and exercised.

(c) Material and equipment with fixed contamination levels that exceed the limits specified in appendix $\mathrm{D}$ to this part may be released for use in controlled areas outside of the radiological areas with the following provisions:

(1) Removable contamination levels are below the level specified in appendix D of this part; and

(2) Materials shall be routinely monitored, clearly labeled, or tagged to alert personnel of the contaminated status; appropriate administrative procedures shall be established and exercised to maintain control of these items.

(d) The records for release of material and equipment shall describe the property, date on which the release survey was performed, identity of the individual who performed the survey, type and identification number of the survey instrument used, and results of the survey."

\section{REQUIREMINT SOURCE: DOE/EH0256T(940431) Chapter 4, Part 2, Article 422.1}

"Release to Uncontrolled Areas

Material in Controlled Areas or Radioactive Material Areas, documented to have been released from Contamination, High Contamination, or Airborne Radioactivity Areas, shall be surveyed prior to release to uncontrolled areas."

\section{REQUIREMENT SOURCE: DOE/EH0256T(940431) Chapter 4, Part 2, Article 422.2}

"DOE 5400.5 describes radiological criteria for releasing material to uncontrolled areas. Material being released shall also be evaluated for internal contamination and contamination under any coatings." 


\section{REQUIREMENT SOURCE: DOE/EH0256T(940431) Chapter 4, Part 2, Article 422.3}

"DOE 5400.5 describes criteria for releasing radioactive material that has been contaminated in depth or volume, such as activated material or smelted contaminated material."

\section{REQUIREMENT SOURCE: DOE/EH0256T(940431) Chapter 4, Part 2, Article 422.4}

"Material not immediately released after survey shall be controlled to prevent contamination while awaiting release."

\section{REQUIREMENT SOURCE: DOE/EH0256T(940431) Chapter 4, Part 2, Article 422.5}

"Radiological labeling shall be removed from or defaced on material prior to release for unrestricted use."

\section{REQUIREMENT SOURCE: DOE/EH0256T(940431) Chapter 5, Part 5, Article 554.2}

"Surveys for the release of radioactive materials shall be conducted in accordance with Articles 421 and $422 . "$

\section{REQUIREMIENT SOURCE: DOE/EH0256T(940431) Chapter 5, Part 5, Article 554.5}

"The requirements for assessing representative samples of bulk material, such as sand, sweeping compounds or plate steel, which are not suitable for normal loose and fixed contamination-level assessment techniques, are specified in DOE 5400.5."

\section{REQUIREMENT SOURCE: DOE5400.5 Chapter II, Section 5.c, Items (1)-(4)}

"Release of Materials and Equipment.

(1) Surface Contamination Levels. Prior to being released, property shall be surveyed to determine whether both removable and total surface contamination (including contamination present on and under any coating) is greater than the levels given in Figure IV-1 and that the contamination has been subjected to the ALARA process.

(2) Potential for Contamination. Property shall be considered to be potentially contaminated if it has been used or stored in radiation areas that could contain unconfined radioactive material or that are exposed to beams of particles capable of causing activation (neutrons, protons, etc.).

(3) Surveys. Surfaces of potentially contaminated property shall be surveyed using instruments and techniques appropriate for detecting the limits stated in Figure IV-1.

(4) Inaccessible Areas. Where potentially contaminated surfaces are not accessible for measurement (as in some pipes, drains, and ductwork), such property may be released after case-by-case evaluation and documentation based on both the history of its use and available measurements demonstrate that the unsurveyable surfaces are likely to be within the limits given in Figure IV-1." 


\section{$\underline{11.5 .3}$}

Specific Nuclide Control

Author's Note: This subelement also includes requirements for controlling "Hot Particles" (high specific activity individual radioactive particles) which may be encountered at the facility.

\section{REQUIREMENT SOURCE: DOE/EH0256T(940431) Chapter 3, Part 4, Article 348.2}

"Measures for controlling hot particles, as identified in items 3 through 7 of this Article, should be implemented under the following conditions:

a. Upon identification of hot particles;

b. During new or non-routine operations with a high potential for hot particles, based on previous history;

c. Upon direction of the Radiological Control Organization."

\section{REQUIREMENT SOURCE: DOE/EH0256T(940431) Chapter 3, Part 4, Article 348.3}

Author's Note: See Section 11.2.3 Contamination Monitoring and Surveying for requirements to Article 554.7.

"Areas or operations with the potential for hot particle contamination should be surveyed in accordance with Article 554.7."

\section{REQUIREMENT SOURCE: DOE/EH0256T(940431) Chapter 3, Part 4, Article 348.4}

"Contamination Area posting should be annotated to specifically identify the presence of hot particles."

\section{REQUIREMENT SOURCE: DOE/EH0256T(940431) Chapter 3, Part 4, Article 348.5}

"Access to hot particle areas should be controlled by a job-specific RWP. The following controls should be considered for inclusion on the RWP:

a. Periodic personnel monitoring during the work activity, at a frequency based on the potential magnitude of skin exposure;

b. Additional Personal Protective Equipment and clothing;

c. Direct Radiological Control coverage during work or assistance during protective clothing removal;

d. Use of sticky pads or multiple step-off pads." 


\section{REQUIREMENT SOURCE: DOE/EH0256T(940431) Chapter 3, Part 4, Article 348.6}

"Personal Protective Equipment and clothing used in hot particle areas should be segregated from other radiological protective equipment and clothing during laundering and surveyed prior to reuse."

\section{REQUIREMENT SOURCE: DOE/EH0256T(940431) Chapter 3, Part 4, Article} 348.7

Author's Note: Only Sections $a, b, \& d$ apply to the facility.

"Response to hot particle skin contamination of personnel should include the following:

a. Immediate removal and retention of the hot particle for subsequent analysis;

b. Analysis of the particle;

c. Assessment of worker dose;

d. Evaluation of work control adequacy."

Sealed Source Management

REQUIREMENT SOURCE: DOE/EH0256T(940431) Chapter 4, Part 3, Article 431.1

"DOE N 5400.9 (extended by DOE N 5400.10) describes how sealed radioactive sources shall be controlled and maintained, and specifies requirements for receipt, inventory, storage, transfer, disposal and integrity testing. Unsealed sources shall be controlled and maintained in a similar manner except for integrity testing."

\section{REQUIREMIanT SOURCE: DOE/EH0256T(940431) Chapter 4, Part 3, Article 431.2}

"Procurement of radioactive sources shall be coordinated with the Radiological Control Organization."

\section{REQUIREMIENT SOURCE: DOE/EH0256T(940431) Chapter 4, Part 3, Article 431.3}

"Receipt surveys of radiological material shipments shall be performed by the Radiological Control Organization."

REQUIREMENT SOURCE: DOE/EH0256T(940431) Chapter 4, Part 3, Article 431.4

"Radioactive sources, including radiography sources, shall not be brought on-site by external organizations without the prior written approval of the Radiological Control Organization. " 
11.6

$\underline{11.6 .1}$

$\underline{11.6 .1 .1}$

CONTAMINATION CONTROL

\section{Personnel, Equipment and Area Contamination Control}

Personnel Contamination Monitoring

Author's Note: Requirement DOE/EH0256T(940431), Chapter 5, Part 4, Article 541.3, as located in subelement 11.6.2, is also applicable to this subelement.

Author's Note: DOE 6430.1A, Division 1300, Section 6.5.3, as located in element 11.2, is also applicable to this subelement.

\section{REQUIREMENT SOURCE: 10CFR835 Part 404(f)}

"Appropriate monitoring to detect and prevent the spread of contamination shall be performed by individuals exiting radiological areas established to control removable contamination and/or airbome radioactivity."

REQUIREMENT SOURCE: DOE/EH0256T(940431) Chapter 3, Part 3, Article 338.1

"Monitoring for Personnel Contamination Personnel shall perform a whole body frisk under the following conditions:

a. Immediately upon entry into an uncontaminated area after exiting Contamination Areas, High Contamination Areas and Airborne Radioactivity Areas;

b. As directed by the RWP or the Radiological Control Organization."

\section{REQUIREMENT SOURCE: DOE/EH0256T(940431) Chapter 3, Part 3, Article 338.2}

"In addition to the above, personnel exiting a Radiological Buffer Area containing Contamination, High Contamination or Airborne Radioactivity Areas should, at a minimum, perform a hand and foot frisk. This frisk is optional if the Radiological Buffer Area exit is immediately adjacent to the location where the exiting worker has already performed a whole body frisk."

\section{REQUIREMINT SOURCE: DOE/EH0256T(940431) Chapter 3, Part 3, Article} 338.3

"Where frisking cannot be performed at the exit from Contamination Areas, High Contamination Areas or Airborne Radioactivity Areas due to high background radiation levels, personnel shall:

a. Remove all protective equipment and clothing at the exit;

b. Proceed directly to the nearest designated monitoring station;

c. Conduct a whole body frisk." 
REQUIREMENT SOURCE: DOE/EH0256T(940431) Chapter 3, Part 3, Article 338.4

"Personnel frisking shall be performed after removal of protective clothing and prior to washing or showering."

\section{REQUIREMENT SOURCE: DOE/EH0256T(940431) Chapter 3, Part 3, Article 338.5}

"Personnel frisking shall be performed using instruments that meet the minimum detection requirements of Article 221.2. Guidelines for personnel frisking are provided in Appendix 3D."

\section{REQUIREMENT SOURCE: DOE/EH0256T(940431) Chapter 3, Part 3, Article 338.7}

"Personal items, such as notebooks, papers and flashlights, shall be subject to the same frisking requirements as the person carrying them."

\section{REQUIREMENT SOURCE: DOE/EH0256T(940431) Chapter 3, Part 3, Article 338.8}

"Instructions for personnel frisking should be posted adjacent to personnel frisking instruments or monitors."

\section{REQUIREMENT SOURCE: DOE/EH0256T(940431) Chapter 5, Part 4, Article 541.2}

"When personnel detect skin contamination, they shall notify the Radiological Control Organization."

Personnel Contamination Control

Author's Note: Requirement DOE/EH0256T(940431), Chapter 2, Part 2, 222.1, as located in subelement 11.4.1.2, is also applicable to this subelement.

\section{REQUIREMENT SOURCE: 10CFR835 Part 404(g)}

"Protective clothing shall be required for entry to areas in which removable contamination exists at levels exceeding those specified in appendix D to this part."

\section{REQUIREMENT SOURCE: DOE/EH0256T(940431) Chapter 3, Part 4, Article 342.11}

"To minimize intakes of radioactive material by personnel, smoking, eating, or chewing shall not be permitted in Contamination, High Contamination or Airborne Radioactivity Areas. When a potential exists for personnel heat stress, drinking may be permitted within a Contamination Area under the following conditions and controls:

a. The potential for heat stress cannot be reduced by the use of administrative or engineering controls;

b. All drinking is from approved containers or sources; 
c. At a minimum, worker's hands and faces are monitored for contamination prior to drinking.

d. Participating workers are monitored as part of the bioassay program.

e. The applicable requirements and controls are described in approved procedures."

\section{REQUIREMINT SOURCE: DOE/EH0256T(940431) Chapter 5, Part 4, Article 542.1}

"Contaminated Wounds

Emergency medical care should be administered immediately for injuries involving radioactive materials in accordance with National Council on Radiation Protection and Measurements Report Number 65. Medical treatment of injuries takes precedence over radiological considerations."

\section{REQUIREMENT SOURCE: DOE/EH0256T(940431) Chapter 5, Part 4, Article} 542.2

"The treatment of contaminated injuries should include the following:

a. Treatment of contaminated wounds by medically qualified personnel;

b. Monitoring of wounds and associated bandages for contamination, including alpha emitters if applicable;

c. Identification of the radionuclides involved;

d. Medical determination of the need for therapeutic intervention such as blocking or chelating agents;

e. Initiation of appropriate bioassay monitoring;

f. Determination of need for work restrictions. "

11.6.1.3 Equipment and Area Contamination Control

\section{REQUIREMENT SOURCE: 10CFR835 Part 404(b)}

"Appropriate controls shall be maintained and verified which prevent the inadvertent transfer of removable contamination to locations outside of radiological areas under normal operating conditions."

\section{REQUIREMENT SOURCE: 10CFR835 Part 404(c)}

"Any area in which contamination levels exceed the values specified in appendix D of this part shall be:

(1) Posted in accordance with $\S 835.603$; and

(2) Controlled in a manner commensurate with the physical and chemical characteristics of the contaminant, the radionuclides present, and the fixed and removable contamination levels." 


\section{REQUIREMENT SOURCE: 10CFR835 Part 404(d)}

"Areas with fixed contamination exceeding the total radioactivity values specified in appendix D of this part may be located outside of radiological areas provided the following conditions are met:

(1) Removable contamination levels are below the levels specified in appendix D of this part;

(2) Unrestricted access to the area is not likely to cause any individual to receive a total effective dose equivalent in excess of 0.1 rem ( 0.001 sievert) in a year;

(3) The area is routinely monitored;

(4) The area is clearly marked to alert personnel of the contaminated status;

(5) Appropriate administrative procedures are established and exercised to maintain control of these areas; and

(6) Dose rates do not exceed levels which would require posting in accordance with § 835.603."

\section{REQUIREMENT SOURCE: DOE/EH0256T(940431) Chapter 1, Part 2, Article 125.10}

"Conditions that could cause or promote the spread of contamination, such as a leaking roof or piping, should be identified and corrected on a priority basis."

\section{REQUIREMENT SOURCE: DOE/EH0256T(940431) Chapter 2, Part 2, Article 222.3}

"In addition to the posting criteria in Article 235, the conditions for establishing and maintaining Fixed Contamination Areas include all of the following:

a. Radiological surveys shall be performed to detect contamination that may become removable over time.

b. A formal inventory shall be maintained of Fixed Contamination Areas.

c. Markings shall be kept legible.

d. Removable contamination should not exceed Table 2-2 values and should be reduced as far below Table 2-2 as is reasonably achievable before fixative coating is applied.

e. Fixed contamination should be covered with two layers of fixative coatings having different colors.

f. Markings should include the standard radiation symbol, be clearly visible from all directions and contrast with the colors of the surface coatings.

g. Additional coating should be applied when the bottom color appears.

h. A plan for identifying and adding to the inventory of existing areas of fixed contamination not included in the initial inventory should be developed." 
REQUIREMENT SOURCE: DOE/EH0256T(940431) Chapter 2, Part 2, Article 222.6

"For contaminated soil that is not releasable in accordance with DOE 5400.5, a Soil

Contamination Area shall be established that:

a. Is posted as specified in Article 235. Posting should include instructions or special warnings to workers such as "Consult With Radiological Control Organization Before Digging" or "Subsurface Contamination Exists."

b. Meets the requirements of Article 231.1 through 231.8."

REQURREMENT SOURCE: DOE/EH0256T(940431) Chapter 2, Part 2, Article 222.7

"Soil Contamination Areas may be located outside a Radiological Buffer Area."

REQUIREMENT SOURCE: DOE/EH0256T(940431) Chapter 3, Part 3, Article 337.1

"Use solid barriers to enclose areas wherever practicable"

REQUIREMENT SOURCE: DOE/EH0256T(940431) Chapter 3, Part 3, Article 337.2

"Mark and secure items such as hoses and cords that cross the boundary"

REQUIREMENT SOURCE: DOE/EH0256T(940431) Chapter 3, Part 3, Article 337.3

"Control and direct airflow from areas of lesser to greater removable contamination;"

REQUIREMENT SOURCE: DOE/EH0256T(940431) Chapter 3, Part 3, Article 337.4

"Use engineering controls and containment devices such as glovebags, gloveboxes and tents."

REQUIREMINT SOURCE: DOE/EH0256T(940431) Chapter 3, Part 4, Article 342. 2

"Tools and equipment should be inspected to verify operability before being brought into Contamination, High Contamination or Airborne Radioactivity Areas."

REQUIREMENT SOURCE: DOE/EH0256T(940431) Chapter 3, Part 4, Article 342.3

"The use of radiologically clean tools or equipment in Contamination, High Contamination or Airborne Radioactivity Areas should be minimized by the implementation of a contaminated tool crib in accordance with Article 492.5. When such use is necessary, tools or equipment with complex or inaccessible areas should be wrapped or sleeved to minimize contamination." 

342. 4

"Engineering controls, such as containment devices, portable or auxiliary ventilation and temporary shielding, should be installed in accordance with the technical work documents and inspected prior to use."

\section{REQUIREMENT SOURCE: DOE/EH0256T(940431) Chapter 3, Part 4, Article} 342.5

"Hoses and cables entering the work area should be secured to prevent the spread of contamination or safety hazards."

\section{REQUIREMENT SOURCE: DOE/EH0256T(940431) Chapter 3, Part 7, Article} 372.1

"The use of covers, wind screens and runoff collection basins to preclude the inadvertent spread of radioactive material ${ }^{n}$

\section{REQUIREMINT SOURCE: DOE/EH0256T(940431) Chapter 3, Part 7, Article} 372.2

"Provisions for worksite personnel to assemble and be monitored prior to release or reestablishment of work."

\section{REQUIREMENT SOURCE: DOE/EH0256T(940431) Chapter 3, Part 7, Article} 372.3

"Evaluation of work area to determine if a need exists for modified work controls or decontamination."

Personnel, Equipment and Area Decontamination

REQUIREMENT SOURCE: DOE/EH0256T(940431) Chapter 2, Part 2, Article 222.2

"Surfaces exceeding the values of Table 2-2 for total contamination may be covered with a fixative coating to prevent the spread of contamination. However, reasonable efforts should be made to decontaminate an area before a coating is applied. A fixative coating shall not be applied without the approval of the Radiological Control Manager."

REQUIREMENT SOURCE: DOE/EH0256T(940431) Chapter 3, Part 4, Article 342. 1

"Work Conduct and Practices

Contamination levels caused by ongoing work shall be monitored and maintained ALARA. Work should be curtailed and decontamination performed at preestablished levels, taking into account worker exposure. " 
REQUIREMINT SOURCE: DOE/EH0256T(940431) Chapter 3, Part 4, Article 342.10

"Requirements for area cleanup should be included in the technical work documents. Work activities should not be considered complete until support material and equipment have been removed and the area has been returned to at least prework status."

REQUIREMENT SOURCE: DOE/EH0256T(940431) Chapter 4, Part 6, Article 463.7

"Facility line management should be responsible for directing decontamination efforts."

\section{REQUIREMENT SOURCE: DOE/EH0256T(940431) Chapter 5, Part 4, Article 541.3}

"The extent of skin contamination should be determined prior to initiating decontamination procedures."

\section{REQUIREMENT SOURCE: DOE/EH0256T(940431) Chapter 5, Part 4, Article 541.4}

"Skin decontamination methods should be established for site-specific radionuclides. Skin abrasion should be avoided during the decontamination process. Intrusive decontamination methods, such as tissue removal, require medical assistance."

$\underline{11.6 .3}$

$\underline{11.6 .4}$

11.7

\section{Respiratory Protection Program}

Author's Note: Requirements for a Respiratory Protection Program are contained in the Occupational Safety and Health Company and Facility Functional Areas.

\section{Source Containment, Confinement, and Ventilation Control}

\section{REQUIREMIENT SOURCE: DOE/EH0256T(940431) Chapter 4, Part 5, Article 453.2}

"The Radiological Control Organization shall be notified when engineering controls that prevent worker exposure to airborne radioactivity, such as barriers, gloveboxes and glovebags, are compromised. An evaluation should be made of continuing operations with compromised engineering controls. The use of respiratory protection to continue activities under these conditions is discouraged. Implementation of short-term engineering modifications that provide a commensurate level of worker protection is the preferred alternative."

\section{REQUIREMENT SOURCE: DOE/EH0256T(940431) Chapter 4, Part 5, Article 453.3}

"Preventive maintenance and surveillance procedures shall be established to ensure equipment controls are maintained in an operable condition for containment of airborne radioactivity."

\section{LABORATORY ANALYSIS}

Author's Note: Any applicable requirements for this element are defined in the WHC Radiation Protection S/RID, Sections 11.2, Monitoring and Surveys and Section 11.3, Personnel Exposure Monitoring. 
11.8

$\underline{11.8 .1}$

$\underline{11.8 .2}$

$\underline{11.8 .3}$

\section{RADIOLOGICAL PROTECTION EQUIPMENT AND SUPPLIES}

\section{Monitoring and Survey Instrumentation}

The elements within this section are specific to the equipment itself. Requirements relative to surveys performed with the equipment or the monitoring of facility areas using the equipment are included in Section 11.2, Facility Monitoring and Surveys.

\section{Respiratory Equipment and Supplies}

Author's Note: Requirements for a Respiratory Protection Program are contained in Occupational Safety and Health Functional Area for both Company and Facility levels.

\section{Protective Clothing}

Author's Note: Additional requirements can be found in Section 11.6.1.2, Personnel Contamination Control.

\section{REQUIREMENT SOURCE: DOE/EH0256T(940431) Chapter 3, Part 2, Article} 325.1

"Personal Protective Equipment and Clothing

Personnel shall wear protective clothing during the following activities:

a. Handling of contaminated materials with removable contamination in excess of Table $2-2$ levels;

b. Work in Contamination, High Contamination and Airborne Radioactivity Areas;

c. As directed by the Radiological Control Organization or as required by the RWP."

\section{REQUIREMENT SOURCE: DOE/EH0256T(940431) Chapter 3, Part 2, Article} 325.2

"Protective clothing and shoes designated for radiological control shall be:

a. Marked in accordance with Article 451;

b. Used only for radiological control purposes. "

\section{REQUIREMENT SOURCE: DOE/EH0256T(940431) Chapter 3, Part 2, Article} 325.3

"Protective clothing dress-out areas should be established directly adjacent to the work area. Workers should proceed directly to the radiological work area after donning Personal Protective Equipment and clothing."

\section{REQUIREMENT SOURCE: DOE/EH0256T(940431) Chapter 3, Part 2, Article} 325.4

"Personal Protective Equipment and clothing shall be selected as prescribed by the controlling RWP. General guidelines for protective clothing selection and use are provided in Appendix $3 \mathrm{C}$ and in Table 3-1." 
REQUIREMENT SOURCE: DOE/EH0256T(940431) Chapter 3, Part 2, Article 325.5

"The use of lab coats as radiological protective clothing is appropriate for limited applications such as those discussed in Appendix $3 \mathrm{C}$ where the potential for personal contamination is limited to the hands, arms, and upper front portion of the body. Lab coats should not be used as protective clothing for performing physical work activities in Contamination, High Contamination or Airborne Radioactivity Areas. "

\section{REQUIREMENT SOURCE: DOE/EH0256T(940431) Chapter 3, Part 2, Article 325.6}

"Instructions for donning and removing protective clothing should be posted at the dress-out and step-off pad areas."

\section{REQUIREMENT SOURCE: DOE/EH0256T(940431) Chapter 3, Part 2, Article 325.7}

"The use of Personal Protective Equipment or clothing (including respiratory protection) beyond that authorized by the Radiological Control Organization detracts from work performance and is contrary to ALARA principles and waste minimization practices. Such use should not be authorized."

\section{REQUIREMENT SOURCE: DOE/EH0256T(940431) Chapter 3, Part 2, Article 325.8}

"Company-issued clothing, such as work coveralls and shoes, should be considered the same as personal clothing. Company-issued clothing should not be used for radiological control purposes."

\section{REQUIREMENT SOURCE: DOE/EH0256T(940431) Chapter 4, Part 6, Article 462.6}

"Cleaned Personal Protective Equipment and laundered protective clothing shall be inspected prior to use. Clothing should be free of tears, separated seams, deterioration and damage, or repaired in a manner that provides the original level of protection."

\section{Equipment Maintenance and Calibration}

Author's Note: Requirement DOE/EH0256T(940431), Chapter 5, Part 6, Article 562.1, as located in element 11.2 , is also applicable to this subelement.

\section{REQUIREMENT SOURCE: DOE/EH0256T(940431) Chapter 5, Part 6, Article 562.8}

"Instruments whose "as found" readings indicate that the instrument may have been used while out of calibration shall be reported to the Radiological Control Organization. The Radiological Control Organization should review surveys performed with the instrument while it was out of calibration. " 
REQUIREMENT SOURCE: DOE/EH0256T(940431) Chapter 5, Part 6, Article 563.3

"Radiological instruments shall undergo calibration prior to use following any preventive or corrective maintenance or any adjustment that voids the previous calibration. A battery change is not normally considered maintenance."

\section{REQUIREMENT SOURCE: DOE/EH0256T(940431) Chapter 5, Part 6, Article 564.1}

"Calibration facilities should perform inspections, calibrations, performance tests, calibration equipment selection and quality assurance in accordance with the recommendations of ANSI N323 and take the following actions:

a. Locate activities in a manner to minimize radiation exposure to operating personnel and to personnel in adjacent areas;

b. Minimize sources of interference, such as backscatter and non-ionizing radiation, during the calibration of instrumentation and correct for interferences as necessary;

c. Operate in accordance with the referenced standards;

d. Generate records of calibration, functional tests and maintenance in accordance with the referenced standards."

RADIATION PROTECTION OF THE PUBLIC AND ENVIRONMIENT

\section{Dose Limits}

Dose limits and other requirements related to general public exposures and exposures from discharges/effluents are included in the Environmental Protection Functional Area.

11.9.2 Liquid Waste Discharges

Requirements which specify control of radioactive liquid discharges to surface waters, aquifers or public sewage systems are included in the Environmental Protection Functional Area and Waste Management Functional Area.

\section{$\underline{\text { 11.9.3 }} \quad \underline{\text { Solid Waste Disposal }}$}

Requirements which regulate the disposal of solid radioactive waste are included in the Waste Management Functional Area.

\section{Demonstration of Compliance}

Requirements for the monitoring and surveillance of radioactive effluents are included in the Waste Management Functional Area and the Environmental Protection Functional Area.

\section{KEY INTERFACES}

Radiation Protection is a unique functional area in that all other functional areas at some time are likely to interface with Radiation Protection in the extension of their prescribed responsibilities. The following sections do not address this type of interface as it is understood 
$\underline{11.10 .1}$

$\underline{11.10 .2}$

$\underline{11.10 .3}$

$\underline{11.10 .4}$

$\underline{11.10 .5}$

$\underline{11.10 .6}$

that any group which has need to access or otherwise impact a radiologically controlled area will have some level of interface with the Radiation Protection functional area.

\section{Management Systems}

The Management Systems functional area delineates the administrative programs which establish policies relevant to Radiation Protection in regard to human resources and document control. Due to the potential liability associated with improper record retention within the RP area this is an especially important facet of the interface.

This interface provides a vehicle to ensure a commitment to radiation protection is incorporated into related areas at a proper management level.

\section{Quality Assurance}

Quality Assurance is vital in confirming that the RP program is being implemented according to procedure. This interface helps to improve the $R P$ organization and aids in preventing the continuance of negative implementation trends.

A proper interface with QA involving regular interaction and feedback ensures the requirements for the safety of both workers and the general public are met, along with the associated reporting requirements being implemented.

\section{Configuration Management}

The interface with Configuration Management ensures a control change process is executed for both emergency and normal procedures. This is a key element in maintaining a properly and consistently implemented RP program. Additionally this interface safeguards from the possibility of plant modifications or significant variations in activities not receiving proper consideration from the RP department.

\section{Training and Oualifications}

Properly implementing a Radiation Protection plan is dependent to a large part on the proper level of individual qualification, and appropriate initial and supplemental training being given. The Training and Qualification functional area provides the vehicle by which jobs are defined (i.e., job task analysis) and training is designed and subsequently administered.

Further, a successful RP program leans heavily on the level of knowledge which the balance of the workforce has in the area of safe radiation protection techniques on the job-site. This need is addressed within the general employee training program.

\section{Emergency Planning}

The interface between Radiation Protection and Emergency Planning is substantial due to the fact many of the incidents which might occur have clear radiological ramifications.

Additionally RP personnel are used as key support during emergencies, thus the interface is important to ensure proper understanding of individual responsibilities.

\section{Engineering Program}

The ALARA principle is an important consideration in all new construction including design changes to facilities and systems. The interface with Engineering is necessary to ensure RP input during the planning and design phase of construction or modification activities. 
$\underline{11.10 .7}$

11.10 .8

$\underline{11.10 .9}$

11.10 .10

$\underline{11.10 .11}$

$\underline{11.10 .12}$

$\underline{11.10 .13}$

11.11

11.11.1

\section{Operations}

This interface is daily and routine. To be able to properly implement the ALARA philosophy and good RP principles the Operations department and the RP department must be jointly planning work, both routine and non-routine.

\section{Maintenance}

This interface is also daily and routine. To be able to properly implement the ALARA philosophy and good RP principles the Maintenance department and the RP department must be jointly planning work, both routine and non-routine. Additionally Maintenance is responsible for maintaining some RP monitoring equipment which requires RP awareness if problems arise.

Since RP personnel have a large presence throughout the Tank Farms they have the ability to make observations of the physical condition of equipment (such as leaks) and give feedback to maintenance. This aspect of the interface is unofficial however, it can be very beneficial.

\section{Packaging and Transportation}

Radiation Protection personnel perform radiological surveys on item which are being transported or received at the facility; to perform this they must receive information from PT as to the disposition of such items.

\section{Research and Development and Experimental Activities}

This functional area is not applicable to Tank Farms.

\section{Nuclear Safety}

The Nuclear Safety functional area encompasses the operation of nuclear facilities from design through decommissioning, thus an interface with RP is essential to ensure radiation protection standards are incorporated into the nuclear safety program.

\section{Environmental Protection}

This interface exists to help ensure environmental release limits are not exceeded. This is accomplished by communication, monitoring, surveillance, and waste minimization at a minimum.

\section{Occupational Safety and Health}

The Occupational Safety and Health Functional Area provides respiratory equipment and supplies as well as heat stress procedures in support of Radiation Protection Program functions.

\section{REFERENCES}

\section{Requirement Source Documents}

The following documents were used as requirement sources in the development of this S/RID:

10 CFR 835, Occupational Radiation Protection, 12/13/93 
DOE 5400.5, Radiation Protection of the Public and the Environment, 02/08/90

DOE-EH0256T, DOE Radiological Control Manual, 04/30/94

\section{$\underline{11.11 .2}$}

\section{Reviewed Documents Not Used as Requirement Sources}

The following Documents were reviewed as requirement sources but were not used in the development of this S/RID:

10 CFR 20, Standards for Protection Against Radiation, 12/31/93

DOE 5000.3B, Occurrence Reporting and Processing of Operations Information, 02/22/93

DOE 5400.1, General Environmental Protection Program, 06/29/90

DOE 5480.11, Radiation Protection for Occupational Workers, 06/17/92

DOE 5480.15, Department of Energy Laboratory Accreditation Program for Personnel Dosimetry, $12 / 14 / 87$

DOE 5484.1, Environmental Protection, Safety, and Health Protection Information Reporting Requirements, 2/24/81

DOE 6430.1A, General Design Criteria, 04/06/89

DOE/EH0173T, Environmental Regulatory Guide for Radiological Effluent Monitoring and Environmental Surveillance, 01/91

DOE 5400.9, Sealed Radioactive Source Accountability, 02/08/90

DOE 5480.1B, Environmental, Safety, and Health Protection Program for DOE Operations, $09 / 23 / 86$

DOE 5480.5A, Safety of Nuclear Facilities, 08/02/90

DOE 5480.15, Department of Energy Laboratory Accreditation Program for Personnel Dosimetry, 12/14/87

DOE 5480.19, Conduct of Operations for DOE Facilities, 05/18/92

DOE 5480.20, Personnel Selection, Qualification, Training and Staffing Requirements at DOE Reactor and Non-Reactor Nuclear Facilities, 06/19/91

DOE 5480.24, Nuclear Criticality Safety Program, 08/12/92

DOE 5483.1B, Occupational Safety and Health Program for DOE Contractor Employees at Government-Owned Contractor-Operated (GOCO) Facilities, 05/31/89

WAC 246-243, Department of Health, 01/01/90

WAC 402-24, Washington Administrative Code-Standards for Protection against Radiation, $12 / 31 / 89$

NUREG-0041, Manual of Respiratory Protection Against Radioactive Materials, 10/76 
NUREG-0761, Radiation Protection for Nuclear Power Plant Licensees, 03/01/81

ANSI/ASME N510, Testing of Nuclear Air Cleaning Systems, 1980

ANSI-N13.14-1983, Internal Dosimetry Standard for Tritium, 1983

ANSI N13.15-1985, Performance of Personnel Thermoluminescence Dosimetry, 1985

ANSI-N13.27-1981, Performance Requirements for Pocket-Sized Alarm Dosimeters and Alarm Ratemeters, 1981

ANSI-N42.6-1980, Bases for GM counter tubes interrelationship of Quartz-Fiber Electrometer Type Exposure Meters and Companion Exposure Meter Charges, 1980

ANSI-N42.9-1972, IEEE Standard Test Procedures for Photomultipliers for Scintillation Counting and Glossary for Scintillation Counting Field, 1972

ANSI-N42.12-1980, Sodium Iodide Detector Systems, Calibration and Usage, 1980

ANSI-N42.15-1980, Performance verification of Liquid-Scintillation Counting Systems, 1980

ANSI-N43.3-1993, Installations using Non-Medical X-Ray and Sealed Gamma Ray Sources Energies up to $10 \mathrm{Mev}, 01 / 28 / 93$

ANSI-N322-1977, Inspection and Test Specification for Direct and Indirect Quartz Fiber Pocket Dosimeters 1983

ICRP 54, Individual Monitoring For Intakes of Radionuclides by workers: Design and Interpretation, 1988

ICRU 14, Radiation Dosimetry: X-rays and Gamma Rays with Maximum Photon Energies between 0.6 and $50 \mathrm{MeV}, 09 / 15 / 69$

NCRP 65, Management of Persons Accidentally Contaminated with Radionuclides, 04/15/80

NCRP 84, General Concepts for the Dosimetry of Internally Deposited Radionuclides, $09 / 30 / 85$

NCRP 87, Use of Bioassay Procedures for Assessment of Internal Radionuclide Deposition, $02 / 28 / 87$ 


\section{TABLE OF CONTENTS}

12.1.1

12.1 .2

12.1.2.1

12.1.2.2

12.1.2.3

12.1 .2 .4

12.1 .2 .5

12.1.2.6

12.1.2.7

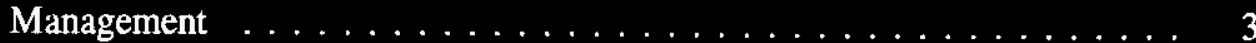

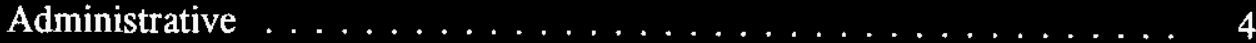

Fire Prevention Procedures $\ldots \ldots \ldots \ldots \ldots$

Assessment Results Tracking Program $\ldots \ldots \ldots \ldots$

Interim Compensatory Measures $\ldots \ldots \ldots \ldots \ldots$

Operability Specifications $\ldots \ldots \ldots \ldots \ldots$

Emergency Planning $\ldots \ldots \ldots \ldots \ldots \ldots$

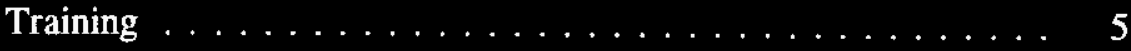

Communications $\ldots \ldots \ldots \ldots \ldots \ldots \ldots \ldots$

12.2
12.2.1.1

12.2.1.1.1

12.2.1.1.2

12.2 .1 .1 .3

12.2.1.1.4

12.2.1.1.5

12.2.1.1.6

12.2.1.1.7

12.2.1.2

12.2.1.3

12.2 .2

Automatic Fire Suppression Provisions $\ldots \ldots \ldots \ldots$

Automatic Sprinkler Systems $\ldots \ldots \ldots \ldots$

Wet Pipe Systems . . . . . . . . . . . . . 8

Dry Pipe Systems $\ldots \ldots \ldots \ldots \ldots$

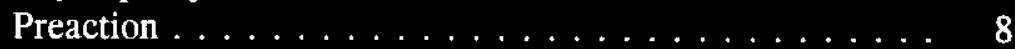

Deluge $\ldots \ldots \ldots \ldots \ldots \ldots \ldots$

Pressure-Relief Valves . . . . . . . . . . . . 9

Pressure-Reducing Valves $\ldots \ldots \ldots \ldots \ldots \ldots$

Special Fire Suppression Systems $\ldots \ldots \ldots \ldots \ldots$

Control of Liquid Runoff $\ldots \ldots \ldots \ldots \ldots$

Water Supply and Distribution Systems . . . . . . . . . . . . . . . 10

12.2.2.1

Water Supply Systems $\ldots \ldots \ldots \ldots \ldots$

12.2.2.1.1

12.2.2.1.2

12.2.2.1.3

12.2.2.1.4

12.2.2.1.5

12.2.2.1.6

12.2.2.1.7

12.2.2.1.8

12.2.2.1.9

12.2.2.1.10

12.2.2.1.11

12.2.2.1.12
Mains, Water Storage, and Fire Pumps . . . . . . . . 11

Fire Hydrant Capacity $\ldots \ldots \ldots \ldots 11$

Fire Hydrant Spacing and Location $\ldots \ldots \ldots$

Air Release and Vacuum Valves ... . . . . . . . . . 12

Distribution Systems Mains Depth . . . . . . . . . . . 12

Water Distribution Loop Systems . . . . . . . . . . . . . 12

Sprinkler Supply Lead-Ins . . . . . . . . . . . . . . . . . 13

Combined Fire and Domestic Process Water Systems . . . 13

Sprinkler Risers $\ldots \ldots \ldots \ldots \ldots \ldots \ldots$

Outside Control Valves . . . . . . . . . . . . . . 13

Key Operated Buried Valves $\ldots \ldots \ldots \ldots$

Sprinkler Systems Lead-Ins and Fire Hydrants . . . . . . 14 
Corridor Widths $\ldots \ldots \ldots \ldots \ldots \ldots \ldots \ldots \ldots$

12.2.4.1.4

Door Encroachment . . . . . . . . . . . . . . . 16

12.2.4.1.5

Security Areas $\ldots \ldots \ldots \ldots \ldots \ldots \ldots \ldots . \ldots 16$

12.2.4.1.6

Zoning for Automatic Control . . . . . . . . . . . . . . 17

12.2.4.1.7

Life Safety in Hazardous Areas

12.2 .5

12.2 .6

12.2 .7

12.2 .8

12.2 .8 .1

12.2.8.2

12.2 .8 .3

12.2 .8 .4

12.2 .8 .5

Improved Risk Facilities . . . . . . . . . . . . . . . . . . . 18

Decommissioning Planning $\ldots \ldots \ldots \ldots \ldots \ldots \ldots \ldots \ldots$

Construction ........................... 19

Fire Alarm Systems $\ldots \ldots \ldots \ldots \ldots \ldots \ldots \ldots \ldots \ldots \ldots . \ldots \ldots$

Fire Detection Systems

Fire Detection and Alarm Systems Design, Installation, Inspection, and Testing $\ldots \ldots \ldots \ldots \ldots \ldots \ldots \ldots \ldots$ Fire Alarm System Features . . . . . . . . . . . . . 21 Compatibility of Alarm Systems $\ldots \ldots \ldots \ldots \ldots \ldots \ldots$

Fire Watch and Alarm Systems . . . . . . . . . . . . . 21 Underground Cables for Alarm Systems $\ldots \ldots \ldots \ldots . \ldots 22$

12.4 .1

12.4 .2

12.4 .3

12.4 .4

12.4.4.1

12.4 .4 .2

12.4.4.3

12.4.4.4

12.4 .4 .5

12.4 .4 .6
Performance Objectives in the Design of DOE Facilities . . . . . . . . 25

Exterior Fire Protection Systems and Features . . . . . . . . . . . 26

Fire Resistance for Materials and Construction . . . . . . . . . . . 26

Control of Combustibles . . . . . . . . . . . . . . . . . 27

Interior Finish Materials . . . . . . . . . . . . . . . . 27

Interior Floor Coverings . . . . . . . . . . . . . . . . 27

Control of Combustible Materials by Building Design . . . . . . . 27

Quantities of Stored Materials . . . . . . . . . . . . . . . . . . 27

Fire and Explosion Potential of the Materials . . . . . . . . . . . 28

Storage and Use of Compressed Gases . . . . . . . . . . . . 29

Electrical Systems . . . . . . . . . . . . . . . . . . . . . . . . 29 
12.4.5.1

12.4 .5 .2

12.4 .5 .3

12.4 .5 .4

12.4 .5 .5

12.4 .6

12.4.6.1

12.4 .6 .2

12.4.6.3

12.4.6.4

12.4.6.5

12.4 .6 .6
Ignition Source by Electrical Equipment . . . . . . . . . . . . 29

Listing Requirements for Electrical Materials and Equipment . . . 29

Conduits . . . . . . . . . . . . . . . . . . 30

Redundant Electric Circuits . . . . . . . . . . . . . 30

Primary, Auxiliary, Emergency, and Standby Power Systems . . 30
12.4 .7

12.4 .8

12.4 .9

12.5

12.6

12.6.1

12.6 .3

12.7

12.7 .8

12.7 .9

12.7 .10

12.7 .11

12.7 .12

12.7 .13

12.8
Exhaust and Ventilation Systems $\ldots \ldots \ldots \ldots \ldots \ldots$

Ductwork and Air Ventilation Systems . . . . . . . . . . 31

Smoke Pressurization and Evacuation Systems _ . . . . . . . 32

Confinement Systems Function During the DBF . . . . . . . . 32

Confinement Systems and Fire Protection . . . . . . . . . . 32

Design Features for Lower Flammability Limit . . . . . . . . . . . 32

HEPA Filters . . . . . . . . . . . . . . . 32

Lighting Protection $\ldots \ldots \ldots \ldots \ldots \ldots \ldots \ldots \ldots$

Seismic Requirements . . . . . . . . . . . . . . . . . 33

Safety Class Equipment $\ldots \ldots \ldots \ldots \ldots \ldots$

FIRE, HAZMAT AND MEDICAL SUPPORT . . . . . . . . . . . . . . 34

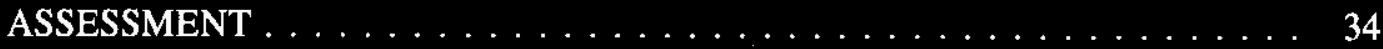

Fire Protection Investigation and Reporting $\ldots \ldots \ldots \ldots . \ldots 34$

Control of Fire Protection Impairments . . . . . . . . . . . . 38

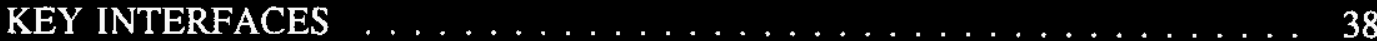

Configuration Management $\ldots \ldots \ldots \ldots \ldots$

Engineering Program $\ldots \ldots \ldots \ldots \ldots \ldots \ldots$

Emergency Management . . . . . . . . . . . . . . . . . . . . 39

Nuclear Safety . . . . . . . . . . . . . . . . . . . . . 39

Occupational Safety and Health . . . . . . . . . . . . . 39

Management Systems . . . . . . . . . . . . . . . . . . . 39

REFERENCES . . . . . . . . . . . . . . . . . . . . . 40

12.8 .8

Requirement Source Documents . . . . . . . . . . . . . . . . . 40

Reviewed Documents Not Used as Requirement Sources . . . . . . . . . . 40 


\subsection{FIRE PROTECTION}

\section{NTRODUCTION}

A Standards/Requirements Identification Document (S/RID) sets forth the Environmental Safety and Health (ES\&H) standards/requirements. This S/RID is applicable to the appropriate life cycle phases of design, construction, operation, and preparation for decommissioning for each of the categories of facilities addressed in Revision 5 of the Department of Energy Implementation Plan for the Defense Nuclear Facilities Safety Board (DNFSB) Recommendation 90-2. This Recommendation calls for the strengthening of DOE weapons complex activities through the identification and application of relevant DOE Orders, regulations, industry codes/standards, industry guidance documents and, as appropriate, good industry practices. These standards/requirements are adequate to ensure protection of the health and safety of workers, the public, and the environment.

The Tank Farms S/RID contains standards/requirements that are necessary for safe operation of the Tank Farms and its associated facilities, and that are the direct responsibility of the specific facility manager. The Fire Protection Program defined in this document is described in general accordance with the Environment, Safety, and Health Configuration Guide, Revision 0, dated July 30, 1993, and is presented in program elements and subelements. The specific DOE Orders, regulations, industry codes/ standards, guidance documents and good industry practices that serve as the basis for each element/subelement are identified and aligned with each subelement.

This S/RID contains only those requirements that Tank Farms personnel are clearly responsible to satisfy. Other requirements that are applicable to Tank Farms, but are satisfied by others, are defined in the Westinghouse Hanford Company (WHC) Level S/RID. For application in this S/RID, the words "shall" and "should" in requirements statements both indicate mandatory compliance. The Key interface information contained in the Functional Area documents is provided for general recognition and understanding and is not considered to contain prescriptive requirements. Additionally, some of the requirements cited in this document are intentionally duplicated in the corresponding Company Level S/RID. This was necessary to address required implementation responsibilities occurring at both the company and facility levels.

\section{SCOPE}

This S/RID applies to the Tank Waste Remediation Systems (TWRS) Organization which includes the following:

- $\quad$ East Tank Farm Transition Project

West Tank Farm Transition Project

Evaporator Project

Interim Stabilization Project

Characterization Sampling Project (Excluding the Labs) 
High Level Waste Storage

Tank Farms/242-A Evaporator

Standards/Requirements Identification Document

12.0 Fire Protection
WHC-SD-MP-SRID-001 January 10, 1996

Rev. 0

Page 2 of 40

The near-term mission of TWRS is to store, treat, and immobilize the highly radioactive Hanford Site Waste. 
MANAGEMENT AND ADMINISTRATION

Management

REQUIREMENT SOURCE: 29CFR1926 Part 150(a)(2)

"Access to all available firefighting equipment shall be maintained at all times."

REQUIREMENT SOURCE: 29CFR1926 Part 150(a)(3)

"All firefighting equipment, provided by the employer, shall be conspicuously located."

REQUREMENT SOURCE: 29CFR1926 Part 150(a)(4)

"All firefighting equipment shall be periodically inspected and maintained in operating condition. Defective equipment shall be immediately replaced."

\section{REQUIREMINT SOURCE: 29CFR1926 Part 150(a)(5)}

"As warranted by the project, the employer shall provide a trained and equipped firefighting organization (Fire Brigade) to assure adequate protection to life."

\section{REQUIREMINT SOURCE: DOE5480.7A Section 8.i}

Author's Note: Only sections 2, 3, and 5 thru 8 apply to the facility.

"As required by the PSO or the Heads of Field Organizations and directed by the Contracting Officer, contractors shall be required to:

(1) Provide and maintain a level of fire protection to meet the objectives of paragraph 4 , and the criteria of paragraph 9 .

(2) Provide and maintain a system to ensure that the requirements of the DOE fire protection program are documented and incorporated in the plans and specifications for all new facilities and for major modifications of existing facilities. This includes review and comment by a qualified fire protection engineer of plans, specifications and test procedures and results for fire protection features.

(3) Assists DOE in coordinating fire safety assessments at those facilities included in the survey program, establish action plans for compliance with recommendations resulting from the assessments, and forward compliance plans, exemption requests, and other requested data to DOE field organizations.

(4) Establish and maintain a list of facilities for which the contractor has fire protection assessment responsibility.

(5) Conduct fire protection assessments of facilities according to the scope and frequency established by this Order.

(6) Provide fire protection technical assistance to DOE.

(7) Submit request for exemptions and fire safety equivalencies to the Head of the Field Organization for those facilities where compliance with specific program elements is not attainable and where an acceptable level of safety has been achieved. 
(8) Maintain or have access to an adequate fire protection staff, including a qualified fire protection engineer(s). Continuing education and training should be provided to maintain and enhance the level of competency of the fire protection staff."

\section{Administrative}

Author's Note: The requirements implementation is the joint responsibility of the site and facility.

\section{REQUIREMENT SOURCE: DOE5480.7A Section 9(1)}

"A DOE facility shall be characterized by a level of fire protection sufficient to fulfill the requirements for the best protected class of industrial risks (Highly Protected Risks/Improved Risks). This program is characterized by the inclusion of a continuing, sincere interest on the part of management and employees in minimizing losses from fire and related perils and the inclusion of preventive features necessary to ensure the satisfaction of objectives related to safety."

\section{REQUIREMENT SOURCE: DOE5480.7A Section 9(2)}

"Based on the above paragraph the DOE Fire Protection Program shall meet or exceed the minimum requirements established by the National Fire Protection Association as directed by the PSO. Basic requirements shall include: a reliable water supply of acceptable capacity for fire suppression; noncombustible construction of an acceptable nature for the occupancy of the facility; automatic fire extinguishing systems; a fully staffed, trained, and equipped emergency response force; a means to summon the emergency response force in the event of a fire; and a means to notify and evacuate building occupants in the event of a fire. For areas subject to significant life safety risks, serious property damage, program interruption, or loss of safety class equipment as defined in the relevant facility SAR, additional protection measures may be necessary as determined by the AHJ."

Fire Prevention Procedures

\section{REQUIREMINT SOURCE: DOE5480.7A Section 9.c.(1)}

"Fire Prevention Procedures. Facilities shall have procedures governing the use and storage of combustible, flammable, radioactive and hazardous materials as to minimize the risk from fire. Such procedures shall also exist for activities, such as smoking limitations, isolation of hot work, and other fire prevention measures, which contribute to the decrease in fire risk."

\section{REQUIREMENT SOURCE: DOE5480.7A Section 9.c.(2)}

"Assessment Results Tracking Program. There shall be a program to identify, prioritized and monitor the status of fire protection related assessment findings/recommendations until resolution is achieved. Resolution could be achieved by either: plant modification, procedure change, fire safety equivalency, or exemption." 
$\underline{12.1 .2 .3}$

$\underline{12.1 .2 .4}$

$\underline{12.1 .2 .5}$

$\underline{12.1 .2 .6}$

$\underline{12.1 .2 .7}$

12.2

$\underline{12.2 .1}$
Interim Compensatory Measures

REQUIREMINT SOURCE: DOE5480.7A Section 9.c.(3)

"Interim Compensatory Measures. When final resolution of a finding/recommendation will be significantly delayed because of funding, scheduling, or other considerations, appropriate interim compensatory measures (e.g., fire watches, fire patrols, enhanced hazards control procedures, temporary fire protection features) shall be implemented to minimize the fire risk."

Operability Specifications

\section{REQUIREMENT SOURCE: DOE5480.7A Section 9.c.(4)}

"Operability Specifications. Minimum requirements to establish "operability" shall be developed for fire protection features such as: fire doors, fire dampers, fire detection and suppression systems, fire protection water supplies, etc. Periodic tests, conducted to satisfy the applicable NFPA codes and standards or other DOE criteria shall confirm that these features are operable. If fire protection will be inoperable for a significant period of time, interim compensatory measures shall be implemented until operability is restored."

\section{Emergency Planning}

\section{REQUIREMENT SOURCE: DOE5480.7A Section 9.c.(5)}

"Emergency Planning. Information from the fire protection program shall be incorporated in the Emergency Plan. The facility fire protection organization shall be involved in the development of the Emergency Plan and in all related training and drills."

Training

Author's Note: Refer to the WHC Site Fire Protection Functional Area document for requirements pertaining to Fire Protection.

Communications

\section{REQUIREMENT SOURCE: DOE5480.7A Section 9.c.(7)}

"Communications. Emergency communications shall be outlined in the emergency plan. The communications capability among potential responders to an emergency shall be coordinated to avoid confusion and interference. This capability shall be tested on a frequency established by the authority having jurisdiction in accordance with DOE criteria."

\section{FIRE PROTECTION PROGRAM}

Author's Note: Per DOE 5480.7A, this order has primacy over all other DOE Orders with respect to matters concerning Fire Protection.

Fire Protection Suppression Systems 
Author's Note: Facility complies with NFPA in its entirety, per DOE Order $5480.7 \mathrm{~A}$, Section 5 , which lists the mandatory requirements, one of which is the NFPA Codes and Standards.

\section{REQUIREMIENT SOURCE: DOE5480.7A Section 9.b.( 3)}

"Automatic Fire Protection - Complete automatic fire suppression systems designed in accordance with applicable NFPA standards shall be provided as follows:

(a) In all new structures over $\mathbf{5 0 0 0}$ square feet

(b) In all structures having an MPFL in excess of $\$ 1,000,000$. or where the maximum credible fire will result in the loss of use of a vital structures for a period longer than that specified as acceptable by the applicable PSO."

\section{REQUIREMENT SOURCE: DOE5480.7A Section 9.b.( 4)}

"Redundant Fire Protection -

(a) When the MPFL exceeds $\$ 50$ million, a redundant fire protection system is provided that, despite the failure of the primary fire protection system, will limit the loss to $\$ 50$ million.

(b) When the MPFL exceeds $\$ 150$ million, a redundant fire protection system and a 3-hour fire barrier are required to limit the maximum possible fire loss to $\$ 150$ million."

\section{REQUIREMENT SOURCE: DOE6430.1A Section 1161.3}

"Automatic fire suppression provisions shall comply with DOE 6430.1A, Section 1530-99, Special Features. When an automatic fire suppression system is mandatory and protection against loss from fire originating within the enclosure system is required, a highly reliable, fast-acting system shall be provided. Instead of such a system, an inert atmosphere can be used with in the enclosure, provided its reliability is commensurate with and approved fire suppression system (e.g. dedicated gas supply, component quality and redundancy where appropriate). The oxygen concentration shall be less than the minimum concentration that would allow ignition or combustion of the enclosure contents. Where automatic systems are not required, fire detection shall be installed. Fire detection systems shall be integrated with any central alarm location and any associated automatic fire suppression systems."

\section{REQUIREMENT SOURCE: DOE6430.1A Section 1530-4.1}

"Automatic Sprinkler Protection - All sprinkler systems shall comply with NFPA 13."

\section{REQUIREMENT SOURCE: DOE6430.1A Section 1530-99.0[ 2]}

"Fire protection systems shall not: (1) prevent a facility from achieving and maintaining a safe shutdown condition, (2) prevent the mitigation of DBA consequences, or (3) cause an inadvertent nuclear criticality."

\section{REQUIREMENT SOURCE: DOE6430.1A Section 1530-99.0[ 3]}

"Total reliance shall not be placed on a single fire suppression system. Appropriate backup capability shall be provided." 


\section{REQUIREMENT SOURCE: DOE6430.1A Section 1530-99.0[ 4]}

"To ensure that redundant safety class components shall be capable of performing the necessary safety functions, the facility design shall provide appropriate separation against fire, explosion, and failure of fire suppression systems. "

\section{REQUIREMINT SOURCE: DOE6430.1A Section 1530-99.0[ 5]}

"Fire protection systems, or portions of them, that must function to control effects of a DBA event (as determined by safety analysis accident scenarios) shall be designed to be functional for all conditions included in the accident scenario. This shall include both the event initial cause and its consequences."

\section{REQUIREMENT SOURCE: DOE6430.1A Section 1530-99.0[ 6]}

"Mechanical- and fluid-system portions of the fire protection system shall meet the appropriate NFPA requirements. "

\section{REQUIREMENT SOURCE: DOE6430.1A Section 1530-99.0[ 7]}

"The operation or failure of a fire protection system that interfaces with a safety class system, such as a safety class water system, shall not prevent the safety class system from completing its safety functions when required. Wherever practical, special facilities shall be designed and constructed using building components of fire-resistant and noncombustible material, particularly in locations vital to the functioning of confinement systems. To the extent practicable, combustible materials shall not be used in the construction of process system confinement barriers."

\section{REQUIREMENT SOURCE: DOE6430.1A Section 1530-99.0[ 9]}

"When the use of water sprinkler coverage is precluded because of nuclear criticality or other hazards, nonaqueous extinguishing systems (i.e., inert gas, carbon dioxide, high-expansion foam, or halogenated organics) shall be used."

\section{REQUIREMENT SOURCE: DOE6430.1A Section 1530-99.0[10]}

"Fire protection systems shall be designed so that the failure of any active component (equipment or control device) shall not disable the fire protection system. Fire protection systems and components shall have fail-safe features and audible and visual alarms for operability and trouble indications."

\section{REQUIREMENT SOURCE: DOE6430.1A Section 1530-99.0[16]}

"Automatic water sprinkler coverage shall be provided throughout the facility except in areas where nuclear criticality or other hazards specifically preclude its use or where Halon systems are required to reduce equipment damage."

\section{REQUIREMENT SOURCE: DOE6430.1A Section 1530-3.1}

"Water Flow and Pressure Requirements for Fire Protection - Total volume, pressure, and design flow rate of water necessary to provide fire protection for facilities shall be determined by the methods described in the following paragraphs. All sprinkler or other automatic fire 
12.2.1.1.2

\section{$\underline{12.2 .1 .1 .3}$}

12.2.1.1.4

$\underline{12.2 .1 .1 .5}$ suppression system components shall be UL- or FM-approved for the particular application chosen."

\section{REQUIREMENT SOURCE: DOE6430.1A Section 1530-3.2}

"Occupancy Hazard Classification - NFPA 13 shall be used to determine the Occupancy Hazard Classification for any facility. Light hazard occupancy rules are prohibited."

Wet Pipe Systems

\section{REQUIREMENT SOURCE: DOE6430.1A Section 1530-4.2.1}

"Wet Pipe - Sprinkler systems shall normally be wet pipe using pipe schedule sizes listed in NFPA 13 for ordinary installations. Hydraulic designs shall be considered for all systems. The system shall be hydraulically designed where residual pressure is marginal, water application rate is high, response time is critical, or special risks are involved."

\section{Dry Pipe Systems}

\section{REQUIREMENT SOURCE: DOE6430.1A Section 1530-4.2.2}

"Dry Pipe - In unheated areas or other areas subject to freezing temperatures, dry pipe systems shall be provided. Because of the time delays associated with release of the air in the system, water demands for dry pipe systems shall be computed over areas 30 percent greater than for comparable wet pipe systems. Where the unheated area is small it may be cost effective to install an antifreeze system or small dry pipe system supplied from the wet pipe system in the main heated area."

\section{Preaction}

\section{REQUIREMENT SOURCE: DOE6430.1A Section 1530-4.2.3}

"Preaction - A preaction system shall be used where it is particularly important to prevent the accidental discharge of water. Need for a preaction system shall be based on review by and recommendation of a professional fire protection engineer. The detection system chosen to activate the preaction valve shall have high reliability and a separate alarm/supervisory signal to indicate status. The detection system must be designed to be more sensitive than the closed sprinklers in the preaction system, but should not be so sensitive as to cause false alarms and unnecessary actuation of the preaction valve."

\section{Deluge}

\section{REQUIREMENT SOURCE: DOE6430.1A Section 1530.4.2.4}

"Deluge - For extra hazard areas and specific hard-to-extinguish fuels such as explosives and pyrophoric metals, a deluge system with open sprinkler heads may be used to wet down the entire protected area simultaneously. Deluge systems shall comply with NFPA 13. If quick response is required, deluge system piping may be primed with water. The nozzles must be provided with blow-off caps for water-filled deluge systems." 
$\underline{12.2 .1 .1 .6}$

$\underline{12.2 .1 .1 .7}$

$\underline{12.2 .1 .2}$

\section{Pressure-Relief Valves}

\section{REQUIREMENT SOURCE: DOE6430.1A Section 1540-1.6.1(B)}

"Wherever a pressure-reducing valve's failure may cause equipment damage or unsafe conditions, a pressure-relief valve shall be provided downstream of the reducing valve."

\section{Pressure-Reducing Valves}

\section{REQUIREMENT SOURCE: DOE6430.1A Section 1540-1.6.1(A)}

"Pressure-reducing valves shall be provided where service pressure at fixtures or devices exceeds the normal operating range recommended by the manufacturer."

\section{Special Fire Suppression Systems}

\section{REQUIREMENT SOURCE: DOE5480.7A Section 9.b.(13)}

"Special Hazard Protection - Hazards unique to DOE and not addressed by mandatory codes and standards listed in Paragraph 5 shall be protected by isolation, segregation or use of special fire control systems (inert gas, explosion suppression, etc) as determined by the AHJ. In addition devices for limiting or controlling the effects of a fire (relief valves, filters, blast walls, emergency shutdown systems, scuppers, etc.) shall be provided. "

\section{REQUIREMINT SOURCE: DOE6430.1A Section 1530-5.1}

"Special Protection Systems - Special protection systems may be used to extinguish or control fire in easily ignited, fast-burning substances such as flammable liquids, some gases, and chemicals. They shall also be used to protect ordinary combustibles in certain high-value occupancies especially susceptible to damage. Special protection systems supplement automatic sprinklers as described by NFPA and shall not be used to substitute for them except where water is not available for sprinkler protection. The added expense of the supplementary system shall be supported by documented justification."

\section{REQUIREMENT SOURCE: DOE6430.1A Section 1530-5.1[2]}

"The selection of a particular special suppression system shall be based on:

- The effectiveness of that system or agent for the type of hazard

The damage likely to be caused by the extinguishing agent, including cleanup and downtime."

\section{Control of Liquid Runoff}

\section{REQUIREMENT SOURCE: DOE5480.7A Section 9.b.(10)}

"Liquid Run-off Control - Natural or artificial means of controlling liquid run offs from a maximum credible fire shall be provided so that contaminated or polluting liquids will not escape the site, including potentially contaminated water resulting from fire fighting operations. The amount of fire water that must be controlled and the design of the containment system shall be determined based on consultations with the cognizant DOE fire protection engineer." 


\section{$\underline{12.2 .2}$}

$\underline{12.2 .2 .1}$

\title{
REQUIREMENT SOURCE: DOE6430.1A Section 1540-99.0.2(1)
}

"Collection systems shall be provided for water runoff, such as from firefighting activities, from areas within special facilities containing radioactive material. Nuclear criticality prevention (if necessary) confinement, sampling, volume determination, and retrievability of liquids and solids shall be provided for in the design of collection systems. The size of the collection system for firefighting water shall be based on the maximum amount of water that would be collected in fighting the DBF. The configuration of the system components shall be based on conservative assumptions as to the concentration of fissile or other materials capable of sustaining a chain reaction that might collect in the system. Recirculating systems shall also be considered when there is no possibility of contamination."

\section{Water Supply and Distribution Systems}

\section{Water Supply Systems}

\section{REQUIREMENT SOURCE: DOE6430.1A Division 15, Section 1530-3.3.1, Paragraph 2}

\begin{abstract}
"Precautions shall be taken to ensure that adequate residual pressure exists at full demand flow rate to fulfill the density and coverage requirements for schedule-designed systems. If water supply or pressure is marginal the pressure loss from the base of the riser to the most remote head should be calculated to confirm that the schedule designed-system will meet requirements, or the system shall be hydraulically designed."
\end{abstract}

\section{REQUIREMENT SOURCE: DOE6430.1A Section 1530-3.3.2}

"Hydraulically Designed Sprinkler Systems - NFPA 13 shall be used to determine water supply requirements for hose streams (gpm) and duration (min). Density curves presented in NFPA 13 shall be used for calculating sprinkler demand for hydraulically designed systems. For hazard classifications not covered in NFPA 13 and certain other special occupancies or hazards, design density and area of coverage shall be as specified by other more appropriate standards referenced in NFPA 13 or project-specific requirements as determined by the cognizant DOE fire protection engineer. For ordinary hazard occupancies and above, hose stream requirements shall be a minimum of $500 \mathrm{gpm}$ regardless of the hose stream demands listed in the above references unless otherwise specified by the DOE project criteria. Determination of adequacy of water supply shall be made on the basis of actual flow test data gathered using the methods in NFPA 13, Appendix B."

\section{REQUIREMENT SOURCE: DOE6430.1A Section 1530-3.3.3}

"Fire Hydrant Demand - Where reliance is placed on fire department response, either for protection of unsprinklered buildings or where the fire department will serve as redundant (backup) protection, as a general rule the water supply should be adequate to supply at least $0.03 \mathrm{gpm}$ per cubic foot of fuel (building and contents) in the largest fire area (for high-BTU-content fuels, convert to equivalent ordinary BTU loads). This water supply should be available at 20 psig residual pressure at the hydrants." 


\section{REQUIREMENT SOURCE: DOE6430.1A Section 1540-99.0.5}

Author's Note: The requirement is the joint responsibility of the site and facility.

"On site water supplies and other utilities shall be provided as necessity for emergency use. The design of each utility service or cooling water system shall consider the demands for normal operations, anticipated operational occurrences and DBA conditions."

\section{REQUIREMENT SOURCE: RLID5480.7 Section 8.9}

"The Fire Protection Program must include a fire protection system winterization program to ensure that fire protection systems are protected against cold weather effects. The winterization program shall require that:

a. Each operation or facility with fire protection systems is inspected annually, prior to the month of November, to ensure that freeze protection systems are provided where fire suppression systems, subject to damage by freezing, are located.

b. As a minimum, fire protection system auxiliary drains, drip lines, fire pump test headers, and fire department connections are adequately drained to prevent fire system freeze up. The program shall also ensure that dry pipe system air pressures are normal, and air compressors and air maintenance devices for dry systems are operational.

c. Heating systems utilizing fuel systems have an adequate supply of fuel and a strategy to replenish fuel supply during cold weather periods.

d. Freeze protection systems are properly functioning throughout the freezing weather period."

12.2.2.1.1

$\underline{12.2 .2 .1 .2}$
Mains, Water Storage, and Fire Pumps

\section{REQUIREMINT SOURCE: DOE6430.1A Section 0260-2[3]}

"All water mains, supplying fire protection systems, fire hydrants, etc., shall be treated as fire mains and installed in accordance with NFPA 24."

\section{REQUIREMENT SOURCE: DOE6430.1A Section 1530-9[ 3]}

"Underground fire water mains or combined fire and domestic water mains, including valves, hydrants, and fittings, shall be installed, flushed, sterilized, and tested in accordance with NFPA 24 and Section 0260, Piped Utility Materials. Water storage tanks shall comply with NFPA 22. Fire pumps shall comply with NFPA 20 . Water storage shall be sufficient to meet the density, pressure, and duration requirements of NFPA 13."

\section{Fire Hydrant Capacity}

Author's Note: This requirement is the joint responsibility of the site and facility.

\section{REQUIREMENT SOURCE: DOE6430.1A Section 0266-4( 3)}

"Each fire hydrant within the distribution system must be capable of delivering $1000 \mathrm{gpm}$ at a residual pressure of not less than 10 psi. Where domestic water distribution systems are to serve initernal fire protection systems (i.e. sprinklers or foamite systems), adequate residual pressures shall be maintained for proper operation of such fire protection systems." 
12.2.2.1.3

$\underline{12.2 .2 .1 .4}$

12.2 .2 .1 .5

$\underline{12.2 .2 .1 .6}$
Fire Hydrant Spacing and Location

\section{REQUIREMENT SOURCE: DOE6430.1A Section 0266-4( 9)}

"Fire hydrants shall be installed at a maximum spacing of 400 feet. Fire hydrants shall not be located more than 300 feet from the building to be protected. Each building shall be protected by a minimum of two hydrants."

Air Release and Vacuum Valves

REQUIREMENT SOURCE: DOE6430.1A Section 0266-4(10)

"Air release and vacuum valves shall be installed, as necessary at high points within the distribution system and long supply mains."

Distribution Systems Mains Depth

REQUIREMENT SOURCE: DOE6430.1A Section 0266-4(11)

"Distribution system mains shall have a minimum depth of cover of 2-1/2 feet, Additional cover shall be provided to prevent freezing in cold climates, at roadway crossings in high traffic areas, and at railroad crossings."

Water Distribution Loop Systems

\section{REQUIREMENT SOURCE: DOE6430.1A Section 1530-9[ 4]}

Author's Note: This requirement is the joint responsibility of site and facility.

"Whenever feasible, all water distribution systems shall be of the looped grid type providing two-way flow with sectional valving arranged to provide alternate water flow paths to any point in the system."

\section{REQUIREMENT SOURCE: RLID5480.7 Section 8.1.b}

"Sectional valves shall be installed in the following manner for new installations and water distribution main upgrades:

(1) Multiple sectional isolation valves shall be provided at each intersection between a supply source and a main loop (one valve for each leg).

(2) Sectional valves shall be installed in accordance with a point system, such that no more than six points accumulate between sectional valves. The points for this arrangement are: one point for a fire hydrant, and two points for a automatic sprinkler system."

\section{REQUIREMENT SOURCE: RLID5480.7 Section 8.1.c}

"Water supplies for fire protection shall be of the looped grid type, providing two points of supply and two-way flow with sectional valving arranged to provide alternate water flow paths from the source to any point in the distribution system, where MPFL exceeds $\$ 1$ million." 
$\underline{12.2 .2 .1 .7}$

$\underline{12.2 .2 .1 .8}$

12.2.2.1.9

$\underline{12.2 .2 .1 .10}$

12.2.2.1.11
Sprinkler Supply Lead-Ins

\section{REQUIREMENT SOURCE: DOE6430.1A Section 1530-9[ 6]}

"Sprinkler supply lead-ins should be at least 6 inches, except lead-ins of 4 inches may be used for very small sprinkler systems when substantiated by hydraulic calculations. In no case shall the lead-in be smaller than the sprinkler riser."

Combined Fire and Domestic Process Water Systems

REQUIREMENT SOURCE: DOE6430.1A Section 1530-9[ 7]

"Where combined fire and domestic-process water systems are used, the supplies to each building shall be arranged and valved so that the domestic and process systems can be shut down without shutting off the fire system supply."

\section{REQUIREMENT SOURCE: DOE6430.1A Section 1540-1.1(2)}

"Domestic water shall be supplied by a separate service line and not be a combined fire protection and potable water service or a combined process water and potable water system within the building."

\section{Sprinkler Risers}

\section{REQUIREMINT SOURCE: DOE6430.1A Section 1530-9[ 8]}

"Sprinkler risers should be located at an exterior wall. Sprinkler supply lead-ins should run under buildings the minimum distance possible. Where a riser must be located in a potentially contaminated area, consideration should be given to locating the riser exterior to the building in a heated enclosure."

\section{Outside Control Valves}

\section{REQUIREMENT SOURCE: DOE6430.1A Section 1530-9[ 9]}

"Outside control valves that can be locked open shall be provided on each supply lead-in, located if possible a minimum distance of 40 feet from the building. PIVs should be used where possible. If site conditions preclude the use of PIVs, such as where they would be subject to mechanical damage and cannot be properly guarded, OS\&Y valves in pits may be used."

\section{Key Operated Buried Valves}

\section{REQUIREMENT SOURCE: DOE6430.1A Section 1530-9[10]}

"Key-operated buried valves shall not be used for sprinkler control valves. In no case shall there be more than one valve controlling a sprinkler supply lead-in." 


\subsection{2}

$\underline{12.2 .2 .1 .13}$

$\underline{12.2 .3}$

$\underline{12.2 .3 .1}$

\section{Sprinkler Systems Lead-Ins and Fire Hydrants}

\section{REQUIREMENT SOURCE: DOE6430.1A Section 1530-9[11]}

"All lead-ins shall be connected with the sprinkler system at the base of the riser. Alarm valves shall be located as close as practical to the building entry point. Hydrants shall be provided so that hose lays from hydrants to all exterior portions of a protected building are no more than $\mathbf{3 0 0}$ feet. Hydrants shall not be closer to buildings than $\mathbf{5 0}$ feet. "

\section{Pining Protection Against Differential Settlements}

\section{REQUIREMENT SOURCE: DOE6430.1A Section 1540-1.3.1}

"Where domestic or fire water service lines enter buildings, suitable flexibility shall be provided to protect against differential settlement or seismic activity in accordance either the NSPC or NFPA 13 , respectively. "

\section{Passive Fire Protection}

The concept of passive fire protection is to confine the fire in the originating "enclosure" by providing fire resistive construction such as fire rated wall, ceiling, floor, doors, penetrations, etc., and provide sufficient separation from combustible materials or buildings to prevent the spreading of fire from one area to another.

Fire Barrier Design Requirements

\section{REQUIREMINT SOURCE: DOE6430.1A Section 0110-6.3}

"Fire Resistance Ratings - All facilities shall be divided into areas in which the total potential fire loss to each area and its equipment does not exceed $\$ 75$ million as described in DOE Order 5480.7 . These areas shall be separated by fire walls and barriers with not less than 4-hour fire-resistance ratings. Where exceptions are necessary for reasons of operations and equipment, exemption procedures shall comply with DOE Order 5480.7."

\section{REQUIREMENT SOURCE: DOE6430.1A Section 0727, General}

"Firestopping shall comply with NFPA 101, Chapter 6.

Firestopping materials and assemblies shall be tested for their fire resistance and listed by UL or similar nationally accredited testing laboratories, or shall be listed for their fire resistance as approved by FM or similar national insurance organizations. Unrated and unapproved assemblies shall be tested and approved before being considered for use in a DOE facility.

Where fire-rated assemblies (walls, floors-ceilings, roof-ceilings) are either partially or fully penetrated by pipes, ducts, conduits or other such building elements, firestopping material shall be placed in and around the penetrations to maintain the fire resistance rating of the assembly."

\section{REQUIREMENT SOURCE: DOE6430.1A Section 1530-99.0[19]}

"Where fire barriers are penetrated by the confinement system's ventilation ducting, fire dampers shall be appropriately used to maintain the barrier integrity. However, the closure of such dampers shall not compromise the functions of the confinement system where the loss of confinement might pose a greater threat than the spread of fire. In such cases, alternative fire protection means (e.g., duct wrapping) shall be used as a substitute for fire barrier closure. In 
no case shall a sprinkler system (including safety class sprinklers) be considered a fire barrier substitute."

\section{2 .3 .2}

Fire Doors and Windows

\section{REQUIREMENT SOURCE: DOE6430.1A Section 0800-1.2}

"Doors - Fire Protection - Fire doors, frames, and hardware shall be either tested and listed by UL or similar nationally accredited testing laboratories or approved by FM or similar national insurance organizations. Fire doors, frames, and hardware shall be installed with label attached in accordance with NFPA $80 . "$

\section{REQUIREMENT SOURCE: DOE6430.1A Section 0800-2.2}

"Windows - Fire Protection - Where required by code, fire windows, frames, and hardware shall be either tested and listed by UL or similar nationally recognized testing laboratories or approved by FM or similar national insurance organizations. Such fire windows, frames, and hardware shall be installed with label attached in accordance with NFPA 80."

\subsection{4}

$\underline{12.2 .4 .1}$

\section{Life Safety}

\section{Facility Buildings}

Author's Note: Only items 1 and 3 from EH0135 FP. 2 provide additional value to requirements specified in this S/RID. The remaining items listed are either a duplicate of or conflict with requirements contained in DOE Order $5480.7 \mathrm{~A}$. This condition exists because EH0135 was issued prior to 5480.7A.

\section{REQUIREMENT SOURCE: DOE5480.7A Section 9.b.(2)}

"Life Safety - Life safety provisions shall be provided for all facilities in accordance with the Life Safety Code (LSC), NFPA Standard 101. The methods outlined in NFPA 101M may be used to obtain an equivalent level of life safety where strict compliance is not possible. Exit requirements for toxic and explosive environments shall be as determined by the AHJ. In addition, for explosive environments, exits shall reflect the criteria contained in the DOE Explosives Safety Manual, (DOE/EV 06194). Where noncompliance with some Life Safety Code provisions may be required for public safety, as in some containment structures, additional protective systems and personnel limits should be maintained. Compliance with the Life Safety Code shall be considered to satisfy the exit requirements of the applicable building code and OSHA 29 CFR 1910."

\section{Life Safety for Laboratories}

\section{REQUIREMENT SOURCE: DOE6430.1A Section 0110-99.0.4(2)}

"A minimum number of entrances shall be provided for security areas. However, exits shall comply with NFPA 101. Some exits shall be provided for emergency use only, and equipped with alarm devices and seals. At least two exits shall be provided in rooms where hazardous materials are handled." 


\section{$\underline{12.2 .4 .1 .2}$}

\section{$\underline{12.2 .4 .1 .3}$}

$\underline{12.2 .4 .1 .4}$

$\underline{12.2 .4 .1 .5}$

\section{Egress}

\section{REQUIREMENT SOURCE: DOE6430.1A Section 0110-99.0.4(3)}

"In those areas where an accidental breach of a primary confinement system could expose personnel to radioactive material, a distance of 75 feet as measured by the method in the NFPA 101 shall be the maximum travel distance to ensure that personnel can exit through the next confinement.etc."

\section{REQUIREMINT SOURCE: DOE6430.1A Section 0281-3[3]}

"Vehicle circulation facilities shall be designed to provide safe and convenient access for deliveries, collections, fire protection, emergencies, maintenance, repair, and other essential services. Where feasible, internal street systems shall be designed to discourage use by through-traffic."

\section{REQUIREMENT SOURCE: DOE6430.1A Section 0283-3.1[5]}

"ECP designs shall also facilitate ingress and egress of emergency vehicles nd fire protection equipment."

\section{Corridor Widhs}

\section{REQUTREMENT SOURCE: DOE6430.1A Section 0110-99.0.4(12)}

"Corridor width(s) can be a controlling factor in the overall building size, and corridors shall be no wider than required for facility functions. All Corridors and door openings, shall meet NFPA 101 or more stringent requirements based on the hazards of materials to be handled or operations to be performed, as established by the cognizant DOE health and safety authority. The size and arrangement of interior corridors shall accommodate the following:

- Personnel traffic flow patterns

- Safety of building occupants

- Movement of equipment ( including initial equipment installations, facility operations and future replacement or removal)

- Ultimate decontamination and decommissioning of the facility including equipment required during decontamination."

\section{Door Encroachment}

\section{REQUIREMENT SOURCE: DOE6430.1A Section 0110-99.04(13)}

"Where room doors open into corridors, frames shall be recessed to prevent the open doors from encroaching on clear corridor spaces."

\section{Security Areas}

\section{REQUIREMENT SOURCE: DOE6430.1A Section 0800-1.3(4)}

"Doors that serve as exits from security areas shall comply with NFPA 101, Chapter 5, and with DOE security requirements, except the use of panic hardware on doors from security area shall be limited to assembly, educational, and hazardous occupancy classifications of UBC as determined by the cognizant DOE authority." 


\subsubsection{6}

$\underline{12.2 .4 .1 .7}$

\section{Zoning for Automatic Control}

\section{REQUIREMENT SOURCE: DOE6430.1A Division 15, Section 1595-2}

"Zoning for automatic control of space temperatures, static pressures, humidities, ventilation, smoke and fire detection, security and lighting shall satisfy health and safety requirements as indicated in DOE project criteria, NFPA 101, space operational and occupancy requirements, and zoning exposure with relation to building size, orientation and configuration.

Zoning requirements are as follows:

o Each HVAC system shall have a separate thermostat for space temperature regulation and a separate humidistat if humidity control is provided.

o No zone shall contain more than a single building floor regardless of floor space.

o Automatic controls shall be provided to shut off heating or cooling to any individual zone.

o Interior zones shall not be combined with external zones.

o Interior space zones shall be placed on separate air handling systems from external, if cost effective. External space zones shall be selected for each individual exposure.

o For office facilities and similar occupancies, each major orientation shall be zoned to have no more than 2,000 square feet of floor area with exterior exposure, and no more than 3,000 square feet of floor area with no exterior exposure."

\section{Life Safety in Hazardous Areas}

\section{REQUIREMENT SOURCE: DOE6430.1A Section 0110-6.4}

"Hazardous Areas - When exemptions are granted to specific DOE fire protection standards for reasons unique to DOE facilities, as in the case of some containment structures, fire protection shall be provided so as to assure the life safety of facility occupants as required by the cognizant DOE fire protection authority."

\section{REQUIREMENT SOURCE: DOE6430.1A Section 0110-6.4[2]}

"Hazardous areas, such as radioactive spaces with inert atmospheres, shall have sufficient alarms and interlocks to assure that access by emergency personnel will not endanger such personnel or result in a public hazard."

\section{REQUIREMENT SOURCE: DOE6430.1A Section 0110-6.4[3]}

"The design of hazardous areas shall facilitate access by emergency personnel from the exterior and, at the same time, shall maintain any required confinement or containment using air locks or other features." 
"Higher Standard of Protection - A higher standard of protection, which includes fire protection features beyond those stipulated above, may be warranted under certain circumstances. These features shall be determined by the PSO . The following factors shall be considered:
(a) importance
(b) effect on production
(c) costs versus benefits
(d) future conditions"

\section{REQUIREMENT SOURCE: DOE6430.1A Section 1530-2.1}

"Improved Risk Concept for Fire Protection Systems - Fire protection design shall incorporate an "improved risk" level of fire protection as directed in DOE Order 5480.7 as well as Section 0110-5, Health and Safety."

\section{REQUIREMENT SOURCE: DOE6430.1A Section 1530-2.2}

"Vital Programs - Fire protection systems for vital programs shall incorporate a "higher standard of protection" than the "improved risk" level as directed by DOE Order 5480.7."

\section{REQUIREMENT SOURCE: DOE6430.1A Section 1530-2.3.1}

"Maximum Possible Fire Loss - The "improved risk" level of protection requires that the "maximum possible fire loss" shall be the basis for determining the need to provide automatic fire suppression systems and for additional fire protection systems and features. "Maximum possible fire loss" is defined in DOE Order 5480.7, Criteria I through V as discussed in DOE Order 5480.7 correspond with Section 1530.2.3.2, Criterion I, through Section 1530.2.3.6, Criterion V. The application of these criteria shall be considered by an experienced fire protection engineer."

\section{2 .6}

Decommissioning Planning

\section{REQUIREMENT SOURCE: RLID5480.7 Section 8.3}

"Required fire protection features (includes fire department emergency response capabilities) shall be maintained throughout the life of a facility or operation. When a facility is no longer required for a DOE mission and is scheduled for shutdown, decommissioning, and demolition, all of the following must be completed before any fire protection feature is deactivated, no longer maintained, and/or removed from service:

a. Property book value of the facility or operations (includes building and building contents) must be devaluated below levels, which would require certain fire protection features. Even if property has no inherent value but property is shown to have record value, fire protection must be maintained until recorded value is lowered below protection requirements.

b. An analysis must be performed to demonstrate that a radiological or hazardous material release, beyond DOE guidelines, is not possible. The analysis must be performed or reviewed by a qualified Fire Protection Engineer. If fire protection feature(s) are determined necessary to prevent a radiological or hazardous release, then fire protection feature(s) must remain in place until radiological or hazardous materials are removed. 
c. For life safety purposes, fire protection features may only be deactivated after personnel are no longer occupying the facility. For purpose of this section, a facility is considered to be occupied, as defined by NFPA 101, Life Safety Code.

d. Decommission and demolition activities must be coordinated with the Hanford Fire Department for fire and emergency medical response services."

Construction

\section{REQUIREMIENT SOURCE: DOE6430.1A Section 1161-2[1], Sentences 1 thru 4}

"Noncombustible or fire-resistant and corrosion-resistant materials shall be used for enclosures and, to the maximum extent practicable, for any required radiation shielding. In no ease shall the total combustible loading located in a fire area exceed the fire resistance rating of the structural envelope (see Section 0110-99.0.6, Fire Resistance). This shall be documented in a fire risk analysis performed according to a methodology approved by the DOE Fire Protection Authority. This analysis should include estimated fire area combustible loadings, ventilation parameters, room dimensions, maximum average gas temperature, fire duration, maximum average heat flux, and the calculational method used."

\section{REQUIREMINT SOURCE: DOE6430.1A Section 1530-2.3.5}

"Criterion IV - Whenever the maximum possible fire loss exceeds $\$ 25$ million, the area shall be subdivided with free-standing fire rated walls or suitable redundant fire protection systems to limit the credible loss to less than $\$ 25$ million even in the event the primary system fails. In no case shall the maximum loss potential exceed the $\$ 75$ million loss limit established in DOE Order 5480.7; failure-proof systems such as physical separations shall be provided to prevent this possibility."

\section{REQUIREMINT SOURCE: DOE6430.1A Section 1530-99.0}

"Special Facilities - Nonreactor Nuclear Facilities - An assessment shall be made early in the design or modification to determine the facility structures, systems, and components that shall be protected against the effects of a DBF and explosion. A fire protection engineer or person knowledgeable in applying the principles of fire protection shall develop the fire protection system. To maximize the protection against fire, the system shall contain an appropriate integration of fire prevention, detection, and suppression features. ${ }^{n}$

\section{REQUIREMENT SOURCE: DOE6430.1A Section 1530-99.0[12]}

"The designers of the fire protection system shall consider the fire and explosion potential of the materials being processed and the solvents used during processing. In addition, the design shall include facility-specific fire protection systems to mitigate the damage from pyrophoric and other materials that are fire hazards, (e.g., magnesium, ion exchange resins, nitrate solvent and nitrate reduction reactions, and zirconium fuel element cladding hulls)."

\section{REQUIREMENT SOURCE: RLID5480.7 Section 8.2.a}

"Fire rated assemblies shall be installed, as required in DOE 6430.1 version in effect and other applicable standards, to reduce loss potentials." 


\section{REQUIREMENT SOURCE: RLID5480.7 Section 8.4.a}

"Fire protection must be provided on all construction sites, as required by applicable sections of NFPA 241, Safeguarding Construction, Alteration, And Demolition Operations, and NFPA 1141, Fire Protection In Planned Building Groups."

\section{REQUIREMENT SOURCE: RLID5480.7 Section 8.4.b}

"Where underground water mains and hydrants are to be provided, they shall be installed, completed, and in service, prior to accumulation of combustible materials on the project site, and prior to the completion of any project structure.

\section{REQUIREMINT SOURCE: RLID5480.7 Section 8.4.c}

"Construction sites shall provide and maintain fire department vehicle access. The access roads shall have an unobstructed driving surface width of at least 20 feet during all weather conditions, and be able to withstand the live loads of fire department apparatus."

\section{$\underline{12.2 .8}$}

\section{Fire Alarm Systems}

Author's Note: NFPA 71, 72A, B, C, D, E, F, G, H, and 74 have been consolidated into NFPA 72.

Signals from detection systems are fed to fire alarm panels which in turn are transmitted to local fire alarms and the Central Alarm Stations.

\section{REQUIREMENT SOURCE: DOE5480.7A Section 9.b.(11)}

"Fire Alarm Systems - Where fire suppression or fire alarm systems are provided local alarms in the protected area and alarm transmission to an acceptable re-mote attended location shall be provided."

\section{REQUIREMENT SOURCE: DOE6430.1A Section 1530-99.8[2]}

"The fire protection systems shall comply with DOE/EP 0108 and NFPA 75. All sprinkler systems should be hydraulically designed for the appropriate water density based on occupancy."

12.2.8.1 Fire Detection and Alarm Systems Design, Installation, Inspection, and Testing

\section{REQUIREMENT SOURCE: DOE6430.1A Section 1530-8.1}

"Fire Detection and Alarm Systems - All fire detection and alarm devices shall have UL-listed components or be FM-approved. Devices and systems shall comply with NFPA 71, NFPA 72A, NFPA 72B, NFPA 72C, NFPA 72D, NFPA 72E, NFPA 72F, NFPA 72G, and NFPA $72 \mathrm{H}$ as applicable."

\section{REQUIREMENT SOURCE: DOE6430.1A Section 1530-99.8[3]}

"Automatic fire detection systems shall be provided in all centers. Each system shall provide for automatic alarm transmission to local sounding devices and to the cognizant fire alarm center." 


\section{REQUIREMENT SOURCE: DOE6430.1A Section 1530-99.8[4]}

"The detection system shall perform the following functions:

Initiate an alarm to the building alarm system and to the local fire alarm control center.

$\neg$ Shut off electric power to computer-electronic data processing equipment in those areas where fire may operate sprinkler heads before manual power shutdown could be accomplished. - Activate the appropriate HVAC system control sequence to provide smoke evacuation. A manual reset shall be provided to reenergize the interrupted electrical systems."

\section{REQUTREMENT SOURCE: DOE6430.1A Section 1671-1.3}

"Telecommunications and alarm equipment and conductors shall be located outside areas subject to explosion, fire, flood, chemical fumes, excessive dust, radiation or vibration, and excessive electrical or electromagnetic noise levels. Where telecommunications and alarm services must be extended into these areas, equipment and installation shall be suitable for the hazard."

Fire Alarm System Features

\section{REQUIREMENT SOURCE: DOE6430.1A Section 1530-8.2.1}

"Fire alarm systems shall have the following basic features:

$\frown \quad$ Transmission of signals to the DOE facility fire department alarm center and other constantly attended locations in accordance with the appropriate NFPA Signaling Systems Standard.

Local alarms for the building or zone in alarm.

$\frown \quad$ Trouble signals as required by the appropriate NFPA Signalling Systems Standard.

Emergency battery backup for system operation.

Electric supervision of all circuits as required by the appropriate NFPA standard.

- Supervisory devices for all critical functions (valve position switches, water level, temperature).

Capability of annunciating at least three separate conditions: 1) a fire alarm, 2) a supervisory alarm, and 3) a trouble signal indicating a fault in either of the first two. Annunciation of each condition shall be separate and distinct from the other two."

\section{REQUIREMENT SOURCE: DOE6430.1A Section 1671-2}

"Fire alarm and signaling systems shall comply with NFPA 72A, NFPA 72B, NFPA 72C, NFPA 72D, NFPA 72E, NFPA 72F, NFPA 72G, and NFPA 72H."

\section{$\underline{12.2 .8 .3}$}

\section{Compatibility of Alarm Systems}

\section{REQUIREMENT SOURCE: DOE6430.1A Section 1530-8.2.1[2]}

"Fire alarm systems for new DOE buildings shall be compatible with those for the DOE complex where the new building is to be located." 
Alarms that respond to flow of water shall be provided wherever a sprinkler system is installed and shall comply with requirements of the NFPA standard for the type of signaling system used.

$\neg$ A manual fire notification method such as manual fire alarm boxes shall be provided and located in accordance with the appropriate NFPA standard.

$\sim$ Combined watch reporting and fire alarm systems, if used, shall be in accordance with the appropriate NFPA standard."

\section{Underground Cables for Alarm Systems}

\section{REQUIREMINT SOURCE: DOE6430.1A Section 1670-2}

"Fire alarm and supervisory systems shall comply with NFPA 71, NFPA 72A, NFPA 72B, NFPA 72C, NFPA 72D, NFPA 72E, NFPA 72F, NFPA 72G, NFPA 72H, NFPA 1221, and ANSI C2 as appropriate for the location. Outside cable plant for the alarm and supervisory systems shall comply with the standards for telephone cable plant. In the joint use of poles for electric power distribution and for supporting fire alarm and telephone cables, separate fire alarm cable shall be placed below the telephone cable.

Fire alarm cables installed in underground ducts shall be distinctively marked within manholes and handholes that are shared with other communication cables and shall be kept physical separated from all power conductors.

Exterior fire alarm pull boxes and emergency-reporting telephones shall be installed in weatherproof housings manufactured specifically for the mechanism."

\section{$\underline{12.2 .9}$}

\section{Fire Detection Systems}

\section{REQUIREMENT SOURCE: DOE6430.1A Section 1530-8.3.4}

"Smoke Detectors - Smoke detectors shall be installed in all areas where required by the appropriate NFPA standard or by the cognizant DOE fire protection authority. Smoke detectors shall be of a type operating on one of the principles described in NFPA 72E. A mixture of detector types may be appropriate. Location and required spacing of smoke detectors shall be determined by the methods of NFPA 72E and its Appendix C. Spacing shall be based on threshold fire size, fire growth rate, and ceiling height as described in these standards."

\section{REQUIREMENT SOURCE: DOE6430.1A Section 1660-99.0.2}

"A protection system is a system that initiates corrective action, e.g., fire detection/Halon.

The protection system shall provide automatic initiation of protective actions that require rapid response and automatic control of interlocks that prevent unsafe operator action.

The protection system shall be designed to sense potentially hazardous conditions and to initiate actions to ensure that specific acceptable design limits are not exceeded as a result of anticipated operational occurrences."

\section{FIRE HAZARD ANALYSIS}

Author's Note: DOE Order 5480.7A Section 9.a(3) has omitted the letter (k) when identifying the 15 elements of a fire hazards analysis. The text provided below identifies the same 15 elements in the same order as the source document. 


\section{REQUIREMENT SOURCE: DOE5480.7A Section 9.a.(3)}

"Fire Hazards Analyses. The purpose of a fire hazards analysis (FHA) is to comprehensively assess the risk from fire within individual fire areas in a DOE facility in relation to existing or proposed fire protection so as to ascertain whether the objectives of paragraph 4 , are met. A graded FHA, that reflects the risks from fire in a facility, shall be performed for new facilities as directed by DOE 6430.1A, for nuclear facilities where safety analyses are required by DOE 5480.23, and as directed by the PSO. A Safety Analysis Report (SAR) that addresses the following elements will satisfy the requirements for an FHA. A graded FHA shall contain, but not be limited to, the following elements:

(a) Description of construction

(b) Protection of essential safety class equipment

(c) Fire protection features

(d) Description of fire hazards

(e) Life safety considerations

(f) Critical process equipment

(g) High value property

(h) Damage potential: Maximum Credible Fire Loss (MCFL) and Maximum Possible Fire Loss (MPFL)

(i) Fire Department/Brigade response

(j) Recovery potential

(l) Potential for a toxic, biological and/or radiation incident due to a fire

(m) Emergency planning

(n) Security considerations related to fire protection

(o) Natural hazards (earthquake, flood, wind) impact on fire safety

(p) Exposure fire potential, including the potential for fire spread between fire areas.

An FHA shall be performed under the direction of a qualified fire protection engineer."

\section{REQUIREMINT SOURCE: RLID5480.7 Section 6.2}

"RL Contractors shall assure that facilities and programs under their jurisdiction provide a level of fire protection adequate to meet the objectives of DOE 5480.7A for protection of the public, personnel, environment, and property. RL Contractors shall also:

a. Submit the "Annual Industrial Summary of Fire and Other Property Damage Experience" report (three copies) for the previous calendar year to the RL Director of QSH by February 1st of each year, as required by DOE 5484.1 and as supplemented by RL direction.

b. Report fires to QSH and losses, in accordance with paragraph 8.8 of this directive.

c. Property loss valuation shall be determined by utilizing the property valuation and loss estimation guidelines found in DOE 5484.1.

d. Schedule and preform fire protection assessments for all facilities, including those for which the contractor has only landlord or lessee responsibility. Assure that the fire protection program elements, described in DOE 5480.7A and this directive, are being implemented. (1) Annual fire protection assessments shall be made of facilities valued in excess of $\$ 50$ million; where considered to be moderate (Category 2 Hazard) or high hazard (Category 1 Hazard), as defined in DOE 5481.1B, for non-nuclear facilities and in DOE 5480.23, for nuclear facilities; or in which vital programs are involved.

(2) Fire protection assessments shall be made at least every two years of facilities valued at $\$ 10$ million to $\$ 50$ million.

(3) Fire protection assessments shall be made at least every three years of facilities valued and $\$ 1$ million to $\$ 10$ million.

(4) Except for paragraph 6.2d.(5) of this directive, fire protection facility assessments shall contain the required nature and scope elements contained in DOE 5480.7A. Facility 
assessments shall also contain findings and observations of fire protection deficiencies identified.

(5) Facilities, where property is less than $\$ 1$ million, shall not require a fire protection facility assessment that contains the required nature and scope elements contained in DOE 5480.7A, unless significant programmatic impacts, hazardous materials, or radioactive materials are involved. Such facility assessments shall be made at least every three years.

Exception: A fire protection assessment shall be made at least every three years of facilities valued at $\$ 250,000$ to $\$ 1$ million. The documented assessment for these facilities only needs to include findings, observations, and recommendations. Where applicable, these assessments should include, as a minimum, findings and observations and supporting documentation that identify fire hazards that could cause facility loss or life safety concerns.

(6) Fire protection facility assessments shall retained by the contractor, and made available to RL representatives upon request. Copies of the two most recent assessment reports shall be kept readily accessible on file.

(7) Facility assessments findings, observations, and/or recommendations shall be entered into data base tracking system and assigned and appropriate prioritization, to ensure that effective actions are being taken to correct deficiencies identified in accordance with RLID 1000.1. (8) MCFL and MPFL values described in the assessments shall be as required by DOE 5480.7A utilizing the property valuation and loss estimation guidelines found in DOE 5484.1. (9) Maintain a list of facilities which require assessment, indicating the assessment frequency. e. Perform FHA of facilities in accordance with DOE 5480.7A and EH-31.3, Guidance on Performance of Fire Hazard Analyses, memorandum dated 11-07-91. FHA shall be completed for all new facilities, as required by DOE 6430.1 version in effect, and all existing nuclear facilities, where safety analyses are required by DOE 5480.23 . The development of a facility design basis fire in accordance with DOE 6430.1 version in effect, as required in safety analysis documentation, must be consistent with the MPFL event and documented in the facility FHA.

The FHA shall be referenced by the safety analysis documentation. MCFL and MPFL values described in the FHA shall be as required by DOE $5480.7 \mathrm{~A}$, utilizing the property valuation and loss estimation guidelines found in DOE 5484.1. New facility and nuclear facility FHA shall be reviewed and approved by QSH. When directed by the PSO, the FHA shall also follow the same review and approval process as safety analysis documentation for DOE 5480.23. A copy of the current FHA shall be retained by the contractor and be kept readily accessible on file.

f. Provide fire protection overview and assistance for subcontractor activities and facilities. g. Carry out those responsibilities assigned by DOE $5480.7 \mathrm{~A}$, paragraphs $8 \mathrm{i}(1)$ through $8 \mathrm{i}(8)$, and comply with the applicable provisions of DOE 6430.1 versions in effect.

h. Establish a written and documented fire protection program for facilities and operations managed, including:

(1) A statement of management commitment to achieve the above stated objectives.

(2) A policy statement that implements DOE 5480.7A, other DOE fire protection related mandatory codes and standards, and requirements contained in this directive.

(3) Fire protection criteria that reflect site-specific aspects of the fire protection program, including the organization and responsibilities of the fire protection staff, administrative aspects of the Fire Protection Program, and requirements for physical fire protection features.

(4) See paragraph 8.12 of this directive for guidance on developing the documented fire protection program.

i. Maintain a current statement of programmatic impact on every vital program, as determined by RL or the PSO. The statement of programmatic impact will be updated every three years. The statement will include facilities, material, and equipment that are vital to the operation of that program.

j. Each prime contractor shall have on staff at least one qualified Fire Protection Engineer (see paragraph 5.2).

k. Provide and maintain a system to ensure that the requirements of the DOE Fire Protection Program are documented and incorporated in the plans and specifications for all new facilities, 
and for major modifications of existing facilities. This includes review and comment by the fire protection engineering group of design documentation and testing of fire protection features.

1. Provide fire protection representation at the Hanford Fire Protection Forum meeting, as described in the Hanford Fire Protection Forum Charter.

$\mathrm{m}$. Attend and provide representation at the monthly program interface meetings with the RL fire protection representative."

\section{FIRE PREVENTION (BUILDING DESIGN)}

This element when worked with Section 12.2.4, Life Safety, identifies the requirements for building design, materials, furnishings, etc.

\section{REQUIREMINT SOURCE: DOE/EV-0043 101}

"This standard applies to all portable or relocatable structures including trailers, (hereafter referred to as portable structure) in a single fire area where any one of the following conditions exists:

o Creates a life hazard.

o Endangers the public or environment.

o Replacement value exceeds $\$ 250,000$. (Structure and Contents)

o Is vital to a DOE program."

\section{REQUIREMENT SOURCE: DOE6430.1A Section 0110-6.1}

Author's Note: DOE Order 5480.7A takes primacy over all other Orders regarding Fire Protection.

"Fire Protection - General - Facilities shall comply with the following:

- DOE Order 5480.4 Attachment 2, Section 2.c

$\neg$ DOE Order 5480.7

Section 1530, Fire Protection

Facilities shall also comply with 29 CFR 1926 and 29 CFR 1910. Except as required by other sections of these criteria, NFPA 101 shall apply where 29 CFR 1926 and 29 CFR 1910 does not apply or where NFPA 101 exceeds the requirements of 29 CFR 1926 and 29 CFR 1910."

\section{REQUIREMENT SOURCE: DOE6430.1A Section 0110-6.1[2]}

"Definitions, fire resistance ratings, and types of construction shall be as contained in the UBC. Any materials with unusual fire characteristics, such as urethane foams, and any materials that develop significant quantities of toxic or harmful products of combustion, shall not be used as interior finishes or other interior applications without the approval of the cognizant DOE fire protection authority. The use of foam plastics in construction shall be prohibited unless it fully complies with FM 1-57."

\section{REQUIREMENT SOURCE: DOE5480.7A Section 9.b.( 6)}

"Quality Construction - New Permanent structures in excess of 5000 square feet of area shall be of noncombustible or fire resistive construction." 


\section{REQUIREMENT SOURCE: DOE6430.1A Section 0110-6.2[3]}

"Special precautions for preventing the spread of fires, such as multiple fire suppression systems, rapid detection of incipient fires, confining fires, increased fire ratings of construction materials, and rapid-response fire departments shall be provided. "

\section{REQUIREMINT SOURCE: DOE6430.1A Section 0110-6.2[4]}

"A general fire-protection design analysis shall be made of each facility to ascertain and limit the cost of future damage repair and replacement of facilities and their contents from fire. The analysis shall be made using those parameters established in DOE Order 5480.7. The analysis shall determine the special fire prevention and protection features and controls deemed by the cognizant DOE fire protection authority to achieve a level of improved risk fire protection that limits damage to an acceptable level. The analysis shall be documented in report form in the facility project files and referenced by the SAR."

\section{REQUIREMINT SOURCE: DOE6430.1A Section 0110-6.2[5]}

"Fire protection design analysis shall be done as soon as possible and included as a portion of the Title I Design Summary document required by DOE 4700.1."

\section{Exterior Fire Protection Systems and Features}

\section{REQUIREMENT SOURCE: DOE6430.1A Section 0110-6.4[4]}

"The design of the exteriors of facilities shall follow the recommendations of NFPA 80A. Facilities that are not separated as recommended by NFPA $80 \mathrm{~A}$ shall have fire protection systems such as exterior sprinklers or barrier walls."

\section{Fire Resistance for Materials and Construction}

\section{REQUIREMENT SOURCE: DOE6430.1A Section 0110-6.3[3]}

"Wall, floor and ceiling, and roof and ceiling assemblies shall be tested and rated for their fire resistance by UL or similar nationally accredited testing laboratories, or shall be listed for their fire resistance as approved by FM or similar national insurance organizations. Untested, unrated or unapproved assemblies shall be approved by the cognizant DOE fire protection authority before being considered for use in a facility. "

\section{REQUIREMENT SOURCE: DOE6430.1A Section 0110-99.0.6}

"Fire Resistance - Development of the DBF shall include consideration of conditions that may exist during normal operations and special situations (e.g., during periods of decontamination, renovation, modification, repair, and maintenance). The structural shell surrounding critical areas and their supporting members shall remain standing and continue to act as a confinement structure during the DBF under conditions of failure of any fire suppression system not designed as a safety class item. Fire resistance of this shell shall be attained by an integral part of the structure (concrete slabs, walls, beams, and columns) and not by composite assembly (membrane fireproofing). In no event shall the fire resistance rating be less than two hours under conditions of failure of any fire suppression system not designed as a safety class item. Penetrations in this shell shall incorporate, as a minimum, protection against DBF exposures unless greater protection is required by other sections of these criteria." 


\section{4 .4}

$\underline{12.4 .4 .1}$

$\underline{12.4 .4 .2}$

$\underline{12.4 .4 .3}$

$\underline{12.4 .4 .4}$

\section{Control of Combustibles}

Interior Finish Materials

\section{REQUIREMENT SOURCE: RLID5480.7 Section 8.2.e}

"Nuclear facilities and laboratories shall have interior finish materials (decorations, furnishings, and exposed wall or insulating materials) that have an Underwriters Laboratories (ASTM E-84/NFPA 255) flame spread rating of 25 or less, and smoke developed rating of 50 or less, except for acoustical materials, which shall have a smoke developed rating of 100 or less. The minimum average critical radiant flux for floor covering material shall be 0.45 watts pre square centimeter, when tested in accordance with ASTM E-648 (NFPA 253)."

\section{Interior Floor Coverings}

\section{REQUIREMENT SOURCE: DOE6430.1A Section 1260-4}

"Rugs and Mats shall comply as furnishings with NFPA 101, Chapter 31 (sections concerning furnishings, decorations and treated finishes), in all occupancy classifications except those of storage and industrial.

Rugs and mats used in storage or industrial occupancies shall have a critical radiant flux not less than the following:

* 0.45 watts per square centimeter where there are no sprinklers complying with NFPA13;

* 0.22 watts per square centimeter where there are sprinklers complying with NFPA 13"

\section{Control of Combustible Materials by Building Design}

\section{REQUIREMENT SOURCE: DOE6430.1A Section 0110-99.0.4(4)}

"The facility design shall provide space to accommodate all planned activities, operations, and maintenances (e.g., processing, research and development, scrap and waste handling, sample analysis, shipping and receiving and material staging required for equipment installation and modifications). The design shall-minimize the hazard of handling flammable and other hazardous materials. In addition to the usual industrial safety features required in a nuclear facility, the design shall also include the following safety features as appropriate:

- Layout of the facility shall provide specific control and isolation, if possible, of quantities of flammable, toxic and explosive gases, chemicals, and other hazardous materials admitted to the facility."

\section{Quantities of Stored Materials}

\section{REQUIREMENT SOURCE: DOE6430.1A Section 0110-99.0.4(8)}

"Suitable physical compartmentalization shall be provided, as determined from the safety analysis, to limit the quantities of stored materials in each compartment to safety levels; ensure the necessary access features and controls; and satisfy the loss limitation criteria in Section 0110-99.0.7, Loss Limitations." 


\section{REQUIREMENT SOURCE: RLID5480.7 Section 8.5}

"The generation, treatment, storage, and disposal of ignitable and reactive wastes, defined in Dangerous Waste Regulations, WAC 173-303, that are utilized in the facilities and operations covered under the Tri-Party Agreement shall comply with this directive and shall:

a. Comply with the fire protection provisions of WAC 173-303.

b. Be located in areas that are designed, operated, and maintained in a manner equivalent to the Uniform Code (UFC), when ignitable and reactive wastes are stored in containers.

c. Be inspected on an annual basis by a person familiar with the UFC, where wastes are stored."

\section{REQUIREMENT SOURCE: WAC-173-303 Section 395(1)}

"Precautions for ignitable, reactive, or incompatible wastes.

(a) The owner or operator must take precautions to prevent accidental ignition or reaction of ignitable or reactive waste. This waste must be separated and protected from sources of ignition or reaction including, but not limited to, open flames, smoking, cutting and welding, hot surfaces, frictional heat, sparks (static, electrical, or mechanical), spontaneous ignition (e.g., from heat-producing chemical reactions), and radiant heat. While ignitable or reactive waste is being handled, the owner or operator must confine smoking and open flame to specially designated locations. "No smoking" signs must be conspicuously placed wherever there is a hazard from ignitable or reactive waste.

(b) Where specifically required by other sections of this chapter 173-303 WAC, the treatment, storage, or disposal of ignitable or reactive waste, and the mixture or commingling of incompatible wastes, or incompatible wastes and materials, must be conducted so that it does not:

(i) Generate extreme heat or pressure, fire or explosion, or violent reaction;

(ii) Produce uncontrolled toxic mists, fumes, dusts, or gases in sufficient quantities to threaten human health or the environment;

(iii) Produce uncontrolled flammable fumes or gases in sufficient quantities to pose a risk of fire or explosions;

(iv) Damage the structural integrity of the facility or device containing the waste; or

(v) Through other like means, threaten human health or the environment.

(c) When required to comply with (a) and (b) of this subsection, the owner or operator must document that compliance in the operating record required under WAC 173-303-380(1). This documentation may be based on references to published scientific or engineering literature, data from trial tests, waste analyses, or the results of the treatment of similar wastes by similar treatment processes and under similar operating conditions.

(d) At least yearly, the owner or operator shall inspect those areas of his facility where ignitable or reactive wastes are stored. This inspection shall be performed in the presence of a professional person who is familiar with the Uniform Fire Code, or in the presence of the local, state, or federal fire marshal. The owner or operator shall enter the following information in his inspection log or operating record as a result of this inspection: 
(i) The date and time of the inspection;

(ii) The name of the professional inspector or fire marshal;

(iii) A notation of the observations made; and

(iv) Any remedial actions which were taken as a result of the inspection."

\section{REQUIREMENT SOURCE: WAC-173-303 Section 630( 8)}

"Special requirements for ignitable or reactive waste.

(a) Containers holding reactive waste exhibiting a characteristic specified in WAC 173-303-090 (7)(a)(vi), (vii) or (viii) must be stored in a manner equivalent to the Uniform Fire Code's "American Table of Distances for Storage of Explosives," Table 77-201, 1979 edition.

(b) The owner or operator shall design, operate, and maintain ignitable waste and reactive waste (other than a reactive waste which must meet (a) of this subsection) container storage in a manner equivalent with the Uniform Fire Code. Where no specific standard or requirements are specified in the Uniform Fire Code, or in existing state or local fire codes, applicable sections of the NFPA Pamphlet \# 30, "Flammable and Combustible Liquids Code," shall be used. The owner/operator shall also comply with the requirements of WAC 173-303-395 (1)(d)."

\section{$\underline{12.4 .4 .6}$}

\section{$\underline{12.4 .5}$}

$\underline{12.4 .5 .1}$

\section{Storage and Use of Compressed Gases}

Fire protection requirements for the storage and use of compressed gases, acetylene, hydrogen, flammable and combustible liquids, and LPG shall be in accordance with 29 CFR 1910 Subpart H, Hazardous Materials.

\section{Electrical Systems}

Ignition Source by Electrical Equipment

\section{REQUIREMENT SOURCE: DOE6430.1A Section 1530-99.0[21]}

"Because of flammable or potentially flammable atmospheres, electrical installations in hazardous process locations shall be designed to preclude the introduction of any ignition source by the electrical equipment."

\section{Listing Requirements for Electrical Materials and Equipment}

\section{REQUIREMENT SOURCE: DOE6430.1A Section 1605-1(2)}

"Electrical materials and equipment shall be UL or FM tested, with label attached, for the purpose intended, whenever such products are available. Where there are no UL of FM listed products of the type, testing and certification by another nationally recognized testing agency may be acceptable. Installation methods shall be in accordance with the manufacturer's instructions, with NFPA 70, and with other applicable requirements."

\section{REQUIREMENT SOURCE: DOE6430.1A Section 1640-2.3}

"Interior service transformer installations shall comply with NFPA 70. The minimum number of transformers necessary to satisfy initial and projected facility loads and operational 


\section{$\underline{\text { 12.4.5.3 }} \quad \underline{\text { Conduits }}$}

y, safety, and security requirements shall be used. Transformer protection and appurtenances shall comply with IEEE CC37.91. Transformer installation shall comply with FM 5-4/14-8"

\section{REQUIREMENT SOURCE: DOE6430.1A Division 16, Section 1605-2.1.4}

"Rigid steel conduit shall be used in locations classified as hazardous by NFPA 70.

Only rigid steel conduit or intermediate metal conduit shall be used to route secure circuits through nonsecured areas. Such circuits shall be capable of detecting tamper with the line."

\section{REQUIREMENT SOURCE: DOE6430.1A Section 1630-1.3}

"Facilities designated by the cognizant DOE authority as critical shall be served by dedicated, redundant electric circuits. The two services shall be separated by a 4-hour fire-rated barrier and shall be served from separate sources. In lieu of providing two separate services, a single service supplied from a loop-type transmission or distribution system having sectionalizing features may be provided when the reliably of the single service proves adequate when considered in conformance with IEEE 399 and IEEE 493."

\section{REQUIREMIENT SOURCE: DOE6430.1A Division 16, Section 1660-1, Paragraph 1}

"Standby and emergency systems shall serve loads set forth in NFPA 110. Additional standby or emergency systems shall be provided to support systems or equipment components whose operating continuity is determined to be vital by the cognizant DOE authorities for protection of health, life, property, and safeguards and security systems. Safety Class 1 items shall be provided with emergency power. "

\section{REQUIREMINT SOURCE: DOE6430.1A Section 1530-99.0[11]}

"An emergency source of electric power shall be provided to operate fire protection systems. Fire protection systems shall be capable of operating during a normal power outage. The emergency power sources and the electrical distribution circuits shall have independence and testability to ensure performance of their safety functions assuming any single failure."

\section{REQUIREMENT SOURCE: DOE6430.1A Section 1640-3.2}

"Normal primary power for protective alarm and communications systems shall come directly from the on-site power distribution system or, in the case of isolated facilities, shall come directly from the public utility. Where several primary power sources are available, the most reliable source shall be used."

\section{REQUIREMENT SOURCE: DOE6430.1A Section 1640-3.3}

"Standby or emergency power supplies for security, communications, and alarm systems shall be provided in accordance with DOE 6430.1A Section 1660, Special Systems." 


\section{REQUIREMENT SOURCE: DOE6430.1A Section 1660-1(4)}

"Emergency power shall be provided for protective alarm and communications systems as dictated by the system requirements. Switchover to emergency power shall be automatic on failure of the primary power source and shall be indicated on an annunciator panel. The annunciator shall be located in an occupied area and shall indicate any problems with the emergency system. Definition of "emergency systems", " legally required standby systems", and "operational standby systems" shall be in accordance with NFPA 70."

\section{REQUIREMIENT SOURCE: DOE6430.1A Section 1660-2}

"Emergency power systems shall be capable of maintaining full operation of emergency loads for the full time period specified by the cognizant DOE authority (nominally, a minimum of 24 hours). Such power sources shall have the necessary built-in features to facilitate operation testing on a periodic basis to verify their readiness.

Emergency power systems shall comply with NFPA 37, NFPA 70, NFPA 101, NFPA110, and IEEE 446."

\section{$\underline{12.4 .6}$}

12.4 .6 .1

\section{Exhaust and Ventilation Systems}

Ductwork and Air Ventilation Systems

\section{REQUIREMIENT SOURCE: DOE5480.7A Section 9.b.(12)}

"Containment Systems for Ventilation - Facilities which require ventilation containment systems shall be protected from the effects from fire to preclude release of radioactive, toxic, or other hazardous materials."

\section{REQUIREMENT SOURCE: DOE6430.1A Section 1550-2.5.6}

"Ductwork, accessories, and support systems shall be designed to comply with the following: NFPA 45

Ductwork shall also be designed to comply with NFPA 90A including specification and installation of smoke and fire dampers at fire wall penetrations and smoke pressurization/containment dampers as required for smoke pressurization/evacuation systems. Fire dampers shall not be used on exhaust system ducting if it is required to maintain confinement of hazardous materials during and after a fire event.

Exhaust ductwork shall comply with NFPA 91. Ductwork for kitchen exhaust shall comply with NFPA 96."

\section{REQUIREMENT SOURCE: DOE6430.1A Section 1595-6.5[3]}

"All supply, return, relief, and exhaust air ventilation systems shall have interlock controls that interface with fire and smoke detection system controls and either turn off or selectively operate fans and dampers to prevent the spread of smoke and fire throughout the building. These controls shall comply with NFPA 90A." 


\section{4 .6 .2}

$\underline{12.4 .6 .3}$

$\underline{12.4 .6 .4}$

$\underline{12.4 .6 .5}$

12.4 .6 .6
Smoke Pressurization and Evacuation Systems

\section{REQUIREMENT SOURCE: DOE6430.1A Section 1595-6.5}

"Control of Air Handling Systems - Fire and Smoke Detection and Protection Controls -

Engineered smoke pressurization and evacuation systems shall comply with the following:

$\frown$ NFPA 90A

$\frown$ NFPA 72E

ASHRAE Mamual, Design of Smoke Control Systems for Buildings

$\frown$ ASHRAE Systems Handbook"

\section{Confinement Systems Function During the DBF}

\section{REQURREMINT SOURCE: DOE6430.1A Section 1530-99.0[ 8]}

"Confinement systems, particularly the building structural shell and its associated ventilation system, shall be designed with the capability of retaining the confinement function during the DBF."

\section{Confinement Systems and Fire Protection}

\section{REQUIREMENT SOURCE: DOE6430.1A Section 1530-99.0[18]}

"To protect the integrity of process confinement systems, fire protection systems shall include the following features:

- Automatic and redundant fire detection devices.

- A fire-extinguishing system to rapidly remove heat produced by fire to prevent or minimize the Pressurization of a process confinement and to rapidly extinguish a fire to minimize the loading of ventilation system filters with combustion products.

- The introduction of the extinguishing agent in a way that does not result in over-pressurization of the confinement barriers."

Design Features for Lower Flammability Limit

REQUIREMENT SOURCE: DOE6430.1A Section 1530-99.0[13]

"When the process uses or produces combustible gases or vapors, the design shall include features such as inert gas purging, premixing hydrogen to a nonflammable percent with inert gas, and increasing the air flow within process confinement barriers to provide the dilution required to maintain the concentration of gases or vapors below the lower limit for flammability."

HEPA Filters

REQUREMENT SOURCE: DOE6430.1A Section 1161-4(2)

"...The design of the enclosure ventilation flow pattern shall minimize the spread of fire, and fire screens shall be provided where applicable."

REQUIREMENT SOURCE: DOE6430.1A Section 1550-2.5.5(9)

"Heating, Ventilating and Air-Conditioning Systems - Air Cleansing Devices - Fire Protection of HEPA Filter Assemblies - In providing fire protection for the HEPA filters, the design shall 
separate prefilters or fire screens equipped with water spray sufficiently from the EPA filters to restrict impingement of moisture on the HEPA filters. Under conditions of limited separation, moisture eliminators or other means of reducing entrained moisture shall be provided. Moisture eliminators may be omitted where system design provided sufficient filter redundancy to ensure continued effluent filtration in the event of fire within any portion of the system. The HEPA filter fire protection system shall be activated in a manner consistent with the fire protection system in the room or building in which the filters are located and as directed by the cognizant DOE fire protection authority."

\section{REQUIREMENT SOURCE: RLID5480.7 Section 8.2.c}

"Nuclear facility final exhaust/confinement high efficiency particulate air filters shall be protected for failure due to a fire. The level of protection required shall be determined using the Filter Plenum Fire Protection Criteria contained in the DOE Fire Protection Resource Manual."

\section{Lighting Protection}

\section{REQUIREMENT SOURCE: DOE6430.1A Section 1630-5}

Author's Note: NFPA 78 has been changed to NFPA 780.

"Lighting protection systems shall comply with NFPA 78. Lightning protection systems shall be considered for buildings containing facilities for the use, processing, and storage of radioactive, explosive and similarly hazardous materials; for buildings over $\mathbf{5 0}$ feet in height; and for buildings containing valuable equipment. A risk assessment using the guide in Appendix I of NFPA 78 shall be made of these buildings to determine the risk of loss due to lightning."

\section{$\underline{12.4 .8}$}

\section{Seismic Requirements}

\section{REQUIREMENT SOURCE: DOE5480.7A Section 9.b.(15)}

"Seismic Criteria - The design of fire protection systems to withstand seismic events shall be in accordance with the criteria developed by the National Fire Protection Association, except as required by other DOE criteria."

\section{$\underline{12.4 .9}$}

\section{Safety Class Equipment}

\section{REQUIREMENT SOURCE: DOE5480.7A Preamble, Section 5.f}

"DOE/EP-0108, "Standards for Fire Protection of AEC Electronic Computer Data Processing Systems"."

\section{REQUIREMENT SOURCE: DOE5480.7A Section 9.b.( 1)}

"Safety Class Equipment - In areas where a fire could cause damage to safety class equipment and where no redundant safety capability exists, a redundant fire protection system shall be provided for the safety class equipment. For new facilities, redundant Safety Class equipment shall be located in separate fire areas. Fire suppression systems shall be designed such that their actuation will not damage safety class equipment or cause a criticality incident." 


\section{REQUIREMENT SOURCE: DOE6430.1A Section 1660-99.0.1(4)}

"Redundant safety class electric systems shall be physically protected or separated to prevent a common external event from causing a failure of the redundant systems. IEEE 379 and IEEE 384 shall be used as redundancy and separation criteria."

\section{REQUIREMENT SOURCE: DOE6430.1A Section 1660-99.0.5}

"The design of protection systems and safety class instrumentation and control systems shall provide for the periodic in-place testing and calibration of instrument channels and interlocks. The design shall allow periodic testing of protective functions to determine whether failure or loss of redundancy may have occurred."

\section{FIRE, HAZMAT AND MEDICAL SUPPORT}

Requirements for this section are covered in the WHC Fire Protection Functional Area.

12.6

\section{$\underline{12.6 .1}$}

\section{ASSESSMENT}

\section{Fire Protection Investigation and Reporting}

\section{REQUIREMENT SOURCE: DOE5480.7A Section 9.a.(2)}

Author's Note:

Headquarters requirements are not applicable to contractor. Contractors/Facility Managers:

- Bullets 1-3 and 5 apply to facility;

$\neg$ Bullets 4 and 5 apply to company;

Program-Related applies to both company and facility levels.

Bullets 1, 3-6 apply to the company;

Bullets 2-4 and 7-8 apply to the facility.

Facility-Related applies to facility-level.

Combined Aspects (Program \& Facility) applies to both company and facility levels.

Bullets 1-3 apply to the company;

$\cap$ Bullets 3-7 apply to the facility.

"Assessments. Documented evaluations of the fire protection program, including field walkdowns of facilities, shall be performed as follows:

(a) Facilities/contractors shall be assessed to establish that they conform with DOE fire protection criteria.

(b) Minimum Frequency

Headquarters:

$\neg$ PSO assessment of field offices 3 years 
Field Office:

$\sim$ Field office assessment of the fire protection program of each contractor 2 years

Contractors/Facility Managers:

- Annual fire protection assessments shall be made of facilities valued in excess of $\$ 50$ million; where considered to be a moderate (Category 2 Hazard) or high hazard (Category 1 Hazard) as defined in DOE 5481.1B, SAFETY ANALYSIS AND REVIEW SYSTEM, for nonnuclear facilities and in DOE 5480.23, NUCLEAR SAFETY ANALYSIS REPORTS, for nuclear facilities; or in which vital programs are involved.

- Fire protection assessments shall be made at least every two years of facilities plus equipment valued at $\$ 10$ million to $\$ 50$ million.

$\frown$ Remaining facilities shall be assessed at least every three years or at frequencies determined by the AHJ.

Comprehensive assessments of fire protection program elements shall be made every two years.

$\frown$ Copies of the two most recent assessment reports shall be kept on file.

(c) Nature and Scope - Assessments shall include an evaluation of the following elements of the fire protection program:

Program-Related:

$\neg$ Comprehensiveness of the fire protection program.

$\sim$ Procedures for engineering design and review.

$\sim$ Procedures for maintenance, testing and inspection.

- Fire protection engineering staff (number, qualifications, training).

- Fire suppression organization (personnel and training).

$\frown$ Fire suppression mutual aid agreements.

$\sim$ Management support.

$\neg$ Exemptions and documented equivalencies.

Facility-Related:

- Fire protection of safety class equipment.

- Life safety considerations.

$\neg$ Fire protection of vital programs.

$\neg$ Fire protection of high value property.

$\neg$ Fire suppression equipment.

$\sim$ Water runoff.

$\frown$ Pre-fire plans.

$\sim$ Fire apparatus accessibility.

- Completeness of fire hazards analyses.

$\neg$ Fire barrier integrity.

- Completeness of fire loss potential (MPFL/MCFL) determinations.

- Fire safety training. 
Inspection, testing, and maintenance reports.

Adequacy of facility appraisal reports.

Tests of fire suppression systems, water supplies, and procedures for maintaining these in working order.

Administrative controls.

Temporary protection and compensatory measures.

Status of findings from previous assessments.

- Conformance with applicable Orders, codes and standards. "

\section{REQUIREMENT SOURCE: DOE5480.7A Section 9.b.( 5)}

"Testing and Maintenance - Fire protection systems shall be tested and maintained in accordance with the applicable NFPA standards and as supplemented by criteria in the DOE Fire Protection Resource Manual."

\section{REQUIREMENT SOURCE: DOE6430.1A Section 0110-6.2}

"Fire Protection Design Analysis - A special fire protection design analysis shall be made of each facility vital to DOE mission accomplishment. The analysis shall use time parameters established in accordance with DOE Order 5480.7. The analysis shall identify the special fire prevention and protection features and controls deemed by the cognizant DOE fire protection authority to achieve a level of fire protection for vital facilities and programs that meets or exceeds the "improved risk" level."

\section{REQUIREMIENT SOURCE: DOE6430.1A Section 1530-99.0}

"Special Facilities - Nonreactor Nuclear Facilities - An assessment shall be made early in the design or modification to determine the facility structures, systems, and components that shall be protected against the effects of a DBF and explosion. A fire protection engineer or person knowledgeable in applying the principles of fire protection shall develop the fire protection system. To maximize the protection against fire, the system shall contain an appropriate integration of fire prevention, detection, and suppression features."

\section{REQUIREMENT SOURCE: RLID5480.7 Section 6.2}

"RL Contractors shall assure that facilities and programs under their jurisdiction provide a level of fire protection adequate to meet the objectives of DOE 5480.7A for protection of the public, personnel, environment, and property. RL Contractors shall also:

a. Submit the "Annual Industrial Summary of Fire and Other Property Damage Experience" report (three copies) for the previous calendar year to the RL Director of QSH by February 1st of each year, as required by DOE 5484.1 and as supplemented by RL direction.

b. Report fires to QSH and losses, in accordance with paragraph 8.8 of this directive. c. Property loss valuation shall be determined by utilizing the property valuation and loss estimation guidelines found in DOE 5484.1.

d. Schedule and preform fire protection assessments for all facilities, including those for which the contractor has only landlord or lessee responsibility. Assure that the fire protection program elements, described in DOE 5480.7A and this directive, are being implemented. (1) Annual fire protection assessments shall be made of facilities valued in excess of $\$ 50$ million; where considered to be moderate (Category 2 Hazard) or high hazard (Category 1 Hazard), as defined in DOE 5481.1B, for non-nuclear facilities and in DOE 5480.23, for nuclear facilities; or in which vital programs are involved.

(2) Fire protection assessments shall be made at least every two years of facilities valued at $\$ 10$ million to $\$ 50$ million.

(3) Fire protection assessments shall be made at least every three years of facilities valued and $\$ 1$ million to $\$ 10$ million. 
(4) Except for paragraph 6.2d.(5) of this directive, fire protection facility assessments shall contain the required nature and scope elements contained in DOE 5480.7A. Facility assessments shall also contain findings and observations of fire protection deficiencies identified.

(5) Facilities, where property is less than $\$ 1$ million, shall not require a fire protection facility assessment that contains the required nature and scope elements contained in DOE 5480.7A, unless significant programmatic impacts, hazardous materials, or radioactive materials are involved. Such facility assessments shall be made at least every three years.

Exception: A fire protection assessment shall be made at least every three years of facilities valued at $\$ 250,000$ to $\$ 1$ million. The documented assessment for these facilities only needs to include findings, observations, and recommendations. Where applicable, these assessments should include, as a minimum, findings and observations and supporting documentation that identify fire hazards that could cause facility loss or life safety concerns.

(6) Fire protection facility assessments shall retained by the contractor, and made available to RL representatives upon request. Copies of the two most recent assessment reports shall be kept readily accessible on file.

(7) Facility assessments findings, observations, and/or recommendations shall be entered into data base tracking system and assigned and appropriate prioritization, to ensure that effective actions are being taken to correct deficiencies identified in accordance with RLID 1000.1. (8) MCFL and MPFL values described in the assessments shall be as required by DOE 5480.7A utilizing the property valuation and loss estimation guidelines found in DOE 5484.1. (9) Maintain a list of facilities which require assessment, indicating the assessment frequency. e. Perform FHA of facilities in accordance with DOE 5480.7A and EH-31.3, Guidance on Performance of Fire Hazard Analyses, memorandum dated 11-07-91. FHA shall be completed for all new facilities, as required by DOE 6430.1 version in effect, and all existing nuclear facilities, where safety analyses are required by DOE 5480.23 . The development of a facility design basis fire in accordance with DOE 6430.1 version in effect, as required in safety analysis documentation, must be consistent with the MPFL event and documented in the facility FHA.

The FHA shall be referenced by the safety analysis documentation. MCFL and MPFL values described in the FHA shall be as required by DOE $5480.7 \mathrm{~A}$, utilizing the property valuation and loss estimation guidelines found in DOE 5484.1. New facility and nuclear facility FHA shall be reviewed and approved by QSH. When directed by the PSO, the FHA shall also follow the same review and approval process as safety analysis documentation for DOE 5480.23. A copy of the current FHA shall be retained by the contractor and be kept readily accessible on file.

f. Provide fire protection overview and assistance for subcontractor activities and facilities. g. Carry out those responsibilities assigned by DOE $5480.7 \mathrm{~A}$, paragraphs $8 \mathrm{i}(1)$ through $8 \mathrm{i}(8)$, and comply with the applicable provisions of DOE 6430.1 versions in effect.

h. Establish a written and documented fire protection program for facilities and operations managed, including:

(1) A statement of management commitment to achieve the above stated objectives.

(2) A policy statement that implements DOE 5480.7A, other DOE fire protection related mandatory codes and standards, and requirements contained in this directive.

(3) Fire protection criteria that reflect site-specific aspects of the fire protection program, including the organization and responsibilities of the fire protection staff, administrative aspects of the Fire Protection Program, and requirements for physical fire protection features.

(4) See paragraph 8.12 of this directive for guidance on developing the documented fire protection program.

i. Maintain a current statement of programmatic impact on every vital program, as determined by RL or the PSO. The statement of programmatic impact will be updated every three years. The statement will include facilities, material, and equipment that are vital to the operation of that program.

j. Each prime contractor shall have on staff at least one qualified Fire Protection Engineer (see paragraph 5.2). 
k. Provide and maintain a system to ensure that the requirements of the DOE Fire Protection Program are documented and incorporated in the plans and specifications for all new facilities, and for major modifications of existing facilities. This includes review and comment by the fire protection engineering group of design documentation and testing of fire protection features.

1. Provide fire protection representation at the Hanford Fire Protection Fonum meeting, as described in the Hanford Fire Protection Forum Charter.

$\mathrm{m}$. Attend and provide representation at the monthly program interface meetings with the RL fire protection representative."

\section{REQUIREMENT SOURCE: RLID5480.7 Section 8.2.b}

"A program for the inspection and/or testing and maintenance of fire doors, fire dampers, and fire walls or separations shall be developed and implemented for each contractor."

\section{REQUIREMENT SOURCE: RLID5480.7 Section 8.8}

"Fire investigations and reports shall be performed and prepared, in accordance with DOE 5000.3B and DOE 5485.1."

\section{Control of Fire Protection Impairments}

\section{REQUIREMENT SOURCE: DOE5480.7A Section 9.b.(16)}

"Impairment Control - A fire protection system impaiment program shall be provided for control of operation and tracking of impairments during periods when fire protection systems are out of service."

\section{REQUIREMINT SOURCE: RLID5480.7 Section 8.6}

"The Fire Protection Program must include a fire protection system impairment strategy to minimize the duration and impact of fire protection system impairments. Elements of the fire protection impairment strategy must provide that:

a. Fire protection system impairments are identified, assigned priority, and promptly corrected in a reasonable amount of time.

b. A documented impairment program is administrated by trained personnel.

c. Fire protection staff and fire department personnel are advised and updated on impairments.

d. A policy is established for immediate and expedient repair of impaiments.

e. Compensatory measures are implemented until the impaired system is restored."

12.7

$\underline{12.7 .8}$

12.7 .9

\section{KEY INTERFACES}

\section{Configuration Management}

The Configuration Management Functional Area maintains the technical baseline of the installed fire protection systems and related equipment, construction services, and temporary modifications to existing and new facilities.

\section{Engineering Program}

The Engineering Program ensures that design features needed to mitigate fire hazards identified by the Fire Protection Functional Area are incorporated into the design. The Engineering Program provides the necessary facility support services required by fire 
protection systems. Specific requirements for the Fire Protection Functional Area should include the following subelements:

a. Design and operability standards for fire protection features;

b. Test of fire protection features to ensure operability and compliance with applicable codes and standards;

c. Interim compensatory measures; and

d. Design control of procurement and construction.

$\underline{12.7 .10}$

\section{Emergency Management}

The Emergency Management Functional Area addresses the general requirements applicable to the Fire Protection Functional Area for fire-related HAZMAT, medical or other emergency responses. Development of specific Fire Protection requirements should be coordinated with, and supported by, the Emergency Management Functional Area which includes the following subelements:

a. Coordination of off-site fire department emergency responses and training;

b. Fire drill criteria development;

c. Emergency medical, search, and rescue operations;

d. Emergency Plan Development; and

e. Emergency communications.

$\underline{12.7 .11}$

12.7.12

$\underline{12.7 .13}$

\section{Nuclear Safety}

The Nuclear Safety Functional Area details the provisions for the preparation of Safety Analysis Reports (SARs) and preparation of Technical Safety Requirements (TSRs). SARs and TSRs may be used as a basis for creation of a Fire Hazards Analysis for activities or as a source of Fire Protection information elements which may satisfy the need for an Fire Hazards Analysis (FHA).

\section{Occupational Safety and Health}

An integrated approach should be taken by Occupational Safety and Health Act ( OSHA) and the Fire Protection Functional Area to ensure both are current in standards and guidelines associated with the National Fire Protection Association and OSHA.

\section{Management Srstems}

The Management Systems Functional Area establishes organizational responsibilities and structure and the creation of appropriate implementing policies and procedures to develop and implement a Fire Protection Program. Additionally the Management Systems Functional Area ensures adequate guidance and oversight for the implementation of these policies and procedures, and maintains a commitment of resources to perform the required functions. 


\section{8}

$\underline{12.8 .8}$

$\underline{12.8 .9}$

\section{REFERENCES}

\section{Requirement Source Documents}

The following documents were used as requirement sources in the development of this S/RID:

29 CFR 1926, Code of Federal Regulations, 7-1-92

WAC-173-303, Dangerous Waste Regulations, 12-8-93

DOE 5480.7A, Fire Protection, 2-17-93

DOE 6430.1A, General Design Criteria, 4-6-89

RLID 5480.7, Fire Protection, 1-17-94

DOE EV-0043, Standard On Fire Protection For Portable Structures, 8-79

\section{Reviewed Documents Not Used as Requirement Sources}

The following documents were reviewed as requirement sources but were not used in the development of this S/RID:

DOE 5480.4, Environmental Protection, Safety, and Health Protection Standards, 1-7-93

DOE 5480.19, Conduct of Operations Requirements For DOE Facilities, 7-7-90 Page Change 1: $5-18-92$

DOE 5700.6C, Quality Assurance, 8-21-91

DOE EP/0108, Standard For Fire Protection Of AEC Electronic Computer Data Processing Systems, 1-84

NFPA Codes and Standards

Uniform Fire Code

Uniform Building Code

DOE/RL-91-28 Rev 1, Hanford Facility Dangerous Waste Permit Application, General Information, Appendix 7A, Hanford Facility Contingency Plan, May 93

DOE EH0135 Performance Objectives and Criteria For Technical Safety Appraisals at Department of Energy Facilities and Sites, 6-90 


\section{TABLE OF CONTENTS}

\subsection{PACKAGING AND TRANSPORTATION}

13.2.1

13.2 .2

13.2 .3

13.2 .4

13.2 .5

13.2 .6

13.2.6.1

13.2.6.2

13.2.6.3

13.2.7

13.2.7.1

13.2.7.2

13.2 .8

13.2 .9

13.2 .10

13.2.11

13.2.12

13.2.13

13.3

13.3.1

13.3.2

13.3.3

13.3.4

13.3.5

13.4

13.4.1

13.4 .2

13.4 .3

13.4 .4

Packaging $\ldots \ldots \ldots \ldots \ldots \ldots \ldots \ldots \ldots \ldots \ldots$

Coordination and Planning of Base Technology . . . . . . . . . . 11

Vehicle and Equipment Control and Maintenance . . . . . . . . . . . . 11

Onsite Material Tracking . . . . . . . . . . . . . . . . . . . . 11

Offsite Transportation Management $\ldots \ldots \ldots \ldots \ldots \ldots \ldots \ldots$

Marking, Labeling and Placarding $\ldots \ldots \ldots \ldots \ldots \ldots \ldots, 11$

Marking Requirements . . . . . . . . . . . . . . . . 11

Labeling Requirements $\ldots \ldots \ldots \ldots \ldots \ldots \ldots \ldots$

Placarding Requirements $\ldots \ldots \ldots \ldots \ldots \ldots \ldots \ldots 22$

Shipping Papers, Bills of Lading and Manifests . . . . . . . . . 26

Waste Manifests $\ldots \ldots \ldots \ldots \ldots \ldots \ldots \ldots \ldots \ldots 26$

Shipping Papers $\ldots \ldots \ldots \ldots \ldots \ldots \ldots \ldots \ldots \ldots \ldots \ldots$

Shipment Plans . . . . . . . . . . . . . . . . . 33

Notification of State Authorities of Shipments of High-Hazard Materials . 34

Emergency Response Information . . . . . . . . . . . . . . . . . . 34

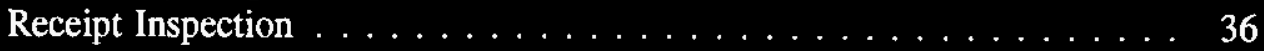

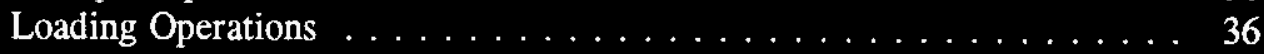

Transportation Operations $\ldots \ldots \ldots \ldots \ldots \ldots \ldots \ldots \ldots \ldots$

OFFSITE SAFETY $\ldots \ldots \ldots \ldots \ldots \ldots \ldots \ldots \ldots \ldots \ldots \ldots$

Package Standards and Certifications $\ldots \ldots \ldots \ldots \ldots \ldots . \ldots . \ldots 39$

Safety Analysis . . . . . . . . . . . . . . . . . . . . 39

Design, Fabrication, Assembly and Testing QA for OffSite Shipping

Containers . . . . . . . . . . . . . . . . . . . . . . . 39

Physical Protection for Security . . . . . . . . . . . . . . . . . 39

Nuclear Explosives, Components, and Assemblies . . . . . . . . . . . . 39

ONSITE SAFETY $\ldots \ldots \ldots \ldots \ldots \ldots \ldots \ldots \ldots \ldots \ldots \ldots \ldots \ldots$

Coordination of Material Transfers $\ldots \ldots \ldots \ldots \ldots \ldots$. . . . . . 40

Safety Analysis . . . . . . . . . . . . . . . . . . 41

Requirements for Potentially Explosive and Hazardous Materials . . . . . 41

Personnel Protection During Movement of Hazardous Materials . . . . . 41

KEY INTERFACES $\ldots \ldots \ldots \ldots \ldots \ldots \ldots \ldots \ldots \ldots \ldots \ldots \ldots$

Training and Qualification $\ldots \ldots \ldots \ldots \ldots \ldots \ldots \ldots \ldots \ldots$

Safeguards and Security $\ldots \ldots \ldots \ldots \ldots \ldots \ldots \ldots \ldots \ldots \ldots$ 
13.5 .3

13.5 .4

13.5 .5

13.5 .6

13.6

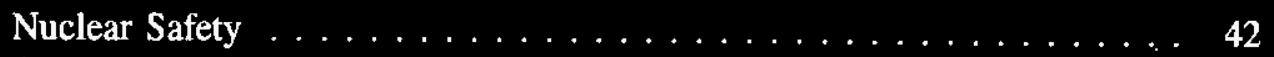

Emergency Management . . . . . . . . . . . . . . . 42

Radiation Protection . . . . . . . . . . . . . . . . . . 42

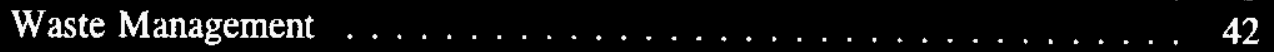

13.6.1

13.6.2

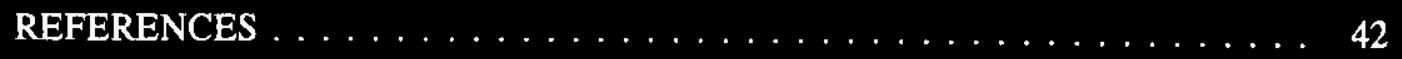

Requirement Source Documents . . . . . . . . . . . . . . . . . . . . 42

Reviewed Documents Not Used as Requirement Sources . . . . . . . . . . 43 


\subsection{PACKAGING AND TRANSPORTATION}

\section{INTRODUCTION}

A Standards/Requirements Identification Document (S/RID) sets forth the Environmental Safety and Health (ES\&H) standards/requirements. This S/RID is applicable to the appropriate life cycle phases of design, construction, operation, and preparation for decommissioning for each of the categories of facilities addressed in Revision 5 of the Department of Energy Implementation Plan for the Defense Nuclear Facilities Safety Board (DNFSB) Recommendation 90-2. This Recommendation calls for the strengthening of DOE weapons complex activities through the identification and application of relevant DOE Orders, regulations, industry codes/standards, industry guidance documents and, as appropriate, good industry practices. These standards/requirements are adequate to ensure protection of the health and safety of workers, the public, and the environment.

The Tank Farms S/RID, contains standards/requirements that are necessary for safe operation of the Tank Farms and its associated facilities, and that are the direct responsibility of the specific facility manager. The Packaging and Transportation (P\&T) Program defined in this document is described in general accordance with the Environment, Safety, and Health Configuration Guide, Revision 0, dated July 30, 1993, and is presented in program elements and subelements. The specific DOE Orders, regulations, industry codes/standards, guidance documents and good industry practices that serve as the basis for each element/subelement are identified and aligned with each subelement.

This S/RID contains only those requirements that Tank Farms personnel are clearly responsible to satisfy. Other requirements that are applicable to Tank Farms, but are satisfied by others, are defined in the Westinghouse Hanford Company (WHC) Level S/RID. For application in this S/RID, the words "shall" and "should" in requirement statements both indicate mandatory compliance. The key interface information contained in the Functional Area documents is provided for general recognition and understanding and is not considered to contain prescriptive requirements. Additionally, some of the requirements cited in this document are intentionally duplicated in the corresponding Company Level S/RID. This was necessary to address required implementation responsibilities occurring at both the company and facility levels.

\section{SCOPE}

This S/RID applies to the Tank Waste Remediation Systems (TWRS) Organization which includes the following:

- East Tank Farm Transition Project

- West Tank Farm Transition Project

- Evaporator Project

- Interim Stabilization Project

- Characterization Sampling Project (Excluding the Labs) 
The near-term mission of TWRS is to store, treat, and immobilize the highly radioactive Hanford Site Waste. The waste storage tanks provide for storage of high-level radioactive slurries, containing hazardous constituents. These tanks continue to receive waste periodically from various onsite generators through piping and transfer truck. Although the wastes contain transuranic components, the waste material are generally not of a sufficient concentration to be classified as transuranic per DOE 5820.2A; therefore technical requirements for TRU waste are not applicable. Most, if not all of the P\&T activities at Tank Farms is for "waste" materials.

The terms "onsite" and "offsite" will be used to describe shipments throughout this document. Onsite refers to any shipment made within the boundaries of the Hanford Site. Offsite refers to shipments made over public roads and highways. It is WHC best management policy that all shipments of hazardous and/or radioactive materials are to be performed in accordance with all federal, state and that Department of Transportation (DOT) regulations will be applied.

Onsite shipment activities include the shipment of hazardous waste, radioactive materials/waste and mixed waste. Radioactive materials/waste is shipped as either limited quantity or low specific activity (LSA); mixed waste is shipped as limited quantity, LSA, Type A. These wastes are prepared and shipped to the appropriate Solid Waste Disposal Facility within the 200 Area of the Hanford Site.

Offsite shipment activities include the shipment of low level radioactive materials (samples, contaminated compactible materials/equipment) to offsite laboratories, decontamination facilities, or DOE-RL contractor facilities for compaction. Compacted wastes are returned to the Hanford Site for final disposal/storage. Shipments consist of LSA or limited quantities.

This Tank Farm P\&T S/RID is based upon the WHC P\&T S/RID, and outlines those areas of P\&T that are Tank Farm specific. All general P\&T requirements are outlined in the WHC P\&T S/RID. Self assessments by the applicable organizations will verify compliance to these requirements.

The P\&T Functional Area includes program elements that are necessary to assure that operations at DOE facilities are conducted safely, effectively, and in accordance with specified DOE requirements and selected industry codes, standards, and guidelines.

The scope of the P\&T Functional Area encompasses the programmatic controls for activities associated with onsite and offsite packaging and transportation of hazardous and radioactive materials/wastes. The basis for selecting the requirements applicable to the Tank Farms is described in the following key points:

1. Company T\&P personnel are responsible for the following:

- Program management

- Carrier selection

- Safety analysis

- Package standards and certification

- Design, fabrication, assembly, and testing for shipping containers

- Training program content

2. The Tank Farm offsite shipments consist of "Limited Quantity", or "Low Specific Activity" materials to the Hanford Site, 300 area; laboratories; and DOE-RL contractors. 
3. LSA shipments are exclusive use in strong, tight packages.

4. Equipment transported to another Hanford facility under Tank Farm Facilities Long Length Contaminated Equipment Program, falls under the decision making authority of that facility to determine decon activities and/or storage until treatment issues.

The DOE requirements that govern P\&T activities are primarily contained in a series of DOE Orders and in the Department of Transportation (DOT), EPA. The DOE Orders are currently being expanded to provide a more complete definition of requirements, and are being restructured to improve their use. The Functional Area elements are discussed in Sections 13.1 through 13.4 Key Program Interfaces with other functional areas are discussed in Section 13.5 
Author's Note: Management and Administration requirements are addressed in the Management Systems Functional Area.

\section{PACKAGING AND TRANSPORTATION OPERATIONS}

\section{Packaging}

\section{REQUIREMENT SOURCE: 49CFR173 Part 12}

"Exceptions for shipment of waste materials.

(a) Open head drums. If a hazardous material that is a hazardous waste is required by this subchapter to be shipped in a closed head drum (i.e., a drum with a $7.0 \mathrm{~cm}$ ( 3 inches) or less bung opening) and the hazardous waste contains solids or semisolids that make its placement in a closed head drum impracticable, an equivalent (except for closure) open head drum may be used for the hazardous waste.

(b) Lab packs.

(1) Waste materials classed as Class or Division 3, 4.1, 4.2, 4.3, 5.1, 6.1, 8, or 9 are excepted from the specification packaging requirements of this subchapter for combination packagings if packaged in accordance with this paragraph and transported for disposal or recovery by highway only. In addition, a generic description from the 172.101 Table may be used in place of specific chemical names, when two or more chemically compatible waste materials in the same hazard class are packaged in the same outside packaging.

(2) Additional packaging requirements are as follows:

(i) The outer packaging must be a UN 1A2 or UN 1B2 metal drum, a UN 1D plywood drum, a UN $1 \mathrm{G}$ fiber drum or a UN $1 \mathrm{H} 2$ plastic drum tested and marked at least for the Packing Group III performance level for liquids or solids;

(ii) The inner packagings must be either glass, not exceeding $4 \mathrm{~L}$ (1 gallon) rated capacity, or metal or plastic, not exceeding 20 L (5.3 gallons) rated capacity;

(iii) Each outer packaging may contain only one class of hazardous material;

(iv) Inner packagings containing liquid must be surrounded by a chemically compatible absorbent material in sufficient quantity to absorb the total liquid contents; and

(v) Gross weight of the complete package may not exceed $205 \mathrm{~kg}$ (452 lbs).

(3) Prohibited materials. Materials meeting the definition of Division 6.1, Packing Group I, or Division 4.2, Packing Group I, and bromine pentafluoride; bromine trifluoride; chloric acid; and oleum (fuming sulfuric acid) may not be packaged or described under the provisions of this paragraph.

(c) Reuse of packagings. A previously used packaging may be reused for the shipment of hazardous waste to designated facilities, not subject to the reconditioning and reuse provisions contained in 173.28 and part 178 of this subchapter, under the following conditions:

(1) Except as authorized by this paragraph, the waste must be packaged in accordance with this part and offered for transportation in accordance with the requirements of this subchapter.

(2) Transportation is performed by highway only. 
(3) A package is not offered for transportation less than 24 hours after it is finally closed for transportation, and each package is inspected for leakage and is found to be free from leaks immediately prior to being offered for transportation.

(4) Each package is loaded by the shipper and unloaded by the consignee, unless the motor carrier is a private or contract carrier.

(5) The packaging may be used only once under this paragraph and may not be used again for shipment of hazardous materials except in accordance with 173.28.

(d) Technical names for n.o.s. descriptions. The requirements for the inclusion of technical names for n.o.s. descriptions on shipping papers and package markings, 172.203 and 172.301 of this subchapter, respectively, do not apply to packagings prepared in accordance with paragraph (b) of this section, except as follows:

(1) Packages containing materials meeting the definition of a hazardous substance must be described as required in 172.203(c) of this subchapter and marked as required in 172.324 of this subchapter; and

(2) Packages containing hazardous materials subject to the provisions of 172.203(m) of this subchapter must be described in accordance with 172.203(m) of this subchapter."

\section{REQUIREMIENT SOURCE: 49CFR173 Part 22(a)(1) thru (2)}

"Shipper's responsibility.

(a) Except as otherwise provided in this part, a person may offer a hazardous material for transportation in a packaging or container required by this part only in accordance with the following:

(1) The person shall class and describe the hazardous material in accordance with parts 172 and 173 of this subchapter, and

(2) The person shall determine that the packaging or container is an authorized packaging, including part 173 requirements, and that it has been manufactured, assembled, and marked in accordance with:

(i) Section 173.7(a) and parts 173,178 , or 179 of this subchapter;

(ii) A specification of the Department in effect at the date of manufacture of the packaging or container;

(iii) An approval issued under this subchapter; or

(iv) An exemption issued under subchapter B of this chapter."

\section{REQUIREMENT SOURCE: 49CFR173 Part 22(a)(3)}

"(3) In making the determination under paragraph (a)(2) of this section, the person may accept:

(i) The manufacturer's certification, specification, approval, or exemption marking (see 178.02 and 179.1 of this subchapter); or

(ii) With respect to cargo tanks provided by a carrier, the manufacturer's identification plate or a written certification of specification or exemption provided by the carrier." 


\section{REQUIREMINT SOURCE: 49CFR173 Part 421(2)(a)}

"Requirements for multiple hazard limited quantity radioactive materials. Except as provided in paragraph (b) of this section or in $\mathbf{1 7 3 . 4}$ of this subchapter, when a limited quantity Class 7 material meets the definition of another hazard class or division, it shall be:

(1) Classed for the additional hazard;

(2) Packaged to conform with the requirements specified in 173.421 (a) through (e) or 173.422 (a) through $(\mathrm{g})$, as appropriate; and

(3) Offered for transportation in accordance with the requirements applicable to the hazard for which it is classed."

\section{REQUIREMENT SOURCE: 49CFR173 Part 421(2)(b)}

"When a limited quantity Class 7 material meets the definition of Class 9 or is a combustible liquid in a non-bulk packaging, it shall be:

(1) Classed as a Class 7 material if:

(i) The material is not a hazardous waste or hazardous substance; and

(ii) The material is offered for transportation in a mode to which requirements of this subchapter pertaining to the specific material do not apply;

(2) Classed combustible liquid or Class 9, as appropriate, if:

(i) The material is a hazardous waste or hazardous substance; or

(ii) The material is offered for transportation in a mode to which requirements of this subchapter pertaining to the specific material do apply;

(3) Packaged to conform with requirements specified in 173.421 (a) through (e) or 173.422 (a) through (g), as appropriate; and

(4) Offered for transportation in accordance with requirements applicable to the hazard for which it is classed."

\section{REQUIREMENT SOURCE: 49CFR173 Part 421(2)(c)}

"A limited quantity Class 7 material which is classed other than Class 7 under the provisions of paragraph (a) or (b) of this section is excepted from the requirements of 173.421 1(a), 172.203(d), and 172.204 (c)(4) of this subchapter if the entry "Limited quantity radioactive material" appears on the shipping paper in association with the basic description."

\section{REQUIREMENT SOURCE: 49CFR173 Part 421-1}

"Additional requirements for excepted packages containing Class 7 (radioactive) materials.

(a) Excepted packages prepared for shipment under the provisions of $\$ \S 173.421,173.422,173.424$, or 173.427 of this subpart must be certified as being acceptable for transportation by having a notice enclosed in or on the package, included with the packing list, or otherwise forwarded with the package. This notice must include the name of the consignor or consignee and the statement "This package conforms to the conditions and limitations specified in 49 CFR 173.421 for radioactive material, excepted package-limited quantity of material, UN2910; 49 CFR 173.422 for radioactive for radioactive material, excepted package--articles manufactured from natural or depleted uranium or natural thorium, 
UN2910; or 49 CFR 173.427 for radioactive material, excepted package--empty packages, UN2908", as appropriate.

(b) An excepted radioactive material classed radioactive material and prepared for shipment under the provisions of $\$ 173.421, \S 173.422, \S 173.424, \S 173.427$ or $\$ 173.421-2$ is not subject to the requirements of this subchapter, except for:

(1) Sections $171.15,171.16,174.750,176.710$ and 177.861 of this subchapter pertaining to the reporting of incidents and decontamination when transported by a mode other than air; or

(2) Sections $171.15,171.16,175.45$, and $175.700(\mathrm{~b})$ of this subchapter pertaining to the reporting of incidents and decontamination if transported by aircraft."

\section{REQUIREMENT SOURCE: 49CFR173 Part 425}

"Transport requirements for low specific activity (LSA) radioactive materials.

In addition to other applicable requirements specified in this subchapter, low specific activity (LSA) materials shall be transported in accordance with paragraph (a) of this section, or if transported as exclusive-use may be transported in accordance with paragraph (b) or (c) of this section.

(a) DOT Specification 7A (178.350 of this subchapter) Type A package. The requirements of 173.412 (a), (b), (d), and (n) do not apply.

(b) Packaged shipments of LSA material consigned as exclusive use shall either be in accordance with paragraph (a) of this section or shall comply with the following in which case they are excepted from specification packaging, marking and labeling:

(1) Materials must be packaged in strong, tight packages so that there will be no leakage of radioactive material under conditions normally incident to transportation.

(2) Packages must not have any significant removable surface contamination (see 173.443).

(3) External radiation levels must comply with $\mathbf{1 7 3 . 4 4 1 .}$

(4) Shipments must be loaded by consignor and unloaded by consignee from the conveyance or freight contained in which originally loaded.

(5) There must be no loose radioactive material in the conveyance.

(6) Shipment must be braced so as to prevent shifting of lading under conditions normally incident to transportation.

(7) Except for shipments of unconcentrated uranium or thorium ores, the transport vehicle must be placarded with the placards prescribed in accordance with subpart F of part 172 of this subchapter, as appropriate.

(8) The exterior of each package must be stenciled or otherwise marked "Radioactive-LSA". Packages, with a capacity of 110 gallons or less, that contain a hazardous substance, must be stenciled or otherwise marked with the letters " $R Q$ "' in association with the above description.

(9) Specific instructions for maintenance of exclusive use shipment controls must be provided by the shipper to the carrier. Such instructions must be included with the shipping paper information.

(10) Transportation by aircraft is prohibited. 
(c) Unpackaged (bulk) shipments of LSA materials shall be transported only in exclusive use closed transport vehicles and shall comply with the following:

(1) Authorized materials are limited to the following:

(i) Uranium or thorium ores and physical or chemical concentrates of those ores.

(ii) Uranium metal or natural thorium metal, or alloys of these materials.

(iii) Materials of low radioactive concentration, if the average estimated radioactivity concentration does not exceed 0.001 millicurie per gram and the contribution from materials with an $\mathrm{A} 2$ value (see 173.435) of less than 0.05 curie does not exceed one percent of the total radioactivity.

(iv) Objects of nonradioactive material externally contaminated with radioactive material, if the radioactive material is not readily dispersible and the surface contamination, when averaged over one square meter, does not exceed 0.0001 millicurie per square centimeter of radionuclides for which the A2 value is less than 0.05 or 0.001 millicurie per square centimeter of other radionuclides. Such objects must be suitably wrapped or enclosed.

(2) Bulk liquids must be transported in the following:

(i) Specification 103CW, 111A60W7 $(179.200,179.201,179.202$ of this subchapter) tank cars. Bottom openings in tanks prohibited.

(ii) Specification MC 310, MC 311, MC 312, or MC 331 (178.343 or 178.337 of this subchapter) cargo tanks. Authorized only where the radioactivity concentration does not exceed 10 percent of the specified low specific activity levels (see 173.403(n)). The requirements of 173.412(n) do not apply to these cargo tanks. Bottom fittings and valves are not authorized. Trailer-on-flat-car service is not authorized.

(3) External radiation levels must comply with $173.441(\mathrm{~b})$.

(4) Shipments must be loaded by the consignor, and unloaded by the consignee from the conveyance or freight container in which originally loaded.

(5) Except for shipments of unconcentrated uranium or thorium ores, the transport vehicle must be placarded with the placards prescribed in subpart F of part 172 of this subchapter, as appropriate.

(6) There must be no leakage of radioactive materials from the vehicle.

(7) Specific instructions for maintenance of exclusive use shipment controls must be provided by the shipper to the carrier. Such instructions must be included with the shipping paper information.

(8) Transportation by aircraft is prohibited.

(d) Except for transportation by aircraft, low specific activity material that conforms with the provisions specified in 10 CFR 20.306 is excepted from all requirements of this subchapter pertaining to radioactive materials when offered for transportation for disposal or recovery. A material which meets the definition of another hazard class is subject to the provisions of this subchapter relating to that hazard class." 


\section{REQUIREMINT SOURCE: 49CFR173 Part 441}

"Radiation level limitations.

(a) Except as provided in paragraph (b) of this section, each package of radioactive materials offered for transportation shall be designed and prepared for shipment so that under conditions normally incident to transportation the radiation level does not exceed 200 millirem per hour at any point on the external surface of the package, and the transport index does not exceed 10.

(b) A package which exceeds the radiation level limits specified in paragraph (a) of this section shall be transported by exclusive use shipment only and the radiation levels for such shipment must not exceed the following during transportation:

(1) 200 millirem per hour ( 2 millisievert per hour) on the external surface of the package unless the following conditions are met, in which case the limit is 1000 millirem per hour (10 millisievert per hour).

(i) The shipment is made in a closed transport vehicle;

(ii) The package is secured within the vehicle so that its position remains fixed during transportation; and

(iii) There are no loading or unloading operations between the beginning and end of the transportation;

(2) 200 millirem per hour ( 2 millisievert per hour) at any point on the outer surfaces of the vehicle, including the top and underside of the vehicle; or in the case of a flat-bed style vehicle, at any point on the vertical planes projected from the outer edges of the vehicle, on the upper surface of the load (or enclosure is used), and on the lower external surface of the vehicle;

(3) 10 millirem per hour ( 0.1 millisievert per hour) at any point 2 meters $(6.6$ feet) from the outer lateral surfaces of the vehicle (excluding the top and underside of the vehicle); or in the case of a flat-bed style vehicle, at any point 2 meters ( 6.6 feet) from the vertical planes projected by the outer edges of the vehicle (excluding the top and underside of the vehicle); and

(4) 2 millirem per hour ( 0.02 millisievert per hour) in any normally occupied space, except that this provision does not apply to private carriers if exposed personnel under their control wear radiation dosimetry devices and operate under provisions of a State or Federally regulated radiation protection program.

(c) For shipments made under the provisions of paragraph (b) of this section, the shipper shall provide specific written instructions for maintenance of the exclusive use shipment controls to the carrier. The instructions shall be included with the shipping paper information.

(d) Packages exceeding the radiation level or transport index prescribed in paragraph (a) of this section shall not be transported by aircraft.

(e) The written instructions required for exclusive use shipments must be sufficient so that, when followed, they will cause the carrier to avoid actions which will unnecessarily delay delivery or unnecessarily result in increased radiation levels or radiation exposures.

(The information collection requirements contained in paragraph (c) were approved by the Office of Management and Budget under control number 2137 0536)"

\section{REQUIREMINT SOURCE: 49 CFR173 Part 442}

"Thermal limitations.

Each package of radioactive material shall be designed, constructed, and loaded so that: 
(a) The heat generated within the package because of the radioactive contents will not, at any time during transportation, affect the integrity of the package under conditions normally incident to transportation; and

(b) The temperature of the accessible external surfaces of the loaded package will not, assuming still air in the shade at an ambient temperature of $38^{\circ} \mathrm{C}\left(100^{\circ} \mathrm{F}\right)$, exceed either:

(1) $50^{\circ} \mathrm{C}(122 \mathrm{~F})$ in other than an exclusive use shipment; or

(2) $82^{\circ} \mathrm{C}(180 \mathrm{~F})$ in an exclusive use shipment."

\section{REQUIREMENT SOURCE: 49CFR173 Part 443}

"Contamination control.

(a) The level of non-fixed (removable) radioactive contamination on the external surfaces of each package offered for shipment shall be kept as low as practicable. The level of non-fixed radioactive contamination may be determined by wiping an area of 300 square centimeters of the surface concerned with an absorbent material, using moderate pressure, and measuring the activity on the wiping material. Sufficient measurements shall be taken in the most appropriate locations to yield a representative assessment of the non-fixed contamination levels. Except as provided in paragraph (b) of this section, the amount of radioactivity measured on any single wiping material when averaged over the surface wiped shall not exceed the limits given in Table 10 at any time during transport. Other methods of assessment of equal or greater efficiency may be used. When other methods are used the detection efficiency of the method used shall be taken into account and in no case shall the non-fixed contamination on the external surfaces of the package exceed ten times the limits listed in Table 10. HAZDOCS-2 Table No. 90

(b) Except as provided in paragraph (d) of this section, in the case of packages transported as exclusive use shipments by rail or public highway only, the removable (non-fixed) radioactive contamination on any package at any time during transport shall not exceed ten times the levels prescribed in paragraph (a) of this section. The levels at the beginning of transport shall not exceed the levels prescribed in paragraph (a) of this section.

(c) Except as provided in paragraph (d) of this section, each transport vehicle used for transporting radioactive materials as an exclusive use shipment which utilizes the provisions of paragraph (b) of this section shall be surveyed with appropriate radiation detection instruments after each use. A vehicle shall not be returned to service until the radiation dose rate at each accessible surface is 0.5 millirem per hour or less, and there is no significant removable (non-fixed) radioactive surface contamination as specified in paragraph (a) of this section.

(d) Paragraph (b) and (c) of this section do not apply to any closed transport vehicle used solely for the transportation by public highway of radioactive material packages with contamination levels that do not exceed 10 times the levels prescribed in paragraph (a) of this section if:

(1) A survey of the interior surfaces of the empty vehicle shows that the radiation dose rate at any point does not exceed 10 millirem per hour at the surface or 2 millirem per hour at 1 meter $(3.3$. feet) from the surface;

(2) Each vehicle is stenciled with the words "For Radioactive Materials Use Only" in letters at least 76 millimeters ( 3 inches) high in a conspicuous place on both sides of the exterior of the vehicle; and

(3) Each vehicle is kept closed except for loading or unloading." 
$\underline{13.2 .2}$

13.2 .3

$\underline{13.2 .4}$

$\underline{13.2 .5}$

$\underline{13.2 .6}$

$\underline{13.2 .6 .1}$

\section{Coordination and Planning of Base Technology}

No requirements applicable to the Tank Farms were identified within this subelement.

\section{Vehicle and Equipment Control and Maintenance}

No requirements pertaining to vehicle and equipment control and maintenance are applicable to the TWRS, as this is the responsibility of another company organization. The applicable requirements are delineated in the Westinghouse Hanford Company (WHC) S/RID.

\section{Onsite Material Tracking}

Author's Note: No requirements were identified as applicable to TWRS in this subelement.

\section{Offsite Transportation Management}

The requirements applicable to Offsite Transportation Management are the responsibility of the WHC TP Organization and are delineated within the WHC S/RID.

\section{Marking, Labeling and Placarding}

\section{Marking Requirements}

\section{REQUIREMENT SOURCE: 49CFR172 Part 300}

"Applicability.

(a) Each person who offers a hazardous material for transportation shall mark each package, freight container, and transport vehicle containing the hazardous material in the manner required by this subpart.

(b) When assigned the function by this subpart, each carrier that transports a hazardous material shall mark each package, freight container, and transport vehicle containing the hazardous material in the manner required by this subpart.

\section{REQUIREMENT SOURCE: 49CFR172 Part 301}

"General marking requirements for non-bulk packagings.

(a) Proper shipping name and identification number.

(1) Except as otherwise provided by this subchapter, each person who offers for transportation a hazardous material in a non-bulk packaging shall mark the package with the proper shipping name and identification number (preceded by "UN" or "NA", as appropriate) for the material as shown in the 172.101 table.

(2) The proper shipping name for a hazardous waste (as defined in 171.8 of this subchapter) is not required to include the word "waste" if the package bears the EPA marking prescribed by 40 CFR 262.32 .

(b) Technical names. In addition to the marking required by paragraph (a) of this section, each non-bulk packaging containing hazardous materials subject to the provisions of $\$ 172.203(\mathrm{k})$ of this part shall be marked with the technical name in parentheses in association with the proper shipping name in accordance with the requirements and exceptions specified for display of technical descriptions on shipping papers in $\$ 172.203(\mathrm{k})$ of this part. 
(c) Exemption packagings. The outside of each package authorized by an exemption shall be plainly and durably marked "DOT E" followed by the exemption number assigned.

(d) Consignee's or consignor's name and address. Each person who offers for transportation a hazardous material in a non-bulk package shall mark that package with the name and address of the consignor or consignee except when the package is--

(1) Transported by highway only and will not be transferred from one motor carrier to another; or

(2) Part of a carload lot, truckload lot or freight container load, and the entire contents of the rail car, truck or freight container are shipped from one consignor to one consignee.

(e) Previously marked packagings. A package which has been previously marked as required for the material it contains and on which the marking remains legible, need not be remarked. (For empty packagings, see $\$ 173.29$ of this subchapter.)

(f) Marking exceptions.

(1) Identification numbers are not required on packages which contain only limited quantities, as defined in $\$ 171.8$ of this subchapter, or ORM-D materials.

(2) The marking of technical names on non-bulk packagings filled for shipment prior to December 31 , 1990 is not required until December 31, 1991."

\section{REQUIREMIENT SOURCE: 49CFR172 Part 303}

"Prohibited marking.

(a) No person may offer for transportation or transport a package which is marked with the proper shipping name or identification number of a hazardous material unless the package contains the identified hazardous material or its residue.

(b) This section does not apply to_

(1) Transportation of a package in a transport vehicle or freight container if the package is not visible during transportation and is loaded by the shipper and unloaded by the shipper or consignee.

(2) Markings on a package which are securely covered in transportation.

(3) The marking of a shipping name on a package when the name describes a material not regulated under this subchapter."

\section{REQUIREMENT SOURCE: 49CFR172 Part 304}

"Marking requirements.

(a) The marking required in this subpart

(1) Must be durable, in English and printed on or affixed to the surface of a package or on a label, tag, or sign.

(2) Must be displayed on a background of sharply contrasting color;

(3) Must be unobscured by labels or attachments; and

(4) Must be located away from any other marking (such as advertising) that could substantially reduce its effectiveness." 


\section{REQUIREMENT SOURCE: 49CFR172 Part 310}

"Radioactive materials.

(a) In addition to any other markings required by this subpart, each package containing radioactive materials must be marked as follows:

(1) Each package of radioactive materials in excess of 110 pounds ( 50 kilograms) must have its gross weight plainly and durably marked on the outside of the package.

(2) Each package of radioactive materials which conforms to the requirements for Type A or Type B packaging (173.403 of this subchapter) must be plainly and durably marked on the outside of the package in letters at least -inch $(13 \mathrm{~mm}$.) high, with the words "TYPE A" or "TYPE B" as appropriate. A packaging which is not in compliance with these requirements may not be so marked.

(3) Each package of radioactive material destined for export shipment must also be marked "USA" in conjunction with the specification marking, or other package certificate identification. (See 173.471 173.472 , and 173.473 of this subchapter.)"

\section{REQUIREMENT SOURCE: 49 CFR172 Part 312}

"Liquid hazardous materials in non-bulk packagings.

(a) Except as provided in this section, each non-bulk combination package having inner packagings containing liquid hazardous materials must be:

(1) Packed with closures upward, and

(2) Legibly marked, with package orientation markings that conform pictorially to ISO Standard 780 1985 , on two opposite vertical sides of the package with the arrows pointing in the correct upright direction. Depicting a rectangular border around the arrows is optional.

(b) Arrows for purposes other than indicating proper package orientation may not be displayed on a package containing a liquid hazardous material.

(c) The requirements of paragraph (a) of this section do not apply to

(1) A non-bulk package with inner packagings which are cylinders.

(2) Except when offered or intended for transportation by aircraft, packages containing flammable liquids in inner packagings of one liter or less prepared in accordance with 173.150 (b) or (c) of this subchapter.

(3) When offered or intended for transportation by aircraft, packages containing flammable liquids in inner packagings of $120 \mathrm{ml}$ (4 fluid oz.) or less prepared in accordance with 173.150 (b) or (c) of this subchapter when packed with sufficient absorption material between the inner and outer packagings to completely absorb the liquid contents.

(4) Liquids contained in manufactured articles (e.g., alcohol or mercury in thermometers) which are leak-tight in all orientations.

(5) A non-bulk package with hermetically-sealed inner packagings. " 


\section{REQUIREMENT SOURCE: 49CFR172 Part 332}

"Identification number markings.

(a) General. When required by $172.302,172.326,172.328,172.330$, or 172.331 of this subpart, identification numbers shall be displayed on orange panels or placards as specified in this section or, when appropriate, on white square-on-point configurations as prescribed in $172.336(b)$.

(b) Orange panels. Display of an identification number on an orange panel shall be in conformance with the following:

(1) The orange panel must be $160 \mathrm{~mm}$ (6.3 inches) high by $400 \mathrm{~mm}$ (15.7 inches) wide with a $15 \mathrm{~mm}$ ( 0.6 inches) black outer border. The identification number shall be displayed in $100 \mathrm{~mm}$ ( 3.9 inches) black Helvetica Medium numerals on the orange panel. Measurements may vary from those specified plus or minus $5 \mathrm{~mm}$ ( 0.2 inches).

(2) The orange panel may be made of any durable material prescribed for placards in 172.519 , and shall be of the orange color specified for labels or placards in appendix $A$ to this part.

(3) The name and hazard class of a material may be shown in the upper left border of the orange panel in letters not more than 18 points high.

(4) Except for size and color, the orange panel and identification numbers shall be as illustrated for Liquefied petroleum gas:

(c) Placards. Display of an identification number on a hazard warning placard shall be in conformance with the following:

(1) The identification number shall be displayed across the center area of the placard in $88 \mathrm{~mm}(3.5$ inches) black Alpine Gothic or Alternate Gothic No. 3 numerals on a white background $100 \mathrm{~mm}$ ( 3.9 inches) high and approximately $215 \mathrm{~mm}$ ( 8.5 inches) wide and may be outlined with a solid or dotted line border.

(2) The top of the $100 \mathrm{~mm}$ (3.9 inches) high white background shall be approximately $40 \mathrm{~mm}$ (1.6 inches) above the placard horizontal center line.

(3) An identification number may be displayed only on a placard corresponding to the primary hazard class of the hazardous material.

(4) For a COMBUSTIBLE placard used to display an identification number, the entire background below the white background for the identification number must be white during transportation by rail and may be white during transportation by highway.

(5) The name of the hazardous material and the hazard class may be shown in letters not more than 18 points high immediately within the upper border of the space on the placard bearing the identification number of the material.

(6) If an identification number is placed over the word(s) on a placard, the word(s) should be substantially covered to maximize the effectiveness of the identification number.

(d) Except for size and color, the display of an identification number on a placard shall be as illustrated for Acetone:" 


\section{REQUIREMENT SOURCE: 49CFR172 Part 334}

"Identification numbers; prohibited display.

(a) No person may display an identification number on a RADIOACTIVE, EXPLOSIVES 1.1, 1.2, $1.3,1.4,1.5$ or 1.6 , DANGEROUS, or subsidiary hazard placard.

(b) No person may display an identification number on a placard, orange panel or white square-on-point display configuration unless_

(1) The identification number is specified for the material in 172.101 ;

(2) The identification number is displayed on the placard, orange panel or white square-on-point configuration authorized by 172.332 or $172.336(b)$, as appropriate, and any placard used for display of the identification number corresponds to the hazard class of the material specified in 172.504;

(3) Except as provided under 172.336 (c)(4) or (c)(5) the package, freight container, or transport vehicle on which the number is displayed contains the hazardous material associated with that identification number in 172.101.

(c) Except as required by 172.332 (c)(4) for a combustible liquid, the identification number of a material may be displayed only on the placards required by the tables in 172.504 .

(d) Except as provided in 172.336, a placard bearing an identification number may not be used to meet the requirements of subpart $\mathrm{F}$ of this part unless it is the correct identification number for all hazardous materials of the same class in the transport vehicle or freight container on which it is displayed.

(e) Except as specified in 172.338, an identification number may not be displayed on an orange panel on a cargo tank unless affixed to the cargo tank by the person offering the hazardous material for transportation in the cargo tank.

(f) If a placard is required by 172.504 , an identification number may not be displayed on an orange panel unless it is displayed in proximity to the placard.

(g) No person shall add any color, number, letter, symbol, or word other than as specified in this subchapter, to any identification number marking display which is required or authorized by this subchapter."

\section{REQUIREMENT SOURCE: 49CFR172 Part 336}

"Identification numbers; special provisions.

(a) When not required or prohibited by this subpart, identification numbers may be displayed on a transport vehicle or a freight container in the manner prescribed by this subpart.

(b) For hazardous materials in hazard classes for which hazard warning placards are not specified, identification numbers, when required, must be displayed on either orange panels (see 172.332(b)) or on a plain white square-on-point display configuration having the same outside dimensions as a placard. In addition, for materials in hazard classes for which placards are specified and identification number displays are required, but for which identification numbers may not be displayed on the placards authorized for the material (see 172.334(a)), identification numbers must be displayed on orange panels or on the plain white square-on-point display configuration in association with the required placards.

An identification number displayed on a white square-on-point display configuration is not considered to be a placard. 
(1) The $100 \mathrm{~mm}$ ( $3.9 \mathrm{inch})$ by $215 \mathrm{~mm}$ ( 8.5 inches) area containing the identification number shall be located as prescribed by $172.332(\mathrm{c})(1)$ and $(c)(2)$ and may be outlined with a solid or dotted line border.

(2) [Reserved]

(c) Identification numbers are not required:

(1) On the ends of a portable tank, cargo tank or tank car having more than one compartment if hazardous materials having different identification numbers are being transported therein. In such a circumstance, the identification numbers on the sides of the tank shall be displayed in the same sequence as the compartments containing the materials they identify.

(2) On a cargo tank containing only gasoline, if the cargo tank is marked "Gasoline" on each side and rear in letters no less than $50 \mathrm{~mm}$ ( 2 inches) high, or is placarded in accordance with 172.542(c).

(3) On a cargo tank containing only fuel oil, if the cargo tank is marked "Fuel Oil" on each side and rear in letters no less than $50 \mathrm{~mm}$ ( 2 inches) high, or is placarded in accordance with 172.544(c).

(4) For each of the different liquid petroleum distillate fuels, including gasoline and gasohol in a compartmented cargo tank or tank car, if the identification number is displayed for the distillate fuel having the lowest flash point.

(5) For each of the different liquid petroleum distillate fuels, including gasoline and gasohol transported in a cargo tank, if the identification number is displayed for the liquid petroleum distillate fuel having the lowest flash point.

(6) On nurse tanks meeting the provisions of $173.315(\mathrm{~m})$ of this subchapter."

\section{REQUIREMENT SOURCE: 49CFR172 Part 338}

"Replacement of identification numbers.

If more than one of the identification number markings on placards, orange panels, or white square-on-point display configurations that are required to be displayed are lost, damaged or destroyed during transportation, the carrier shall replace all the missing or damaged identification numbers as soon as practicable. However, in such a case, the numbers may be entered by hand on the appropriate placard, orange panel or white square-on-point display configuration providing the correct identification numbers are entered legibly using an indelible marking material. When entered by hand, the identification numbers must be located in the white display area specified in 172.332. This section does not preclude required compliance with the placarding requirements of subpart $F$ of this subchapter."

\section{REQUIREMENT SOURCE: 49CFR172(941001) Part 308}

"Authorized abbreviations.

(a) Abbreviations may not be used in a proper shipping name marking except as authorized in this section.

(b) For marking descriptions of ammunition, such as Ammunition for cannon without projectile, etc., the words "with" or "without" may be abbreviated as "W" or "W/O". For example:

"Ammunition for cannon W/O projectile."

(c) The abbreviation "ORM" may be used in place of the words "Other Regulated Material." 
(d) Abbreviations which appear as authorized descriptions in Column 2 of the $\$ 172.101$ Table (e.g., "TNT" and "2,4-D") are authorized."

\section{Labeling Requirements}

\section{REQUIREMENT SOURCE: 49CFR172 Part 400}

"General labeling requirements.

(a) Except as specified in 172.400 a, each person who offers for transportation or transports a hazardous material in any of the following packages or containment devices, shall label the package or containment device with labels specified for the material in the 172.101 Table and in this subpart:

(1) A non-bulk package;

(2) A bulk packaging, other than a cargo tank, portable tank, or tank car, with a volumetric capacity of less than $18 \mathrm{~m} 3$ ( 640 cubic feet), unless placarded in accordance with subpart $F$ of this part;

(3) A portable tank of less than $3785 \mathrm{~L}$ (1000 gallons) capacity, unless placarded in accordance with subpart F of this part;

(4) A DOT Specification 106 or 110 multi-unit tank car tank, unless placarded in accordance with subpart $\mathrm{F}$ of this part; and

(5) An overpack, freight container or unit load device, of less than $18 \mathrm{~m} 3$ (640 cubic feet), which contains a package for which labels are required, unless placarded or marked in accordance with 172.512 of this part.

(b) Labeling is required for a hazardous material which meets one or more hazard class definitions, in accordance with Column 6 of the 172.101 Table and the following table: HAZDOCS-2 Table No. 16"

\section{REQUIREMENT SOURCE: 49CFR172 Part 401}

"Prohibited labeling.

(a) Except as provided in paragraph (c) of this section, no person may offer for transportation and no carrier may transport any package bearing a label specified in this subpart unless:

(1) The package contains a material that is a hazardous material, and

(2) The label represents a hazard of the hazardous material in the package.

(b) No person may offer for transportation and no carrier may transport a package bearing any marking or label which by its color, design, or shape could be confused with or conflict with a label prescribed by this part.

(c) The restrictions in paragraphs (a) and (b) of this section, do not apply to packages labeled in conformance with:

(1) Any United Nations recommendation, including the class number (see 172.407), in the document entitled "Transport of Dangerous Goods.";

(2) The International Maritime Organization (IMO) requirements, including the class number (see 172.407), in the document entitled "International Maritime Dangerous Goods Code";

(3) The ICAO Technical Instructions; or

(4) The TDG Regulations." 


\section{REQUIREMENT SOURCE: 49CFR172 Part 402}

"Additional labeling requirements.

(a) Subsidiary hazard labels. Each package containing a hazardous material

(1) Shall be labeled with primary and subsidiary hazard labels as specified in Column 6 of the 172.101 Table; and

(2) For other than Class 2 or Class 1 materials (for subsidiary labeling requirements for Class 1 materials see paragraph (e) of this section), if not already labeled under paragraph (a)(1) of this section, shall be labeled with subsidiary hazard labels in accordance with the following table: HAZDOCS-2

Table No. 17

(b) Display of hazard class on labels. The appropriate hazard class or, for Division 5.1 or 5.2 the division number, shall be displayed in the lower corner of a primary hazard label and may not be displayed on a subsidiary label.

(c) Cargo Aircraft Only label. Each person who offers for transportation or transports by aircraft a package containing a hazardous material which is authorized on cargo aircraft only shall label the package with a CARGO AIRCRAFT ONLY label specified in 172.448 of this subpart.

(d) Radioactive Materials. Each package containing a radioactive material that also meets the definition of one or more additional hazards, except Class 9, shall be labeled as a radioactive material as required by 172.403 of this subpart and for each additional hazard.

(e) Class 1 (explosive) Materials. In addition to the label specified in Column 6 of the 172.101 Table, each package of Class 1 material that also meets the definition for:

(1) Division 6.1, Packing Groups I or II, shall be labeled POISON; or

(2) Class 7 , shall be labeled in accordance with $\mathbf{1 7 2 . 4 0 3}$ of this subpart."

\section{REQUIREMENT SOURCE: 49CFR172 Part 403}

"Radioactive material.

(a) Unless excepted from labeling by 173.421 through 173.425 of this subchapter, each package of radioactive material must be labeled as provided in this section.

(b) The proper label to affix to a package of radioactive material is based on the radiation level at the surface of the package, the transport index (173.403 of this subchapter) and, if appropriate, the fissile characteristics of the package. The proper category of label shall be determined in accordance with paragraph (c) of this section. The label to be applied shall be the highest category required for any of the three determining conditions for the package. Radioactive White-I is the lowest category and Radioactive Yellow-III is the highest. For example: a package with a transport index of 0.8 and a maximum surface radiation level of 60 millirem per hour which contains no fissile material must bear a Radioactive Yellow-III label.

(c) Category of Label to be Applied to Radioactive Materials Packages:

HAZDOCS-2 Table No. 18

(d) EMPTY label. See 173.427(d) of this subchapter for EMPTY labeling requirements.

(e) [Reserved] 
(f) Each package required by this section to be labeled with a RADIOACTIVE label must have two of these labels, affixed to opposite sides of the package. (See 172.406(e)(3) for freight container label requirements).

(g) The following applicable items of information must be entered in the blank spaces on the RADIOACTIVE label by legible printing (manual or mechanical), using a durable weather resistant means of marking:

(1) Contents. The name of the radionuclides as taken from the listing of radionuclides in 173.435, of this subchapter (symbols which conform to established radiation protection terminology are authorized, i.e., $99 \mathrm{Mo}, 60 \mathrm{Co}$, etc.). For mixtures of radionuclides, the most restrictive radionuclides on the basis of radiotoxicity must be listed as space on the label allows.

(2) Activity. Units shall be expressed in appropriate curie units, i.e., curies (Ci), millicuries (mCi) or microcuries $(\mathrm{uCi})$ (abbreviations are authorized). For a fissile material, the weight in grams or kilograms of the fissile radioisotope also may be inserted.

(3) Transport index. (See 173.403 of this subchapter.)"

\section{REQUIREMENT SOURCE: 49CFR172 Part 404}

"Labels for mixed and consolidated packaging.

(a) Mixed packaging. When hazardous materials having different hazard classes are packed within the same packaging, or within the same outside container or overpack as described in 173.25 and authorized by 173.21 of this subchapter, the packaging, outside container or overpack must be labeled as required for each class of hazardous material contained therein.

(b) Consolidated packaging. When two or more packages containing compatible hazardous material (see 173.21 of this subchapter) are placed within the same outside container or overpack, the outside container or overpack must be labeled as required for each class of hazardous material contained therein."

\section{REQUIREMENT SOURCE: 49CFR172 Part 405}

"Authorized label modifications.

(a) For Classes 1, 2, 3, 4, 5, 6, and 8, text indicating a hazard (for example FLAMMABLE LIQUID) is not required on a primary or subsidiary label when

(1) The label otherwise conforms to the provisions of this subpart, and

(2) The hazard class or, for Division 5.1 or 5.2 the division number, is displayed in the lower corner of the label, if the label corresponds to the primary hazard class of the hazardous material.

(b) For a package containing Oxygen, compressed, or Oxygen, refrigerated liquid, the OXIDIZER label specified in 172.426 of this subpart, modified to display the word "OXYGEN" instead of "OXIDIZER", and the class number " 2 " instead of " 5.1 ", may be used in place of the NON-FLAMMABLE GAS and OXIDIZER labels. Notwithstanding the provisions of paragraph (a) of this section, the word "OXYGEN" must appear on the label."

\section{REQUIREMENT SOURCE: 49CFR172 Part 406}

"Placement of labels.

(a) General.

(1) Except as provided in paragraphs (b) and (e) of this section, each label required by this subpart must- 
(i) Be printed on or affixed to a surface (other than the bottom) of the package or containment device containing the hazardous material; and

(ii) Be located on the same surface of the package and near the proper shipping name marking, if the package dimensions are adequate.

(2) Except as provided in paragraph (e) of this section, duplicate labeling not required on a package or containment device (such as to satisfy redundant labeling requirements).

(b) Exceptions. A label may be printed on or placed on a securely affixed tag, or may be affixed by other suitable means to:

(1) A package that contains no radioactive material and which has dimensions less than those of the required label;

(2) A cylinder; and

(3) A package which has such an irregular surface that a label cannot be satisfactorily affixed.

(c) Placement of multiple labels. When primary and subsidiary hazard labels are required, they must be displayed next to each other. Placement conforms to this requirement if labels are within $150 \mathrm{~mm}$ (6 inches) of one another.

(d) Contrast with background. Each label must be printed on or affixed to a background of contrasting color, or must have a dotted or solid line outer border.

(e) Duplicate labeling. Generally, only one of each different required label must be displayed on a package. However, duplicate labels must be displayed on at least two sides or two ends (other than the bottom) of

(1) Each non-bulk package or overpack having a volume of $1.8 \mathrm{~m} \backslash 3 \backslash$ (64 cubic feet) or more;

(2) Each non-bulk package containing a radioactive material;

(3) Each DOT 106 or 110 multi-unit tank car tank. Labels must be displayed on each end;

(4) Each portable tank of less than 3,785 L (1000 gallons) capacity; and

(5) Each freight container or aircraft unit load device having a volume of $1.8 \mathrm{~m} \backslash 3 \backslash$ (64 cubic feet) or more, but less than $18 \mathrm{~m} \backslash 3 \backslash$ ( 640 cubic feet). One of each required label must be displayed on or near the closure.

(f) Visibility. A label must be clearly visible and may not be obscured by markings or attachments."

\section{REQUIREMENT SOURCE: 49CFR172 Part 407}

"Label specifications.

(a) Durability Each label, whether printed on or affixed to a package, must be durable and weather resistant. A label on a package must be able to withstand, without deterioration or a substantial change in color, a 30-day exposure to conditions incident to transportation that reasonably could be expected to be encountered by the labeled package.

(b) Design.

(1) Except for size and color, the printing, inner border, and symbol on each label must be as shown in 172.411 through 172.448 of this subpart, as appropriate.

(2) The dotted line border shown on each label is not part of the label specification, except when used as an alternative for the solid line outer border to meet the requirements of 172.406 (d) of this subpart. 
(c) Size.

(1) Each diamond (square-on-point) label prescribed in this subpart must be at least $100 \mathrm{~mm}$ (3.9 inches) on each side with each side having a solid line inner border 5.0 to $6.3 \mathrm{~mm}$ ( 0.2 to 0.25 inches) from the edge.

(2) The CARGO AIRCRAFT ONLY label must be a rectangle measuring at least $110 \mathrm{~mm}$ (4.3 inches) in height by $120 \mathrm{~mm}$ ( 4.7 inches) in width. The word "DANGER" must be shown in letters measuring at least $12.7 \mathrm{~mm}$ (0.5 inches) in height.

(3) Except as otherwise provided in this subpart, the hazard class number, or division number, as appropriate, must be at least $6.3 \mathrm{~mm}(0.25$ inches) and not greater than $12.7 \mathrm{~mm}$ (0.5 inches).

(4) When text indicating a hazard is displayed on a label, the label name must be shown in letters measuring at least $7.6 \mathrm{~mm}$ (0.3 inches) in height except that

(i) For a SPONTANEOUSLY COMBUSTIBLE or DANGEROUS WHEN WET label, respectively, the words "Spontaneously" and "When Wet" must be shown in letters measuring at least $5.1 \mathrm{~mm}$ (0.2 inches) in height.

(ii) For a KEEP AWAY FROM FOOD label, the word "HARMFUL" must be shown in letters measuring at least $7.6 \mathrm{~mm}$ ( 0.3 inches) in height.

(5) The symbol on each label must be proportionate in size to that shown in the appropriate section of this subpart.

(d) Color.

(1) The background color on each label must be as prescribed in 172.411 through 172.448 of this subpart, as appropriate.

(2) The symbol, text, numbers, and border must be shown in black on a label except that

(i) White may be used on a label with a one color background of green, red or blue; and

(ii) White must be used for the text and class number for the CORROSIVE label.

(3) Black and any color on a label must be able to withstand, without substantial change, a 72-hour fadeometer test (for a description of equipment designed for this purpose, see ASTM G 2369 (1975) or ASTM G 26 70).

(4) (i) A color on a label, upon visual examination, must fall within the color tolerances_

(A) Displayed on color charts conforming to the technical specifications for charts set forth in Table 1 or 2 in appendix $A$ to this part; or

(B) For labels printed on packaging surfaces, specified in Table 3 in appendix A to this part.

(ii) Color charts conforming to appendix A to this part are on display in Room 8421, Nassif Building, 400 Seventh Street, SW., Washington DC 205900001.

(5) The specified label color must extend to the edge of the label in the area designated on each label except the CORROSIVE, RADIOACTIVE YELLOW II AND RADIOACTIVE YELLOW III labels on which the color must extend only to the inner border. 
(e) Form identification. A label may contain form identification information, including the name of its maker, provided that information is printed outside the solid line inner border in no larger than 10-point type.

(f) Exceptions. A label conforming to specifications in the UN Recommendations may be used in place of a corresponding label which conforms to the requirements of this subpart."

\section{Placarding Requirements}

\section{REQUIREMENT SOURCE: 49 CFR172 Part 500}

"Applicability of placarding requirements.

(a) Each person who offers for transportation or transports any hazardous material subject to this subchapter shall comply with the applicable placarding requirements of this subpart.

(b) This subpart does not apply to

(1) Infectious substances;

(2) Hazardous materials classed as ORM D;

(3) Hazardous materials authorized by this subchapter to be offered for transportation as Limited Quantities when identified as such on shipping papers in accordance with 172.203(b);

(4) Hazardous materials which are packaged as small quantities under the provisions of 173.4 of this subchapter; and

(5) Combustible liquids in non-bulk packagings."

\section{REQUIREMIENT SOURCE: 49CFR172 Part 502}

"Prohibited and permissive placarding.

(a) Prohibited placarding. Except as provided in paragraph (b) of this section, no person may affix or display on a packaging, freight container, unit load device, motor vehicle or rail car

(1) Any placard described in this subpart unless

(i) The material being offered or transported is a hazardous material;

(ii) The placard represents a hazard of the hazardous material being offered or transported; and

(iii) Any placarding conforms to the requirements of this subpart.

(2) Any sign or other device that, by its color, design, shape or content, could be confused with any placard prescribed in this subpart.

(b) Exceptions.

(1) The restrictions in paragraph (a) of this section do not apply to a bulk packaging, freight container, unit load device, transport vehicle or rail car which is placarded in conformance with the TDG Regulations, the IMDG Code or the UN Recommendations.

(2) The restrictions of paragraph (a) of this section do not apply to the display of an identification number on a white square-on-point configuration in accordance with $172.336(b)$ of this part. 
(c) Permissive placarding. Placards may be displayed for a hazardous material, even when not required, if the placarding otherwise conforms to the requirements of this subpart."

\section{REQUIREMENT SOURCE: 49CFR172 Part 504}

"General placarding requirements.

(a) General. Except as otherwise provided in this subchapter, each bulk packaging, freight container, unit load device, transport vehicle or rail car containing any quantity of a hazardous material must be placarded on each side and each end with the type of placards specified in Tables 1 and 2 of this section and in accordance with other placarding requirements of this subpart, including the specifications for the placards named in the tables and described in detail in 172.519 through 172.560.

(b) DANGEROUS placard. A freight container, unit load device, transport vehicle or rail car which contains non-bulk packagings with two or more categories of hazardous materials that require different placards specified in Table 2 may be placarded with DANGEROUS placards instead of the separate placarding specified for each of the materials in Table 2 . However, when $2,268 \mathrm{~kg}(5,000$ pounds $)$ or more of one category of material is loaded therein at one loading facility, the placard specified in Table 2 of paragraph (e) of this section for that category must be applied.

(c) Exception for less than $454 \mathrm{~kg}$ (1,001 pounds). Except for bulk packagings and hazardous materials subject to 172.505, when hazardous materials covered by Table 2 of this section are transported by highway or rail, placards are not required on-

(1) A transport vehicle or freight container which contains less than $454 \mathrm{~kg}$ (1001 pounds) aggregate gross weight of hazardous materials covered by Table 2 of paragraph (e) of this section; or

(2) A rail car loaded with transport vehicles or freight containers, none of which is required to be placarded. The exceptions provided in paragraph (c) of this section do not prohibit the display of placards in the manner prescribed in this subpart, if not otherwise prohibited (see 172.502), on transport vehicles or freight containers which are not required to be placarded.

(d) Exception for empty non-bulk packages. A non-bulk packaging that contains only the residue of a hazardous material covered by Table 2 of paragraph (e) of this section need not be included in determining placarding requirements.

(e) Placarding tables. Placards are specified for hazardous materials in accordance with the following tables:

HAZDOCS-2 Table No. 19

HAZDOCS-2 Table No. 20

(f) Additional placarding exceptions.

(1) When more than one division placard is required for Class 1 materials on a transport vehicle, rail car, freight container or unit load device, only the placard representing the lowest division number must be displayed.

(2) A FLAMMABLE placard may be used in place of a COMBUSTIBLE placard on-

(i) A cargo tank or portable tank.

(ii) A compartmented tank car which contains both flammable and combustible liquids. 
(3) A NON-FLAMMABLE GAS placard is not required on a transport vehicle which contains non-flammable gas if the transport vehicle also contains flammable gas or oxygen and it is placarded with FLAMMABLE GAS or OXYGEN placards, as required.

(4) OXIDIZER placards are not required for Division 5.1 materials on freight containers, unit load devices, transport vehicles or rail cars which also contain Division 1.1 or 1.2 materials and which are placarded with EXPLOSIVES 1.1 or 1.2 placards, as required.

(5) For transportation by transport vehicle or rail car only, an OXIDIZER placard is not required for Division 5.1 materials on a transport vehicle, rail car or freight container which also contains Division 1.5 explosives and is placarded with EXPLOSIVES 1.5 placards, as required.

(6) The EXPLOSIVE 1.4 placard is not required for those Division 1.4 Compatibility Group S (1.4S) materials that are not required to be labeled $1.4 \mathrm{~S}$.

(7) For domestic transportation of oxygen, compressed or oxygen, refrigerated liquid, the OXYGEN placard in 172.530 of this subpart may be used in place of a NON-FLAMMABLE GAS placard.

(8) Except for a material classed as a combustible liquid that also meets the definition of a Class 9 material, a COMBUSTIBLE placard is not required for a material classed as a combustible liquid when transported in a non-bulk packaging. For a material in a non-bulk packaging classed as a combustible liquid that also meets the definition of a Class 9 material, the CLASS 9 placard may be substituted for the COMBUSTIBLE placard.

(9) For domestic transportation, a Class 9 placard is not required. A bulk packaging containing a Class 9 material must be marked on each side and each end with the appropriate identification number displayed on an orange panel or a white-square-on-point display configuration are required by subpart D of this part.

(10) For domestic transportation of Division 6.1, PG III materials, a POISON placard may be used in place of a KEEP AWAY FROM FOOD placard.

(g) For shipments of Class 1 (explosive) materials by aircraft or vessel, the applicable compatibility group letter must be displayed on the placards required by this section."

\section{REQUIREMENT SOURCE: 49CFR172 Part 505}

"Placarding for subsidiary hazards.

(a) Each transport vehicle, freight container, portable tank and unit load device that contains a poisonous material subject to the "Poison-Inhalation Hazard" shipping description of 172.203(m)(3) must be placarded with a POISON or POISON GAS placard, as appropriate, on each side and each end, in addition to any other placard required for that material in 172.504. Duplication of the POISON or POISON GAS placard is not required.

(b) In addition to the RADIOACTIVE placard which may be required by $172.504(\mathrm{e})$ of this subpart, each transport vehicle, portable tank or freight container that contains $454 \mathrm{~kg}$ (1001 pounds) or more gross weight of fissile or low specific activity uranium hexafluoride shall be placarded with a CORROSIVE placard on each side and each end.

(c) Each transport vehicle, portable tank, freight container or unit load device that contains a material which has a subsidiary hazard of being dangerous when wet, as defined in 173.124 of this subchapter, shall be placarded with DANGEROUS WHEN WET placards, on each side and each end, in addition to the placards required by $\mathbf{1 7 2 . 5 0 4}$. 
(d) Hazardous materials that possess secondary hazards may exhibit subsidiary placards that correspond to the placards described in this part, even when not required by this part (see also 172.519(b) (4) of this subpart)."

\section{REQUIREMENT SOURCE: 49CFR172 Part 506}

"Providing and affixing placards: Highway.

(a) Each person offering a motor carrier a hazardous material for transportation by highway shall provide to the motor carrier the required placards for the material being offered prior to or at the same time the material is offered for transportation, unless the carrier's motor vehicle is already placarded for the material as required by this subpart.

(1) No motor carrier may transport a hazardous material in a motor vehicle, unless the placards required for the hazardous material are affixed thereto as required by this subpart.

(2) [Reserved]

(b) [Reserved]"

\section{REQUIREMINT SOURCE: 49CFR172 Part 508}

"Placarding and affixing placards: Rail.

(a) Each person offering a hazardous material for transportation by rail shall affix to the rail car containing the material, the placards specified by this subpart. Placards displayed on motor vehicles, transport containers, or portable tanks may be used to satisfy this requirement, if the placards otherwise conform to the provisions of this subpart.

(b) No rail carrier may accept a rail car containing a hazardous material for transportation unless the placards for the hazardous material are affixed thereto as required by this subpart."

\section{REQUIREMENT SOURCE: 49CFR172 Part 516}

"Visibility and display of placards.

(a) Each placard on a motor vehicle and each placard on a rail car must be readily visible from the direction it faces except from the direction of another motor vehicle or rail car to which the motor vehicle or rail car is coupled. This requirement may be met by the placards displayed on the freight containers or portable tanks loaded on a motor vehicle or rail car.

(b) The required placarding of the front of a motor vehicle may be on the front of a truck-tractor instead of or in addition to the placarding on the front of the cargo body to which a truck-tractor is attached.

(c) Each placard on a transport vehicle, bulk packaging, freight container or aircraft unit load device must

(1) Be securely attached or affixed thereto or placed in a holder thereon. (See appendix C to this part.);

(2) Be located clear of appurtenances and devices such as ladders, pipes, doors, and tarpaulins;

(3) So far as practicable, be located so that dirt or water is not directed to it from the wheels of the transport vehicle; 
(4) Be located away from any marking (such as advertising) that could substantially reduce its effectiveness, and in any case at least 3 inches $(76.0 \mathrm{~mm}$.) away from such marking;

(5) Have the words or identification number (when authorized) printed on it displayed horizontally, reading from left to right.

(6) Be maintained by the carrier in a condition so that the format, legibility, color, and visibility of the placard will not be substantially reduced due to damage, deterioration, or obscurement by dirt or other matter.

(7) Be affixed to a background of contrasting color, or must have a dotted or solid line outer border which contrasts with the background color.

(d) Recommended specifications for a placard holder are set forth in appendix $\mathrm{C}$ of this part. Except for a placard holder similar to that contained in appendix $\mathrm{C}$ to this part, the means used to attach a placard may not obscure any part of its surface other than the borders.

(e) A placard or placard holder may be hinged provided the required format, color, and legibility of the placard are maintained."

$\underline{13.2 .7}$

$\underline{13.2 .7 .1}$

\title{
Shipping Papers, Bills of Lading and Manifests
}

\author{
Waste Manifests
}

\section{REQUIREMENT SOURCE: 49CFR172 Part 205}

"Hazardous waste manifest.

(a) No person may offer, transport, transfer, or deliver a hazardous waste (waste) unless an EPA Form 870022 and $870022 \mathrm{~A}$ (when necessary) hazardous waste manifest (manifest) is prepared in accordance with 40 CFR 262.20 and is signed, carried, and given as required of that person by this section.

(b) The shipper (generator) shall prepare the manifest in accordance with 40 CFR part 262.

(c) The original copy of the manifest must be dated by, and bear the handwritten signature of, the person representing:

(1) The shipper (generator) of the waste at the time it is offered for transportation, and

(2) The initial carrier accepting the waste for transportation.

(d) A copy of the manifest must be dated by, and bear the handwritten signature of the person representing:

(1) Each subsequent carrier accepting the waste for transportation, at the time of acceptance, and

(2) The designated facility receiving the waste, upon receipt.

(e) A copy of the manifest bearing all required dates and signatures must be:

(1) Given to a person representing each carrier accepting the waste for transportation,

(2) Carried during transportation in the same manner as required by this subchapter for shipping papers,

(3) Given to a person representing the designated facility receiving the waste, 
(4) Returned to the shipper (generator) by the carrier that transported the waste from the United States to a foreign destination with a notation of the date of departure from the United States, and

(5) Retained by the shipper (generator) and by the initial and each subsequent carrier for three years from the date the waste was accepted by the initial carrier. Each retained copy must bear all required signatures and dates up to and including those entered by the next person who received the waste.

(f) The requirements of paragraphs (d) and (e) of this section do not apply to a rail carrier when waste is delivered to a designated facility by railroad if:

(1) All of the information required to be entered on the manifest (except generator and carrier identification numbers and the generator's certification) is entered on the shipping paper carried in accordance with 174.26 (c) of this subchapter;

(2) The delivering rail carrier obtains and retains a receipt for the waste that is dated by and bears the handwritten signature of the person representing the designated facility; and

(3) A copy of the shipping paper is retained for three years by each railroad transporting the waste.

(g) The person delivering a hazardous waste to an initial rail carrier shall send a copy of the manifest, dated and signed by a representative of the rail carrier, to the person representing the designated facility.

(h) A hazardous waste manifest required by 40 CFR part 262, containing all of the information required by this subpart, may be used as the shipping paper required by this subpart. (Approved by the Office of Management and Budget under control number 2137 0034)"

\section{REQUIREMENT SOURCE: RCRA-B(DW)(940829) Part II.Q.1}

"Documentation must accompany any on-site dangerous waste which is transported to or from any TSD unit subject to this Permit through or within the 600 Area, unless the roadway is closed to general public access at the time of shipment. Waste transported by rail or by pipeline is exempt from this Condition. This documentation shall include the following information, unless other unit-specified provisions are designated in Part III or V.

a. Generator's name, location and telephone number;

b. Receiving TSD unit's name, location, and telephone number;

c. Description of waste;

d. Number and type of containers;

e. Total quantity of waste;

f. Unit volume/weight;

g. Dangerous waste number(s); and,

h. Any special handling instructions."

\section{Shipping Papers}

\section{REQUIREMENT SOURCE: 49CFR172 Part 101(c)(8)}

"Hazardous substances. The appendix to this section lists materials which are listed or designated as hazardous substances under section 101(14) of the Comprehensive Environmental Response, Compensation, and Liability Act (CERCLA). Proper shipping namès for hazardous substances (see appendix to this section and 171.8 of this subchapter) shall be determined as follows:

(i) If the hazardous substance appears in the Table by technical name, then the technical name is the proper shipping name. 
(ii) If the hazardous substance does not appear in the Table and is not a forbidden material, then an appropriate generic, or "n.o.s.", shipping name shall be selected corresponding to the hazard class (and packing group, if any) of the material as determined by the defining criteria of this subchapter (see 173.2 and 173.2a of this chapter). For example, a hazardous substance which is listed in the appendix but not in the Table and which meets the definition of a flammable liquid might be described as "Flammable liquid, n.o.s." or other appropriate shipping name corresponding to the flammable liquid hazard class."

\section{REQUIREMENT SOURCE: 49CFR172 Part 101(c)(9)}

"Hazardous wastes. If the word "waste" is not included in the hazardous material description in Column 2 of the Table, the proper shipping name for a hazardous waste (as defined in 171.8 of this subchapter), shall include the word "Waste" preceding the proper shipping name of the material. For example: Waste acetone."

\section{REQUIREMENT SOURCE: 49CFR172 Part 101(c)(12)}

"Except when the proper shipping name in the Table is preceded by a plus $(+)--$

(i) If it is specifically determined that a material meets the definition of a hazard class or packing group, other than the class or packing group shown in association with the proper shipping name, or does not meet the defining criteria for a subsidiary hazard shown in Column 6 of the Table, the material shall be described by an appropriate proper shipping name listed in association with the correct hazard class, packing group, or subsidiary hazard for the material.

(ii) Generic or n.o.s. descriptions. If an appropriate technical name is not shown in the Table, selection of a proper shipping name shall be made from the generic or n.o.s. descriptions corresponding to the specific hazard class, packing group, or subsidiary hazard, if any, for the material. The name that most appropriately describes the material shall be used; e.g., an alcohol not listed by its technical name in the Table shall be described as "Alcohol, n.o.s." rather than "Flammable liquid, n.o.s.". Some mixtures may be more appropriately described according to their application, such as "Coating solution" or Extracts, flavoring, liquid", rather than by an n.o.s. entry, such as "Flammable liquid, n.o.s." It should be noted, however, that an n.o.s. description as proper shipping name may not provide sufficient information for shipping papers and package markings. Under the provisions of subparts $C$ and D of this part, the technical name of the constituent which makes the product a hazardous material may be required in association with the proper shipping name.

(iii) Multiple hazard materials. If a material meets the definition of more than one hazard class, and is not identified in the Table by a specific description, the hazard class of the material shall be determined by using the precedence specified in 173.2a of this subchapter, and appropriate shipping description (e.g., "Flammable liquid, corrosive n.o.s.") shall be selected as described in paragraph (c)(12)(ii) of this section. Except for a pesticide, a subsidiary hazard of Division 6.1 Packing Group III, need not be considered for selecting a shipping description.

(iv) If it is specifically determined that a material is not a forbidden material and does not meet the definition of any hazard class, the material is not a hazardous material."

\section{REQUIREMENT SOURCE: 49CFR172 Part 200}

"Applicability.

(a) Description of hazardous materials required. Except as otherwise provided in this subpart, each person who offers a hazardous material for transportation shall describe the hazardous material on the shipping paper in the manner required by this subpart. 
(b) This subpart does not apply to any material, other than a hazardous waste or a hazardous substance, that is--

(1) Identified by the letter " $A$ " in Column 1 of the 172.101 Table, except when the material is offered or intended for transportation by air; or

(2) Identified by the letter " $W$ " in Column 1 of the 172.101 Table, except when the material is offered or intended for transportation by water; or

(3) An ORM-D, except when the material is offered or intended for transportation by air."

\section{REQUIREMIENT SOURCE: 49CFR172 Part 201}

"General entries.

(a) Contents. When a description of hazardous material is required to be included on a shipping paper, that description must conform to the following requirements:

(1) When a hazardous material and a material not subject to the requirements of this subchapter are described on the same shipping paper, the hazardous material description entries required by $\mathbf{1 7 2 . 2 0 2}$ and those additional entries that may be required by 172.203 :

(i) Must be entered first, or

(ii) Must be entered in a color that clearly contrasts with any description on the shipping paper of a material not subject to the requirements of this subchapter, except that a description on a reproduction of a shipping paper may be highlighted, rather than printed, in a contrasting color (the provisions of this paragraph apply only to the basic description required by 172.202 (a) (1) and (2), and (3)), or

(iii) Must be identified by the entry of an " $X$ " placed before the proper shipping name in a column captioned "HM." (The "X" may be replaced by "RQ," if appropriate.)

(2) The required shipping description on a shipping paper and all copies thereof used for transportation purposes, must be legible and printed (manually or mechanically) in English.

(3) Unless it is specifically authorized or required in this subchapter, the required shipping description may not contain any code or abbreviation.

(4) A shipping paper may contain additional information concerning the material provided the information is not inconsistent with the required description. Unless otherwise permitted or required by this subpart, additional information must be placed after the basic description required by 172.202(a).

(b) Name of shipper. A shipping paper for a shipment by water must contain the name of the shipper.

(c) Continuation page. A shipping paper may consist of more than one page, if each page is consecutively numbered and the first page bears a notation specifying the total number of pages included in the shipping paper. For example, "Page 1 of 4 pages."

(d) Emergency response telephone number. A shipping paper must contain an emergency response telephone number, as prescribed in subpart G of part 172 of this subchapter."

\section{REQUIREMENT SOURCE: 49CFR172 Part 202}

"Description of hazardous material on shipping papers.

(a) The shipping description of a hazardous material on the shipping paper must include: 
(1) The proper shipping name prescribed for the material in Column 2 of the 172.101 Table;

(2) The hazard class or division prescribed for the material as shown in Column 3 of the 172.101 Table (class names or subsidiary hazard class number may be entered following the numerical hazard class, or following the basic description). The hazard class need not be included for the entry "Combustible liquid, n.o.s.";

(3) The identification number prescribed for the material as shown in Column 4 of the 172.101 Table;

(4) The packing group, in Roman numerals, prescribed for the material in Column 5 of the 172.101 Table, if any. The packing group may be preceded by the letters "PG" (e.g., "PG II"); and

(5) Except for empty packagings (see 173.29 of this subchapter), cylinders for Class 2 (compressed gases) materials, and bulk packagings, the total quantity (by net or gross mass, capacity, or as otherwise appropriate), including the unit of measurement, of the hazardous material covered by the description (e.g., "800 lbs", "55 gal.", "3629 kg", or "208 L"). For cylinders for Class 2 (compressed gases) materials and bulk packagings, some indication of total quantity must be shown (e.g., "10 cylinders" or " 1 cargo tank").

(b) Except as provided in this subpart, the basic description specified in paragraphs (a) (1), (2), (3) and (4) of this section must be shown in sequence with no additional information interspersed. For example: "Gasoline, 3, UN 1203, PG II".

(c) The total quantity of the material covered by one description must appear before or after, or both before and after, the description required and authorized by this subpart. The type of packaging and destination marks may be entered in any appropriate manner before or after the basic description. Abbreviations may be used to express units of measurement and types of packagings.

(d) Technical and chemical group names may be entered in parentheses between the proper shipping name and hazard class or following the basic description. An appropriate modifier, such as "contains" or "containing," may be used. For example: "Flammable liquids, n.o.s. (contains Xylene and Benzene), 3, UN 1993, II".

(e) Except for those materials in the UN Recommendations, the ICAO Technical Instructions, or the IMDG Code, a material that is not a hazardous material according to this subchapter may not be offered for transportation or transported when its description on a shipping paper includes a hazard class or an identification number specified in 172.101."

\section{REQUIREMENT SOURCE: 49CFR172 Part 203(a)}

"Exemptions. Each shipping paper issued in connection with a shipment made under an exemption must bear the notation "DOT E" followed by the exemption number assigned and so located that the notation is clearly associated with the description to which the exemption applies."

\section{REQUIREMENT SOURCE: 49CFR172 Part 203(b)}

"Limited quantities. The description for a material offered for transportation as "limited quantity," as authorized by this subchapter, must include the words "Limited Quantity" or "Ltd Qty" following the basic description."

\section{REQUIREMENT SOURCE: 49CFR172 Part 203(c)}

"Hazardous substances.

(1) Except for radioactive materials described in accordance with paragraph (d) of this section, if the proper shipping name for a material that is a hazardous substance does not identify the hazardous 
substance by name, one of the following descriptions shall be entered, in parentheses, in association with the basic description:

(i) The name of the hazardous substance as shown in the Appendix A to 171.101; or

(ii) For wastes which exhibit an EPA characteristic of ignitability, corrosivity, reactivity, or Toxicity, the letters "EPA" followed by the word "ignitability", or "corrosivity", or "reactivity", or "Toxicity", as appropriate or the corresponding " $D$ " number, as appropriate.

(2) The letters "RQ" shall be entered on the shipping paper either before or after, the basic description required by 172.202 for each hazardous substance (see definition in 171.8 of this subchapter). For example: "RQ, Allyl alcohol, 6.1, Un 1098, I"; or "Environmentally hazardous substance, solid, n.o.s., 9, UN 3077, III, RQ (Adipic acid)"."

\section{REQUIREMENT SOURCE: 49CFR172 Part 203(d)}

"Radioactive material. The description for a shipment of a Class 7 (radioactive) material must include the following additional entries as appropriate:

(1) The words "RADIOACTIVE MATERIAL" unless these words are contained in the proper shipping name.

(2) The name of each radionuclide in the radioactive material that is listed in 173.435 of this subchapter. Abbreviations, e.g., "99Mo" are authorized.

(3) A description of the physical and chemical form of the material, if the material is not in special form (generic chemical description is acceptable for chemical form).

(4) The activity contained in each package of the shipment in terms of curies, millicuries, or microcuries. Abbreviations are authorized. For the shipment of a package containing a highway route controlled quantity of radioactive materials (see 173.403(1) of this subchapter), the words "Highway route controlled quantity" must be entered in association with the basic description.

(5) The category of label applied to each package in the shipment. For example: "RADIOACTIVE WHITE I."

(6) The transport index assigned to each package in the shipment bearing RADIOACTIVE YELLOW II or RADIOACTIVE YELLOW III labels.

(7) For a shipment of fissile radioactive materials:

(i) The words "Fissile Exempt," if the package is exempt pursuant to 173.453 of this subchapter, or

(ii) If not exempt, the fissile class of each package in the shipment, pursuant to 173.455 of this subchapter; and

(iii) For a Fissile Class III shipment, the additional notation: "Warning-Fissile Class III Shipment. Do not Load More Than *** Packages per Vehicle." (Asterisks to be replaced by appropriate number.) "In loading and Storage Areas, Keep at Least 20 Feet $(6$ Meters), from Other Packages Bearing Radioactive Labels."

(iv) If a Fissile Class III shipment is to be transported by water, the supplementary notation must also include the following statement. "For shipment by water, only one Fissile Class III shipment is permitted in each hold." 
(8) For a package approved by the U.S. Department of Energy (DOE) or U.S. Nuclear Regulatory Commission (USNRC), a notation of the package identification marking as prescribed in the applicable DOE or USNRC approval. (See 173.471 of the subchapter.)

(9) For an export shipment or a shipment in a foreign made package, a notation of the package identification marking as prescribed in the applicable International Atomic Energy Agency (IAEA) Certificate of Competent Authority which has been issued for the package (See 173.473 of the subchapter.)"

\section{REQUIREMENT SOURCE: 49CFR172 Part 203(e)}

"Empty packagings.

(1) The description on the shipping paper for a packaging containing the residue of a hazardous material may include the words "RESIDUE: Last Contained ***" in association with the basic description of the hazardous material last contained in the packaging.

(2) For a tank car containing the residue (as defined in 171.8) of a hazardous material, the requirements of $174.25(\mathrm{c})$ and paragraph $(\mathrm{e})(3)$ of this section apply.

(3) If a packaging, including a tank car contains a residue that is a hazardous substance, the description on the shipping papers must be prefaced with the phrase, "RESIDUE: Last Contained ***" and the letters "RQ" must be entered on the shipping paper either before or after the basic description."

\section{REQUIREMENT SOURCE: 49CFR172 Part 203(g)}

Author's Note: Only (1) applies to TWRS.

"Transportation by rail.

(1) The shipping paper for a rail car containing a hazardous material must contain the notation "Placarded" followed by the name of the placard required for the rail car.

(2) The shipping paper for each Class DOT-113 tank car containing a flammable gas must contain an appropriate notation, such as "DOT-113A," and the statement "Do Not Hump or Cut Off Car While in Motion."

(3) When shipments of elevated temperature materials are transported under the exception permitted in $173.247(\mathrm{~h})(3)$ of this subchapter, the shipping paper must contain an appropriate notation, such as "Maximum Operating Speed $15 \mathrm{mph}$. " "

\section{REQUIREMENT SOURCE: 49CFR172 Part 204}

Author's Note: All of section (c) not applicable to TWRS. No transportation by air.

"Shipper's certification.

(a) General. Except as provided in paragraphs (b) and (c) of this section, each person who offers a hazardous material for transportation shall certify that the material is offered for transportation in accordance with this subchapter by printing (manually or mechanically) on the shipping paper containing the required shipping description the certification contained in paragraph (a)(1) of this section or the certification (declaration) containing the language contained in paragraph (a)(2) of this section.

(1) "This is to certify that the above-named materials are properly classified, described, packaged, marked and labeled, and are in proper condition for transportation according to the applicable regulations of the Department of Transportation." Note: In line one of the certification the words "herein-named" may be substituted for the words "above-named". 
(2) "I hereby declare that the contents of this consignment are fully and accurately described above by proper shipping name and are classified, packed, marked and labeled, and are in all respects in proper condition for transport by [*] according to applicable international and national governmental regulations." *Additional language indicating the modes of transportation to be used may be inserted at this point in the certification. All modes of transportation may be indicated provided that any mode not applicable to a specific shipment is deleted (lined out).

(b) Exceptions.

(1) Except for a hazardous waste, no certification is required for a hazardous materials offered for transportation by motor vehicle and transported:

(i) In a cargo tank supplied by the carrier, or

(ii) By the shipper as a private carrier except for a hazardous material that is to be reshipped or transferred from one carrier to another.

(2) No certification is required for the return of an empty tank car which previously contained a hazardous material and which has not been cleaned or purged.

\section{(c) Transportation by air}

(1) General. Certification containing the following language may be used in place of the certification required by paragraph (a) of this section: I hereby certify that the contents of this consignment are fully and accurately described above by proper shipping name and are classified, packed, marked and labeled, and in proper condition for carriage by air according to applicable national governmental regulations.

(2) Certificate in duplicate. Each person who offers a hazardous material to an aircraft operator for transportation by air shall provide two copies of the certification required in this section. (See 175.30 of this subchapter.)

(3) Passenger and cargo aircraft. Each person who offers for transportation by air a hazardous material authorized for air transportation shall add to the certification required in this section the following statement: This shipment is within the limitations prescribed for passenger aircraft/cargo aircraft only (delete nonapplicable).

(4) Radioactive material. Each person who offers any radioactive material for transportation aboard a passenger-carrying aircraft shall sign (mechanically or manually) a printed certificate stating that the shipment contains radioactive material intended for use in, or incident to, research, or medical diagnosis or treatment.

(d) Signature. The certifications required by paragraph (a) or (c) of this section:

(1) Must be legibly signed by a principal, officer, partner, or employee of the shipper or his agent; and

(2) May be legibly signed manually, by typewriter, or by other mechanical means.

Editorial Note: For Federal Register citations affecting 172.204, see the List of CFR Sections Affected appearing in the Finding Aids section of this volume."

\section{Shipment Plans}

Author's Note: Shipment Plan requirements are not applicable to TWRS. 


\section{Notification of State Authorities of Shipments of High-Hazard Materials}

The requirements identified under this subelement are the responsibility of the WHC TP Organization and are contained in the WHC S/RID.

\section{Emergency Response Information}

Author's Note: Patrol Operations Center provides support for this function.

\section{REQUIREMENT SOURCE: 49CFR172 Part 600}

"Applicability and general requirements.

(a) Scope. Except as provided in paragraph (d) of this section, this subpart prescribes requirements for providing and maintaining emergency response information during transportation and at facilities where hazardous materials are loaded for transportation, stored incidental to transportation or otherwise handled during any phase of transportation.

(b) Applicability. This subpart applies to persons who offer for transportation, accept for transportation, transfer or otherwise handle hazardous materials during transportation.

(c) General requirements. No person to whom this subpart applies may offer for transportation, accept for transportation, transfer, store or otherwise handle during transportation a hazardous material unless:

(1) Emergency response information conforming to this subpart is immediately available for use at all times the hazardous material is present; and

(2) Emergency response information, including the emergency response telephone number, required by this subpart is immediately available to any person who, as a representative of a Federal, state or local government agency, responds to an incident involving a hazardous material, or is conducting an investigation which involves a hazardous material.

(d) Exception. The requirements of this subpart do not apply to hazardous materials which are excepted from the shipping paper requirements of this subchapter."

\section{REQUIREMENT SOURCE: 49CFR172 Part 602}

"Emergency response information.

(a) Information required. For purposes of this subpart, the term "emergency response information" means information that can be used in the mitigation of an incident involving hazardous materials and, as a minimum, must contain the following information:

(1) The basic description and technical name of the hazardous material as required by 172.202 and 172.203(k), the ICAO Technical Instructions, the IMDG Code, or the TDG Regulations, as appropriate;

(2) Immediate hazards to health;

(3) Risks of fire or explosion;

(4) Immediate precautions to be taken in the event of an accident or incident;

(5) Immediate methods for handling fires;

(6) Initial methods for handling spills or leaks in the absence of fire; and 
(7) Preliminary first aid measures.

(b) Form of information. The information required for a hazardous material by paragraph (a) of this section must be:

(1) Printed legibly in English;

(2) Available for use away from the package containing the hazardous material; and

(3) Presented-

(i) On a shipping paper;

(ii) In a document, other than a shipping paper, that includes both the basic description and technical name of the hazardous material as required by 172.202 and $172.203(\mathrm{k})$, the ICAO Technical Instructions, the IMDG Code, or the TDG Regulations, as appropriate, and the emergency response information required by this subpart (e.g., a material safety data sheet); or

(iii) Related to the information on a shipping paper, a written notification to pilot-in-command, or a dangerous cargo manifest, in a separate document (e.g., an emergency response guidance document), in a manner that cross-references the description of the hazardous material on the shipping paper with the emergency response information contained in the document. Aboard aircraft, the ICAO "Emergency Response Guidance for Aircraft Incidents Involving Dangerous Goods" and, aboard vessels, the IMO "Emergency Procedures for Ships Carrying Dangerous Goods", or equivalent documents, may be used to satisfy the requirements of this section for a separate document.

(c) Maintenance of information. Emergency response information shall be maintained as follows:

(1) Carriers. Each carrier who transports a hazardous material shall maintain the information specified in paragraph (a) of this section in the same manner as prescribed for shipping papers, except that the information must be maintained in the same manner aboard aircraft as the notification to pilot-in-command, and aboard vessels in the same manner as the dangerous cargo manifest. This information must be immediately accessible to train crew personnel, drivers of motor vehicles, flight crew members, and bridge personnel on vessels for use in the event of incidents involving hazardous materials.

(2) Facility operators. Each operator of a facility where a hazardous material is received, stored or handled during transportation, shall maintain the information required by paragraph (a) of this section whenever the hazardous material is present. This information must be in a location that is immediately accessible to facility personnel in the event of an incident involving the hazardous material."

\section{REQUIREMENT SOURCE: 49CFR172 Part 604}

"Emergency response telephone number.

(a) A person who offers a hazardous material for transportation must provide a 24-hour emergency response telephone number (including the area code or international access code) for use in the event of an emergency involving the hazardous material. The telephone number must be

(1) Monitored at all times the hazardous material is in transportation, including storage incidental to transportation;

(2) The number of a person who is either knowledgeable of the hazardous material being shipped and has comprehensive emergency response and incident mitigation information for that material, or has immediate access to a person who possesses such knowledge and information; and

(3) Entered on a shipping paper, as follows: 
(i) Immediately following the description of the hazardous material required by subpart $\mathrm{C}$ of this part 172 ; or

(ii) Entered once on the shipping paper in a clearly visible location. This provision may be used only if the telephone number applies to each hazardous material entered on the shipping paper, and if it is indicated that the telephone number is for emergency response information (for example:

"EMERGENCY CONTACT: ***).

(b) The telephone number required by paragraph (a) of this section must be the number of the person offering the hazardous material for transportation or the number of an agency or organization capable of, and accepting responsibility for, providing the detailed information concerning the hazardous material. A person offering a hazardous material for transportation who lists the telephone number of an agency or organization shall ensure that agency or organization has received current information on the material, as required by paragraph (a)(2) of this section before it is offered for transportation."

\section{$\underline{13.2 .11}$}

$\underline{13.2 .12}$

\section{Recejpt Inspection}

The requirements identified under this subelement are the responsibility of the WHC TP Organization and are contained in the Packaging and Transportation Functional Area of the WHC S/RID.

\section{Loading Operations}

Author's Note: DOE Order 1540.1A Chapter II loading provisions are not applicable to TWRS personnel.

\section{REQUIREMENT SOURCE: 49CFR173 Part 448}

Author's Note: Sections (d thru f) are not applicable to Tank Farms.

"General transportation requirements.

(a) Each shipment of radioactive materials shall be secured in order to prevent shifting during normal transportation conditions.

(b) Except as may be specifically required by the competent authority in the applicable certificate, a package of radioactive materials may be carried among packaged general cargo without special stowage provisions, if:

(1) The heat output in watts does not exceed 0.1 times the minimum package dimension in centimeters; or

(2) The average surface heat flux of the package does not exceed 15 watts per square meter and the immediately surrounding cargo is not in sacks or bags or otherwise in a form that would seriously impede air circulation for heat removal.

(c) Packages bearing labels prescribed in 172.403 of this subchapter may not be carried in compartments occupied by passengers, except in those compartments exclusively reserved for couriers accompanying those packages.

(d) Mixing of different kinds of packages, including Fissile Class I packages with Fissile Class II packages, is authorized in accordance with 173.459.

(e) No person shall offer for transportation aboard a passenger-carrying aircraft any single package with a transport index greater than 3.0 or an overpack with a transport index greater than 3.0. 
(f) No person shall offer for transportation aboard a passenger-carrying aircraft any radioactive material unless that material is intended for use in, or incident to, research, medical diagnosis or treatment.

(g) If an overpack is used to consolidate individual packages of radioactive materials, the packages shall comply with the packaging, marking, and labeling requirements of this subchapter, and the following:

(1) The overpack shall be labeled as prescribed in 172.403 of this subchapter except as follows:

(i) The "contents" entry on the label may state "mixed" unless each inside package contains the same radionuclide(s).

(ii) The "activity" entry on the label must be determined by adding together the number of curies of the radioactive materials packages contained therein.

(iii) For a non-rigid overpack, the required label together with required package markings shall be affixed to the overpack by means of a securely attached, durable tag. The transport index shall be determined by adding together the transport indexes of the radioactive materials packages contained therein.

(iv) For a rigid overpack, the transport index shall be determined by:

(A) Adding together the transport indexes of the radioactive materials packages contained in the overpack; or

(B) Except for fissile radioactive materials, direct measurements as prescribed in 173.403(bb) which have been taken by the person initially offering the packages contained within the overpack for shipment.

(2) The overpack shall be marked as prescribed in subpart D of part 172 of this subchapter and 173.25(a).

(3) The transport index of the overpack shall not exceed 3.0 for passenger-carrying aircraft shipments, or $\mathbf{1 0 . 0}$ for cargo-aircraft only shipments."

\section{REQUIREMENT SOURCE: 49CFR177 Part 848}

"Segregation of hazardous materials

(a) This section applies to materials which meet one or more of the hazard classes defined in this subchapter and are:

(1) In packages which require labels in accordance with part 172 of this subchapter;

(2) In a compartment within a multi-compartmented cargo tank subject to the restrictions in $\mathbf{1 7 3 . 3 3}$ of this subchapter; or

(3) In a portable tank loaded in a transport vehicle or freight container.

(b) When a transport vehicle is to be transported by vessel, other than a ferry vessel, hazardous materials on or within that vehicle must be stowed and segregated in accordance with 176.83 (b) of this subchapter.

(c) In addition to the provisions of paragraph (d) of this section, cyanides or cyanide mixtures may not be loaded or stored with acids. 
(d) Hazardous materials may not be loaded, transported, or stored together, except as provided in this section, and in accordance with the following table:"

\section{Transportation Operations}

\section{REQUIREMENT SOURCE: 49CFR173 Part 474}

"Quality control for construction of packaging.

(a) Prior to the first use of any packaging for the shipment of radioactive material, the shipper shall determine, that:

(1) The packaging meets the quality of design and construction requirements as specified in this subchapter; and

(2) The effectiveness of the shielding, containment, and, when required, the heat transfer characteristics of the package, are within the limits specified for the package design.

(b) [Reserved]"

\section{REQUIREMENT SOURCE: 49CFR173 Part 475}

Author's Note: Sections $(\mathrm{g})$ and $(h)$ are not applicable to Tank Farms.

"Quality control requirements prior to each shipment of radioactive materials.

Before each shipment of any radioactive materials package, the shipper shall ensure by examination or appropriate tests, that:

(a) The packaging is proper for the contents to be shipped;

(b) The packaging is in unimpaired physical condition, except for superficial marks;

(c) Each closure device of the packaging, including any required gasket, is properly installed, secured, and free of defects;

(d) For fissile material, each moderator and neutron absorber, if required, is present and in proper condition;

(e) Each special instruction for filling, closing, and preparation of the packaging for shipment has been followed;

(f) Each closure, valve, or other opening of the containment system through which the radioactive content might escape is properly closed and sealed;

(g) Each packaging containing liquid in excess of an A2 quantity and intended for air shipment has been tested to show that it will not leak under an ambient atmospheric pressure of not more than 0.25 atmosphere, absolute, ( 0.25 kilograms per square centimeter or 3.6 psia). The test must be conducted on the entire containment system, or on any receptacle or vessel within the containment system, to determine compliance with this requirement;

(h) The internal pressure of the containment system will not exceed the design pressure during transportation; and

(i) External radiation and contamination levels are within the allowable limits specified in this subchapter." 


\section{REQUIREMENT SOURCE: DOE1540.1A Chapter II, Section 4.b.(1)(b)}

"Before a shipment is loaded upon a transport vehicle, the shipper shall visually survey the equipment externally to determine its general operating condition, its capability to transport the shipment, the existence of appropriate restraint devices in good condition, and assure the estimated gross weight of the shipment does not exceed the authorized carrying capacity of the conveyance."

13.3

$\underline{13.3 .1}$

$\underline{13.3 .2}$

$\underline{13.3 .3}$

13.3.4

$\underline{13.3 .5}$

13.4

\section{OFFSITE SAFETY}

\section{Package Standards and Certifications}

Author's Note: The requirements identified under this subelement are the responsibility of the WHC TP Organization and are contained in the Packaging and Transportation Functional Area of the WHC S/RID.

\section{Safety Analysis}

Author's Note: The requirements identified under this subelement are the responsibility of the WHC TP Organization and are contained in the Packaging and Transportation Functional Area of the WHC S/RID.

\section{Design, Fabrication, Assembly and Testing OA for OfNSite Shipping Containers}

Author's Note: The requirements identified under this subelement are the responsibility of the WHC TP Organization and are contained in the Packaging and Transportation Functional Area of the WHC S/RID.

\section{Physical Protection for Security}

Author's Note: The requirements identified under this subelement are the responsibility of Safeguards and Security Department. Refer to Packaging and Transportation Functional Area Document in the WHC S/RID.

\section{Nuclear Explosives, Components, and Assemblies}

No applicable requirements for the Tank Farms were identified under this subelement. .

\section{ONSITE SAFETY}

Neither DOT nor NRC have requirements that govern onsite safety for packaging and transportation of hazardous materials. The Department of Labor has allowed that a company may elect to establish the safety requirements for protection of occupational workers. This, therefore, is the driver for establishing the onsite Transportation and Packaging program for TWRS. The program is based on an "Equivalent Degree of Safety" to the DOT Regulations if not economically and technically feasible. Where compliance with DOT regulations is not feasible, compensatory administrative and technical requirements are specified to ensure equivalent safety to workers, the public, and the environment.

Onsite hazardous materials transportation must comply with the Department of Transportation Hazardous Materials Regulations, Title 49 CFR, Parts 171-180, or must contain all of the following provisions:

1) Provide containment of hazardous materials under conditions normally incident to transportation onsite. 
2) Provide for communication to personnel handling the material prior to transport, such that the hazards of the materials being transferred can be assessed by emergency responders during incident response.

3) Provide for communication to alert bystanders or others authorized to be in the area, but who are not directly involved with such transfers.

4) Provide controls appropriate for the level of containment and communication. For fissile radioactive materials, appropriate controls must also be provided to ensure nuclear criticality safety.

5) Provide approved safety documentation that describes in detail the methodology and compliance process to meet onsite packaging and transportation safety requirements that demonstrates an acceptable risk to onsite workers, bystanders, public, or the environment.

6) Ensure that each hazmat employee shall receive function-specific training concerning requirements which are specifically applicable to the functions the employee performs.

TWRS personnel are responsible for the following:

1) Managing onsite SWD shipments of hazardous material originating at the operating facilities and making shipments in compliance with requirements and established procedures.

2) Coordinating with Traffic Operations all planned inbound and outbound offsite shipments of hazardous materials, including radioactive materials. Notifying Hazardous Materials Operations about pending radioactive material shipments that require road closure to transport packages approved only for onsite use over public access roadways on the Hanford Site.

3) Preparing written operating procedures incorporating applicable safety analysis documentation requirements to be used for the packaging, loading, transporting, and unloading of hazardous materials.

4) Packaging, loading, transporting, and unloading hazardous materials in approved packagings, as specified by approved procedures and instructions.

5) Transporting repetitive onsite shipments incidental to production (such as samples and waste) on vehicles assigned to the operating organizations.

6) Ensuring only appropriately trained and qualified personnel are used to inspect, load, monitor, certify, authorize, or transport hazardous material packages.

7) Visually inspecting the vehicle used to transport hazardous material for obvious defects and the vehicle inspection tags to ensure the Class $\mathrm{A} / \mathrm{B}$ preventive maintenance is current.

8) Preparing, maintaining, and retaining an annual inventory of reusable, and approved Type A and Radioactive material shipping packages (including packages approved only for onsite use by a SARP, SEP, or DAP). Ensuring the required periodic integrity inspection is current within the assigned period.

\subsubsection{Coordination of Material Transfers}

Author's Note: The applicable OSHA 1910 requirements are delineated in the Occupational Safety and Health Functional Area document. 


\section{4 .2}

Safety Analysis

1) DOT/DOE/NRC approved shipping containers loaded according to applicable requirements may be used for onsite transfers without further review.

2) SARPs, SEPs, or DAPs, together with the loading procedures and administrative controls, must demonstrate an acceptable risk that the transfer will provide an equivalent degree of safety to the DOT Regulations. Approval is required by Packaging Safety Engineering, Operations via the Plant Review Committee, Safety, Quality Assurance, and the WHC Approval Authority.

3) The Shipper of hazardous material is responsible for proper packaging loading, and verifying that the container is properly secured to the vehicle and in accordance with required tiedown procedures. The vehicle driver is responsible for securing containers to the vehicle in accordance with the tiedown procedure provided by the shipper. The vehicle driver shall also comply with the shipper's administrative requirements. The shipper is responsible for verifying the timely arrival of the container at it's destination.

$\underline{13.4 .3}$

$\underline{13.4 .4}$

\section{5}

\section{$\underline{13.5 .1}$}

\section{Requirements for Potentially Explosive and Hazardous Materials}

No requirements within this subelement were determined to be applicable to the Tank Farms.

\section{Personnel Protection During Movement of Hazardous Materials}

All hazardous material shipments must utilize the marking, labeling, and placarding regulations contained in section 13.2.

The hazards communication regulations prior to transport are covered in chapter 19 under 29 CFR 1910 Part 1200.

Written procedures are required for packaging, loading, transporting, and unloading all transfers of fissile, Type B, and HRCQ radioactive materials. The procedures should be detained to the extent of defining individual steps involved and serve as a basis for a checklist of the main steps to ensure procedural compliance.

Transfers of hazardous materials onsite, or offsite that do not meet DOT regulations, will be made only with approved safety documentation, and will utilize all the administrative controls required by the safety documentation. This may include blockading of the roadway to restrict non-involved workers or the public.

\section{REQUIREMENT SOURCE: 49CFR177 Part 842(e)}

"Persons should not remain unnecessarily in a vehicle containing Class 7 (radioactive) materials."

\section{KEY INTERFACES}

\section{Training and Qualification}

The WHC Technical Training Department provides guidance and assistance in developing training and qualification programs for organizations involved in P\&T of hazardous materials. However, the TP Organization's Transportation Programs and Training Group prepares formal training courses and provides instruction to qualify WHC hazmat employees according to Department of Transportation (DOT), DOE, United States Environmental Protection Agency, and Washington State regulations. 
$\underline{13.5 .2}$

$\underline{13.5 .3}$

$\underline{13.5 .4}$

$\underline{13,5.5}$

$\underline{13.5 .6}$

13.6

$\underline{13.6 .1}$

The Tank Farms management identifies hazmat employees and assures that they receive all required training. Training is provided by the WHC TP Organization.

\section{Safequards and Security}

No TWRS transportation activities require SAS escort services.

\section{Nuclear Safety}

Although nuclear safety is an area of significant interface with P\&T, this is an inherent interface in that nuclear safety is a prominent factor in the regulations governing P\&T of nuclear materials. However, consideration should be given to onsite P\&T operations to ensure that the interaction with the nuclear safety program is carried through where administrative and technical controls are relied upon to satisfy the intent of DOT regulations in lieu of adhering to exact, sometimes unfeasible, requirements.

\section{Emergency Management}

Coordination between the Transportation Program and the Emergency Management Functional Area is required to ensure that commonly handled hazardous materials are known and included in emergency plans for the site and that special equipment or vehicles for transportation are known and available for emergency situations.

\section{Radiation Protection}

Physical management of radioactive material requires an interface to the Radiation Protection Functional Area to ensure proper classifying, labeling, packaging and transportation of those materials.

\section{Waste Management}

The Waste Management Facility personnel are responsible for assuring that the materials to be shipped are packaged correctly. Additionally, they are responsible for determining that all disposal criteria are met. The TP personnel are responsible for verifying compliance with the transportation shipping requirements of hazardous and radioactive materials that are shipped from the WHC site.

\section{REFERENCES}

\section{Requirement Source Documents}

The following references were used as source documents:

49 CFR, 1993, Subtitle B - Other Regulations Relating to Transportation, Parts 100 to 399.

WAC-173-303, Dangerous Waste Regulations, Washington Administrative Code, 06/15/94.

DOE 1540.1A, Materials Transportation and Traffic Management, 07/08/92.

RCRA-B(DW), Dangerous Waste Portion of the RCRA Permit for the Treatment, Storage, and Disposal of Dangerous Waste (RCRA-B), WA7890008967, Washington Department of Ecology, $08 / 29 / 94$ 


\section{Reviewed Documents Not Used as Requirement Sources}

The following documents were reviewed as requirement sources but were not used in the development of this S/RID.

10 CFR, 1994, Part 20, Standards for Protection against Radiation, U.S. Nuclear Regulator Commission, Washington, D.C.

10 CFR, 1994, Part 71, Packaging and Transportation of Radioactive Material, U.S. Nuclear Regulatory Commission, Washington, D.C.

29 CFR, 1993, Part 1910, Occupational Safety and Health Standards, Subpart Z, Toxic and Hazardous Substances, Office of the Federal Register, Washington, D. C.

40 CFR, 1993, Chapter I, Parts 260-299, Protection of Environment, Office of Federal Register, Washington, D.C.

WAC-470-12, 1992, Transportation of Dangerous Cargos, Advisory Committee on, Washington Administrative Code, Olympia, Washington.

DOE 1540.3A, 1992, Base Technology for Radioactive Material Transportation Packaging Systems, U.S. Department of Energy, Washington, D.C.

DOE 5480.1B, Change 5, 1986, Environment, Safety, and Health Program for Department of Energy Operations, U.S. Department of Energy, Washington, D.C.

DOE 5480.3, Safety Requirements for the Packaging and Transportation of Hazardous Materials, Hazardous Substances, and Hazardous Waste, 07/08/95.

DOE 5480.4, Change 4, 1993, Environmental Protection, Safety, and Health Protection Standards, U.S. Department of Energy, Washington, D.C.

DOE 5482.1B, 1986, Environment, Safety, and Health Appraisal Program, U.S. Department of Energy, Washington, D.C.

DOE 5483.1A, 1983, Occupational Safety and Health Program for DOE Contractor Employees at Government-Owned Contractor-Operated Facilities, U.S. Department of Energy, Washington, D.C.

DOE 5632.1C, Physical Protection of Special Nuclear material and Vital Equipment, U.S. Department of Energy, Washington, D.C., July 15, 1994.

DOE 5820.2A, 1988, Radioactive Waste Management, U.S. Department of Energy, Washington, D.C.

DOE/RL-91-28, 1993, Hanford Facility Dangerous Waste Permit Application, General Information, U.S. Department of Energy, Richland Operations, Richland, Washington, Revision 1.

RL Order 5480.1, 1982, Environment, Safety, and Health Program, U.S. Department of Energy, Richland Operations, Richland, Washington, Change I.

RL Order 5480.1A, 1988, Environment, Safety, and Health Program for Department of Energy Operation for Richland Operations, U.S. Department Energy, Richland Operations, Richland, Washington. 


\section{TABLE OF CONTENTS}

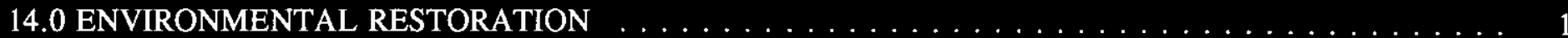




\subsection{ENVIRONMIENTAL RESTORATION}

\section{INTRODUCTION}

This Standards/Requirements Identification Document (S/RID) presents requirements applicable to the High Level Waste Storage Tank Farms and related structures. The Environmental Restoration Functional Area normally describes the programmatic controls, activities, personnel, and programs involved in executing restoration activities, if such activities are included in the current mission of the facility.

\section{SCOPE}

This S/RID applies to the Tank Waste Remediation Systems (TWRS) Organization which includes the following:

- East Tank Farm Transition Project

- West Tank Farm Transition Project

- Evaporator Project

- Interim Stabilization Project

- Characterization Sampling Project (Excluding the Labs)

The near-term mission of TWRS is to store, treat, and immobilize the highly radioactive Hanford Site Waste.

\section{JUSTIFICATION OF FUNCTIONAL AREA NONAPPLICABILITY}

Facilities and activities within the scope of the DP/EM Standards/Requirements Program have been or will be assigned to one of the following four categories in accordance with the Department of Energy (DOE) Implementation Plan, revision 5:

$\begin{array}{lll}- & \text { OP - } & \text { Operational } \\ - & \text { MT - } & \text { Mission Transitional } \\ - & \text { D\&D - } & \text { Decontamination and Decommissioning } \\ - & \text { ER - } & \text { Environmental Restoration }\end{array}$

For each of these facilities/activities, standards and requirements are to be identified that are appropriate for the category and mission. The DOE Implementation Plan characterizes an ER activity by the following elements:

- Is an inactive waste site (i.e., contaminated soil/underground water, not structures);

- Possibly containing highly hazardous materials; 
- Is a remedial investigation subject to applicable requirements of RCRA/CERCLA; and

- May have a generic or site SAR, plus an addendum for the specific activity.

Environmental Restoration activities are normally conducted after the facilities have been transitioned (e.g., post Mission Transitional life cycle phase) and have been decommissioned (e.g., post D\&D phase).

The responsibility for environmental restoration at the Hanford Site, including remedial investigation and remedial action, was transferred to the Hanford Environmental Restoration Contractor (ERC), Bechtel Hanford Incorporated, as of July 1, 1994. Westinghouse is responsible for transitioning facilities, however, the ERC is responsible for D\&D and ER activities.

Standards and requirements for a facility are identified based on the current and near-term mission of the facility. Tank Farms is not an inactive waste site; and Tank Farms is not currently undergoing remedial investigation for cleanup. ER activities are not included in either the current scope of the Westinghouse Hanford Company contract or the Tank Farms mission. Therefore, it is inappropriate, at this time, to identify ER requirements for the Tank Farms.

In consideration of the current Tank Farms mission, and in consideration of site responsibilities assigned to the ERC, the development of an Environmental Restoration Functional Area S/RID for Tank Farms under the direction of Westinghouse Hanford Company is not appropriate. The following provides a discussion of each functional element and a rationale for nonapplicability to Tank Farms.

\section{ER FUNCTIONAL AREA REVIEW}

\section{Environmental Restoration}

The ER Functional Area includes requirements associated with the management and implementation of remedial actions under the Comprehensive Environmental Restoration, Compensation, and Liability Act (CERCLA), corrective actions under a Resource Conservation and Recovery Act (RCRA) permit, remedial actions under the Uranium Mill Tailings Radiation Control Act of 1987 (UMTRCA), and cleanup under the Toxic Substances Control Act (TSCA). The ER requirements also include those for management and implementation of procedures to assure that restoration sites are maintained in a safe and environmentally sound condition prior to and after implementation of the associated restoration activities.

Site Identification and Characterization

This subelement includes requirements used to identify and characterize a site when it has been determined that a release has occurred from an inactive waste site, RCRA disposal facility, TSCA disposal facility, or UMTRCA site. ER actions include CERCLA Removal Site Evaluations, Preliminary Assessments (PA)/Site Investigations (SI), Remedial investigations (RI)/Feasibility Studies (FS), UMTRCA Assessments, RCRA Facility Investigation (RFI)/Corrective Measures Studies (CMS), and TSCA sampling schemes. Although Tank Farms is concerned with operational releases, Tank Farms is not a disposal facility subject to these actions. Operational releases are addressed in the Environmental Protection Functional Area (e.g., reportable quantity releases, tank releases). 
Community Relations and Public Involvement

This subelement contains provisions for preparing a formal community relations plan under CERCLA. The requirements specify provisions for providing public notification of releases, public notifications during response action development and implementation, public hearings, and maintenance of administrative records. The Tank Farms mission does not include community relation activities under CERCLA.

\section{Selection and Implementation of the Action}

This subelement includes requirements for the selection of the Remedial Action under CERCLA, Remedial Action under UMTRCA or Corrective Action under RCRA based on the appropriate, negotiated applicable, relevant and appropriate regulations or cleanup goals/standards and available technologies. These requirements include provisions for issuing Records of Decision and for complying with the National Environmental Policy Act (NEPA) for CERCLA actions, as necessary. NEPA actions for new or modified facilities are addressed in the Environmental Protection Functional Area. Requirements for the remedial action selection process are administered by the ERC.

\section{Current Regulatory Basis}

The current regulatory basis for ER activities is delineated in the Hanford Federal Facility Agreement and Consent Order (FFACO), more commonly referred to as the Tri-Party Agreement (TPA). The TPA draws from federal requirements contained in CERCLA and RCRA and from state equivalent acts. In the event that a contaminated structure is found to be the source of release (or presents a substantial threat of a release) of hazardous substances, hazardous wastes, or hazardous constituents to the environment, the investigation and remediation of such release (to include remediation of structures, as necessary), where subject to CERCLA or RCRA, are subject to the TPA.

Standards and requirements for a facility are identified based on the current and near-term mission of the facility. Environmental restoration activities are not presently identified as integral to the Tank Farms mission. 
High Level Waste Storage

WHC-SD-MP-SRID-001

Tank Farms/242-A Evaporator January 10, 1996

Standards/Requirements Identification Document

Rev. 0

15.0 Decontamination and Decommissioning

Page i of $i$

TABLE OF CONTENTS

15.0 DECONTAMINATION AND DECOMMISSIONING $\ldots \ldots \ldots \ldots \ldots \ldots \ldots \ldots \ldots \ldots \ldots$ 


\subsection{DECONTAMINATION AND DECOMMISSIONING}

\section{INTRODUCTION}

The Decontamination \& Decommissioning (D\&D) Functional Area normally describes the programmatic controls, activities, personnel, and programs involved in safely executing D\&D activities, if such activities are included in the current mission of the facility. This document assesses the applicability of the D\&D program to the current Tank Farms mission.

\section{SCOPE}

This S/RID applies to the Tank Waste Remediation Systems (TWRS) Organization which includes the following:

- $\quad$ East Tank Farm Transition Project

- West Tank Farm Transition Project

- Evaporator Project

- Interim Stabilization Project

- Characterization Sampling Project (Excluding the Labs)

The near-term mission of TWRS is to store, treat, and immobilize the highly radioactive Hanford Site Waste.

\section{JUSTIFICATION OF FUNCTIONAL AREA NONAPPLICABILITY}

The Department of Energy Implementation Plan in response to DNFSB Recommendation 90-2 specifies four facility categories as follows:

\footnotetext{
Operational

- Mission Transitional

- Decontamination and Decommissioning

- Environmental Restoration
}

The Implementation Plan characterizes a D\&D facility as follows:

- Consists of facilities and structures (i.e., not environmental restoration);

- Is usually low hazard

- Is subject to RCRA and CERCLA; and

- Includes facilities in long-term surveillance and maintenance

D\&D facilities are normally in a condition of long term surveillance and maintenance with minimal occupation or are in the process of active deconstruction and demolition. This scope of work is the responsibility of the ERC contractor, Bechtel Hanford, Inc. However, there may be some aspects of 
the D\&D functional area that warrant attention. Therefore, the following discussion assesses each functional element for potential applicability and value to Tank Farms.

\section{D\&D FUNCTIONAL AREA REVIEW}

\section{1; Site Identification, Surveillance and Maintenance}

This element includes requirements to identify contaminated facilities, for placing facilities in a safe storage condition, and for performing long term surveillance and maintenance. There is little value to Tank Farms for its current mission to implement this element.

\section{2; Characterization and Environmental Review Process}

This element includes requirements to collect data to characterize a facility in support of RCRA and CERCLA corrective action requirements and decommissioning alternatives assessment in support of NEPA. There is little value to Tank Farms for its current mission to implement this element.

\section{3; Decontamination Operations}

This element includes requirements used to develop a Decommissioning Project Plan in compliance with applicable e regulations. Tank Farms does perform decontamination operation as part of routine housekeeping operations, however this activity is addressed in the Radiation Protection functional area. There is little value to Tank Farms for its current mission to implement this element.

\section{4; Post-Decommissioning Activities}

this element includes requirements used to develop a final radiological and chemical survey following demolition of the facilities. There is little value to Tank Farms for its current mission to implement this element.

\section{5; Release Criteria}

This element includes requirements used to determine the long-term maintenance and controls for the site or the release criteria for the reuse of the site following decommissioning. Release criteria associated with housekeeping activities are specified in the Radiation protection functional area. There is little value to Tank Farms for its current mission to implement this element.

\section{Current Regulatory Basis}

It should be recognized that the current regulatory basis for D\&D activities is minimal. DOE has provided some definition of technical requirements in DOE Orders 5820.2A and 5400.5. DOE has plans to address D\&D requirements in greater technical detail within about 2 years.

Because of the inadequacy of DOE requirements, previous D\&D functional area documents developed for PUREX and REDOX have drawn from NRC and IAEA standards. However, even the NRC has recognized the inadequacy of their current regulatory structure. Current NRC regulations do not contain explicit radiological criteria for decommissioning. At present, the NRC continues to use criteria and 
practices described in several NRC guidance documents which have been in used for a number of years. This approach ensures protection of public health and safety by guiding decommissioning decisions and generally keeping potential radiological doses to a small fraction of NRC's public dose limit given in 10 CFR Part 20. However, the NRC believes it is necessary to codify, and provide consistency in, radiological criteria for decommissioning.

The NRC believes that radiological criteria for decommissioning should be codified in its regulations so the Commission can more effectively protect public health and the environment at decommissioned sites. To accomplish this, the NRC has published a draft General Environmental Impact Statement for D\&D as required by the NEPA process. This information will be used by the NRC to revise 10 CFR 20 to include radiological release criteria.

\section{CONCLUSION}

Based on the current mission of Tank Farms, the responsibility for D\&D assigned to Bechtel, and the current state of change of standards related to $D \& D$, there is little value at this time to develop the full D\&D functional area document. When Tank Farms has completed its near-term mission and its transitioning to D\&D, the applicable standards should be more fully developed by DOE and NRC. It is recommended that the D\&D functional area be developed at that time. 
TABLE OF CONTENTS

16.1 .1 TRU Waste $\ldots \ldots \ldots \ldots \ldots \ldots \ldots \ldots \ldots \ldots \ldots \ldots$

16.1 .2

16.1 .3

16.2

Low-Level Radioactive Waste $\ldots \ldots \ldots \ldots \ldots \ldots \ldots \ldots \ldots, 4$

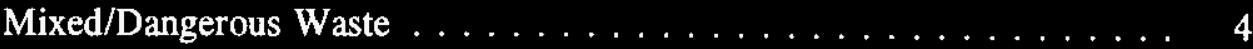

PACKAGING AND LABELING COMPLIANCE $\ldots \ldots \ldots \ldots \ldots \ldots$

16.2 .1

16.2 .2

16.2 .3

16.3

TRANSPORTATION $\ldots \ldots \ldots \ldots \ldots \ldots \ldots \ldots \ldots \ldots \ldots \ldots$

16.4

PLANS, RECORDS AND REPORTING $\ldots \ldots \ldots \ldots \ldots \ldots \ldots$

16.4 .1

TRU Waste $\ldots \ldots \ldots \ldots \ldots \ldots \ldots \ldots \ldots \ldots \ldots \ldots \ldots \ldots$

16.4 .2

16.4 .3

Low-Level Radioactive Waste $\ldots \ldots \ldots \ldots \ldots \ldots \ldots \ldots \ldots . \ldots 37$

16.4 .4

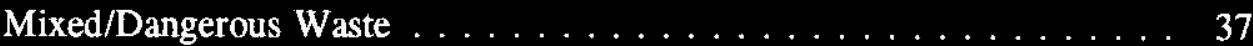

PCB Waste $\ldots \ldots \ldots \ldots \ldots \ldots \ldots \ldots \ldots \ldots \ldots \ldots \ldots$

16.6.1

16.6 .2

16.6 .3

16.6 .4

TRU Waste . . . . . . . . . . . . . . . . . . . . . . . 48

Low-Level Radioactive Waste . . . . . . . . . . . . . . . . . . . 49

Mixed/Dangerous Waste . . . . . . . . . . . . . . . . . . . 49

PCB Waste $\ldots \ldots \ldots \ldots \ldots \ldots \ldots \ldots \ldots \ldots \ldots \ldots \ldots$

WASTE MINIMIZATION $\ldots \ldots \ldots \ldots \ldots \ldots \ldots \ldots \ldots \ldots \ldots$

16.8

WASTE TREATMENT AND DISPOSAL TECHNOLOGY $\ldots \ldots \ldots \ldots, 52$

16.8.1 Low-Level Radioactive Waste $\ldots \ldots \ldots \ldots \ldots \ldots \ldots \ldots \ldots$. 52

16.8 .2 Mixed/Dangerous Waste

16.8.2.1

Management of Containers

16.8 .3

Asbestos Waste $\ldots \ldots \ldots \ldots \ldots \ldots \ldots \ldots \ldots \ldots \ldots \ldots \ldots, 6 \ldots$

16.8 .4

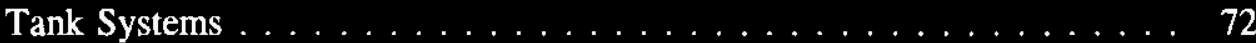

16.8 .5

Closure

16.8 .6

Used Oil 
KEY INTERFACES $\ldots \ldots \ldots \ldots \ldots \ldots \ldots \ldots \ldots \ldots \ldots \ldots$

16.11.1

16.11 .2

16.11 .3

16.11 .4

16.11 .5

16.11 .6

16.11 .7

16.11 .8

16.11 .9

16.11 .10

16.11 .11

16.12

16.12 .1

16.12 .2
Environmental Protection $\ldots \ldots \ldots \ldots \ldots \ldots \ldots \ldots \ldots . \ldots 9$

Emergency Management $\ldots \ldots \ldots \ldots \ldots \ldots \ldots \ldots \ldots \ldots . \ldots \ldots$

Safeguards and Security $\ldots \ldots \ldots \ldots \ldots \ldots \ldots \ldots \ldots \ldots$

Engineering Program $\ldots \ldots \ldots \ldots \ldots \ldots \ldots \ldots \ldots \ldots$

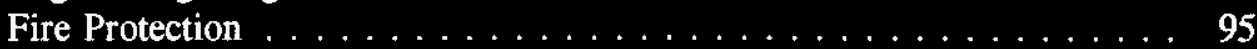

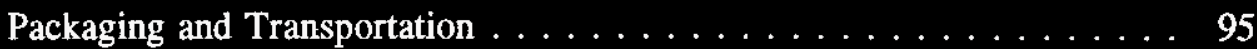

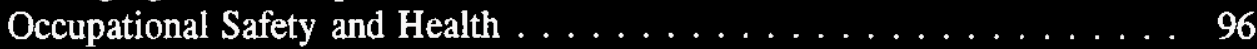

Quality Assurance $\ldots \ldots \ldots \ldots \ldots \ldots \ldots \ldots \ldots \ldots \ldots \ldots$

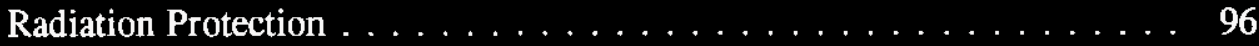

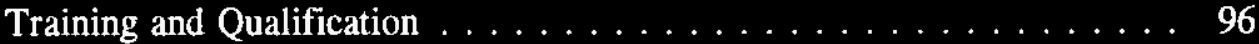

Safeguards and Security $\ldots \ldots \ldots \ldots \ldots \ldots \ldots \ldots \ldots$

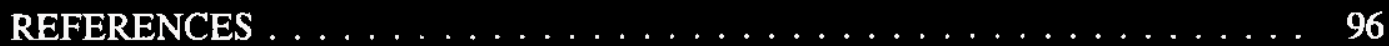

Requirement Source Documents $\ldots \ldots \ldots \ldots \ldots \ldots \ldots \ldots$

Reviewed Documents Not Used as Requirement Sources . . . . . . . . . 97 


\subsection{WASTE MANAGEMIENT}

\section{INTRODUCTION}

A Standards/Requirements Identification Document (S/RID) sets forth the Environmental Safety and Health (ES\&H) standards/requirements. This S/RID is applicable to the appropriate life cycle phases of design, construction, operation, and preparation for decommissioning for each of the categories of facilities addressed in Revision 5 of the Department of Energy Implementation Plan for the Defense Nuclear Facilities Safety Board (DNFSB) Recommendation 90-2. This Recommendation calls for the strengthening of DOE weapons complex activities through the identification and application of relevant DOE Orders, regulations, industry codes/standards, industry guidance documents and, as appropriate, good industry practices. These standards/requirements are adequate to ensure protection of the health and safety of workers, the public, and the environment.

The Tank Farms S/RID contains standards/requirements that are necessary for safe operation of the Tank Farms and its associated facilities and are the direct responsibility of the specific facility manager. The Waste Management (WM) Program defined in this document is described in general accordance with the Environment, Safety, and Health Configuration Guide, Revision 0, dated July 30, 1993, and is presented in program elements and subelements. The specific DOE Orders, regulations, industry codes/standards, guidance documents and good industry practices that serve as the basis for each element/subelement are identified and aligned with each subelement.

Additional subelements and sub-subelements were added to the basic format for further definition and clarity. Element 16.1, Waste characterization and Certification, was augmented with the addition of the following subelements: TRU Waste (16.1.1), Low-Level Radioactive Waste (16.1.2) and, Mixed/Dangerous Waste (16.1.3). Element 16.2, Packaging and Labeling Compliance, was embellished with the addition of the following subelements: Low-Level Radioactive Waste Packaging (16.2.1) Dangerous/Mixed Packaging and Labeling (16.2.2) and PBC Waste Labeling (16.2.3). Element 16.4, Plans, Records and Reporting, was augmented with the addition of: TRU Waste (16.4.1), Low-Level Radioactive Waste (16.4.2) and Mixed/Dangerous Waste (16.4.3). Element 16.6, Waste Acceptance Criteria, was embellished with the addition of the following subelements: TRU Waste (16.6.1), Low-Level Radioactive Waste (16.6.2) Mixed/Dangerous Waste (16.6.3) and PCB Waste (16.6.4). Element 16.8, Waste Treatment and Disposal Technology, was further defined with the addition of the following subelements: TRU Waste (16.8.1), Low-Level Radioactive Waste (16.8.2), Mixed/Dangerous Waste (16.8.3), Asbestos Waste (16.8.4), Tank Systems (16.8.5), Closure (16.8.6) and Used Oil (16.8.7).

Tank Farms generates the following waste types considered in the scope of this document:

- TRU Waste

- Mixed TRU Waste

- Mixed Low-Level Radioactive Waste

- Non-radioactive Dangerous Waste

- Polychlorinatedbiphenyl (PCB) Waste

- Mixed PCB Waste

- Asbestos Waste

- Used Oil 
The element in the WM Functional Area Guide covering permitting is not included here because it is covered in the Environmental Protection Functional Area. In addition, the element for transportation is covered in the Packaging and Transportation Functional Area. The Training Functional Area identifies the requirements from WAC 173-303 for training dangerous waste workers supporting TSD operations. The Emergency Management Functional Area identifies the requirements of WAC 173-303 for contingency planning and emergency response for TSD units.

This S/RID contains only those requirements that Tank Farms personnel are clearly responsible to satisfy. Other requirements that are applicable to Tank Farms, but are satisfied by others, are defined in the Westinghouse Hanford Company (WHC) Level S/RID. For application in this S/RID, the words "shall" and "should" in requirement statements both indicate mandatory compliance. The key interface information contained in the Functional Area documents is provided for general recognition and understanding and is not considered to contain prescriptive requirements.

\section{SCOPE}

This S/RID applies to the Tank Waste Remediation Systems (TWRS) Organization which includes the following:

- East Tank Farm Transition Project

- West Tank Farm Transition Project

- Evaporator Project

- Interim Stabilization Project

- Characterization Sampling Project (Excluding the Labs)

The near-term mission of TWRS is to store, treat, and immobilize the highly radioactive Hanford Site Waste. 


\section{REQUREMENT SOURCE: DOE5820.2A Chapter II, Section 3.a(1)}

"Waste Classification

(1) Any material that is known to be, or suspected of being contaminated with transuranium radionuclides shall be evaluated as soon as possible in the generating process, and determined to be either recoverable material, transuranic waste, low-level waste, mixed waste, or non-radioactive trash in order to avoid commingling the various material streams."

\section{REQUIREMINT SOURCE: DOE5820.2A Chapter II, Section 3.a(2)}

"The lower concentration limit for transuranic waste $(>100 \mathrm{nCi} / \mathrm{g}$ of waste) shall apply to the contents of any single waste package at the time of assay. The mass of the waste container including shielding shall not be used in calculating the specific activity of the waste."

\section{REQUIREMENT SOURCE: DOE5820.2A Chapter II, Section 3.a(3)}

"Radioactive wastes with quantities of transuranic radionuclides in concentrations of $100 \mathrm{nCi} / \mathrm{g}$ of waste or less shall be considered to be low-level waste, and shall be managed according to the requirements of Chapter III of this Order."

\section{REQUIREMINT SOURCE: DOE5820.2A Chapter II, Section 3.a(4)}

"Mixed transuranic waste:

(a) Mixed transuranic waste meeting the requirements of the Waste Isolation Pilot Plant-Waste Acceptance Criteria shall be sent to the Waste Isolation Pilot Plant.

(b) The Data Package prepared by the generators for the Waste Isolation Pilot Plant shall include information on the kinds and quantities of hazardous components contained in a waste package in accordance with applicable Resource Conservation and Recovery Act regulations.

(c) The determination whether the transuranic waste exhibits any hazardous characteristics or contains listed hazardous components may be based on knowledge of the waste generating process when the performance of a chemical analysis would significantly increase the radiation hazard to personnel."

\section{REQUIREMENT SOURCE: DOE5820.2A Chapter II, Section 3.c(1)}

\section{"Transuranic Waste Certification}

Transuranic waste shall be certified, pursuant to the Waste Isolation Pilot Plant-Waste Acceptance Criteria, placed in interim storage, and sent to the Waste Isolation Pilot Plant when it becomes operational. "

\section{REQUIREMENT SOURCE: DOE5820.2A Chapter II, Section 3.c(8)}

"Approved certification and associated quality assurance plans shall be implemented by the generating sites using specific, written operational procedures." 


\section{REQUIREMENT SOURCE: DOE5820.2A Chapter II, Section 3.c(9)}

"Certification activities conducted under approved plans and procedures shall be audited periodically, in accordance with a written audit program plan on a continuing basis by the Waste Isolation Pilot Plant-Waste Acceptance Criteria Certification Committee. An Environmental Evaluation Group representative may accompany the Waste Isolation Pilot Plant-Waste Acceptance Criteria Certification Committee audit team as an observer during site audits. The Waste Isolation Pilot Plant-Waste Acceptance Criteria Certification Committee may grant certifying authority to the site following successful completion of an audit."

\section{REQUIREMENT SOURCE: DOE5820.2A Chapter II, Section 3.c(11)}

"Failure to resolve and close out previous audit findings and recommendations or sending noncomplying waste to the Waste Isolation Pilot Plant when judged by the Waste Acceptance Criteria Certification Committee to be a serious violation, shall result in suspension of certifying authority, pending satisfactory resolution."

\section{$\underline{16.1 .2}$}

\section{Low-Level Radioactive Waste}

\section{REQUIREMENT SOURCE: DOE5820.2A Chapter III, Section 3.d(1)}

\section{"Waste Characterization}

(1) Low-level waste shall be characterized with sufficient accuracy to permit proper segregation, treatment, storage, and disposal. This characterization shall ensure that, upon generation and after processing, the actual physical and chemical characteristics and major radionuclide content are recorded and known during all stages of the waste management process."

\section{REQUIREMENT SOURCE: DOE5820.2A Chapter III, Section 3.d(2)}

"Waste characterization data shall be recorded on a waste manifest, as required by paragraph 3.m., and shall include:

(a) The physical and chemical characteristics of the waste;

(b) Volume of the waste (total of waste and any solidification or absorbent media);

(c) Weight of the waste (total of waste and any solidification or absorbent media);

(d) Major radionuclides and their concentrations;

(e) Packaging date, package weight, and external volume."

\section{REQUIREMENT SOURCE: DOE5820.2A Chapter III, Section 3.e(3)}

"Generators of waste shall implement a low-level waste certification program to provide assurance that the waste acceptance criteria for any low-level waste treatment, storage, or disposal facility used by the generator are met. Generators and facilities receiving the waste are jointly responsible for assuring compliance with waste acceptance criteria. Generators are financially responsible for actions required due to nonconformance."

\section{REQUIREMINT SOURCE: 40CFR262 Part 11(a) thru (c)}

"Hazardous waste determination. A person who generates a solid waste as defined in 40 CFR 261.2 must determine if that waste is a hazardous waste using the following method: 
(a) He should first determine if the waste is excluded from regulation under 40 CFR 261.4.

(b) He must then determine if the waste is listed as a hazardous waste in subpart D of 40 CFR part 261.

Note: Even if the waste is listed the generator still has an opportunity under 40 CFR 260.22 to demonstrate to the Administrator that the waste from his particular facility or operation is not a hazardous waste.

(c) For purposes of compliance with 40 CFR part 268 or if the waste is not listed in subpart D of 40 CFR part 261 the generator must then determine whether the waste is identified in subpart C of 40 CFR part 261 by either:

(1) Testing the waste according to the methods set forth in subpart C of 40 CFR part 261 or according to an equivalent method approved by the Administrator under 40 CFR 260.21; or

(2) Applying knowledge of the hazard characteristic of the waste in light of the materials or the processes used."

\section{REQUIREMENT SOURCE: 40CFR262 Part 11(d)}

"If the waste is determined to be hazardous, the generator must refer to parts 264,265 , and 268 of this chapter for possible exclusions or restrictions pertaining to management of his specific waste."

\section{REQUIREMENT SOURCE: 40CFR268 Part 7(b)(4)}

"A notice must be sent with each waste shipment to the land disposal facility which includess the following information, except that debris excluded from the definition of hazardous waste under 261.3(e) of this chapter (i.e. debris treated by an extraction or destruction technology provided by Table 1, 268.45, and debris that the Director has determined does not contain hazardous waste) is subject to the notification and certification requirements of paragraph (d) of this section rather than these notification requirements:

(i) EPA Hazardous Waste Number;

(ii) The corresponding treatment standards for wastes F001-F005, F039, wastes prohibited pursuant to 268.32 or RCRA section 3004(d), and for underlying hazardous constituents (as defined in 268.2 of this part), in D001 and D002 wastes if those wastes are prohibited under 268.37 of this part).) Treatment standards for all other restricted wastes must either be included, or be referenced by including on the notification the applicable wastewater (as defined in 268.2(f) or nonwastewater (as defined in 268.2(d) category, the applicable subdivisions made within a waste code based on waste-specific criteria (such as D003 reactive cyanides), and the CFR section(s) and paragraph(s) where the applicable treatment standard appears.) Where the applicable treatment standards are expressed as specified technologies in 268.42, the applicable five-letter treatment code found in Table 1 of 268.42 (e.g. INCIN, WETOX) also must be included on the notification.

(iii) The manifest number associated with the shipment of the waste; and

(iv) Waste analysis data, where available." 


\section{REQUIREMENT SOURCE: 40CFR268 Part 7(b)(5), and (5)(i) and (ii)}

"The treatment facility must submit a certification with each shipment of waste or treatment residue of a restricted waste to the land disposal facility stating that the waste or treatment residue has been treated in compliance with the applicable performance standards specified in subpart D of this part and the applicable prohibitions set forth in 268.32 of RCRA section 3004(d). Debris excluded from the definition of hazardous under 261.3(e) of this chapter (i.e. debris treated by an extraction or destruction technology provided by Table 1, 268.45, and debris that the Director has determined does not contain hazardous waste), however, is subject to the notification and certification requirements of this paragraph (d) of this section rather than the certification requirements of this paragraph (b)(5).

(i) For wastes with treatment standards expressed as concentrations in the waste extract or in the waste (268.41 or 268.43 ), or for wastes prohibited under 268.32 of this part of RCRA section 3004(d) which are not subject to any treatment standards under subpart D of this part, the certification must be signed by an authorized representative and must state the following:

I certify under penalty of law that I have personally examined and am familiar with the treatment technology and operation of the treatment process used to support this certification and that, based on my inquiry of those individuals immediately responsible for obtaining this information, I believe that the treatment process has been operated and maintained properly so as to comply with the performance levels specified in 40 CFR part 268 , subpart D, and all applicable prohibitions set forth in 40 CFR 268.32 or RCRA section 3004(d) with impermissible dilution of the prohibited waste. I am aware that there are significant penalties for submitting a false certification, including the possibility of fine and imprisonment.

(ii) For wastes with treatment standards expressed as technologies (268.42), the certification must be signed by an authorized representative and must state the following:

I certify under penalty of law that the waste has been treated in accordance with the requirements of 40 CFR 268.42 . I am aware that there are significant penalties for submitting a false certification, including the possibility of fine and imprisonment."

\section{REQUIREMENT SOURCE: 40CFR268 Part 7(b)(6)}

"If the waste or treatment residue will be further managed at a different treatment or storage facility, the treatment, storage or disposal facility sending the waste or treatment residue off-site must comply with the notice and certification requirements applicable to generators under this section."

\section{REQUIREMINT SOURCE: 40CFR268(940701) Part 7(a) Introduction}

"Except as specified in $\S 268.32$, if a generator's waste is listed in 40 CFR part 261 subpart $\mathrm{D}$, the generator must test his waste or test an extract using test method 1311 (the Toxicity Characteristic Leaching Procedure described in "Test Methods for Evaluating Solid Waste Physical/Chemical Methods," EPA Publication SW-846 as incorporated by reference in $\S$ 260.11 of this chapter) or use knowledge of the waste, to determine if the waste is restricted from land disposal under this part. Except as specified in $\S 268.32$, if a generator's waste exhibits one or more of the characteristics set out at 40 CFR part 261 subpart C the generator must test an extract using test method 1311 (the Toxicity Characteristic Leaching Procedure described in "Test Methods for Evaluating Solid Waste Physical/Chemical Methods" (SW-846)) or use knowledge of the waste, to determine if the waste is restricted from land disposal under this Part. If the generator determines that his waste exhibits the characteristic of ignitability (D001) (and is not in the High TOC Ignitable Liquids Subcategory or is not treated by CMBST or RORGS of 268.42 , Table 1), or the characteristic of corrosivity (D002), 
and is prohibited under $\$ 268.37$; and/or the characteristic of organic toxicity (D012-D043) and is prohibited under $\S 268.38$, the generator must determine the underlying hazardous constituents (as defined in $\S 268.2$, in the D001, D002, or D012-D043 wastes."

\section{REQUIREMENT SOURCE: 40CFR268(940701) Part 7(a)(1)}

"If a generator determines that he is managing a restricted waste under this part and the waste does not meet the applicable treatment standards set forth in subpart D of this part or it exceeds the applicable prohibition levels set forth in $\$ 268.32$ or RCRA section 3004(d) with each shipment of waste the generator must notify the treatment or storage facility in writing. The notice must include the following information:

(i) EPA Hazardous Waste Number;

(ii) The waste constituents that the treater will monitor if monitoring will not include all regulated constituents for wastes F001-F005 F039, D001, D002, D012-D043 and in $\$ 268.32$ or RCRA section 3004(d). Generators must also include whether the waste is a nonwastewater or wastewater (as defined in 268.2 (d) and (f)), and indicate the subcategory of the waste (such as "D003 reactive cyanide") if applicable;

(iii) The manifest number associated with the shipment of waste;

(iv) For hazardous debris the contaminants subject to treatment as provided by $\S 268.45$ (b) and the following statement: "This hazardous debris is subject to the alternative treatment standards of 40 CFR 268(940701).45;"

(v) The waste analysis data where available; and,

(vi) The date the waste is subject to the prohibitions."

\section{REQUIREMENT SOURCE: 40CFR268(940701) Part 7(a)(2)}

"If a generator determines that he is managing a restricted waste under this Part and determines that the waste can be land disposed without further treatment with each shipment of waste he must submit to the treatment, storage, or land disposal facility a notice and a certification stating that the waste meets the applicable treatment standards set forth in subpart D of this part and the applicable prohibition levels set forth in $\S 268.32$ or RCRA section 3004(d). Generators of hazardous debris that is excluded from the definition of hazardous waste under $\S 261.3(\mathrm{e})(2)$ of this chapter (i.e., debris that the Director has determined does not contain hazardous waste) however are not subject to these notification and certification requirements.

(i) The notice must include the following information:

(A) EPA Hazardous Waste Number;

(B) The waste constituents that the treater will monitor if monitoring will not include all regulated constituents for wastes F001-F005 F039, D001, D002, D012-D043 and $\S 268.32$ or RCRA section 3004(d). Generators must also include whether the waste is a nonwastewater or wastewater (as defined in $\S 268.2$ (d) and (f) and indicate the subcategory of the waste (such as "D003 reactive cyanide") if applicable;

(C) The manifest number associated with the shipment of waste;

(D) Waste analysis data where available. 
(ii) The certification must be signed by an authorized representative and must state the following:

I certify under penalty of law that I personally have examined and am familiar with the waste through analysis and testing or through knowledge of the waste to support this certification that the waste complies with the treatment standards specified in 40 CFR Part 268 Subpart D and all applicable prohibitions set forth in 40 CFR 268(940701).32 or RCRA section 3004(d). I believe that the information I submitted is true accurate and complete. I am aware that there are significant penalties for submitting a false certification including the possibility of a fine and imprisonment."

\section{REQUTREMINT SOURCE: 40CFR268(940701) Part 7(a)(3)}

"If a generator's waste is subject to an exemption from a prohibition on the type of land disposal method utilized for the waste (such as but not limited to, a case-by-case extension under $\S 268.5$, an exemption under $\S 268.6$, or a nationwide capacity variance under subpart C of this part) with each shipment of waste he must submit a notice to the facility receiving his waste stating that the waste is not prohibited from land disposal. The notice must include the following information:

(i) EPA Hazardous Waste Number;

(ii) The waste constituents that the treater will monitor if monitoring will not include all regulated constituents for wastes F001-F005 F039, D001, D002, and D012-D043. Generators must also include whether the waste is a nonwastewater or wastewater (as defined in $\$ 268.2$ (d) and (f)), and indicate the subcategory of the waste (such as "D003 reactive cyanide") if applicable;

(iii) The manifest number associated with the shipment of waste;

(iv) Waste analysis data where available;

(v) For hazardous debris when using the alternative treatment technologies provided by $\S$ 268.45:

(A) The contaminants subject to treatment as described in 268.45(b); and

(B) An indication that these contaminants are being treated to comply with $\S 268.45$.

(vi) For hazardous debris when using the treatment standards for the contaminating waste(s) in 268.40: the requirements described in paragraphs (a)(3) (i) (ii), (iii), (iv), and (vii) of this section; and

(vii) The date the waste is subject to the prohibitions. "

\section{REQUIREMENT SOURCE: 40CFR268(940701) Part 7(a)(4)}

"If a generator is managing prohibited waste in tanks containers or containment buildings regulated under 40 CFR 262.34 and is treating such waste in such tanks, containers, or containment buildings to meet applicable treatment standards under subpart D of this part the generator must develop and follow a written waste analysis plan which describes the procedures the generator will carry out to comply with the treatment standards. (Generators treating hazardous debris under the alternative treatment standards of Table 1268.45 , however, are not subject to these waste analysis requirements.) The plan must be kept on site in the generator's records and the following requirements must be met: 
(i) The waste analysis plan must be based on a detailed chemical and physical analysis of a representative sample of the prohibited waste(s) being treated and contain all information necessary to treat the waste(s) in accordance with the requirements of this Part including the selected testing frequency.

(ii) Such plan must be filed with the EPA Regional Administrator (or his designated representative) or State authorized to implement Part 268 requirements a minimum of 30 days prior to the treatment activity with delivery verified.

(iii) Wastes shipped off-site pursuant to this paragraph must comply with the notification requirements of $\S 268.7(\mathrm{a})(2)$."

\section{REQUIREMENT SOURCE: 40CFR268(940701) Part 7(a)(5)}

"If a generator determines whether the waste is restricted based solely on his knowledge of the waste all supporting data used to make this determination must be retained on-site in the generator's files. If a generator determines whether the waste is restricted based on testing this waste or an extract developed using the test method described in Appendix I of this part all waste analysis data must be retained on-site in the generator's files."

\section{REQUIREMINT SOURCE: 40CFR268(940701) Part 7(a)(6)}

"If a generator determines that he is managing a restricted waste that is excluded from the definition of hazardous or solid waste or exempt from Subtitle $C$ regulation under 40 CFR 261.2 through 261.6 subsequent to the point of generation he must place a one-time notice stating such generation subsequent exclusion from the definition of hazardous or solid waste or exemption from RCRA Subtitle C regulation and the disposition of the waste in the facility's file."

\section{REQUIREMENT SOURCE: 40CFR268(940701) Part 7(a)(7)}

"Generators must retain on-site a copy of all notices certifications demonstrations, waste analysis data, and other documentation produced pursuant to this section for at least five years from the date that the waste that is the subject of such documentation was last sent to on-site or off-site treatment storage or disposal. The five year record retention period is automatically extended during the course of any unresolved enforcement action regarding the regulated activity or as requested by the Administrator. The requirements of this paragraph apply to solid wastes even when the hazardous characteristic is removed prior to disposal or when the waste is excluded from the definition of hazardous or solid waste under 40 CFR 261.2 through 261.6 or exempted from RCRA Subtitle C regulation subsequent to the point of generation. "

\section{REQUIREMENT SOURCE: 40CFR268(940701) Part 7(a)(8)}

"If a generator is managing a lab pack that contains none of the wastes specified in appendix IV of part 268 and wishes to use the alternative treatment standard under $\$ 268.42$ (c), with each shipment of waste the generator must submit a notice to the treatment facility in accordance with paragraph (a)(1) of this section except that underlying hazardous constituents need not be determined. The generator must also comply with the requirements in paragraphs (a)(5) and (a)(6) of this section and must submit the following certification which must be signed by an authorized representative:

I certify under penalty of law that I personally have examined and am familiar with the waste and that the lab pack does not contain any wastes identified at Appendix IV to part 268. I am aware that there are significant penalties for submitting a false certification including possibility of fine or imprisonment." 


\section{REQUIREMENT SOURCE: 40CFR268(940701) Part 7(b) Introduction}

"Treatment facilities must test their wastes according to the frequency specified in their waste analysis plans as required by 264.13 or 265.13 . Such testing must be performed as provided in paragraphs (b)(1) (b)(2) and (b)(3) of this section."

\section{REQUIREMENT SOURCE: 40CFR268(940701) Part 7(b)(1)}

"For wastes with treatment standards expressed as concentrations in the waste extract (268.41), the owner or operator of the treatment facility must test the treatment residues or an extract of such residues developed using the test method described in appendix I of this part to assure that the treatment residues or extract meet the applicable treatment standards. ${ }^{n}$

\section{REQUIREMENT SOURCE: 40CFR268(940701) Part 7(b)(2)}

"For wastes that are prohibited under 268.32 of this part or RCRA section 3004(d) but not subject to any treatment standards under subpart D of this part the owner or operator of the treatment facility must test the treatment residues according to the generator testing requirements specified in 268.32 to assure that the treatment residues comply with the applicable prohibitions."

\section{REQUIREMENT SOURCE: 40CFR268(940701) Part 7(b)(3)}

"For wastes with treatment standards expressed as concentrations in the waste (268.43), the owner or operator of the treatment facility must test the treatment residues (not an extract of such residues) to assure that the treatment residues meet the applicable treatment standards."

\section{REQUIREMENT SOURCE: 40CFR268(940701) Part 9(a)}

"The initial generator of a solid waste must determine each EPA Hazardous Waste Number (waste code) applicable to the waste in order to determine the applicable treatment standards under subpart D of this part. For purposes of part 268 the waste will carry the waste code for any applicable listing under 40 CFR 261 subpart D. In addition, the waste will carry one or more of the waste codes under 40 CFR 261 subpart $C$, where the waste exhibits a characteristic except in the case when the treatment standard for the waste listed in part 261 subpart D operates in lieu of the treatment standard for the waste under part 261 subpart C, as specified in paragraph (b) of this section. If the generator determines that his waste displays the characteristic of ignitability (D001) (and is not in the High TOC Ignitable Liquids Subcategory or is not treated by CMBST or RORGS), or the characteristic of corrosivity (D002) and is prohibited under $\S 268.37$; or that his waste displays the characteristic of toxicity (D012-D043) and is prohibited under $\S 268.38$, the generator must determine the underlying hazardous constituents (as defined in $\$ 268.2$ ), in the D001, D002, or D012-D043 wastes."

\section{REQUIREMENT SOURCE: 40CFR268(940701) Part 9(b)}

"Where a prohibited waste is both listed under 40 CFR part 261 subpart D and exhibits a characteristic under 40 CFR part 261 subpart $C$, the treatment standard for the waste code listed in 40 CFR part 261 subpart D will operate in lieu of the standard for the waste code under 40 CFR part 261 subpart C, provided that the treatment standard for the listed waste includes a treatment standard for the constituent that causes the waste to exhibit the characteristic. Otherwise the waste must meet the treatment standards for all applicable listed and characteristic waste codes." 


\section{REQUIREMENT SOURCE: 40CFR268(940701) Part 9(c)}

"In addition to any applicable standards determined from the initial point of generation no prohibited waste which exhibits a characteristic under 40 CFR part 261 subpart C may be land disposed unless the waste complies with the treatment standards under subpart D of this part. "

\section{REQUIREMINT SOURCE: 40CFR268(940701) Part 9(d)}

"Wastes that exhibit a characteristic are also subject to 268.7 requirements, except that once the waste is no longer hazardous a one-time notification and certification must be placed in the generators or treaters files and sent to the EPA region or authorized state. The notification and certification that is placed in the generators or treaters files must be updated if the process or operation generating the waste changes and/or if the subtitle D facility receiving the waste changes. However the generator or treater need only notify the EPA region or an authorized state on an annual basis if such changes occur. Such notification and certification should be sent to the EPA region or authorized state by the end of the calendar year but no later that December 31.

(1) The notification must include the following information:

(i) Name and address of the RCRA Subtitle D facility receiving the waste shipment; and (ii) A description of the waste as initially generated including the applicable EPA Hazardous Waste Number(s) treatability group(s), and underlying hazardous constituents (as defined in $\S$ 268.2(i) in D001 and D002 wastes prohibited under $\$ 268.37$, or D012-D043 wastes under $\S$ 268.38.

(2) The certification must be signed by an authorized representative and must state the language found in $268.7(\mathrm{~b})(5)$.

(i) If treatment removes the characteristic but does not treat underlying hazardous constituents then the certification found in $\S 268.7(\mathrm{~b})(5)$ (iv) applies. "

\section{REQUIREMENT SOURCE: WAC-173-303(940523) Section 070(2)(a)}

"Once a material has been determined to be a dangerous waste, then any solid waste generated from the recycling, treatment, storage, or disposal of that dangerous waste is a dangerous waste unless and until:

(i) The generator has been able to accurately describe the variability or uniformity of the waste over time, and has been able to obtain demonstration samples which are representative of the waste's variability or uniformity; and

(ii)(A) It does not exhibit any of the characteristics of WAC 173-303-090; and

(B) If it was a listed waste under WAC 173-303-080 through 173-303-083, it also has been exempted pursuant to WAC 173-303-910; or

(iii) If originally designated only through WAC $173-303-100$, it does not exhibit any of the criteria of WAC 173-303-100.

Such solid waste shall include but not be limited to any sludge, spill residue, ash emission control dust, leachate, or precipitation run-off. Precipitation run-off will not be considered a dangerous waste if it can be shown that the run-off has not been contaminated with the dangerous waste, or that the run-off is adequately addressed under existing state laws (e.g. 
chapter $90.48 \mathrm{RCW}$ ), or that the run-off does not exhibit any of the criteria or characteristics described in WAC 173-303-100."

\section{REQUIREMINT SOURCE: WAC-173-303(940523) Section 070(2)(b)}

"Materials that are reclaimed from solid wastes and that are used beneficially (as provided in WAC 173-303-016 and 173-303-017 are not solid wastes and hence are not dangerous wastes under this section unless the reclaimed material is burned for energy recovery or used in a manner constituting disposal."

\section{REQUIREMENT SOURCE: WAC-173 303(940523) Section 070(3)}

"Designation procedures.

(a) To determine whether or not a waste is designated a person shall check the waste against the following sections, and in the following order:

(i) First, Discarded chemical products, WAC 173-303-081;

(ii) Second, Dangerous waste sources, WAC 173-303-082;

(iii) Third, Dangerous waste characteristics, WAC 173-303-090; and

(iv) Fourth, Dangerous waste criteria, WAC 173-303-100.

(b) A person shall check each section, in the order set forth, until he determines whether the waste is designated as a dangerous waste. Once the waste is designated through the lists, characteristics, or criteria he need not determine any other designations for the waste, except as required by subsection (4) or (5) of this section, or for the purposes of compliance with the federal land disposal restrictions, as adopted by reference in WAC 173-303-140. If the designation procedures identify a waste as both EHW and DW (e.g., a waste may be DW for corrosivity and EHW for toxicity characteristic), the waste must be designated EHW. If a person has checked the waste against each section and the waste is not designated, then the waste is not subject to the requirements of chapter 173-303 WAC.

Any person who wishes to seek an exemption for a waste which has been designated DW or EHW shall comply with the requirements of WAC 173-303-072.

(c) For the purpose of determining if a solid waste is a dangerous waste as identified in WAC 173-303-080 through 173-303-100, a person shall either:

(i) Test the waste according to the methods, or an approved equivalent method, set forth in WAC 173-303-110; or

(ii) Apply knowledge of the waste in light of the materials or the process used, when:

(A) Such knowledge can be demonstrated to be sufficient for determining whether or not it designated and/or designated properly; and

(B) All data and records supporting this determination in accordance with WAC 173-303-210

(3) are retained on-site."

\section{REQUIREMENT SOURCE: WAC-173-303(940523) Section 070(4)}

"Testing required. Notwithstanding any other provisions of this chapter, the department may require any person to test a waste according to the methods, or an approved equivalent method, set forth in WAC 173-303-110 to determine whether or not the waste is designated under the dangerous waste lists, characteristics, or criteria, WAC 173-303-080 through 173-303-100. Such testing may be required if the department has reason to believe that the 
waste would be designated DW or EHW by the dangerous waste lists, characteristics, or criteria, or if the department has reason to believe that the waste is designated improperly (e.g., the waste has been designated DW but should actually be designated EHW). If a person, pursuant to the requirements of this subsection, determines that the waste is a dangerous waste or that its designation must be changed, then he shall be subject to the applicable requirements of this chapter 173-303 WAC. The department shall base a requirement to test a waste on evidence that includes, but is not limited to:

(a) Test information indicating that the person's waste may be DW or EHW;

(b) Evidence that the person's waste is very similar to another persons' already designated DW or EHW;

(c) Evidence that the persons' waste has historically been a DW or EHW;

(d) Evidence or information about a person's manufacturing materials or processes which indicate that the wastes may be DW or EHW; or

(e) Evidence that the knowledge or test results a person has regarding a waste is not sufficient for determining whether or not it designated and/or designated properly."

\section{REQUIREMINT SOURCE: WAC-173-303(940523) Section 070(5)}

"Special knowledge. If a generator has designated his waste under the dangerous waste lists, WAC 173-303-080 through 173-303-082, or characteristics, WAC 173-303-090, and has knowledge that the waste also exhibits any of the dangerous waste characteristics, WAC 173-303-090, or that the waste also meets any of the dangerous waste criteria, WAC 173-303-100, then he shall also designate the waste in accordance with those dangerous waste characteristics, or criteria, or both."

\section{REQUIREMINT SOURCE: WAC-173-303(940523) Section 070(6)}

"Dangerous waste numbers. When a person is reporting or keeping records on a dangerous waste, he shall use all the dangerous waste numbers which he knows are assignable to his waste from the dangerous waste lists, characteristics, or criteria. For example, if his waste is ignitable and contains extremely hazardous concentrations of halogenated hydrocarbons, he shall use the dangerous waste numbers of D001 and WP01. This shall not be construed as requiring a person to designate his waste beyond those designation requirements set forth in subsections (2), (3), (4), and (5) of this section."

\section{REQUIREMENT SOURCE: WAC-173-303(940523) Section 081(1)}

"A waste shall be designated as a dangerous waste if it is handled in any of the manners described in (e) of this subsection, and if it is a residue from the management of:

(a) A commercial chemical product or manufacturing chemical intermediate which has the generic name listed in the discarded chemical products list, WAC 173-303-9903;

(b) An off-specification commercial chemical product or manufacturing chemical intermediate which if it had met specifications would have the generic name listed in the discarded chemical products list, WAC 173-303-9903;

(c) Any containers, inner liners, or residue remaining in a container or in an inner liner removed from a container that has held any commercial chemical product or manufacturing chemical intermediate that has, or any off-specification commercial chemical product or 
manufacturing chemical intermediate which if it had met specifications would have, the generic name listed on the acutely dangerous chemical products list of WAC 173-303-9903, unless the containers or inner liners are empty as described in WAC 173-303-160 (2);

(d) Any residue or contaminated soil, water, or other debris resulting from the cleanup of a spill of a commercial chemical product or manufacturing chemical intermediate which has, or of an off-specification commercial chemical product or manufacturing chemical intermediate which if it had met specifications would have, the generic name listed in the discarded chemical products list, WAC 173-303-9903;

(e) The materials or items described in (a), (b), (c), and (d) of this subsection are dangerous wastes when they are:

(i) Discarded or intended to be discarded as described in WAC 173-303-016 (3)(b)(i);

(ii) Burned for purposes of energy recovery in lieu of their original intended use;

(iii) Used to produce fuels in lieu of their original intended use;

(iv) Applied to the land in lieu of their original intended use; or

(v) Contained in products that are applied to the land in lieu of their original intended use."

\section{REQUIREMENT SOURCE: WAC-173-303(940523) Section 081(3)}

"Dangerous waste numbers and mixtures. A waste which has been designated as a discarded chemical product dangerous waste shall be assigned the dangerous waste number or numbers listed in WAC 173-303-9903 next to the generic chemical or chemicals which caused the waste to be designated. If a person mixes a solid waste with a waste that would be designated as a discarded chemical product under this section, then the entire mixture shall be designated. The mixture designation shall be the same as the designation for the discarded chemical product which was mixed with the solid waste. For example, a mixture containing $2.2 \mathrm{lbs}$. $(1 \mathrm{~kg})$ of Aldrin (dangerous waste number P004; EHW designation) and $22 \mathrm{lbs}$. $(10 \mathrm{~kg})$ of a solid waste, would be designated as an EHW, and would have the dangerous waste number P004."

\section{REQUIREMENT SOURCE: WAC-173-303(940523) Section 081(4)}

"For the purposes of this chapter, the term "acutely hazardous waste" shall include discarded chemical products (listed in WAC 173-303-9903) that are identified with a dangerous waste number beginning with a "P" or that show an " $\mathrm{X}$ " or " $\mathrm{A}$ " in the reason for designation column."

\section{REQUIREMINT SOURCE: WAC-173-303(940523) Section 082(1)}

"The dangerous waste sources list appears in WAC 173-303-9904. Any waste which is listed or which is a residue from the management of a waste listed on the dangerous waste sources list shall be designated a dangerous waste, and shall be identified as DW, except that WAC 173-303-9904 includes several footnotes describing circumstances under which certain dangerous waste sources should be designated EHW rather than DW."

\section{REQUIREMENT SOURCE: WAC-173-303(940523) Section 082(2)}

"Quantity exclusion limit. A person whose waste is listed in WAC 173-303-9904 (including residues from the management of such wastes) shall be a dangerous waste generator (and may not be considered a small quantity generator as provided in WAC 173-303-070 (8)) if the amount of his waste exceeds the following quantity exclusion limits:

(a) $2.2 \mathrm{lbs}$. (1 kg) per month or per batch for wastes listed with the dangerous waste numbers F020, F021, F022, F023, F026, or F027. For the purposes of this chapter, the term "acutely 
hazardous waste" shall include dangerous waste sources F020, F021, F022, F023, F026, and F027;

(b) $220 \mathrm{lbs}$. $(100 \mathrm{~kg})$ per month or per batch of any residue or contaminated soil, waste or other debris resulting from the cleanup of a spill, into or on any land or water of a waste listed in (a) of this subsection; or

(c) $220 \mathrm{lbs}$. $(100 \mathrm{~kg})$ per month or per batch for all other wastes."

\section{REQUIREMENT SOURCE: WAC-173-303(940523) Section 082(3)}

"Care should be taken in the proper designation of these wastes and of mixtures of these wastes and solid wastes. If a person mixes a solid waste with a waste that would be designated as a dangerous waste source under this section, then the entire mixture shall be designated as a dangerous waste source. The mixture shall have the same designation (DW or EHW), and shall have the same dangerous waste number as the dangerous waste source which was mixed with the solid waste."

\section{REQUIREMIENT SOURCE: WAC-173-303(940523) Section 082(4)}

"For the purposes of this section, any dangerous waste source listed in WAC 173-303-9904 which lists more than one chemical compound must be designated as a dangerous waste if it contains any one or any combination of the listed chemical compounds. For example, a spent nonhalogenated solvent containing both xylene and acetone must be designated as dangerous waste source F003."

\section{REQUIREMINT SOURCE: WAC-173-303(940523) Section 090(5)}

"Characteristic of ignitability.

(a) A solid waste exhibits the characteristic of ignitability if a representative sample of the waste has any of the following properties:

(i) It is a liquid, other than an aqueous solution containing less than 24 percent alcohol by volume, and has a flash point less than 60 degrees $C$ ( 140 degrees $F$ ), as determined by a Pensky-Martens Closed Cup Tester, using the test method specified in ASTM Standard D-93-79 or D-93-80, or a Setaflash Closed Cup Tester, using the test method specified in ASTM Standard D-3278-78;

(ii) It is not a liquid and is capable, under standard temperature and pressure, of causing fire through friction, absorption of moisture or spontaneous chemical changes and, when ignited, burns so vigorously and persistently that it creates a hazard;

(iii) It is an ignitable compressed gas as defined in 49 CFR 173.300 and as determined by the test methods described in that regulation; or,

(iv) It is an oxidizer as defined in 49 CFR 173.151.

(b) A solid waste that exhibits the characteristic of ignitability shall be designated DW, and shall be assigned the dangerous waste number of D001."

\section{REQUIREMENT SOURCE: WAC-173-303(940523) Section 090(6)}

"Characteristic of corrosivity.

(a) A solid waste exhibits the characteristic of corrosivity if a representative sample of the waste has any one or more of the following properties: 
(i) It is aqueous, and has a pH less than or equal to 2, or greater than or equal to 12.5 , using Method 9040 or 9041 in Test Methods for Evaluating Solid Waste (SW 846), Physical/Chemical Methods, available from the department;

(ii) It is liquid, and corrodes steel (SAE 1020) at a rate greater than 0.250 inch $(6.35 \mathrm{~mm}$ ) per year at a test temperature of 55 degrees $\mathrm{C}(130$ degrees $\mathrm{F})$ as determined by the test method specified in NACE (National Association of Corrosion Engineers) Standard TM-01-69 as standardized in Test Methods for the Evaluation of Solid Waste, Physical/Chemical Methods. The NACE Standard is available from the department; or

(iii) It is solid or semi-solid, and when mixed with an equal weight of water results in a solution, the liquid portion of which has the property specified in (a)(i) of this subsection. Procedures for preparing and extracting the solution and liquid are described in the test procedures of WAC 173-303-110(3)(a).

(b) A solid waste that exhibits the characteristic of corrosivity shall be designated DW, and shall be assigned the dangerous waste number of D002."

\section{REQUIREMENT SOURCE: WAC-173-303(940523) Section 090(7)}

"Characteristic of reactivity.

(a) A solid waste exhibits the characteristic of reactivity if a representative sample of the waste has any of the following properties:

(i) It is normally unstable and readily undergoes violent change without detonating;

(ii) It reacts violently with water;

(iii) It forms potentially explosive mixtures with water;

(iv) When mixed with water, it generates toxic gases, vapors or fumes in a quantity sufficient to present a danger to human health or the environment;

(v) It is a cyanide or sulfide bearing waste which, when exposed to $\mathrm{pH}$ conditions between 2 and 12.5 can generate toxic gases, vapors or fumes in a quantity sufficient to present a danger to human health or the environment;

(vi) It is capable of detonation or explosive reaction if it is subjected to a strong initiating source or if heated under confinement;

(vii) It is readily capable of detonation or explosive decomposition or reaction at standard temperature and pressure; or

(viii) It is a forbidden explosive as defined in 49 CFR 173.51, or a Class A explosive as defined in 49 CFR 173.53, or a Class B explosive as defined in 49 CFR 173.88.

(b) A solid waste that exhibits the characteristic of reactivity shall be designated DW, and shall be assigned the dangerous waste number of D003."

\section{REQUREMENT SOURCE: WAC-173-303(940523) Section 090(8)}

"Toxicity characteristic.

(a) A solid waste exhibits the toxicity characteristic if, using the Toxicity Characteristic Leaching Procedure (TCLP, found in Appendix II of 40 CFR Part 261 or available upon request from the department) or equivalent methods approved by the department under WAC 
173-303-110 (5), the extract from a representative sample of the waste contains any of the contaminants listed in the toxicity characteristic list in (c) of this subsection, at concentrations equal to or greater than the respective value given in the list. When the waste contains less than 0.5 percent filterable solids, the waste itself, after filtering using the methodology outlined in the TCLP, is considered to be the extract for the purposes of this subsection.

(b) A solid waste that exhibits the toxicity characteristic has the dangerous waste number specified in the list which corresponds to the toxic contaminant causing it to be dangerous.

(c) Toxicity characteristic list. Two levels of concentration are established for the contaminants listed. Any waste containing one or more contaminants with concentrations at or above the EHW threshold shall cause that waste to be designated EHW. Any waste containing contaminants which occur at concentrations at or above the DW threshold only (i.e., no EHW contaminants), shall be designated DW.

\section{TOXICITY CHARACTERISTICS LIST:}

Maximum Concentration of Contaminants for the Toxicity Characteristic

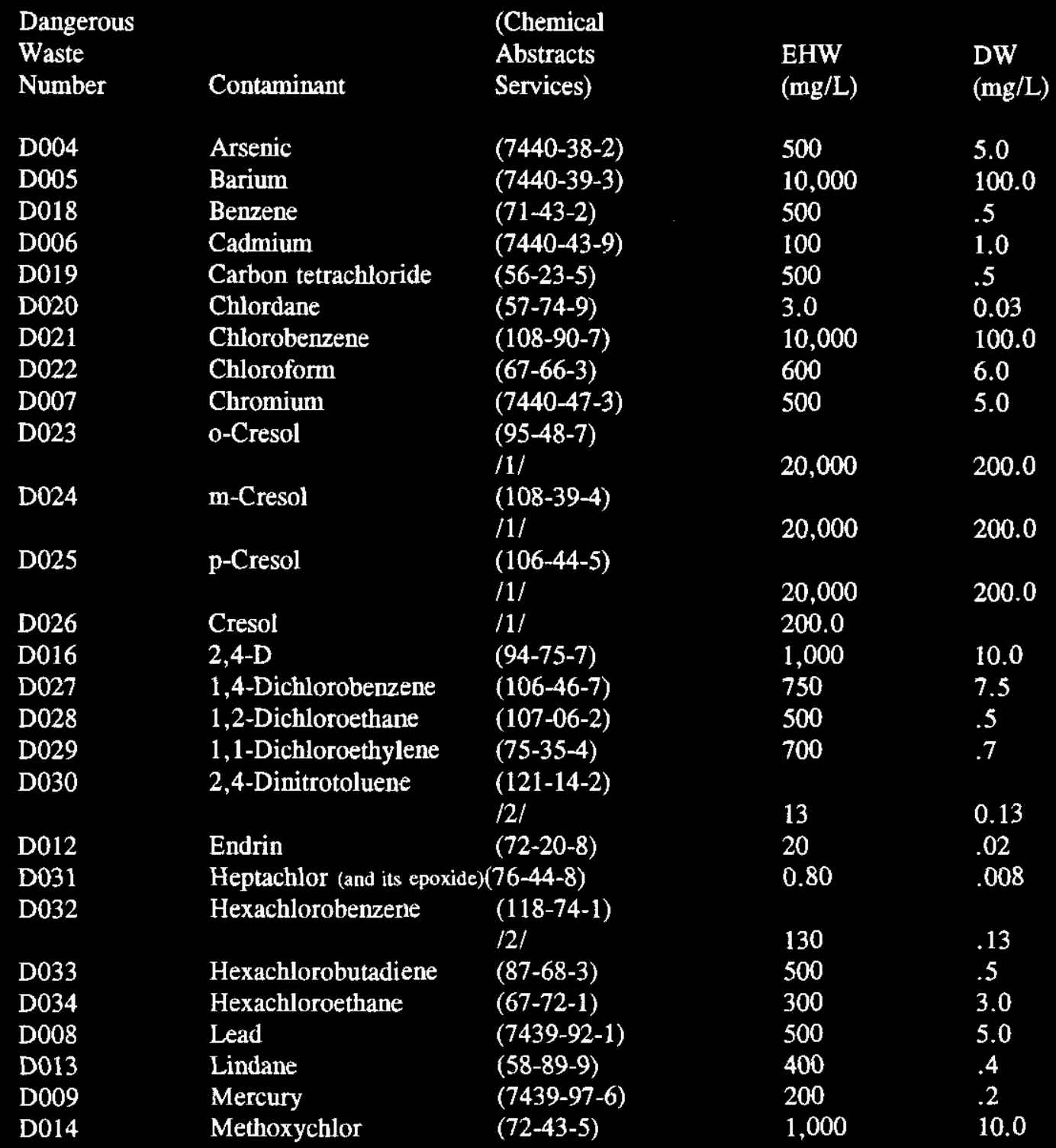




$\begin{array}{lllll}\text { D035 } & \text { Methylethyl ketone } & (78-93-3) & 20,000 & 200.0 \\ \text { D036 } & \text { Nitrobenzene } & (98-95-3) & 200 & 2.0 \\ \text { D037 } & \text { Pentachlorophenol } & (87-86-5) & 10,000 & 100.0 \\ \text { D038 } & \text { Pyridine } & (110-86-1) & & \\ & & 12 / & 500 & 5.0 \\ \text { D010 } & \text { Selenium } & (7782-49-2) & 100 & 1.0 \\ \text { D011 } & \text { Silver } & (7440-22-4) & 500 & 5.0 \\ \text { D039 } & \text { Tetrachloroethylene } & (127-18-4) & 700 & .7 \\ \text { D015 } & \text { Toxaphene } & (8001-35-2) & 500 & .5 \\ \text { D040 } & \text { Trichloroethylene } & (79-01-6) & 500 & .5 \\ \text { D041 } & \text { 2,4,5-Trichlorophenol } & (95-95-4) & 40,000 & 400.0 \\ \text { D042 } & \text { 2,4,6-Trichlorophenol } & (88-06-2) & 200 & 2.0 \\ \text { D017 } & \text { 2,4,5-TP (Silvex) } & (93-72-1) & 100 & 1.0 \\ \text { D043 } & \text { Vinyl chloride } & (75-01-4) & 200 & .2\end{array}$

/1/ If $0-, \mathrm{m}-$, and $\mathrm{p}-\mathrm{Cresol}$ concentrations cannot be differentiated, the total cresol (D026) concentration is used. The DW level for total cresol is $200 \mathrm{mg} / \mathrm{L}$ and the EHW level for total cresol is $20,000 \mathrm{mg} / \mathrm{L}$.

/2/ Quantitation limit is greater than the calculated regulatory level. The quantitation limit therefore becomes the regulatory level."

\section{REQUIREMENT SOURCE: WAC-173-303(940523) Section 100(3)}

"A person shall use data which is available to him, and, when such data is inadequate for the purposes of this section, shall refer to the NIOSH RTECS to determine:

(a) Toxicity data or toxic category for each known constituent in the waste;

(b) Whether or not each known constituent of the waste is a halogenated hydrocarbon or a polycyclic aromatic hydrocarbon with greater than three rings and less than seven rings."

\section{REQUIREMENT SOURCE: WAC-173-303(940523) Section 100(5)}

"Toxicity criteria. Except as provided in WAC 173-303-070 (4) or (5), a person shall determine if a solid waste meets the toxicity criteria under this section by following either the instructions for book designation, when his knowledge of the waste is sufficient, or by testing the waste using the biological testing methods adopted under WAC 173-303-110 (3)."

\section{REQUIREMENT SOURCE: WAC-173-303(940523) Section 100(5)(a)}

"Except as provided in WAC 173-303-070 (4) or (5), if a person knows only some of the toxic constituents in the waste or only some of the constituent concentrations, and if the waste is undesignated for those known constituents or concentrations, then the waste is not designated for toxicity under this subsection."

\section{REQUIREMENT SOURCE: WAC-173-303(940523) Section 100(5)(b)}

"Book designation procedure. A person may determine if a waste meets the toxicity criteria by following the book designation instructions as follows:

(i) A person shall determine the toxic category for each known constituent. The toxic category for each constituent may be determined from available data, or by obtaining data from the NIOSH RTECS and checking this data against the toxic category table, below. If data is available for more than one of the four toxicity criteria (aquatic, oral, inhalation, or dermal), 
then the data indicating severest toxicity shall be used, and the most acutely toxic category shall be assigned to the constituent. If the NIOSH RTECS or other data sources do not agree on the same category, then the category arrived at using the NIOSH RTECS will be used to determine the toxic category. If toxicity data for a constituent cannot be found in the NIOSH RTECS, or other source reasonably available to a person, then the toxic category need not be determined for that constituent.

\section{TOXIC CATEGORY TABLE}

\begin{tabular}{|c|c|c|c|c|}
\hline & \multicolumn{2}{|c|}{ TLm96 (Fish) or, Aquatic } & Inhalation & Dermal \\
\hline Toxic & (Fish) & Oral (Rat) & (Rat) & (Rabbit) \\
\hline Category & LC50(ppm) & LD50 $(\mathrm{mg} / \mathrm{kg})$ & $\mathrm{LC50}(\mathrm{mg} / \mathrm{L})$ & $\mathrm{LD} 50(\mathrm{mg} / \mathrm{kg})$ \\
\hline $\mathbf{X}$ & $<.1$ & $<.5$ & $<.02$ & $<2$ \\
\hline A & $.1-<1$ & $.5-<5$ & $.02-<.2$ & $2-<20$ \\
\hline B & $1-<10$ & $5-<50$ & $.2-<2$ & $20-<200$ \\
\hline C & $10-<100$ & $50-<500$ & $2-<20$ & $200-<2000$ \\
\hline D & $100-1000$ & $500-5000$ & $20-200$ & $2000-20,000$ \\
\hline
\end{tabular}

(ii) A person whose waste contains one or more toxic constituents shall determine the equivalent concentration for the waste from the following formula:

$$
\begin{aligned}
& \text { Equivalent } \stackrel{+}{\text { Concentration }(\%)}=\mathbf{n} \mathrm{X} \%
\end{aligned}
$$

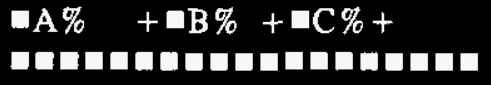

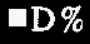

ㅁㅁם

10,000

where $\square(X, A, B, C$, or $D) \%$ is the sum of all the concentration percentages for a particular toxic category.

Example 1. A person's waste contains: Category) - .01\%; Diuron (B Category)

Aldrin (X Category) - 4\%; Phenol (C Category) - $1 \%$; Benzene $(\mathrm{C}$ Category) - 5\%; Water (nontoxic) - 2\%; Cyclohexane (C The equivalent concentration (E.C.) would be:
E.C. $(\%)=$
$.01 \%+0 \%+1 \%$
$+(4 \%+2 \%+5 \%)$

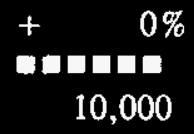
10
100
1000
10,000

$$
=.01 \%+0 \%+.01 \%+.011 \%+0 \%=.031 \%
$$

So the equivalent concentration equals $.031 \%$.

(iii) A person whose waste contains toxic constituents shall determine its designation from the toxic dangerous waste graph in WAC 173-303-9906 by finding the equivalent concentration percentage for the waste along the abscissa, finding the total waste quantity along the ordinate, and plotting the point on the graph where the horizontal line drawn from the total waste quantity intersects the vertical line drawn from the waste's equivalent concentration. If the plotted point is in the area marked DW, the person shall designate the waste as DW, and shall assign the dangerous waste number of WT02; if the plotted point is in the area marked EHW, the person shall designate the waste as EHW, and shall assign the dangerous waste number of WT01.

(iv) Toxic dangerous waste graph. The toxic dangerous waste graph appears in WAC 173-303-9906. 


\section{REQUIREMENT SOURCE: WAC-173-303(940523) Section 100(5)(c)}

"Designation from bioassay data. A person may determine if a waste meets the toxicity criteria by following the bioassay designation instructions as follows:

(i) A person shall establish the toxicity category range (D category toxicity, or C category or greater toxicity) of a waste by means of the biological testing methods (bioassay) adopted under WAC 173-303-110(3).

(ii) A person shall designate a waste according to the toxic dangerous waste designation table below.

\section{TOXIC DANGEROUS WASTE DESIGNATION TABLE}

\begin{tabular}{|c|c|c|}
\hline $\begin{array}{l}\text { If your waste's } \\
\text { toxicity range } \\
\text { is . . }\end{array}$ & $\begin{array}{l}\text { And your monthly } \\
\text { or batch waste } \\
\text { quantity is . . }\end{array}$ & $\begin{array}{l}\text { Then your waste's } \\
\text { designation, and waste } \\
\text { numbers are . . }\end{array}$ \\
\hline D Category: & $\begin{array}{l}\text { Any quantity } \\
\text { (LC50 } 1000 \mathrm{mg} / \mathrm{L} \\
\text { to } 100 \mathrm{mg} / \mathrm{L} \text {, or } \\
\mathrm{LD} 505000 \mathrm{mg} / \mathrm{kg} \\
\text { to } 500 \mathrm{mg} / \mathrm{kg} \text { ) }\end{array}$ & DW, WT02 \\
\hline \multirow[t]{2}{*}{$\mathrm{X}, \mathrm{A}, \mathrm{B}$, or $\mathrm{C}$} & $\begin{array}{l}\text { Less than } 220 \mathrm{lbs} \text {. } \\
\text { (LC50 less than }(100 \mathrm{~kg}) \\
100 \mathrm{mg} / \mathrm{L} \text {, or } \\
\text { LD50 less than } \\
500 \mathrm{mg} / \mathrm{kg} \text { ) }\end{array}$ & DW, WT02 \\
\hline & $\begin{array}{l}\text { Greater than or } \\
\text { equal to } 220 \mathrm{lbs} .(100 \mathrm{~kg})\end{array}$ & EHW, WT01 \\
\hline
\end{tabular}

REQUIREMENT SOURCE: WAC-173-303(940523) Section 100(5)(d)

"If the designation acquired from book designation and bioassay data do not agree, then bioassay data will be used to designate a waste. If a waste is designated as DW or EHW following the book designation procedure, a person may test the waste by means of the biological testing methods (bioassay) adopted under WAC 173-303-110 (3), using both static acute fish and acute oral rat methods, to demonstrate that the waste is not a dangerous waste or should be designated as DW and not EHW."

\section{REQUIREMINT SOURCE: WAC-173-303(940523) Section 100(5)(e)}

"A waste designated as DW by toxicity criteria shall be assigned the dangerous waste number of WT02. A waste designated as EHW by toxicity criteria shall be assigned the dangerous waste number of WT01."

\section{REQUIREMENT SOURCE: WAC-173-303(940523) Section 100(6)}

"Persistence criteria. For the purposes of this section, persistent constituents are chemical compounds which are either halogenated hydrocarbons $(\mathrm{HH})$, or polycyclic aromatic hydrocarbons (PAH), as defined under WAC 173-303-040. Except as provided in WAC 173-303-070 (4) or (5), a person may determine the identity and concentration of persistent 
constituents by either applying knowledge of the waste or by testing the waste according to the chemical testing methods for complying with the dangerous waste regulation adopted under WAC 173-303-110 (3)."

\section{REQUIREMENT SOURCE: WAC-173-303(940523) Section 100(6)(a)}

"Except as provided in WAC 173-303-070 (4) and (5), if a person knows only some of the persistent constituents in the waste, or only some of the constituent concentrations, and if the waste is undesignated for those known constituents or concentrations, then the waste is not designated for persistence under this subsection."

\section{REQUIREMENT SOURCE: WAC-173-303(940523) Section 100(6)(b)}

"When a waste contains one or more halogenated hydrocarbons (HH) for which the concentrations are known, the total halogenated hydrocarbon concentration shall be determined by summing the concentration percentages for all of the halogenated hydrocarbons for which the concentrations are known.

Example 2. A waste contains: Carbon tetrachloride - $-009 \%$; DDT - $-012 \% ; 1,1,1$ trichloroethylene $-.020 \%$. The total halogenated hydrocarbon concentration would be:

-Total HH Concentration $(\%)=.009 \%+.012 \%+.020 \%=.041 \% "$

\section{REQUIREMENT SOURCE: WAC-173-303(940523) Section 100(6)(c)}

"A person whose waste contains one or more polycyclic aromatic hydrocarbons (PAH) with more than three rings and less than seven rings for which the concentrations are known shall determine the total polycyclic aromatic hydrocarbon concentration by summing the concentration percentages for all of those polycyclic aromatic hydrocarbons with more than three rings and less than seven rings about which he knows the concentration in the waste.

Example 3. A person's waste contains: Chrysene $-.08 \% ; 3,4-$ benzo[a]pyrene $-1.22 \%$. The total polycyclic aromatic hydrocarbon concentration would be:

Total PAH Concentration $(\%)=.08 \%+1.22 \%=1.30 \%$

(d) A person whose waste contains halogenated hydrocarbons and/or polycyclic aromatic hydrocarbons shall determine its designation from the persistent dangerous waste table or persistent dangerous waste criteria graph WAC 173-303-9907.

\section{PERSISTENT DANGEROUS WASTE TABLE}

If your waste

contains. . .

Halogenated

Hydrocarbons

Polycyclic Aromatic Hydrocarbons
At a total concentration level of. . .

$0.01 \%$ to $1.0 \%$

(HH)greater than $1.0 \%$

greater than $1.0 \%$

(PAH)
Then your waste's

designation, and

waste numbers are. . .

DW, WP02

EHW, WP01

EHW*, WP01

* No DW concentration level for PAH. 


\section{REQUIREMINT SOURCE: WAC-173-303(940523) Section 100(7)(a)}

"Criteria. For the purposes of this section, a carcinogenic substance shall be a substance which has sufficient or limited evidence as a human or animal carcinogen as listed in both:

(i) The National Institute for Occupational Safety and Health (NIOSH) Registry of Toxic Effects of Chemical Substances (RTECS) as an International Agency for Research on Cancer (IARC) carcinogen; and

(ii) The Integrated Risk Information System (IRIS) or Health Effects Assessment Summary Table (HEAST).

(iii) A list of carcinogenic substances is available from the department. Any IARC identified substance that is an inorganic, respiratory carcinogen shall be a carcinogenic substance only if it occurs in a friable format (i.e., if it is in a waste which easily crumbles and forms dust which can be inhaled). Any IARC human or animal, sufficient or limited carcinogen that is so rated because of studies involving implantation of the substance into test animals as the sole cause for the carcinogenic IARC rating, shall not be a carcinogenic substance. This additional information is available in the IARC Monographs on the Evaluation of the Carcinogenic Risk of Chemicals to Humans."

\section{REQUIREMENT SOURCE: WAC-173-303(940523) Section 100(7)(b)}

"Except as provided in WAC 173-303-070 (4) and (5), if a person knows only some of the carcinogenic substances in the waste, or only some of the substance concentrations, and if the waste is undesignated for those known substances or concentrations, then the waste is not designated for carcinogens under this subsection."

\section{REQUIREMENT SOURCE: WAC-173-303(940523) Section 100(7)(c)}

"Designation. A solid waste that contains one or more carcinogenic substances shall be designated DW and assigned the waste number of WC02 if either,

(i) The concentration of any one carcinogenic substance exceeds $0.01 \%$ of the waste quantity; or

(ii) The total concentration summed for all carcinogenic substances exceeds $1.0 \%$ of the waste quantity."

\section{REQUIREMINT SOURCE: WAC-173-303(940523) Section 120(1)}

"This section describes the requirements for persons who recycle materials that are solid wastes and dangerous. Except as provided in subsections (2) and (3) of this section, dangerous wastes that are recycled are subject to the requirements for generators, transporters, and storage facilities of subsection (4) of this section. Dangerous wastes that are recycled will be known as "recyclable materials."

\section{REQUIREMENT SOURCE: WAC-173-303(940523) Section 120(2)}

"(a) The following recyclable materials are solid wastes and sometimes are dangerous wastes. However, they are subject only to the requirements of (b) of this subsection, WAC 173-303-050, 173-303-145 and 173-303-960:

(i) Industrial ethyl alcohol that is reclaimed;

(ii) Used batteries (or used battery cells) returned to a battery manufacturer for regeneration; 
(iii) Used oil that exhibits one or more of the characteristics or criteria of dangerous waste and is recycled in some manner other than:

(A) Being burned for energy recovery; or

(B) Being used in a manner constituting disposal, except when such use is by the generator on his own property;

(iv) Scrap metal;

(v) Fuels produced from the refining of oil-bearing dangerous wastes along with normal process streams at a petroleum refining facility if such wastes result from normal petroleum refining, production, and transportation practices;

(vi) Oil reclaimed from dangerous waste resulting from normal petroleum refining, production, and transportation practices, which oil is to be refined along with normal process streams at a petroleum refining facility;

(vii) Coke and coal tar from the iron and steel industry that contains dangerous waste from the iron and steel production process;

(viii)(A) Dangerous waste fuel produced from oil-bearing dangerous wastes from petroleum refining, production, or transportation practices, or produced from oil reclaimed from such dangerous wastes, where such dangerous wastes are reintroduced into a process that does not use distillation or does not produce products from crude oil so long as the resulting fuel meets the used oil specification under WAC 173-303-515(1)(d) and so long as no other dangerous wastes are used to produce the dangerous waste fuel;

(B) Dangerous waste fuel produced from oil-bearing dangerous waste from petroleum refining production, and transportation practices, where such dangerous wastes are reintroduced into a refining process after a point at which contaminants are removed, so long as the fuel meets the used oil fuel specification under WAC 173-303-515 (1)(d); and

(C) Oil reclaimed from oil-bearing dangerous wastes from petroleum refining, production, and transportation practices, which reclaimed oil is burned as a fuel without reintroduction to a refining process, so long as the reclaimed oil meets the used oil fuel specification under WAC $173-303-515(1)(\mathrm{e})$; and

(ix) Petroleum coke produced from petroleum refinery dangerous wastes containing oil at the same facility at which such wastes were generated, unless the resulting coke product exhibits one or more of the characteristics of dangerous waste in WAC 173-303-090.

(b) Any recyclable material listed in (a) of this subsection will be subject to the applicable requirements listed in subsection (4) of this section if the department determines, on a case-by-case basis, that:

(i) It is being accumulated, used, reused, or handled in a manner that poses a threat to public health or the environment; or

(ii) Due to the dangerous constituent(s) in it, any use or reuse would pose a threat to public health or the environment. Such recyclable material will be listed in WAC 173-303-016 (6)."

\section{REQUIREMENT SOURCE: WAC-173-303(940523) Section 120(3)}

"The following recyclable materials are not subject to the requirements of this section but are subject to the requirements of WAC 173-303-070 through 173-303-110, 173-303-160, 
173-303-500 through 173-303-525, and all applicable provisions of WAC 173-303-800 through 173-303-840:

(a) Recycling requirements for state-only dangerous wastes (see WAC 173-303-500);

(b) Recyclable materials used in a manner constituting disposal (see WAC 173-303-505);

(c) Spent CFC or HCFC refrigerants that are recycled on-site or sent to be reclaimed off-site (see WAC 173-303-506);

(d) Dangerous wastes burned for energy recovery in boilers and industrial furnaces that are not regulated under Subpart O of 40 CFR Part 265 or WAC 173-303-670 (see WAC

173-303-510);

(e) Used oil that is burned for energy recovery in boilers and industrial furnaces that are not regulated under Subpart O of 40 CFR Part 265 or WAC 173-303-670, if such used oil:

(i) Exhibits one or more of the characteristics of a dangerous waste; or

(ii) Is designated as DW solely through WAC $173-303-100$; or

(iii) Is designated solely as W001, (see WAC 173-303-515);

(f) Spent lead-acid batteries that are being reclaimed (see WAC 173-303-520);

(g) Recyclable materials from which precious metals are reclaimed (see WAC 173-303-525)."

\section{REQUIREMINT SOURCE: WAC-173-303(940523) Section 120(4)}

"Those recycling processes not specifically discussed in subsections (2) and (3) of this section are generally subject to regulation only up to and including storage prior to recycling. For the purpose of this section, recyclable materials received from off-site shall be considered stored unless they are moved into an active recycling process within twenty-four hours after being received. An active recycling process refers to a dynamic recycling operation that occurs within a recycling unit such as a distillation or centrifuge unit. The phrase does not refer to passive storage-like activities that occur, for example, when tanks or containers are used for phase separation or for settling impurities. Passive storage-like activities are not eligible for the recycling exemption under this subsection.

The recycling process itself is generally exempt from regulation unless the department determines, on a case-by-case basis, that the recycling process poses a threat to public health or the environment."

\section{REQUIREMENT SOURCE: WAC-173-303(940523) Section 140(4)}

"Land disposal restrictions and prohibitions. The land disposal requirements of this subsection apply to land disposal in Washington state."

\section{REQUIREMENT SOURCE: WAC-173-303(940523) Section 140(4)(a)}

"Disposal of extremely hazardous waste (EHW). No person shall land dispose of EHW, except as provided in subsection (5) of this section, at any land disposal facility in the state. No person shall land dispose of EHW at the facility established under RCW 70.105.050, except as provided by subsections (5), (6), and (7) of this section. A person is encouraged to reclaim, recycle, recover, treat, detoxify, neutralize, or otherwise process EHW to remove or reduce its harmful properties or characteristics, provided that such processing is performed in accordance with the requirements of this chapter." 


\section{REQUIREMENT SOURCE: WAC-173-303(940523) Section 140(4)(b)}

"Disposal of liquid waste. Special requirements for the disposal of liquid waste in landfills. (i) Bulk or noncontainerized liquid waste or waste containing free liquids must not be placed in a landfill unless, before disposal, the liquid waste or waste containing free liquids is treated so that free liquids are no longer present.

(ii) Containers holding free liquids must not be placed in a landfill unless:

(A) All free-standing liquid:

(I) Has been removed by decanting, or other methods; or

(II) Has been mixed with absorbent or stabilized (solidified) so that free-standing liquid is no longer observed; or

(III) Has been otherwise eliminated; or

(B) The container is very small, such as an ampule; or

(C) The container is a lab pack and is disposed of in accordance with WAC 173-303-161 and this chapter.

(iii) To demonstrate the absence or presence of free liquids in either a containerized or a bulk waste, the following tests must be used: Method 9095 (Paint Filter Liquids Test) as described in Test Methods for Evaluating Solid Wastes, Physical/Chemical Methods. (EPA Publication No. SW-846.)"

\section{REQUIREMENT SOURCE: WAC-173-303(940523) Section 140(4)(c)}

"Disposal of solid acid waste. No person shall land dispose solid acid waste, except as provided in subsections (5), (6), or (7) of this section. A person is encouraged to reclaim, recycle, recover, treat, detoxify, neutralize, or otherwise process these wastes to remove or reduce their harmful properties or characteristics, provided that such processing is performed in accordance with the requirements of this chapter."

\section{REQUIREMENT SOURCE: WAC-173-303(940523) Section 140(4)(d)}

"Disposal of organic/carbonaceous waste.

(i) No person shall land dispose organic/carbonaceous waste, except as provided in subsections (5), (6), or (7) of this section. A person is encouraged to reclaim, recycle, recover, treat, detoxify, or otherwise process these wastes to remove or reduce their harmful properties or characteristics, provided that such processing is performed in accordance with the requirements of this chapter. Organic/carbonaceous wastes must be incinerated as a minimum management method according to the dangerous waste management priorities as defined in subsection (1)(a) of this section.

(ii) This prohibition against the land disposal of organic/carbonaceous waste does not apply to black mud generated from the caustic leach recovery of cryolite at primary aluminum smelting plants.

(iii) This prohibition against the land disposal of organic/carbonaceous waste does not apply to any person who certifies to the department that recycling, treatment and incineration facilities are not available within a radius of one thousand miles from Washington state's borders. Such certification must be sent to the department by certified mail and must include: The name, address and telephone number of the person certifying; a brief description of the 
organic/carbonaceous waste covered by the certification; a discussion of the efforts undertaken to identify available recycling, treatment and incineration facilities; and the signature of the person responsible for the certification and development of information used to support the certification. Records and information supporting the certification must be retained by the certifying person and must be made available to the department upon request.

A certification that has been properly submitted to the department will remain valid until the department determines that a recycling, treatment or incineration facility is available within a radius of one thousand miles from Washington state's borders and the person who submitted the certification is unable to demonstrate otherwise. A recycling, treatment or incineration facility will be considered by the department to be available if such facility: Is operating, and; can safely and legally recycle, treat or incinerate the organic/carbonaceous waste, and; has sufficient capacity to receive and handle significant amounts of the waste, and; agrees to accept the waste."

\section{REQUIREMENT SOURCE: WAC-173-303(940523) Section 150(1)}

"Any action taken to evade the intent of this regulation by dividing or diluting wastes to change their designation shall be prohibited, except for the purposes of treating, neutralizing, or detoxifying such wastes. "

\section{REQUIREMENT SOURCE: WAC-173-303(940523) Section 150(2)}

"Separation of a homogeneous waste into heterogeneous phases (e.g., separation of a suspension into sludge and liquid phases, or of a solvent/water mixture into solvent and water phases, etc.) shall not be considered as division, provided that the person generating the waste either:

(a) Designates the homogeneous waste before separation, and handles the entire waste accordingly; or

(b) Designates each phase of the heterogeneous waste, in accordance with the dangerous waste designation requirements of this chapter, and handles each phase accordingly."

\section{REQUIREMINT SOURCE: WAC-173-303(940523) Section 150(3)}

"For the purposes of designation, quantities of continuously generated wastes shall be summed monthly. All wastes generated less frequently than once a month shall be considered as batch or single event wastes."

\section{REQUIREMENT SOURCE: WAC-173-303(940523) Section 170(1)}

"A person shall be a dangerous waste generator if his solid waste is designated by the requirements of WAC 173-303-070 through 173-303-100.

(a) The generator shall be responsible for designating his waste as DW or EHW.

(b) The generator may request an exemption for his dangerous waste according to the procedures of WAC 173-303-072."

\section{REQUIREMENT SOURCE: WAC-173-303(940523) Section 170(2)}

"A dangerous waste generator shall notify the department and obtain an EPA/state identification number as required by WAC 173-303-060, and shall comply with the requirements of WAC 173-303-170 through 173-303-230." 


\section{REQUIREMENT SOURCE: WAC-173-303(940523) Section 170(3)}

"Any generator who stores, treats, or disposes of dangerous waste on-site shall perform his operations in accordance with the TSD facility requirements with the following exceptions:

(a) Generators who accumulate dangerous wastes for less than ninety days as allowed under WAC 173-303-200 or for less than one hundred eighty days as allowed under WAC 173-303-201 and 173-303-202;

(b) Generators who treat dangerous waste on-site in accumulation tanks and containers provided that the generator maintains a log showing the date and amount of waste treated and complies with:

(i) WAC 173-303-200 or 173-303-201, and for tanks, WAC 173-303-202; and

(ii) WAC 173-303-283 (3);

(c) Generators who treat special waste in units other than accumulation tanks or containers provided:

(i) The treatment occurs within the appropriate accumulation time frame;

(ii) The unit is designed, constructed, and operated in a manner that prevents:

(A) A release of waste and waste constituents to the environment;

(B) Endangerment of health of employees or the public;

(C) Excessive noise;

(D) Negative aesthetic impact on the use of adjacent property.

(iii) The treatment unit must also be inspected routinely for deterioration that would lead to a release and repairs must be conducted promptly."

\section{REQUIREMENT SOURCE: WAC-173-303(940523) Section 170(4)}

"The generator of a special waste may, upon approval by the department, for special waste only:

(a) Develop and implement an alternative manifest mechanism in lieu of the requirements of WAC 173-303-180 for special waste shipments. Such alternative mechanism might employ a single manifest for multiple shipments of the same special waste, might not require signatures or multiple copies for transporters or designated receiving facilities, and might include such other factors as the generator might develop and the department approve. The generator must, however, demonstrate to the department's satisfaction before implementing the alternative mechanism that it will assure accurate tracking and recording of waste shipments, and that the mechanism provides for the proper submission of exception reports as specified in WAC 173-303-220 (2). The generator shall be responsible for assuring that all transporters and facilities involved in implementing the alternative manifest mechanism are complying with the terms and conditions of the mechanism as approved by the department; and

(b) Pursuant to the requirements of WAC 173-303-200, accumulate special waste in containers and tanks for up to one hundred eighty days, and accumulate special waste in piles for up to ninety days provided that he complies with WAC 173-303-660 (2), (3)(a), (b)(i), (ii)(A), (7), $(8)$, and (9)(a)." 


\section{REQUIREMENT SOURCE: WAC-173-303(940523) Section 170(5)}

"The generator must comply with the special land disposal restrictions for certain dangerous wastes in WAC 173-303-140."

\section{PACKAGING AND LABELING COMPLIANCE}

The requirements of 49 CFR 172 for packaging and labeling of radioactive and hazardous wastes are covered in the Packaging and Transportation Functional Area. Packaging and labeling requirements from DOE 5820.2A and WAC 173-303 are specified in the following subelements.

\section{$\underline{16.2 .1}$}

\section{Low-Level Radioactive Waste Packaging}

\section{REQUIREMENT SOURCE: DOE5820.2A Chapter III, Section 3.i(5)(a)}

"The following are additional disposal requirements intended either to improve stability of the disposal site or to facilitate handling and provide protection of the health and safety of personnel at the disposal site:

(a) Waste must not be packaged for disposal in cardboard or fiberboard boxes, unless such boxes meet DOT requirements and contain stabilized waste with a minimum of void space. For all types of containers, void spaces within the waste and between the waste and its packaging shall be reduced as much as practical."

\section{REQUIREMENT SOURCE: DOE5820.2A Chapter III, Section 3.i(5)(b)}

"Liquid wastes, or wastes containing free liquid, must be converted into a form that contains as little freestanding and noncorrosive liquid as is reasonably achievable, but, in no case, shall the liquid exceed 1 percent of the volume of the waste when the waste is in a disposal container, or 0.5 percent of the volume of the waste processed to a stable form."

\section{REQUIREMENT SOURCE: DOE5820.2A Chapter II, Section 3.i(5)(c)}

"Waste must not be readily capable of detonation or of explosive decomposition or reaction at normal pressures and temperatures, or of explosive reaction with water."

\section{REQUIREMENT SOURCE: DOE5820.2A Chapter III, Section 3.i(5)(d)}

"Waste must not contain, or be capable of generating, quantities of toxic gases, vapors, or fumes harmful to persons transporting, handling, or disposing of the waste. This does not apply to radioactive gaseous waste packaged as identified in paragraph 3.i.(5)(e)."

\section{REQUIREMENT SOURCE: DOE5820.2A Chapter III, Section 3.i(5)(e)}

"Waste in a gaseous form must be packaged at a pressure that does not exceed 1.5 atmospheres at $20^{\circ} \mathrm{C}$."

\section{REQUIREMINT SOURCE: DOE5820.2A Chapter III, Section 3.i(5)(f)}

"Waste must not be pyrophoric. Pyrophoric materials contained in waste shall be treated, prepared, and packaged to be nonflammable." 


\section{REQUIREMENT SOURCE: WAC-173-303(940523) Section 104(2)}

"Characteristics. A waste which exhibits any of the dangerous waste characteristics, WAC 173-303-090, shall be assigned the dangerous waste number corresponding to the characteristic(s) exhibited by the waste."

\section{REQUIREMINT SOURCE: WAC-173-303(940523) Section 161}

"Small containers of dangerous waste may be placed in overpacked drums (or labpacks) provided that the following conditions are met:

(1) Dangerous waste must be packaged in nonleaking inside containers. The inside containers must be of a design and constructed of a material that will not react dangerously with, be decomposed by, or be ignited by the contained waste. Inside containers must be tightly and securely sealed and, to the extent possible, should be full and have as little air as possible in them to minimize voids. The inside containers must be of the size and type specified in the Department of Transportation (DOT) hazardous materials regulations (49 CFR Parts 173, 178, and 179), if those regulations specify a particular inside container for the waste;

(2) The inside containers must be overpacked in an open head DOT-specification metal or fiber drum shipping container which meets all of the requirements of 49 CFR Parts 178 and 179. The overpack container must not exceed a capacity of 416-liter (110 gallon). The overpack container must have a sufficient quantity of absorbent material to completely absorb all of the liquid contents of the inside containers. The metal or fiber outer container must be full after packing with inside containers and absorbent material;

(3) The absorbent material used must not be capable of reacting dangerously with, being decomposed by, or being ignited by the contents of the inside containers in accordance with WAC 173-303-395 (1)(b);

(4) Incompatible wastes, as defined in WAC 173-303-040, must not be placed in the same outside container; and

(5) Reactive wastes, other than cyanide- or sulfide-bearing waste as defined in WAC 173-303-090 (7)(a)(v), must be treated or rendered nonreactive prior to packaging in accordance with subsections (1) through (4) of this section. Cyanide- and sulfide-bearing reactive waste may be packed in accordance with subsections (1) through (4) of this section without first being treated or rendered nonreactive.

(6) An itemized listing of the chemicals, their concentrations and quantities per labpack must be kept by the generator and must be readily available in case of an emergency during shipment, and for the purposes of preparing annual reports under WAC 173-303-220."

\section{REQUIREMENT SOURCE: WAC-173-303(940523) Section 395(1)(d)}

"At least yearly, the owner or operator shall inspect those areas of his facility where ignitable or reactive wastes are stored. This inspection shall be performed in the presence of a professional person who is familiar with the Uniform Fire Code, or in the presence of the local, state, or federal fire marshal. The owner or operator shall enter the following information in his inspection log or operating record as a result of this inspection:

(i) The date and time of the inspection;

(ii) The name of the professional inspector or fire marshal; 
(iii) A notation of the observations made; and

(iv) Any remedial actions which were taken as a result of the inspection."

REQUIREMENT SOURCE: WAC-173-303(940523) Section 395(6)

"Labeling for containers and tanks. The owner or operator must label containers and tanks in a manner which adequately identifies the major risk(s) associated with the contents for employees, emergency response personnel and the public (Note--If there is already a system in use that performs this function in accordance with local, state or federal regulations, then such system will be adequate). The owner or operator must ensure that labels are not obscured, removed, or otherwise unreadable in the course of inspection required under WAC 173-303-320. For tanks, the label or sign shall be legible at a distance of at least fifty feet. For containers, the owner or operator must affix labels upon transfer of dangerous waste from one container to another. The owner or operator must destroy or otherwise remove labels from the emptied container, unless the container will continue to be used for storing dangerous waste at the facility. "

\section{PCB Waste Labeling}

\section{REQUIREMENT SOURCE: 40CFR761 Part 40(a)(1)}

"Each of the following items in existence on or after July 1, 1978 shall be marked as illustrated in Figure 1 in 761.45(a): The mark illustrated in Figure 1 is referred to as ML throughout this subpart.

(1) PCB Containers;"

\section{REQUIREMENT SOURCE: 40CFR761 Part 40(a)(2)}

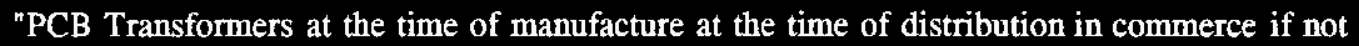
already marked and at the time of removal from use if not already marked. [Marking of PCB-Contaminated Electrical Equipment is not required];"

\section{REQUIREMENT SOURCE: 40CFR761 Part 40(a)(3)}

"PCB Large High Voltage Capacitors at the time of manufacture at the time of distribution in commerce if not already marked and at the time of removal from use if not already marked;"

\section{REQUIREMENT SOURCE: 40CFR761 Part 40(a)(4)}

"Equipment containing a PCB Transformer or a PCB Large High Voltage Capacitor at the time of manufacture at the time of distribution in commerce if not already marked and at the time of removal of the equipment from use if not already marked;"

\section{REQUIREMINT SOURCE: 40CFR761 Part 40(a)(5)}

"PCB Large Low Voltage Capacitors at the time of removal from use;"

\section{REQUIREMENT SOURCE: 40CFR761 Part 40(a)(6)}

"Electric motors using PCB coolants (See also paragraph (e) of this section)."

\section{REQUIREMENT SOURCE: 40CFR761 Part 40(a)(7)}

"Hydraulic systems using PCB hydraulic fluid (See also paragraph (e) of this section);" 


\section{REQUIREMINT SOURCE: 40CFR761 Part 40(a)(8)}

"Heat transfer systems (other than PCB Transformers) using PCBs (See also paragraph (e) of this section);"

\section{REQUIREMENT SOURCE: 40CFR761 Part 40(a)(9)}

"PCB Article Containers containing articles or equipment that must be marked under paragraphs (a) (1) through (8) of this section;"

\section{REQUIREMINT SOURCE: 40CFR761 Part 40(b)}

"As of October 1, 1978, each transport vehicle shall be marked on each end and side with ML as described in 761.45(a) if it is loaded with PCB Containers that contain more than $45 \mathrm{~kg}$ (99.4 lbs.) of PCBs in the liquid phase or with one or more PCB Transformers (See also paragraph (e) of this section)."

\section{REQUIREMENT SOURCE: 40CFR761 Part 40(e)}

"(e) As of October 1, 1979, applicable PCB Items in paragraph (a)(1), (6), (7), and (8) of this section containing PCBs in concentrations of 50 to $500 \mathrm{ppm}$ and applicable transport vehicles in paragraph (b) of this section loaded with PCB Containers that contain more than $45 \mathrm{~kg}$ (99.4 lbs.) of liquid PCBs in concentrations of $50 \mathrm{ppm}$ to $500 \mathrm{ppm}$ shall be marked with mark ML as described in $\$ 61.45(a) . "$

\section{REQUIREMENT SOURCE: 40CFR761 Part 40(h)}

"(h) All marks required by this subpart must be placed in a position on the exterior of the PCB Items or transport vehicles so that the marks can be easily read by any persons inspecting or servicing the marked PCB Items or transport vehicles. "

\section{REQUIREMENT SOURCE: 40CFR761 Part 45}

"The following formats shall be used for marking:

(a) Large PCB Mark - ML. Mark ML shall be as shown in Figure 1, letters and striping on a white or yellow background and shall be sufficiently durable to equal or exceed the life (including storage for disposal) of the PCB Article, PCB Equipment, or PCB Container. The size of the mark shall be at least $15.25 \mathrm{~cm}$ (6 inches) on each side. If the PCB Article or PCB Equipment is too small to accommodate this size, the mark may be reduced in size proportionately down to a minimum of $5 \mathrm{~cm}$ ( 2 inches) on each side.

(b) Small PCB Mark - Ms. Mark Ms shall be as shown in Figure 2, letters and striping on a white or yellow background, and shall be sufficiently durable to equal or exceed the life (including storage for disposal) of the PCB Article, PCB Equipment, or PCB Container. The mark shall be a rectangle 2.5 by $5 \mathrm{~cm}$ ( 1 inch by 2 inches). If the PCB Article or PCB Equipment is too small to accommodate this size, the mark may be reduced in size proportionately down to a minimum of 1 by $2 \mathrm{~cm}$ ( .4 by .8 inches)."

\section{REQUIREMENT SOURCE: 40CFR761 Part 60(a)(1) and (2)}

"(1) Except as provided in paragraphs (a)(2), (3), (4), and (5) of this section, PCBs at concentrations of $50 \mathrm{ppm}$ or greater must be disposed of in an incinerator which complies with 761.70 . 
(2) Mineral oil dielectric fluid from PCB-Contaminated Electrical Equipment containing a PCB concentration of $50 \mathrm{ppm}$ or greater, but less than $500 \mathrm{ppm}$, must be disposed of in one of the following:

(i) In an incinerator that complies with 761.70 ;

(ii) In a chemical waste landfill that complies with 761.75 if information is provided to the owner or operator of the chemical waste landfill that shows that the mineral oil dielectric fluid does not exceed 500 ppm PCB and is not an ignitable waste as described in 761.75(b)(8)(iii);"

\section{REQUIREMENT SOURCE: 40CFR761 Part 60(a)(2)(iii)(D)(3)}

"Liquids, other than mineral oil dielectric fluid, containing a PCB concentration of $50 \mathrm{ppm}$ or greater, but less than $500 \mathrm{ppm}$, shall be disposed of:

(i) In an incinerator which complies with 761.70 ;

(ii) In a chemical waste landfill which complies with 761.75 if information is provided to the owner or operator of the chemical waste landfill that shows that the waste does not exceed 500 ppm PCB and is not an ignitable waste as described in 761.75(b)(8)(iii);

\section{REQUIREMENT SOURCE: 40CFR761 Part 60(a)(2)(iii)(D)(3)(iii)(E)(4)}

"Any non-liquid PCBs at concentrations of $50 \mathrm{ppm}$ or greater in the form of contaminated soil, rags, or other debris shall be disposed of:

(i) In an incinerator which complies with 761.70 ; or

(ii) In a chemical waste landfill which complies with 761.75 .

Note: Except as provided in $761.75(\mathrm{~b})(8)$ (ii), liquid PCBs shall not be processed into non-liquid forms to circumvent the high temperature incineration requirements of 761.60(a)."

REQUIREMINT SOURCE: 40CFR761 Part 60(a)(2)(iii)(D)(3)(iii)(E)(6)

"When storage is desired prior to disposal, PCBs at concentrations of $50 \mathrm{ppm}$ or greater shall be stored in a facility which complies with 761.65."

\section{REQUIREMINT SOURCE: 40CFR761 Part 60(b)}

"PCB Articles-

(1) Transformers.

(i) PCB Transformers shall be disposed of in accordance with either of the following:

(A) In an incinerator that complies with 761.70 ; or

(B) In a chemical waste landfill which complies with 761.75 ; Provided That the transformer is first drained of all free flowing liquid filled with solvent, allowed to stand for at least 18 hours and then drained thoroughly. PCB liquids that are removed shall be disposed of in accordance with paragraph (a) of this section. Solvents may include kerosene xylene, toluene and other solvents in which PCBs are readily soluble. Precautionary measures should be taken however, that the solvent flushing procedure is conducted in accordance with applicable safety and health standards as required by Federal or State regulations.

(ii) [Reserved] 
(2) PCB Capacitors.

(i) The disposal of any capacitor shall comply with all requirements of this subpart unless it is known from label or nameplate information manufacturer's literature (including documented communications with the manufacturer) or chemical analysis that the capacitor does not contain PCBs.

(ii) Any person may dispose of PCB Small Capacitors as municipal solid waste unless that person is subject to the requirements of paragraph (b)(2)(iv) of this section.

(iii) Any PCB Large High or Low Voltage Capacitor which contains 500 ppm or greater PCBs owned by any person, shall be disposed of in accordance with either of the following:

(A) Disposal in an incinerator that complies with 761.70 ; or

(B) Until March 1 1981, disposal in a chemical waste landfill that complies with 761.75 .

(iv) Any PCB Small Capacitor owned by any person who manufactures or at any time manufactured PCB Capacitors or PCB Equipment and acquired the PCB Capacitors in the course of such manufacturing shall be disposed of in accordance with either of the following:

(A) Disposal in an incinerator which complies with 761.70 ; or

(B) Until March 1 1981, disposal in a chemical waste landfill which complies with 761.75 .

(v) Notwithstanding the restrictions imposed by paragraph (b)(2)(iii)(B) or (b)(2)(iv)(B) of this section PCB capacitors may be disposed of in PCB chemical waste landfills that comply with 761.75 subsequent to March 1, 1981, if the Assistant Administrator for Prevention Pesticides and Toxic Substances publishes a notice in the Federal Register declaring that those landfills are available for such disposal and explaining the reasons for the extension or reopening. An extension or reopening for disposal of PCB capacitors that is granted under this subsection shall be subject to such terms and conditions as the Assistant Administrator may prescribe and shall be in effect for such period as the Assistant Administrator may prescribe. The Assistant Administrator may permit disposal of PCB capacitors in EPA approved chemical waste landfills after March 1 1981, if in his opinion,

(A) Adequate incineration capability for PCB capacitors is not available or

(B) The incineration of PCB capacitors will significantly interfere with the incineration of liquid PCBs or

(C) There is other good cause shown.

As part of this evaluation the Assistant Administrator will consider the impact of his action on the incentives to construct or expand PCB incinerators.

(vi) Prior to disposal in a 761.75 chemical waste landfill, all large PCB capacitors and all small PCB capacitors described in paragraph (b)(2)(iv) of this section shall be placed in one of the Department of Transportation specification containers identified in $761.65(\mathrm{c})(6)$ or in containers that comply with 49 CFR 178.118 (specification $17 \mathrm{H}$ containers). Large PCB capacitors which are too big to fit inside one of these containers shall be placed in a container with strength and durability equivalent to the DOT specification containers. In all cases interstitial space in the container shall be filled with sufficient absorbent material (such as sawdust or soil) to absorb any liquid PCBs remaining in the capacitors.

(3) PCB hydraulic machines. PCB hydraulic machines containing PCBs at concentrations of $50 \mathrm{ppm}$ or greater such as die casting machines may be disposed of as municipal solid waste or 
salvage provided that the machines are drained of all free-flowing liquid and the liquid is disposed of in accordance with the provisions of paragraph (a) of this section. If the PCB liquid contains $1000 \mathrm{ppm}$ PCB or greater then the hydraulic machine must be flushed prior to disposal with a solvent containing less than $50 \mathrm{ppm}$ PCB under transformer solvents at paragraph (b)(1)(i)(B) of this section and the solvent disposed of in accordance with paragraph (a) of this section.

(4) PCB-Contaminated Electrical Equipment. All PCB-Contaminated Electrical Equipment except capacitors shall be disposed of by draining all free flowing liquid from the electrical equipment and disposing of the liquid in accordance with paragraph (a)(2) or (3) of this section. The disposal of the drained electrical equipment is not regulated by this rule. Capacitors that contain between 50 and 500 ppm PCBs shall be disposed of in an incinerator that complies with 761.70 or in a chemical waste landfill that complies with 761.75 .

(5) Other PCB Articles.

(i) PCB articles with concentrations at 500 ppm or greater must be disposed of:

(A) In an incinerator that complies with 761.70 ; or

(B) In a chemical waste landfill that complies with 761.75 , provided that all free-flowing liquid PCBs have been thoroughly drained from any articles before the articles are placed in the chemical waste landfill and that the drained liquids are disposed of in an incinerator that complies with 761.70 .

(ii) PCB Articles with a PCB concentration between 50 and 500 ppm must be disposed of by draining all free flowing liquid from the article and disposing of the liquid in accordance with paragraph (a)(2) or (3) of this section. The disposal of the drained article is not regulated by this rule.

(6) Storage of PCB Articles. Except for a PCB Article described in paragraph (b)(2)(ii) of this section and hydraulic machines that comply with the municipal solid waste disposal provisions described in paragraph (b)(3) of this section any PCB Article, with PCB concentrations at 50 ppm or greater shall be stored in accordance with 761.65 prior to disposal."

\section{REQUIREMENT SOURCE: 40CFR761 Part 60(c)}

"PCB Containers.

(1) Unless decontaminated in compliance with $\$ 761.79$ or as provided in paragraph (c)(2) of this section, a PCB container with PCB concentrations at 500 ppm or greater shall be disposed of:

(i) In an incinerator which complies with $\$ 761.70$, or

(ii) In a chemical waste landfill that complies with $\$ 761.75$; provided that if there are PCBs in a liquid state the PCB Container shall first be drained and the PCB liquid disposed of in accordance with paragraph (a) of this section.

(2) Any PCB Container used to contain only PCBs at a concentration less than 500 ppm shall be disposed of as municipal solid wastes; provided that if the PCBs are in a liquid state the PCB Container shall first be drained and the PCB liquid shall be disposed of in accordance with paragraph (a) of this section.

(3) Prior to disposal a PCB container with PCB concentrations at 50 ppm or greater shall be stored in a facility which complies with $\$ 761.65 . "$ 


\section{REQUIREMENT SOURCE: 40CFR761 Part 65(c)(1)}

"The following PCB Items may be stored temporarily in an area that does not comply with the requirements of paragraph (b) of this section for up to thirty days from the date of their removal from service, provided that a notation is attached to the PCB Item or a PCB Container (containing the item) indicating the date the item was removed from service:

(i) Non-leaking PCB Articles and PCB Equipment;

(ii) Leaking PCB Articles and PCB Equipment if the PCB Items are placed in a non-leaking PCB Container that contains sufficient sorbent materials to absorb any liquid PCBs remaining in the PCB Items;

(iii) PCB Containers containing non-liquid PCBs such as contaminated soil, rags, and debris; and

(iv) PCB Containers containing liquid PCBs at a concentration between 50 and $500 \mathrm{ppm}$, provided a Spill Prevention, Control and Countermeasure Plan has been prepared for the temporary storage area in accordance with 40 CFR Part 112. In addition, each container must bear a notation that indicates that the liquids in the drum do not exceed 500 ppm PCB."

\section{REQUIREMENT SOURCE: 40CFR761 Part 65(c)(2)}

"Non-leaking and structurally undamaged PCB Large High Voltage Capacitors and PCB-Contaminated Electrical Equipment that have not been drained of free flowing dielectric fluid may be stored on pallets next to a storage facility that meets the requirements of paragraph (b) of this section. PCB-Contaminated Electrical Equipment that has been drained of free flowing dielectric fluid is not subject to the storage provisions of 761.65. Storage under this subparagraph will be permitted only when the storage facility has immediately available unfilled storage space equal to 10 percent of the volume of capacitors and equipment stored outside the facility. The capacitors and equipment temporarily stored outside the facility shall be checked for leaks weekly."

\section{REQUIREMENT SOURCE: 40CFR761 Part 65(c)(3)}

"Any storage area subject to the requirements of paragraph (b) or paragraph (c)(1) of this section shall be marked as required in subpart C -- 761.40(a)(10)."

\section{REQUIREMENT SOURCE: 40CFR761 Part 65(c)(4)}

"No item of movable equipment that is used for handling PCBs and PCB Items in the storage facilities and that comes in direct contact with PCBs shall be removed from the storage facility area unless it has been decontaminated as specified in 761.79."

\section{REQUIREMENT SOURCE: 40CFR761 Part 65(c)(5)}

"All PCB Articles and PCB Containers in storage shall be checked for leaks at least once every 30 days. Any leaking PCB Articles and PCB Containers and their contents shall be transferred immediately to properly marked non-leaking containers. Any spilled or leaked materials shall be immediately cleaned up, using sorbents or other adequate means, and the PCB-contaminated materials and residues shall be disposed of in accordance with 761.60(a)(4). " 


\section{REQUIREMENT SOURCE: 40CFR761 Part 65(c)(6)}

"Except as provided in paragraph (c)(7) of this section, any container used for the storage of liquid PCBs shall comply with the Shipping Container Specification of the Department of Transportation (DOT), 49 CFR 178.80 (Specification 5 container without removable head), 178.82 (Specification 5B container without removable head), 178.102 (Specification 6D overpack with Specification 2 S(178.35) or 2SL(178.35a) polyethylene containers) or 178.116 (Specification 17E container). Any container used for the storage of non-liquid PCBs shall comply with the specifications of 49 CFR 178.80 (Specification 5 container), 178.82 (Specification 5B container) or 178.115 (Specification 17C container). As an alternate, containers larger than those specified in DOT Specifications 5, 5B, or 17C may be used for non-liquid PCBs if the containers are designed and constructed in a manner that will provide as much protection against leaking and exposure to the environment as the DOT Specification containers, and are of the same relative strength and durability as the DOT Specification containers."

\section{REQUIREMENT SOURCE: 40CFR761 Part 65(c)(7)}

"Storage containers for liquid PCBs can be larger than the containers specified in paragraph (c)(6) of this section provided that:

(i) The containers are designed, constructed, and operated in compliance with Occupational Safety and Health Standards, 29 CFR 1910.106, Flammable and combustible liquids. Before using these containers for storing PCBs, the design of the containers must be reviewed to determine the effect on the structural safety of the containers that will result from placing liquids with the specific gravity of PCBs into the containers (see 29 CFR 1910.106(b)(1)(i)(f)).

(ii) The owners or operators of any facility using containers described in paragraph (c)(7)(i) of this section, shall prepare and implement a Spill Prevention Control and Countermeasure (SPCC) Plan as described in Part 112 of this title. In complying with 40 CFR Part 112, the owner or operator shall read "oil(s)" as "PCB(s)" whenever it appears. The exemptions for storag capacity, 40 CFR 112.1(d)(2), and the amendment of SPCC plans by the Regional Administrator, 40 CFR 112.4, shall not apply unless some fraction of the liquids stored in the container are oils as defined by section 311 of the Clean Water Act."

\section{REQUIREMENT SOURCE: 40CFR761 Part 65(c)(8)}

"PCB Articles and PCB Containers shall be dated on the article or container when they are placed in storage. The storage shall be managed so that the PCB Articles and PCB Containers can be located by the date they entered storage. Storage containers provided in paragraph (c)(7) of this section, shall have a record that includes for each batch of PCBs the quantity of the batch and date the batch was added to the container. The record shall also include the date, quantity, and disposition of any batch of PCBs removed from the container."

\section{REQULREMENT SOURCE: 40CFR761 Part 65(c)(9)}

"Owners or operators of storage facilities shall establish and maintain records as provided in 761.180."

\section{TRANSPORTATION}

Waste transportation regulations are covered in the Packaging and Transportation Functional Area and will not be repeated here. 
This element specifies the requirements for plans, records, and reporting applicable to waste generated, stored, treated, shipped, and disposed. In addition, requirements for waste minimization, manifesting, facility record keeping, and test results are included. Plans and record keeping for environmental monitoring and releases are included in the Environmental Protection Functional Area.

TRU Waste

\section{REQUIREMENT SOURCE: DOE5820.2A Chapter II, Section 3.e(6)}

"Facilities which store transuranic waste shall have a contingency plan designed to minimize the adverse impacts of fire, explosion, or accidental release of hazardous components of the waste to the environment. "

\section{Low-Level Radioactive Waste}

\section{REQUIREMENT SOURCE: DOE5820.2A Chapter III, Section 3.c(2)}

"Waste Generation Reduction. All DOE-low-level waste generators shall establish auditable programs (goals, incentives, procedures, and reports) to assure that the amount of low-level waste generated and/or shipped for disposal is minimized."

\section{REQUIREMENT SOURCE: DOE5820.2A Chapter III, Section 3.m(1)}

"Records and Reports

(1) Each field organization shall develop and maintain a record keeping system that records the following: a historical record of waste generated, treated, stored, shipped, disposed of, or both, at the facilities under its cognizance. The data maintained shall include all data necessary to show that the waste was properly classified, treated, stored, shipped, and/or disposed of. The data maintained in the system shall be based on the data recorded on waste manifests."

\section{REQUIREMENT SOURCE: DOE5820.2A Chapter III, Section 3.m(2)}

"Waste Manifest. Records shall be kept and accompany each waste package from generator through final disposal. The manifest shall contain data necessary to document the proper classification, and assist in determining proper treatment, storage, and disposal of the waste. Waste manifests will be kept as permanent records. At a minimum, the following data will be included:

(a) Waste physical and chemical characteristics,

(b) Quantity of each major radionuclide present,

(c) Weight of the waste (total of waste and any solidification or absorbent media),

(d) Volume of waste (total of waste and any solidification or absorbent media), and

(e) Other data necessary to demonstrate compliance with waste acceptance criteria."

\section{Mixed/Dangerous Waste}

Contingency planning per WAC-173-303-350 is covered in the Emergency Management Functional Area. Dangerous Waste Management Records and Closure Plans are covered in this subelement. 


\section{REQUIREMENT SOURCE: 40CFR761 Part 180(a)}

"This section contains recordkeeping and reporting requirements that apply to PCBs, PCB Items, and PCB storage and disposal facilities that are subject to the requirements of the part.

(a) PCBs and PCB Items in service or projected for disposal. Beginning February 5, 1990, each owner or operator of a facility, other than a commercial storer or a disposer of PCB waste, using or storing at any one time at least 45 kilograms (99.4 pounds) of PCBs contained in PCB Container(s), or one or more PCB Transformers, or 50 or more PCB Large High or Low Voltage Capacitors shall develop and maintain at the facility, or a central facility provided they are maintained at that facility, all annual records and the written annual document log of the disposition of PCBs and PCB Items. The written annual document log must be prepared for each facility by July 1 covering the previous calendar year (January through December). The annual document log shall be maintained for at least 3 years after the facility ceases using or storing PCBs and PCB Items in the quantities prescribed in this paragraph. Annual records (manifests and certificates of disposal) shall be maintained for the same period. The annual records and the annual document $\log$ shall be available for inspection at the facility where they are maintained by authorized representatives of EPA during normal business hours, and each owner or operator of a facility subject to these requirements shall know the location of these records. All records and annual documents required to be prepared and maintained by this section prior to February 5, 1990 shall continue to be maintained at the facility for the same time as the annual records and the annual document log. The annual document required for 1989 shall cover the period from January 1, 1989 to February 5, 1990.

(1) The annual records shall include the following:

(i) All signed manifests generated by the facility during the calendar year.

(ii) All Certificates of Disposal that have been received by the facility during the calendar year.

(2) The written annual document log shall include the following:

(i) The name, address, and EPA identification number of the facility covered by the annual document $\log$ and the calendar year covered by the annual document log.

(ii) The unique manifest number of every manifest generated by the facility during the calendar year, and from each manifest and for unmanifested waste that may be stored at the facility, the following information:

(A) For bulk PCB waste (e.g., in a tanker or truck), its weight in kilograms, the first date it was removed from service for disposal, the date it was placed into transport for off-site storage or disposal, and the date of disposal, if known.

(B) The serial number (if available) or other means of identifying each PCB Article (e.g., transformer or capacitor), the weight in kilograms of the PCB waste in each transformer or capacitor, the date it was removed from service for disposal, the date it was placed in transport for off-site storage or disposal, and the date of disposal, if known.

(C) A unique number identifying each PCB Container, a description of the contents of each PCB Container, such as liquid, soil, cleanup debris, etc., including the total weight of the material in kilograms in each PCB Container, the first date material placed in each PCB Container was removed from service for disposal, and the date each PCB Container was placed in transport for off-site storage or disposal, and the date of disposal (if known). 
(D) A unique number identifying each PCB Article Container, a description of the contents of each PCB Article Container, such as pipes, capacitors, electric motors, pumps, etc., including the total weight in kilograms of the content of each PCB Article Container, the first date a PCB Article placed in each PCB Article Container was removed from service for disposal, and the date the PCB Article Container was placed in transport for off-site storage or disposal, and the date of disposal (if known.)

(iii) The total number by specific type of PCB Articles and the total weight in kilograms of PCBs in PCB Articles, the total number of PCB Article Containers and total weight in kilograms of the contents of PCB Article Containers, the total number of PCB Containers and the total weight in kilograms of the contents of PCB Containers, and the total weight in kilograms of bulk PCB waste that was placed into storage for disposal or disposed during the calendar year.

(iv) The total number of PCB Transformers and total weight in kilograms of PCBs contained in the transformers remaining in service at the end of the calendar year.

(v) The total number of Large High or Low Voltage PCB Capacitors remaining in service at the end of the calendar year.

(vi) The total weight in kilograms of any PCBs and PCB Items in PCB Containers, including the identification of container contents, remaining in service at the facility at the end of the calendar year.

(vii) For any PCBs or PCB item received from or shipped to another facility owned or operated by the same generator, the information required under paragraph (a)(2)(ii)(A) through (a)(2)(ii)(D) of this section.

(viii) A record of each telephone call, or other means of verification agreed upon by both parties, made to each designated commercial storer or designated disposer to confirm receipt of PCB waste transported by an independent transporter, as required by 761.208."

\section{REQUIREMENT SOURCE: TPA Part Five, Article XXXVI, Section 113}

"Each Party to this Agreement shall preserve for a minimum of ten (10) years after termination of this Agreement all of the records in its or its contractors possession related to sampling, analysis, investigations, and monitoring conducted in accordance with this Agreement. After this ten year period, DOE shall notify the EPA and Ecology at least forty-five (45) days prior to destruction or disposal of any such records. Upon request, the Parties shall make such records or true copies available, to the other Parties subject to Article XLV (Classified and Confidential Information)."

\section{REQUIREMENT SOURCE: WAC-173-303(940523) Section 060(1)}

"Any person who generates, transports, offers for transport, or transfers a dangerous waste, or who owns or operates a dangerous waste TSD facility shall have a current EPA/state identification number (EPA/state ID number). Any person who offers a dangerous waste to a transporter or to a dangerous waste TSD facility which does not have an EPA/state ID number, or whose EPA/state ID number has been cancelled or withdrawn, shall be in violation of this regulation."

REQUIREMENT SOURCE: WAC-173-303(940523) Section 060(5)

"Any person with a current EPA/state ID number must submit an annual report as required by WAC 173-303-070, 173-303-220, and 173-303-390. Any person that has withdrawn or 
cancelled their ID number and received confirmation from the department must submit an annual report for the calendar year in which their request was approved."

\section{REQUIREMENT SOURCE: WAC-173-303(940523) Section 210(1)}

"The generator shall keep a copy of each manifest signed by the initial transporter in accordance with WAC 173-303-180 (3), manifest procedures, for three years, or until he receives a signed copy from the designated facility which received the waste. The signed facility copy shall be retained for at least five years from the date the waste was accepted by the initial transporter."

\section{REQUIREMENT SOURCE: WAC-173-303(940523) Section 210(2)}

"The generator shall keep a copy of each annual report and exception report as required by WAC 173-303-220 for a period of at least five years from the due date of each report. The generator shall keep a copy of his most recent notification (Form 2) until he is no longer defined as a generator under this chapter."

\section{REQUIREMINT SOURCE: WAC-173-303(940523) Section 210(3)}

"Waste designation records.

(a) The generator shall keep records of any test results, waste analyses, or other determinations made in accordance with WAC 173-303-170 (1) for designating dangerous waste for at least five years from the date that the waste was last transferred for on-site or off-site treatment, storage, or disposal.

(b) At a minimum, test results must include:

(i) The sample source, sampling date, and sampling procedure used;

(ii) The laboratory performing the test;

(iii) The testing date, and testing method used;

(iv) The analytical result, or the quantitative range of the testing method for analytes not detected."

\section{REQUIREMENT SOURCE: WAC-173-303(940523) Section 210(4)}

"Any other records required for generators accumulating wastes on-site as described in WAC 173-303-170 (4)(b) or 173-303-200 must be retained for at least five years, including, but not limited to such items as inspection logs."

\section{REQUIREMENT SOURCE: WAC-173-303(940523) Section 210(5)}

"The periods of retention for any records described in this section shall be automatically extended during the course of any unresolved enforcement action requiring those records or upon request by the director."

\section{REQUIREMENT SOURCE: WAC-173-303(940523) Section 210(0)}

"All generator records, including plans required by this chapter, shall be made available and furnished upon request by the director."

REQUIREMENT SOURCE: WAC-173-303(940523) Section 220(1)

"Annual reports. 
(a) A generator or any person who has obtained an EPA/state identification number pursuant to WAC 173-303-060 shall submit an annual report to the department, on the Generator Annual Dangerous Waste Report - Form 4 according to the instructions on the form (copies are available from the department), no later than March 1 for the preceding calendar year.

(b) In addition, any generator who stores, treats, or disposes of dangerous waste on-site shall comply with the annual reporting requirements of WAC 173-303-390, Facility reporting."

\section{REQUIREMENT SOURCE: WAC-173-303(940523) Section 380(1)}

"Operating record. The owner or operator of a facility shall keep a written operating record at his facility. The following information shall be recorded, as it becomes available, and maintained in the operating record until closure of the facility:

(a) A description of and the quantity of each dangerous waste received or managed on-site, and the method(s) and date(s) of its treatment, storage, or disposal at the facility as required by subsection (2) of this section, recordkeeping instructions;

(b) The location of each dangerous waste within the facility and the quantity at each location. For disposal facilities, the location and quantity of each dangerous waste must be recorded on a map or diagram of each cell or disposal area. For all facilities, this information must include cross-references to specific manifest document numbers, if the waste was accompanied by a manifest;

(c) Records and results of waste analyses required by WAC 173-303-300, General waste analysis;

(d) Summary reports and details of all incidents that require implementing the contingency plan, as specified in WAC 173-303-360 (2)(k);

(e) Records and results of inspections as required by WAC 173-303-320 (2)(d), General inspection (except such information need be kept only for five years);

(f) Monitoring, testing, or analytical data, and corrective action where required by $40 \mathrm{CFR}$ Part 265 Subparts F through R for interim status facilities, and by WAC 173-303-630 through 173-303-680 for final status facilities;

(g) All closure and post-closure cost estimates required for the facility; and

(h) For off-site facilities, copies of notices to generators informing them that the facility has all appropriate permits, as required by WAC 173-303-290, Required notices."

\section{REQUIREMENT SOURCE: WAC-173-303(940523) Section 380(2) Introduction}

"Recordkeeping instructions. This paragraph provides instructions for recording the portions of the operating record which are related to describing the types, quantities, and management of dangerous wastes at the facility. This information shall be kept in the operating record, as follows:"

\section{REQUIREMINT SOURCE: WAC-173-303(940523) Section 380(2)(a)}

"Each dangerous waste received or managed shall be described by its common name and by its dangerous waste number(s) from WAC 173-303-080 through 173-303-104. Where a dangerous waste contains more than one process waste or waste constituent the waste description must include all applicable dangerous waste numbers. If the dangerous waste 
number is not listed then the waste description shall include the process which generated the waste;"

REQUIREMENT SOURCE: WAC-173-303(940523) Section 380(2)(b)

"The waste description shall include the waste's physical form (i.e., liquid, solid, sludge, or gas);"

\section{REQUIREMINT SOURCE: WAC-173-303(940523) Section 380(2)(c)}

"The weight, or volume and density, of the dangerous waste shall be recorded, using one of the units of measure specified in Table $1, \ldots$ "

\section{REQUIREMENT SOURCE: WAC-173-303(940523) Section 380(2)(d)}

"And, the date(s) and method(s) of management for each dangerous waste received or managed (treated, recycled, stored, or disposed of) shall be recorded, using the handling code(s) specified in Table $2, \ldots$ ".

\section{REQUIREMENT SOURCE: WAC-173-303(940523) Section 390(1)}

"Unmanifested waste reports. If a facility accepts any dangerous waste from an off-site source without an accompanying manifest or shipping paper, and if the waste is not excluded from the manifest requirements of this chapter 173-303 WAC, then the owner or operator must prepare and submit a single copy of a report to the department within fifteen days after receiving the waste. The report form and instructions in the Unmanifested Dangerous Waste Report - Form 6 (which may be obtained from the department) must be used for this report. The report must include at least the following information:

(a) The EPA/state identification number, name, and address of the facility;

(b) The date the facility received the waste;

(c) The EPA/state identification number, name, and address of the generator and the transporter, if available;

(d) A description and the quantity of each unmanifested dangerous waste the facility received;

(e) The method of management for each dangerous waste;

(f) The certification signed by the owner or operator of the facility or his authorized representative; and

(g) A brief explanation of why the waste was unmanifested, if known. "

\section{REQUIREMENT SOURCE: WAC-173-303(940523) Section 390(2)}

"Annual reports. The owner or operator of a facility that holds an active EPA/state identification number shall prepare and submit a single copy of an annual report to the department by March 1 of each year. The report form and instructions in the TSD Facility Annual Dangerous Waste Report - Form 5 (which may be obtained from the department) must be used for this report. In addition, any facility which ships dangerous waste off-site must comply with the annual reporting requirements of WAC 173-303-220. The annual report must 
cover facility activities during the previous calendar year and must include, but is not limited to the following information:

(a) The EPA/state identification number, name, and address of the facility;

(b) The calendar year covered by the report;

(c) For off-site facilities, the EPA/state identification number of each dangerous waste generator from which the facility received a dangerous waste during the year. For imported shipments, the report must give the name and address of the foreign generator;

(d) A description and the quantity of each dangerous waste the facility received during the year. For off-site facilities, this information must be listed by EPA/state identification number of each generator;

(e) The method of treatment, storage, or disposal for each dangerous waste;

(f) The most recent closure cost estimate under WAC 173-303-620 (3) (or 40 CFR 265.142 for interim status facilities), and for disposal facilities, the most recent post-closure cost estimate under WAC 173-303-620 (5) (or 40 CFR 265.144 for interim status facilities); and

(g) The certification signed in accordance with the requirements of WAC 173-303-810 (12)."

\section{REQUIREMINT SOURCE: WAC-173-303(940523) Section 390(3)}

"Additional reports. The owner or operator shall also report to the department releases of dangerous wastes, fires, and explosions as specified in WAC 173-303-360 (2)(k) and interim status groundwater monitoring data, as specified in 40 CFR 265.94 (a)(2) and (b)(2).

In addition, the owner or operator shall submit any other reports (including engineering reports, plans, and specifications) required by the department."

\section{REQUIREMINT SOURCE: WAC-173-303(940523) Section 390(4)}

"Recordkeeping. The owner/operator of a facility shall keep a copy of all unmanifested waste reports, anmual reports, and any other reports submitted to the department according to the requirements of this section for a period of three years from the date the report was submitted."

\section{REQUIREMINT SOURCE: WAC-173-303(940523) Section 610(3)}

"Closure plan; amendment of plan.

(a) The owner or operator of a dangerous waste management facility must have a written closure plan. In addition, certain surface impoundments and waste piles from which the owner or operator intends to remove or decontaminate the dangerous waste at partial or final closure are required by WAC 173-303-650 (6) and 173-303-660 (9) to have contingent closure plans. The plan must be submitted with the permit application, in accordance with WAC 173-303-806 (4), and approved by the department as part of the permit issuance procedures under WAC 173-303-840. The approved closure plan will become a condition of any permit. The department's decision must assure that the approved closure plan is consistent with subsections (2), (3), (4), (5), and (6) of this section, and the applicable requirements of WAC 173-303-630 (10), 173-303-640 (8), 173-303-645, 173-303-650 (6), 173-303-655 (8), 173-303-660 (9), 173-303-665 (6), 173-303-670 (8), and 173-303-680 (2). A copy of the approved plan and all revisions to the plan must be furnished to the department upon request, including request by mail until final closure is completed and certified in accordance with subsection (6) of this 
section. The plan must identify steps necessary to perform partial and/or final closure of the facility at any point during its active life. The closure plan must include at least:

(i) A description of how each dangerous waste management unit at the facility will be closed in accordance with subsection (2) of this section;

(ii) A description of how final closure of the facility will be conducted in accordance with subsection (2) of this section. The description must identify the maximum extent of the operation which will be unclosed during the active life of the facility;

(iii) An estimate of the maximum inventory of dangerous wastes ever on-site over the active life of the facility. (Any change in this estimate is a minor modification under WAC 173-303-830 (4));

(iv) A detailed description of the methods to be used during partial closures and final closure, including, but not limited to, methods for removing, transporting, treating, storing, or disposing of all dangerous wastes, and identification of the type(s) of the off-site dangerous waste management units to be used, if applicable;

(v) A detailed description of the steps needed to remove or decontaminate all dangerous waste residues and contaminated containment system components, equipment, structures, and soils during partial and final closure, including, but not limited to, procedures for cleaning equipment and removing contaminated soils, methods for sampling and testing surrounding soils, and criteria for determining the extent of decontamination required to satisfy the closure performance standard;

(vi) A detailed description of other activities necessary during the closure period to ensure that all partial closures and final closure satisfy the closure performance standards, including, but not limited to, ground water monitoring, leachate collection, and run-on and run-off control; and

(vii) A schedule for closure of each dangerous waste management unit and for final closure of the facility. The schedule must include, at a minimum, the total time required to close each dangerous waste management unit and the time required for intervening closure activities which will allow tracking of the progress of partial and final closure. (For example, in the case of a landfill unit, estimates of the time required to treat or dispose of all dangerous waste inventory and of the time required to place a final cover must be included.) Additionally, for facilities that use trust funds to establish financial assurance under WAC 173-303-620 (4) or (6) and that are expected to close prior to the expiration of the permit, an estimate of the expected year of final closure."

\section{REQUIREMENT SOURCE: WAC-173-303(940523) Section 610(3)(b)}

"The owner or operator must submit a written notification of or request for a permit modification to authorize a change in operating plans, facility design, or the approved closure plan in accordance with the applicable procedures in WAC 173-303-800 through 173-303-840. The written notification or request must include a copy of the amended closure plan for review or approval by the department."

\section{REQUIREMENT SOURCE: WAC-173-303(940523) Section 610(3)(b)(i)}

"The owner or operator may submit a written notification or request to the department for a permit modification to amend the closure plan at any time prior to the notification of partial or final closure of the facility." 
"The owner or operator must submit a written notification of or request for a permit modification to authorize a change in the approved closure plan whenever:

(A) Changes in operating plans or facility design affect the closure plan; or

(B) There is a change in the expected year of closure, if applicable; or

(C) In conducting partial or final closure activities, unexpected events require a modification of the approved closure plan."

\section{REQUIREMENT SOURCE: WAC-173-303(940523) Section 610(3)(b)(iii)}

"The owner or operator must submit a written request for a permit modification including a copy of the amended closure plan for approval at least sixty days prior to the proposed change in facility design or operation, or no later than sixty days after an unexpected event has occurred which has affected the closure plan. If an unexpected event occurs during the partial or final closure period, the owner or operator must request a permit modification no later than thirty days after the unexpected event. An owner or operator of a surface impoundment or waste pile that intends to remove all dangerous waste at closure and is not otherwise required to prepare a contingent closure plan under WAC 173-303-650 (6) or 173-303-660 (9), must submit an amended closure plan to the department no later than sixty days from the date that the owner or operator or department determines that the dangerous waste management unit must be closed as a landfill, subject to the requirements of WAC 173-303-665, or no later than thirty days from that date if the determination is made during partial or final closure. The department will approve, disapprove, or modify this amended plan in accordance with the procedures in WAC 173-303-800 through 173-303-840. The approved closure plan will become a condition of any permit issued."

\section{REQUIREMENT SOURCE: WAC-173-303(940523) Section 610(3)(b)(iv)}

"The department may request modifications to the plan under the conditions described in (b)(ii) of this subsection. The owner or operator must submit the modified plan within sixty days of the department's request, or within thirty days if the change in facility conditions occurs during partial or final closure. Any modifications requested by the department will be approved in accordance with the procedures in WAC 173-303-800 through 173-303-840."

\section{REQUIREMENT SOURCE: WAC-173-303(940523) Section 610(3)(c)(i)}

"The owner or operator must notify the department in writing at least sixty days prior to the date on which he expects to begin closure of a surface impoundment, waste pile, land treatment, or landfill unit, or final closure of a facility with such a unit. The owner or operator must notify the department in writing at least forty-five days prior to the date on which he expects to begin final closure of a facility with only treatment or storage tanks, container storage, or incinerator units to be closed."

\section{REQUIREMENT SOURCE: WAC-173-303(940523) Section 610(3)(c)(ii)}

"The date when he "expects to begin closure" must be either:

(A) No later than thirty days after the date on which any dangerous waste management unit receives the known final volume of dangerous wastes or, if there is a reasonable possibility that the dangerous waste management unit will receive additional dangerous wastes, no later than one year after the date on which the unit received the most recent volume of dangerous waste. If the owner or operator of a dangerous waste management unit can demonstrate to the 
department that the dangerous waste management unit or facility has the capacity to receive additional dangerous wastes and he has taken, and will continue to take, all steps to prevent threats to human health and the environment, including compliance with all applicable permit requirements, the department may approve an extension to this one-year limit; or

(B) For units meeting the requirements of subsection (4)(d) of this section, no later than thirty days after the date on which the dangerous waste management unit receives the known final volume of nondangerous wastes, or if there is a reasonable possibility that the dangerous waste management unit will receive additional nondangerous wastes, no later than one year after the date on which the unit received the most recent volume of nondangerous wastes. If the owner or operator can demonstrate to the department that the dangerous waste management unit has the capacity to receive additional nondangerous wastes and he has taken, and will continue to take, all steps to prevent threats to human health and the environment, including compliance with all applicable permit requirements, the department may approve an extension to this one-year limit."

\section{REQUIREMENT SOURCE: WAC-173-303(940523) Section 610(3)(c)(iii)}

"If the facility's permit is terminated, or if the facility is otherwise ordered, by judicial decree or final order to cease receiving dangerous wastes or to close, then the requirements of $(\mathfrak{c})$ of this subsection do not apply. However, the owner or operator must close the facility in accordance with the deadlines established in subsection (4) of this section."

\section{REQUIREMENT SOURCE: WAC-173-303(940523) Section 610(3)(c)(iv)}

"Removal of wastes and decontamination or dismantling of equipment. Nothing in this subsection shall preclude the owner or operator from removing dangerous wastes and decontaminating or dismantling equipment in accordance with the approved partial or final closure plan at any time before or after notification of partial or final closure."

\section{REQUIREMENT SOURCE: WAC-173-303(940523) Section 610(4)(a)}

"Within ninety days after receiving the final volume of dangerous wastes, or the final volume of nondangerous wastes if the owner or operator complies with all applicable requirements in (d) and (e) of this subsection, at a dangerous waste management unit or facility, the owner or operator must treat, remove from the unit or facility, or dispose of on site, all dangerous wastes in accordance with the approved closure plan. The department may approve a longer period if the owner or operator complies with all applicable requirements for requesting a modification to the permit and demonstrates that he has taken and will continue to take all steps to prevent threats to human health and the environment, including compliance with all applicable permit requirements, and either:

(i) The activities required to comply with this paragraph will, of necessity, take longer than ninety days to complete; or

(ii)(A) The dangerous waste management unit or facility has the capacity to receive additional dangerous wastes, or has the capacity to receive nondangerous wastes if the owner or operator complies with (d) and (e) of this subsection;

(B) There is a reasonable likelihood that he or another person will recommence operation of the dangerous waste management unit or the facility within one year; and

(C) Closure of the dangerous waste management unit or facility would be incompatible with continued operation of the site." 


\section{REQUIREMENT SOURCE: WAC-173-303(940523) Section 610(4)(b)}

"The owner or operator must complete partial and final closure activities in accordance with the approved closure plan and within one hundred eighty days after receiving the final volume of dangerous wastes, or the final volume of nondangerous wastes if the owner or operator complies with all applicable requirements in (d) and (e) of this subsection, at the dangerous waste management unit or facility. The department may approve an extension to the closure period if the owner or operator complies with all applicable requirements for requesting a modification to the permit and demonstrates that he has taken and will continue to take all steps to prevent threats to human health and the environment from the unclosed but not operating dangerous waste management unit or facility, including compliance with all applicable permit requirements, and either:

(i) The partial or final closure activities will, of necessity, take longer than one hundred eighty days to complete; or

(ii)(A) The dangerous waste management unit or facility has the capacity to receive additional dangerous wastes, or has the capacity to receive nondangerous wastes if the owner or operator complies with (d) and (e) of this subsection;

(B) There is reasonable likelihood that he or another person will recommence operation of the dangerous waste management unit or the facility within one year; and

(C) Closure of the dangerous waste management unit or facility would be incompatible with continued operation of the site."

\section{REQUIREMENT SOURCE: WAC-173-303(940523) Section 610(4)(c)}

"The demonstrations referred to in (a) and (b) of this subsection must be made as follows: The demonstrations in (a) of this subsection must be made at least thirty days prior to the expiration of the specified ninety-day period; and the demonstration in (b) of this subsection must be made at least thirty days prior to the expiration of the specified one hundred eighty-day period unless the owner or operator is otherwise subject to the deadlines in (d) of this subsection."

\section{REQUIREMENT SOURCE: WAC-173-303(940523) Section 610(4)(d)}

"The department may allow an owner or operator to receive only nondangerous wastes in a landfill, land treatment, or surface impoundment unit after the final receipt of dangerous wastes at that unit if:

(i) The owner or operator requests a permit modification in compliance with all applicable requirements in WAC 173-303-830 and 40 CFR Part 124 and in the permit modification request demonstrates that:

(A) The unit has the existing design capacity as indicated on the part A application to receive nondangerous wastes; and

(B) There is a reasonable likelihood that the owner or operator or another person will receive nondangerous wastes in the unit within one year after the final receipt of dangerous wastes; and

(C) The nondangerous wastes will not be incompatible with any remaining wastes in the unit, or with the facility design and operating requirements of the unit or facility under this part; and 
(D) Closure of the dangerous waste management unit would be incompatible with continued operation of the unit or facility; and

(E) The owner or operator is operating and will continue to operate in compliance with all applicable permit requirements; and

(ii) The request to modify the permit includes an amended wastes analysis plan, ground water monitoring and response program, human exposure assessment required under RCRA section 3019 , and closure and postclosure plan, and updated cost estimates and demonstrations of financial assurance for closure and postclosure care as necessary and appropriate, to reflect any changes due to the presence of dangerous constituents in the nondangerous wastes, and changes in closure activities, including the expected year of closure if applicable under subsection (3)(a)(vii) of this section, as a result of the receipt of nondangerous wastes following the final receipt of dangerous wastes; and

(iii) The request to modify the permit includes revisions, as necessary and appropriate, to affected conditions of the permit to account for the receipt of nondangerous wastes following receipt of the final volume of dangerous wastes; and

(iv) The request to modify the permit and the demonstration referred to in (d)(i) and (ii) of this subsection are submitted to the department no later than one hundred twenty days prior to the date on which the owner or operator of the facility receives the known final volume of dangerous wastes at the unit, or no later than ninety days after the effective date of this rule in the state in which the unit is located, whichever is later."

\section{REQUIREMENT SOURCE: WAC-173-303(940523) Section 610(5)}

"Disposal or decontamination of equipment, structures and soils. During the partial and final closure periods, all contaminated equipment, structures and soils must be properly disposed of or decontaminated unless otherwise specified in WAC 173-303-640 (8), 173-303-650 (6), 173-303-655 (8), 173-303-660 (9), 173-303-665 (6), or under the authority of WAC 173-303-680 (2) and (4). By removing any dangerous wastes or dangerous constituents during partial and final closure, the owner or operator may become a generator of dangerous waste and must handle that waste in accordance with all applicable requirements of WAC 173-303-170 through 173-303-230."

16.5

16.6

$\underline{16.6 .1}$

\section{PERMITTING}

Permitting regulations are covered in the Environmental Protection Functional Area and will not be repeated here.

WASTE ACCEPTANCE CRITERIA

TRU Waste

\section{REQUIREMENT SOURCE: DOE5820.2A Chapter II, Section 3.d}

"Transuranic Waste Packaging.

(1) Newly generated transuranic waste shall be placed in noncombustible packaging that meets DOT requirements.

(2) All Type A transuranic waste containers shall be equipped with a method to prevent pressure buildup. Acceptable pressure-relief devices include permeable gaskets, vent clips, and filtered vents. 
(3) The waste packages shall be marked, labeled, and sealed in accordance with the Waste Isolation Pilot Plant-Waste Acceptance Criteria, EPA, and DOT requirements, as defined in the WIPP-DOE-069, 40 CFR 262, Subpart C, and 49 CFR 172, Subparts D, E, and 49 CFR 173 , Subpart I, where applicable, prior to shipping."

\section{Low-Level Radioactive Waste}

\section{REQUIREMENT SOURCE: DOE5820.2A Chapter III, Section 3.e(2)}

"Waste acceptance criteria shall be established for each low-level waste treatment, storage, and disposal facility, and submitted to the cognizant field organization."

\section{REQUIREMENT SOURCE: DOE5820.2A Chapter III, Section 3.e(4)}

"Generator low-level waste certification programs shall be subject to a periodic audit by operators of facilities to which the waste is sent by the generator."

\section{REQUIREMENT SOURCE: DOE5820.2A Chapter III, Section 3.e(5)}

"The waste acceptance criteria for storage, treatment, or disposal facilities shall address the following issues:

(a) Allowable quantities/concentrations of specific radioisotopes to be handled, processed, stored, or disposed of;

(b) Criticality safety requirements (waste forms and geometries);

(c) Restrictions regarding low-level waste classified for security reasons;

(d) External radiation and internal heat generation;

(e) Restrictions on the generation of harmful gases, vapors, or liquids in waste;

(f) Chemical and structural stability of waste packages, radiation effects, microbial activity, chemical reactions, and moisture;

(g) Restrictions for chelating and complexing agents having the potential for mobilizing radionuclides; and

(h) Quantity of free liquids."

\section{Mixed/Dangerous Waste}

\section{REQUIREMENT SOURCE: 40CFR268(940701) Part 40(a)}

"A waste identified in the table "Treatment Standards for Hazardous Wastes" may be land disposed only if it meets the requirements found in the table. For each waste, the table identifies one of three type of treatment standard requirements:

(1) All hazardous constituents in the waste or in the treatment residue must be at or below the values found in the table for that waste (total waste standards"); or

(2) The hazardous constituents in the extract of the waste or in the extract of the treatment residue must be at or below the values found in the table ("waste extract standards"); or 
(3) The waste must be treated using the technology specified in the table ("technology standard"), which are described in detail in $\S 268.42$, Table 1--Technology Codes and Description of Technology-Based Standards."

\section{REQUIREMENT SOURCE: 40CFR268(940701) Part 40(b)}

"For wastewaters, compliance with concentration level standards is based on maximum for any one day, except for D004 through D011 wastes for which the previously promulgated treatment standards based on grab samples remain in effect. For all nonwastewaters, compliance with concentration level standards is based on grab sampling. For wastes covered by the waste extract standards, the test Method 1311, the Toxicity Characteristic Leaching Procedure found in "Test Methods for Evaluating Sold Waste, Physical/Chemical Methods", EPA Publication SW-846, as incorporated by reference in $\S 260.11$, must be used to measure compliance. An exception is made for D004 and D008, for which either of two test methods may be used: Method 1311, or Method 1310, the Extraction Procedure Toxicity Test. For wastes covered by a technology standard, the wastes may be land disposed after being treated using that specified technology or an equivalent treatment technology approved by the Administrator under the procedures set forth in $\S 268.42(b)$. "

\section{REQUIREMENT SOURCE: 40CFR268(940701) Part 40(c)}

"When wastes with differing treatment standards for a constituent of concern are combined for purposes of treatment, the treatment residue must meet the lowest treatment standard for the constituent of concern."

\section{REQUIREMENT SOURCE: 40CFR268(940701) Part 40(e)}

"For characteristic wastes (D001, D002, and D012-D043 that are subject to treatment standards in the following table "Treatment Standards for Hazardous Wastes," all underlying hazardous constituents (as defined in 267.2(i)) must meet Universal Treatment Standards, found in 268.48, Table UTS, prior to land disposal."

\section{REQUIREMENT SOURCE: 40CFR268(940701) Part 40(f)}

"The treatment standards for F001-F005 nonwastewater constituents carbon disulfide, cyclohexanone, and/or methanol apply to wastes which contain only one, two, or three of these constituents. Compliance is measured for these constituents in the waste extract from test Method 1311, the Toxicity Characteristic Leaching Procedure found in "Test Methods for Evaluating Solid Waste, Physical/Chemical Methods", EPA Publication SW-846, as incorporated by reference in 260.11 . If the waste contains any of these three constituents along with any of the other 25 constituents found in F001-F005, then compliance with treatment standards for carbon disulfide, cyclohexanone, and/or methanol are not required."

PCB Waste

\section{REQUIREMENT SOURCE: 40CFR761 Part 79}

"(a) Any PCB Container to be decontaminated shall be decontaminated by flushing the internal surfaces of the container three times with a solvent containing less than 50 ppm PCB. The solubility of PCBs in the solvent must be five percent or more by weight. Each rinse shall use a volume of the normal diluent equal to approximately ten (10) percent of the PCB Container capacity. The solvent may be reused for decontamination until it contains $50 \mathrm{ppm}$ PCB. The solvent shall then be disposed of as a PCB in accordance with 761.60(a). Non-liquid PCBs 
resulting from the decontamination procedures shall be disposed of in accordance with the provisions of 761.60(a)(4).

(b) Movable equipment used in storage areas shall be decontaminated by swabbing surfaces that have contacted PCBs with a solvent meeting the criteria of paragraph (a) of this section."

16.7

\section{WASTE MINIMIZATION}

\section{REQUIREMENT SOURCE: DOE5820.2A Chapter II, Section 3.b(1)}

"Transuranic Waste Generation and Treatment

(1) Technical and administrative controls shall be directed to reducing the gross volume of waste generated and/or the amount of radioactivity requiring disposal. Transuranic waste reduction efforts shall be based on the implementation of techniques such as process modification, process optimization, materials substitution, decontamination, assay of suspect waste, and new technology development. Volume reduction techniques, such as incineration, compaction, extraction, and shredding, shall be implemented wherever cost effective and practical. Treatment facilities shall be permitted by the appropriate regulatory authority."

\section{REQUIREMENT SOURCE: DOE5820.2A Chapter II, Section 3.b(2)}

"Transuranic waste shall be assayed or otherwise evaluated to determine the kinds and quantities of transuranic radionuclides present prior to storage. Additionally, hazardous waste components shall be estimated or analyzed, whichever is appropriate."

\section{REQUIREMENT SOURCE: DOE5820.2A Chapter II, Section 3.b(3)}

"Mixed transuranic waste shall be treated, where feasible and practical, to destroy the hazardous waste component."

\section{REQUIREMENT SOURCE: DOE5820.2A Chapter II, Section 3.e Introduction and 3.e(1)}

"Temporary Storage at Generating Sites

(e) The following activities shall be performed to assure the safe storage of transuranic wastes consistent with the requirements of applicable Resource Conservation and Recovery Act regulations:

(1) Transuranic waste shall be segregated or otherwise clearly identified to avoid the commingling of transuranic waste streams with high-level waste or low-level waste."

\section{REQUIREMENT SOURCE: DOE5820.2A Chapter III, Section 3.c(1)}

"Technical and administrative controls shall be directed to reducing the gross volume of waste generated and/or the amount of radioactivity requiring disposal. Waste reduction efforts shall include consideration of process modification, process optimization, materials substitution and decontamination."

\section{REQUIREMIENT SOURCE: DOE5820.2A Chapter III, Section 3.c(3)}

"Waste Segregation. Each DOE-low-level waste generator shall separate uncontaminated waste from low-level waste to facilitate cost effective treatment and disposal." 


\section{REQUIREMENT SOURCE: DOE5820.2A Chapter III, Section 3.c(4)}

"Waste Minimization. Each DOE-low-level waste generator preparing a design for a new process or process change shall incorporate principles into the design that will minimize the generation of low-level waste."

WASTE TREATMINT AND DISPOSAL TECHNOLOGY

Low-Level Radioactive Waste

\section{REQUIREMENT SOURCE: DOE5820.2A Chapter III, Section 3.a(2)}

"Assure that external exposure to the waste and concentrations of radioactive material which may be released into surface water, ground water, soil, plants and animals results in an effective dose equivalent that does not exceed $25 \mathrm{mrem} / \mathrm{yr}$ to any member of the public. Releases to the atmosphere shall meet the requirements of 40 CFR 61 . Reasonable effort should be made to maintain releases of radioactivity in effluents to the general environment as low as is reasonably achievable."

\section{REQUIREMENT SOURCE: DOE5820.2A Chapter III, Section 3.f(1)}

"Waste Treatment

(1) Waste shall be treated by appropriate methods so that the disposal site can meet the performance objectives stated in paragraph 3.a."

\section{REQUIREMENT SOURCE: DOE5820.2A Chapter III, Section 3.f(3)}

"The development of large scale waste treatment facilities shall be supported by the appropriate National Environmental Policy Act documentation in addition to the following:

(a) A document shall be prepared that analyzes waste streams needing treatment, treatment options considered, and a rationale for selection of proposed treatment processes;

(b) A construction design report including projected waste throughput and treatment methods, construction and operating cost estimates; and

(c) A Safety Analysis Report."

\section{REQUIREMENT SOURCE: DOE5820.2A Chapter III, Section 3.f(4)}

"Operation of waste treatment facilities shall be supported by adequate documentation including the following:

(a) Operation and maintenance procedures;

(b) Personnel training and qualification procedures;

(c) Monitoring and emergency response plans; and

(d) Records shall be maintained for each package of low-level waste that enters and leaves the treatment facility."

\section{REQUIREMENT SOURCE: WAC-173-303(940523) Section 141(1)}

"A person shall only offer a designated dangerous waste to a TSD facility which is operating either: Under a permit issued pursuant to the requirements of this chapter; or, if the TSD facility is located outside of this state, under interim status or a permit issued by United States 
EPA under 40 CFR Part 270, or under interim status or a permit issued by another state which has been authorized by United States EPA pursuant to 40 CFR Part 271."

\section{REQUIREMENT SOURCE: WAC-173-303(940523) Section 141(2)}

"A person may offer a state only designated dangerous waste (not regulated as a hazardous waste by EPA) to a facility which is located outside of this state and which does not meet the requirements of subsection (1) of this section if:

(a) The facility receiving the waste will legitimately treat or recycle the dangerous waste (disposal is an unacceptable management practice);

(b) The generator has on file a letter or copy of a letter signed by the regulatory authority in the receiving state that the receiving facility may accept the waste;

(c) The generator uses a transporter with a valid EPA/state identification number;

(d) The generator complies with all other applicable requirements, including manifesting, packaging and labeling, with respect to the shipping of the waste. However, the EPA/state identification number for the receiving facility is not required on the manifest or annual report; and

(e) The generator receives from the receiving facility a signed and dated copy of the manifest."

\section{Mixed/Dangerous Waste}

Requirements for container management and PCB waste storage are also specified.

\section{REQUIREMENT SOURCE: WAC-173-303(940523) Section 283(3)}

"Performance standards. Unless authorized by state, local, or federal laws, or unless otherwise authorized in this regulation, the owner/operator shall design, construct, operate, or maintain a dangerous waste facility that to the maximum extent practical given the limits of technology prevents:

(a) Degradation of ground water quality;

(b) Degradation of air quality by open burning or other activities;

(c) Degradation of surface water quality;

(d) Destruction or impairment of flora and fauna outside the active portion of the facility;

(e) Excessive noise;

(f) Conditions that constitute a negative aesthetic impact for the public using rights of ways, or public lands, or for landowners of adjacent properties;

(g) Unstable hillsides or soils as a result of trenches, impoundments, excavations, etc.;

(h) The use of processes that do not treat, detoxify, recycle, reclaim, and recover waste material to the extent economically feasible; and

(i) Endangerment of the health of employees, or the public near the facility." 


\section{REQUIREMENT SOURCE: WAC-173-303(940523) Section 300(2)}

"The owner or operator shall obtain a detailed chemical, physical, and/or biological analysis of a dangerous waste, or nondangerous wastes if applicable under WAC 173-303-610(4)(d), before he stores, treats, or disposes of it. This analysis must contain the information necessary to manage the waste in accordance with the requirements of this chapter 173-303 WAC. The analysis may include or consist of existing published or documented data on the dangerous waste, or on waste generated from similar processes, or data obtained by testing, if necessary."

\section{REQUIREMENT SOURCE: WAC-173-303(940523) Section 300(4)}

"Analysis shall be repeated as necessary to ensure that it is accurate and current. At a minimum, analysis must be repeated:

(a) When the owner or operator has been notified, or has reason to believe, that the process or operation generating the dangerous waste, or nondangerous wastes if applicable under WAC 173-303-610(4)(d), has significantly changed; and

(b) When a dangerous waste received at an off-site facility does not match the identity of the waste specified on the manifest or the shipping paper. ${ }^{n}$

\section{REQUIREMENT SOURCE: WAC-173-303(940523) Section 300(5)}

"Waste analysis plan. The owner or operator shall develop and follow a written waste analysis plan which describes the procedures he will use to comply with the waste analysis requirements of subsections (1), (2), (3), and (4) of this section. He must keep this plan at the facility, and the plan must contain at least:

(a) The parameters for which each dangerous waste, or nondangerous waste if applicable under WAC 173-303-610(4)(d), will be analyzed, and the rationale for selecting these parameters;

(b) The methods of obtaining or testing for these parameters;

(c) The methods for obtaining representative samples of wastes for analysis (representative sampling methods are discussed in WAC 173-303-110 (2));

(d) The frequency with which analysis of a waste will be reviewed or repeated to ensure that the analysis is accurate and current;

(e) The waste analyses which generators have agreed to supply;

(f) Where applicable, the methods for meeting the additional waste analysis requirements for specific waste management methods as specified in 40 CFR Part 265 Subparts F through $R$ for interim status facilities and in WAC 173-303-395 (1) and in WAC 173-303-630 through 173-303-670 for final status facilities; and

(g) For off-site facilities, the procedures for confirming that each dangerous waste received matches the identity of the waste specified on the accompanying manifest or shipping paper. This includes at least:

(i) The procedures for identifying each waste movement at the facility; and

(ii) The method for obtaining a representative sample of the waste to be identified, if the identification method includes sampling. " 


\section{REQUIREMENT SOURCE: WAC-173-303(940523) Section 395(1)(a)}

"The owner or operator must take precautions to prevent accidental ignition or reaction of ignitable or reactive waste. This waste must be separated and protected from sources of ignition or reaction including, but not limited to, open flames, smoking, cutting and welding, hot surfaces, frictional heat, sparks (static, electrical, or mechanical), spontaneous ignition (e.g., from heat-producing chemical reactions), and radiant heat. While ignitable or reactive waste is being handled, the owner or operator must confine smoking and open flame to specially designated locations. "No smoking" signs must be conspicuously placed wherever there is a hazard from ignitable or reactive waste."

\section{REQUIREMENT SOURCE: WAC-173-303(940523) Section 395(1)(b)}

"Where specifically required by other sections of this chapter 173-303 WAC, the treatment, storage, or disposal of ignitable or reactive waste, and the mixture or commingling of incompatible wastes, or incompatible wastes and materials, must be conducted so that it does not:

(i) Generate extreme heat or pressure, fire or explosion, or violent reaction;

(ii) Produce uncontrolled toxic mists, fumes, dusts, or gases in sufficient quantities to threaten human health or the environment;

(iii) Produce uncontrolled flammable fumes or gases in sufficient quantities to pose a risk of fire or explosions;

(iv) Damage the structural integrity of the facility or device containing the waste; or

(v) Through other like means, threaten human health or the environment."

\section{REQUIREMINT SOURCE: WAC-173-303(940523) Section 395(1)(c)}

"When required to comply with (a) and (b) of this subsection, the owner or operator must document that compliance in the operating record required under WAC 173-303-380 (1). This documentation may be based on references to published scientific or engineering literature, data from trial tests, waste analyses, or the results of the treatment of similar wastes by similar treatment processes and under similar operating conditions. "

\section{REQUIREMENT SOURCE: WAC-173-303(940523) Section 395(1)(d)}

"At least yearly, the owner or operator shall inspect those areas of his facility where ignitable or reactive wastes are stored. This inspection shall be performed in the presence of a professional person who is familiar with the Uniform Fire Code, or in the presence of the local, state, or federal fire marshal. The owner or operator shall enter the following information in his inspection log or operating record as a result of this inspection:

(i) The date and time of the inspection;

(ii) The name of the professional inspector or fire marshal;

(iii) A notation of the observations made; and

(iv) Any remedial actions which were taken as a result of the inspection." 


\section{REQUIREMENT SOURCE: WAC-173-303(940523) Section 395(2)}

"Compliance with other environmental protection laws and regulations. In receiving, storing, handling, treating, processing, or disposing of dangerous wastes, the owner/operator shall design, maintain and operate his dangerous waste facility in compliance with all applicable federal, state and local laws and regulations (e.g., control of stormwater or sanitary water discharge, control of volatile air emissions, etc.)."

\section{REQUIREMENT SOURCE: WAC-173-303(940523) Section 395(3)}

"Asbestos dangerous waste disposal requirements. All asbestos containing waste material shall be disposed of at waste disposal sites which are operated in accordance with 40 CFR Part 61 Subpart M. Such sites will not need to comply with any other standards of chapter 173-303 WAC, if they comply with 40 CFR Part $61 . "$

\section{REQUIREMENT SOURCE: WAC-173-303(940523) Section 395(4)}

"Loading and unloading areas. TSD facilities which receive or ship manifested shipments of liquid dangerous waste for treatment, storage or disposal must provide for and use an area (or areas) for loading and unloading waste shipments. The loading and unloading area(s) must be designed, constructed, operated and maintained to:

(a) Contain spills and leaks that might occur during loading or unloading;

(b) Prevent release of dangerous waste or dangerous waste constituents to ground or surface waters;

(c) Contain wash waters (if any) resulting from the cleaning of contaminated transport vehicles and load/unload equipment; and

(d) Allow for removal, as soon as possible, of collected wastes resulting from spills, leaks and equipment cleaning (if any) in a manner which assures compliance with (b) of this subsection."

\section{REQUIREMINT SOURCE: WAC-173-303(940523) Section 395(5)(a)}

"Except as provided in (b) or (c) of this subsection, dangerous waste shall not be stored in a surface impoundment or waste pile for more than five years after the waste was first placed in the impoundment or pile. For the purposes of this requirement, the five-year limit, for waste regulated under this chapter and being stored in impoundments or piles on the effective date of this requirement, will begin on August 1, 1984. The age of stored wastes must be determined on a monthly basis. The owner/operator of a surface impoundment or waste pile used for storing dangerous waste must develop a written plan, to be kept at the facility, for complying with the five-year storage limit. The plan must describe the operating conditions, waste identification procedures (for keeping track of the age of the wastes), and a waste removal schedule, and at a minimum the plan must include the following elements:

(i) Methods for identifying the age of dangerous wastes placed in the impoundment or pile;

(ii) Where practical, procedures for segregating wastes of different ages. If the wastes cannot be practically segregated, then the age of all wastes placed in the impoundment or pile shall be deemed the same age as the oldest waste in the impoundment or pile;

(iii) A schedule for removing dangerous waste from the impoundment or pile, or for disposing of them in a timely manner to assure compliance with the five-year limit; 
(iv) A description of the actions to be taken according to the schedule required by (a)(iii) of this subsection;

(v) Procedures for noting in the operating record required by WAC 173-303-380 (1) that the requirements of this subsection have been satisfied; and

(vi) Such other requirements as the department specifies."

\section{REQUIREMENT SOURCE: WAC-173-303(940523) Section 395(5)(b)}

"If the owner/operator of a surface impoundment or waste pile can develop a written plan and schedule for developing and implementing a recycling or treatment process for the wastes stored in his impoundment or pile, then the department may grant an extension to the storage time limit required in (a) of this subsection. Such extension will be granted only once, will only apply to those dangerous wastes covered by the recycling or treatment plan and which are less than five years old on the date that the plan is approved by the department, and will not exceed five years: Provided, That on a case-by-case basis the department may grant an extension of longer than five years, but in no case will any extension be granted for longer than ten years, if the owner/operator of the impoundment or pile can demonstrate to the department's satisfaction that an extension of more than five years will not pose a threat to public health or the environment, and is necessary because: Other treatment or recycling options of shorter durations are not available; the treatment or recycling plan developed by the owner/operator cannot be implemented within five years due to technological circumstances; or, such other reasons as are determined acceptable by the department. Until the department grants the extension by approving the recycling or treatment plan, the owner/operator must continue to comply with the requirements of (a) of this subsection. The recycling or treatment plan and schedule, at a minimum, must:

(i) Specify the wastes which will be recycled or treated in accordance with the plan;

(ii) Describe in detail the recycling or treatment which the owner/operator intends to perform. If the recycling or treatment will involve physical changes to the owner's/operator's facility, the plan must include descriptions of all necessary equipment, processes to be used, site plans, and maps to show any new structures, pipes, channels, waste handling areas, roads, etc.;

(iii) Discuss any permit actions (including issuance or modification) necessary under this chapter, and any other permits which will be required under other federal, state or local laws;

(iv) Establish a schedule for complying with the plan. The schedule must, at a minimum, cover:

(A) The rate at which wastes will be recycled or treated in order to comply with the extension granted by the department;

(B) Construction and equipment installation times as appropriate;

(C) Timing for complying with all required permit actions; and

(D) Such other elements as the department might require;

(v) Describe how the owner/operator will continue to comply with the requirements of (a) of this subsection for all wastes not specified in (b)(i) of this subsection;

(vi) Identify any future occurrences or situations which the owner/operator could reasonably expect to occur and which might cause him to fail to comply with his recycling or treatment 
plan. The owner/operator must also describe what actions he would take in the event that such occurrences or situations happen;

(vii) Be approved by the department. The plan shall not be implemented until it is approved by the department including, if necessary, issuance or modification of a facility permit as required by this chapter. Any extension granted by the department will begin on the date that the plan is approved, or the date five years after the effective date of this subsection, whichever is later; and

(viii) Include any other elements that the department might require."

\section{REQUIREMIENT SOURCE: WAC-173-303(940523) Section 395(5)(c)}

"The owner/operator of a surface impoundment or waste pile is exempted from the requirements of (a) and (b) of this subsection if:

(i) The owner/operator of a surface impoundment or waste pile can demonstrate to the department's satisfaction that the impoundment or pile is not used primarily for storage, but that it is primarily used to actively and effectively neutralize, detoxify, or other wise treat dangerous waste; or

(ii) The owner/operator of a surface impoundment or waste pile can demonstrate to the department's satisfaction that dangerous waste is removed on a frequent basis (at least four times a year) for treatment, recycling or disposal, provided that the amount of waste removed during any five-year period must equal or exceed the amount of waste placed in the impoundment or pile during that five-year period. However, this exemption does not apply to waste removal which is being performed pursuant to a recycling or treatment plan developed and approved under (b) of this subsection; or

(iii) The owner/operator of a surface impoundment or waste pile has demonstrated, through his permit, closure plan or other instrument, that the impoundment or pile is being operated as a land disposal unit and that it will be closed as a landfill."

\section{REQUIREMENT SOURCE: WAC-173-303(940523) Section 395(6)}

"Labeling for containers and tanks. The owner or operator must label containers and tanks in a manner which adequately identifies the major risk(s) associated with the contents for employees, emergency response personnel and the public (Note--If there is already a system in use that performs this function in accordance with local, state or federal regulations, then such system will be adequate). The owner or operator must ensure that labels are not obscured, removed, or otherwise unreadable in the course of inspection required under WAC 173-303-320. For tanks, the label or sign shall be legible at a distance of at least fifty feet. For containers, the owner or operator must affix labels upon transfer of dangerous waste from one container to another. The owner or operator must destroy or otherwise remove labels from the emptied container, unless the container will continue to be used for storing dangerous waste at the facility."

\section{REQUIREMENT SOURCE: WAC-173-303(940523) Section 160(1)}

"Waste quantity. Containers and inner liners shall not be considered as a part of the waste when measuring or calculating the quantity of a dangerous waste. Only the weight of the residues in nonempty or nonrinsed containers or inner liners will be considered when determining waste quantities." 


\section{REQUIREMINT SOURCE: WAC-173-303(940523) Section 160(2)}

"A container or inner liner is "empty" when:

(a) All wastes in it have been taken out that can be removed using practices commonly employed to remove materials from that type of container or inner liner (e.g., pouring, pumping, aspirating, etc.) and, whichever quantity is least, either less than one inch of waste remains at the bottom of the container or inner liner, or the volume of waste remaining in the container or inner liner is equal to one percent or less of the container's total capacity, or, if the container's total capacity is greater than one hundred ten gallons, the volume of waste remaining in the container or inner liner is no more than 0.3 percent of the container's total capacity. A container which held compressed gas is empty when the pressure inside the container equals or nearly equals atmospheric pressure; and

(b) If the container or inner liner held acutely hazardous waste, as defined in WAC 173-303-040, or pesticides bearing the danger or warning label, the container or inner liner has been rinsed at least three times with an appropriate cleaner or solvent. The volume of cleaner or solvent used for each rinsing shall be ten percent or more of the container's or inner liner's capacity. In lieu of rinsing for containers that might be damaged or made unusable by rinsing with liquids (e.g., fiber or cardboard containers without inner liners), an empty container may be vacuum cleaned, struck, with the open end of the container up, three times (e.g., on the ground, with a hammer or hand) to remove or loosen particles from the inner walls and corners, and vacuum cleaned again. Equipment used for the vacuum cleaning of residues from containers or inner liners must be decontaminated before discarding, in accordance with procedures approved by the department.

Any rinsate or vacuumed residue which results from the cleaning of containers or inner liners shall whenever possible be reused in a manner consistent with the original intended purpose of the substance in the container or inner liner. In the case of a farmer, if the rinsate is a pesticide residue then the rinsate shall be managed or reused in a manner consistent with the instructions on the pesticide label, provided that when the label instructions specify disposal or burial, such disposal or burial must be on the farmer's own (including rented, leased or tenanted) property. Otherwise, the rinsate shall be checked against the designation requirements (WAC 173-303-070 through 173-303-100 and, if designated, managed according to the requirements of this chapter.

(c) In the case of a container, the inner liner, that prevented the container from contact with the commercial chemical product or manufacturing chemical, has been removed."

\section{REQUIREMENT SOURCE: WAC-173-303(940523) Section 200(1)}

"A generator, not to include transporters as referenced in WAC 173-303-240 (3), may accumulate dangerous waste on-site without a permit for ninety days or less after the date of generation, provided that:

(a) All such waste is shipped off-site to a designated facility or placed in an on-site facility which is permitted by the department under WAC 173-303-800 through 173-303-845 or recycled or treated on-site in ninety days or less. The department may, on a case-by-case basis, grant a maximum thirty day extension to this ninety day period if dangerous wastes must remain on-site due to unforeseen, temporary and uncontrollable circumstances. A generator who accumulates dangerous waste for more than ninety days is an operator of a storage facility and is subject to the facility requirements of this chapter and the permit requirements of this chapter as a storage facility unless he has been granted an extension to the ninety day period allowed pursuant to this subsection; 
(b) The waste is placed in containers and the generator complies with WAC 173-303-630 (2), (3), (4), (5), (6), (8), (9), and (10), or the waste is placed in tanks and the generator complies with WAC 173-303-640 (2) through (10), except WAC 173-303-640(8)(c) and the second sentence of WAC 173-303-640 (8)(a).

(Note: A generator, unless otherwise required to do so, does not have to prepare a closure plan, a cost estimate for closure, or provide financial responsibility for his tank system to satisfy the requirements of this section.)

Such a generator is exempt from the requirements of WAC 173-303-620 and 173-303-610, except for WAC 173-303-610 (2) and (5). For container accumulation (including satellite areas as described in subsection (2) of this section), the department may require that the accumulation area include secondary containment in accordance with WAC 173-303-630 (7), if the department determines that there is a potential threat to public health or the environment due to the nature of the wastes being accumulated, or due to a history of spills or releases from accumulated containers. In addition, any new container accumulation areas (but not including new satellite areas, unless required by the department) constructed or installed after September 30, 1986, must comply with the provisions of WAC 173-303-630 (7);

(c) The date upon which each period of accumulation begins is marked and clearly visible for inspection on each container;

(d) While being accumulated on site, each container and tank is labeled or marked clearly with the words "dangerous waste" or "hazardous waste." Each container or tank must also be marked with a label or sign which identifies the major risk(s) associated with the waste in the container or tank for employees, emergency response personnel and the public (Note--If there is already a system in use that performs this function in accordance with local, state, or federal regulations, then such system will be adequate). The department may also require that a sign be posted at each entrance to the accumulation area, bearing the legend, "danger--unauthorized personnel keep out," or an equivalent legend, written in English, and legible from a distance of twenty-five feet or more; and

(e) The generator complies with the requirements for facility operators contained in:

(i) WAC 173-303-330 through 173-303-360 (personnel training, preparedness and prevention, contingency plan and emergency procedures, and emergencies) except for WAC 173-303-355 (SARA Title III coordination); and

(ii) WAC 173-303-320 (1), (2)(a), (b), (d), and (3) (general inspection). "

\section{REQUIREMENT SOURCE: WAC-173-303(940523) Section 630(2)}

"Condition of containers. If a container holding dangerous waste is not in good condition (e.g., severe rusting, apparent structural defects) or if it begins to leak, the owner or operator must transfer the dangerous waste from the container to a container that is in good condition or manage the waste in some other way that complies with the requirements of chapter 173-303 WAC. In addition, the owner or operator must address leaks and spills in accordance with the applicable provisions of WAC 173-303-145 and 173-303-360."

\section{REQUIREMENT SOURCE: WAC-173-303(940523) Section 630(3)}

"Identification of containers. The owner or operator must label containers in a manner which adequately identifies the major risk(s) associated with the contents of the containers for employees, emergency response personnel and the public (Note--If there is already a system in use that performs this function in accordance with local, state or federal regulations, then such 
system will be adequate). The owner or operator must affix labels upon transfer of dangerous wastes from one container to another. The owner or operator must destroy or otherwise remove labels from the emptied container, unless the container will continue to be used for storing dangerous waste at the facility. The owner or operator must ensure that labels are not obscured, removed, or otherwise unreadable in the course of inspection required under WAC 173-303-320."

\section{REQUIREMENT SOURCE: WAC-173-303(940523) Section 630(4)}

"Compatibility of waste with containers. The owner or operator must use a container made of or lined with materials which will not react with, and are otherwise compatible with, the dangerous waste to be stored, so that the ability of the container to contain the waste is not impaired."

\section{REQUIREMENT SOURCE: WAC-173-303(940523) Section 630(5)(a)}

"A container holding dangerous waste must always be closed, except when it is necessary to add or remove waste."

\section{REQUIREMENT SOURCE: WAC-173-303(940523) Section 630(5)(b)}

"A container holding dangerous waste must not be opened, handled, or stored in a manner which may rupture the container or cause it to leak."

\section{REQUIREMENT SOURCE: WAC-173-303(940523) Section 630(5)(c)}

"A minimum thirty-inch separation is required between aisles of containers holding dangerous waste(s). A row of drums must be no more than two drums wide."

\section{REQUIREMENT SOURCE: WAC-173-303(940523) Section 630(6)}

"Inspections. At least weekly, the owner or operator must inspect areas where containers are stored, looking for leaking containers and for deterioration of containers and the containment system caused by corrosion, deterioration, or other factors. The owner or operator shall keep an inspection log including at least the date and time of the inspection, the printed name and the handwritten signature of the inspector, a notation of the observations made and the date and nature of any repairs or remedial actions taken. The log must be kept at the facility for at least five years from the date of inspection."

\section{REQUIREMENT SOURCE: WAC-173-303(940523) Section 630(7)(a)}

"Container storage areas must have a containment system that is capable of collecting and holding spills and leaks. In addition to the necessary leak containment capacity, uncovered storage areas must be capable of holding the additional volume that would result from the precipitation of a maximum twenty-five year storm of twenty-four hours duration. The containment system must:

(i) Have a base underlying the containers which is free of cracks or gaps and is sufficiently impervious to contain leaks, spills, and accumulated rainfall until the collected material is detected and removed. The base must be sloped or the containment system must be otherwise designed and operated to drain and remove liquids resulting from leaks, spills, or precipitation, unless the containers are elevated or are otherwise protected from contact with accumulated liquids; 
(ii) Be designed for positive drainage control (such as a locked drainage valve) to prevent release of contaminated liquids and so that uncontaminated precipitation can be drained promptly for convenience of operation. Spilled or leaked waste and accumulated precipitation must be removed from the containment system in as timely a manner as is necessary to prevent overflow; and

(iii) Have sufficient capacity to contain ten percent of the volume of all containers or the volume of the largest container, whichever is greater. Only containers holding free liquids, or holding wastes designated as F020, F021, F022, F023, F026, or F027 need to be considered in this determination."

\section{REQUIREMENT SOURCE: WAC-173-303(940523) Section 630(7)(b)}

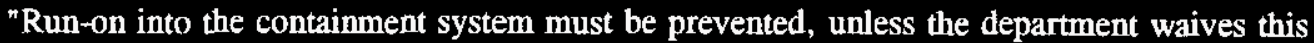
requirement in the permit after determining that the collection system has sufficient excess capacity in addition to that required in (a)(iii) of this subsection to accommodate any run-on which might enter the system."

\section{REQUIREMENT SOURCE: WAC-173-303(940523) Section 630(7)(c)}

"Storage areas that store containers holding only wastes that do not contain free liquids, do not exhibit either the characteristic of ignitability or reactivity as described in WAC 173-303-090

(5) or (7), and are not designated as F020, F021, F022, F023, F026, or F027, need not have a containment system as described in this subsection: Provided, That:

(i) The storage area is sloped or is otherwise designed and operated to drain and remove liquid resulting from precipitation; or

(ii) The containers are elevated or are otherwise protected from contact with accumulated liquids."

\section{REQUIREMENT SOURCE: WAC-173-303(940523) Section 630(7)(d)}

"EHW in containers must be protected from the elements by means of a building or other protective covering that otherwise allows adequate inspection under subsection (6) of this section."

\section{REQUIREMENT SOURCE: WAC-173-303(940523) Section 630(8)(a)}

"Containers holding reactive waste exhibiting a characteristic specified in WAC 173-303-090 (7)(a)(vi), (vii) or (viii) must be stored in a manner equivalent to the Uniform Fire Code's "American Table of Distances for Storage of Explosives," Table 77-201, 1979 edition or the version adopted by the local fire district."

\section{REQUIREMENT SOURCE: WAC-173-303(940523) Section 630(8)(b)}

"The owner or operator shall design, operate, and maintain ignitable waste and reactive waste (other than a reactive waste which must meet (a) of this subsection) container storage in a manner equivalent with the Uniform Fire Code. Where no specific standard or requirements are specified in the Uniform Fire Code, or in existing state or local fire codes, applicable sections of the NFPA Pamphlet \# 30, "Flammable and Combustible Liquids Code," shall be used. The owner/operator shall also comply with the requirements of WAC 173-303-395 (1)(d)." 


\section{REQUIREMENT SOURCE: WAC-173-303(940523) Section 630(9)(a)}

"Incompatible wastes, or incompatible wastes and materials must not be placed in the same container, unless WAC 173-303-395 (1)(b) is complied with."

\section{REQUIREMENT SOURCE: WAC-173-303(940523) Section 630(9)(b)}

"Dangerous waste must not be placed in an unwashed container that previously held an incompatible waste or material."

\section{REQUIREMENT SOURCE: WAC-173-303(940523) Section 630(9)(c)}

"A storage container holding a dangerous waste that is incompatible with any waste or other materials stored nearby in other containers, piles, open tanks, or surface impoundments must be separated from the other materials or protected from them by means of a dike, berm, wall, or other device. Containment systems for incompatible wastes shall be separate."

\section{REQUIREMENT SOURCE: WAC-173-303(940523) Section 630(10)}

"Closure. At closure, all dangerous waste and dangerous waste residues must be removed from the containment system. Remaining containers, liners, bases, and soil containing or contaminated with dangerous waste or dangerous waste residues must be decontaminated or removed."

\section{Waste Treatment}

\section{REQUIREMINT SOURCE: 40 CFR265 Part 400}

"Applicability. The regulations in this subpart apply to owners and operators of facilities which treat hazardous wastes by chemical, physical, or biological methods in other than tanks, surface impoundments, and land treatment facilities, except as 265.1 provides otherwise. Chemical, physical, and biological treatment of hazardous waste in tanks, surface impoundments, and land treatment facilities must be conducted in accordance with subparts $\mathrm{J}$, $\mathrm{K}$, and $\mathrm{M}$, respectively."

\section{REQUIREMENT SOURCE: 40CFR265 Part 401}

"General operating requirements.

(a) Chemical, physical, or biological treatment of hazardous waste must comply with 265.17(b).

(b) Hazardous wastes or treatment reagents must not be placed in the treatment process or equipment if they could cause the treatment process or equipment to rupture, leak, corrode, or otherwise fail before the end of its intended life.

(c) Where hazardous waste is continuously fed into a treatment process or equipment, the process or equipment must be equipped with a means to stop this inflow (e.g., a waste feed cut-off system or by-pass system to a standby containment device).

[Comment: These systems are intended to be used in the event of a malfunction in the treatment process or equipment.]" 


\section{REQUIREMINT SOURCE: 40CFR265 Part 402}

"Waste analysis and trial tests.

(a) In addition to the waste analysis required by 265.13 , whenever:

(1) A hazardous waste which is substantially different from waste previously treated in a treatment process or equipment at the facility is to be treated in that process or equipment, or

(2) A substantially different process than any previously used at the facility is to be used to chemically treat hazardous waste; the owner or operator must, before treating the different waste or using the different process or equipment:

(i) Conduct waste analyses and trial treatment tests (e.g., bench scale or pilot plant scale tests); or

(ii) Obtain written, documented information on similar treatment of similar waste under similar operating conditions; to show that this proposed treatment will meet all applicable requirements of 265.401 (a) and (b).

[Comment: As required by 265.13, the waste analysis plan must include analyses needed to comply with 265.405 and 265.406 . As required by 265.73 , the owner or operator must place the results from each waste analysis and trial test, or the documented information, in the operating record of the facility. $]^{n}$

\section{REQUIREMENT SOURCE: 40CFR265 Part 403}

"Inspections.

(a) The owner or operator of a treatment facility must inspect, where present:

1) Discharge control and safety equipment (e.g., waste feed cut-off systems, by-pass systems, drainage systems, and pressure relief systems) at least once each operating day, to ensure that it is in good working order;

(2) Data gathered from monitoring equipment (e.g., pressure and temperature gauges), at least once each operating day, to ensure that the treatment process or equipment is being operated according to its design;

(3) The construction materials of the treatment process or equipment, at least weekly, to detect corrosion or leaking of fixtures or seams; and

(4) The construction materials of, and the area immediately surrounding, discharge confinement structures (e.g., dikes), at least weekly, to detect erosion or obvious signs of leakage (e.g., wet spots or dead vegetation).

[Comment: As required by 265.15 (c), the owner or operator must remedy any deterioration or malfunction he finds. $]^{n}$

\section{REQUIREMENT SOURCE: 40CFR265 Part 404}

"Closure. At closure, all hazardous waste and hazardous waste residues must be removed from treatment processes or equipment, discharge control equipment, and discharge confinement structures.

[Comment: At closure, as throughout the operating period, unless the owner or operator can demonstrate, in accordance with 261.3 (c) or (d) of this chapter, that any solid waste removed from his treatment process or equipment is not a hazardous waste, the owner or operator 
becomes a generator of hazardous waste and must manage it in accordance with all applicable requirements of parts 262,263 , and 265 of this chapter. ${ }^{n}$

\section{REQUIREMIENT SOURCE: 40CFR265 Part 405}

"Special requirements for ignitable or reactive waste.

(a) Ignitable or reactive waste must not be placed in a treatment process or equipment unless:

(1) The waste is treated, rendered, or mixed before or immediately after placement in the treatment process or equipment so that (i) the resulting waste, mixture, or dissolution of material no longer meets the definition of ignitable or reactive waste under261.21 or 261.23 or this chapter, and (ii) 265.17 (b) is complied with; or

(2) The waste is treated in such a way that it is protected from any material or conditions which may cause the waste to ignite or react."

\section{REQUIREMENT SOURCE: 40CFR265 Part 406}

"Special requirements for incompatible wastes.

(a) Incompatible wastes, or incompatible wastes and materials, (see appendix $\mathrm{V}$ for examples) must not be placed in the same treatment process or equipment, unless $265.17(\mathrm{~b})$ is complied with.

(b) Hazardous waste must not be placed in unwashed treatment equipment which previously held an incompatible waste or material, unless 265.17 (b) is complied with."

\section{$\underline{16.8 .3}$}

\section{Ashestos Waste}

\section{REQUIREMINT SOURCE: 40CFR61 Part 145(b)}

Author's Note: Only 40 CFR 61 Part 145 Subparts (b)(3)(i)-(b)(3)(iv) apply.

"Notification requirements. Each owner or operator of a demolition or renovation activity to which this section applies shall:

(1) Provide the Administrator with written notice of intention to demolish or renovate.

Delivery of the notice by U.S. Postal Service, commercial delivery service, or hand delivery is acceptable.

(2) Update notice, as necessary, including when the amount of asbestos affected changes by at least 20 percent.

(3) Postmark or deliver the notice as follows:

(i) At least 10 working days before asbestos stripping or removal work or any other activity begins (such as site preparation that would break up, dislodge or similarly disturb asbestos material), if the operation is described in paragraphs (a) (1) and (4) (except (a)(4)(iii) and (a)(4)(iv)) of this section. If the operation is as described in paragraph (a)(2) of this section, notification is required 10 working days before demolition begins.

(ii) At least 10 working days before the end of the calendar year preceding the year for which notice is being given for renovations described in paragraph (a)(4)(iii) of this section. 
(iii) As early as possible before, but not later than, the following working day if the operation is a demolition ordered according to paragraph (a)(3) of this section or, if the operation is a renovation described in paragraph (a)(4)(iv) of this section.

(iv) For asbestos stripping or removal work in a demolition or renovation operation, described in paragraphs (a) (1) and (4) (except (a)(4)(iii) and (a)(4)(iv)) of this section, and for a demolition described in paragraph (a)(2) of this section, that will begin on a date other than the one contained in the original notice, notice of the new start date must be provided to the Administrator as follows:

(A) When the asbestos stripping or removal operation or demolition operation covered by this paragraph will begin after the date contained in the notice,

(1) Notify the Administrator of the new start date by telephone as soon as possible before the original start date, and

(2) Provide the Administrator with a written notice of the new start date as soon as possible before, and no later than, the original start date. Delivery of the updated notice by the U.S. Postal Service, commercial delivery service, or hand delivery is acceptable.

(B) When the asbestos stripping or removal operation or demolition operation covered by this paragraph will begin on a date earlier than the original start date,

(1) Provide the Administrator with a written notice of the new start date at least 10 working days before asbestos stripping or removal work begins.

(2) For demolitions covered by paragraph (a)(2) of this section, provide the Administrator written notice of a new start date at least 10 working days before commencement of demolition. Delivery of updated notice by U.S. Postal Service, commercial delivery service, or hand delivery is acceptable.

(C) In no event shall an operation covered by this paragraph begin on a date other than the date contained in the written notice of the new start date.

(4) Include the following in the notice:

(i) An indication of whether the notice is the original or a revised notification.

(ii) Name, address, and telephone number of both the facility owner and operator and the asbestos removal contractor owner or operator.

(iii) Type of operation: demolition or renovation.

(iv) Description of the facility or affected part of the facility including the size (square meters [square feet] and number of floors), age, and present and prior use of the facility.

(v) Procedure, including analytical methods, employed to detect the presence of RACM and Category I and Category II nonfriable ACM.

(vi) Estimate of the approximate amount of RACM to be removed from the facility in terms of length of pipe in linear meters (linear feet), surface area in square meters (square feet) on other facility components, or volume in cubic meters (cubic feet) if off the facility components. Also, estimate the approximate amount of Category I and Category II nonfriable ACM in the affected part of the facility that will not be removed before demolition. 
(vii) Location and street address (including building number or name and floor or room number, if appropriate), city, county, and state, of the facility being demolished or renovated.

(viii) Scheduled starting and completion dates of asbestos removal work (or any other activity, such as site preparation that would break up, dislodge, or similarly disturb asbestos material) in a demolition or renovation; planned renovation operations involving individual nonscheduled operations shall only include the beginning and ending dates of the report period as described in paragraph (a)(4)(iii) of this section.

(ix) Scheduled starting and completion dates of demolition or renovation.

(x) Description of planned demolition or renovation work to be performed and method(s) to be employed, including demolition or renovation techniques to be used and description of affected facility components.

(xi) Description of work practices and engineering controls to be used to comply with the requirements of this subpart, including asbestos removal and waste-handling emission control procedures.

(xii) Name and location of the waste disposal site where the asbestos-containing waste material will be deposited.

(xiii) A certification that at least one person trained as required by paragraph (c)(8) of this section will supervise the stripping and removal described by this notification. This requirement shall become effective 1 year after promulgation of this regulation.

(xiv) For facilities described in paragraph (a)(3) of this section, the name, title, and authority of the State or local government representative who has ordered the demolition, the date that the order was issued, and the date on which the demolition was ordered to begin. A copy of the order shall be attached to the notification.

(xv) For emergency renovations described in paragraph (a)(4)(iv) of this section, the date and hour that the emergency occurred, a description of the sudden, unexpected event, and an explanation of how the event caused an unsafe condition, or would cause equipment damage or an unreasonable financial burden.

(xvi) Description of procedures to be followed in the event that unexpected RACM is found or Category II nonfriable ACM becomes crumbled, pulverized, or reduced to powder.

(xvii) Name, address, and telephone number of the waste transporter.

(5) The information required in paragraph (b)(4) of this section must be reported using a form similar to that shown in Figure 3."

\section{REQUIREMENT SOURCE: 40CFR61 Part 150(a)(1)}

"Discharge no visible emissions to the outside air during the collection, processing (including incineration), packaging, or transporting of any asbestos-containing waste material generated by the source, or use one of the emission control and waste treatment methods specified in paragraphs (a) (1) through (4) of this section.

Adequately wet asbestos-containing waste material as follows:

(i) Mix control device asbestos waste to form a slurry; adequately wet other asbestos-containing waste material; and 
(ii) Discharge no visible emissions to the outside air from collection, mixing, wetting, and handling operations, or use the methods specified by 61.152 to clean emissions containing particulate asbestos material before they escape to, or are vented to, the outside air; and

(iii) After wetting, seal all asbestos-containing waste material in leak-tight containers while wet; or, for materials that will not fit into containers without additional breaking, put materials into leak-tight wrapping; and

(iv) Label the containers or wrapped materials specified in paragraph (a)(1)(iii) of this section using warning labels specified by Occupational Safety and Health Standards of the Department of Labor, Occupational Safety and Health Administration (OSHA) under 29 CFR $1910.1001(\mathrm{j})(2)$ or $1926.58(\mathrm{k})(2)(\mathrm{iii})$. The labels shall be printed in letters of sufficient size and contrast so as to be readily visible and legible.

(v) For asbestos-containing waste material to be transported off the facility site, label containers or wrapped materials with the name of the waste generator and the location at which the waste was generated."

\section{REQUIREMENT SOURCE: 40CFR61 Part 150(a)(2)}

"Process asbestos-containing waste material into nonfriable forms as follows:

(i) Form all asbestos-containing waste material into nonfriable pellets or other shapes;

(ii) Discharge no visible emissions to the outside air from collection and processing operations, including incineration, or use the method specified by 61.152 to clean emissions containing particulate asbestos material before they escape to, or are vented to, the outside air. "

\section{REQUIREMENT SOURCE: 40CFR61 Part 150(a)(4)}

"Use an alternative emission control and waste treatment method that has received prior approval by the Administrator according to the procedure described in 61.149(c)(2)."

\section{REQUIREMENT SOURCE: 40CFR61 Part 150(a)(5)}

"As applied to demolition and renovation, the requirements of paragraph (a) of this section do not apply to Category I nonfriable ACM waste and Category II nonfriable ACM waste that did not become crumbled, pulverized, or reduced to powder. "

\section{REQUIREMENT SOURCE: 94-FDB-015 Section A}

\section{"DISPOSAL:}

Disposal of Regulated Asbestos-Containing Material shall be in accordance with 40 CFR 61.150 and this Agreement as more specifically set forth below for on-site disposal:

1. Asbestos containing waste shall be disposed of at the Hanford Site Central Landfill or other appropriate asbestos disposal facility, normally within five days of collection, unless handled as a dangerous waste in accordance with WAC $173-303$ or as a radioactive material.

2. When it is determined to be impractical to dispose of asbestos waste within five (5) working days after collection for disposal, asbestos waste containers, while on the Hanford Site, shall be handled, transported, and disposed of in accordance with the following: 
(a) Asbestos waste containers shall be accumulated in securable locations not accessible to the general public.

(b) Asbestos waste containers placed in an accumulation location shall be free of dangerous waste or radioactive contamination.

(c) Only employees authorized by RL and its contractors shall have access and use of asbestos waste accumulation locations.

(d) Access to accumulation locations shall be controlled at all times.

(e) Containers not containing asbestos waste, if present at an accumulation location, will be segregated from the asbestos waste containers.

(f) Accumulation locations and the outer surface of asbestos waste containers shall be maintained free of uncontained asbestos waste."

\section{REQUIREMENT SOURCE: 94-FDB-015 Section B}

"Notifications:

Notifications shall be in accordance with 40 CFR 61.145(b)(3)(ii) and 40 CFR 61.145(b)(3)(i,)(iii), or (iv) and this Agreement as more specifically set forth below

1. Annual notification for projects under Regulation 1 thresholds will be submitted annually and the prescribed filing fee will be billed to the Westinghouse Hanford Company (WHC), or such other contractor as RL may direct by written notification.

2. Annual notification for asbestos projects between the Regulation 1 and NESHAP thresholds will also be reported annually and the filing fee as prescribed in Regulation 1 will also be billed to WHC, or such other contractor as RL may direct by written notification.

3. All other asbestos projects that exceed the NESHAP 260 liner feet and 160 square feet threshold will be reported to BFCCAA on a case by case basis and a separate filing fee will be billed to WHC, or such other contractor as RL may direct by written notification."

\section{REQUIREMINT SOURCE: WAC-296-65 Section 020}

"Notification requirements.

(1) Before any person or individual begins an asbestos project involving more than forty-eight square feet or ten linear feet, unless the surface area of the pipe is greater than forty-eight square feet, of asbestos containing material, written notification shall be provided to the department. Notices shall include:

(a) Name and address of the owner and contractor.

(b) Description of the facility including size, age, and prior use of the facility.

(c) Amount of asbestos-containing material to be removed or encapsulated.

(d) Location of the facility.

(e) Exact starting and completion dates of the asbestos project, including shifts during which abatement work will be accomplished. These dates must correspond to the dates specified in 
the contract. Any change in these dates or work shifts shall be communicated to the department by an amended notice.

(f) Nature of the project and methods used to remove or encapsulate the material.

(2) Failure to provide such notification will result in the loss of the exemption specified in WAC 296-65-030.

(3) Notices must be received by the department no later than ten days prior to the start of the project. Notices shall be sent directly to the department of labor and industries regional office having jurisdiction on the project.

(4) The director may waive the prenotification requirement upon written request of an owner for large-scale, on-going projects. In granting such a waiver, the director shall require the owner to provide prenotification if significant changes in personnel, methodologies, equipment, work site, or work procedures occur or are likely to occur. The director shall further require annual resubmittal of such notification.

(5) The director, upon review of an owner's reports, work practices, or other data available as a result of inspections, audits, or other authorized activities, may reduce the size threshold for prenotification required by this section. Such a change shall be based on the director's determination that significant problems in personnel, methodologies, equipment, work site, or work procedures are creating the potential for violations of this chapter.

(6) Emergency projects which disturb or release asbestos into the air shall be reported to the department within three working days after commencement of the project in the manner otherwise required under this chapter. The employees, the employees' collective bargaining representative or employee representative, if any, and other persons at the project area shall be notified of the emergency as soon as possible by the person undertaking the emergency project. A notice describing the nature of the emergency project shall be clearly posted adjacent to the work area.

(7) Incremental phasing in the conduct or design of asbestos projects or otherwise conducting or designing asbestos projects of a size less than the threshold exemption specified in subsection (1) of this section, with the intent of avoiding the notification requirements, is a violation of this chapter."

\section{REQUIREMENT SOURCE: WAC-296-65 Section 030}

"Methods of compliance.

(1) Before submitting a bid or working on an asbestos abatement project, any person or individual shall obtain an asbestos contractor certificate as provided in WAC 296-65-017 and shall have in its employ at least one certified asbestos supervisor responsible for supervising all asbestos projects undertaken by the contractor.

(2) A certified asbestos supervisor will not be required on projects involving less than forty-eight square feet or ten linear feet of asbestos-containing material unless the surface area of the pipe is greater than forty-eight square feet.

(3) No employee or other individual is eligible to do work or supervise an asbestos project without being issued a certificate by the department except, in the case of an asbestos project undertaken by any partnership, firm, association, corporation, or sole proprietorship, and conducted in its own facility and by its own employees under the direct, on-site supervision of a certified asbestos supervisor. This exception does not apply to the state of Washington or its political subdivisions. 
(4) No person may assign any employee, contract with, or permit any individual, to remove or encapsulate asbestos in any facility without the project being performed by a certified asbestos worker and under the direct, on-site supervision of a certified asbestos supervisor, except in the case of an asbestos project undertaken by any partnership, firm, association, corporation, or sole proprietorship, and conducted in its own facility and by its own employees under the direct, on-site supervision of a certified asbestos supervisor.

(5) Any partnership, firm association, corporation, or sole proprietorship that begins any construction, renovation, remodeling, maintenance, repair, or demolition project without meeting the requirements of WAC 296-65-07707 and the notification requirements as provided in subsection (6) of this section, shall lose the exemptions provided in subsections (3) and (4) of this section.

(6) In cases excepted under subsections (3) and (4) of this section:

(a) Direct, on-site supervision by a certified asbestos supervisor shall be required for asbestos projects performed at one project location by workers who are not certified.

(b) If a project is conducted using only certified workers, or if a certified worker functions as a foreman or lead person, supervision can be performed in the regular course of a supervisor's duties and need not be direct and on-site.

(c) The partnership, firm, association, corporation, or sole proprietorship shall annually submit, to the department, a written description which includes at least the following information:

(i) The kinds of asbestos projects expected to be undertaken during a period of time not to exceed one year from the date of submission;

(ii) The procedures to be used in undertaking the asbestos projects;

(iii) Methods of compliance with applicable department regulations;

(iv) Methods of compliance with any additional procedures required by law for the safe demolition, removal encapsulation, salvage, and disposal of asbestos;

(v) A copy of the written inspection report or statement as required by WAC 296-65-07707; and

(vi) The name, address and certification number of the supervising certified asbestos supervisor.

(7) The written descriptions required in this section shall be submitted to the department prior to commencing any project described.

(8) A further written description must be submitted to the department prior to commencing a project, if previously unidentified or new asbestos projects are proposed during the one year period covered by the written description submitted to the department in accordance with subsection (6) of this section.

(9) Written descriptions, shall be mailed to:

Asbestos Certification Program, Department of Labor and Industries, HC-412 805 Plum Street S.E. 
P.O. Box 207

Olympia, Washington 98504

(10) In addition to losing the exemption in subsection (5) of this section, any partnership, firm, association, corporation, or sole proprietorship who fails to comply with subsections (6) through (9) of this section shall be subject to a mandatory fine of not less than two hundred fifty dollars for each violation. Each day the violation continues shall be considered a separate violation. In addition, any construction, renovation, remodeling, maintenance, repair, or demolition which was started without meeting the requirements of this section shall be halted immediately and cannot be resumed before meeting such requirements."

Tank Systems

REQUIREMENT SOURCE: DOE5820.2A Chapter II, Section 3.e(4)

"Transuranic wastes in storage shall be monitored periodically to ensure that the wastes are not releasing their radioactive and/or hazardous constituents."

\section{REQUIREMENT SOURCE: DOE5820.2A Chapter I, Section 3.e(5)}

"Transuranic waste storage facilities shall be designed, constructed, maintained, and operated to minimize the possibilities of fire, explosion, or accidental release of radioactive and/or hazardous components of the waste to the environment."

\section{REQUIREMENT SOURCE: DOE5820.2A Chapter II, Section 3.e(7)}

"Transuranic waste shall be stored in such a way so as to maintain radiation exposures as low as reasonably achievable."

\section{REQUIREMENT SOURCE: DOE5820.2A Chapter II, Section 3.g(3)}

"Existing interim storage sites shall be reviewed for consistency with the items in paragraph 3.g.(2). Any necessary corrective actions shall be performed based on a compliance schedule approved by appropriate regulatory authorities. "

\section{REQUIREMENT SOURCE: WAC.173-303(940523) Section 640(1)(a)}

"The regulations in WAC 173-303-640 apply to owners and operators of facilities that use tank systems to treat or store dangerous waste, except as (b) and (c) of this subsection provides otherwise."

\section{REQUIREMINT SOURCE: WAC-173-303(940523) Section 640(1)(b)}

"Tank systems that are used to store or treat dangerous waste which contain no free liquids and are situated inside a building with an impermeable floor are exempted from the requirements in subsection (4) of this section. To demonstrate the absence or presence of free liquids in the stored/treated waste, the test method described in WAC 173-303-110 (3)(c)(i) must be used."

\section{REQUIREMENT SOURCE: WAC-173-303(940523) Section 640(1)(c)}

"Tank systems, including sumps, as defined in WAC 173-303-040, that serve as part of a secondary containment system to collect or contain releases of dangerous wastes are exempted from the requirements in subsection (4)(a) of this section." 


\section{REQUIREMENT SOURCE: WAC-173-303(940523) Section 640(2)(a)}

"For each existing tank system, the owner or operator must determine that the tank system is not leaking or is unfit for use. Except as provided in (b) of this subsection, the owner or operator must obtain and keep on file at the facility a written assessment reviewed and certified by an independent, qualified registered professional engineer, in accordance with WAC 173-303-810 (13)(a), that attests to the tank system's integrity by January 12, 1988, for underground tanks that do not meet the requirements of subsection (4) of this section and that cannot be entered for inspection, or by January 12,1990 , for all other tank systems."

\section{REQUIREMENT SOURCE: WAC-173-303(940523) Section 640(2)(b)}

"Tank systems that store or treat materials that become dangerous wastes subsequent to January 12,1989 , must conduct this assessment within twelve months after the date that the waste becomes a dangerous waste."

\section{REQUIREMENT SOURCE: WAC-173-303(940523) Section 640(2)(c)}

"This assessment must determine that the tank system is adequately designed and has sufficient structural strength and compatibility with the waste(s) to be stored or treated, to ensure that it will not collapse, rupture, or fail. At a minimum, this assessment must consider the following:

(i) Design standard(s), if available, according to which the tank system was constructed;

(ii) Dangerous characteristics of the waste(s) that have been and will be handled;

(iii) Existing corrosion protection measures;

(iv) Documented age of the tank system, if available (otherwise, an estimate of the age); and

(v) Results of a leak test, internal inspection, or other tank system integrity examination such that:

(A) For nonenterable underground tanks, the assessment must include a leak test that is capable of taking into account the effects of temperature variations, tank end deflection, vapor pockets, and high water table effects; and

(B) For other than nonenterable underground tanks and for ancillary equipment, this assessment must include either a leak test, as described above, or other integrity examination, that is certified by an independent, qualified, registered professional engineer, in accordance with WAC 173-303-810 (13)(a), that addresses cracks, leaks, corrosion, and erosion.

Note: The practices described in the American Petroleum Institute (API) Publication, Guide for Inspection of Refinery Equipment, Chapter XIII, "Atmospheric and Low-Pressure Storage Tanks, " 4th edition, 1981, may be used, where applicable, as guidelines in conducting other than a leak test."

\section{REQUIREMENT SOURCE: WAC-173-303(940523) Section 640(2)(d)}

"If, as a result of the assessment conducted in accordance with (a) of this subsection, a tank system is found to be leaking or unfit for use, the owner or operator must comply with the requirements of subsection (7) of this section." 


\section{REQUIREMENT SOURCE: WAC-173-303(940523) Section 640(2)(e)}

"The owner or operator must develop a schedule for conducting integrity assessments over the life of the tank to ensure that the tank retains its structural integrity and will not collapse, rupture, or fail. The schedule must be based on the results of past integrity assessments, age of the tank system, materials of construction, characteristics of the waste, and any other relevant factors. "

\section{REQUIREMENT SOURCE: WAC-173-303(940523) Section 640(3)(a)}

"Owners or operators of new tank systems or components must obtain (and for facilities that are pursuing or have obtained a final status permit, submit to the department, at time of submittal of Part B information) a written assessment, reviewed and certified by an independent, qualified registered professional engineer, in accordance with WAC 173-303-810 (13)(a), attesting that the tank system has sufficient structural integrity and is acceptable for the storing and treating of dangerous waste. The assessment must show that the foundation, structural support, seams, connections, and pressure controls (if applicable) are adequately designed and that the tank system has sufficient structural strength, compatibility with the waste(s) to be stored or treated, and corrosion protection to ensure that it will not collapse, rupture, or fail. This assessment (which will be used by the department to review and approve or disapprove the acceptability of the tank system design at facilities which are pursuing or have obtained a final status permit) must include, at a minimum, the following information:

(i) Design standard(s) according to which tank system(s) are constructed;

(ii) Dangerous characteristics of the waste(s) to be handled;

(iii) For new tank systems or components in which the external shell of a metal tank or any external metal component of the tank system will be in contact with the soil or with water, a determination by a corrosion expert of:

(A) Factors affecting the potential for corrosion, including but not limited to:

(I) Soil moisture content;

(II) Soil pH;

(III) Soil sulfides level;

(IV) Soil resistivity;

(V) Structure to soil potential;

(VI) Influence of nearby underground metal structures (e.g., piping);

(VII) Existence of stray electric current;

(VIII) Existing corrosion-protection measures (e.g., coating, cathodic protection); and

(B) The type and degree of external corrosion protection that are needed to ensure the integrity of the tank system during the use of the tank system or component, consisting of one or more of the following:

(I) Corrosion-resistant materials of construction such as special alloys, fiberglass reinforced plastic, etc.;

(II) Corrosion-resistant coating (such as epoxy, fiberglass, etc.,) with cathodic protection (e.g., impressed current or sacrificial anodes); and

(III) Electrical isolation devices such as insulating joints, flanges, etc.

Note: The practices described in the National Association of Corrosion Engineers (NACE) standard, "Recommended Practice (RP-02-85)--Control of External Corrosion on Metallic Buried, Partially Buried, or Submerged Liquid Storage Systems," and the American Petroleum 
Institute (API) Publication 1632, "Cathodic Protection of Underground Petroleum Storage Tanks and Piping Systems, " may be used, where applicable, as guidelines in providing corrosion protection for tank systems.

(iv) For underground tank system components that are likely to be adversely affected by vehicular traffic, a determination of design or operational measures that will protect the tank system against potential damage; and

(v) Design considerations to ensure that:

(A) Tank foundations will maintain the load of a full tank;

(B) Tank systems will be anchored to prevent flotation or dislodgment where the tank system is either placed in a saturated zone, or is located less than five hundred feet from a fault which has had displacement in Holocene times; and

(C) Tank systems will withstand the effects of frost heave."

\section{REQUIREMENT SOURCE: WAC-173-303(940523) Section 640(3)(b)}

"The owner or operator must develop a schedule for conducting integrity assessments over the life of the tank to ensure that the tank retains its structural integrity and will not collapse, rupture or fail. The schedule must be based on the results of past integrity assessments, age of the tank system, materials of construction, characteristics of the waste, and any other relevant factors."

\section{REQUIREMINT SOURCE: WAC-173-303(940523) Section 640(3)(c)}

"The owner or operator of a new tank system must ensure that proper handling procedures are adhered to in order to prevent damage to the system during installation. Prior to covering, enclosing, or placing a new tank system or component in use, an independent, qualified installation inspector or an independent, qualified, registered professional engineer, either of whom is trained and experienced in the proper installation of tank systems or components, must inspect the system for the presence of any of the following items:

(i) Weld breaks;

(ii) Punctures;

(iii) Scrapes of protective coatings;

(iv) Cracks;

(v) Corrosion;

(vi) Other structural damage or inadequate construction/installation.

All discrepancies must be remedied before the tank system is covered, enclosed, or placed in use."

\section{REQUIREMENT SOURCE: WAC-173-303(940523) Section 640(3)(d)}

"New tank systems or components that are placed underground and that are backfilled must be provided with a backfill material that is a noncorrosive, porous, homogeneous substance and that is installed so that the backfill is placed completely around the tank and compacted to ensure that the tank and piping are fully and uniformly supported." 


\section{REQUIREMENT SOURCE: WAC-173-303(940523) Section 640(3)(e)}

"All new tanks and ancillary equipment must be tested for tightness prior to being covered, enclosed, or placed in use. If a tank system is found not to be tight, all repairs necessary to remedy the leak(s) in the system must be performed prior to the tank system being covered, enclosed, or placed into use."

\section{REQUIREMENT SOURCE: WAC-173-303(940523) Section 640(3)(f)}

"Ancillary equipment must be supported and protected against physical damage and excessive stress due to settlement, vibration, expansion, or contraction.

Note: The piping system installation procedures described in American Petroleum Institute (API) Publication 1615 (November 1979), "Installation of Underground Petroleum Storage Systems, " or ANSI Standard B31.3, "Petroleum Refinery Piping," and ANSI Standard B31.4 "Liquid Petroleum Transportation Piping System," may be used, where applicable, as guidelines for proper installation of piping systems. "

\section{REQUIREMENT SOURCE: WAC-173-303(940523) Section 640(3)(g)}

"The owner or operator must provide the type and degree of corrosion protection recommended by an independent corrosion expert, based on the information provided under (a)(iii) of this subsection, or other corrosion protection if the department believes other corrosion protection is necessary to ensure the integrity of the tank system during use of the tank system. The installation of a corrosion protection system that is field fabricated must be supervised by an independent corrosion expert to ensure proper installation."

\section{REQUIREMENT SOURCE: WAC-173-303(940523) Section 640(3)(h)}

"The owner or operator must obtain and keep on file at the facility written statements by those persons required to certify the design of the tank system and supervise the installation of the tank system in accordance with the requirements of (b) through (g) of this subsection, that attest that the tank system was properly designed and installed and that repairs, pursuant to (c) and (e) of this subsection, were performed. These written statements must also include the certification statement as required in WAC 173-303-810 (13)(a)."

\section{REQUIREMENT SOURCE: WAC-173-303(940523) Section 640(4)(a)}

"In order to prevent the release of dangerous waste or dangerous constituents to the environment, secondary containment that meets the requirements of this subsection must be provided (except as provided in ( $f$ ) and $(g)$ of this subsection):

(i) For all new tank systems or components, prior to their being put into service;

(ii) For all existing tank systems used to store or treat Dangerous Waste Nos. F020, F021, F022, F023, F026, and F027, within two years after January 12, 1989;

(iii) For those existing tank systems of known and documented age, within two years after January 12,1989 , or when the tank system has reached fifteen years of age, whichever comes later;

(iv) For those existing tank systems for which the age cannot be documented, within eight years of January 12,1989 ; but if the age of the facility is greater than seven years, secondary 
containment must be provided by the time the facility reaches fifteen years of age, or within two years of January 12, 1989, whichever comes later; and

(v) For tank systems that store or treat materials that become dangerous wastes subsequent to January 12,1989 , within the time intervals required in (a)(i) through (iv) of this subsection, except that the date that a material becomes a dangerous waste must be used in place of January 12, 1989."

\section{REQUIREMENT SOURCE: WAC-173-303(940523) Section 640(4)(b)}

"Secondary containment systems must be:

(i) Designed, installed, and operated to prevent any migration of wastes or accumulated liquid out of the system to the soil, ground water, or surface water at any time during the use of the tank system; and

(ii) Capable of detecting and collecting releases and accumulated liquids until the collected material is removed. "

\section{REQUIREMENT SOURCE: WAC-173-303(940523) Section 640(4)(c)}

"To meet the requirements of (b) of this subsection, secondary containment systems must be at a minimum:

(i) Constructed of or lined with materials that are compatible with the waste(s) to be placed in the tank system and must have sufficient strength and thickness to prevent failure owing to pressure gradients (including static head and external hydrological forces), physical contact with the waste to which it is exposed, climatic conditions, and the stress of daily operations (including stresses from nearby vehicular traffic);

(ii) Placed on a foundation or base capable of providing support to the secondary containment system, resistance to pressure gradients above and below the system, and capable of preventing failure due to settlement, compression, or uplift;

(iii) Provided with a leak-detection system that is designed and operated so that it will detect the failure of either the primary or secondary containment structure or the presence of any release of dangerous waste or accumulated liquid in the secondary containment system within twenty-four hours, or at the earliest practicable time if the owner or operator can demonstrate to the deparment that existing detection technologies or site conditions will not allow detection of a release within twenty-four hours; and

(iv) Sloped or otherwise designed or operated to drain and remove liquids resulting from leaks, spills, or precipitation. Spilled or leaked waste and accumulated precipitation must be removed from the secondary containment system within twenty-four hours, or in as timely a manner as is possible to prevent harm to human health and the environment, if the owner or operator can demonstrate to the department that removal of the released waste or accumulated precipitation cannot be accomplished within twenty-four hours."

\section{REQUIREMENT SOURCE: WAC-173-303(940523) Section 640(4)(d)}

"Secondary containment for tanks must include one or more of the following devices:

(i) A liner (external to the tank);

(ii) A vault;

(iii) A double-walled tank; or 
(iv) An equivalent device as approved by the department."

\section{REQUIREMENT SOURCE: WAC-173-303(940523) Section 640(4)(e)}

"In addition to the requirements of (b), (c), and (d) of this subsection, secondary containment systems must satisfy the following requirements:

(i) External liner systems must be:

(A) Designed or operated to contain one hundred percent of the capacity of the largest tank within its boundary;

(B) Designed or operated to prevent run-on or infiltration of precipitation into the secondary containment system unless the collection system has sufficient excess capacity to contain run-on or infiltration. Such additional capacity must be sufficient to contain precipitation from a twenty-five-year, twenty-four-hour rainfall event.

(C) Free of cracks or gaps; and

(D) Designed and installed to surround the tank completely and to cover all surrounding earth likely to come into contact with the waste if the waste is released from the tank(s) (i.e., capable of preventing lateral as well as vertical migration of the waste).

(ii) Vault systems must be:

(A) Designed or operated to contain one hundred percent of the capacity of the largest tank within its boundary;

(B) Designed or operated to prevent run-on or infiltration of precipitation into the secondary containment system unless the collection system has sufficient excess capacity to contain run-on or infiltration. Such additional capacity must be sufficient to contain precipitation from a twenty-five-year, twenty-four-hour rainfall event;

(C) Constructed with chemical-resistant water stops in place at all joints (if any);

(D) Provided with an impermeable interior coating or lining that is compatible with the stored waste and that will prevent migration of waste into the concrete;

(E) Provided with a means to protect against the formation of and ignition of vapors within the vault, if the waste being stored or treated:

(I) Meets the definition of ignitable waste under WAC 173-303-090 (5); or

(II) Meets the definition of reactive waste under WAC 173-303-090 (7), and may form an ignitable or explosive vapor.

(F) Provided with an exterior moisture barrier or be otherwise designed or operated to prevent migration of moisture into the vault if the vault is subject to hydraulic pressure.

(iii) Double-walled tanks must be:

(A) Designed as an integral structure (i.e., an inner tank completely enveloped within an outer shell) so that any release from the inner tank is contained by the outer shell; 
(B) Protected, if constructed of metal, from both corrosion of the primary tank interior and of the external surface of the outer shell; and

(C) Provided with a built-in continuous leak detection system capable of detecting a release within twenty-four hours, or at the earliest practicable time, if the owner or operator can demonstrate to the department, and the department concludes, that the existing detection technology or site conditions would not allow detection of a release within twenty-four hours.

Note: The provisions outlined in the Steel Tank Institute's (STI) "Standard for Dual Wall Underground Steel Storage Tanks" may be used as guidelines for aspects of the design of underground steel double-walled tanks."

\section{REQUIREMENT SOURCE: WAC-173-303(940523) Section 640(4)(f)}

${ }^{\text {n}}$ Ancillary equipment must be provided with secondary containment (e.g., trench, jacketing, double-walled piping) that meets the requirements of (b) and (c) of this subsection except for:

(i) Aboveground piping (exclusive of flanges, joints, valves, and other connections) that are visually inspected for leaks on a daily basis;

(ii) Welded flanges, welded joints, and welded connections, that are visually inspected for leaks on a daily basis;

(iii) Sealless or magnetic coupling pumps and sealless valves, that are visually inspected for leaks on a daily basis; and

(iv) Pressurized aboveground piping systems with automatic shut-off devices (e.g., excess flow check valves, flow metering shutdown devices, loss of pressure actuated shut-off devices) that are visually inspected for leaks on a daily basis."

\section{REQUIREMENT SOURCE: WAC-173-303(940523) Section 640(4)(i)}

"All tank systems, until such time as secondary containment that meets the requirements of this section is provided, must comply with the following:

(A) For nonenterable underground tanks, a leak test that meets the requirements of subsection (2)(c)(v) of this section or other tank integrity method, as approved or required by the department, must be conducted at least annually.

(B) For other than nonenterable underground tanks, the owner or operator must either conduct a leak test as in (i)(A) of this subsection or develop a schedule and procedure for an assessment of the overall condition of the tank system by an independent, qualified registered professional engineer. The schedule and procedure must be adequate to detect obvious cracks, leaks, and corrosion or erosion that may lead to cracks and leaks. The owner or operator must remove the stored waste from the tank, if necessary, to allow the condition of all internal tank surfaces to be assessed. The frequency of these assessments must be based on the material of construction of the tank and its ancillary equipment, the age of the system, the type of corrosion or erosion protection used, the rate of corrosion or erosion observed during the previous inspection, and the characteristics of the waste being stored or treated.

(C) For ancillary equipment, a leak test or other integrity assessment as approved by the department must be conducted at least annually.

Note: The practices described in the American Petroleum Institute (API) Publication Guide for Inspection of Refinery Equipment, Chapter XIII, "Atmospheric and Low-Pressure Storage 
Tanks," 4th edition, 1981, may be used, where applicable, as guidelines for assessing the overall condition of the tank system.

(D) The owner or operator must maintain on file at the facility a record of the results of the assessments conducted in accordance with (h)(iv)(A) through (C) of this subsection.

(E) If a tank system or component is found to be leaking or unfit for use as a result of the leak test or assessment in (h)(iv)(A) through (C) of this subsection, the owner or operator must comply with the requirements of subsection (7) of this section."

\section{REQUIREMENT SOURCE: WAC-173-303(940523) Section 640(5)(a)}

"Dangerous wastes or treatment reagents must not be placed in a tank system if they could cause the tank, its ancillary equipment, or the containment system to rupture, leak, corrode, or otherwise fail."

\section{REQUIREMENT SOURCE: WAC-173-303(940523) Section 640(5)(b)}

"The owner or operator must use appropriate controls and practices to prevent spills and overflows from tank or containment systems. These include at a minimum:

(i) Spill prevention controls (e.g., check valves, dry disconnect couplings);

(ii) Overfill prevention controls (e.g., level sensing devices, high level alarms, automatic feed cutoff, or bypass to a standby tank); and

(iii) Maintenance of sufficient freeboard in uncovered tanks to prevent overtopping by wave or wind action or by precipitation."

\section{REQUIREMENT SOURCE: WAC-173-303(940523) Section 640(5)(c)}

"The owner or operator must comply with the requirements of subsection (7) of this section if a leak or spill occurs in the tank system."

\section{REQUIREMENT SOURCE: WAC-173-303(940523) Section 640(5)(d)}

"All tank systems holding dangerous waste shall be marked with labels or signs to identify the waste contained in the tank. The label or sign shall be legible at a distance of at least fifty feet, and shall bear a legend which identifies the waste in a manner which adequately warns employees, emergency response personnel, and the public of the major risk(s) associated with the waste being stored or treated in the tank system(s).

(Note--If there already is a system in use that performs this function in accordance with local, state or federal regulations, then such system will be adequate.)"

\section{REQUIREMINT SOURCE: WAC-173-303(940523) Section 640(5)(e)}

"All tank systems holding EHW which is acutely or chronically toxic by inhalation must be designed to prevent escape of vapors, fumes, or other emissions into the air."

\section{REQUIREMENT SOURCE: WAC-173-303(940523) Section 640(6)(a)}

"The owner or operator must develop and follow a schedule and procedure for inspecting overfill controls." 


\section{REQUIREMENT SOURCE: WAC-173-303(940523) Section 640(6)(b)}

"The owner or operator must inspect at least once each operating day:

(i) Aboveground portions of the tank system, if any, to detect corrosion or releases of waste;

(ii) Data gathered from monitoring any leak detection equipment (e.g., pressure or temperature gauges, monitoring wells) to ensure that the tank system is being operated according to its design; and

(iii) The construction materials and the area immediately surrounding the externally accessible portion of the tank system, including the secondary containment system (e.g., dikes) to detect erosion or signs of releases of dangerous waste (e.g., wet spots, dead vegetation).

Note: WAC 173-303-320 requires the owner or operator to remedy any deterioration or malfunction he finds. Subsection (7) of this section requires the owner or operator to notify the department within twenty-four hours of confirming a leak. Also, 40 CFR Part 302 may require the owner or operator to notify the National Response Center of a release."

\section{REQUIREMENT SOURCE: WAC-173-303(940523) Section 640(O)(c)}

"The owner or operator must inspect cathodic protection systems, if present, according to, at a minimum, the following schedule to ensure that they are functioning properly:

(i) The proper operation of the cathodic protection system must be confirmed within six months after initial installation and annually thereafter; and

(ii) All sources of impressed current must be inspected and/or tested, as appropriate, at least bimonthly (i.e., every other month).

Note: The practices described in the National Association of Corrosion Engineers (NACE) standard, "Recommended Practice (RP-02-85)--Control of External Corrosion on Metallic Buried, Partially Buried, or Submerged Liquid Storage Systems," and the American Petroleum Institute (API) Publication 1632, "Cathodic Protection of Underground Petroleum Storage Tanks and Piping Systems, "may be used, where applicable, as guidelines in maintaining and inspecting cathodic protection systems."

\section{REQUIREMINT SOURCE: WAC-173-303(940523) Section 640(6)(d)}

"The owner or operator must document in the operating record of the facility an inspection of those items in (a) through (c) of this subsection. The owner or operator shall keep an inspection log including at least the date and time of the inspection, the printed name and the handwritten signature of the inspector, a notation of the observations made and the date and nature of any repairs or remedial actions taken. The log must be kept at the facility for at least five years from the date of inspection."

\section{REQUIREMENT SOURCE: WAC-173-303(940523) Section 640(7) and (7)(a)}

"(7) Response to leaks or spills and disposition of leaking or unfit-for-use tank systems.

A tank system or secondary containment system from which there has been a leak or spill, or which is unfit for use, must be removed from service immediately, and the owner or operator must satisfy the following requirements: 
(a) Cessation of use; prevent flow or addition of wastes. The owner or operator must immediately stop the flow of dangerous waste into the tank system or secondary containment system and inspect the system to determine the cause of the release."

\section{REQUIREMENT SOURCE: WAC-173-303(940523) Section 640(7)(b)(i)}

"If the release was from the tank system, the owner/operator must, within twenty-four hours after detection of the leak or, if the owner/operator demonstrates that it is not possible, at the earliest practicable time, remove as much of the waste as is necessary to prevent further release of dangerous waste to the environment and to allow inspection and repair of the tank system to be performed."

\section{REQUIREMENT SOURCE: WAC-173-303(940523) Section 640(7)(b)(ii)}

"If the material released was to a secondary containment system, all released materials must be removed within twenty-four hours or in as timely a manner as is possible to prevent harm to human health and the environment."

\section{REQUIREMINT SOURCE: WAC-173-303(940523) Section 640(7)(c)}

"Containment of visible releases to the environment. The owner/operator must immediately conduct a visual inspection of the release and, based upon that inspection:

(i) Prevent further migration of the leak or spill to soils or surface water; and

(ii) Remove, and properly dispose of, any visible contamination of the soil or surface water."

\section{REQUIREMENT SOURCE: WAC-173-303(940523) Section 640(7)(d)}

"Notifications, reports.

(i) Any release to the environment, except as provided in (d)(ii) of this subsection, must be reported to the department within twenty-four hours of its detection. Any release above the "reportable quantity" must also be reported to the National Response Center pursuant to 40 CFR Part 302.

(ii) A leak or spill of dangerous waste is exempted from the requirements of (d) of this subsection if it is:

(A) Less than or equal to a quantity of one pound, or the "Reportable Quantity" (RQ) established in 40 CFR Part 302, whichever is less; and

(B) Immediately contained and cleaned-up.

(iii) Within thirty days of detection of a release to the environment, a report containing the following information must be submitted to the department:

(A) Likely route of migration of the release;

(B) Characteristics of the surrounding soil (soil composition, geology, hydrogeology, climate);

(C) Results of any monitoring or sampling conducted in connection with the release (if available). If sampling or monitoring data relating to the release are not available within thirty days, these data must be submitted to the department as soon as they become available;

(D) Proximity to downgradient drinking water, surface water, and populated areas; and 
(E) Description of response actions taken or planned."

\section{REQUIREMENT SOURCE: WAC-173-303(940523) Section 640(7)(e) and (7)(e)(i)}

"(e) Provision of secondary containment, repair, or closure.

(i) Unless the owner/operator satisfies the requirements of (e)(ii) through (iv) of this subsection, the tank system must be closed in accordance with subsection (8) of this section."

\section{REQUIREMENT SOURCE: WAC-173-303(940523) Section 640(7)(e)(ii)}

"If the cause of the release was a spill that has not damaged the integrity of the system, the owner/operator may return the system to service as soon as the released waste is removed and repairs, if necessary, are made."

\section{REQUIREMENT SOURCE: WAC-173-303(940523) Section 640(7)(e)(iii)}

"If the cause of the release was a leak from the primary tank system into the secondary containment system, the system must be repaired prior to returning the tank system to service."

\section{REQUIREMENT SOURCE: WAC-173-303(940523) Section 640(7)(e)(iv)}

"If the source of the release was a leak to the environment from a component of a tank system without secondary containment, the owner/operator must provide the component of the system from which the leak occurred with secondary containment that satisfies the requirements of subsection (4) of this section before it can be returned to service, unless the source of the leak is an aboveground portion of a tank system that can be inspected visually. If the source is an aboveground component that can be inspected visually, the component must be repaired and may be returned to service without secondary containment as long as the requirements of $(f)$ of this subsection are satisfied. If a component is replaced to comply with the requirements of this subitem, that component must satisfy the requirements for new tank systems or components in subsections (3) and (4) of this section. Additionally, if a leak has occurred in any portion of a tank system component that is not readily accessible for visual inspection (e.g., the bottom of an inground or onground tank), the entire component must be provided with secondary containment in accordance with subsection (4) of this section prior to being returned to use."

\section{REQUIREMENT SOURCE: WAC-173-303(940523) Section 640(7)(f)}

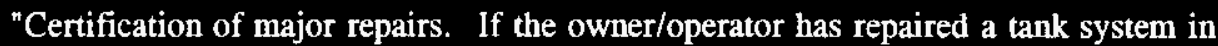
accordance with (e) of this subsection, and the repair has been extensive (e.g., installation of an internal liner; repair of a ruptured primary containment or secondary containment vessel), the tank system must not be returned to service unless the owner/operator has obtained a certification by an independent, qualified, registered, professional engineer in accordance with WAC 173-303-810 (13)(a) that the repaired system is capable of handling dangerous wastes without release for the intended life of the system. This certification must be submitted to the department within seven days after returning the tank system to use.

Note: See WAC 173-303-320 for the requirements necessary to remedy a failure. Also, 40 CFR Part 302 may require the owner or operator to notify the National Response Center of certain releases." 


\section{REQUIREMENT SOURCE: WAC-173-303(940523) Section 640(8)(a)}

"At closure of a tank system, the owner or operator must remove or decontaminate all waste residues, contaminated containment system components (liners, etc.), contaminated soils, and structures and equipment contaminated with waste, and manage them as dangerous waste, unless WAC 173-303-070 (2)(a) applies. The closure plan, closure activities, cost estimates for closure, and financial responsibility for tank systems must meet all of the requirements specified in WAC 173-303-610 and 173-303-620."

\section{REQUIREMENT SOURCE: WAC-173-303(940523) Section 640(8)(b)}

"If the owner or operator demonstrates that not all contaminated soils can be practicably removed or decontaminated as required in (a) of this subsection, then the owner or operator must close the tank system and perform post-closure care in accordance with the closure and post-closure care requirements that apply to landfills (see WAC 173-303-665 (6)). In addition, for the purposes of closure, post-closure, and financial responsibility, such a tank system is then considered to be a landfill, and the owner or operator must meet all of the requirements for landfills specified in WAC 173-303-610 and 173-303-620."

\section{REQUIREMIENT SOURCE: WAC-173-303(940523) Section 640(8)(c)}

"If an owner or operator has a tank system that does not have secondary containment that meets the requirements of subsection (4)(b) through (f) of this section and is not exempt from the secondary containment requirements in accordance with subsection $(4)(\mathrm{g})$ of this section, then:

(i) The closure plan for the tank system must include both a plan for complying with (a) of this subsection and a contingent plan for complying with (b) of this subsection.

(ii) A contingent post-closure plan for complying with (b) of this subsection must be prepared and submitted as part of the permit application.

(iii) The cost estimates calculated for closure and post-closure care must reflect the costs of complying with the contingent closure plan and the contingent post-closure plan, if those costs are greater than the costs of complying with the closure plan prepared for the expected closure under (a) of this subsection.

(iv) Financial assurance must be based on the cost estimates in (c)(iii) of this subsection.

(v) For the purposes of the contingent closure and post-closure plans, such a tank system is considered to be a landfill, and the contingent plans must meet all of the closure, post-closure, and financial responsibility requirements for landfills under this chapter (WAC 173-303-610 and 173-303-620)."

\section{REQUIREMENT SOURCE: WAC-173-303(940523) Section 640(9)(a)}

"Ignitable or reactive waste must not be placed in tank systems unless:

(i) The waste is treated, rendered, or mixed before or immediately after placement in the tank system so that the resulting waste, mixture, or dissolution of material no longer meets the definition of ignitable or reactive waste under WAC 173-303-090, and 173-303-395 (1)(b) is complied with; or

(ii) The waste is stored or treated in such a way that it is protected from any material or conditions which may cause the waste to ignite or react; or 
(iii) The tank system is used solely for emergencies."

\section{REQUIREMINT SOURCE: WAC-173-303(940523) Section 640(9)(b)}

"The owner or operator of a facility which treats or stores ignitable or reactive waste in tanks must locate the tanks in a manner equivalent to the National Fire Protection Association's buffer zone requirements for tanks, contained in Tables 2-1 through 2-6 of the NFPA-30 Flammable and Combustible Liquids Code - 1981, or as required by state and local fire codes when such codes are more stringent. The owner or operator shall also comply with the requirements of WAC 173-303-395(1)(d). "

\section{REQUIREMENT SOURCE: WAC-173-303(940523) Section 640(10)(a)}

"Incompatible wastes, or incompatible wastes and materials, must not be placed in the same tank system, unless WAC 173-303-395 (1)(b) is complied with."

\section{REQUIREMENT SOURCE: WAC-173-303(940523) Section 640(10)(b)}

"Dangerous waste must not be placed in a tank system that has not been decontaminated and that previously held an incompatible waste or material, unless WAC 173-303-395 (1)(b) is complied with."

\section{Closure}

This subelement specifies requirements for TSD Closure.

\section{REQUIREMENT SOURCE: TPA Attachment 2, Section 6.3.1}

\section{"Clean Closure}

In some cases, it may be possible to remove all hazardous wastes and constituents associated with a TSD unit and thereby achieve "clean closure." The process to complete clean closure of any unit will be carried out in accordance with all applicable requirements described in 173-303 WAC and 40 CFR 270.1. Any demonstration for clean closure of a disposal unit, or selected treatment or storage units as determined by the lead regulatory agency, must include documentation that groundwater and soils have not been adversely impacted by that TSD group/unit, as described in 173-303-645 WAC.

After completion of clean closure activities, a closed storage unit may be reused for generator accumulation (less than 90 day storage)."

\section{REQUIREMENT SOURCE: WAC-173-303(940523) Section 610(1)(a)}

"Subsections (2) through (6) of this section, (which concern closure), apply to the owners and operators of all dangerous waste facilities."

\section{REQUIREMENT SOURCE: WAC-173-303(940523) Section 610(1)(c)}

"For the purposes of the closure and postclosure requirements, any portion of a facility which closes is subject to the applicable closure and postclosure standards even if the rest of the facility does not close and continues to operate." 


\section{REQUIREMENT SOURCE: WAC-173-303(940523) Section 610(10)(a)}

"No later than sixty days after certification of closure of each dangerous waste disposal unit, the owner or operator must submit to the local zoning authority, or the authority with jurisdiction over local land use, and to the department a record of the type, location, and quantity of dangerous wastes disposed of within each cell or other disposal unit of the facility. For hazardous wastes (as defined in WAC 173-303-040) disposed of before January 12, 1981, the owner or operator must identify the type, location, and quantity of the dangerous wastes to the best of his knowledge and in accordance with any records he has kept."

\section{REQUIREMINT SOURCE: WAC-173-303(940523) Section 610(10)(b)}

"Within sixty days of certification of closure of the first dangerous waste disposal unit and within sixty days of certification of closure of the last dangerous waste disposal unit, the owner or operator must:

(i) Record, in accordance with state law, a notation on the deed to the facility property, or on some other instrument which is normally examined during title search, that will in perpetuity notify any potential purchaser of the property that:

(A) The land has been used to manage dangerous wastes;

(B) Its use is restricted under this section; and

(C) The survey plat and record of the type, location, and quantity of dangerous wastes disposed of within each cell or other dangerous waste disposal unit of the facility required in subsection (9) of this section have been filed with the local zoning authority, or the authority with jurisdiction over local land use, and with the department; and

(ii) Submit a certification, signed by the owner or operator, that he has recorded the notation specified in

(b)(i) of this subsection, including a copy of the document in which the notation has been placed, to the department."

\section{REQUIREMENT SOURCE: WAC-173-303(940523) Section 610(10)(c)}

"If the owner or operator or any subsequent owner of the land upon which a dangerous waste facility was located wishes to remove dangerous wastes and dangerous waste residues, the liner, if any, or contaminated soils, he must request a modification to the postclosure permit in accordance with the applicable requirements in WAC 173-303-800 through 173-303-840. The owner or operator must demonstrate that the removal of dangerous wastes will satisfy the criteria of subsection (7)(d) of this section. By removing dangerous waste, the owner or operator may become a generator of dangerous waste and must manage it in accordance with all applicable requirements of this chapter.If he is granted a permit modification or otherwise granted approval to conduct such removal activities, the owner or operator may request that the department approve either:

(i) The removal of the notation on the deed to the facility property or other instrument normally examined during title search; or

(ii) The addition of a notation to the deed or instrument indicating the removal of the dangerous waste." 


\section{REQUIREMENT SOURCE: WAC-173-303(940523) Section 610(11)}

"Certification of completion of postclosure care. No later than sixty days after completion of the established postclosure care period for each dangerous waste disposal unit, the owner or operator must submit to the department, by registered mail, a certification that the postclosure care period for the dangerous waste disposal unit was performed in accordance with the specifications in the approved postclosure plan. The certification must be signed by the owner or operator and an independent registered professional engineer. Documentation supporting the independent registered professional engineer's certification must be furnished to the department upon request until he releases the owner or operator from the financial assurance requirements for postclosure care under WAC 173-303-620 (6)."

\section{REQUIREMIENT SOURCE: WAC-173-303(940523) Section 610(2) and (2)(a)}

"(2) Closure performance standard. The owner or operator must close the facility in a manner that:

(a)(i) Minimizes the need for further maintenance;

(ii) Controls, minimizes or eliminates to the extent necessary to protect human health and the environment, postclosure escape of dangerous waste, dangerous constituents, leachate, contaminated run-off, or dangerous waste decomposition products to the ground, surface water, ground water, or the atmosphere; and

(iii) Returns the land to the appearance and use of surrounding land areas to the degree possible given the nature of the previous dangerous waste activity."

\section{REQUIREMENT SOURCE: WAC-173-303(940523) Section 610(2)(b)}

"Where the closure requirements of this section, or of WAC 173-303-630(10), 173-303-640 (8), 173-303-650 (6), 173-303-655 (8), 173-303-660 (9), 173-303-670 (8), or 173-303-680 (2) through (4) call for the removal or decontamination of dangerous wastes, waste residues, or equipment, bases, liners, soils or other materials containing or contaminated with dangerous wastes or waste residue, then such removal or decontamination must assure that the levels of dangerous waste or dangerous waste constituents or residues do not exceed:

(i) For soils, ground water, surface water, and air, the numeric cleanup levels calculated using residential exposure assumptions according to the Model Toxics Control Act Regulations, chapter 173-340 WAC as now or hereafter amended. Primarily, these will be numeric cleanup levels calculated according to MTCA Method B, although MTCA Method A may be used as appropriate, see WAC 173-340-700 through 173-340-760, excluding WAC 173-340-745; and

(ii) For all structures, equipment, bases, liners, etc., clean closure standards shall be set by the department on a case-by-case basis in accordance with the closure performance standards of WAC 173-303-610 (2)(a)(ii) and in a manner that minimizes or eliminates post-closure escape of dangerous waste constituents."

\section{REQUIREMENT SOURCE: WAC-173-303(940523) Section 610(5)}

"Disposal or decontamination of equipment, structures and soils. During the partial and final closure periods, all contaminated equipment, structures and soils must be properly disposed of or decontaminated unless otherwise specified in WAC 173-303-640 (8), 173-303-650 (6), 173-303-655 (8), 173-303-660 (9), 173-303-665 (6), or under the authority of WAC 173-303-680 (2) and (4). By removing any dangerous wastes or dangerous constituents during partial and final closure, the owner or operator may become a generator of dangerous waste 
and must handle that waste in accordance with all applicable requirements of WAC 173-303-170 through 173-303-230."

\section{REQUIREMENT SOURCE: WAC-173-303(940523) Section 610(6)}

"Certification of closure. Within sixty days of completion of closure of each dangerous waste management unit (including tank systems and container storage areas), and within sixty days of the completion of final closure, the owner or operator must submit to the department by registered mail, a certification that the dangerous waste management unit or facility, as applicable, has been closed in accordance with the specifications in the approved closure plan. The certification must be signed by the owner or operator and by an independent registered professional engineer. Documentation supporting the independent registered professional engineer's certification must be furnished to the department upon request until it releases the owner or operator from the financial assurance requirements for closure under WAC $173-303-620$ (4)."

\section{REQUIREMENT SOURCE: WAC-173-303(940523) Section 610(7)(a)}

"Postclosure care for each dangerous waste management unit subject to postclosure requirements must begin after completion of closure of the unit and continue for thirty years after that date and must consist of at least the following:

(i) Ground water monitoring and reporting as applicable; and

(ii) Maintenance and monitoring of waste containment systems as applicable."

\section{REQUIREMENT SOURCE: WAC-173-303(940523) Section 610(7)(b)}

"Any time preceding partial closure of a dangerous waste management unit subject to postclosure care requirements or final closure, or any time during the postclosure period for a particular unit, the department may, in accordance with the permit modification procedures in WAC 173-303-800 through 173-303-840:

(i) Shorten the postclosure care period applicable to the dangerous waste management unit, or facility, if all disposal units have been closed, if it finds that the reduced period is sufficient to protect human health and the environment (e.g., leachate or ground water monitoring results, characteristics of the dangerous waste, application of advanced technology, or alternative disposal, treatment, or reuse techniques indicate that the dangerous waste management unit or facility is secure); or

(ii) Extend the postclosure care period applicable to the dangerous waste management unit or facility if it finds that the extended period is necessary to protect human health and the environment (e.g., leachate or ground water monitoring results indicate a potential for migration of dangerous waste at levels which may be harmful to human health and the environment)."

\section{REQUIREMENT SOURCE: WAC-173-303(940523) Section 610(7)(c)}

"The department may require, at partial or final closure, continuation of any of the security requirements of WAC 173-303-310 during part or all of the postclosure period when:

(i) Dangerous wastes may remain exposed after completion of partial or final closure; or

(ii) Access by the public or domestic livestock may pose a hazard to human health." 


\section{REQUIREMENT SOURCE: WAC-173-303(940523) Section 610(7)(d)}

"Postclosure use of property on or in which dangerous wastes remain after partial or final closure must never be allowed to disturb the integrity of the final cover, liner(s), or any other components of any containment system, or the function of the facility's monitoring systems, unless the department finds that the disturbance:

(i) Is necessary to the proposed use of the property, and will not increase the potential hazard to human health or the environment; or

(ii) Is necessary to reduce a threat to human health or the environment."

\section{REQUIREMINT SOURCE: WAC-173-303(940523) Section 610(7)(e)}

"All postclosure care activities must be in accordance with the provisions of the approved postclosure plan as specified in subsection (8) of this section."

\section{REQUIREMENT SOURCE: WAC-173-303(940523) Section 610(8)(a)}

"The owner or operator of a dangerous waste disposal unit must have a written postclosure plan. In addition, certain surface impoundments and certain piles from which the owner or operator intends to remove or decontaminate the dangerous wastes at partial or final closure are required by WAC 173-303-650 and 173-303-660, respectively, to have written contingent postclosure plans. Owners or operators of surface impoundments and waste piles not otherwise required to prepare contingent postclosure plans under WAC 173-303-650 or 173-303-660 must submit a postclosure plan to the department within ninety days from the date that the owner or operator or department determines that the dangerous waste management unit must be closed as a landfill, subject to the postclosure requirements. The plan must be submitted with the permit application, in accordance with WAC 173-303-806, and approved by the department as part of the permit issuance procedures under WAC 173-303-840. The approved postclosure plan will become a condition of any permit issued."

\section{REQUIREMENT SOURCE: WAC-173-303(940523) Section 610(8)(b)}

"For each dangerous waste management unit subject to the requirements of this subsection, the postclosure plan must identify the activities which will be carried on after closure and the frequency of these activities, and include at least:

(i) A description of the planned ground water monitoring activities and frequencies at which they will be performed;

(ii) A description of the planned maintenance activities, and frequencies at which they will be performed, to ensure:

(A) The integrity of the cap and final cover or other containment structures where applicable; and

(B) The function of the facility monitoring equipment;

(iii) And the name, address, and phone number of the person or office to contact about the dangerous waste disposal unit or facility during the postclosure care period." 


\section{REQUIREMENT SOURCE: WAC-173-303(940523) Section 610(8)(c)}

"Until final closure of the facility, a copy of the approved postclosure plan must be furnished to the department upon request, including request by mail. After final closure has been certified, the person or office specified in (b)(iii) of this subsection must keep the approved postclosure plan during the remainder of the postclosure period. ${ }^{n}$

\section{REQUIREMENT SOURCE: WAC-173-303(940523) Section 610(8)(d)}

"Amendment of plan. The owner or operator must submit a written notification of or request for a permit modification to authorize a change in the approved postclosure plan in accordance with the applicable requirements of WAC 173-303-800 through 173-303-840. The written notification or request must include a copy of the amended postclosure plan for review or approval by the department."

\section{REQUIREMENT SOURCE: WAC-173-303(940523) Section 610(8)(d)(i)}

"The owner or operator may submit a written notification or request to the department for a permit modification to amend the postclosure plan at any time during the active life of the facility or during the postclosure care period."

\section{REQUIREMENT SOURCE: WAC-173-303(940523) Section 610(8)(d)(ii)}

"The owner or operator must submit a written notification of or request for a permit modification to authorize a change in the approved postclosure plan whenever:

(A) Changes in operating plans or facility design affect the approved postclosure plan; or

(B) There is a change in the expected year of final closure, if applicable; or

(C) Events which occur during the active life of the facility, including partial and final closures, affect the approved postclosure plan."

\section{REQUIREMENT SOURCE: WAC-173-303(940523) Section 610(8)(d)(iii)}

"The owner or operator must submit a written request for a permit modification at least sixty days prior to the proposed change in facility design or operation, or no later than sixty days after an unexpected event has occurred which has affected the postclosure plan. An owner or operator of a surface impoundment or waste pile that intends to remove all dangerous waste at closure and is not otherwise required to submit a contingent postclosure plan under WAC 173-303-650 or 173-303-660 must submit a postclosure plan to the department no later than ninety days after the date that the owner or operator or department determines that the dangerous waste management unit must be closed as a landfill, subject to the requirements of WAC 173-303-665. The department will approve, disapprove, or modify this plan in accordance with the procedures in WAC 173-303-800 through 173-303-840. The approved postclosure plan will become a permit condition."

\section{REQUIREMENT SOURCE: WAC-173-303(940523) Section 610(8)(d)(iv)}

"The department may request modifications to the plan under the conditions described in (d)(ii) of this subsection. The owner or operator must submit the modified plan no later than sixty days after the department's request, or no later than ninety days if the unit is a surface impoundment or waste pile not previously required to prepare a contingent postclosure plan. Any modifications requested by the department will be approved, disapproved, or modified in accordance with the procedures in WAC 173-303-800 through 173-303-840." 


\section{REQUIREMENT SOURCE: WAC-173-303(940523) Section 610(9)}

"Notice to local land authority. No later than the submission of the certification of closure of each dangerous waste disposal unit, the owner or operator of a disposal facility must submit to the local zoning authority or the authority with jurisdiction over local land use and to the department a survey plat indicating the location and dimensions of landfill cells or other dangerous waste disposal units with respect to permanently surveyed benchmarks. This plat must be prepared and certified by a professional land surveyor. The plat filed with the local zoning authority or the authority with jurisdiction over local land use must contain a note, prominently displayed, which states the owner's or operator's obligation to restrict disturbance of the dangerous waste disposal unit in accordance with the applicable requirements of this section.In addition, no later than sixty days after certification of closure of each dangerous waste disposal unit, the owner or operator must submit to the local zoning authority or the authority with jurisdiction over local land use and to the department, a record of the type, location, and quantity of dangerous wastes disposed of within each cell or other disposal unit of the facility. For wastes disposed of before November 19, 1980 (March 12, 1982, for facilities subject to this chapter but not subject to 40 CFR Part 264), the owner or operator must identify the type, location, and quantity of the dangerous wastes to the best of his knowledge and in accordance with any records he has kept."

\section{Used Oil}

\section{REQUIREMENT SOURCE: 40CFR279 Part 10(b)(1)}

"Mixtures of used oil and hazardous waste--

Listed hazardous waste.

(i) Mixtures of used oil and hazardous waste that is listed in subpart D of part 261 of this chapter are subject to regulation as hazardous waste under parts 260 through $266,268,270$, and 124 of this chapter, rather than as used oil under this part.

(ii) Rebuttable presumption for used oil. Used oil containing more than 1,000 ppm total halogens is presumed to be a hazardous waste because it has been mixed with halogenated hazardous waste listed in subpart D of part 261 of this chapter. Persons may rebut this presumption by demonstrating that the used oil does not contain hazardous waste (for example, by using an analytical method from SW-846, Edition III, to show that the used oil does not contain significant concentrations of halogenated hazardous constituents listed in appendix VIII of part 261 of this chapter). EPA Publication SW-846, Third Edition, is available from the Government Printing Office, Superintendent of Documents, P.O. Box 371954, Pittsburgh, PA 15250-7954, (202) 783-3238 (document number 955-001-00000-1).

(A) The rebuttable presumption does not apply to metalworking oils/fluids containing chlorinated paraffins, if they are processed, through a tolling arrangement as described in 279.24(c), to reclaim metalworking oils/fluids. The presumption does apply to metalworking oils/fluids if such oils/fluids are recycled in any other manner, or disposed.

(B) The rebuttable presumption does not apply to used oils contaminated with chlorofluorocarbons (CFCs) removed from refrigeration units where the CFCs are destined for reclamation. The rebuttable presumption does apply to used oils contaminated with CFCs that have been mixed with used oil from sources other than refrigeration units."

\section{REQUIREMENT SOURCE: 40CFR279 Part 10(b)(2)}

"Characteristic hazardous waste. Mixtures of used oil and hazardous waste that solely exhibits one or more of the hazardous waste characteristic identified in subpart $C$ of part 261 of this chapter and mixtures of used oil and hazardous waste that is listed in subpart D solely because 
it exhibits one or more of the characteristics of hazardous waste identified in subpart $\mathrm{C}$ are subject to:

(i) Except as provided in paragraph (b)(2)(iii) of this section, regulation as hazardous waste under parts 260 through $266,268,270$, and 124 of this chapter rather than as used oil under this part, if the resultant mixture exhibits any characteristics of hazardous waste identified in subpart $C$ of part 261 of this chapter; or

(ii) Except as specified in 279.10 (b)(2)(iii) regulation as used oil under this part, if the resultant mixture does not exhibit any characteristics of hazardous waste identified under subpart $\mathrm{C}$ of part 261 of this chapter.

(iii) Regulation as used oil under this part, if the mixture is of used oil and a waste which is hazardous solely because it exhibits the characteristic of ignitability (e.g., ignitable-only mineral spirits), provided that the resultant mixture does not exhibit the characteristic of ignitability under 261.21 of this chapter."

\section{REQUIREMENT SOURCE: 40CFR279 Part 21}

"Hazardous waste mixing.

(a) Mixtures of used oil and hazardous waste must be managed in accordance with 279.10(b).

(b) The rebuttable presumption for used oil of 279.10 (b)(1)(ii) applies to used oil managed by generators. Under the rebuttable presumption for used oil of $279.10(\mathrm{~b})(1)(\mathrm{ii})$, used oil containing greater than 1,000 ppm total halogens is presumed to be a hazardous waste and thus must be managed as hazardous waste and not as used oil unless the presumption is rebutted.However, the rebuttable presumption does not apply to certain metalworking oils/fluids and certain used oils removed from refrigeration units."

\section{REQUIREMENT SOURCE: 40CFR279 Part 22}

"279.22 Used oil storage. Used oil generators are subject to all applicable Spill Prevention, Control and Countermeasures (40 CFR part 112) in addition to the requirements of this Subpart. Used oil generators are also subject to the Underground Storage Tank ( 40 CFR part 280) standards for used oil stored in underground tanks whether or not the used oil exhibits any characteristics of hazardous waste, in addition to the requirements of this subpart.

(a) Storage units. Used oil generators shall not store used oil in units other than tanks, containers, or units subject to regulation under parts 264 or 265 of this chapter.

(b) Condition of units. Containers and aboveground tanks used to store used oil at generator facilities must be:

(1) In good condition (no severe rusting, apparent structural defects or deterioration); and

(2) Not leaking (no visible leaks).

(c) Labels.

(1) Containers and aboveground tanks used to store used oil at generator facilities must be labeled or marked clearly with the words "Used Oil."

(2) Fill pipes used to transfer used oil into underground storage tanks at generator facilities must be labeled or marked clearly with the words "Used Oil." 
(d) Response to releases. Upon detection of a release of used oil to the environment not subject to the requirements of part 280 , subpart $F$ of this chapter which has occurred after the effective date of the authorized used oil program for the State in which the release is located, a generator must perform the following cleanup steps:

(1) Stop the release;

(2) Contain the released used oil;

(3) Clean up and manage properly the released used oil and other materials; and

(4) If necessary to prevent future releases, repair or replace any leaking used oil storage containers or tanks prior to returning them to service."

\section{REQUIREMINT SOURCE: 40CFR279 Part 81}

\section{"279.81 Disposal.}

(a) Disposal of hazardous used oils. Used oils that are identified as a hazardous waste and cannot be recycled in accordance with this part must be managed in accordance with the hazardous waste management requirements of parts 260 through 266, 268, 270 and 124 of this chapter.

(b) Disposal of nonhazardous used oils. Used oils that are not hazardous wastes and cannot be recycled under this part must be disposed in accordance with the requirements of parts 257 and 258 of this chapter."

\section{REQUIREMENT SOURCE: WAC-173-303(940523) Section 515(1)(a)}

"This section applies to used oil that is burned for energy recovery in any boiler or industrial furnace that is not regulated under Subpart O of 40 CFR Part 265 or WAC 173-303-670, if such used oil:

(i) Exhibits any characteristic of a dangerous waste identified in WAC 173-303-090; or

(ii) Is designated as DW solely through WAC $173-303-100$; or

(iii) Is designated solely as W001."

\section{REQUIREMENT SOURCE: WAC-173-303(940523) Section 515(1)(b)}

"(b)(i) This section does not apply to used oil burned for energy recovery that is mixed with a listed waste (except as provided in (a)(iii) of this subsection) or that is designated as EHW through WAC 173-303-100. Such used oil is subject to the requirements of WAC 173-303-510.

(ii) Used oil containing more than $1000 \mathrm{ppm}$ of total halogens is presumed to be a dangerous waste because it has been mixed with halogenated dangerous waste listed in WAC 173-303-9903 or 173-303-9904. Such dangerous wastes are subject to the requirements of WAC 173-303-510. Persons may rebut this presumption by demonstrating that the used oil does not contain dangerous waste (for example, by showing that the used oil does not contain significant concentrations of halogenated dangerous constituents listed in WAC 173-303-9905).

(iii) This section does not apply to used oil that is designated for any reason other than being listed as W001 if such used oil is burned for energy recovery by the generator of the used oil in his own marine or diesel engines." 


\section{REQUIREMENT SOURCE: WAC-173-303(940523) Section 515(1)(c)}

"If a used oil subject to this section does not exceed any of the specifications of Table 1 , it is subject only to the analysis and recordkeeping requirements under subsection (4)(b)(i) and (vi) of this section; otherwise, it is subject to all applicable provisions of this section."

\section{REQUIREMENT SOURCE: WAC-173-303(940523) Section 515(1)(d)}

"For the purposes of this chapter:

(i) "Used oil" means any oil that has been refined from crude oil, used, and, as a result of such use, is contaminated by physical or chemical impurities;

(ii) Used oil fuel includes any fuel produced from used oil by processing, blending, or other treatments;

(iii) Used oil fuel that exceeds any specification level (described in Table 1) is termed "off-specification used oil fuel."

TABLE 1

USED OIL EXCEEDING ANY SPECIFICATION LEVEL IS SUBJECT TO THIS SECTION WHEN BURNED FOR ENERGY RECOVERY

Constituent/property

Arsenic

Cadmium

Chromium

Lead

Flash point

Total halogens

Polychlorinated Biphenyls
Allowable level

5 ppm maximum

$2 \mathrm{ppm}$ maximum

$10 \mathrm{ppm}$ maximum

100 ppm maximum

$100^{\circ} \mathrm{F}$ minimum

$4,000 \mathrm{ppm}$ maximum*

2 ppm maximum

* Used oil containing more than $1,000 \mathrm{ppm}$ total halogens is presumed to be a dangerous waste under the rebuttable presumption provided under (b)(ii) of this subsection. Such used oil is subject to WAC 173-303-510 rather than this section when burned for energy recovery unless the presumption of mixing can be successfully rebutted. "

\section{RADIOLOGICAL PERFORMANCE ASSESSMMENT}

Not applicable; Tank Farms is not a permanent waste disposal facility.

\section{WASTE CATEGORIES}

Not applicable; Waste Categories have been addressed as Program requirements in elements 16.1 through 16.9.

\section{KEY INTERFACES}

This element describes key functional area interfaces including Engineering, Emergency Planning and Management, Environmental Protection, Occupational Safety and Health (OSH), Packaging and Transportation, Quality Assurance, Radiation Protection, and Training and Qualification. 


\section{$\underline{16.11 .1}$}

$\underline{16.11 .2}$

$\underline{16.11 .3}$

$\underline{16.11 .4}$

$\underline{16.11 .5}$

$\underline{16.11 .6}$

\section{Environmental Protection}

The Environmental Protection Functional Area develops and implements programs that direct the WM Program and provides oversight, confirmation, and independent verification of on-going WM program. Specific environmental programmatic interfaces for the WM Program should include the following:

a. A process which ensures programs are in place requiring monitoring, surveillance, and inspection and are designed to prevent, detect, and mitigate leaks, spills, uncontrolled effluent discharges.

b. A process that ensures the appropriate identification of necessary environmental permits, permit application processes, permit contents, permit modification, permit tracking systems, and closure.

c. A process in which facilities must observe to comply with environmental protection laws and regulations.

d. A process which addresses the development of an environmental database that defines a reference point against which all future activities may be measured.

\section{Emergency Management}

The Emergency Management Functional Area addresses the centralized management within WM regarding emergency planning, preparedness, and response activities. These functions are segregated into two major areas; the Transportation Emergency Preparedness Program and the site Emergency Preparedness Program.

\section{Safequards and Security}

The Safeguards and Security Functional Area is not applicable to Tank Farms.

\section{Engineering Program}

The WM Functional Area interfaces with the Engineering Program Functional Area in that the engineering program must have organizational interaction with state or federal regulators in the design requirements for permitted waste facilities. In addition, changes to waste operations and modification of processes may require regulatory approval.

\section{Fire Protection}

The Fire Protection Functional Area interfaces with the WM Functional Area in that the Fire Protection Functional Area includes administrative control of hazardous substances or processes, inspection, maintenance and testing of fire protection features and for other relevant fire protection activities. Waste generation, accumulation, storage, treatment and disposal facilities would need to be included in the program establishing such hazard controls.

\section{Packaging and Transportation}

The Packaging and Transportation Functional Area addresses and ensures all hazardous materials (particularly radioactive), substances, and waste, can be efficiently, economically, safely, and legally packaged and transported. The Packaging and Transportation functional area maintains the responsibility with any waste packaging and transport of materials from the areas within the site boundary. 
$\underline{16.11 .7}$

$\underline{16.11 .8}$

16.11 .9

$\underline{16.11 .10}$

$\underline{16.11 .11}$

16.12

16.12 .1

\section{Occupational Safety and Health}

The OS\&H Functional Area addresses broad DOE safety and health goals and objectives and incorporates them into site-specific Westinghouse Hanford procedures and requirements. The WM Program must rely on the OS\&H functional area for establishing the health and safety controls required to perform WM functions. Specifically, the OS\&H functional area provides implementation procedures to control hazardous or toxic materials; physical hazards; hazards identification, surveillance, and communication; asbestos removal operation; hazardous materials handling and emergency response; posting of danger signs and tags or safety instructional materials; storage of pressurized gases; lockout and tagout activities; and explosive or combustible materials handling, processing, storage, transportation, and shipping. The WM Program should integrate the OS\&H Functional Area into its Program which identifies the basic policy, responsibilities, authorities, program requirements and implementation criteria.

\section{Quality Assurance}

The Quality Assurance Functional Area and its requirements apply to all items, activities, and processes managed by the WM Program. The Quality Assurance Functional Area is integrated into the WM Program with three fundamental categories: management, performance and assessment. The integration of these categories should be included in the WM Program procedures.

\section{Radiation Protection}

The Radiation Protection Functional Area addresses the radiological safety of WHC employees, Hanford personnel, public, and the environment during all WM activities.

\section{Training and Oualification}

The Training and Qualification Functional Area is integrated into the WM Program by defining the appropriate personnel selection, training, qualifications, and resources necessary to safely and efficiently perform WM activities.

\section{Safeguards and Security}

The Safeguards and Security Functional Area provides security, computer security, access to the facility, sabotage considerations, etc., in support of TWRS activities.

\section{REFERENCES}

\section{Requirement Source Documents}

The following documents were reviewed and cited in the Waste Management Functional Area document.

40 CFR 61, National Emissions Standards for Hazardous Air Pollutants, as amended by 59 FR $36301,07 / 15 / 94$

40 CFR 262, Standards Applicable to Generators of Hazardous Waste, as amended by 58 FR $34370,06 / 25 / 93$

40 CFR 265, Interim Status Standards for the Treatment, Storage, and Disposal of Hazardous Waste, as amended by 59FR 48041, 09/19/94 
40 CFR 268, EPA Regulations on Land Disposal Restrictions, as amended by 59 FR 48041, $09 / 19 / 94$

40 CFR 279, Standards for the Management of Used Oil, as amended by 59 FR 10559, $03 / 04 / 94$

40 CFR 761, Polychlorinated Biphenals (PCBs) Manufacturing, Processing, Distribution in Commerce, and use Prohibitions, effective 12/09/93

WAC-173-303, Dangerous Waste Regulations, effective 12/08/93

WAC-296-65, Asbestos Removal and Encapsulation, effective 01/01/92

DOE 5820.2A, Radioactive Waste Management, effective 09/26/88

Hanford Federal Facility Agreement and Consent Order (Tri-Party Agreement), Rev. 4, $03 / 01 / 94$

94-FDB-015, Agreement Relating to Removal and Encapsulation of Asbestos Material, effective 02/17/94

\subsection{2 .2}

\section{Reviewed Documents Not Used as Requirement Sources}

The following reference documents were reviewed, but were not cited.

DOE 5400.1, General Environmental Protection Program, effective 06/29/90

WAC-173-304, Minimum Function Standards for Solid Waste Handling, effective 11/5/88

Washington State Register Issue 94-12, dated 6/15/94 

High Level Waste Storage WHC-SD-MP-SRID-001

Tank Farms/242-A Evaporator January 10, 1996

Standards/Requirements Identification Document

17.0 Research and Development and Experimental Activities

Rev. 0

Page $i$ of $i$

TABLE OF CONTENTS

17.0 RESEARCH AND DEVELOPMENT AND EXPERIMENTAL ACTIVITIES $\ldots \ldots \ldots \ldots \ldots \ldots \ldots \ldots$ 


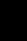




\subsection{RESEARCH AND DEVELOPMENT AND EXPERIMENTAL ACTIVITIES}

\section{INTRODUCTION}

This Standards/Requirements Identification Document (S/RID) presents requirements applicable to the High Level Waste Storage Tank Farms and related structures. The Research and Development and Experimental Activities Functional Area normally describes the programmatic controls, activities, personnel, and programs involved in executing research and development activities, if such activities are included in the current mission of the facility.

\section{SCOPE}

This S/RID applies to the Tank Waste Remediation Systems (TWRS) Organization which includes the following:

East Tank Farm Transition Project

West Tank Farm Transition Project

$\curvearrowright$ Evaporator Project

- Interim Stabilization Project

- Characterization Sampling Project (Excluding the Labs)

The near-term mission of TWRS is to store, treat, and immobilize the highly radioactive Hanford Site Waste.

\section{JUSTIFICATION OF FUNCTIONAL AREA NONAPPLICABILITY}

The primary near-term mission of the Tank Farms is to safely store the highly radioactive Hanford Site Waste (current and future tank waste) by utilizing existing technologies. Some research and development (new technology) activities are currently being performed to support resolution of tank safety issues and characterization of the tank wastes. However, these activities have been assigned to and are the responsibility of Pacific Northwest Laboratories (PNL) who will be developing S/RIDs for their workscope.

In consideration of the assignment of the responsibility for performing research and development activities for the Tank Farms to PNL who will develop their own S/RID, the development of a Research and Development and Experimental Activities Functional Area S/RID for Tank Farms is not appropriate. 


\section{TABLE OF CONTENTS}

18.0 NUCLEAR SAFETY

18.1

18.2

18.2.1

18.2 .2

18.2 .3

18.3

18.3.1

18.3.2

18.4

18.5

18.6

18.6.1

18.6.2

18.7

18.7.1

18.7.2

18.7.3

18.7 .4

18.7.5

18.7.6

18.7.7

18.7.8

18.7 .9

18.7.10

18.7.11

18.8

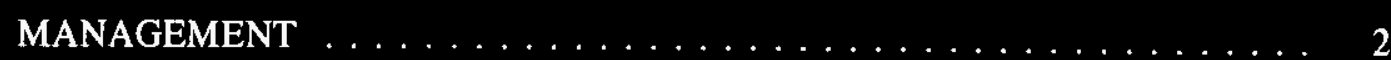

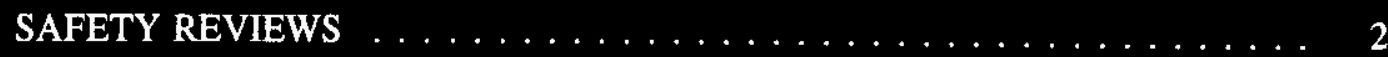

Independent Peer Review $\ldots \ldots \ldots \ldots \ldots 2$

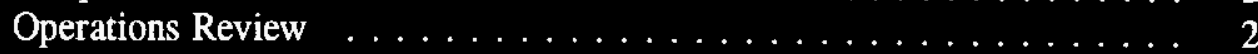

Safety Oversight Review .................... 2

SAFETY ANALYSIS $\ldots \ldots \ldots \ldots \ldots \ldots \ldots$

Safety Analysis Report $\ldots \ldots \ldots \ldots 3$

Hazard Classification $\ldots \ldots \ldots \ldots \ldots \ldots \ldots \ldots$

TECHNICAL SAFETY REQUIREMENTS $\ldots \ldots \ldots \ldots \ldots \ldots \ldots$

UNREVIEWED SAFETY QUESTIONS $\ldots \ldots \ldots \ldots \ldots \ldots \ldots \ldots$

NUCLEAR CRITICALITY SAFETY . . . . . . . . . . . . . 13

Criticality Safety Design Practices . . . . . . . . . . . . . 14

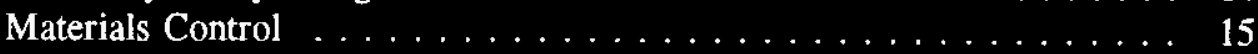

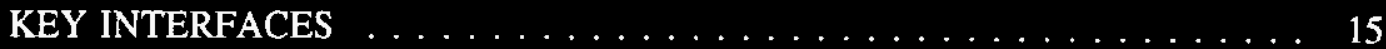

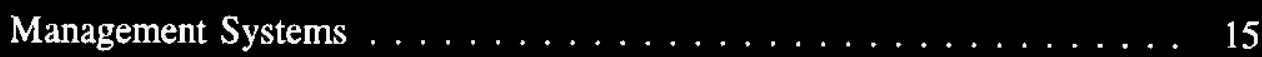

Quality Assurance ........................ 15

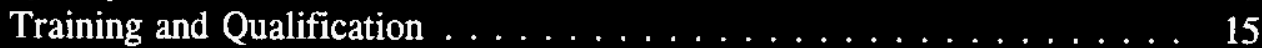

Emergency Management . . . . . . . . . . . . . . . . . 15

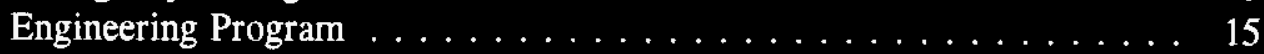

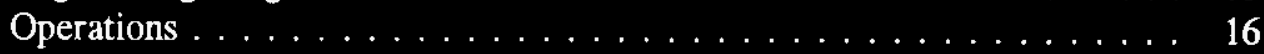

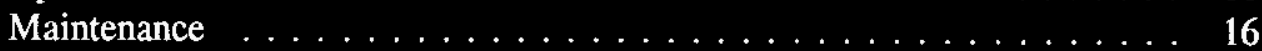

Radiation Protection . . . . . . . . . . . . . . . 16

Packaging and Transportation $\ldots \ldots \ldots \ldots \ldots$

Fire Protection . . . . . . . . . . . . . . . . 16

Occupational Safety and Health . . . . . . . . . . . . . 16

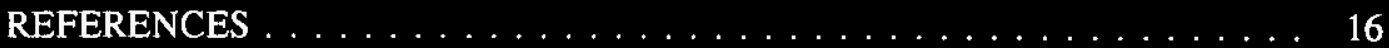

18.8.1 Requirement Source Documents $\ldots \ldots \ldots \ldots \ldots$

18.8.2 Reviewed Documents Not Used as Requirement Sources . . . . . . . . 17 


\title{
18.0 NUCLEAR SAFETY
}

\section{INTRODUCTION}

A Standards/Requirements Identification Document (S/RID) sets forth the Environmental Safety and Health (ES\&H) standards/requirements. This S/RID is applicable to the appropriate life cycle phases of design, construction, operation, and preparation for decommissioning for each of the categories of facilities addressed in Revision 5 of the Department of Energy Implementation Plan for the Defense Nuclear Facilities Safety Board (DNFSB) Recommendation 90-2. This Recommendation calls for the strengthening of DOE weapons complex activities through the identification and application of relevant DOE Orders, regulations, industry codes/standards, industry guidance documents and, as appropriate, good industry practices. These standards/requirements are adequate to ensure protection of the health and safety of workers, the public, and the environment.

The Tank Farms S/RID contains standards/requirements that are necessary for safe operation of the Tank Farms and its associated facilities, and that are the direct responsibility of the specific facility manager. The Nuclear Safety Program defined in this document is described in general accordance with the Environment, Safety, and Health Configuration Guide, Revision 0, dated July 30, 1993, and is presented in program elements and subelements. The specific DOE Orders, regulations, industry codes/standards, guidance documents and good industry practices that serve as the basis for each element/subelement are identified and aligned with each subelement.

This S/RID contains only those requirements that Tank Farms personnel are clearly responsible to satisfy. Other requirements that are applicable to Tank Farms, but are satisfied by others, are defined in the Westinghouse Hanford Company (WHC) Level S/RID. For application in this S/RID, the words "shall" and "should" in requirement statements both indicate mandatory compliance. The key interface information contained in the Functional Area documents is provided for general recognition and understanding and is not considered to contain prescriptive requirements.

\section{SCOPE}

This S/RID applies to the Tank Waste Remediation Systems (TWRS) Organization which includes the following:

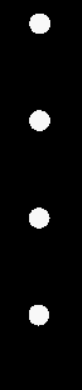

\author{
East Tank Farm Transition Project \\ West Tank Farm Transition Project \\ Evaporator Project
}

Interim Stabilization Project

Characterization Sampling Project (Excluding the Labs)

The near-term mission of TWRS is to store, treat, and immobilize the highly radioactive Hanford Site Waste. 
18.1

18.2

$\underline{18.2 .1}$

$\underline{18.2 .2}$

$\underline{18.2 .3}$

18.3

\section{MANAGEMENT}

The general aspects of management, policy, staffing, and training are covered in the Management Systems Functional Area.

\section{SAFETY REVIEWS}

\section{Independent Peer Review}

Author's Note: Peer review requirements for processes within the scope of Nuclear Safety are noted in Tank Farms Nuclear Safety S/RID elements 18.3 through 18.6, where applicable.

\section{Operations Review}

Author's Note: Review requirements for Operational procedures are included within Tank Farm S/RID functional areas 1.0, Management Systems, and 9.0, Operations.

Author's Note: Review requirements for safety analyses and design changes to ensure that any proposed change or operation falls within the safety bases of the facility are included within the Tank Farm Nuclear Safety S/RID elements 18.3 through 18.6, where applicable.

Author's Note: Requirements for Operational Readiness Review are included in the Management Systems Functional Area.

\section{Safety Oversight Review}

Author's Note: Refer to the Westinghouse Hanford Company S/RID QA Functional Area document for requirements under this subelement. There are no specific Tank Farm Nuclear Safety requirements.

\section{SAFETY ANALYSIS}

Author's Note: Tank Farms will verify facility risk assessments are performed in accordance with facility risk analysis procedures.

\section{REQUIREMINT SOURCE: DOE5480.23(940310) Section 8}

"A contractor, as designated in writing by the PSO, who is responsible for the design, construction, or operation of DOE nuclear facilities shall be required to perform a safety analysis that develops and evaluates the adequacy of the safety basis for each such facility. The safety basis to be analyzed shall include management, design, construction, operation, and engineering characteristics necessary to protect the public, workers, and the environment from the safety and health hazards posed by the nuclear facility or nonfacility nuclear operations. All contractors shall be held responsible for adhering to assumptions and commitments set forth in the safety analysis. Contractors shall be required to prepare, and shall submit to DOE for its approval, SARs documenting safety analyses for each DOE nuclear facility under their cognizance. Contractors responsible for conducting one or more nonfacility nuclear operations are required to maintain up to date analyses of the safety of such operations and analyses documented in a form that is auditable by DOE. Attachment 1 provides guidance in greater detail than the requirements of this Order." 


\section{REQUIREMENT SOURCE: DOE5480.23(940310) Section 8.a.(1)}

"Justification for the level of analyses and documentation for each hazard considered shall be provided as part of the plan and schedule submitted in accordance with paragraph $9(\mathrm{~b})(2)$ of this Order. The level of analysis and documentation for each facility must be commensurate with:

(a) The magnitude of the hazards being addressed;

(b) The complexity of the facility and/or systems being relied on to maintain an acceptable level of risk; and

(c) The stage or stages of the facility life cycle for which DOE approval is sought."

\section{REQUIREMENT SOURCE: DOE5480.24 Section 7.f.(1)}

"Contractors shall establish guidelines for permitting fire fighting water or other moderating materials used to suppress fires within or adjacent to moderation controlled areas. These guidelines shall be based on comparisons of risk and consequences of accidental criticality with the risks and consequences of postulated fires for the respective area(s). The basis for the guidelines shall be fully documented in a DOE approved Safety Analysis."

\section{Safety Analysis Report}

\section{REQUIREMENT SOURCE: DOE5480.23(940310) Section 8.b.(1)}

"SARs shall define the safety basis, document the logic of its derivation, demonstrate adherence to the safety basis, and justify its adequacy. "

\section{REQUIREMENT SOURCE: DOE5480.23(940310) Section 8.b.(2)}

"Each SAR required by this Order shall include thorough documentation of the assumptions employed in the safety analysis."

\section{REQUIREMENT SOURCE: DOE5480.23(940310) Section 8.b.(3)}

"A SAR shall include the results of the safety analysis that identifies the dominant contributors to the risk of the facility so that these vulnerabilities can be better managed. The safety analysis report shall address the following topics:

(a) Executive summary;

(b) Applicable statutes, rules, regulations and Departmental Orders;

(c) Site characteristics;

(d) Facility description and operation, including design of principal structures, components, all systems, engineered safety features, and processes;

(e) Hazard analysis and classification of the facility;

(f) Principal health and safety criteria;

(g) Radioactive and hazardous material waste management; 
(h) Inadvertent criticality protection;

(i) Radiation protection;

(j) Hazardous material protection;

(k) Analysis of normal, abnormal, and accident conditions, including design basis accidents; assessment of risks; consideration of natural and manmade external events; assessment of contributory and casual events, mechanisms, and phenomena; and evaluation of the need for an analysis of beyond-design-basis accidents; however, the SAR is to exclude acts of sabotage and other malevolent acts since these actions are covered under security protection of the facility.

(l) Management, organization, and institutional safety provisions;

(m) Procedures and training;

(n) Human factors;

(o) Initial testing, inservice surveillance, and maintenance;

(p) Derivation of TSRs;

(q) Operational safety;

(r) Quality assurance;

(s) Emergency preparedness;

(t) Provisions for decontamination and decommissioning; and

(u) Applicable Facility design codes and standards."

\section{REQUIREMENT SOURCE: DOE5480.23(940310) Section 8.d}

"Document Control. Contractors with the primary responsibility for the design, construction, operation, or decommissioning of DOE nuclear facilities must maintain such document control as may be necessary to ensure that all users of SARs and their supporting documentation designated by DOE or the contractor as authorized users, including DOE line management and the Department's safety oversight groups, have current editions. "

\section{REQUIREMENT SOURCE: DOE5480.23(940310) Section 9.a.(1), Sentence 1}

"Contractors shall be required to obtain PSO approval of Preliminary Safety Analysis Reports (PSARs) prior to undertaking procurement of materials and components, construction, and preoperational testing of DOE nuclear facilities."

\section{REQUIREMENT SOURCE: DOE5480.23(940310) Section 9.a.(1), Sentence 3}

"PSARs shall document the adequacy of the safety basis for a new nuclear facility and provide assurance that the facility can be constructed, operated, maintained, and shut down safely and in compliance with applicable laws and regulations." 


\section{REQUIREMINT SOURCE: DOE5480.23(940310) Section 9.a.(2)}

"Contractors shall be required to submit Final Safety Analysis Reports (FSARs) to the PSO for approval and authorization to operate DOE nuclear facilities. FSARs shall document the adequacy of the safety basis and provide assurance that the facility can be operated, maintained, and shut down safely and in compliance with applicable laws and regulations."

\section{REQUIREMENT SOURCE: DOE5480.23(940310) Section 9.b.(2)}

"Plan and Schedule for Safety Analysis Reports. Each contractor responsible for submitting a SAR shall be required to submit to the PSO, for its review and approval, an overall plan and schedule for completing this effort. For existing facilities or operations, the plan and schedule shall be submitted to the Department for approval by 6 months after the date of issuance of this Order. This submittal shall describe the need for upgrading the SAR and shall include a preliminary assessment of facility hazards, the basis for the content, schedule, and level of detail proposed, bases for interim operation or restrictions on interim operations, and administrative controls during the upgrade process. Once a submitted plan and schedule is approved by DOE, the contractor shall comply with the plan and schedule, including any DOE modifications. The plan and schedule submitted by a contractor shall be considered approved 180 days after submittal, including any modifications made or directed by DOE during or after this period, unless it is approved by DOE at an earlier date. Approved plans and schedules may be changed, but such changes must be approved in the same manner as initial plans and schedules."

\section{REQUIREMENT SOURCE: DOE5480.23(940310) Section 9.c.}

"Periodic Updates of Safety Analysis Reports. Contractors shall be required to review and update as necessary, SARs annually, pursuant to this Order to ensure that the information in each SAR is current and remains applicable. Revisions shall be submitted to the PSO at least annually and shall reflect all changes implemented up to 6 months prior to the filing of the updated SAR. The DOE approval of any Unreviewed Safety Question Pursuant to DOE 5480.21, amendments to the TSR's, and the material submitted by the contractor to the PSO in support of these approvals shall be considered and addendum to the SAR until the information is incorporated into the SAR as part of the next annual update."

\section{REQUIREMENT SOURCE: DOE5480.24 Section 7.c. Paragraph 1}

"Nuclear criticality safety programs shall be fully documented. In addition to the requirements of the ANS standards, contractors shall perform detailed nuclear criticality safety analyses for specific operations, storage arrangements, and the handling and transportation of fissionable materials."

\section{REQUIREMENT SOURCE: DOE5480.24 Section 7.c. Paragraph 2, Sentence 1 and} 2

"The basis for criticality safety shall be included in the facility SAR. Additionally, the limiting conditions of operation for criticality safety shall be included in the facility TSRs."

\section{REQUIREMENT SOURCE: DOE5480.24 Section 7.c.(1)}

"A description, using appropriate sketches or drawings, of equipment and facilities in which the hazard of criticality exists showing dimensions in sufficient detail to permit evaluation of the information mentioned in subparagraphs $7 \mathrm{c}(3)$ through $7 \mathrm{c}(6)$ below." 


\section{REQUIREMENT SOURCE: DOE5480.24 Section 7.c.(2)}

"A statement of the chemical and physical form of fissionable material in each step of the process, including isotopic content, the nature of any material, and the resulting concentrations, densities, and degrees of moderation throughout the steps of the process."

\section{REQUIREMINT SOURCE: DOE5480.24 Section 7.c.(3)}

"A statement of the maximum quantities of fissionable material at any one time in each step of the process, including a description of the technical practices which are intended to prevent exceeding these maximum quantities."

\section{REQUIREMENT SOURCE: DOE5480.24 Section 7.c.(4)}

"A description of the methods of collection, handling, and transportation products from each process area or individual operation and evaluation of the nuclear safety of these methods."

\section{REQUIREMINT SOURCE: DOE5480.24 Section 7.c.(5)}

Author's Note: A CAS is not required at Tank Farms.

"An analysis of criticality incident scenarios and their impact on health and safety of the workers and/or public. This analysis will be used to determine the conditions of operation for criticality safety, the design of the CAS as noted in subparagraph (7) below, and the need for audible and/or visual alarms."

\section{REQUIREMENT SOURCE: DOE5480.24 Section 7.c.(0)}

"A description of the safety control parameters which are intended to prevent criticality resulting from such events as: accumulation of fissionable material in scrap or waste, lathe turnings, crucible slag, pickling solutions, choppings, sumps, filters, etc. Also included shall be the description of the technical practices used to prevent exceeding the safety control parameters."

\section{REQUIREMENT SOURCE: DOE5480.24 Section 7.c.(8)}

\section{Author's Note: Substitute 10 CFR 830, Nuclear Safety Management, for reference to} DOE $5700.6 C$.

"A description of the technical practices and measurement control program (including reliability and operability characteristics) used in determining the quantities of fissionable material (or other materials such as soluble poisons to prevent accidental criticality) present in any location and the uncertainties of the measured values. The measurement control program shall be in accordance with the latest edition of DOE 5700.6C, "QUALITY ASSURANCE." "

\section{REQUIREMENT SOURCE: DOE5480.7A Section 9.a.(3)}

Author's Note: Preparation and contents of the FHA is included in the Fire Protection Functional Area. Nuclear Safety personnel will assure that the FHA is addressed in the SAR.

"Fire Hazards Analyses. The purpose of a fire hazards analysis (FHA) is to comprehensively assess the risk from fire within individual fire areas in a DOE facility in relation to existing or proposed fire protection so as to ascertain whether the objectives of paragraph 4 , are met. A graded FHA, that reflects the risks from fire in a facility, shall be performed for new facilities 
as directed by DOE $6430.1 \mathrm{~A}$, for nuclear facilities where safety analyses are required by DOE 5480.23, and as directed by the PSO. A Safety Analysis Report (SAR) that addresses the following elements will satisfy the requirements for an FHA. A graded FHA shall contain, but not be limited to, the following elements:

(a) Description of construction

(b) Protection of essential safety class equipment

(c) Fire protection features

(d) Description of fire hazards

(e) Life safety considerations

(f) Critical process equipment

(g) High value property

(h) Damage potential: Maximum Credible Fire Loss (MCFL) and Maximum Possible Fire Loss (MPFL)

(i) Fire Department/Brigade response

(j) Recovery potential

(1) Potential for a toxic, biological and/or radiation incident due to a fire

(m) Emergency planning

(n) Security considerations related to fire protection

(o) Natural hazards (earthquake, flood, wind) impact on fire safety

(p) Exposure fire potential, including the potential for fire spread between fire areas.

An FHA shall be performed under the direction of a qualified fire protection engineer."

Hazard Classification

\section{REQUIREMENT SOURCE: DOE5480.23(940310) Section 8.c.(1)}

"Classification Categories. The consequences of unmitigated releases of radioactive and/or hazardous material shall be evaluated and classified by the following hazard categories:

(a) Category 1 Hazard. The hazard analysis shows the potential for significant offsite consequences.

(b) Category 2 Hazard. The hazard analysis shows the potential for significant onsite consequences.

(c) Category 3 Hazard. The hazard analysis shows the potential for only significant localized consequences."

\section{REQUIREMENT SOURCE: DOE5480.23(940310) Section 8.c.(2)}

"Inventory of Hazardous Materials. The hazard analysis shall be based on an inventory enveloping all radioactive and nonradioactive hazardous materials that are stored, utilized, or may be formed within a nuclear facility."

\section{REQUIREMENT SOURCE: DOE5480.23(940310) Section 8.c.(3)}

"Evaluation of Potential Releases. The hazard analysis shall identify energy sources or processes that might contribute to the generation or uncontrolled release of hazardous materials. The hazard analysis shall estimate the consequences of accidents in which the facility or process and/or materials in the inventory are assumed to interact, react, or be released in a manner to produce a threat or challenge to the health and safety of individuals on site and off site." 


\section{REQUIREMENT SOURCE: DOE5480.23(940310) Section 8.c.(4)}

"Submission of Hazard Analysis to DOE. The hazard analysis shall be submitted to DOE for approval in accordance with the safety analysis plan and schedule required by paragraph 9(b)(2) of this Order."

\section{TECHNICAL SAFETY REQUIREMIENTS}

\section{REQUIREMENT SOURCE: DOE5480.22 Section 9.a}

"A contractor responsible for the operation of a DOE nuclear facility shall:

(1) prepare Technical Safety Requirements for the facility;

(2) submit the Technical Safety Requirements to the PSO for approval; and

(3) operate the facility in accordance with the Technical Safety Requirements as approved by the PSO including any modification by the PSO;"

\section{REQUIREMENT SOURCE: DOE5480.22 Section 9.b, Sentences 1 and 2}

"Technical Safety Requirements shall define the operating limits and surveillance requirements, the basis thereof, safety boundaries, and management or administrative controls necessary to protect the health and safety of the public and to minimize the potential risk to workers from the uncontrolled release of radioactive or other hazardous materials and from radiation exposure due to inadvertent criticality. Technical Safety Requirements shall be based on the facility Safety Analysis Report and shall set forth specific limits and other requirements as specified in this Order and Attachment 1 to this Order, "Guidelines for Technical Safety Requirements." "

\section{REQUIREMENT SOURCE: DOE5480.22 Section 9.e.(1)}

"Use and Application. Definitions of terms, operating modes, frequency notations, and actions to be taken in the event of violation of Technical Safety Requirements operating limits or surveillance requirements are to be included in the Use and Application section. This section of the Technical Safety Requirements shall contain the basic instructions for using and applying the safety restriction contained in the Technical Safety Requirements."

\section{REQUIREMENT SOURCE: DOE5480.22 Section 9.e.(2)}

\section{Author's Note: Substitute DOE Order 5000.3B for the referenced document DOE Order} 5000.3A.

"Safety Limits (SL). Safety Limits are limits on process variables associated with those physical barriers, generally passive, that are necessary for the intended facility function and which are found to be required to guard against the uncontrolled release of radioactivity and other hazardous materials (this includes releases into the complex and/or the community). If any Safety Limit is exceeded at any reactor or nonreactor nuclear facility, action shall begin immediately to place the facility in the most stable, safe condition attainable including total shutdown of either reactor or nonreactor nuclear facilities. The appropriate time frame for the completion of the action for each nuclear facility has to be developed and justified by the contractor, as appropriate, in the TSR document which requires PSO approval. The SLs shall describe the action to be taken when an SL is exceeded. If a SL is exceeded, the contractor shall notify DOE in accordance with DOE 5000.3A, review the matter, and record the results 
of the review. The review shall include the cause of the condition and the basis for any corrective actions taken to preclude reoccurrence. The safe, stable condition entered as corrective action shall be maintained until the cognizant Program Manager authorizes further operations. ${ }^{n}$

\section{REQUIREMENT SOURCE: DOE5480.22 Section 9.e.(3)(a)}

\section{Author's Note: Substitute DOE Order 5000.3B for the referenced document DOE Order} 5000.3A.

"Limiting Control Settings (LCS). Limiting Control Settings are settings on safety systems that control process variables to prevent exceeding Safety Limits. This subsection of the Technical Safety Requirements shall contain the settings for automatic alarms and automatic or non-automatic initiation of protective actions related to those variables having significant safety functions. The specific settings shall be chosen such that if exceeded, sufficient time is available to automatically or manually correct the condition prior to exceeding Safety Limits. If the automatic alarms or protective devices do not function as required during applicable operating modes, the contractor shall take action as defined in the Limiting Control Setting to maintain the variables within the requirements and to promptly repair the automatic devices or the affected part of the process or, if required, the facility shall be placed in its most safe, stable condition. The LCS shall describe the action to be taken in case of exceedance of LCS. If an LCS is exceeded, the contractor shall notify DOE in accordance with DOE 5000.3A, review the matter, and record the results of the review including the cause of the condition and the basis for any corrective actions taken to preclude reoccurrence."

\section{REQUTREMENT SOURCE: DOE5480.22 Section 9.e.(3)(b)}

\section{Author's Note: Substitute DOE Order 5000.3B for the referenced document DOE Order $5000.3 A$.}

"Limiting Conditions for Operation (LCO). Limiting Conditions for Operation are the lowest functional capability or performance level of safety-related structures, systems, component and their support systems required for normal safe operation of the facility. This subsection of the TSR shall contain the limits on functional capability or performance level. When a Limiting Condition for Operation is not met, the contractor shall take remedial actions defined by the Technical Safety Requirements until the condition can be met. The LCO shall describe the action to be taken in case of exceedance of the LCO. In cases of exceedance of an LCO, the contractor shall notify DOE in accordance with DOE 5000.3A, review the matter, and record the results of the review including the cause of the condition and the basis for any corrective actions taken to preclude reoccurrence."

\section{REQUIREMENT SOURCE: DOE5480.22 Section 9.e.(4)}

"Surveillance Requirements. Surveillance Requirements are requirements relating to test, calibration, or inspection to ensure that the necessary operability and quality of safety-related structures, systems, components, and their support systems required for safe operation of the facility are maintained. This section of the Technical Safety Requirements shall contain the requirements necessary to maintain operation of the facility within the Safety Limits, Limiting Control Settings, and Limiting Conditions for Operations. In the event that Surveillance Requirements are not successfully completed or accomplished within their required frequency, the systems or components involved shall be assumed to be inoperative and actions defined by the Limiting Condition for Operation or Limiting Control Setting shall be taken until the systems or components can be shown to be operable." 


\section{REQUIREMENT SOURCE: DOE5480.22 Section 9.e.(5)}

"Administrative Controls. Administrative Controls are the provisions relating to organization and management, procedures, recordkeeping, reviews, and audits necessary to ensure safe operation of the facility. This section of the Technical Safety Requirements shall contain the requirements associated with Administrative Controls including those for reporting deviations from Technical Safety Requirements (i.e., exceedances of LCO, LCS, or SR, or violation of TSR). Staffing requirements for facility position important to safe operation of the facility shall be provided in the Administrative Controls sections. Physical and administrative controls of the criticality safety program shall also be provided in the Administration Controls section."

\section{REQUIREMENT SOURCE: DOE5480.22 Section 9.e.(6)}

"Appendices. The following information shall be in the Appendices:

(a) Basis. This Appendix shall provide summary statements of the reasons for the operating limits and associated surveillance requirements. The basis shall show how the numeric value, the condition, or the surveillance does fulfill the purpose derived from the safety documentation. The primary purpose for describing the basis for each requirement will not affect its original intent or purpose.

(b) Design Features. This Appendix shall describe passive design features of the facility which, if altered or modified, would have a significant effect on safe operation. If Design Features are in a DOE-approved Safety Analysis Report, this Appendix is not required."

\section{REQUIREMENT SOURCE: DOE5480.22 Section 9.f}

"The TSR shall be kept current at all times so that it reflects the facility as it exists and as it is analyzed in Safety Analysis Reports. Contractors shall determine whether revisions to the Technical Safety Requirements are required upon originating or proposing a revision to a Safety Analysis Report, and, if so, shall prepare revisions and submit them with their basis for PSO approval concurrent with the revisions to the Safety Analysis Report. The TSR must be approved prior to facility or facility practice change. To assure that the TSR is current, it shall be reviewed at least annually along with the facility Safety Analysis Report."

\section{REQUIREMENT SOURCE: DOE5480.22 Section 9.g}

"All proposed revisions to Technical Safety Requirements or its Appendices shall be submitted for PSO approval. Such submittals shall include the basis for the proposed revision. Revision implementation shall occur only after PSO approval. "

\section{REQUIREMENT SOURCE: DOE5480.22 Section 9.h}

"Only the current PSO-approved Technical Safety Requirements shall be used for the operation of the facility. The current PSO-approved Technical Safety Requirements shall be a controlled document."

\section{REQUIREMINT SOURCE: DOE5480.22 Section 9.i}

"A contractor may take emergency actions that depart from the approved Technical Safety Requirements when no actions consistent with the Technical Safety Requirements are immediately apparent, and when these actions are needed to protect the public health and safety. Such contractor actions shall be approved, as a minimum, by a certified operator or supervisor certified on that system through an accredited training program. If emergency 
actions are taken, verbal notifications shall be made to the Head of the Field Element within 2 hours and by written reports to the PSO within 24 hours."

\section{UNREVIEWED SAFETY QUESTIONS}

\section{REQUIREMENT SOURCE: DOE5480.21 Chapter III, Section 2, Sentences 1 and 2}

"Once the contractor organization has determined the various sources of change, it must then determine the process by which these sources of change should be integrated into the USQ review process. This process should ensure that the need for completion of a safety evaluation is not overlooked and that this process is integrated into existing procedures or that new procedures are developed, as necessary."

\section{REQUIREMENT SOURCE: DOE5480.21 Chapter III, Section 3.c}

"It is expected that, as an initial step toward developing a USQ process, each contractor will define for their facility those aspects and documents that constitute the authorization basis and identify these documents within the facility USQ procedures. "

\section{REQUIREMENT SOURCE: DOE5480.21 Chapter III, Section 4.d}

"The application of screening criteria for administrative changes may prove useful, but contractors must ensure that the use of these criteria do not inappropriately screen out changes that require safety evaluations."

\section{REQUIREMENT SOURCE: DOE5480.21 Chapter III, Section 5.a}

"Contractors are required to develop procedures that provide detailed guidance for the performance and review of USQ determinations. At a minimum, the procedures shall define the purpose of the procedure; set forth the procedure's applicability; provide definitions of appropriate terms, including those set forth in this Order; include screening criteria, as appropriate, and the basis for their application; include detailed guidance on what must be considered and evaluated when performing or reviewing a safety evaluation; define the qualifications needed and responsibilities of personnel performing and reviewing safety evaluations; and include documentation requirements for each USQ determination."

\section{REQUIREMENT SOURCE: DOE5480.21 Chapter III, Section 5.b, Sentences 1 and} 2

"The purpose of the procedure should reflect the purpose of the Order and its implementation as defined herein. The applicability of the procedure should set forth the facility(s) to which it applies and the types of change processes to which it applies."

\section{REQUIREMENT SOURCE: DOE5480.21 Chapter III, Section 5.c, Sentence 1 and 2}

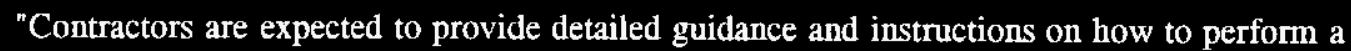
safety evaluation. This guidance should include, at a minimum, the information provided in Chapter IV of this guidance document, refined to include the specifics of the applicable facility." 


\section{REQUIREMENT SOURCE: DOE5480.21 Chapter III, Section 5.d}

"The implementing procedures should address the personnel qualifications needed in order to perform or review a safety evaluation. This includes required educational background, years and/or types of work experience, knowledge of the facility, understanding of DOE requirements, and familiarity with the facility authorization basis. Specific responsibilities of those performing or reviewing safety evaluations should be clearly defined."

\section{REQUIREMENT SOURCE: DOE5480.21 Chapter III, Section 5.e, Sentences 1 and 2}

"Documentation requirements should also be discussed in the USQ implementing procedures. They should identify the level of detail necessary to document performance of the safety evaluation and conclusions reached; a list of references relied upon to reach this conclusion as well as guidance for the retention of records should also be included."

\section{REQUIREMENT SOURCE: DOE5480.21 Chapter III, Section 8, Sentence 1}

"Training. All personnel responsible for performing, reviewing, or approving USQ determinations should receive initial training on the application of the Order and of facility-specific procedures."

\section{REQUIREMENT SOURCE: DOE5480.21 Preamble, Section 8.c}

"Primary responsibility, authority, and accountability for the direction and management of the USQ process reside with the line management of the facility organization responsible for the design and safety analyses."

\section{REQUIREMENT SOURCE: DOE5480.21 Preamble, Section 10.a}

"A contractor authorized to operate DOE nuclear facilities shall:

(1) Perform all safety evaluations required by paragraph (b) of this section to determine whether a situation involves USQ;

(2) Prior to implementation of a proposed action, obtain PSO approval for situations determined to involve a USQ or a Technical Safety Requirements (TSR) change; and

(3) Develop and implement procedures to govern the need for, and the performance of, safety evaluations under this section."

\section{REQUIREMENT SOURCE: DOE5480.21 Preamble, Section 10.b}

"A safety evaluation shall be performed for:

(1) Temporary or permanent changes in the facility as described in the existing safety analyses;

(2) Temporary or permanent changes in the procedures as described in existing safety analyses; or

(3) Test or experiments not described in existing safety analyses. " 


\section{REQUIREMENT SOURCE: DOE5480.21 Preamble, Section 10.c}

"A situation involves a USQ if:

(1) The probability of occurrence or the consequences of an accident or malfunction of equipment important to safety previously evaluated in the facility safety analyses could be increased;

(2) The possibility for an accident or malfunction of a different type than any evaluated previously in the facility safety analyses could be created; or

(3) Any margin of safety, as defined in the bases of the TSRs, could be reduced."

\section{REQUIREMENT SOURCE: DOE5480.21 Preamble, Section 10.d}

"When a contractor identifies information that indicates a potential inadequacy of previous safety analyses or a possible reduction in the margin of safety as defined in the TSRs, the contractor shall:

(1) Notify the PSO of the situation upon discovery of the information;

(2) Make an evaluation in accordance with paragraphs 10a and 10c;

(3) Take action to place the facility in a safe condition until the safety evaluation is completed; and

(4) Submit the completed safety evaluation prior to removing any operational restrictions initiated pursuant to paragraph $10 \mathrm{~d}(2) . "$

\section{REQUIREMENT SOURCE: DOE5480.21 Preamble, Section 10.e}

"For all safety evaluations required under this section, a contractor shall:

(1) Document the basis for the USQ determination, utilizing the procedures provided for in paragraph $10 \mathrm{a}(3)$ of this section and the criteria of paragraph $10 \mathrm{c}$;

(2) Maintain documentation required by paragraph 10e(1) for the authorized operating period of the nuclear facility and ensure the complete transfer of all documentation to any subsequent contractor prior to termination of its contract;

(3) Incorporate in the existing SAR, any changes that are needed as a result of the safety evaluation or any action taken; and

(4) Submit to the PSO, on a schedule corresponding to the periodic updates of the SAR, a report summarizing all situations for which a safety evaluation was required by this section and indicating all "changes" considered in a safety evaluation and implemented 6 months or more before the submittal date of the report."

18.6

NUCLEAR CRITICALITY SAFETY

\section{REQUIREMENT SOURCE: DOE5480.24 Section 7.a. Introduction}

Author's Note: ANS-8.5 and ANS-8.15 are not applicable to Tank Farms. 
"The basic elements and control parameters of programs for nuclear criticality safety shall satisfy the requirements of the following mandatory American Nuclear Society's ANSI/ANS nuclear criticality safety standards:

ANS-8.1, "Nuclear Criticality Safety in Operations with Fissionable Materials Outside Reactors," except paragraphs 4.2.2 and 4.2.3.

ANS-8.3, "Criticality Accident Alarm System," except paragraphs 4.2 and 4.2.2.

ANS-8.5, "Use of Borosilicate-Glass Raschig Rings as a Neutron Absorber in Solutions of Fissile Material."

ANS-8.15, "Nuclear Criticality Control of Special Actinide Elements."

ANS-8.19, "Administrative Practices for Nuclear Criticality Safety."

ANS-8.7, "Guide for Nuclear Criticality Safety in the Storage of Fissile Materials. " "

\section{REQUIREMENT SOURCE: DOE5480.24 Section 7.a.(2)(a)}

"4.2.2 Double Contingency Principle. Process designs shall incorporate sufficient factors of safety to require at least two unlikely, independent, and concurrent changes in process conditions before a criticality accident is possible. Protection shall be provided by either (a) the control of two independent process parameters (which is the preferred approach, if practical) or (b) a system of multiple (at least two) controls on a single parameter. In all cases, no single failure shall result in the potential for a criticality accident. The basis for selecting either approach shall be fully documented."

\section{REQUIREMENT SOURCE: DOE5480.24 Section 7.a.(2)(b)}

"4.2.3 Geometry Control. As a first priority, reliance shall be placed on equipment design in which dimensions of the contained fissionable material and spacing between equipment are limited via passive engineering controls. Where geometry control is not feasible, the preferred order of controls is other passive engineering controls, active engineering controls, and administrative controls. Feasibility is determined by weighing risk versus practicality/cost. Full advantage may be taken of any nuclear characteristics of the process materials and equipment. All dimensions, nuclear properties, and other features upon which reliance is placed shall be verified prior to beginning operations, and control shall be exercised to maintain them. The basis for not selecting geometry control shall be fully documented."

\section{REQUIREMENT SOURCE: DOE5480.24 Section 7.b.(4)}

"The decision to install a criticality detection system rather than a CAS, and the decision that neither a CAS nor a criticality detection system is necessary, must be justified based upon a documented DOE approved Safety Analysis."

\section{REQUIREMENT SOURCE: DOE6430.1A Section 1300- 4 Paragraph 5, Sentence 1}

"Structures, systems, and components that provide nuclear criticality safety shall be designed as safety class systems and be capable of performing their criticality safety functions during and following design basis accidents and events." 


\section{6 .2}

18.7

$\underline{18.7 .1}$

$\underline{18.7 .2}$

$\underline{18.7 .3}$

$\underline{18.7 .4}$

18.7 .5

\section{Materials Control}

\section{REQUIREMENT SOURCE: DOE5480.24 Section 7.d}

"Contractors shall establish a monitoring and surveillance program to prevent accumulations of fissionable materials in, but not limited to, process equipment and storage, pipe, and ventilation systems. If unsafe accumulations are detected, corrective measures shall be taken to prevent criticality hazards. "

\section{REQUIREMENT SOURCE: DOE5480.24 Section 7.e.(1)}

"The requirements of this Order shall apply to all activities where fissionable material is transferred from one operation to another within a facility and from one on-site location to another. "

\section{KEY INTERFACES}

All facility activities are governed by the site wide Nuclear Safety Program. Specific functional areas must implement the programs/requirements developed by Nuclear Safety.

The interfaces between Nuclear Safety and other functional areas within the Tank Farms are as follows:

\section{Management Systems}

Program management systems provides the general aspects of management, policy, staffing, training, occurrence reporting, and self assessment required to run a nuclear facility. Nuclear Safety interacts with program management to determine what programs can be developed to give assurance that Nuclear Safety is maintained.

\section{Quality Assurance}

Quality Assurance (QA) develops the QA program that provides the requirements to be applied to activities determined to be important to quality as described in the Nuclear Safety QA Plan. QA also provides for the performance of audits and surveillances of activities plus quality control inspections to be performed by the QA organization.

\section{Training and Oualification}

Training and Qualification establishes the procedures and requirements that control the training and/or selection of certain technical personnel. Training and Qualification develops training curriculum and keeps records for Nuclear Safety training.

\section{Emergency Management}

Nuclear Safety information is supplied to Emergency Planning and Preparedness so they can design their programs and plans. This information will deal with the potential for accidental criticality and the results of the potential accident.

\section{Engineering Program}

Engineering incorporates Nuclear Safety requirements into design and design modifications. They also develop and update the SAR per Nuclear Safety requirements to identify additional 
$\underline{18.7 .6}$

$\underline{18.7 .7}$

$\underline{18.7 .8}$

$\underline{18.7 .9}$

$\underline{18.7 .10}$

$\underline{18.7 .11}$

18.8

$\underline{18.8 .1}$ engineering nuclear safety features, and to ensure that current safety features are not affected by modifications.

\section{Operations}

The Operations Functional Area interfaces and provides Nuclear Safety input in areas of operations that may be different from the safety analysis basis for determination of any possible USQs. This interface is needed to ensure that nuclear safety principles are incorporated into daily operations.

\section{Maintenance}

Input is received from Maintenance if systems/equipment do not perform per design and determines if there is a safety impact of these problem areas. This interface is also necessary to assure that maintenance personnel are familiar with areas containing material with the potential for accidental criticality events, and to assure that engineered safety systems receive the proper maintenance.

\section{Radiation Protection}

An interface between the Nuclear Safety Functional Area and the Radiation Protection (RP) Functional Area is necessary to ensure that radiation protection standards are incorporated into the nuclear safety program.

\section{Packaging and Transportation}

Physical management of special nuclear material requires an interface to the Packaging and Transportation Functional Area to ensure proper labelling, packaging, and transportation of those materials.

\section{Fire Protection}

Fire Protection provides input to the SAR and provides notification if there are changes to any systems or requirements described in the SAR. This interface is necessary to assure that fire fighting activities do not create the potential for criticality.

\section{Occupational Safety and Health}

Occupational Safety and Health provides information regarding health related areas for inclusion in and modification to the SAR.

\section{REFERENCES}

\section{Requirement Source Documents}

The following documents were used as requirement sources in the development of this S/RID:

DOE 5480.7A, Fire Protection, 02/17/93

DOE 5480.21, Unreviewed Safety Questions, 12/24/91

DOE 5480.22, Technical Safety Requirements, 09/15/92

DOE 5480.23, Nuclear Safety Analysis Reports, 04/10/92 
DOE 5480.24, Nuclear Criticality Safety, 08/12/92

\section{$\underline{18.8 .2}$}

\section{Reviewed Documents Not Used as Requirement Sources}

10 CFR 820, Procedural Rules for Nuclear Activities, Final Rule, Federal Register, Vol. 58, No. 157, Tuesday, 08/17/93, Rules and Regulations

10 CFR Part 830, Nuclear Safety Management, Final Rule, Federal Register, Vol. 59, No. 65, Tuesday, 04/05/94

DOE 5480.1B, Environmental Safety and Health Program for Departmental of Energy Operation, 09/23/86

DOE-RL 5480.1, Safety of Department of Energy Owned Reactors, 06/24/82

RL 5480.1A, Environment, Safety, and Health Program for Department of Energy Operations, 10/31/83

DOE 5480.4, Environmental Protection, Safety, Health Protection Standards, 01/07/93

ANSI/ANS-8.20-1991, Nuclear Criticality Safety Training

RLIP 5480.4C, Environmental Protection, Safety, and Health Protection Standards for RL, $11 / 06 / 92$

DOE-RL 5480.5, Safety of Nuclear Facilities, 10/15/84

RL 5481.1, Safety Analysis and Review System, 10/05/83

DOE 5480.30, Nuclear Reactor Safety Design Criteria, 01/19/93

DOE 5480.28, Natural Phenomena Hazards Mitigation, 01/15/93

DOE 5482.1B, Environment, Safety, and Health Appraisal Program, 11/18/91

DOE-RL-5482.1B, Environment, Safety, Health, and Quality Assurance Appraisal and Surveillance Program, 03/04/87

DOE 6430.1A, General Design Criteria, 04/06/89

ANSI/ANS-8.1-1993, Nuclear Criticality Safety in Operations with Fissionable Materials Outside Reactors

ANSI/ANS-8.3-1986, Criticality Accident Alarm System

ANSI/ANS-8.19-1984, Administrative Practices for Nuclear Criticality Safety

ANSI N16.5-1975 (ANS-8.7), American National Standard Guide for Nuclear Criticality Safety in the Storage of Fissile Materials

DOE-SEN-35-91, Nuclear Safety Policy, 09/09/91

DOE-STD-1027-92, Hazard Categorization and Accident Analysis Techniques for Compliance with DOE Order 5480.23 Nuclear Safety Analysis Reports, 12/01/92 
DOE/EH0135, Performance Objectives and Criteria for Technical Safety Appraisals at DOE Facilities and Sites, 06/01/90 


\section{TABLE OF CONTENTS}

19.0 OCCUPATIONAL SAFETY AND HEALTH $\ldots \ldots \ldots \ldots \ldots \ldots \ldots$

19.1

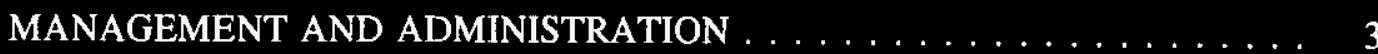

19.1.1

19.1.2

19.1.3

19.2

19.2.1

19.2.2

19.2.3

19.2 .4

19.2 .5

19.3

19.3.1

19.3.2

19.3.2.1

19.3.2.2

19.3.2.3

Program Policy $\ldots \ldots \ldots \ldots \ldots$

Occupational Safety and Health Goals and Objectives . . . . . . . 3

Requests for Exemptions/Variances $\ldots \ldots \ldots \ldots \ldots$

HAZARD ANTICIPATION, IDENTIFICATION AND EVALUATION . . . . . 5

Hazard Assessment Program $\ldots \ldots \ldots \ldots \ldots$

Hazards Reporting System . . . . . . . . . . . . . . 6

Investigation of Occurrences, Accidents, and Near Misses . . . . . . 8

Injury and Illness Trend Analysis $\ldots \ldots \ldots \ldots$

Occupational Safety and Health Hazard Inventory System . . . . . . 8

OSH HAZARD PREVENTION AND CONTROL $\ldots \ldots \ldots \ldots \ldots \ldots \ldots$

Hazard Monitoring, Sampling, and Surveillance . . . . . . . . 8

Hazard Controls $\ldots \ldots \ldots \ldots \ldots \ldots \ldots$

19.3.3

Safety Inspection and Maintenance $\ldots \ldots \ldots \ldots 21$

19.4

OCCUPATIONAL HEALTH PROGRAM $\ldots \ldots \ldots \ldots \ldots \ldots \ldots$

19.4.1

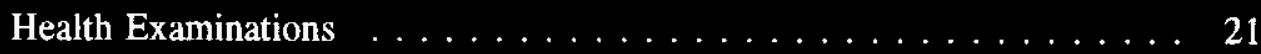

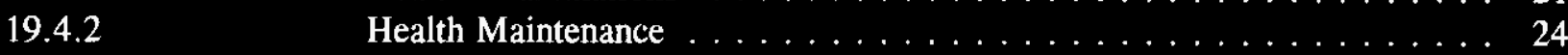

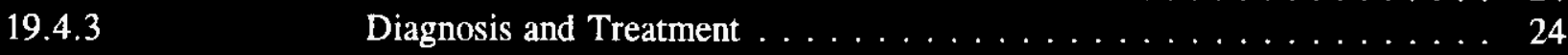

19.4 .4

19.4 .5

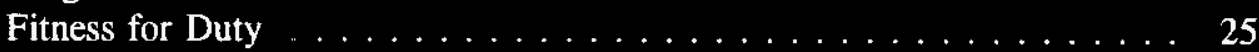

Medical Facilities and Equipment ............... 25

19.4.6

19.4 .7

19.4 .8

Professional Development of Occupational Staff $\ldots \ldots \ldots \ldots . \ldots . \ldots 25$

Health Records and Reporting . . . . . . . . . . . . . . . . . 25

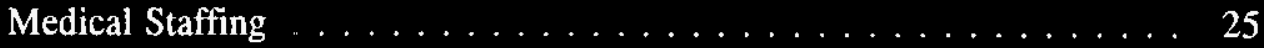

$19.5 \quad$ OCCUPATIONAL SAFETY AND HEALTH TRAINING $\ldots \ldots \ldots \ldots$

19.6

RECORDKEEPING AND REPORTING $\ldots \ldots \ldots \ldots \ldots \ldots \ldots \ldots$

19.6.1

Occupational Injury and Illness Reporting ... . . . . . . . . 26

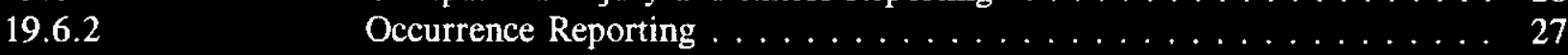


19.7.3

19.7 .4

19.7 .5

19.8

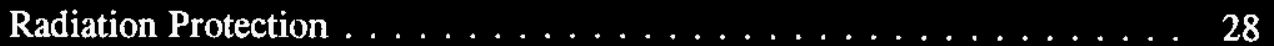

Training and Qualification ... . . . . . . . . . . . . 28

Management Systems . . . . . . . . . . . . . . . 28

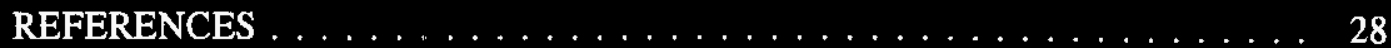

19.8.1

Requirement Source Documents . . . . . . . . . . . . . . . . . . 28

19.8 .2

Reviewed Documents Not Used as Requirement Sources 


\subsection{OCCUPATIONAL SAFETY AND FIEALTH}

\section{INTRODUCTION}

A Standards/Requirements Identification Document (S/RID) sets forth the Environmental Safety and Health (ES\&H) standards/requirements. This S/RID is applicable to the appropriate life cycle phases of design, construction, operation, and preparation for decommissioning for each of the categories of facilities addressed in Revision 5 of the Department of Energy Implementation Plan for the Defense Nuclear Facilities Safety Board (DNFSB) Recommendation 90-2. This Recommendation calls for the strengthening of DOE weapons complex activities through the identification and application of relevant DOE Orders, regulations, industry codes/standards, industry guidance documents and, as appropriate, good industry practices. These standards/requirements are adequate to ensure protection of the health and safety of workers, the public, and the environment.

The Tank Farms S/RID contains standards/requirements that are necessary for safe operation of the Tank Farms and its associated facilities, and that are the direct responsibility of the specific facility manager. The Occupational Safety and Health Program defined in this document is described in general accordance with the Environment, Safety, and Health Configuration Guide, Revision 0, dated July 30, 1993, and is presented in program elements and subelements. The specific DOE Orders, regulations, industry codes/standards, guidance documents and good industry practices that serve as the basis for each element/subelement are identified and aligned with each subelement.

This S/RID contains only those requirements that Tank Farms personnel are clearly responsible to satisfy. Other requirements that are applicable to Tank Farms, but are satisfied by others, are defined in the Westinghouse Hanford Company (WHC) Level S/RID. For application in this S/RID, the words "shall" and "should" in requirements statements both indicate mandatory compliance. The Key interface information contained in the Functional Area documents is provided for general recognition and understanding and is not considered to contain prescriptive requirements. Additionally, some of the requirements cited in this document are intentionally duplicated in the corresponding Company Level S/RID. This was necessary to address required implementation responsibilities occurring at both the company and facility levels.

The Department of Energy (DOE) Orders 5483.1A, 5480.10, 5480.8A, and 5480.4 direct contractors at DOE Defense Nuclear Facilities to comply with Federal Regulations for employee safety and health programs subject to U.S. Department of Labor, Occupational Safety and Health Administration (OSHA) regulations. These orders invoke OSHA 29 CFR 1910, 29 CFR 1926, specific American National Standards Institute (ANSI) standards and the American Conference of Governmental Industrial Hygienist (ACGIH) Threshold Limit Values for Chemical Substances and Physical Agents and Biological Exposure Indices which provide the basis for establishing the Occupational Health and Safety requirements applicable to the Tank Waste Remediation Systems facilities and operations. TWRS commits to implement applicable requirements from the sources listed above. This document contains the specific Occupational Safety and Health requirements applicable to the current mission at TWRS. 
High Level Waste Storage

WHC-SD-MP-SRID-001

Tank Farms/242-A Evaporator

Standards/Requirements Identification Document January 10, 1996 Rev. 0

19.0 Occupational Safety and Health

Page 2 of 29

SCOPE

This S/RID applies to the Tank Waste Remediation Systems (TWRS) Organization which includes the following:

- East Tank Farm Transition Project

- West Tank Farm Transition Project

- Evaporator Project

- Interim Stabilization Project

- Characterization Sampling Project (Excluding the Labs)

The near-term mission of TWRS is to store, treat, and immobilize the highly radioactive Hanford Site Waste. 
19.1

$\underline{19.1 .1}$

\section{MANAGEMIENT AND ADMINISTRATION}

\section{Program Policy}

Author's Note: "Facilities implement 54FR3904 "The Voluntary Protection Program," however, the Program requirements are contained in the Company level OH Functional Area."

\section{REQUIREMIENT SOURCE: DOE5480.10 Section 9.a(1)}

"The Operating Organization having line safety and health responsibilities should be required to:

(a) conduct operations consistent with established health and safety procedures;"

\section{REQUIREMENT SOURCE: DOE5480.10 Section 9.a(5)}

"Employees should be required to:

(a) observe all safety and health rules;

(b) use all prescribed personal protective equipment;

(c) follow established health and safety practices and procedures; and

(d) notify supervisors immediately of suspected exposures to harmful agents or conditions."

\section{REQUIREMINT SOURCE: DOE5480.10 Section 9.d(1)}

"The staff responsible for the direction and operation of the industrial hygiene program must be professionally qualified, adequate in number, and have sufficient time and authority to design and implement the industrial hygiene program set forth in this Order."

\section{REQUIREMINT SOURCE: PUBLIC-LAW-91-596 Section 5(a)(1)}

"Each employer - shall furnish to each of his employees employment and a place of employment which are free from recognized hazards that are causing or are likely to cause death or serious physical harm to his employees;"

$\underline{19.1 .2}$

\section{Occupational Safety and Health Goals and Objectives}

Additional requirements for this subelement are found in the WHC Occupational Safety and Health S/RID.

\section{REQUIREMENT SOURCE: 54FR3904 Part (c)(1)(ii)}

"Establish and communicate a clear goal for the safety and health program and objectives for meeting that goal, so that all members of the organization understand the results desired and the measures planned for achieving them."

\section{Requests for Exemptions/Variances}

\section{REQUIREMINT SOURCE: DOE5483.1A Chapter I, Section 4.a}

"Temporary Variances.

(1) A contractor may apply to the appropriate $\mathrm{CO}$ or $\mathrm{CO}$ representative for a temporary variance from the DOE-prescribed OSHA standards. A request for a temporary variance shall contain: 
(a) A specification of the standard from which the contractor seeks a variance.

(b) A representation that the contractor is portable to comply with the standard and a detailed statement of the reasons therefor.

(c) A statement of the steps the contractor has taken and will take to protect employees from the hazard covered by the standard, to include the conditions the contractor must maintain and the practices, means, methods, operations, and processes which must be adopted and utilized to the extent they provide protection equivalent to that of the standard for which the variance is requested.

(d) A certification that the contractor has informed employees of the application by giving a copy thereof to their authorized representative (where applicable), posting a statement, giving a summary of the request, and specifying where a copy may be examined (e.g., at the place or places where notices to employees are normally posted) and by other appropriate means. A description of how employees have been informed shall be contained in the certification. The information to employees also shall inform them that they may comment on the request to the appropriate $\mathrm{CO}$ or $\mathrm{CO}$ representative.

(e) A statement of when the contractor will be able to comply with the standard and what steps have been taken and will be taken by the contractor to come into compliance with the standard.

(2) The $\mathrm{CO}$ or $\mathrm{CO}$ representative, the safety and health manager, and other appropriate elements of the field organization shall review the contractor's request and the employees' comments and submit the field organization's recommendation, together with the contractor's request and contractor employee comments, to the Director of Operational Safety (EP-32) within 30 days of receipt of the request. After review and evaluation of the request, comments, and recommendation and after coordination with the appropriate program office(s), EP-32 shall approve a temporary variance if the request establishes that (a) the contractor is unable to comply with the standard because of unavailability of professional or technical personnel materials or equipment funding needed to come into compliance with the standard, or because necessary construction or alteration of facilities must be completed in order to comply; (b) the contractor is taking all available steps to safeguard employees against the hazards covered by the standard; and (c) the contractor has an effective program for coming into compliance with the standard as quickly as practicable.

(3) A temporary variance may be in effect for no longer than the period needed by the contractor to achieve compliance with the standard or 1 year, whichever is shorter, except that in unusual circumstances (e.g., lack of programmatic funding) such a temporary variance may be renewed not more than once. Such a renewal also shall be in effect for no longer than 1 year. An application for renewal must be filed and processed in the manner specified in paragraph $4 \mathrm{a}(2)$, above at least 90 days prior to expiration of the temporary variance. Employees also shall be given an opportunity to review and comment on a request for a renewal as outlined on page $1-2$, paragraph $4 \mathrm{a}(1)(\mathrm{d})$.

(4) The Director of Operational Safety shall inform the field organization of the results of the evaluation of the request for a temporary variance or the extension thereof, within 180 days of receipt of the request."

\section{REQUIREMENT SOURCE: DOE5483.1A Chapter I, Section 4.b}

"Permanent Variances.

(1) DOE contractors may apply to the appropriate $\mathrm{CO}$ or $\mathrm{CO}$ representative for a permanent variance from the prescribed OSHA standards. The request for variance shall contain the 
same information specified on page $I-2$, paragraphs $4 \mathrm{a}(1)(\mathrm{a})-(\mathrm{d})$. The CO or CO representative, the local safety and health office, and other appropriate elements of the field organization shall review the contractor's request and the employees comments and submit their recommendation together with the contractor's request and contractor employee comments, to the Director of Operational Safety (EP-32) within 30 days of receipt of the request. After review and evaluation of the request, comments, and recommendation, and after coordination with the appropriate program office, EP-32 shall submit a recommendation to the Assistant Secretary, Environmental Protection Safety, and Emergency Preparedness (EP-1), for consideration.

(2) If EP-1 determines that the contractor has demonstrated that the conditions practices, means, methods, operations, or processes to be used will provide employment and a place of employment which is as safe and healthful as those which would prevail if the contractor complied with the standard, a permanent variance shall be approved and the requesting organization shall be notified accordingly, within 180 days of receipt of the request by EP-32.

(3) However, if the permanent variance request is not approved by EP-1, the requesting organization shall be notified of the rationale for the determination, within 180 days of receipt of the request by EP-32."

\section{REQUIREMENT SOURCE: DOE5483.1A Chapter I, Section 4.c}

"Exceptions. The CO or CO representative may grant exceptions from the DOE-prescribed OSHA standards after evaluation of a contractor's request for a temporary or permanent variance. To provide such an evaluation, the $\mathrm{CO}$ or $\mathrm{CO}$ representative shall consult with the safety and health director and other appropriate elements of the field organization. An exception shall be granted only where the contractor has demonstrated that contractor employees will be provided protection equivalent to that provided by the standard(s) for which the temporary or permanent variance is being requested. The exception is to be effective only until a decision on the issuance of a variance is made by Headquarters, but in no case is an exception to be effective for longer than 180 days, beginning with the date of Headquarters receipt of the request. The exception shall not be renewable."

\section{HAZARD ANTICIPATION, IDENTIFICATION AND EVALUATION}

\section{Hazard Assessment Program}

Additional requirements for this subelement are found in the WHC Occupational Safety and Health S/RID.

\section{REQUIREMENT SOURCE: DOE5480.10 Section 9.a(3)}

"Purchasing and Contracting Organizations should be required to:

(a) participate as requested by the industrial hygiene staff to assure that potentially hazardous material or equipment being procured are adequately identified, evaluated, and controlled; and

(b) require contractors or subcontractors performing potentially hazardous operations within a DOE or DOE-controlled facility to comply with the mandatory industrial hygiene standards of DOE 5480.4 and make provisions to allow the industrial hygiene staff to monitor compliance." 


\section{REQUIREMENT SOURCE: DOE5480.10 Section 9.b Introduction and 9.b(1)}

"Functions. The industrial hygiene program shall be designed to preserve employee health and well-being. This shall be accomplished by identification, evaluation, and control of environmental factors and stresses found in the workplace. These environmental factors and stresses include: chemical (e.g., liquid, particulate, vapor, and gas); physical (e.g., electromagnetic radiation, noise, vibration, and magnetic fields); biological (e.g., agents of infectious diseases); and ergonomic (e.g., body position in relation to task, repetitive motion, and mental or physical fatigue). The contractor industrial hygiene program must have the following features:

(1) Identification of Health Hazards. The industrial hygiene staff shall identify and document existing and potential occupational health hazards through: knowledge and assessment of the operations; periodic walk-through surveys; information provided by interorganizational communication; the review of proposed projects, facilities, engineering plan, and specifications; and maintenance of a hazards inventory or tracking system."

\section{REQUIREMINT SOURCE: DOE5480.10 Section 9.b(2)}

"Hazard Evaluation. Once potential health hazards are identified, the industrial hygiene staff must determine the extent of the hazard through appropriate consultation with other professionals, sound judgment, and the application of established standards or guides and such evaluation techniques as air sampling and bioassay. A report shall be sent to the first level supervisor with the industrial hygiene staff's evaluation of whether occupational exposures are within permissible limits, together with supporting evidence. The permissible exposure limits used in hazard evaluation shall not exceed those in the mandatory industrial hygiene standards of DOE 5480.4, Attachment 2, paragraph 2.d.(3). When a potential health hazard is identified that has no assigned permissible exposure limit, a guideline on evaluation and control should be developed based on the best available information (refer to paragraph 10.a.(1))."

\section{Hazards Reporting Svstem}

Additional requirements for this subelement are found in the WHC Occupational Safety and Health S/RID.

\section{REQUIREMENT SOURCE: DOE5483.1A Chapter I, Section 5.a.(1)}

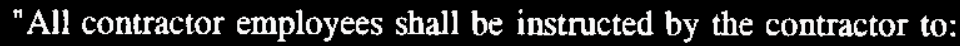

(1) Observe the DOE-prescribed OSHA standards applicable to their work and report promptly to the contractor any condition which may lead to a violation of these standards."

\section{REQUIREMINT SOURCE: DOE5483.1A Chapter II, Section 1.a}

"Initially, contractor employees or representatives thereof should attempt a resolution of their complaints by submitting to their contractor management, either directly or through their authorized employee representative, reports of any conditions or practices which they consider hazardous to their safety or health, or which they believe are in violation of the DOE prescribed OSHA standards."

\section{REQUIREMENT SOURCE: DOE5483.1A Chapter II, Section 1.b}

"Contractor employees or their representatives may submit complaints directly to the DOE field organization safety and health manager or the $\mathrm{CO}$ or $\mathrm{CO}$ representative, particularly in 
situations where the complainant wishes to remain anonymous (to the contractor), or where the complainant believes that unsafe/unhealthful conditions still exist or violations of standards still remain after being brought to the attention of and addressed by contractor personnel."

\section{REQUIREMINT SOURCE: DOE5483.1A Chapter II, Section 2}

"a. Should the contractor receive a complaint from an employee or an authorized representative, the contractor shall confer with the employee or the authorized representative and conduct a joint inspection of the conditions or circumstances identified by the complaint.

b. Should the field organization receive a complaint, the facts and circumstances of the complaint shall be reviewed and, if determined necessary by the DOE, an inspection shall be made to investigate the complaint allegations within 15 days of receipt of the complaint. However, the inspection should be made as immediately as is possible. In making the inspection, the same procedures set forth on pages I-5 through $1-7$, paragraphs $6 \mathrm{~b}-\mathrm{g}$, shall apply. Follow-up compliance inspections shall be conducted, as appropriate."

\section{REQUIREMENT SOURCE: DOE5483.1A Chapter II, Section 3}

\section{"IMMINENT DANGER COMPLAINTS - SUBMISSION AND INSPECTION.}

a. Any employee or authorized representative of employees who believes that an imminent danger exists, shall bring this matter to the attention of the appropriate contractor, supervisor, or designated official. If the imminent danger is determined to be valid, the contractor shall take immediate and effective remedial actions to remove employees from the danger area and/or eliminate the danger. The contractor shall conduct an inspection as soon as possible thereafter to assure that appropriate actions have been taken to preclude recurrence of the imminent danger situation.

b. The employee or the authorized representative also may visit or call the DOE at the field organization level to request an immediate elimination of the danger and an inspection of the alleged imminent danger situation. DOE shall ascertain immediately whether there is a reasonable basis for the imminent danger complaint. If the complaint is determined to be valid, DOE shall take immediate and effective actions to remove employees from the danger area and/or eliminate the danger. This may be accomplished by conducting an immediate DOE inspection and/or by contacting the contractor immediately. In any event DOE shall conduct an inspection as soon as possible to assure that appropriate actions have been taken to preclude recurrence of the imminent danger situation. In making the inspection, the same procedures set forth on pages I-5 through I-7, paragraphs $6 \mathrm{~b}-\mathrm{g}$, shall apply. Follow-up compliance inspections shall be conducted as appropriate."

\section{REQUIREMENT SOURCE: DOE5483.1A Chapter II, Section 4}

Author's Note: Only section (a) applies to the facility.

"a. The contractor shall inform each complainant of the results of the inspection and the actions taken to address and/or correct the safety and health concerns, problems, and/or violations of the DOE-prescribed OSHA standards noted by a complaint filed with the contractor.

b. For complaints filed with DOE, DOE shall provide a written response to the complainant within 15 days after the completion of the complaint inspection, except, obviously, in those situations where the complainant's identity cannot be determined. The response shall be sent to the complainant's home address, unless he or she has specifically requested that mail be sent to his or her place of employment. The response shall provide the results of the DOE 
$\underline{19.2 .3}$

$\underline{19.2 .4}$

$\underline{19.2 .5}$

19.3

19.3.1

$\underline{19.3 .2}$

inspection prompted by the complaint, and shall document all actions taken on complaint-related allegations of unsafe/unhealthful conditions and/or violations of the DOE-prescribed OSHA standards. If it is determined that no inspection is necessary, DOE shall respond to the complainant within 15 days of receipt of the complaint and state why an inspection was not conducted."

\section{Investigation of Occurrences, Accidents, and Near Misses}

Requirements for Accidents and Near Misses are found in the WHC Occupational Safety and Health S/RID. Requirements related to investigation of occurrences are located in the facility Management Systems Functional Area.

\section{Injury and Illness Trend Analysis}

While the facility has the responsibility of analyzing injury and illness trends, the requirements for this subelement are found in the WHC Occupational Safety and Health S/RID.

\section{Occupational Safety and Health Hazard Inventory System}

\section{REQUIREMENT SOURCE: DOE5480.10 Section 9.f(1)}

"An inventory of occupational health hazards shall be maintained. The inventory should be a listing of potential chemical, physical, and biological health hazards by location and/or job category of users and indicate when the hazards were present."

\section{OSH HAZARD PREVENTION AND CONTROL}

This element interfaces with and relies upon support from other Functional Areas such as: Operations, Fire Protection, Maintenance, Nuclear Safety, Quality Assurance, and Radiation Protection.

Author's Note: 29 CFR 1926 requirements pertain only to construction activity.

Hazard Monitoring, Sampling, and Surveillance

\section{REQUIREMENT SOURCE: DOE5480.10 Section 9.b(4)}

"Periodic Review. The satisfactory control of occupational health hazards shall be given continuing attention despite the imposition of control measures. Periodic monitoring is essential to assure maintenance of satisfactory conditions. The industrial hygiene staff shall determine the type and frequency of periodic monitoring. The industrial hygiene staff shall report to line management regarding the continuing adequacy of controls, the need for additional controls, or recommendations for maintenance or reemphasis of administrative controls. Employees of DOE contractor organizations shall be provided the results of the monitoring program for toxic materials or harmful physical agents, upon request."

\section{Hazard Controls}

\section{REQUREMENT SOURCE: 29CFR1910 Part 151(a) and (b)}

"(a) The employer shall ensure the ready availability of medical personnel for advice and consultation on matters of plant bealth. 
(b) In the absence of an infirmary, clinic, or hospital in near proximity to the workplace which is used for the treatment of all injured employees, a person or persons shall be adequately trained to render first aid. First aid supplies approved by the consulting physician shall be readily available."

\section{REQUREMENT SOURCE: 29CFR1910 Part 151(c)}

"Where the eyes or body of any person may be exposed to injurious corrosive materials, suitable facilities for quick drenching or flushing of the eyes and body shall be provided within the work area for immediate emergency use."

\section{REQUIREMENT SOURCE: 29CFR1910 Subpart D - Table of Contents [Restated]}

Walking-Working Surfaces

1910.22 General Requirements

1910.23 contains requirements that address guarding floor and wall openings and holes

1910.24 contains requirements that address fixed industrial stairs

1910.25 contains requirements that address portable wood ladders

1910.26 contains requirements that address portable metal ladders

1910.27 contains requirements that address fixed ladders

1910.28 contains requirements that address safety requirements for scaffolding

1910.29 contains requirements that address manually propelled mobile ladder stands and scaffolds (towers).

1910.30 contains requirements that address other working surfaces.

\section{REQUIREMENT SOURCE: 29CFR1910 Subpart E - Table of Contents [Restated]}

\section{Means of Egress}

1910.36 General requirements

1910.37 contains requirements that address means of egress, general

1910.38 contains requirements that address employee emergency plans and fire prevention plans.

\section{REQUIREMENT SOURCE: 29CFR1910 Subpart F - Table of Contents [Restated]}

Powered Platforms, Manlifts \& Vehicle-Mounted Work Platforms

1910.66 contains requirements that address power platforms for exterior building maintenance 1910.67 contains requirements that address vehicle-mounted elevating and rotating work platforms

1910.68 contains requirements that address manlifts

\section{REQUIREMENT SOURCE: 29CFR1910 Subpart G - Table of Contents [Restated]}

Author's Note: 29CFR1910.96 was handed off to Radiation Protection.

Occupational Health and Environmental Control

1910.94 contains requirements that address ventilation

1910.95 contains requirements that address occupational noise exposure

1910.96 contains requirements that address ionizing radiation

1910.97 contains requirements that address nonionizing radiation 


\title{
REQUIREMENT SOURCE: 29CFR1910 Subpart H - Table of Contents [Restated]
}

Author's Note: 29 CFR 1910.120 requirements are located in section 19.3.2.1 Administrative Controls.

Hazardous Materials

1910.101 contains requirements that address compressed gases (general requirements)

1910.102 contains requirements that address acetylene

1910.103 contains requirements that address hydrogen

1910.104 contains requirements that address oxygen

1910.105 contains requirements that address nitrous oxide

1910.106 contains requirements that address flammable and combustible liquids

1910.107 contains requirements that address spray finishing using flammable or combustible liquids

1910.108 contains requirements that address dip tanks containing flammable or combustible liquids

1910. 110 contains requirements that address storage and handling of liquefied petroleum gases 1910.111 contains requirements that address storage and handling of anhydrous ammonia 1910.119 contains requirements that address Process Safety Management of Highly Hazardous Chemicals

1910.120 Hazardous Waste Operations and emergency response.

\section{REQUIREMENT SOURCE: 29CFR1910 Subpart I - Table of Contents [Restated]}

\author{
Author's Note: Respiratory Protection requirements are identified and contained in the \\ company level OH Functional Area.
}

Author's Note: Additional respiratory protection requirements can be found in ANSI Z88.2-1992.

Personal Protective Equipment

1910.132 General requirements

1910.133 contains requirements that address eye and face protection

1910.134 contains requirements that address respiratory protection

1910.135 contains requirements that address occupational head protection

1910.136 contains requirements that address occupational foot protection

1910.137 contains requirements that address electrical protective devices

1910.138 contains requirements that address hand protection

\section{REQUIREMENT SOURCE: 29CFR1910 Subpart J - Table of Contents [Restated]}

General Environmental Controls

1910.141 contains requirements that address sanitation

1910.143 contains requirements that address nonwater carriage disposal systems

1910.144 contains requirements that address safety color code for marking physical hazards

1910.145 contains requirements that address specifications for accident prevention signs and tags.

1910.146 contains requirements that address permit required confined space

Note: This section contains requirements for practices and procedures to protect employees in general industry from the hazards of entry into permit-required confined spaces.

1910.147 contains requirements that address the control of hazardous energy (lockout/tagout) 
Compressed Gas and Compressed Air Equipment

1910.169 contains requirements that address air receivers

\section{REQUIREMENT SOURCE: 29CFR1910 Subpart N - Table of Contents [Restated]}

Materials Handling and Storage

1910.176 contains requirements that address handling material-general

1910.177 contains requirements that address servicing multi-piece and single piece rim wheels 1910.178 contains requirements that address powered industrial trucks

1910.179 contains requirements that address overhead and gantry cranes

1910.180 contains requirements that address crawler locomotive and truck cranes

1910.183 contains requirements that address helicopters

1910.184 contains requirements that address slings.

\section{REQUTREMENT SOURCE: 29CFR1910 Subpart O - Table of Contents [Restated]}

Machinery and Machine Guarding

1910.212 contains requirements that address general requirements for all machines.

1910.213 contains requirements that address woodworking Machinery Requirements

1910.214 contains requirements that address cooperage machinery

1910.215 contains requirements that address abrasive wheel machinery

1910.217 contains requirements that address mechanical power presses

1910.218 contains requirements that address forging machines

1910.219 contains requirements that address mechanical power-transmission apparatus.

\section{REQUIREMENT SOURCE: 29CFR1910 Subpart P - Table of Contents [Restated]}

Hand and Portable Powered Tools

1910.242 contains requirements that address hand and portable powered tools and equipment, general

1910.243 contains requirements that address guarding of portable powered tools.

1910.244 contains requirements that address other portable tools and equipment.

\section{REQUIREMIENT SOURCE: 29CFR1910 Subpart Q - Table of Contents [Restated]}

Welding, Cutting, and Brazing

1910.252 contains requirements that address general requirements

1910.253 contains requirements that address oxygen-fuel gas welding and cutting

1910.254 contains requirements that address arc welding and cutting

1910.255 contains requirements that address resistance welding

\section{REQUIREMINT SOURCE: 29CFR1910 Subpart S - Table of Contents [Restated]}

Design Safety Standards for Electrical Systems

1910.302 contains requirements that address electric utilization systems

1910.303 general requirements

1910.304 contains requirements that address wiring design and protection

1910.305 contains requirements that address wiring methods, components, and equipment for general use

1910.306 contains requirements that address specific purpose equipment and installations

1910.307 contains requirements that address hazardous (classified) locations

1910.308 contains requirements that address special systems 
Safety-Related Work Practices

1910.332 contains requirements that address training

1910.333 contains requirements that address selection and use of work practices

1910.334 contains requirements that address use of equipment

1910.335 contains requirements that address safeguards for personnel protection

\section{REQUIREMINT SOURCE: 29CFR1910 Subpart Z - Table of Contents [Restated]}

Toxic and Hazardous Substances

1910.1000 contains requirements that address air contaminants.

1910.1001 contains requirements that address asbestos.

1910.1002 contains requirements that address coal tar pitch volatiles.

1910.1003 contains requirements that address 4-Nitrophenyl.

1910.1004 contains requirements that address Alpha Naphthylamine.

1910.1006 contains requirements that address Methyl Chloromethyl Ether.

1910.1007 contains requirements that address 3,3' Dichlorobenzidine.

1910.1008 contains requirements that address Bis-chloromethyl ether.

1910.1009 contains requirements that address Beta Naphthylamine.

1910. 1010 contains requirements that address Benzidine.

1910.1011 contains requirements that address 4-Aminodiphenyl.

1910.1012 contains requirements that address Ethyleneamine.

1910.1013 contains requirements that address Beta-propiolactone.

1910.1014 contains requirements that address 2-Acetylaminofluorene.

1910.1015 contains requirements that address 4-Dimethylaminoazobenzene.

1910.1016 contains requirements that address $\mathrm{N}$-Nitrosodimethylamine.

1910.1017 contains requirements that address Vinyl Chloride.

1910.1018 contains requirements that address inorganic arsenic.

1910.1025 contains requirements that address lead.

1910.1027 contains requirements that address cadmium.

1910.1028 contains requirements that address Benzene.

1910.1030 contains requirements that address bloodborne pathogens.

1910.1044 contains requirements that address 1,2-dibrome-3-chloropropane.

1910.1045 contains requirements that address Acrylonitrile.

1910.1047 contains requirements that address Ethylene oxide.

1910.1048 contains requirements that address Formaldehyde.

1910.1050 contains requirements that address Methylenedianline.

1910.1200 contains requirements that address hazard communication.

1910.1450 contains requirements that address occupational exposure to hazardous chemicals in laboratories.

\section{REQUIREMENT SOURCE: ACGIH Table of Contents Chemical Substances 1994-1995 [Restated]}

Threshold Limit Values (TLV's) of Chemical Substances in the Work Environment include:

Adopted TLV's

Appendix A - Carcinogens

Appendix B - Substances of Variable Composition

Appendix C - TLV's for Mixtures

Appendix D - Particle Size-Selective Sampling Criteria for airborne particulate matter

Biological Exposure Indices

Adopted Biological Exposure Determinants 


\section{REQUIREMENT SOURCE: ACGIH Table of Contents Physical Substances} 1994-1995 [Restated]

Adopted TLV's that include:

- Airborne Upper Sonic and Ultrasonic Radiation

- Cold Stress

- Hand-Arm (Segmental) Vibration

- Heat Stress

- Lasers (ANSI Z136.1 would be the best standard to use for laser safety. Some aspects of laser safety are included in OSHA eye/face protection standards)

- Light and Near-Infrared Radiation

- Noise

Continuous or Intermittent

Impulsive or Impact

- Radiofrequency/Microwave Radiation

- Static Magnetic Fields

- Sub-Radiofrequency ( $30 \mathrm{kHz}$ and below) Magnetic Fields

- Sub-Radiofrequency (30 kHz and below) Magnetic Fields and Static Electric Fields

- Ultraviolet Radiation

\section{REQUIREMIENT SOURCE: DOE5480.10 Section 9.b(3)}

"Control Measures. Control measures shall be implemented whenever it is determined that a potential health hazard exists sufficient to produce illness or injury or that applicable standards are not being followed. The industrial hygiene staff shall formally recommend control measures to the first level supervisor who must respond promptly. Where feasible, engineering control measures, process change, or material substitution shall be used to prevent or minimize exposure to hazards. Administrative controls and personal protective equipment should supplement engineering controls as appropriate."

\section{REQUIREMENT SOURCE: DOE5480.10 Section 9.c(4)(b)}

"Regulated areas shall be established where chemical carcinogens are used. The characteristics of regulated areas shall be appropriate to assure that access is controlled and will depend on the quantity and physical properties of the material being used and on the operations being performed. A record shall be maintained of all personnel working in regulated areas."

\section{REQUIREMENT SOURCE: DOE5480.10 Section 9.c(4)(d)}

"Signs warning of the presence of chemical carcinogens shall be posted at all entrances to regulated work areas. Labels should be used on all carcinogen containers to identify the chemical and to warn of the carcinogenic hazard." 


\section{REQUIREMIENT SOURCE: DOE5480.10 Section 9.c(4)(e)}

"Good hygiene shall be maintained through work practices, such as: use of protective clothing; availability of showers and change rooms; bans on eating, drinking, and smoking in regulated areas; and use of nonpermeable work surfaces."

Administrative Controls

Author's Note: The Tank Farms are permitted as a RCRA TSD hazardous waste site, however, some uncontrolled hazardous waste site requirements have been imposed to ensure worker safety and health. The requirements are found in 29 CFR 1910.120 and are implemented through the Tank Farm Health and Safety Plan.

\section{REQUIREMENT SOURCE: 29CFR1910 Part 120(b)(1)(iv)}

"Contractors and sub-contractors. An employer who retains contractor or sub-contractor services for work in hazardous waste operations shall inform those contractors, sub-contractors, or their representatives of the site emergency response procedures and any potential fire, explosion, health, safety or other hazards of the hazardous waste operation that have been identified by the employer, including those identified in the employer's information program."

\section{REQUIREMENT SOURCE: 29CFR1910 Part 120(b)(1)(v)}

"Program availability. The written safety and health program shall be made available to any contractor or subcontractor or their representative who will be involved with the hazardous waste operation; to employees; to employee designated representatives; to OSHA personnel, and to personnel of other Federal, state, or local agencies with regulatory authority over the site."

\section{REQUIREMENT SOURCE: 29CFR1910 Part 120(b)(4)}

"Site-specific safety and health plan part of the program. --

(i) General. The site safety and health plan, which must be kept on site, shall address the safety and health hazards of each phase of site operation and include the requirements and procedures for employee protection."

\section{REQUIREMENT SOURCE: 29CFR1910 Part 120(g)(2)}

"Engineering controls, work practices, and PPE for substances not regulated in sub parts G and $Z$. An appropriate combination of engineering controls, work practices and personal protective equipment shall be used to reduce and maintain employee exposure to or below published exposure levels for hazardous substances and health hazards not regulated by 29 CFR part 1910, sub parts $G$ and $Z$. The employer may use the published literature and MSDS as a guide in making the employer's determination as to what level of protection the employer believes is appropriate for hazardous substances and health hazards for which there is no permissible exposure limit or published exposure limit."

\section{REQUIREMENT SOURCE: 29CFR1910 Part 120(j)(1)(viii)}

"Where major spills may occur, a spill containment program, which is part of the employer's safety and health program required in paragraph (b) of this section, shall be implemented to contain and isolate the entire volume of the hazardous substance being transferred." 


\section{REQUIREMINT SOURCE: 29CFR1910 Part 120(j)(9)}

"Tank and vault procedures

(i) Tanks and vaults containing hazardous substances shall be handled in a manner similar to that for drums and containers, taking into consideration the size of the tank or vault."

REQUIREMINT SOURCE: 29CFR1910 Part 120(j)(9)(ii)

"Appropriate tank or vault entry procedures as described in the employer's safety and health plan shall be followed whenever employees must enter a tank or vault."

\section{REQUIREMENT SOURCE: 29CFR1910 Part 120(k)(2)(i)}

"Decontamination procedures. A decontamination procedure shall be developed, communicated to employees and implemented before any employees or equipment may enter areas on site where potential for exposure to hazardous substances exists."

\section{REQUIREMENT SOURCE: 29CFR1910 Part 120(k)(2)(ii)}

"Decontamination procedures. Standard operating procedures shall be developed to minimize employee contact with hazardous substances or with equipment that has contacted hazardous substances."

\section{REQUIREMENT SOURCE: 29CFR1910 Part 120(k)(8)}

"Showers and change rooms. Where the decontamination procedure indicates a need for regular showers and change rooms outside of a contaminated area, they shall be provided and meet the requirements of 29 CFR 1910.141. If temperature conditions prevent the effective use of water, then other effective means for cleansing shall be provided and used. "

REQUIREMENT SOURCE: 29CFR1910 Part 120(n)(2)(ii)

"Nonpotable water. There shall be no cross-connection, open or potential, between a system furnishing potable water and a system furnishing nonpotable water."

\section{REQUIREMENT SOURCE: 29CFR1910 Part 120(n)(3)(iii)}

"Hazardous waste sites not provided with a sanitary sewer shall be provided with the following toilet facilities unless prohibited by local codes:

(A) Chemical toilets;

(B) Recirculating toilets;

(C) Combustion toilets; or

(D) Flush toilets."

\section{REQUIREMENT SOURCE: 29CFR1910 Part 120(n)(6)}

"Washing facilities. The employer shall provide adequate washing facilities for employees engaged in operations where hazardous substances may be harmful to employees. Such facilities shall be in near proximity to the worksite; in areas where exposures are below permissible exposure limits and published exposure levels and which are under the controls of the employer; and shall be so equipped as to enable employees to remove hazardous substances from themselves." 


\section{REQUIREMINT SOURCE: 29CFR1910 Part 120(g)(3)(i)}

"Personal protective equipment selection. Personal protective equipment (PPE) shall be selected and used which will protect employees from the hazards and potential hazards they are likely to encounter as identified during the site characterization and analysis."

\section{REQUIREMENT SOURCE: 29CFR1910 Part 120(g)(3)(iii)}

"Positive pressure self-contained breathing apparatus, or positive pressure air-line respirators equipped with an escape air supply, shall be used when chemical exposure levels present will create a substantial possibility of immediate death, immediate serious illness or injury, or impair the ability to escape."

\section{REQUIREMENT SOURCE: 29CFR1910 Part 120(g)(4)(i)}

"Totally-encapsulating chemical protective suits. Totally-encapsulating suits shall protect employees from the particular hazards which are identified during site characterization and analysis."

\section{REQUIREMINT SOURCE: 29CFR1910 Part 120(g)(5)}

"Personal protective equipment (PPE) program. A written personal protective equipment program, which is part of the employer's safety and health program required in paragraph (b) of this section or required in paragraph $(p)(1)$ of this section and which is also a part of the site-specific safety and health plan shall be established. The PPE program shall address the elements listed below. When elements, such as donning and doffing procedures, are provided by the manufacturer of a piece of equipment and are attached to the plan, they need not be rewritten into the plan as long as they adequately address the procedure or element.

(i) PPE selection based upon site hazards,

(ii) PPE use and limitations of the equipment,

(iii) Work mission duration,

(iv) PPE maintenance and storage,

(v) PPE decontamination and disposal,

(vi) PPE training and proper fitting,

(vii) PPE donning and doffing procedures,

(viii) PPE inspection procedures prior to, during, and after use,

(ix) Evaluation of the effectiveness of the PPE program, and

(x) Limitations during temperature extremes, heat stress, and other appropriate medical considerations."

\section{REQUIREMENT SOURCE: 29CFR1926 Subpart C - Table of Contents [Restated]}

Author's Note: $1926.29 ; 1926.33 ; 1926.34$; and 1926.35 do not apply at this time.

General Safety and Health Provisions

1926.20 contains requirements that address general safety and health provisions.

1926.21 contains requirements that address safety training and education.

1926.23 contains requirements that address first aid and medical attention.

1926.24 contains requirements that address fire protection and prevention. 
1926.25 contains requirements that address housekeeping.

1926.26 contains requirements that address illumination

1926.27 contains requirements that address sanitation.

1926.28 contains requirements that address personal protective equipment.

1926.29 contains requirements that address acceptable certifications.

1926.33 contains requirements that address access to employee exposure and medical records.

1926.34 contains requirements that address means of egress.

1926.35 contains requirements that address employee action plans.

\section{REQUIREMENT SOURCE: 29CFR1926 Subpart D - Table of Contents [Restated]}

Author's Note: 29 CFR 1926.53 was handed off to Radiation Protection.

Occupational Health and Environmental Controls

1926.50 contains requirements that address medical services and first aid.

1926.51 contains requirements that address sanitation.

1926.52 contains requirements that address occupational noise exposure.

1926.53 contains requirements that address ionizing radiation.

1926.54 contains requirements that address nonionizing radiation.

1926.55 contains requirements that address gases, vapors, fumes, dusts, and mists.

1926.56 contains requirements that address illumination.

1926.57 contains requirements that address ventilation.

1926.58 contains requirements that address asbestos, tremolite, anthophyllite, and actinolite.

1926.59 contains requirements that address hazard communication.

1926.62 contains requirements that address lead.

1926.62 contains requirements that address process safety management of highly hazardous chemicals.

1926.64 contains requirements that address process safety management of highly hazardous chemicals

1926.65 contains requirements that address hazardous waste operations and emergency

response.

\section{REQUIREMENT SOURCE: 29CFR1926 Subpart G - Table of Contents [Restated]}

Signs, Signals and Barricades

1926. 200 contains requirements that address accident prevention signs and tags.

1926.201 contains requirements that address signaling.

1926.202 contains requirements that address barricades.

\section{REQUIREMENT SOURCE: 29CFR1926 Subpart H - Table of Contents [Restated]}

Materials Handling Storage, Use and Disposal

1926.250 contains requirements that address general requirements for storage.

1926.251 contains requirements that address rigging equipment for material handling.

1926.252 contains requirements that address disposal of waste materials.

\section{REQUIREMINT SOURCE: 29CFR1926 Subpart I - Table of Contents [Restated]}

Tools-Hand and Power

1926.300 General requirements.

1926.301 contains requirements that address hand tools.

1926.302 contains requirements that address power operated hand tools.

1926.303 contains requirements that address abrasive wheels and tools.

1926.304 contains requirements that address woodworking Tools

1926.305 contains requirements that address jacks-lever and ratchet, screw and hydraulic. 
1926.306 contains requirements that address air receivers.

1926.307 contains requirements that address mechanical power-transmission apparatus.

\section{REQUIREMENT SOURCE: 29CFR1926 Subpart J - Table of Contents [Restated]}

Welding and Cutting

1926.350 contains requirements that address gas welding and cutting.

1926.351 contains requirements that address arc welding and cutting.

1926.352 contains requirements that address fire prevention.

1926.353 contains requirements that address ventilation and protection in welding, cutting, and heating.

1926.354 contains requirements that address welding, cutting and heating in way of

preservative coatings.

\section{REQUIREMENT SOURCE: 29CFR1926 Subpart K - Table of Contents [Restated]}

Electrical-Installation Safety Requirements

1926.403 General requirements

1926.404 contains requirements that address wiring design and protection.

1926. 405 contains requirements that address wiring methods, components, and equipment for general use.

1926.406 contains requirements that address specific purpose equipment and installations.

1926.407 contains requirements that address hazardous (classified) locations.

1926.408 contains requirements that address special systems.

Safety-Related Work Practices

1926.416 contains requirements that address general requirements.

1926.417 contains requirements that address lockout and tagging of circuits.

Safety-Related Maintenance \& Environmental Considerations

1926.431 contains requirements that address maintenance of equipment.

1926.432 contains requirements that address environmental deterioration of equipment.

Safety Requirements for Special Equipment

1926.441 contains requirements that address battery locations and battery charging.

\section{REQUIREMENT SOURCE: 29CFR1926 Subpart L - Table of Contents [Restated]}

Ladders and Scaffolding

1926.451 contains requirements that address scaffolding.

1926.453 contains requirements for manually propelled mobile ladder stands and scaffolds (towers).

\section{REQUIREMENT SOURCE: 29CFR1926 Subpart M - Table of Contents [Restated]}

Floors and Wall Openings, and Stairways

1926.500 contains requirements that address guardrails, handrails, and covers.

\section{REQUIREMENT SOURCE: 29CFR1926 Subpart N - Table of Contents [Restated]}

Cranes, Derricks, Hoists, Elevators, and Conveyors

1926.550 contains requirements that address cranes and derricks.

1926.552 contains requirements that address material hoists, personnel hoists and elevators.

1926.553 contains requirements that address base-mounted drum hoists. 
1926.554 contains requirements that address overhead hoists.

1926.555 contains requirements that address conveyors.

1926.556 contains requirements that address aerial lifts.

\section{REQUIREMINT SOURCE: 29CFR1926 Subpart O - Table of Contents [Restated]}

Motor Vehicles, Mechanized Equipment \& Marine Operations

1926.600 contains requirements that address equipment.

1926.601 contains requirements that address motor vehicles.

1926.602 contains requirements that address material handling equipment.

1926.603 pile driving equipment.

1926.604 contains requirements that address site clearing.

\section{REQUIREMENT SOURCE: 29CFR1926 Subpart P - Table of Contents [Restated]}

Excavations

1926.651 General requirements

1926.652 contains requirements that address protective systems.

Appendix A-Soil Classification

Appendix B-Sloping And Benching

Appendix C-Timber Shoring For Trenches

Appendix D-Aluminum Hydraulic Shoring For Trenches

Appendix E-Alternatives To Timber Shoring

Appendix F-Selection Of Protective Systems

\section{REQUIREMENT SOURCE: 29CFR1926 Subpart Q - Table of Contents [Restated]}

Concrete and Masonry Construction

1926.701 contains requirements that address general requirements.

1926.702 contains requirements that address equipment and tools.

1926.703 contains requirements that address cast-in-place concrete.

1926.704 contains requirements that address precast concrete.

1926.705 contains requirements that address lift-slab construction operations.

1926.706 contains requirements that address masonry construction.

\section{REQUIREMENT SOURCE: 29CFR1926 Subpart R - Table of Contents [Restated]}

Steel Erection

1926.750 contains requirements that address flooring.

1926.751 contains requirements that address structural steel assembly.

1926.752 contains requirements that address bolting, riveting, fitting-up, and plumbing-up.

\section{REQUIREMINT SOURCE: 29CFR1926 Subpart V - Table of Contents [Restated]}

Power Transmission and Distribution

1926.950 General requirements

1926.951 contains requirements that address tools and protective equipment.

1926.952 contains requirements that address mechanical equipment.

1926.953 contains requirements that address material handling.

1926.954 contains requirements that address grounding for protection employees.

1926.955 contains requirements that address overhead lines.

1926.956 contains requirements that address underground lines.

1926.957 contains requirements that address construction in energized substations. 
1926.959 contains requirements that address lineman's body belts, safety straps, and lanyards.

\section{REQUIREMENT SOURCE: 29CFR1926 Subpart W - Table of Contents [Restated]}

Rollover Protective Structures; Overhead Protection 1926.1000 contains requirements that address Rollover Protective Structures (ROPS) for material handling equipment.

1926. 1001 contains requirements that address minimum performance criteria for rollover protective structures for designated scrapers, loaders, dozers, graders, and crawler tractors. 1926. 1002 contains requirements that address protective frame (ROPS) test procedures and performance requirements for wheel-type agricultural and industrial tractors used in construction.

1926. 1003 contains requirements that address overhead protection for operators of agricultural and industrial tractors.

\section{REQUIREMENT SOURCE: 29CFR1926 Subpart X - Table of Contents [Restated]}

Stairways and Ladders

1926.1051 General requirements

1926. 1052 contains requirements that address stairways.

1926. 1053 contains requirements that address ladders.

1926. 1060 contains requirements that address training requirements.

Appendix A to Subpart X - contains requirements that address ladders.

\section{REQUIREMENT SOURCE: 29CFR1926 Subpart Z - Table of Contents [Restated]}

Toxic and Hazardous Substances

1926.1102 contains requirements that address Coal Tar Pitch Volatiles.

1926. 1103 contains requirements that address 4-Nitrophenyl.

1926.1104 contains requirements that address alpha-naphthylamine.

1926.1106 contains requirements that address Methyl Chloromethyl Ether.

1926.1107 contains requirements that address 3,3' Dichlorobenzidine.

1926. 1108 contains requirements that address bis-chloromethyl ether.

1926. 1109 contains requirements that address beth-naphthylamine.

1926.1110 contains requirements that address Benzidine.

1926.1111 contains requirements that address 4-Aminodiphenyl.

1926.1112 contains requirements that address Ethyleneimine.

1926.1113 contains requirements that address beta-Propiolactone.

1926.1114 contains requirements that address 2-Acetylaminofluorene

1926.1115 contains requirements that address 4-Dimethylaminoazobenzene

1926. 1116 contains requirements that address $\mathrm{N}$-Nitrosodimethylamine

1926.1117 contains requirements that address Vinyl chloride.

1926.1118 contains requirements that address Inorganic arsenic.

1926.1128 contains requirements that address Benzene.

1926.1144 contains requirements that address 1, 2-dibromo-3-chloropropane.

1926.1145 contains requirements that address Acrylonitrile.

1926.1147 contains requirements that address Ethylene oxide.

1926.1148 contains requirements that address Formaldehyde. 
$\underline{19.3 .3}$

19.4

19.4.1

\section{Safety Inspection and Maintenance}

\section{REQUIREMENT SOURCE: 29CFR1910 Part 120(b)(4)(iv)}

"The site safety and health plan, as a minimum shall address the following: Effectiveness of site safety and health plan. Inspections shall be conducted by the site safety and health supervisor or, in the absence of that individual, another individual who is knowledgeable in occupational safety and health, acting on behalf of the employer as necessary to determine the effectiveness of the site safety and health plan. Any deficiencies in the effectiveness of the site safety and health plan shall be corrected by the employer. "

\section{OCCUPATIONAL HEALTH PROGRAM}

The Hanford Environmental Health Foundation (HEHF) is a primary provider of medical services to the Hanford Site. Requirements applicable to medical activities are contained in HEHF specific documents.

\section{Health Examinations}

\section{REQUIREMENT SOURCE: 29CFR1910 Part 120(f)(2)}

"Employees covered. The medical surveillance program shall be instituted by the employer for the following employees:

(i) All employees who are or may be exposed to hazardous substances or health hazards at or above the permissible exposure limits, or, if there is no permissible exposure limit, above the published exposure levels for these substances, without regard to the use of respirators, for 30 days or more a year;

(ii) All employees who wear a respirator for 30 days or more a year or as required by $\S$ 1910.134;

(iii) All employees who are injured, become ill or develop signs or symptoms due to possible overexposure involving hazardous substances or health hazards from an emergency response or hazardous waste operation; and

(iv) Members of HAZMAT teams."

\section{REQUIREMENT SOURCE: 29CFR1910 Part 120(f)(3)(i)}

"Frequency of medical examinations and consultations. For employees covered under paragraphs (f)(2)(i), (f)(2)(ii), and (f)(2)(iv):

(A) Prior to assignment;

(B) At least once every twelve months for each employee covered unless the attending physician believes a longer interval (not greater than biennially) is appropriate;

(C) At termination of employment or reassignment to an area where the employee would not be covered if the employee has not had an examination within the last six months;

(D) As soon as possible upon notification by an employee that the employee has developed signs or symptoms indicating possible overexposure to hazardous substances or health hazards 
or that the employee has been injured or exposed above the permissible exposure limits or published exposure levels in an emergency situation;

(E) At more frequent times, if the examining physician determines that an increased frequency of examination is medically necessary."

\section{REQUIREMENT SOURCE: 29CFR1910 Part 120(f)(4)(i)}

"Content of medical examinations and consultations. Medical examinations required by paragraph (f)(3) of this section shall include a medical and work history (or updated history if one is in the employee's file) with special emphasis on symptoms related to the handling of hazardous substances and health hazards, and to fitness for duty including the ability to wear any required PPE under conditions (i.e., temperature extremes) that may be expected at the work site."

\section{REQUIREMENT SOURCE: 29CFR1910 Part 120(I)(5)}

"Examination by a physician and costs. All medical examinations and procedures shall be performed by or under the supervision of a licensed physician, preferably one knowledgeable in occupational medicine, and shall be provided without cost to the employee, without loss of pay, and at a reasonable time and place."

\section{REQUIREMENT SOURCE: 29CFR1910 Part 120(f)(6)}

"Information provided to the physician. The employer shall provide one copy of this standard and its appendixes to the attending physician, and in addition the following for each employee:

(i) A description of the employee's duties as they relate to the employee's exposures.

(ii) The employee's exposure levels or anticipated exposure levels.

(iii) A description of any personal protective equipment used or to be used.

(iv) Information from previous medical examinations of the employee which is not readily available to the examining physician.

(v) Information required by $\S 1910.134 . "$

\section{REQUIREMENT SOURCE: 29CFR1910 Part 120(f)(7)(i)}

"Physician's written opinion. The employer shall obtain and furnish the employee with a copy of a written opinion from the attending physician containing the following:

(A) The physician's opinion as to whether the employee has any detectable medical conditions which would place the employee at increased risk of material impaiment of the employee's health from work in hazardous waste operations or emergency response, or from respirator use.

(B) The physician's recommended limitations upon the employee's assigned work.

(C) The results of the medical examination and tests if requested by the employee.

(D) A statement that the employee has been informed by the physician of the results of the medical examination and any medical conditions which require further examination or treatment." 


\section{REQUIREMENT SOURCE: DOE5480.10 Section 9.b(6)}

"Medical Monitoring. The industrial hygiene staff shall inform the medical organization of potential and existing health hazards identified, the results of hazard evaluations, and other industrial hygiene information needed for operation of a medical monitoring program. The industrial hygiene staff should be available to accompany medical staff on periodic worksite visits (refer to DOE 5480.1A, Chapter VIII, paragraph 4a(2))."

\section{REQUIREMENT SOURCE: DOE5480.8A Section 11.b(3)(a)}

"Preplacement Evaluations.

1 A medical evaluation of an individual shall be conducted after the job offer, but prior to the performance of job duties, and in the case of an employee, prior to a job transfer. The health status and fitness for duty of the individual shall be determined, thereby assuring that assigned duties can be performed in a safe and reliable manner and consistent with the Americans with Disabilities Act of 1990.

2 Contractor management shall provide to the Site Occupational Medical Director a job task analysis pertaining to the applicant/employee to enable the medical examiner to assess the individual as required in $11 \mathrm{~b}(3)(\mathrm{a}) 1$.

3 The scope of the initial preplacement evaluation shall be a comprehensive examination as outlined in paragraph $11 \mathrm{~b}(2)$. The Site Occupational Medical Director shall determine additional examination content, considering such factors as special physical or mental requirements of the job, potential hazardous exposures, or medical surveillance requirements mandated by the Occupational Safety and Health Act, 29 CFR 1910 or 29 CFR 1926.

4 Those contractor operations requiring large numbers of preplacement evaluations may defer the comprehensive evaluation of individuals not assigned to hazardous work or potentially hazardous exposures after a review of the individual's medical history. The evaluation shall be performed within 6 months of the hire date.

5 The occupational medical department shall be informed of all job transfers. The Occupational Medical Director or designee should determine whether a medical evaluation is necessary."

\section{REQUIREMENT SOURCE: DOE5480.8A Section 11.b(3)(b)}

"Medical Surveillance Examinations and Health Monitoring. Standards and requirements for special health examinations and health monitoring of employees who work in jobs involving specific physical, chemical, or biological hazards shall be in accordance with applicable OSHA/DOE standards. When employees are exposed to potential hazards not covered by regulations, appropriate special examinations may be required as determined by the Site Medical Director and approved by the DOE Director, Office of Occupational Medicine."

\section{REQUIREMENT SOURCE: DOE5480.8A Section 11.b(3)(c)}

"Qualification Examinations.

1 Examinations shall be conducted to qualify employees for specific job assignments for which specific medical qualification standards exist (e.g., drivers, pilots, protective force personnel, and respirator wearers).

2 Special medical evaluations shall be performed in response to contractor management's request to determine employee fitness for duty." 


\title{
REQUIREMENT SOURCE: DOE5480.8A Section 11.h(3)(e)
}

\author{
"Return-to-Work Health Evaluations.
}

1 Occupational Injury or Illness. All employees with occupationally-related injuries or illnesses shall be evaluated before returning to work. The scope and content of this evaluation shall be determined by the OHE, based upon the nature and extent of the injury or disease, and shall be sufficient to ensure that the employee may return to work without undue health risk to self or others. Written clearance from the occupational medical department shall be required before such an employee may return to work.

2 Nonoccupational Injury or Illness. Contractor management, in the following situations, shall ensure that employees will not be allowed to return to work until they receive a health evaluation and written clearance from the occupational medical department. Situations warranting evaluation and clearance include nonoccupational-related illnesses or injuries causing absence from work for 5 consecutive workdays or more, procedures or treatments that would affect negatively the employee's ability to perform in a safe and reliable manner, and hospitalization. The employee shall provide relevant medical information from their private physician to assist in this determination. The final decision for health-related work recommendations shall reside with the Site Medical Director if a disagreement exists regarding return-to-work suitability."

\section{REQUIREMENT SOURCE: DOE5480.8A Section 11.b(3)(f)}

"Termination Health Evaluations. A health status review shall be made available for all terminating employees. Based upon the information obtained, a health examination (the content to be determined by the Site Occupational Medical Director) shall be conducted, whenever possible, on employees with known occupational illnesses or injuries, documented or presumed exposures required by OSHA regulations, or when more than 1 year has elapsed since the last examination. This should include a review of the medical record, associated exposure information, and a signed response by the employee to each of the following questions:

1 Have there been recent occupational illnesses or injuries not previously reported?

2 Have you ever been informed of an exposure to radiation or toxic materials above permissible limits?

3 Do you have any complaints or concerns related to prior illnesses, injuries, or exposures?

4 Do you have any current medical complaints?"

Health Maintenance

Requirements for this subelement are found in the WHC Occupational Safety and Health S/RID.

\section{Diagnosis and Treatment}

Author's Note: Diagnosis and Treatment requirements are under the direction of HEHF, and contained in the HEHF specific documents. 


\section{REQUIREMENT SOURCE: DOE5480.8A Section 11.c(3)}

"Monitored Care. Monitored care of ill or injured employees by occupational medical physicians is highly desirable to maximize recovery and safe retum to work and to minimize lost time and associated costs. Contractor management has the responsibility to advise the occupational medical department when an employee has been absent because of an illness or injury for more than 5 consecutive workdays, or has experienced excessive absenteeism. Worker's compensation cases should be monitored when appropriate through frequent return visits and physician-to-physician communication with private physicians where applicable. The goal is to assist the employees in their recovery and to facilitate their return to duty at the earliest practicable time. Reasonable accommodations or restrictions may be a part of this rehabilitation process and need to be closely coordinated with the human resources department and line management."

\subsubsection{Fitness for Duty}

Requirements for this subelement are under the direction of HEHF, and contained in their HEHF specific documents.

19.4 .5

$\underline{19.4 .6}$

$\underline{19.4 .7}$

$\underline{19.4 .8}$

19.5

\section{Medical Facilities and Equipment}

This subelement does not apply - WHC does not have medical facilities or equipment, therefore this does not apply to Tank Farms.

\section{Professional Development of Occunational Staff}

This subelement does not apply to WHC, therefore it does not apply to Tank Farms.

\section{Health Records and Reporting}

Author's Note:

All medical records are maintained by HEHF.

Requirements related to exposure records are found in the company level OH Functional Area.

\section{Medical Staffing}

This subelement does not apply - WHC does not maintain the medical staff (HEHF).

\section{OCCUPATIONAL SAFETY AND HEALTH TRAINING}

Additional requirements for this subelement are found in the WHC Occupational Safety and Health S/RID.

\section{REQUIREMENT SOURCE: DOE5480.10 Section 9.a(4)}

"First-line Supervisors should be required to:

(a) maintain healthful working conditions within his or her own organization and implement industrial hygiene recommendations;

(b) train employees to perform assignments in a safe manner; and 
(c) follow administrative procedures to allow appropriate disciplinary action to be taken when health and safety rules are violated."

\section{REQUIREMENT SOURCE: DOE5480.10 Section 9.b(5)}

"Employee Education. The industrial hygiene staff shall assist the first level supervisor in the development of an employee information and training program whenever a potential health hazard exists requiring engineering controls, administrative procedures, or personal protective equipment. The program shall include written notification of employees of environmental monitoring results when the results indicate that the employees are exposed above permissible limits. Training should include information on operations that may lead to exposure, the potential health effects of the hazard, the content of applicable standards, and the purpose and results of environmental monitoring. "

19.6

$\underline{19.6 .1}$

\section{RECORDKEEPING AND REPORTING}

\section{Occupational Injury and Illness Reporting}

Additional requirements for this subelement are found in the WHC Occupational Safety and Health S/RID.

\section{REQUIREMIENT SOURCE: DOE5480.10 Section 9.f(2)}

"The industrial hygiene staff's evaluation of potential health hazards shall be documented in written reports. If a deficiency is identified the report shall recommend corrective actions. The report, along with any response from line management and/or documentation of corrective actions, shall be retained."

\section{REQUIREMENT SOURCE: DOE5483.1A Chapter I, Section 5.d}

"All contractor employees shall be informed that the contractor is required to monitor the employee's workplace for radiation exposure and known toxic materials or harmful physical agents which are used or produced at the GOCO facility, and to maintain records of the data as required by Title 29 CFR Part 1910.20, "Access to Employee Exposure and Medical Records. " Employees or their authorized representatives are to be provided with an opportunity to observe monitoring or measuring for toxic materials and harmful physical agents and to have access to the results thereof. Each employee or former employee or representative thereof, within 15 days of a written request, shall be provided access to or copies of any records of cumulative recorded occupational radiation dose or any monitoring or bioassay records relevant to potential exposure to toxic materials or harmful physical agents during employment. Employees will be notified of any information indicating that a radiation dose or an exposure to toxic materials or harmful physical agents may have exceeded the limits specified by the DOE-prescribed OSHA standards."

\section{REQUIREMENT SOURCE: DOE5483.1A Chapter I, Section 5.e}

"All contractor employees or former employees shall have access to their personal safety, health, and medical records consistent with the provisions of the Freedom of Information Act and the Privacy Act." 


\title{
REQUIREMENT SOURCE: DOE5483.1A Chapter III, 2
}

\author{
"RECORDKEEPING.
}

a. Contractors subject to the provisions of DOE PR 9-50.704-2(a) shall be responsible for recording and reporting recordable occupational illnesses and injuries, as required by DOE 5484.1, ENVIRONMENTAL PROTECTION, SAFETY, AND HEALTH PROTECTION INFORMATION REPORTING REQUIREMENTS, of 2-24-81.

b. All contractors shall be responsible for maintaining records of employees exposures to toxic materials or harmful physical agents as appropriate. Such records shall be maintained in perpetuity.

c. A central file of all violations of DOE-prescribed OSHA standards noted during inspections (and abatement actions) shall be maintained by field organizations. A central file also shall be maintained by the field organizations of formal employee safety and health complaints and their disposition. Upon request, any of these safety and health violation or complaint-related records shall be made available for review by employees directly affected by such information, or by their authorized representatives. DOE 1324.1, RECORDS DISPOSITION, of 5-28-80, Attachment IV, DOE Records Schedule 25, paragraph 1b, specifies the retention period for these records.

d. DOE contractors subject to the provisions of DOE PR 9-50.704-2(a) shall respond to requests for injury/illness recordkeeping information from the U.S. Department of Labor, Bureau of Labor Statistics, or the Bureau's cooperating State agencies, as appropriate. The information shall be returned to the requestor on OSHA Form 200-S (included with the request) in accordance with the instructions accompanying the request, and a copy thereof shall be provided to the safety and health director of the field organization. The contractor shall include a statement on the OSHA Form 200-S which states: "With respect to work performed under contract with the DOE at (name of contractor and/or GOCO facility) this employer is not subject to the Occupational Safety and Health Act of 1970, under section 4(b)(1) of that Act. "

\section{Occurrence Reporting}

Requirements for this subelement are found in the facility Management Systems Functional Area.

\section{KEY INTERFACES}

The implementation and administration of an Occupational Safety and Health Program requires the definition of interfaces with other functional areas. All Westinghouse Hanford Company work activities are governed by the WHC Occupational Safety and health Program. Specific organizations and functional areas shall implement the programs and requirements developed by the Safety and Health Organization. Several functional areas have significant interfaces which are described in the following sections.

The Engineering Program Functional Area supports the industrial hygiene staff in defining the processes necessary to design engineering controls for health and safety hazards. This interface is essential during the actual design or pre-engineering phase. 
$\underline{19.7 .2}$

$\underline{19.7 .3}$

$\underline{19.7 .4}$

$\underline{19.7 .5}$

19.8

$\underline{19.8 .1}$

$\underline{19.8 .2}$

\section{Operations}

The Operations Organization should work closely with the Occupational Safety and Health Program on all routine and non-routine operations.

\section{Radiation Protection}

Personnel working in radiological controlled areas must adhere to all As-Low-As-Reasonably-Achievable (ALARA) policies and Occupational Safety and Health Act (OSHA) controls. The Radiation Protection Functional Area must coordinate all routine and non-routine activities with the OS\&H Program.

\section{Training and Qualification}

The Training Organization provides qualified instructors and course material that complies with applicable requirements.

\section{Management Systems}

The Management Systems Functional Area provides the necessary controls for developing, using, and maintaining facility policies and procedures. Management Systems provides systems for Issues Management and Tracking. In addition, the Safety and Health Organization shall participate in Occurrence/Event reporting activities which are included in this area.

\section{REFERENCES}

\section{Requirement Source Documents}

The following documents were reviewed and incorporated for Regulatory Requirements and Industry Accepted Good Practices:

29CFR1910, Occupational Safety and Health Standards, 07/01/93

29CFR1926, Safety and Health Regulations for Construction, 07/01/94

Federal Register, Vol. 54 No. 16, Thursday, January 26, 1989/Notices, Department of Labor, Occupational Safety and Health Administration, Issuance of Voluntary Guidelines.

DOE Order 5480.8A, Contractor Occupational Medical Program, 06/26/92

DOE Order 5480.10, Contractor Industrial Hygiene Program, 06/26/85

DOE Order 5483.1A, Occupational Safety and Health Program for DOE Contractor Employees at Government-Owned Contractor-Operated Facilities, 06/22/83

\section{Reviewed Documents Not Used as Requirement Sources}

The following documents were reviewed as requirement sources but were not used in the development of this S/RID:

29CFR1904, Recording and Reporting Occupational Injuries and Illness, 07/01/94

29CFR1904, Recording and Reporting Occupational Injuries and Illnesses, 07/01/92 
WAC-173, Washington Administrative Code, Dangerous Waste Regulations, 06/93

WAC 296-24, Washington Administrative Code, Industrial Safety and Health Standards, 06/93

WAC 296-45, Safety Standards - Electrical Workers, 06/30/89

RLID 5480.29, Employee Concerns Management Systems, 12/13/94

WAC-296-155, Industrial Safety and Health Standards for Construction, 06/93

DOE 5480.8A, Contractor Occupational Medical Program, 06/26/92

DOE 5480.10, Contractor Industrial Hygiene Program, 06/26/85

DOE 5480.19, Conduct of Operations Requirements for DOE Facilities, 05/19/92

DOE 5480.20, Personnel Selection, Qualification, Training, and Staffing Requirements at DOE Reactor and Non-Reactor Nuclear Facilities, 02/20/91

DOE 5483.1A, Occupational Safety and Health Program for DOE Contractor Employees at Government-Owned Contractor-Operated Facilities, 06/22/83

DOE 5484.1, Environmental Protection, Safety and Health Protection Information Reporting Requirements, 02/24/81

DOE 6430.1A, General Design Criteria, 04/06/81

Federal Register, Vol. 54 No. 16, Thursday, 01/26/89/Notices, Department of Labor, Occupational Safety and Health Administration, Issuance of Voluntary Guidelines

RLIP 5480.4C, Environmental Protection, Safety, and Health Protection Standards For RL, $11 / 06 / 92$

ANSI-Z244.1-1982, American National Standard for personnel protection, lockout/tagout of energy sources, minimum safety requirements, Approved 03/08/82

DOE-RL-92-36, Hanford Site Hoisting and Rigging Manual, 01/93

DOE-STD-1030-92, Guide to Good Practices for Lockouts and Tagouts, United States Department of Energy, 11/92

EEI Guide to Effective Drug and Alcohol/Fitness for Duty Policy Development, 08/85

DOE/EH 0135 Criteria for Technical Safety Appraisals, 06/90

Edison Electric Institute Guide to Effective Drug and Alcohol/Fitness for Duty Policy Development, 08/85 


\section{TABLE OF CONTENTS}

20.0 ENVIRONMENTAL PROTECTION

20.1

ENVIRONMENTAL POLICY MANAGEMENT $\ldots \ldots \ldots \ldots \ldots \ldots \ldots$

20.1.1

20.1 .2

National Environmental Policy Act $\ldots \ldots \ldots \ldots \ldots$

State Environmental Policy Act . . . . . . . . . . . . . . . 9

20.2

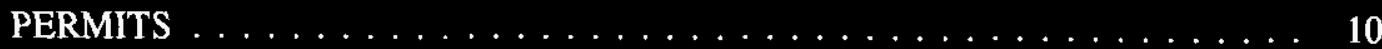

20.2.1

Clean Water Permits

20.2.1.1

Underground Injection Control (UIC) Registration

20.2 .2

Clean Air Permits

20.2.2.1

Notice of Construction $\ldots \ldots \ldots \ldots \ldots \ldots$

20.2.2.2

Toxic Air Pollutants .

Monitoring, Surveillance and Inspection Plans and Procedures . . . . . 39

Tank Systems . . . . . . . . . . . . . . . . . . . . . . . 47

20.3.3

Quality Assurance 
20.7.3

20.7 .4

20.7 .5

20.8

20.8 .1

20.8 .2
Occupational Safety and Health . . . . . . . . . . . . . 107

Quality Assurance . . . . . . . . . . . . . . . . . . . 107

Radiation Protection $\ldots \ldots \ldots \ldots \ldots \ldots$. . . . . . . . . . 108

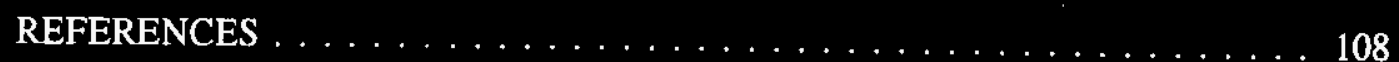

Requirement Source Documents $\ldots \ldots \ldots$. . . . . . . . . . 108

Reviewed Documents Not Used as Requirement Sources . . . . . . . . 110 


\subsection{ENVIRONMENTAL PROTECTION}

\section{INTRODUCTION}

A Standards/Requirements Identification Document (S/RID) sets forth the Environmental Safety and Health (ES\&H) standards/requirements. This S/RID is applicable to the appropriate life cycle phases of design, construction, operation, and preparation for decommissioning for each of the categories of facilities addressed in Revision 5 of the Department of Energy Implementation Plan for the Defense Nuclear Facilities Safety Board (DNFSB) Recommendation 90-2. This Recommendation calls for the strengthening of DOE weapons complex activities through the identification and application of relevant DOE Orders, regulations, industry codes/standards, industry guidance documents and, as appropriate, good industry practices. These standards/requirements are adequate to ensure protection of the health and safety of workers, the public, and the environment.

The Tank Farms S/RID, contains standards/requirements that are necessary for safe operation of the Tank Farms and its associated facilities, and that are the direct responsibility of the specific facility manager. The Environmental Protection Program defined in this document is described in general accordance with the Environment, Safety, and Health Configuration Guide, Revision 0, dated July 30, 1993, and is presented in program elements and subelements. The specific DOE Orders, regulations, industry codes/standards, guidance documents and good industry practices that serve as the basis for each element/subelement are identified and aligned with each subelement. Several additional subelements have been included in this S/RID that are not specifically identified in the ES\&H Configuration Guide. This has been done to improve the readability and usability of the S/RID. Some subelements have been divided in order to allow readers to focus on requirements in logical groups. Additional subelements were added to the basic format for further definition and clarity. Element 20.1, Environmental Policy Management was further clarified with the addition of subelements 20.1.1, National Environmental Policy Act, 20.1.2, State Environmental Policy Act, and 20.1.3, Natural and Cultural Resources. Element 20.2, Permits, was further defined with the addition of subelements 20.2. 1, Clean Water Permits, 20.2.2, Clean Air Permits, RCRA TSD Facility Permits, and 20.2.4, Underground Storage Tanks. Element 20.3, Environmental Monitoring, Surveillance and Inspection, was further enhanced by the addition of subelements 20.3.1, Radiological Effluents, 20.3.2, Tank Systems, 20.3.3, Monitoring, Surveillance and Inspection Plans and Procedures, and 20.3.4, Quality Assurance. Element 20.4, Environmental Control Standards was further defined by the addition of subelements 20.4.1, Water Quality, 20.4.2, Air Quality, and 20.4.3, Radiological Effluents. Element 20.6, Recordkeeping, Reports and Notifications, was further clarified by the addition of subelements 20.6.1, Incident Investigation and Reporting, 20.6.2, Reporting Requirements, 20.6.3, Underground Storage Tanks, and 20.6.4, Records Management. Element 20.7, Key Interfaces, was further enhanced with the addition of subelements 20.7.1, Waste Management, 20.7.2, Emergency Management, 20.7.3, Occupational Safety and Health (OSH), 20.7.4, Quality Assurance, and 20.7.5, Radiological Protection. Element 20.8 was renamed References and contains the references for the applied source documents and considered documents.

This S/RID contains only those requirements that Tank Farms personnel are clearly responsible to satisfy. Other requirements that are applicable to Tank Farms, but are satisfied by others, are defined in the Westinghouse Hanford Company (WHC) Level S/RID. For application in this S/RID, the words "shall" and "should" in requirement statements both indicate mandatory compliance. The key interface information contained in the Functional Area documents is provided for general recognition and 
understanding and is not considered to contain prescriptive requirements. Additionally, some of the requirements cited in this document are intentionally duplicated in the corresponding Company level S/RID. This was necessary to address required implementation responsibilities occurring at both the company and facility levels.

WHC is responsible for complying with all applicable federal and state laws and regulations. The approval of the S/RID does not relieve the contractor of the responsibility for complying with applicable laws and regulations.

\section{SCOPE}

This S/RID applies to the Tank Waste Remediation Systems (TWRS) Organization which includes the following:

- East Tank Farm Transition Project

- West Tank Farm Transition Project

- Evaporator Project

- Interim Stabilization Project

- $\quad$ Characterization Sampling Project (Excluding the Labs)

The near-term mission of TWRS is to store, treat, and immobilize the highly radioactive Hanford Sit e Waste. 


\section{ENVIRONMENTAL POLICY MANAGEMENT}

The Environmental Policy Management element normally addresses the management and administrative requirements necessary to ensure the DOE is provided adequate information and documentation to support timely reviews of proposed actions. Policies normally presented in this element address the National Environmental Policy Act and the State Environmental Policy Act. General aspects of management policy, staffing, and training are covered in the Management Systems Functional Area.

\section{National Environmental Policy Act}

The National Environmental Policy Act (NEPA) process is intended to help public officials make decisions that are based on an understanding of environmental consequences and to take actions that protect, restore, and enhance the environment. NEPA regulations provide the direction to achieve this purpose.

40 CFR 1500-1508 provides regulations applicable and binding on all federal agencies for implementing the provisions of NEPA. The DOE has codified NEPA requirements in 10 CFR 1021. The purpose of these requirements is to establish procedures that the DOE shall use to comply with Section 102(2) of NEPA and Council on Environmental Quality (CEQ) regulations for implementing the provisions of NEPA. DOE complies with 10 CFR 1021 in conjunction with the CEQ regulations to satisfy NEPA requirements.

It is DOE's policy to follow the letter and spirit of NEPA, to comply fully with the CEQ regulations, and to apply the NEPA review process early in the planning stages for DOE proposals. 10 CFR 1021 applies to any DOE action affecting the quality of the environment of the United States, its territories, or possessions. NEPA requirements are both procedural and technical. Although only DOE is able to implement the procedural requirements of NEPA, any contractor proposing to implement a DOE action is advised to be cognizant of the requirements. DOE normally relies on the DOE contractor proposing a DOE action to provide technical information in support of NEPA.

DOE has developed policy and DOE Orders for the implementation of NEPA. The Secretary of Energy issued the "Secretarial Policy Statement on the National Environmental Policy Act;" DOE headquarters issued DOE Order 5440.1E, " National Environmental Policy Act Compliance Program;" and DOE-RL has issued RL 5440.1A, "Implementation of the National Environmental Policy Act at the Richland Operations Office." DOE policy and DOE Orders, in conjunction with CEQ regulations, and the Act itself, implement NEPA at DOE sites.

The NEPA requirements applicable to federal facilities (e.g., as delineated in 10 CFR 1021 and 10 CFR 1022) are applicable to Tank Farms as a federal facility. The CEQ requirements (e.g., as delineated in 40 CFR 1500-1507) are also applicable to proposed actions at the Tank Farms. Although Tank Farms provides the technical supporting information for all NEPA documents, Tank Farms management attests to the accuracy of NEPA documentation, and Tank Farms management submits the documentation to DOE, the WHC NEPA Services organization is responsible for preparing the documentation.

\section{REQUIREMIENT SOURCE: 40CFR1500 Part 2}

"Policy. Federal agencies shall to the fullest extent possible:

(a) Interpret and administer the policies, regulations, and public laws of the United States in accordance with the policies set forth in the Act and in these regulations. 
(b) Implement procedures to make the NEPA process more useful to decisionmakers and the public; to reduce paperwork and the accumulation of extraneous background data; and to emphasize real environmental issues and alternatives. Environmental impact statements shall be concise, clear, and to the point, and shall be supported by evidence that agencies have made the necessary environmental analyses.

(c) Integrate the requirements of NEPA with other planning and environmental review procedures required by law or by agency practice so that all such procedures run concurrently rather than consecutively.

(d) Encourage and facilitate public involvement in decisions which affect the quality of the human environment.

(e) Use the NEPA process to identify and assess the reasonable alternatives to proposed actions that will avoid or minimize adverse effects of these actions upon the quality of the human environment.

(f) Use all practicable means, consistent with the requirements of the Act and other essential considerations of national policy, to restore and enhance the quality of the human environment and avoid or minimize any possible adverse effects of their actions upon the quality of the human environment."

\section{REQUIREMIENT SOURCE: 40CFR1501 Part 2}

"Apply NEPA early in the process. Agencies shall integrate the NEPA process with other planning at the earliest possible time to insure that planning and decisions reflect environmental values, to avoid delays later int the process and to head off potential conflicts. Each agency shall:

(a) Comply with the mandate of section 102(2)(A) to "utilize a systematic, interdisciplinary approach which will insure the integrated use of the natural and social sciences and the environmental design arts in planning and in decisionmaking which may have an impact on man's environment: as specified by $\$ 1507.2$.

(b) Identify environmental effects and values in adequate detail so they can be compared to economic and technical analyses. Environmental documents and appropriate analyses shall be circulated and reviewed at the same time as other planning documents.

(c) Study, develop and describe appropriate alternatives to recommended courses of action in any proposal which involves unresolved conflicts concerning alternative uses of available resources as provided by section $102(2)(\mathrm{E})$ of the Act.

(d) Provide for cases where actions are planned by private applicants of other non-Federal entities before Federal involvement so that:

(1) Policies or designated staff are available to advise potential applicants of studies or other information foreseeably required for later Federal action.

(2) The Federal agency consults early with appropriate State and local agencies and Indian tribes and with interested private persons and organizations when its own involvement is reasonably foreseeable.

(3) The Federal agency commences its NEPA process at the earliest possible time." 


\section{RELATED REFERENCES}

1. 10CFR1021 Part 200

2. 10CFR1021 Part 200(a)

\section{REQUIREMENT SOURCE: 40CFR1501 Part 4}

"Whether to prepare an environmental impact statement. In determining whether to prepare an environmental impact statement, the Federal agency shall:

(a) Determine under its procedures supplementing these regulations (described in Section 1507.3) whether the proposal is one which:

(1) Normally requires an environmental impact statement, or

(2) Normally does not require either an environmental impact statement or an environmental assessment (categorical exclusion).

(b) If the proposed action is not covered by paragraph (a) of this section, prepare an environmental assessment (Section 1508.9). The agency shall involve environmental agencies, applicants and the public, to the extent practicable, in preparing assessments required by Section 1508.9(a)(1).

(c) Based on the environmental assessment make its determination whether to prepare an environmental impact statement.

(d) Commence the scoping process (Section 1501.7), if the agency will prepare an environmental impact statement.

(e) Prepare a finding of no significant impact (Section 1508.13), if the agency determines on the basis of the environmental assessment not to prepare a statement."

\section{RELATED REFERENCES}

1. 10CFR1021 Part 321

\section{REQUIREMENT SOURCE: 40CFR1501 Part 5}

"(a) A lead agency shall supervise the preparation of an environmental impact statement if more than one Federal agency either:

(1) Proposes or is involved in the same action; or

(2) Is involved in a group of actions directly related to each other because of their functional interdependence or geographical proximity.

(b) Federal State, or local agencies, including at least one Federal agency may act as joint lead agencies to prepare an environmental impact statement (1506.2).

(c) If an action falls within the provisions of paragraph (a) of this section the potential lead agencies shall determine by letter or memorandum which agency shall be the lead agency and which shall be cooperating agencies. The agencies shall resolve the lead agency question so as not to cause delay. If there is disagreement among the agencies the following factors (which are listed in order of descending importance) shall determine lead agency designation: 
(1) Magnitude of agency's involvement.

(2) Project approval/disapproval authority.

(3) Expertise concerning the action's environmental effects.

(4) Duration of agency's involvement.

(5) Sequence of agency's involvement.

(d) Any Federal agency or any State or local agency or private person substantially affected by the absence of lead agency designation may make a written request to the potential lead agencies that a lead agency be designated.

(e) If Federal agencies are unable to agree on which agency will be the lead agency or if the procedure described in paragraph (c) of this section has not resulted within $\mathbf{4 5}$ days in a lead agency designation any of the agencies or persons concerned may file a request with the Council asking it to determine which Federal agency shall be the lead agency. A copy of the request shall be transmitted to each potential lead agency. The request shall consist of:

(1) A precise description of the nature and extent of the proposed action.

(2) A detailed statement of why each potential lead agency should or should not be the lead agency under the criteria specified in paragraph (c) of this section.

(f) A response may be filed by any potential lead agency concerned within 20 days after a request is filed with the Council. The Council shall determine as soon as possible but not later than 20 days after receiving the request and all responses to it which Federal agency shall be the lead agency and which other Federal agencies shall be cooperating agencies."

\section{RELATED REFERENCES}

1. 10CFR1021 Part 342

\section{REQUIREMENT SOURCE: 40CFR1501 Part 6 Introduction}

"Cooperating agencies. The purpose of this section is to emphasize agency cooperation early in the NEPA process. Upon request of the lead agency any other Federal agency which has jurisdiction by law shall be a cooperating agency. In addition any other Federal agency which has special expertise with respect to any environmental issue which should be addressed in the statement may be a cooperating agency upon request of the lead agency. An agency may request the lead agency to designate it a cooperating agency."

\section{RELATED REFERENCES}

1. 10CFR 1021 Part 342

\section{REQUIREMINT SOURCE: 40CFR1501 Part 6(a)}

"The lead agency shall:

(1) Request the participation of each cooperating agency in the NEPA process at the earliest possible time.

(2) Use the environmental analysis and proposals of cooperating agencies with jurisdiction by law or special expertise to the maximum extent possible consistent with its responsibility as lead agency.

(3) Meet with a cooperating agency at the latter's request." 


\section{REQUIREMIENT SOURCE: 40CFR1501 Part 6(b)}

"Each cooperating agency shall:

(1)Participate in the NEPA process at the earliest possible time.

(2) Participate in the scoping process (described below in 1501.7).

(3) Assume on request of the lead agency responsibility for developing information and preparing environmental analyses including portions of the environmental impact statement concerning which the cooperating agency has special expertise.

(4) Make available staff support at the lead agency's request to enhance the latter's interdisciplinary capability.

(5) Normally use its own funds. The lead agency shall to the extent available funds permit fund those major activities or analyses it requests from cooperating agencies. Potential lead agencies shall include such funding requirements in their budget requests."

\section{REQUIREMENT SOURCE: 40CFR1501 Part 6(c)}

"A cooperating agency may in response to a lead agency's request for assistance in preparing the environmental impact statement (described in paragraph (b)(3) (4), or (5) of this section) reply that other program commitments preclude any involvement or the degree of involvement requested in the action that is the subject of the environmental impact statement. A copy of this reply shall be submitted to the Council."

\section{REQUIREMENT SOURCE: 40CFR1505 Part 2}

"Record of decision in cases requiring environmental impact statements. At the time of its decision (1506.10) or, if appropriate, its recommendation to Congress each agency shall prepare a concise public record of decision. The record which may be integrated into any other record prepared by the agency including that required by OMB Circular A-95 (Revised) part I, sections 6(c) and (d) and part II, section 5(b)(4), shall:

(a) State what the decision was.

(b) Identify all alternatives considered by the agency in reaching its decision specifying the alternative or alternatives which were considered to be environmentally preferable. An agency may discuss preferences among alternatives based on relevant factors including economic and technical considerations and agency statutory missions. An agency shall identify and discuss all such factors including any essential considerations of national policy which were balanced by the agency in making its decision and state how those considerations entered into its decision.

(c) State whether all practicable means to avoid or minimize environmental harm from the alternative selected have been adopted and if not why they were not. A monitoring and enforcement program shall be adopted and summarized where applicable for any mitigation."

\section{RELATED REFERENCES}

1. 10CFR1021 Part 315(b) 
"Limitations on actions during NEPA process. Until an agency issues a record of decision as provided in $\$ 1505.2$ (except as provided in paragraph (c) of this section), no action concerning the proposal shall be taken which would:

(1) Have an adverse environmental impact; or

(2) Limit the choice of reasonable alternatives."

\section{RELATED REFERENCES}

1. 10CFR1021 Part 211

\section{REQUIREMENT SOURCE: 40CFR1506 Part 1(c)}

"While work on a required program environmental impact statement is in progress and the action is not covered by an existing program statement agencies shall not undertake in the interim any major Federal action covered by the program which may significantly affect the quality of the human environment unless such action:

(1) Is justified independently of the program;

(2) Is itself accompanied by an adequate environmental impact statement; and

(3) Will not prejudice the ultimate decision on the program. Interim action prejudices the ultimate decision on the program when it tends to determine subsequent development or limit alternatives. ${ }^{n}$

\section{REQUIREMENT SOURCE: 40CFR1506 Part 9}

"Filing requirements. Environmental impact statements together with comments and responses shall be filed with the Environmental Protection Agency, attention Office of Federal Activities (A-104), 401 M Street SW., Washington, DC 20460. Statements shall be filed with EPA no earlier than they are also transmitted to commenting agencies and made available to the public. EPA shall deliver one copy of each statement to the Council, which shall satisfy the requirement of availability to the President. EPA may issue guidelines to agencies to implement its responsibilities under this section and \$1506.10."

\section{REQUIREMENT SOURCE: 40CFR1506 Part 10(b)}

"No decision on the proposed action shall be made or recorded under $\$ 1505.2$ by a Federal agency until the later of the following dates:

(1) Ninety (90) days after publication of the notice described above in paragraph (a) of this section for a draft environmental impact statement.

(2) Thirty (30) days after publication of the notice described above in paragraph (a) of this section for a final environmental impact statement.

An exception to the rules on timing may be made in the case of an agency decision which is subject to a formal internal appeal. Some agencies have a formally established appeal process which allows other agencies or the public to take appeals on a decision and make their views known after publication of the final environmental impact statement. In such cases where a real opportunity exists to alter the decision the decision may be made and recorded at the same time the environmental impact statement is published. This means that the period for appeal of the decision and the 30-day period prescribed in paragraph (b)(2) of this section may run concurrently. In such cases the environmental impact statement shall explain the timing and 
the public's right of appeal. An agency engaged in rulemaking under the Administrative Procedure Act or other statute for the purpose of protecting the public health or safety may waive the time period in paragraph (b)(2) of this section and publish a decision on the final rule simultaneously with publication of the notice of the availability of the final environmental impact statement as described in paragraph (a) of this section."

\section{RELATED REFERENCES}

\section{10CFR1021 Part 315(a)}

\section{State Environmental Policy Act}

State Environmental Policy Act (SEPA) activities are typically integrated with NEPA activities for proposed actions requiring state or local agency permits or approvals, which trigger the need for SEPA review. The purpose of SEPA is to integrate activities at the earliest possible time to ensure that planning and decisions reflect environmental values, to avoid delays later in the process, and to seek to resolve potential problems early in the decisionmaking process.

Although the vocabulary used within NEPA and SEPA differs, the concepts and process for environmental reviews are similar (e.g., threshold determinations and public scoping). Both NEPA and SEPA regulations state the intent to avoid unnecessary duplication of effort, excessive paperwork, and time delays. The SEPA regulations provide for the use of NEPA documents by state or local agencies. A NEPA environmental assessment may be adopted to satisfy SEPA requirements for a Determination of Nonsignificance (DNS) or a decision to proceed with an Environmental Impact Statement, if certain state requirements are met. NEPA also instructs federal agencies to reduce excessive paperwork by eliminating duplication with state and local procedures.

Agencies specify the amount of detail needed from applicants for early environmental review, consistent with WAC 197-11-100 and 197-11-335, in SEPA or permit procedures. The SEPA checklist used to provide information to the agencies is invoked by WAC 197-11-960. The SEPA process is combined with the existing planning, review, and project approval processes used by each agency with jurisdiction. When environmental documents are required, they are accompanied by a proposal through the existing agency review processes. Any environmental document in compliance with SEPA may be combined with any other agency documents to reduce duplication and paperwork and improve decisionmaking.

Although the Tank Farms is responsible for providing supporting technical information, the WHC Environmental Services organization is responsible for preparing the documentation and for attesting to its accuracy and completeness.

\section{REQUIREMENT SOURCE: WAC-197-11 Section 100}

"Information required of applicants. Further information may be required if the responsible official determines that the information initially supplied is not reasonably adequate to fulfill the purposes for which it is required. An applicant may, at any time, voluntarily submit information beyond that required under these rules. An agency is allowed to require information from an applicant in the following areas:

(1) Environmental checklist. An applicant may be required to complete the environmental checklist in WAC 197-11-960 in connection with filing an application (see WAC 197-11-315). Additional information may be required at an applicant's expense, but not until after initial agency review of the checklist (WAC 197-11-315 and 197-11-335). 
(2) Threshold determination. Any additional information required by an agency after its initial review of the checklist shall be limited to those elements on the checklist for which the lead agency has determined that information accessible to the agency is not reasonably sufficient to evaluate the environmental impacts of the proposal. The lead agency may require field investigations or research by the applicant reasonably related to determining a proposal's environmental impacts (WAC 197-11-335). An applicant may clarify or revise the checklist at any time prior to a threshold determination. Revision of a checklist after a threshold determination is issued shall be made under WAC 197-11-340 or 197-11-360.

(3) Environmental impact statements. The responsible official may require an applicant to provide relevant information that is not in the possession of the lead agency. Although an agency may include additional analysis not required under SEPA in an EIS (WAC 197-11-440 (8), 197-11-448 (4) and 197-11-640), the agency shall not require the applicant to furnish such information, under these rules. An applicant shall not be required to provide information requested of a consulted agency until the agency has responded or the time allowed for the consulted agency's response has elapsed, whichever is earlier. Preparation of an EIS by the applicant is in WAC 197-11-420."

\title{
REQUIREMENT SOURCE: WAC-197-11 Section 335
}

"The lead agency shall make its threshold determination based upon information reasonably sufficient to evaluate the environmental impact of a proposal (WAC 197-11-055 (2) and 197-11-060 (3)). The lead agency may take one or more of the following actions if, after reviewing the checklist, the agency concludes that there is insufficient information to make its threshold determination:

(1) Require an applicant to submit more information on subjects in the checklist;

(2) Make its own further study, including physical investigations on a proposed site;

(3) Consult with other agencies, requesting information on the proposal's potential impacts which lie within the other agencies' jurisdiction or expertise (agencies shall respond in accordance with WAC 197-11-550); or

(4) Decide that all or part of the action or its impacts are not sufficiently definite to allow environmental analysis and commit to timely, subsequent environmental analysis, consistent with WAC 197-11-055 through 197-11-070."

\section{REQUIREMENT SOURCE: WAC-197-11 Section 960}

\begin{abstract}
"The State Environmental Policy Act (SEPA), chapter 43.21C RCW, requires all governmental agencies to consider the environmental impacts of a proposal before making decisions. An environmental impact statement (EIS) must be prepared for all proposals with probable significant adverse impacts on the quality of the environment. The purpose of this checklist is to provide information to help (applicants) and the agency identify impacts from the proposal (and to reduce or avoid impacts from the proposal, if it can be done) and to help the agency decide whether an EIS is required."
\end{abstract}

\section{PERMITS}

Construction of new facilities and significant modifications to existing facilities resulting in hazardous effluents require coordination with regulatory agencies. Depending on the type of facility and/or the significance of the waste stream, environmental permits may be required. 
Element 20.2 includes requirements for determining the need for preparing, and maintaining liquid effluent discharge permits, air emission permits, and solid waste handling permits. The Hanford Site currently has several permits and consent orders that cover site-wide activities (e.g., Tank Farms is addressed by the site-wide general stormwater permit and the Federal Facilities Agreement and Consent Order [referred to as the Tri-Party Agreement or TPA]). In addition to site-wide permits and consent orders, the Tank Farms is required to prepare notices of construction for toxic air emission sources and radioactive air emission sources; is required to register air emission sources; is required to obtain a State Waste Discharge Permit; and is required to permit waste storage and treatment facilities.

\section{Clean Water Permits}

Wastewater discharges having the potential to impact water quality require specific discharge permits. In addition, the 216 Liquid Effluent Consent Order identifies miscellaneous streams requiring the submittal of State Waste Discharge Permit (SWDP) applications.

Author's Note: Unit-specific conditions can be found in "Liquid Effluent Consent Order", DE-91NM-177, 10/27/93.

Tank Farms has retained requirements to allow agency access, to properly operate and maintain the facility, to submit an application if a change is anticipated, and to take action in case of an unauthorized discharge. Tank Farms defers all wastewater and stormwater requirements to the Company-level EP Functional Area Document.

Author's Note: Specific conditions can be found in "Authorization to Discharge under the National Pollutant Discharge Elimination System for Stomwater Discharges Associated with Construction Activities", Permit NO. WAR-00-000F, September 9, 1992; "Authorization to Discharge under the National Pollutant Discharge Elimination System for Stormwater Discharges Associated with Industrial Activity ", Permit NO. WAR-10-000F, September 9, 1992, and "Authorization to Discharge under the National Pollutant Discharge Elimination System", Permit NO. WA000374-3. Modifications to Tank Farms will constitute permit revisions.

The EPA has not delegated authority to Washington State to issue NPDES permits to federal facilities. Therefore, the EPA is the permitting authority for the Hanford Site and the federal NPDES regulations are applicable.

\section{REQUIREMENT SOURCE: WAC-173-216 Section 110(4)}

"The permittee shall at all times be responsible for the proper operation and maintenance of any facilities or systems of control installed by the permittee to achieve compliance with the terms and conditions of the permit. Where design criteria have been established, the permittee shall not permit flows or waste loadings to exceed approved design criteria or approved revisions thereto."

\section{REQUIREMENT SOURCE: WAC-173-216 Section 110(5)}

"A new application, or supplement to the previous application, shall be submitted, along with required engineering plans and reports, whenever a new or increased discharge or change in the nature of the discharge is anticipated which is not specifically authorized by the current permit. Such application shall be submitted at least sixty days prior to any proposed changes." 


\section{REQUIREMENT SOURCE: WAC-173-216 Section 110(6)}

"In the event the permittee is unable to comply with any of the permit terms and conditions due to any cause, the permittee shall:

(a) Immediately take action to stop, contain, and clean up unauthorized discharges or otherwise stop the violation, and correct the problem;

(b) Immediately notify the department of the failure to comply; and

(c) Submit a detailed written report to the department within thirty days, unless requested earlier by the department, describing the nature of the violation, corrective action taken and/or planned, steps to be taken to prevent a recurrence, and any other pertinent information."

\section{REQUIREMENT SOURCE: WAC-173-240 Section 110(1)}

"Prior to the construction or modification of industrial wastewater facilities, engineering reports and plans and specifications for the project shall be submitted to and approved by the department."

\section{REQUIREMENT SOURCE: WAC-173-240 Section 110(2)}

"All engineering reports and plans and specifications should be submitted by the owner consistent with a compliance schedule issued by the department or at least thirty days prior to the time approval is desired. The department will generally review and either approve (or conditionally approve), comment on, or disapprove such plans and reports within the thirty-day period unless circumstances prevent, in which case the owner will be notified and informed of the reason for the delay."

\section{REQUIREMENT SOURCE: WAC-173-240 Section 110(3)}

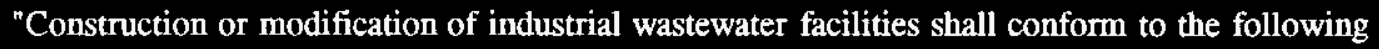
schedule of tasks unless waived in accordance with subsection (5).

(a) Submission and approval of an engineering report;

(b) Submission and approval of plans and specifications;

(c) Submission of an operation and maintenance manual."

\section{REQUIREMIENT SOURCE: WAC-173-240 Section 110(4)}

"Where two or more years has elapsed since approval of the engineering report or plans and specifications, it may be necessary to update that document to reflect changed water quality conditions, regulatory requirements, or engineering technology."

\section{REQUIREMENT SOURCE: WAC-173-240 Section 130(1)}

"The engineering report for an industrial wastewater facility shall be sufficiently complete so that plans and specifications can be developed from it without substantial changes. Two copies of the report shall be submitted to the department for approval."

\section{REQUIREMENT SOURCE: WAC-173-240 Section 130(2)}

"The engineering report shall include the following information together with any other relevant data as requested by the department: 
(a) Type of industry or business.

(b) The kind and quantity of finished product.

(c) The quantity and quality of water used by the industry and a description of how consumed or disposed of, including:

(i) The quantity and quality of all process wastewater and method of disposal;

(ii) The quantity of domestic wastewater and how disposed of; and

(iii) The quantity and quality of noncontact cooling water (including air conditioning) and how disposed of; and

(iv) The quantity of water consumed or lost to evaporation.

(d) The amount and kind of chemicals used in the treatment process, if any.

(e) The basic design data and sizing calculations of the treatment units.

(f) A discussion of the suitability of the proposed site for the facility.

(g) A description of the treatment process and operation, including a flow diagram.

(h) All necessary maps and layout sketches.

(i) Provisions for bypass, if any.

(j) Physical provision for oil and hazardous material spill control and/or accidental discharge prevention.

(k) Results to be expected from the treatment process including the predicted wastewater characteristics, as shown in the waste discharge permit, where applicable.

(1) A description of the receiving water, location of the point of discharge, applicable water quantity standards, and how water quality standards will be met outside of any applicable dilution zone.

(m) Detailed outfall analysis.

(n) The relationship to existing treatment facilities, if any.

(o) Where discharge is to municipal sewerage system, a discussion of that systems ability to transport and treat the proposed industrial waste discharge without exceeding the municipality's allocated industrial capacity. Also, a discussion on the effects of the proposed industrial discharge on municipal sludge utilization or disposal.

(p) Where discharge is through land application, including seepage lagoons, irrigation, and subsurface disposal, a geohydrologic evaluation of such factors as:

(i) Depth to ground water and ground water movement during different times of the year;

(ii) Water balance analysis of the proposed discharge area; 
(iii) Overall effects of the proposed facility upon the ground water in conjunction with any other land application facilities that may be present.

(q) A statement, expressing sound engineering justification through the use of pilot plant data, results from other similar installation, and/or scientific evidence from the literature, that the effluent from the proposed facility will meet applicable permit effluent limitations and/or pretreatment standards.

(r) A discussion of the method of final sludge disposal selected and any alternatives considered with reasons for rejection.

(s) A statement as to who will own, operate, and maintain the system after construction.

(t) A statement regarding compliance with any state or local water quality management plan or any such plan adopted pursuant to the Federal Water Pollution Control Act as amended.

(u) Provisions for any committed future plans.

(v) A discussion of the various alternatives evaluated, if any, and reasons they are unacceptable.

(w) A timetable for final design and construction.

(x) A statement regarding compliance with the State Environmental Policy Act (SEPA) and the National Environmental Policy Act (NEPA), if applicable.

(y) Additional items to be included in an engineering report for a solid waste leachate treatment system are:

(i) A vicinity map and also a site map which shows topography, location of utilities, and location of the leachate collection network, treatment systems, and disposal;

(ii) Discussion of the solid waste site, working areas, soil profile, rainfall data, and ground water movement and usage;

(iii) A statement of the capital costs and the annual operation and maintenance costs;

(iv) A description of all sources of water supply within two thousand feet of the proposed disposal site. Particular attention should be given to showing impact on usable or potentially usable aquifers."

\section{REQUIREMINT SOURCE: WAC-173-240 Section 150(1)}

"A detailed operation and maintenance manual shall be prepared for an industrial wastewater facility which includes mechanical components prior to the completion of construction. The manual is to be submitted to the department for review and approval. The purpose of the manual is to present technical guidance and regulatory requirements to the operator to enhance operation under both normal and emergency conditions."

\section{REQUIREMENT SOURCE: WAC-173-240 Section 150(2)}

"The operation and maintenance manual shall include the following list of topics:

(a) The names and phone numbers of the responsible individuals. 
(b) A description of plant type, flow pattern, operation, and efficiency expected.

(c) The principal design criteria.

(d) A process description of each plant unit, including function, relationship to other plant units, and schematic diagrams.

(e) Explanation of the operational objectives for the various wastewater parameters, i.e. sludge age, settleability, etc.

(f) A discussion of the detailed operation of each unit and description of various controls, recommended settings, fail-safe features, etc.

(g) A discussion of how the facilities are to be operated during anticipated startups and shutdowns, maintenance procedures, and less than design loading conditions, so as to maintain efficient treatment.

(h) A section on laboratory procedures including sampling techniques, monitoring requirements, and sample analysis.

(i) Recordkeeping procedures and sample forms to be used.

(j) A maintenance schedule incorporating manufacturer's recommendations, preventative maintenance and housekeeping schedules, and special tools and equipment usage.

(k) A section on safety.

(1) A section containing the spare parts inventory, address of local suppliers, equipment warranties, and appropriate equipment catalogues.

(m) Emergency plans and procedures."

\section{REQUIREMENT SOURCE: WAC-173-240 Section 160}

"(1) All required engineering reports, and plans and specifications for the construction or modification of wastewater facilities shall be prepared under the supervision of a professional engineer licensed in accordance with chapter 18.43 RCW. All copies of these documents submitted to the department for review shall bear the seal of the professional engineer under whose supervision they have been prepared.

(2) Upon request of the owner, the department may waive the above requirement for construction or modification at industrial wastewater facilities."

\section{REQUIREMENT SOURCE: WAC-173-240 Section 170}

"Pursuant to RCW 90.48.090, the department or its authorized representative shall have the right to enter at all reasonable times in or upon any property, public or private, for the purposes of inspection or investigation relating to the pollution or possible pollution of the waters of the state, including the inspection of construction activities related to domestic or industrial wastewater facilities."

\section{Underground Injection Control (UIC) Registration}

Subelement 20.2.1.1 identifies the requirements for injection of fluids underground through wells. It is a goal of WHC to discontinue use of the soil column for treatment of contaminated 
wastewater. Specific provisions for alternatives to soil column disposal are delineated in the 216 Liquid Effluent Consent Order. Requirements presented in this subelement primarily address restrictions for injecting fluids above the drinking water table that would cause or allow movement of fluid into a drinking water source resulting in a violation of any primary drinking water standard.

\section{REQUIREMENT SOURCE: WAC-173-218 Section 040}

"No fluids may be injected through wells except as authorized pursuant to this chapter."

\section{REQUIREMENT SOURCE: WAC-173-218 Section 090}

"Class V injection wells.

(1) All new Class V injection wells that inject industrial, municipal, or commercial waste fluids into or above an USDW are prohibited.

(2) All persons operating an existing Class V injection well, that inject industrial, commercial, or municipal waste fluids into or above an USDW, must apply to the department for approval to operate within one year of the effective date of this regulation. The department will accept, process, and act upon the application in accordance with the procedures and practices of the State waste discharge permit program, chapter 173-216 WAC.

(3) All other Class V injection well owners and operators must notify the department of the location of injection wells within one year of approval of the state underground injection control program by the United States Environmental Protection Agency. The notification shall be on a form as prescribed by the department and will include the information needed to satisfy the requirements of 40 Code of Federal Regulations Part 146.52."

\section{REQUIREMENT SOURCE: WAC-173-218 Section 100}

"(1) Any permit issued by the department shall specify conditions necessary to prevent and control injection of fluids into the waters of the state, including the following, whenever applicable:

(a) All known, available, and reasonable methods of prevention, control, and treatment;

(b) Applicable requirements as contained in 40 Code of Federal Regulations Parts 124 and 144 as published in Federal Register Volume 48, \#64 (April 1, 1983) and Part 146 as published in Federal Register Volume 45, \#123 (June 24, 1980), Volume 46, \#166(August 27, 1981) and Volume 47, \#23 (February 3, 1982); and

(c) Any conditions necessary to preserve and protect USDW.

(2) Any injection well that causes or allows the movement of fluid into an USDW that may result in a violation of any primary drinking water standard under 40 Code of Federal Regulations Part 141 or that may otherwise adversely affect the beneficial use of an USDW is prohibited."

\section{Domestic Sewage}

In addition to State Waste Discharge Permit applications administered by Ecology, on-site sewage systems are also regulated by the Washington State Department of Health (DOH). The DOH permit requirements for on-site sewage systems (WAC 246-272) are implemented by the site utilities organization (e.g., Kaiser Engineering). 
For sewage systems with a design capacity greater than 14,500 gallons per day, the permittee pursues a permit through Ecology under WAC 173-216-240. The remainder is addressed in this sub-subelement.

\section{REQUIREMENT SOURCE: WAC-246-272(940394) Section 08001( 1)}

"Persons proposing a new LOSS for which the department has jurisdiction by WAC or memorandum of agreement with the department of ecology shall meet the requirements specified in "Design Standards for Large On-site Sewage Systems," 1993, Washington state department of health (available upon written request to the department). ${ }^{n}$

\section{REQUIREMENT SOURCE: WAC-246-272(940394) Section 08001( 2)}

"Persons shall submit the documents and fees specified under (a) through (f) of this subsection and obtain approval from the department before installing a LOSS to serve any facility:

(a) A preliminary report, stamped and signed by an engineer, including:

(i) A discussion of the proposed project, including the schedule of construction;

(ii) A discussion of compliance with other state and local zoning, platting, health, and building regulations as they relate to sewage treatment and disposal;

(iii) An analysis of the site's capacity to treat and dispose of the proposed quantity and quality of sewage;

(iv) An analysis of the factors identified in WAC 246-272-20501 (2)(d)(ii)(A); and

(v) A soil and site evaluation as specified in WAC 246-272-11001 signed by the evaluator;

(vi) A management plan describing the:

(A) Management entity consisting of one of the following:

(I) For residential subdivisions where the lots are individually owned, a public entity serves as the primary management entity, or as the third party trust for a private management entity; or

(II) For other uses, including single ownership, a public entity or a private entity via an appropriate contract or agreement provides management;

(B) Duties of the management entity, including specific tasks and frequency of operation and maintenance;

(C) Controls to ensure the continuity and permanency of proper operation and maintenance;

(D) Methods and frequency of monitoring, recordkeeping, and reporting to the department;

(E) Rights and responsibilities of management; and

(F) Rights and responsibilities of persons purchasing connections to the LOSS.

(b) Complete plans and specifications of the LOSS:

(i) Showing a conventional pressure distribution system with three feet of vertical separation; 
(ii) Meeting all other design criteria within "Design Standards for Large On-site Sewage Systems, "1993, department of health (available upon written request to the department); and

(iii) Stamped and signed by an engineer;

(c) A schedule of inspections to confirm the installation conforms to the plans and specifications;

(d) A draft operation and maintenance manual, describing the LOSS and outlining routine maintenance procedures for proper operation of the system;

(e) Required fees; and

(f) Other information as required by the deparment. "

\section{REQUIREMENT SOURCE: WAC-246-272(940394) Section 08001( 3)}

"Persons desiring to repair, modify or expand a facility served, or to be served by a LOSS shall submit all documents and fees specified under subsection (2)(a through (f) of this section, unless the department waives submission of some elements as unnecessary, and obtain approval from the department."

\section{REQUIREMENT SOURCE: WAC-246-272(940394) Section 08001( 5)}

"A qualified installer shall install the LOSS."

\section{REQUIREMINT SOURCE: WAC-246-272(940394) Section 08001( 6)}

"The applicant or applicant's agent:

(a) Shall comply with all conditions set forth in the department's construction approval;

(b) May request extensions to the construction approval permit; and

(c) Shall comply with any additional conditions upon construction approval extensions set forth by the department, and pay required fees for renewing the approval."

\section{REQUIREMENT SOURCE: WAC-246-272(940394) Section 08001( 7 )}

"Before a new LOSS is used:

(a) An engineer shall stamp, sign, and submit a LOSS construction report to the department within sixty days following the completion of construction of the LOSS including:

(i) A completed form stating the LOSS was constructed in accordance with the department's approved plans and specifications; and

(ii) An "as built" or "record" drawing;

(b) The department shall conduct a final inspection; and

(c) The owner shall:

(i) Submit an operation and maintenance manual developed by an engineer for the installed LOSS to the department for review and approval; and

(ii) Obtain a LOSS operating permit from the department by: 
(A) Completing and submitting forms to the deparment; and

(B) Paying required fees."

\section{REQUIREMENT SOURCE: WAC-246-272(940394) Section 08001( 8)}

"The owner of a LOSS that has been approved by the department or local health officer or constructed after July 1, 1984, shall:

(a) Obtain a LOSS operating permit from the department; and

(b) Annually renew it."

\section{REQUIREMENT SOURCE: WAC-246-272(940394) Section 08001( 9)}

"The owner shall annually renew the LOSS operating permit by:

(a) Continued retention of an approved management entity to operate and maintain the LOSS;

(b) Submitting a report to the department demonstrating the LOSS is operated, maintained, and monitored in accordance with this chapter and the approved operations and maintenance manual; and

(c) Submitting required fees."

\section{REQUIREMENT SOURCE: WAC-246-272(940394) Section 09001( 1)}

"Prior to beginning the construction process, a person proposing the beginning the construction process, a person proposing the installation, repair, modification, connection to, or expansion of an OSS, shall develop and submit the following to the local health officer and obtain approval:

(a) General information including:

(i) Name and address of the property owner and the applicant at the head of each page of submission;

(ii) Parcel number and address, if available, of the site;

(iii) Source of drinking water supply;

(iv) Identification if the property is within the boundaries of a recognized sewer utility;

(v) Size of the parcel;

(vi) Type of permit for which application is being made, for example, new installation, repair, expansion, alteration, or operational;

(vii) Source of sewage, for example, residential, restaurant, or other type of business;

(viii) Location of utilities;

(ix) Name of the site evaluator;

(x) Name of the designer;

(xi) Date of application; and 
(xii) Signature of applicant.

(b) The soil and site evaluation as specified under WAC 246-272-11001(2).

(c) A complete, detailed, and dimensional site plan including:

(i) Designated areas for the proposed initial system and the reserve area;

(ii) The location of all soil logs and other soil tests for the OSS;

(IV) Site drainage characteristics;

(V) The location of existing and proposed encumbrances affecting system placement, including legal access documents if any component of the OSS is not on the lot where the sewage is generated; and

(vi) An arrow indicating north.

(d) A detailed system design meeting the requirements under WAC 246-272-11501 including:

(i) A dimensional drawing showing the location of components of the proposed OSS, and the system designed for the reserve area if reserve site characteristics differ significantly from the initial area;

(ii) Vertical cross-section drawings showing:

(A) The depth of the disposal component, the vertical separation, and depth of soil cover; and

(B) Other OSS components constructed at the site.

(iii) Calculations and assumptions supporting the proposed design, including:

(A) Soil type;

(B) Hydraulic loading rate in the disposal component; and

(C) System's maximum daily flow capacity.

(e) Such additional information as deemed necessary by the local health officer."

\section{REQUIREMENT SOURCE: WAC-246-272(940394) Section 09001( 2 thru 7)}

Author's Note: Items 2 to 4 are not applicable to Tank Farms.

"(2) The local health officer may develop the required information specified in subsection (1) of this section if authorization for such actions is included in local regulations.

(3) The local health officer shall:

(a) Issue a permit when the information submitted under subsection (1) of this section meets the requirements contained in this chapter and in local regulations;p

(b) Identify the permit as a new installation, repair, expansion, modification, or operational permit;

(c) Specify the expiration date on the permit;

(d) Include a reminder on the permit application of the applicant's right of appeal; and 
(e) State the period of validity and date and conditions of renewal when requiring operational permits to be obtained and retained;

(4) The local health officer may revoke or deny a permit for due cause. Examples include, but are not limited to:

(a) Development or continued use of an OSS that threatens the public health;

(b) Misrepresentation or concealment of material fact in information submitted to the local health officer; or

(c) Failure to meet conditions of the permit or the regulations.

(5) Before the local health officer issues a permit for the installation of an OSS to serve more than one development, the applicant shall show;

(a) An approved public entity owning or managing the OSS in perpetuity; or

(b) An arrangement with a management entity acceptable to the local health officer, recorded in covenant, lasting until the on-site system is no longer needed, and containing, but not limited to:

(i) A legal easement allowing access for construction, operation and maintenance, and repair of the OSS; and

(ii) Identification of an adequate financing mechanism to assure the funding of operation, maintenance, and repair of the OSS.

(6) The local health office shall not delegate the authority to issue permits.

(7) The local health officer may stipulate additional requirements for a particular permit if necessary for public health protection."

\section{REQUIREMENT SOURCE: WAC-246-272(940394) Section 09501( 1)}

"Persons shall design and install OSS to meet the minimum horizontal separations show in Table I, Minimum Horizontal Separations:"

\section{REQUIREMENT SOURCE: WAC-246-272(940394) Section 09501( 3)}

"The horizontal separation between an OSS disposal component and an individual water well, spring, or surface water can be reduced to a minimum of seventy-five feet, by the local health officer, and be described as a "conforming" system upon signed approval by the health officer if the applicant demonstrates:

(a) Adequate protective site specific conditions such as physical settings with low hydro-geologic susceptibility from contaminant infiltration. Examples of such conditions include evidence of confining layers and or aquatards separating potable water from the OSS treatment zone, excessive depth to ground water, down-gradient contaminant course, or outside the zone of influence; or

(b) Design and proper operation of an OSS system assuring enhanced treatment performance beyond that accomplished by meeting the vertical separation and effluent distribution requirements described in WAC 246-272-11501 (2)(f) Table IV; or

(c) Evidence of protective conditions involving both (a) and (b) of this subsection." 


\section{REQUIREMINT SOURCE: WAC-246-272(940394) Section 09501( 4)}

"Persons shall design and/or install disposal components only where:

(a) The slope is less than forty-five percent (twenty-four degrees);

(b) The area is not subject to:

(i) Encroachment by buildings or construction such as placement of swimming pools, power poles and underground utilities;

(ii) Cover by impervious material;

(iii) Vehicular traffic; or

(iv) Other activities adversely affecting the soil or the performance of the OSS.

(c) Sufficient reserve area for replacement exists to treat and dispose one hundred percent of the design flow;

(d) The land is stable; and

(e) Surface drainage is directed away from the site."

\section{REQUIREMENT SOURCE: WAC-246-272(940394) Section 13501( 3)}

"The installer described by either subsection (1) or (2) of this section shall:

(a) Follow the approved design;

(b) Have the approved design in possession during installation;

(c) Only install septic tanks, pump chambers, and holding tanks approved by the department;

(d) Be on the site at all times during the excavation and construction of the OSS;

(e) Install the OSS to be watertight, except for the disposal component;

(f) Cover the installation only after the local health officer has given approval to cover; and

(g) Back fill and grade the site to prevent surface water from accumulating over any component of the OSS."

\section{REQUIREMENT SOURCE: WAC-246-272(940394) Section 15501( 1)}

"The OSS owner is responsible for properly operating and maintaining the OSS, and shall:

(a) Determine the level of solids and scum in the septic tank once every three years;

(b) Employ an approved pumper to remove the septage from the tank when the level of solids and scum indicates that removal is necessary;

(c) Protect the OSS area and the reserve area from:

(i) Cover by structures or impervious material;

(ii) Surface drainage;

(iii) Soil compaction, for example by vehicular traffic or livestock; and

(iv) Damage by soil removal and grade alteration;

(d) Keep the flow of sewage to the OSS at or below the approved design both in quantity and waste strength;

(e) Operate and maintain alternative systems as directed by the local health officer; and 
(f) Direct drains, such as footing or roof drains, away from the area where the OSS is located."

\section{REQUIREMENT SOURCE: WAC-246-272(940394) Section 15501( 2)}

"The local health officer shall:

(a) Provide operation and maintenance information to the OSS owner upon approval of any installation, repair, or alteration of an OSS; and

(b) Develop and implement plans to:

(i) Monitor all OSS performance within areas of special concern;

(ii) Initiate periodic monitoring of each OSS no later than January 1, 2000, to assure that each OSS owner properly maintains and operates the OSS in accordance with this section and in accordance with other applicable operation and maintenance requirements.

(iii) Disseminate relevant operation and maintenance information to OSS owners through effective means routinely and upon request; and

(iv) Assist in distributing educational materials to OSS owners."

\section{REQUIREMENT SOURCE: WAC-246-272(940394) Section 16501( 1)}

"When an OSS failure occurs, the OSS owner shall:

(a) Repair or replace the OSS with a conforming system or a Table VI repair either on the:

(i) Property served; or

(ii) Nearby or adjacent property if easements are obtained; or

(b) Connect the residence or facility to a:

(i) Publicly owned LOSS; or

(ii) Privately owned LOSS where it is deemed economically feasible; or

(iii) Public sewer; or

(c) Perform one of the following when requirements in (a) or (b) of this subsection are not feasible:

(i) Use a holding tank; or

(ii) Obtain a National Pollution Discharge Elimination System or state discharge permit from the Washington state department of ecology issued to a public entity or jointly to a public entity and the system owner only when the local health officer determines:

(A) An OSS is not feasible; and

(B) The only realistic method of final disposal of treated effluent is discharge to the surface of the land or into surface water; or

(iii) Abandon the property." 


\section{REQUIREMENT SOURCE: WAC-246-272(940394) Section 16501( 2)}

"Prior to replacing or repairing the effluent disposal component, the OSS owner shall develop and submit information required under WAC 246-272-0900(1)."

\section{REQUIREMENT SOURCE: WAC-246-272(940394) Section 19501( 1)}

"An individual shall be approved by the local health officer as a qualified pumper before removing septage from an OSS."

\section{REQUIREMENT SOURCE: WAC-246-272(940394) Section 19501( 2)}

"Persons removing septage from an OSS shall:

(a) Transport septage or sewage only in vehicles clearly identified with the name of the business and approved by the local health officer;

(b) Record and report septage removal to the local health officer;

(c) Dispose of septage, or apply septage biosolids to land only in a manner consistent with applicable laws."

\section{REQUIREMENT SOURCE: WAC-246-272(950131) Section 18501}

"Abandonment. Persons permanently removing a septic tank, seepage pit, cesspool, or other sewage container from service shall:

(1) Have the septage removed by an approved pumper;

(2) Remove or destroy the lid; and

(3) Fill the void with soil."

\section{$\underline{\underline{20.2 .2}}$}

\section{Clean Air Permits}

Subelement 20.2.2 addresses notifications, registrations, and permit applications for air emission sources. The subelement is divided into Notices of Construction (NOC), requirements for sources of Toxic Air Pollutants, and requirements for radionuclide emission sources. Tank Farms does not currently have priority pollutant emissions warranting a permit [e.g., Prevention of Significant Deterioration (PSD) permit]. If it is determined during preparation of a NOC for any new or modified facilities that priority pollutants could be emitted in quantities warranting PSD consideration, this element will be revised to include those requirements. At this time neither Tank Farms nor the evaporator anticipate priority pollutant emissions.

Author's Note: DOE/RL-95-07, "Hanford Site Air Operating Permit Application," dated May 25, 1995, has been filed with DOH/ECOLOGY. This permit application imposes commitments WHC, and other contractors on the Hanford Site also included in the application, intend to perform. The contents of this application may be revised during the permitting process. Therefore, individual requirements are not listed until final issuance of the permit (anticipated end of FY97). Tank Farms is a contributor to this effort. 


\section{REQUIREMENT SOURCE: 40CFR61 Part 9}

"Notification of startup.

(a) The owner or operator of each stationary source which has an initial startup after the effective date of a standard shall furnish the Administrator with written notification as follows:

(1) A notification of the anticipated date of initial startup of the source not more than 60 days nor less than $\mathbf{3 0}$ days before that date.

(2) A notification of the actual date of initial startup of the source within 15 days after that date.

(b) If any State or local agency requires a notice which contains all the information required in the notification in paragraph (a) of this section, sending the Administrator a copy of that notification will satisfy paragraph (a) of this section."

\section{REQUIREMENT SOURCE: LAPCA-REG1 Article 8, Section 8.03}

"A. In the event of an unexpected discovery of asbestos during a renovation or demolition project, which was originally thought to contain no asbestos, the requirements of either Section 8.01 or 8.02 are applicable, and all work must stop until these requirements have been met.

B. During an approved renovation or demolition project, if an unexpected discovery of additional asbestos is made which increases the project by $20 \%$ or greater than originally reported, an amendment or emergency waiver form must be filed with the Authority before work may continue."

\section{REQUIREMENT SOURCE: WAC-173-400 Section 110(1)}

"Applicability.

(a) A notice of construction application must be filed by the owner or operator and an order of approval issued by ecology or an authority prior to the establishment of any new source or emission unit or modification which is listed in WAC 173-400-100 or required to obtain a permit under RCW 70.94.161.

(b) Ecology or the authority may require that a notice of construction application be filed by the owner or operator of a proposed new source or modification and an order of approval issued by ecology or an authority prior to the establishment of any new source or emission unit or modification, other than a single family or a duplex dwelling.

(c) New source review of a modification shall be limited to the emission unit or units proposed to be added to an existing source or modified and the air contaminants whose emissions would increase as a result of the modification."

\section{REQUIREMENT SOURCE: WAC-173-460(940112) Section 040(1)(a)}

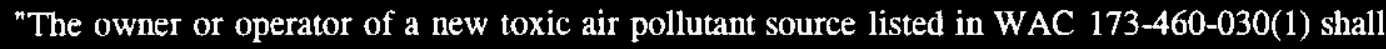
notify the authority prior to the construction, installation, or establishment of a new toxic air pollutant source and shall file a notice of construction application with the authority for the proposed emission unit(s). Notification and notice of construction are not required if the source is an exempt source listed in WAC 173-460-(2) or subsection (2) of this section." 


\section{REQUIREMENT SOURCE: WAC-173-460(940112) Section 080(2)(a)}

"Acceptable source impact analysis. Carcinogenic effects. The owner of operator shall use dispersion modeling to estimate the maximum incremental ambient impact of each Class $\mathrm{A}$ TAP from the source and compare the estimated incremental ambient values to the Class $A$ acceptable source impact levels in WAC 173-460-150. If applicable, the source may use the small quantity emission rate tables in (e) of this subsection."

\section{REQUIREMIENT SOURCE: WAC-246-247(940131) Section 060( 1)}

"Requirements for new construction or modification or emission units.

(a) Early in the design phase, the applicant shall submit a NOC containing the information required in Appendix A.

(b) Within thirty days of receipt of the NOC, the department shall inform the applicant if additional information is required. The department may determine, on the basis of the information submitted, that the requirements of BARCT or ALARACT have been met, or may require the applicant to submit a BARCT or ALARACT demonstration compatible with Appendix B or C, respectively.

(c) Within sixty days of receipt of all required information, the department shall issue an approval or denial to construct. The department may require changes to the final proposed control technology.

(d) The applicant may request a phased approval process by so stating and submitting a limited application. The department may grant a conditional approval to construct for such activities as would not preclude the construction or installation of any control or monitoring equipment required after review of the completed application.

(e) The department shall issue a license, or amend an existing license, authorizing operation of the emission unit(s) when the proposed new construction or modification is complete. For facilities subject to the air operating permit requirements of chapter 173-401 WAC, the license shall become part of the air operating permit issued by the department of ecology or a local air pollution control authority. For new construction, this action shall constitute registration of the emission unit(s)."

\section{REQUIREMENT SOURCE: WAC-246-247(940131) Section 110, Appendix A}

"Application information requirements.

(1) Name and address of the facility, and location (latitude and longitude) of the emission unit(s).

(2) Name, title, address, and phone number of the responsible manager.

(3) Identify the type of proposed action for which this application is submitted:

(a) Construction of new emission unit(s);

(b) Modification of existing emission unit(s); identify whether this is a significant modification;

(c) Modification of existing unit(s), unregistered.

(4) If this project is subject to the requirements of the State Environmental Policy Act (SEPA) contained in chapter 197-11 WAC, provide the name of the lead agency, lead agency contact person, and their phone number.

(5) Describe the chemical and physical processes upstream of the emission unit(s). 
(6) Describe the existing and proposed (as applicable) abatement technology. Describe the basis for the use of the proposed system. Include expected efficiency of each control device, and the annual average volumetric flow rate(s) in meters ${ }^{\wedge} 3 / \mathrm{sec}$ for the emission unit(s).

(7) Provide conceptual drawings showing all applicable control technology components from the point of entry of radionuclides into the vapor space to release to the environment.

(8) Identify each radionuclide that could contribute greater than ten percent of the potential-to-emit TEDE to the MEI, or greater than $0.1 \mathrm{mrem} / \mathrm{yr}$ potential-to-emit TEDE to the MEI.

(9) Describe the effluent monitoring system for the proposed control system. Describe each piece of monitoring equipment and its monitoring capability, including detection limits, for each radionuclide that could contribute greater than ten percent of the potential-to-emit TEDE to the MEI, or greater than $0.1 \mathrm{mrem} / \mathrm{yr}$ potential-to-emit TEDE to the MEI, or greater than twenty-five percent of the TEDE to the MEI, after controls. Describe the method for monitoring or calculating those radionuclide emissions. Describe the method with detail sufficient to demonstrate compliance with the applicable requirements.

(10) Indicate the annual possession quantity for each radionuclide.

(11) Indicate the physical form of each radionuclide in inventory: Solid, particulate solids, liquid, or gas.

(12) Indicate the release form of each radionuclide in inventory: Particulate solids, vapor, or gas. Give the chemical form and ICRP 30 solubility class, if known.

(13) Release rates.

(a) New emission unit(s): Give predicted release rates without any emissions control equipment (the potential-to-emit) and with the proposed control equipment using the efficiencies described in subsection (6) of this section.

(b) Modified emission unit(s): Give predicted release rates without any emissions control equipment (the potential-to-emit) and with the existing and proposed control equipment using the efficiencies described in subsection (6) of this section. Provide the latest year's emissions data or emissions estimates.

In all cases, indicate whether the emission unit is operating in a batch or continuous mode.

(14) Identify the MEI by distance and direction from the emission unit(s). The MEI is determined by considering distance, windrose data, presence of vegetable gardens, and meat or milk producing animals at unrestricted areas surrounding the emission unit.

(15) Calculate the TEDE to the MEI using an approved procedure (see WAC 246-247-085). For each radionuclide identified in subsection (8) of this section, determine the TEDE to the MEI for existing and proposed emission controls, and without any emission controls (the potential-to-emit) using the release rates from subsection (13) of this section. Provide all input data used in the calculations.

(16) Provide cost factors for construction, operation, and maintenance of the proposed control technology components and system, if a BARCT or ALARACT demonstration is not submitted with the NOC. 
(17) Provide an estimate of the lifetime for the facility process with the emission rates provided in this application.

(18) Indicate which of the following control technology standards have been considered and will be complied with in the design and operation of the emission unit(s) described in this application:

ASME/ANSI AG-1, Code on Nuclear Air and Gas Treatment (where there are conflicts in standards with the other listed references, this standard shall take precedence)

ASME/ANSI N509, Nuclear Power Plant Air-Cleaning Units and Components

ASME/ANSI N510, Testing of Nuclear Air Treatment Systems

ANSI/ASME NQA-1, Quality Assurance Program Requirements for Nuclear Facilities

40 CFR 60, Appendix A, Methods 1, 1A, 2, 2A, 2C, 2D, 4, 5, and 17

ANSI N13.1, Guide to Sampling Airborne Radioactive Materials in Nuclear Facilities

For each standard not so indicated, give reason(s) to support adequacy of the design and operation of the emission unit(s) as proposed."

Toxic Air Pollutants

Toxic Air Pollutants are separated into Class A and Class B categories. Subelement 20.2.2.2 includes requirements for determining if a source is exempt, requirements to quantify new source emissions, requirement for control technologies, and requirements for determining health effects. The Tank Farms will evaluate all proposed activities that could potentially result in the release of toxic air pollutants to determine if notification and permitting requirements are needed.

\section{REQUIREMENT SOURCE: WAC-173-460(940112) Section 050(1)(a)}

"Requirement to quantify emissions. New sources. When applying for a notice of construction, an owner or operator of a new toxic air pollution source shall quantify those emissions of each TAP or combination of TAP's that:

(i) Will be used for the modeling procedures in WAC 173-460-080; and

(ii) That may be discharged after applying required control technology. The information shall be submitted to the authority."

\section{REQUIREMENT SOURCE: WAC-173-460(940112) Section 060 Introduction}

"Control technology requirements. Except as provided for in WAC 173-460-040, a person shall not establish, operate, or cause to be established or operated any new toxic air pollutant source which is likely to increase TAP emissions without installing and operating T-BACT. Satisfaction of the performance requirements listed below fulfill the T-BACT requirements for those particular sources. Local air pollution authorities may develop and require performance requirements in lieu of T-BACT provided that ecology approves the performance requirements as equivalent to T-BACT." 


\section{REQUIREMENT SOURCE: WAC-173-460(940112) Section 080(1)}

"When applying for a notice of construction under WAC 173-460-040, the owner or operator of a new toxic air pollutant source which is likely to increase TAP emissions shall complete an acceptable source impact level analysis for Class A and Class B TAPs. The authority may complete this analysis."

\section{REQUIREMENT SOURCE: WAC-173-460(940112) Section 080(2)(b)}

"Other toxic effects. The owner or operator shall use dispersion modeling to estimate the maximum incremental ambient impact of each Class B TAP from the source and compare the estimated ambient values to the Class B acceptable source impact levels in WAC 173-460-160. If applicable, the source may use the small quantity emission rate tables in (e) of this subsection."

\section{REQUIREMENT SOURCE: WAC-173-460(940112) Section 080(2)(d)}

"Averaging times. The owner or operator shall use the average times in (d)(i), (ii), (iii) of this subsection unless alternate averaging times are approved by ecology. Ecology may allow the use of an alternate averaging time if it determines that the operating procedures of the source may cause a high concentration of a TAP for a short period and that consideration of potential health effects due to peak exposures may be warranted for the TAP.

(i) An annual average shall be used for Class A TAPs listed in WAC 173-460-150(2).

(ii) The averaging times specified in WAC 173-460-150(3) shall be used for Class A TAPs listed in WAC 173-460-150(3).

(iii) A twenty-four-hour averaging time shall be used for Class B TAPs listed in WAC 173-460-160."

\section{REQUIREMENT SOURCE: WAC-173-460(940112) Section 100(2)}

"Contents of the application. The applicant shall meet the submittal requirements of WAC 173-460-090(1) and submit all materials required under WAC 173-460-090(4) and (5). The applicant may submit the request for a risk management decision concurrently with the second tier analysis application. Prior denial of the second tier analysis application under WAC $173-460-090(6)$ is not required."

\section{Radionuclide Emissions}

Subelement 20.2.2.3 includes requirements for sources of radionuclide emissions. On February 3, 1994, the DOE, Richland Operations Office (RL) received a Compliance Order and Information Request from the Director of the Air and Toxics Division of the U.S. EPA, Region 10. The Compliance Order required RL to evaluate all radionuclide emission points at the Hanford Site. If the emission point could potentially cause a member of the public to be exposed to $>0.1 \mathrm{mrem} / \mathrm{yr}$, the emission point is considered to be "designated" and is monitored continuously as specified in the standard.

The following requirements are derived primarily from the Permit for Radionuclide Emissions (FF-01) and DOH regulations found in WAC 246-247. These requirements are applicable to the facilities addressed in the site-wide Permit and to radionuclide emission sources in general. 


\section{REQUIREMENT SOURCE: FF-01 Conditions and Limitations}

"Conditions and Limitations

- The collective emissions from all registered sources from all areas on the reservation shall meet the emission requirements of Chapter 173-480-040 WAC.

- Operations shall be consistent with 40 CFR 61, the Washington Clean Air Act (RCW 70.94) and WAC 246-247.

- Site inspections must be allowed following DOE security access requirements to verify these conditions.

- Access requirements to all emissions points shall be clarified by January 1, 1994 .

- The department shall be notified of any source location changes."

\section{REQUIREMENT SOURCE: WAC-246-247(940131) Section 060( 4)}

"The facility shall notify the department at least seven calendar days prior to any planned preoperational tests of new or modified emission units that involve emissions control, monitoring, or containment systems of the emission unit(s). The department reserves the right to witness or require preoperational tests involving the emissions control, monitoring, or containment systems of the emission unit(s)."

\section{REQUIREMENT SOURCE: WAC-246-247(940131) Section 075(11)}

"The planning for any proposed new construction or significant modification of the emission unit must address accidental releases with a probability of occurrence during the expected life of the emission unit of greater than one percent."

\section{REQURREMENT SOURCE: WAC-246-247(940131) Section 085(2)}

"Facilities subject to 40 CFR 61 shall use computer codes or procedures approved by the EPA to determine the TEDE to the MEI; all other facilities shall use computer codes or procedures approved by the department."

\section{REQUIREMENT SOURCE: WAC-246-247(940131) Section 110( 9)}

"Describe the effluent monitoring system for the proposed control system. Describe each piece of monitoring equipment and its monitoring capability, including detection limits, for each radionuclide that could contribute greater than ten percent of the potential-to-emit TEDE to the MEI, or greater than $0.1 \mathrm{mrem} / \mathrm{yr}$ potential-to-emit TEDE to the MEI, or greater than twenty-five percent of the TEDE to the MEI, after controls. Describe the method for monitoring or calculating those radionuclide emissions. Describe the method with detail sufficient to demonstrate compliance with the applicable requirements."

\section{REQUIREMENT SOURCE: WAC-246-247(940131) Section 120, Appendix B}

"BARCT compliance demonstration. Purpose. A BARCT demonstration is used to choose control technologies for the mitigation of emissions of radioactive material from new emission units or significant modifications to emission units. The bases for the BARCT demonstration requirements are the BARCT standard given in WAC 246-247-040, and the definition of BARCT given in WAC 246-247-030. This procedure incorporates certain implementing criteria that enable the deparment to evaluate a facility's compliance with the BARCT 
standard. It is the applicant's responsibility to demonstrate the effectiveness of their BARCT determination to the department. The facility should contact the department at the conceptual design phase for guidance on the BARCT demonstration requirements. The department may adjust this demonstration procedure on a case-by-case basis, as needed, to ensure compliance with the substantive standard.

Scope. The BARCT demonstration includes the abatement technology and indication devices that demonstrate the effectiveness of the abatement technology from entry of radionuclides into the ventilated vapor space to release to the environment. The applicant shall evaluate all available control technologies that can reduce the level of radionuclide emissions.

Technology Standards. The BARCT demonstration and the emission unit design and construction must meet, as applicable, the technology standards shown below if the units potential-to-emit exceeds $0.1 \mathrm{mrem} / \mathrm{yr}$ TEDE to the MEI. If the potential-to-emit is below this value, the standards must be met only to the extent justified by a cost/benefit evaluation.

ASME/ANSI AG-1, Code on Nuclear Air and Gas Treatment (where there are conflicts in standards with the other listed references, this standard shall take precedence) ASME/ANSI N509, Nuclear Power Plant Air Cleaning Units and Components ASME/ANSI N510, Testing of Nuclear Air Treatment Systems

ANSI/ASME NQA-1, Quality Assurance Program Requirements for Nuclear Facilities 40 CFR 60, Appendix A, Methods 1, 1A, 2, 2A, 2C, 2D, 4, 5, and 17 ANSI N13.1, Guide to Sampling Airborne Radioactive Materials in Nuclear Facilities The following standards and references are recommended as guidance only: ANSI/ASME NQA-2, Quality Assurance Requirements for Nuclear Facilities ANSI N42.18, Specification and Performance of On-site Instrumentation for Continuously Monitoring Radioactivity in Effluent

ERDA 76-21, Nuclear Air Cleaning Handbook ACGIH 1988, Industrial Ventilation, A Manual of Recommended Practice, 20th ed., American Conference of Governmental Industrial Hygienists BARCT Demonstration Procedure.

Step 1. Define facility process variables. Describe the physical and chemical process. Include the potential radionuclide release rates (by isotope, in units of curies/year), process variables (such as flow rate, temperature, humidity, chemical composition), and other technical considerations. Base the radionuclide release rate on the potential-to-emit. Radionuclide selected for consideration in the BARCT demonstration shall include those which contribute more than ten percent of the potential TEDE to the MEI or more than $0.1 \mathrm{mrem} / \mathrm{yr}$, and any others which the department determines are necessary.

Step 2. Gather information on all available control technologies. Search for all available technologies that can reduce the emissions levels for the radionuclides selected in Step 1. Sources of information shall include previous BARCT demonstrations, regulatory authorities, industry or regulatory agency data bases, literature searches, information from technology vendors, research and development reports, and any other means necessary to identify all available technologies. "Available teclinology" includes any technology that is commercially available. Recently completed searches may be used with department approval.

Step 3. Determine technical feasibility. Determine technical feasibility by evaluating vendor specifications for available control technologies identified in Step 2 with respect to the process variables identified in Step 1. Evaluate combinations of abatement technology and control devices by component, and the system as a whole. If a control technology has poor safety, reliability, or control effectiveness as achieved in practice under the proposed process conditions, or the technology is not applicable to the emission unit under consideration, the technology may be eliminated with supporting documentation of the technical infeasibility. 
Step 4. List all feasible control technologies in order of effectiveness. Evaluate feasible control technologies for efficiency (effectiveness) in reducing the TEDE to the MEI. List them in order, with the most effective first. If the most effective feasible technology is proposed as BARCT, the demonstration is complete at this step.

Step 5. Evaluate the environment, energy, and economic impacts. Evaluate each control technology in succession, beginning with the most effective. Present an objective evaluation considering both beneficial and adverse impacts. Quantify the data where possible. Impact cost and effectiveness evaluations are incremental and include only that portion of the facility which comes under the authority of this chapter. Evaluate at least the following impacts: Environmental impact-Determine the incremental environmental impact, both beneficial and adverse. Evaluate the beneficial impact of reduction in the TEDE to the surrounding population or, at a minimum, to the MEI due to the abatement of radioactive air emissions. Consider the adverse impacts from waste generation (radioactive and nonradioactive, air and nonair), disposal and stabilization, construction of control equipment, and the health and safety to both radiation workers and the general public.

Energy impact-Determine the incremental energy impact. Include the impact. Include the impact of any resulting need for new services such as energy distribution systems. Economic impact-Determine the incremental economic impact. Determine capital and expense costs including design, development, procurement, construction, operation, maintenance, taxes, waste, disposal, and any other applicable financial components. Base all costs on the expected lifetime of the emission unit and reduce to an annualized cost for evaluation and comparison. The most effective technology may be eliminated from consideration if the applicant can demonstrate to the department's satisfaction that the technology has unacceptable impacts. State clearly the basis for this conclusion and proceed to the next most effective control technology. If the next most effective technology is proposed as BARCT, the demonstration is complete; otherwise, evaluate the control technology for impacts in accordance with this step. If the control technology cannot be eliminated on the basis of its impacts, it is proposed as BARCT.

Reporting. Prepare a BARCT compliance demonstration report for department review. Provide sufficient information such that the department can validate essential results. If no control technology is feasible, and/or emissions are unacceptable, the department reserves the right to prohibit the construction and operation of the emission unit(s)."

\section{REQUIREMIENT SOURCE: WAC-246-247(940131) Section 130, Appendix C}

"Purpose. ALARACT demonstration is used for inspection or audit purposes, and to demonstrate compliance with the substantive ALARACT technology standard as required by this chapter. An ALARACT demonstration is used to evaluate the adequacy of control technology on existing emission units and to choose control technologies for proposed nonsignificant modifications of emission units. The bases for the ALARACT demonstration requirements are the ALARACT standards given in WAC 246-247-040 and the definition of ALARACT given in WAC 246-247-030. It is applicant's responsibility to demonstrate the effectiveness of their ALARACT determination to the department. The department may adjust this demonstration procedure on a case-by-case basis, as needed, to ensure compliance with the substantive standard.

Scope. The ALARACT demonstration includes the abatement technology and indication devices, from entry of radionuclides into the ventilated vapor space to release to the environment. The facility shall evaluate the existing control system in relation to applicable technology standards, and other control technologies that have been successfully operated for similar applications. 
Technology Standards. The ALARACT demonstration and the emission unit design and construction must meet, as applicable, the technology standards shown below if the units potential-to-emit exceeds $0.1 \mathrm{mrem} / \mathrm{yr}$ TEDE to the MEI. If the potential-to-emit is below this value, the standards must be met only to the extent justified by a cost/benefit evaluation.

ASME/ANSI AG-1, Code on Nuclear Air and Gas Treatment (where there are conflicts in standards with the other listed references, this standard shall take precedence)

ASME/ANSI N509, Nuclear Power Plant Air-Cleaning Units and Components ASME/ANSI N510, Testing of Nuclear Air Treatment Systems

ANSI/ASME NQA-1, Quality Assurance Program Requirements for Nuclear Facilities

40 CFR 60, Appendix A, Methods 1, 1A, 2, 2A, 2C, 2D, 4, 5, and 17 ANSI N13.1, Guide to Sampling Airborne Radioactive Materials in Nuclear Facilities

The following standards and references are recommended as guidance only: ANSI NQA-2, Quality Assurance Requirements for Nuclear Facilities ANSI N42.18, Specification and Performance of On-Site Instrumentation for Continuously Monitoring Radioactivity in Effluents ERDA 76-21, Nuclear Air Cleaning Handbook

ACGIH 1988, Industrial Ventilation, A Manual of Recommended Practice, 20th ed., American Conference of Governmental Industrial Hygienists ALARA References. "Health Physics Manual of Good Practice for Reducing Radiation Exposure to Levels that are As Low As Reasonably Achievable (ALARA)", PNL-6577, June, 1988; prepared for the US DOE by Pacific Northwest Laboratories (Battelle Memorial Institute).

"A Guide to Reducing Radiation Exposure to As Low As Reasonably Achievable (ALARA)", DOE/EV/1830-T5, April, 1980, R.L. Kathern and J.M. Selby; prepared for the USDOE by Pacific Northwest Laboratories (Battelle Memorial Institute). "

\section{RCRA TSD Facility Permits}

Subelement 20.2.3 addresses the RCRA TSD facility permit. Permit No. WA7890008967, effective September 28, 1994, was issued to the DOE-RL as owner/operator, and its contractors (WHC and PNL) as co-operators for the treatment, storage and disposal of dangerous waste at Hanford. Requirements from the RCRA permit associated with changes to the permit are applicable to Tank Farms but implemented at the site level. Therefore, Tank Farms defers these requirements to the Hanford Facility RCRA Permit S/RID. Modifications to the Hanford Facility RCRA Permit, reporting of planned changes, and certifications of construction or modification are deferred to the Hanford Facility RCRA Permit S/RID.

\section{REQUIREMENT SOURCE: WAC-173-303 Section 280}

"General requirements for dangerous waste management facilities

(1) Applicability. The requirements of WAC 173-303-280 through 173-303-395 apply to all owners and operators of facilities which store, treat, or dispose of dangerous wastes and which must be permitted under the requirements of this chapter 173-303 WAC, unless otherwise specified in this chapter. The owner or operator of a facility which manages special waste may comply with special requirements specified in WAC 173-303-550 through 173-303-560 in lieu of the general requirements of WAC 173-303-280 through 173-303-395, but only for those special wastes which he manages. Whenever a shipment of dangerous waste is initiated from a facility, the owner or operator of the facility shall comply with the requirements for generators, WAC 173-303-170 through 173-303-230. 
(2) Imminent hazard. Notwithstanding any provisions of this chapter, enforcement actions may be brought in the event that the management practices of a facility present an imminent and substantial hazard to the public health and the environment, regardless of the quantity or concentration of a dangerous waste.

(3) Identification numbers. Every facility owner or operator shall apply for an EPA/state identification number from the department in accordance with WAC 173-303-060.

(4) The owner or operator must comply with the special land disposal restrictions for certain dangerous wastes in WAC 173-303-140.

\section{REQUIREMENT SOURCE: WAC-173-303(931208) Section 281(3)}

"(3) Notice of intent to file for an interim status or a dangerous waste permit.

(a) The notice of intent to be prepared by the owners/operators of the applicable facilities shall consist of:

(i) The name, address, and telephone number of the owner, operator, and corporate officers;

(ii) The location of the proposed facility or expansion on a topographic map with specifications as detailed in WAC 173-303-806 (4)(a)(xviii); (iii) A brief description of the types and amounts of wastes to be managed annually;

(iv) A brief description of the major equipment items proposed, if any, and the waste management activities requiring a permit or revision of an existing permit;

(v) Demonstration of compliance with the siting criteria as required under WAC 173-303-282

(6) and (7). The site conditions with regards to satisfying the criteria are to be assessed as of the date of submittal of the notice of intent to the department;

(vi) For informational purposes a complete summary of compliance violations of permit conditions at hazardous waste management facilities owned or operated by the applicant, its subsidiaries or its parent company, during the ten calendar years preceding the permit application. Along with the summary of compliance violations, as issued by appropriate state or federal regulatory agencies, the applicant shall also submit responses to past violations and any written correspondence with regulatory agencies regarding the compliance status of any hazardous waste management facility owned or operated by the applicant, its subsidiaries or parent company of the owner or operator. A more detailed compliance record must be provided upon request by the department;

(vii) For informational purposes the need for the proposed facility or expansion shall be demonstrated by one of the following methods:

(A) Current overall capacity within Washington is inadequate for dangerous wastes generated in Washington as determined by regional or state dangerous waste management plans; or

(B) The facility is a higher priority management method, as described in RCW 70.105.150, than is currently in place or practical and available for the types of waste proposed to be managed; or

(C) The facility will add to the types of technology available or will reduce cost impacts (not to include transportation costs) to Washington generators for disposal of dangerous wastes; and 
(ix) For informational purposes it shall be shown how the capacity of the proposed facility or expansion will affect the overall capacity within the state, in conjunction with existing facilities in Washington.

(b) The notice of intent shall be filed with the department, and copies shall be made available for public review, no less than one hundred fifty days prior to filing an application for a permit or permit revision. Public notification of the notice of intent to file shall be given at the time of filing by announcement in a daily newspaper within the area of the proposed facility or expansion for a minimum of fourteen consecutive days. In addition, the department shall send a copy of the notice of intent to the elected officials of the lead local government and all local governments within the potentially affected area as required by WAC 173-303-902 (5)(b)(i). The department will continue to coordinate with interested local governments throughout the review of the proposal.

(c) Reserved. "

\section{Underground Storage Tanks}

Subelement 20.2.4 includes requirements from WAC 173-360 associated with permitting and registering underground storage tanks (USTs). Requirements concerning the delivery of regulated substances to USTs are managed at the site level.

\section{REQUIREMENT SOURCE: WAC-173-360 Section 130( 1)}

"Requirement for a permit. After July 1, 1991, no underground storage tank system, as defined in this chapter, shall be operated without a valid permit from the department. However, possession of a valid permit does not preclude enforcement against the owner or operator of the underground storage tank under this or other laws."

\section{REQUIREMENT SOURCE: WAC-173-360 Section 130( 2)}

"Application for a permit. Permits for UST systems shall be obtained as follows:

(a) To apply for a permit for an UST system which is to be newly installed, the owner or operator shall complete a notice of intent to install an UST system, as specified in WAC 173-360-200 (1), and submit it to the department at least thirty days prior to installation of the system. An initial permit, valid for ninety days, will be provided by the department so the UST system can be tested and operation of the system can begin. If necessary, and if circumstances warrant, an additional permit valid for ninety days will be provided by the department. Upon receipt of the following items, a permit valid until the following June 30 , if the UST system remains in compliance, will be provided by the department for the newly installed UST system:

(i) A properly completed UST notification form, as specified in WAC 173-360-200 (2); and (ii) A properly completed installation checklist, as specified in WAC 173-360-200 (3).

(b) To apply for a permit for an existing UST system not previously reported to the department, the owner or operator shall complete a Washington state underground storage tank notification form, as specified in WAC 173-360-200 (2), and submit it to the department with a payment of the applicable annual fee, as specified in WAC 173-360-190, including any fees which should have been paid for earlier fiscal years if the UST system had been properly registered, but which were not paid. 
(c) To apply for a permit for a tank which has been temporarily out of service, the owner or operator shall notify the department of the change in status and follow the provisions of WAC 173-360-380.

(d) Each year the department will request owners and operators of reported UST systems to certify compliance with the requirements of this chapter. UST systems which are in the department's notification data base when the department requests this certification will receive permits by July 1 of each year if:

(i) Adequate documentation of compliance, as specified by the department, is submitted to the department; and

(ii) The documentation of compliance is submitted by the deadline for submittal established by the department in its request."

\section{REQUIREMENT SOURCE: WAC-173-360 Section 130( 4)}

"Delivery of regulated substances. Regulated substances shall not be delivered to any underground storage tank requiring a permit under this section unless a valid permit is displayed on such tank itself or the dispensing or measuring device connected thereto or, where appropriate, in the office or kiosk of the facility where the tank is located. This subsection applies only to suppliers who directly transfer regulated substances into underground storage tank systems."

\section{REQUIREMENT SOURCE: WAC-173-360 Section 130( 7 )}

"Delivery of regulated substances. If a confirmed release occurs from a permitted tank, in addition to meeting the reporting requirements of WAC 173-360-372, within twenty-four hours of having knowledge of the release the owner or operator shall lock the fill pipe and remove from display the permit for the tank from which the release has occurred. At no time can the owner or operator receive regulated substances, except as specified in subsection (10) of this section, until all the applicable requirements of this chapter and chapter 173-340 WAC have been met. If the department determines that reasonable progress is not being made in meeting these requirements it may request that the owner or operator surrender the permit, as specified in subsection (8) of this section, for the tank from which the release occurred."

\section{REQUIREMENT SOURCE: WAC-173-360 Section 130( 8)}

"Permit revocation. The department may request the surrender of a permit for any tank which does not remain in compliance with the requirements of this chapter, including financial responsibility requirements and payment of fees, or for any violation of the chapter by an underground storage tank owner or operator, including refusal of access to property under WAC 173-360-140. Upon request of a representative of the department or delegated agency or upon receipt of a letter from the department or delegated agency requesting surrender of the permit, the owner or operator must return the permit to the department or delegated agency within seven days."

\section{REQUIREMENT SOURCE: WAC-173-360 Section 130( 9)}

"When a tank is closed, any active permit must be returned to ecology within thirty days of the completion of the closure procedures." 


\section{REQUIREMENT SOURCE: WAC-173-360 Section 200(1)}

"Notice of intent to install a new UST system. Except in the circumstances defined in subsection (5) of this section, any owner who intends to install a new UST system shall submit a notice of such intent to the department or delegated agency at least thirty days prior to installing the UST system. Such notice shall meet the following requirements:

(a) The notice of intent shall be provided on the appropriate Washington state form, which is available from the department;

(b) Each UST system to be installed which is regulated under this chapter shall be reported;

(c) Owners may provide notice for more than one UST system using a single form, but UST systems to be installed at separate sites shall be reported on separate forms; and

(d) The completed form shall include all of the information required on the form. "

\section{REQUIREMENT SOURCE: WAC-173-360 Section 200(2)}

"Notification of new UST systems in use. Within thirty days of bringing any newly installed UST system regulated under this chapter into use, the owner shall submit notice of such UST system to the department. This notice shall meet the following requirements:

(a) The notice shall be provided on the appropriate Washington state underground storage tank notification form, which is available from the department;

(b) Each tank regulated under this chapter shall be reported;

(c) Owners may provide notice for more than one tank using a single notification form, but owners who own tanks located at more than one site shall file a separate notification form for each site;

(d) Notification required under this section shall include all of the information required on the form for each tank for which notice must be given; and

(e) Notification for tanks installed after December 22,1988 , shall also certify compliance with the following requirements:

(i) Corrosion protection of steel tanks and piping under WAC 173-360-305 (1) and (2);

(ii) Financial responsibility under WAC 173-360-400 through 173-360-499; and

(iii) Release detection under WAC 173-360-335 and 173-360-340."

\section{REQUIREMENT SOURCE: WAC-173-360 Section 200(3)}

"Installation checklist. All owners and operators of new UST systems shall ensure that a licensed installation supervisor certifies that the methods used to install the tanks and piping comply with the requirements in WAC 173-360-305 (4). Such certification shall be accomplished by completing an installation checklist, which is available from the department, as specified in WAC 173-360-305 (5)."

\section{REQUIREMENT SOURCE: WAC-173-360 Section 200(4)}

"Notification of existing UST systems. Owners of any existing UST system regulated under this chapter which has not previously been reported to the department shall provide notification 
regarding such UST system immediately, following the requirements of subsection (2) (a) through (e) of this section.

Note: Owners and operators of UST systems that were in the ground on or after May 8, 1986, unless taken out of operation on or before January 1, 1974, were required to notify the department in accordance with the Hazardous and Solid Waste Amendments of 1984, Public Law 98-616, on a form published by Washington state unless notice was given pursuant to section 103(c) of CERCLA."

\section{REQUIREMENT SOURCE: WAC-173-360 Section 200(5)}

"Emergency replacement of UST systems.

(a) An exception to the thirty-day notice requirement for new installations in subsection (1) of this section is allowed when an UST system is being replaced on an emergency basis due to a release from the system being replaced. An emergency shall be regarded as a newly discovered release from an UST system which is:

(i) In operation at the time of the release;

(ii) Located at an operating facility; and

(iii) Necessary for the normal operation of the facility.

(b) Under the circumstances described in (a) of this subsection, the notice of intent to install an UST system may be provided after the installation of the new system but no more than seven days after the installation is completed. The information which must be included in the notice of intent form is the same as in subsection (1) of this section. A site assessment meeting the requirements of WAC 173-360-390 shall be completed prior to installing a tank in the excavation pit of a tank being replaced and prior to installing new piping in the piping trench of piping being replaced."

\section{REQUIREMENT SOURCE: WAC-173-360 Section 200(6)}

"Changes to UST systems. Any changes in the information initially reported in the notification form submitted under subsection (2), (4) or (5) of this section, including temporary closure of an UST system that was initially reported as being in use, shall be reported to the department or delegated agency by submitting a new notification form within thirty days after such changes occur."

\section{REQUIREMENT SOURCE: WAC-173-360 Section 200(7)}

"Beginning October 24, 1988, any person who sells a new tank which is intended to be used as an underground storage tank, or an existing UST system or property including an existing UST system which is intended to be used as an UST system, shall notify the purchaser of such tank or UST system of the owner's notification obligations under this section."

\section{REQUIREMENT SOURCE: WAC-173-360 Section 210(1)}

"(1) Reporting. Owners and operators shall submit the information specified in (a) through (e) of this subsection to the department or delegated agency:

(a) Notification for all UST systems (WAC 173-360-200), which includes certification of installation for new UST systems (WAC 173-360-305(5));

(b) Reports of all suspected releases (WAC 173-360-360), confirmed releases (WAC 173-360-372), and spills and overfills (WAC 173-360-375); 
(c) Reports required for corrective action under chapter 173-340 WAC;

(d) A notification before permanent closure or change-in-service (WAC 173-360-385); and

(e) The appropriate forms certificates of compliance, and evidence of financial responsibility (WAC 173-360-446).

(f) Checklists required for tank service activities, site checks, and site assessments shall be submitted by tank services providers or persons registered to perform site checks and site assessments, as applicable."

\section{REQUIREMENT SOURCE: WAC-173-360 Section 210(2)}

"(2) Recordkeeping. Owners and operators shall maintain the following information:

(a) Documentation of operation of corrosion protection equipment (WAC 173-360-320);

(b) Documentation of UST system repairs (WAC 173-360-325(7));

(c) Recent compliance with release detection requirements (WAC 173-360-355);

(d) N/A

(e) Corrective action records in accordance with chapter 173-340 WAC; ${ }^{n}$

\section{REQUIREMENT SOURCE: WAC-173-360 Section 210(3)}

"(3) Availability and maintenance of records. Owners and operators shall keep the records required either:

(a) At the UST site and immediately available for inspection by the department or delegated agency; or

(b) At a readily available alternative site and be provided for inspection to the department or delegated agency upon request."

Element 20.3 includes requirements for monitoring, inspection, and surveillance activities associated with air emission sources, liquid discharges, and waste management.

Ambient water quality monitoring is not conducted under the management authority of Tank Farms. Requirements associated with groundwater monitoring and site assessments are applicable to Tank Farms but are implemented at the site level and are not included in this S/RID. Tank Farms stormwater requirements primarily address pollution prevention. Therefore, stormwater requirements are included in Element 20.5, Pollution Prevention.

The Tank Farms radionuclide air emission sources were evaluated and documented as a result of a Compliance Order issued by the EPA.

Sampling and Analysis Plans (SAPs) are required for Phase I and Phase II liquid effluent streams discharged to the soil column.

\section{Monitoring, Surveillance and Inspection Plans and Procedures}

Subelement 20.3.1 includes requirements for monitoring, surveillance, and inspection of air emission sources, liquid discharges, and waste management activities. Included in this subelement are requirements for preoperational monitoring, emissions monitoring and 
modeling, sampling, inspections to prevent malfunctions, and requirements for assuring access for regulatory personnel.

\section{REQUIREMENT SOURCE: 40CFR61 Part 93(a)}

"To determine compliance with the standard, radionuclide emissions shall be determined and effective dose equivalent values to members of the public calculated using EPA approved sampling procedures, computer models CAP-88 or AIRDOS-PC, or other procedures for which EPA has granted prior approval. DOE facilities for which the maximally exposed individual lives within 3 kilometers of all sources of emissions in the facility, may use EPA's COMPLY model and associated procedures for determining dose for purpose of compliance."

\section{REQUIREMENT SOURCE: DOE5400.1 Chapter IV, Section 3}

"Preoperational Monitoring of Facilities, Sites, and Operations. An environmental study shall be conducted prior to start up of a new site, facility, or process which has the potential for significant adverse environmental impact. The preoperational study should begin not less than 1 year, and preferably 2 years before start up to evaluate seasonal changes. The study shall serve to: characterize existing physical, chemical, and biological conditions that could be affected; establish background levels of radioactive and chemical components; characterize pertinent environmental and ecologic parameters; and identify potential pathways for human exposure or environmental impact as a basis for determining the nature and extent of the subsequent routine operational and emergency effluent monitoring and environmental surveillance programs. Where time and circumstances do not allow for completion of preoperational monitoring prior to start-up, it shall be conducted concurrent with work on the new site, facility, or process. The preoperational study shall be consistent with NEPA compliance activities. Where appropriate, activities and documentation conducted for NEPA compliance may substitute for compliance with this requirement."

\section{REQUIREMENT SOURCE: DOE5400.1 Chapter IV, Section 4}

"Environmental Monitoring Plans. A written environmental monitoring plan shall be prepared for each site, facility, or process that uses, generates, releases, or manages significant pollutants or hazardous materials. The plan shall contain the rationale and design criteria for the monitoring program, extent and frequency of monitoring and measurements, procedures for laboratory analyses, quality assurance requirements, program implementation procedures, and direction for the preparation and disposition of reports. The plan shall be approved by the appropriate Head of Field Organization, or his or her designee. The plan shall be reviewed annually and updated as needed. The plan shall identify and discuss two major activities:

(a) effluent monitoring, and

(b) environmental surveillance. The plan shall reflect the importance of monitoring as a critical element of an effective environmental protection program. The plan shall be reviewed annually and updated every 3 years."

\section{REQUTREMENT SOURCE: DOE5400.1 Chapter IV, Section 5.a}

"Effluent Monitoring

(1) Effluent monitoring shall be conducted at all DOE sites to satisfy the following program objectives:

(a) Verify compliance with applicable Federal, State, and local effluent regulations and DOE Orders. 
(b) Determine compliance with commitments made in Environmental Impact Statements, Environmental Assessments, or other official documents.

(c) Evaluate the effectiveness of effluent treatment and control.

(d) Identify potential environmental problems and evaluate the need for remedial actions or mitigation measures.

(e) Support permit revision and/or reissuance.

(f) Detect, characterize, and report unplanned releases."

\section{REQUIREMENT SOURCE: DOE5400.1 Chapter IV, Section 5.a(2)}

"Effluent monitoring shall comply with applicable regulations and shall be conducted to provide representative measurements of the quantities and concentrations of pollutants in liquid and airborne discharges, and solid wastes.

(a) Monitoring Stations. Effluents from on-site waste treatment or disposal systems shall be monitored in accordance with applicable regulations. Influents to on-site waste treatment or disposal systems should be monitored as needed.

(b) Sampling. Sample collection programs shall reflect specific facility needs. Type and frequency of sampling shall be adequate to characterize effluent streams.

(c) Sample Analysis. Standard analyses shall be used to analyze samples whenever such methods are required by regulatory programs. Exemptions due to analytical problems or for non-routine analyses may be employed after receiving approval from the appropriate regulatory agency. Analyses not required by regulations may be conducted as determined by site-specific conditions.

(d) Monitoring Data Record keeping. Auditable records shall be established in accordance with the requirements of DOE $5700.6 \mathrm{~B}$."

\section{REQUIREMENT SOURCE: DOE5400.1 Chapter IV, Section 5.b(2)}

"Environmental surveillance programs and components should be determined on a site-specific basis by the field organization. Programs should reflect facility characteristics, applicable regulations, hazard potential, quantities and concentrations of materials released, the extent and use of affected air, land, and water, and specific local public interest or concern. Surveillance programs are likely to include one or more of the following:

(a) Monitoring stations;

(b) Sampling and analysis; and

(c) Monitoring data recordkeeping. "

\section{REQUIREMENT SOURCE: DOE5400.1 Chapter IV, Section 7.a}

"Radiological Monitoring - Requirements for the environmental monitoring of radioactive materials are to be found in DOE Orders in the 5400 series dealing with radiation protection of the public and the environment. Airborne radiation and radioactive materials discharged from DOE facilities shall comply with the requirements of 40 CFR Part 61, "National Emission Standards for Hazardous Air Pollutants." Further, for those radioactive materials not regulated under the Clean Air Act, DOE has established standards to meet its responsibilities under the Atomic Energy Act." 


\section{REQUIREMENT SOURCE: DOE5400.1 Chapter IV, Section 7.b}

"An assessment of the potential radiation dose to members of the public which could have resulted from site operations shall be made for facilities required to conduct effluent and environmental radiological monitoring. Assessments shall be made in accordance with the requirements of DOE Orders in the $\mathbf{5 4 0 0}$ series dealing with radiation protection of the public and the environment."

\section{REQUIREMENT SOURCE: DOE5400.1 Chapter IV, Section 8.a(1)}

"Non-Radiological Monitoring - Air Monitoring - Emissions

(1) Air emission monitoring shall be in accordance with the requirements of applicable Federal, State, and local regulations authorized by the Clean Air Act (42 U.S.C. 7401, et. seq.). Section 118 of the Act specifically addresses the control of airborne pollution from federal facilities. Design of air quality monitoring programs should be undertaken with a thorough understanding of the complex framework of air quality management."

\section{REQUIREMENT SOURCE: DOE5400.1 Chapter IV, Section 8.a(2)}

"Where applicable, DOE facilities shall comply with monitoring requirements discussed in 40 CFR Part 60, which includes monitoring of fossil fuel combustion sources and associated test methods. Appendix A of 40 CFR Part 60 provides methods referred to in 40 CFR Part 60.8 (Performance Tests) and 40 CFR Part 60.11 (Compliance with Standards and Maintenance Requirements)."

\section{REQUIREMENT SOURCE: DOE5400.5 Chapter II, Section 6.a}

"Monitoring and Surveillance. General requirements for routine effluent monitoring are part of the environmental monitoring plan prescribed in DOE 5400.1. Specific requirements for radiological effluent monitoring and environmental surveillance and their schedule of implementation are prescribed in DOE Orders in the 5400 series, which deal with radiological effluent monitoring and environmental surveillance. The monitoring requirements are applicable to all DOE and DOE contractor operations that are subject to the standards and requirements of this Order."

\section{REQUIREMENT SOURCE: DOE5400.5 Chapter II, Section 6.b(1)}

"Modeling. Analytical models used for dose evaluations shall be appropriate for characteristics of emissions (e.g., gas, liquid, or particle; depositing or non-depositing; buoyant or non-buoyant); mode of release (e.g., stack or vent; crib or pond; surface water or sewer; continuous or intermittent); environmental transport medium (e.g., air or water); and exposure pathway (e.g., inhalation; ingestion of food, water, or milk; direct radiation). Information on dispersion (transport and diffusion) in the environment, demography, land use (including the location and number of dairy and slaughter animals), food supplies, and exposure pathways used in the dose calculations shall be appropriate to evaluate actual and potential doses in the environs of DOE facilities. Such information shall be updated as necessary to document significant changes that could affect dose evaluations. Dose evaluation models that are codified, approved, or accepted by regulatory or other authorities shall be used where appropriate, such as the AIRDOS/RADRISK codes pursuant to 40 CFR Part 61, Subpart H." 


\section{REQUIREMENT SOURCE: DOE5484.1 Chapter III, Section 5.c(1)(a)}

"Monitoring Guidelines.

(1) General.

(a) As a general rule, monitoring should be conducted in a manner that provides accurate measurements of the quantity and concentration of liquid and airborne pollutants in effluents as a basis for:

1 Determining compliance with applicable discharge and effluent control limits, including self-imposed administrative limits designed to assure compliance with in-plant operating limits, effluent standards or guides, and with environmental standards or guides.

2 Evaluating the adequacy and effectiveness of containment and waste treatment and control as well as of efforts toward achieving levels of radioactivity which are as low as reasonably achievable considering technical and economical constraints.

3 Compiling an annual inventory of the radioactivity released in effluents and onsite discharges."

\section{REQUIREMENT SOURCE: DOE5484.1 Chapter III, Section 5.c(2)}

"Monitoring Locations. Measurements of volume, rate of discharge, content, etc., should be made, insofar as is practical, at the point at which the data most closely represent what is being released. This implies that measurements should be made at the point of discharge, though there are exceptions. Effluents should be monitored at the point at which the applicable standards apply. In the case of onsite discharges, the monitoring location may be the waste treatment or disposal system; and in case of effluents, the monitoring location may be the point of release to the offsite environment after all treatment and control, including retention and decay, have been effected. In many instances, the monitoring location is specified in a discharge or operating permit."

\section{REQUIREMINT SOURCE: DOE5484.1 Chapter III, Section 5.c(3)(a)}

"Type and Frequency of Sampling.

(a) Sampling frequency and type should be determined by considering the purpose for which the data are being obtained, e.g., evaluation of the effectiveness of waste treatment and control, compliance with operating limits of applicable effluent or performance standards, compilation of release data, etc. Continuous sampling is desirable and may be necessary where there is wide variation in the concentrations or mixture of potential pollutants in the effluent stream. However, periodic sampling may suffice when the concentration and mixtures are reasonably constant and there is little likelihood of unusual variations. Similarly, proportional sampling may be necessary when effluent flow rates fluctuate, whereas a representative grab-sample may suffice for batch discharges. The method of sampling may be specified in the applicable regulation or permit."

\section{REQUIREMENT SOURCE: DOE5484.1 Chapter III, Section 5.c(3)(b)}

"For purposes of reporting radiological data, gross radioactivity measurements are generally inadequate. They are appropriate only:

1 When gross radioactivity releases are a small fraction of the offsite Radioactivity Concentration Guides (RCG's) for "unidentified mixtures" and are of no health or environmental significance; 
2 When the relative concentrations of specific radionuclides are so well known by other means that gross radioactivity measurements are truly indicative of the activity being released; or

3 When the activity of waste streams is so low as to preclude specific nuclide measurements. "

\section{REQUIREMENT SOURCE: DOE5820.2A Chapter I, Section 3.b(3)(b)}

"Leak detection systems (e.g., conductivity probes) shall be designed and operated so that they will detect the failure of the primary containment boundary, the occurrence of waste release, or accumulated liquid in the secondary containment system."

\section{REQUIREMINT SOURCE: DOE5820.2A Chapter I, Section 3.b(3)(c)}

"A method for periodically assessing waste storage system integrity (e.g., coupons for corrosion testing, photographic and periscopic inspections, leak detectors, liquid level devices) shall be established, documented, and reported as required in the Waste Management Plan."

\section{REQUIREMENT SOURCE: DOE5820.2A Chapter I, Section 3.b(3)(d)}

"Electrical monitoring and leak detection devices essential to safe operations shall be provided with backup power, as appropriate, to ensure operability under emergency conditions."

\section{REQUIREMENT SOURCE: DOE5820.2A Chapter III, Section 3.k(1)}

"Each operational or non-operational low-level waste treatment, storage, and disposal facility shall be monitored by an environmental monitoring program that conforms with DOE 5484.1 and, at a minimum, meet the requirements of paragraph 3.k.(2) through 3.k.(4)."

\section{REQUIREMENT SOURCE: DOE5820.2A Chapter III, Section 3.k(2)}

"The environmental monitoring program shall be designed to measure:

(a) operational effluent releases;

(b) migration of radionuclides;

(c) disposal unit subsidence; and

(d) changes in disposal facility and disposal site parameters which may affect long-term site performance."

\section{REQUIREMENT SOURCE: DOE5820.2A Chapter III, Section 3.k(3)}

"Based on characteristics of the facility being monitored, the environmental monitoring program may include, but not necessarily be limited to, monitoring surface soil, air, surface water, and, in the subsurface, soil, water, both in the saturated and unsaturated zones."

\section{REQUIREMENT SOURCE: DOE5820.2A Chapter III, Section 3.k(4)}

"The monitoring program shall be capable of detecting changing trends in performance sufficiently in advance to allow application of any necessary corrective action prior to exceeding performance objectives. The monitoring program shall be able to ascertain whether or not effluents from each treatment, storage, or disposal facility or disposal site meet the requirements of applicable EH Orders." 


\section{REQUIREMENT SOURCE: DOE5820.2A Chapter VI, Section 2, Paragraph 1}

"DISCUSSION.

The Order for radioactive waste management emphasizes accountable operational requirements set forth in a prescriptive style. Each site that generates, treats, stores, or disposes of DOE radioactive waste, or decommissions contaminated facilities, is responsible for complying with these requirements in terms of how operations are conducted and how these activities are documented. The documentation serves as the written word that the actual operations are being conducted within the framework of the Order."

\section{REQUIREMENT SOURCE: WAC-173-216 Section 125(1)}

"Monitoring. Use of register or accredited laboratories:

(1) Except as established in subsection (3) of this section, monitoring data submitted to the department in accordance with this chapter shall be prepared by a laboratory accredited under the provisions of chapter 173-50 WAC no later than July 1, 1993, for all state permittees with a permitted average flow rate greater than five million gallons per day. These requirements are effective and binding on all permittees under the authority of rule, regardless of whether they have been included as conditions of a permit."

\section{REQUIREMINT SOURCE: WAC-173-216 Section 125(2)}

"Except as established in subsection (3) of this section, monitoring data submitted to the department in accordance with this chapter shall be prepared by a laboratory registered or accredited under the provisions of chapter 173-50 WAC no later than July 1, 1994, for all state permittees not covered under subsection (1) of this section. These requirements are effective and binding on all permittees under the authority of rule, regardless of whether they have been included as conditions of the permit."

\section{REQUIREMENT SOURCE: WAC-173-303(931208) Section 320(1)}

"The owner or operator shall inspect his facility to prevent malfunctions and deterioration, operator errors, and discharges which may cause or lead to the release of dangerous waste constituents to the environment, or a threat to human health. The owner or operator must conduct these inspections often enough to identify problems in time to correct them before they harm buman health or the environment."

\section{REQUIREMENT SOURCE: WAC-173-303(931208) Section 320(2)}

"The owner or operator shall develop and follow a written schedule for inspecting all monitoring equipment, safety and emergency equipment, security devices, and operating and structural equipment that help prevent, detect, or respond to hazards to the public health or the environment. In addition:

(a) He must keep the schedule at the facility;

(b) The schedule must identify the types of problems which are to be looked for during inspections;

(c) The schedule shall indicate the frequency of inspection for specific items. The frequency should be based on the rate of possible deterioration of equipment, and the probability of an environmental or human health incident. Areas subject to spills must be inspected daily when in use. At a minimum the inspection schedule shall also include the applicable items and 
frequencies required for the specific waste management methods described in 40 CFR Part 265 Subparts F through $R$ for interim status facilities and in WAC 173-303-630 through 173-303-680 for final status facilities; and

(d) The owner or operator shall keep an inspection log or summary, including at least the date and time of the inspection, the printed name and the handwritten signature of the inspector, a notation of the observations made, an account of spills or discharges in accordance with WAC 173-303-145, and the date and nature of any repairs or remedial actions taken. The log or summary must be kept at the facility for at least five years from the date of inspection."

\section{REQUIREMENT SOURCE: WAC-173-303(931208) Section 320(3)}

"The owner or operator shall remedy any problems revealed by the inspection, on a schedule which prevents hazards to the public health and environment. Where a hazard is imminent or has already occurred, remedial action must be taken immediately."

\section{REQUIREMIENT SOURCE: WAC-173-304 Section 190}

"Owner Responsibilities for Solid Waste. The owner, operator, or occupant of any premise, business establishment, or industry shall be responsible for the satisfactory and legal arrangement for the solid waste handling of all solid waste accumulated by then on the property."

\section{REQUIREMENT SOURCE: WAC-246-247(940131) Section 075( 1)}

"All radioactive air emissions monitoring, testing, and quality assurance requirements of 40 CFR 61, Subparts H and I published in the Federal Register on December 15, 1989, are adopted by reference, as applicable as specified by the referenced subparts."

\section{REQUIREMINT SOURCE: WAC-246-247(940131) Section 075( 2)}

"Equipment and procedures used for the continuous monitoring of radioactive air emissions shall conform, as applicable, to the guidance contained in ANSI N131, ANSI N42.18, ANSI N317, reference methods 1, 1A, 2, 2A, 2C, 2D, 4, 5, and 17 of 40 CFR Part 60, Appendix A, 40 CFR Part 52, Appendix E, and any other methods approved by the department."

\section{REQUIREMENT SOURCE: WAC-246-247(940131) Section 075( 3)}

"The operator of an emission unit with a potential-to-emit of less than $0.1 \mathrm{mrem} / \mathrm{yr}$ TEDE to the MEI may estimate those radionuclide emissions, in lieu of monitoring, in accordance with 40 CFR 61 Appendix D, or other procedure approved by the department. The department may require periodic confirmatory measurements (e.g., grab samples) during routine operations to verify the low emissions. Methods to implement periodic confirmatory monitoring shall be approved by the department."

\section{REQUIREMENT SOURCE: WAC-246-247(940131) Section 075( 6)}

"Licensed facilities shall conduct and document a quality assurance program. Except for those types of facilities specified in subsection (5) of this section, the quality assurance program shall be compatible with applicable national standards such as ANSI/ASME NQA-1-1988, ANSI/ASME NQA-2-1986, QAMS-004, and QAMS-005." 


\section{REQUIREMENT SOURCE: WAC-246-247(940131) Section 075( 7)}

"Those types of facilities specified in subsection (5) of this section shall conduct and document a quality assurance program compatible with either the applicable national standards referenced in subsection (6) of this section or the NRC's Regulatory Guide 4.15, dated February 1979."

\section{REQUIREMENT SOURCE: WAC-246-247(940131) Section 075( 8)}

"Facilities shall monitor nonpoint and fugitive emissions of radioactive material."

\section{REQUIREMENT SOURCE: WAC-246-247(940131) Section 075( 9)}

"The department may conduct an environmental surveillance program to ensure that radiation doses to the public from emission units are in compliance with applicable standards. The department may require the operator of any emission unit to conduct stack sampling, ambient air monitoring, or other testing as necessary to demonstrate compliance with the standards in WAC 246-247-040."

\section{REQUIREMENT SOURCE: WAC-246-247(940131) Section 075(10)}

"The department may require the owner or operator of an emission unit to make provision, at existing emission unit sampling stations, for the department to take split or collocated samples of the emissions."

\section{REQUIREMENT SOURCE: WAC-246-247(940131) Section 075(12)}

"All facilities must be able to demonstrate that appropriate supervisors and workers are adequately trained in the use and maintenance of emission control and monitoring systems, and in performance of associated test and emergency response procedures. "

\section{REQUIREMENT SOURCE: WAC-246-247(940131) Section 075(13)}

"All facilities must be able to demonstrate the reliability and accuracy of the radioactive air emissions monitoring data."

\section{REQUIREMINT SOURCE: WAC-246-247(940131) Section 085(1)}

"All procedures for determining compliance with the dose equivalent standards of 40 CFR 61 , Subparts H and I published in the Federal Register on December 15, 1989, are adopted by reference, as applicable as specified by the referenced subparts."

\section{Tank Systems}

Subelement 20.3.2 includes the requirements for the monitoring, inspection, and surveillance of tank systems.

\section{REQUIREMENT SOURCE: WAC-173-303(940523) Section 640( 1)(b)}

"Tank systems that are used to store or treat dangerous waste which contain no free liquids and are situated inside a building with an impermeable floor are exempted from the requirements in subsection (4) of this section. To demonstrate the absence or presence of free liquids in the stored/treated waste, the test method described in WAC 173-303-110 (3)(c)(i) must be used." 


\section{REQUIREMENT SOURCE: WAC-173-303(940523) Section 640( 2)(a)}

"For each existing tank system, the owner or operator must determine that the tank system is not leaking or is unfit for use. Except as provided in (b) of this subsection, the owner or operator must obtain and keep on file at the facility a written assessment reviewed and certified by an independent, qualified registered professional engineer, in accordance with WAC 173-303-810 (13)(a), that attests to the tank system's integrity by January 12,1988 , for underground tanks that do not meet the requirements of subsection (4) of this section and that cannot be entered for inspection, or by January 12, 1990, for all other tank systems."

\section{REQUIREMENT SOURCE: WAC-173-303(940523) Section 640( 2)(b)}

"Tank systems that store or treat materials that become dangerous wastes subsequent to January 12,1989, must conduct this assessment within twelve months after the date that the waste becomes a dangerous waste."

\section{REQUIREMENT SOURCE: WAC-173-303(940523) Section 640( 2)(c)}

"This assessment must determine that the tank system is adequately designed and has sufficient structural strength and compatibility with the waste(s) to be stored or treated, to ensure that it will not collapse, rupture, or fail. At a minimum, this assessment must consider the following:

(i) Design standard(s), if available, according to which the tank system was constructed;

(ii) Dangerous characteristics of the waste(s) that have been and will be handled;

(iii) Existing corrosion protection measures;

(iv) Documented age of the tank system, if available (otherwise, an estimate of the age); and

(v) Results of a leak test, internal inspection, or other tank system integrity examination such that:

(A) For nonenterable underground tanks, the assessment must include a leak test that is capable of taking into account the effects of temperature variations, tank end deflection, vapor pockets, and high water table effects; and

(B) For other than nonenterable underground tanks and for ancillary equipment, this assessment must include either a leak test, as described above, or other integrity examination, that is certified by an independent, qualified, registered professional engineer, in accordance with WAC 173-303-810(13)(a), that addresses cracks, leaks, corrosion, and erosion.

Note: The practices described in the American Petroleum Institute (API) Publication, Guide for Inspection of Refinery Equipment, Chapter XIII, "Atmospheric and Low-Pressure Storage Tanks," 4th edition, 1981, may be used, where applicable, as guidelines in conducting other than a leak test."

\section{REQUIREMENT SOURCE: WAC-173-303(940523) Section 640( 2)(d)}

"If, as a result of the assessment conducted in accordance with (a) of this subsection, a tank system is found to be leaking or unfit for use, the owner or operator must comply with the requirements of subsection (7) of this section."

\section{REQUIREMENT SOURCE: WAC-173-303(940523) Section 640(3)(a)}

"Owners or operators of new tank systems or components must obtain (and for facilities that are pursuing or have obtained a final status permit, submit to the department, at time of 
submittal of Part B information) a written assessment, reviewed and certified by an independent, qualified registered professional engineer, in accordance with WAC 173-303-810 (13)(a), attesting that the tank system has sufficient structural integrity and is acceptable for the storing and treating of dangerous waste. The assessment must show that the foundation, structural support, seams, connections, and pressure controls (if applicable) are adequately designed and that the tank system has sufficient structural strength, compatibility with the waste(s) to be stored or treated, and corrosion protection to ensure that it will not collapse, rupture, or fail. This assessment (which will be used by the department to review and approve or disapprove the acceptability of the tank system design at facilities which are pursuing or have obtained a final status permit) must include, at a minimum, the following information:

(i) Design standard(s) according to which tank system(s) are constructed;

(ii) Dangerous characteristics of the waste(s) to be handled;

(iii) For new tank systems or components in which the external shell of a metal tank or any external metal component of the tank system will be in contact with the soil or with water, a determination by a corrosion expert of:

(A) Factors affecting the potential for corrosion, including but not limited to:

(I) Soil moisture content;

(II) Soil pH;

(III) Soil sulfides level;

(IV) Soil resistivity;

(V) Structure to soil potential;

(VI) Influence of nearby underground metal structures (e.g., piping);

(VII) Existence of stray electric current;

(VIII) Existing corrosion-protection measures (e.g., coating, cathodic protection); and

(B) The type and degree of external corrosion protection that are needed to ensure the integrity of the tank system during the use of the tank system or component, consisting of one or more of the following:

(I) Corrosion-resistant materials of construction such as special alloys, fiberglass reinforced plastic, etc.;

(II) Corrosion-resistant coating (such as epoxy, fiberglass, etc.,) with cathodic protection (e.g., impressed current or sacrificial anodes); and

(III) Electrical isolation devices such as insulating joints, flanges, etc.

Note: The practices described in the National Association of Corrosion Engineers (NACE) standard, "Recommended Practice (RP-02-85)-Control of External Corrosion on Metallic Buried, Partially Buried, or Submerged Liquid Storage Systems, " and the American Petroleum Institute (API) Publication 1632, "Cathodic Protection of Underground Petroleum Storage Tanks and Piping Systems, " may be used, where applicable, as guidelines in providing corrosion protection for tank systems.

(iv) For underground tank system components that are likely to be adversely affected by vehicular traffic, a determination of design or operational measures that will protect the tank system against potential damage; and

(v) Design considerations to ensure that:

(A) Tank foundations will maintain the load of a full tank; 
(B) Tank systems will be anchored to prevent flotation or dislodgment where the tank system is either placed in a saturated zone, or is located less than five hundred feet from a fault which has had displacement in Holocene times; and

(C) Tank systems will withstand the effects of frost heave."

\section{REQUIREMENT SOURCE: WAC-173-303(940523) Section 640( 4)(a)}

"In order to prevent the release of dangerous waste or dangerous constituents to the environment, secondary containment that meets the requirements of this subsection must be provided (except as provided in (f) and (g) of this subsection):

(i) For all new tank systems or components, prior to their being put into service;

(ii) For all existing tank systems used to store or treat Dangerous Waste Nos. F020, F021, F022, F023, F026, and F027, within two years after January 12, 1989;

(iii) For those existing tank systems of known and documented age, within two years after January 12,1989, or when the tank system has reached fifteen years of age, whichever comes later;

(iv) For those existing tank systems for which the age cannot be documented, within eight years of January 12, 1989; but if the age of the facility is greater than seven years, secondary containment must be provided by the time the facility reaches fifteen years of age, or within two years of January 12,1989, whichever comes later; and

(v) For tank systems that store or treat materials that become dangerous wastes subsequent to January 12,1989 , within the time intervals required in (a)(i) through (iv) of this subsection, except that the date that a material becomes a dangerous waste must be used in place of January $12,1989 . "$

\section{REQUIREMENT SOURCE: WAC-173-303(940523) Section 640(4)(b)}

"Secondary containment systems must be:

(i) Designed, installed, and operated to prevent any migration of wastes or accumulated liquid out of the system to the soil, ground water, or surface water at any time during the use of the tank system; and

(ii) Capable of detecting and collecting releases and accumulated liquids until the collected material is removed."

\section{REQUIREMINT SOURCE: WAC-173-303(940523) Section 640( 6)(a)}

"The owner or operator must develop and follow a schedule and procedure for inspecting overfill controls."

\section{REQUIREMENT SOURCE: WAC-173-303(940523) Section 640( 6)(b)}

"The owner or operator must inspect at least once each operating day:

(i) Aboveground portions of the tank system, if any, to detect corrosion or releases of waste; 
(ii) Data gathered from monitoring any leak detection equipment (e.g., pressure or temperature gauges, monitoring wells) to ensure that the tank system is being operated according to its design; and

(iii) The construction materials and the area immediately surrounding the externally accessible portion of the tank system, including the secondary containment system (e.g., dikes) to detect erosion or signs of releases of dangerous waste (e.g., wet spots, dead vegetation).

Note: WAC 173-303-320 requires the owner or operator to remedy any deterioration or malfunction he finds. Subsection (7) of this section requires the owner or operator to notify the department within twenty-four hours of confirming a leak. Also, 40 CFR Part 302 may require the owner or operator to notify the National Response Center of a release."

\section{REQUIREMENT SOURCE: WAC-173-303(940523) Section 640( G)(c)}

"The owner or operator must inspect cathodic protection systems, if present, according to, at a minimum, the following schedule to ensure that they are functioning properly:

(i) The proper operation of the cathodic protection system must be confirmed within six months after initial installation and annually thereafter; and

(ii) All sources of impressed current must be inspected and/or tested, as appropriate, at least bimonthly (i.e., every other month).

Note: The practices described in the National Association of Corrosion Engineers (NACE) standard, "Recommended Practice (RP-02-85)--Control of External Corrosion on Metallic Buried, Partially Buried, or Submerged Liquid Storage Systems, " and the American Petroleum Institute (API) Publication 1632, "Cathodic Protection of Underground Petroleum Storage Tanks and Piping Systems, " may be used, where applicable, as guidelines in maintaining and inspecting cathodic protection systems."

\section{REQUIREMINT SOURCE: WAC-173-303(940523) Section 640( 6)(d)}

"The owner or operator must document in the operating record of the facility an inspection of those items in (a) through (c) of this subsection. The owner or operator shall keep an inspection log including at least the date and time of the inspection, the printed name and the handwritten signature of the inspector, a notation of the observations made and the date and nature of any repairs or remedial actions taken. The log must be kept at the facility for at least five years from the date of inspection."

\section{REQUIREMENT SOURCE: WAC-173-360 Section 300}

"Performance standards for deferred UST systems. In order to prevent releases due to structural failure, corrosion, or spills and overfills for as long as the UST system is used to store regulated substances, no person may install a deferred UST system listed in WAC 173-360-110 (3) for the purpose of storing regulated substances unless the UST system (whether of single-wall or double-wall construction):

(1) Will prevent releases due to corrosion or structural failure for the operational life of the UST system;

(2) Is cathodically protected against corrosion, constructed of noncorrodible material, steel clad with a noncorrodible material, or designed in a manner to prevent the release or threatened release of any stored substance; and 
(3) Is constructed or lined with material that is compatible with the stored substance.

Note: The provisions of WAC 173-360-305 and EPA's publication The Interim Prohibition: Guidance for Design and Installation of Underground Storage Tanks may be used to satisfy the requirements of this section."

\section{REQUIREMINT SOURCE: WAC-173-360 Section 305(1)(b),(2)(b)}

"Performance Standards for Cathodic Protection

If the tank and/or piping (1) routinely contains regulated substances, (2) is in contact with the ground, and (3) is constructed of steel (e.g., not of fiberglass-reinforced plastic or of a steel-fiberglass-reinforced-plastic composite), then it must be cathodically protected in the following manner:

(i) The tank and/or piping is coated with a suitable dielectric material;

(ii) The tank is equipped with a factory-installed or field-installed cathodic protection system designed by a corrosion expert, and field-installed cathodic protection systems for piping are designed by a corrosion expert;

(iii) Cathodic protection systems are designed and installed to include provisions for testing to allow a determination of current operating status as required in WAC 173-360-320(2) and to facilitate testing by Ecology or delegated agency in accordance with WAC 173-360-325 (5) and (6); and

(iv) Cathodic protection systems are operated and maintained in accordance with WAC 173-360-320, or according to guidelines established by Ecology or delegated agency, or the codes and standards listed in WAC 173-360-305 (1)(b)"

\section{REQUIREMENT SOURCE: WAC-173-360 Section 305(3)(a),(b)}

"Spill and Overflow Prevention Equipment

Unless the UST system is filled by transfers of less than 25 gallons at one time, or Ecology-approved alternative equipment is used, then owners and operators will use the following spill and overfill prevention equipment to prevent spilling and overfilling associated with transfer of regulated substances to the UST system:

(i) Spill prevention equipment that will prevent the release of regulated substances to the environment when the transfer hose is detached from the fill pipe (for example, a spill catchment basin); and

(ii) Overfill prevention equipment that will:

(A) Automatically shut off flow into the tank when the tank is no more than $95 \%$ full;

(B) Alert the transfer operator when the tank is no more than $90 \%$ full by restricting the flow into the tank or triggering a high-level alarm; or

(C) Restrict flow thirty minutes prior to overfilling, alert the operator with a high-level alarm one minute before overfilling, or automatically shut off flow into the tank so that none of the fittings located on top of the tank are exposed to regulated substances due to overfilling. 
Note: Overflow prevention equipment that will automatically shut off or restrict flow into the tank should not be used where a pressurized fuel transfer system may be employed since an overflow may occur when the flow is suddenly shut off or restricted."

\section{REQUIREMENT SOURCE: WAC-173-360 Section 323}

"Compatibility. Owners and operators shall use an UST system made of or lined with materials that are compatible with and impermeable to the substance stored in the UST system.

Note: Owners and operators storing alcohol blends may use the following codes to comply with the requirements of this section:

(1) American Petroleum Institute Publication 1626, "Storing and Handling Ethanol and Gasoline-Ethanol Blends at Distribution Terminals and Service Stations"; and

(2) American Petroleum Institute Publication 1627, "Storage and Handling of Gasoline-Methanol/Cosolvent Blends at Distribution Terminals and Service Stations. " "

\section{REQUIREMENT SOURCE: WAC-173-360 Section 325 Introduction}

"Owners and operators of UST systems shall ensure that repairs will prevent releases due to structural failure or corrosion as long as the UST system is used to store regulated substances. Any UST system which is repaired to correct a structural defect must also be upgraded at the time of the time of the repair to meet the requirements specified in WAC 173-360-310 (1)(a) or (b), and must employ a method of release detection for the tank as specified in WAC 183-360-335, 173-360-340 or 173-360-345, as applicable, and a method of release detection for the piping as specified in WAC 173-360-350. The repairs shall meet the following requirements:"

\section{REQUIREMENT SOURCE: WAC-173-360 Section 325(1)}

"Repairs to UST systems shall be properly conducted by a licensed tank services provider in accordance with a code of practice developed by a nationally recognized association or an independent testing laboratory.

Note: The following codes and standards may be used to comply with subsection (1) of this section: National Fire Protection Association Standard 30, "Flammable and Combustible Liquids Code"; American Petroleum Institute Publication 2200, "Repairing Crude Oil, Liquified Petroleum Gas, and Product Pipelines"; American Petroleum Institute Publication 1631, "Recommended Practice for the Interior Lining of Existing Steel Underground Storage Tanks"; and National Leak Prevention Association Standard 631, "Spill Prevention, Minimum 10 Year Life Extension of Existing Steel Underground Tanks by Lining Without the Addition of Cathodic Protection. ${ }^{n "}$

\section{REQUIREMENT SOURCE: WAC-173-360 Section 325(3)}

"Metal pipe sections and fittings that have released regulated substances as a result of corrosion or other damage shall be replaced. Fiberglass pipes and fittings may be repaired in accordance with the manufacturer's specifications." 


\section{REQUIREMENT SOURCE: WAC-173-360 Section 325(4)}

"Repaired tanks and piping shall be tightness tested in accordance with WAC 173-360-345 (6)(d) and 173-360-350 (3)(b) within thirty days following the date of the completion of the repair except as provided in subsection (4) (a) through (c), of this section:

(a) The repaired tank is internally inspected in accordance with a code of practice developed by a nationally recognized association or an independent testing laboratory; or

(b) The repaired portion of the UST system is monitored monthly for releases in accordance with a method specified in WAC 173-360-345 (6)(e) through (6)(i); or

(c) Another test method is used that is determined by the department or delegated agency to be no less protective of human health and the environment than those listed above. "

\section{REQUIREMINT SOURCE: WAC-173-360 Section 325(5)}

"Except as specified in subsection (6) of this section, within six months following the repair of any cathodically protected UST system, the cathodic protection system shall be tested in accordance with WAC 173-360-320 (2) and (3) to ensure that it is operating properly."

\section{REQUIREMENT SOURCE: WAC-173-360 Section 325(6)}

"Any repair to a cathodic protection system shall be tested in accordance with WAC 173-360-320 (2) and (3), at the time of the repair and again between one and six months following the repair."

\section{REQUIREMENT SOURCE: WAC-173-360 Section 325(7)}

"UST system owners and operators shall maintain records of each repair for the remaining operating life of the UST site that demonstrate compliance with the requirements of this section."

\section{REQUIREMINT SOURCE: WAC-173-360 Section 325(8)}

"Tank services providers who perform any of the tank services described in this section shall certify that such services comply with the requirements of this section by submitting the appropriate checklist(s) to the department in accordance with WAC 173-360-630 (12)."

\section{REQUIREMENT SOURCE: WAC-173-360 Section 335}

"Release Detection For Petroleum UST Systems

(1) Owners and operators of new and existing petroleum UST systems shall provide a method, combination of methods, of release detection that:

(a) Can detect a release from any portion of the tank and the connected underground piping that routinely contains a regulated substance;

(b) Is installed, calibrated, operated, and maintained in accordance with the manufacturer's instructions, including routine maintenance and service checks for operability or running condition; and

(c) Meets the performance requirements in WAC $173-360-345$ or $173-360-350$. 
(2) Owners and operators of petroleum UST systems shall monitor tanks and piping for releases as follows:

(a) Tanks. Tanks shall be monitored at least every thirty days for releases using one of the methods listed in WAC 173-360-345(6)(e) through (6)(i) except as provided in WAC $173-360-345(2)$ through (5).

(b) Piping. Underground piping that routinely contains regulated substances shall be monitored for releases as required under WAC 173-360-350.

(3) Owners and operators of any existing UST system that cannot apply a method of release detection that complies with the applicable requirements of WAC 173-360-330 through 173-360-355 shall complete the closure procedures in WAC 173-360-380 through 173-360-398 by the date on which release detection is required for that UST system under WAC 173-360-330.

\section{REQUIREMENT SOURCE: WAC-173-360 Section 345(1)}

"Any method of release detection for tanks shall meet the performance requirements of this section. In addition, methods used after December 22, 1990, except for methods permanently installed prior to that date, shall be capable of detecting the leak rate or quantity specified for that method in subsection (6)(b), (c), (d), and (e) of this section with a probability of detection of 0.95 and a probability of false alarm of 0.05 . (That is, under test conditions, a method will correctly detect at least ninety-five of one hundred actual releases, and will falsely indicate a release no more than five times in one hundred tests of nonleaking systems.)

Note: The establishment of leak indication thresholds is a means of setting a standard for the equipment or method used. It is not in any way meant to imply that actual leak rates less than these limits are allowable. No release is acceptable, and any indication that a release may have occurred should be investigated in accordance with WAC 173-360-360. Manufacturers and tank services providers installing or utilizing leak detection equipment and/or methods are encouraged to follow EPA's standard test procedures for evaluating leak detection methods to demonstrate compliance with the requirements of subsection (1) of this section."

\section{REQUIREMENT SOURCE: WAC-173-360 Section 345(6)(a)}

"Daily inventory control. Daily inventory control (or another test of equivalent performance) shall be conducted in a manner capable of detecting a release of at least 1.0 percent of flow-through plus 130 gallons on a monthly basis in the following manner:

(i) Inventory volume measurements for regulated substance inputs, withdrawals, and the amount still remaining in the tank are recorded each operating day;

(ii) The equipment used is capable of measuring the level of regulated substance in the tank over the full range of the tank's height to the nearest one-eighth of an inch;

(iii) The regulated substance inputs are reconciled with delivery receipts by measurement of the tank inventory volume before and after delivery;

(iv) Deliveries are made through a drop tube that extends to within one foot of the tank bottom;

(v) Dispensing of regulated substances is metered and recorded within the local standards for meter calibration or an accuracy of at least six cubic inches for every five gallons of regulated substances which is withdrawn; and 
(vi) The measurement of any water level in the bottom of the tank is made to the nearest one-eighth of an inch at least once a month.

Note: Practices described in the American Petroleum Institute Publication 1621,

"Recommended Practice for Bulk Liquid Stock Control at Retail Outlets," may be used, where applicable, as guidance in meeting the requirements of this paragraph."

\section{REQUIREMENT SOURCE: WAC-173-360 Section 345(6)(b)}

"Weekly tank gauging. Only tanks of one thousand gallons or less nominal capacity may use weekly tank gauging as the sole method of release detection. Tanks of one thousand to two thousand gallons may use the method in place of daily inventory control in (a) of this subsection, in conjunction with tank tightness testing, as specified in (d) of this subsection. Tanks of greater than two thousand gallons nominal capacity may use this method to meet the requirements of WAC 173-360-330 through 173-360-355 only if such tanks store fuel solely for use by emergency power generators. Weekly tank gauging shall meet the following requirements:

(i) Tank liquid level measurements are taken weekly at the beginning and ending of a period of at least thirty-six hours during which no liquid is added to or removed from the tank;

(ii) Level measurements are based on an average of two consecutive stick readings at both the beginning and ending of the period (that is, four measurements shall be taken, two consecutive measurements at the beginning and two consecutive measurements at the end of the period during which no liquid has been added or removed from the tank);

(iii) The equipment used is capable of measuring the level of regulated substance in the tank over the full range of the tank's height to the nearest one-eighth of an inch;

(iv) If the variation between beginning and ending measurements exceeds the weekly or monthly standards in the following table, a leak may be occurring and the requirements of WAC 173-360-360 through 173-360-375 shall be followed:

$\begin{array}{llc}\text { Nominal/ } & \text { Weekly Standard/ } & \text { Monthly Standard } \\ \text { Tank Capacity/ } & \text { (one test)/ } & 5 \text { gallons } \\ 550 \text { gallons or less/ } & 10 \text { gallons/ } & 7 \text { gallons } \\ 551-1,000 \text { gallons/ } & 13 \text { gallons/ } & 13 \text { gallons } \\ 1,001-2,000 \text { gallons/ } & 26 \text { gallons/ } & .5 \% \text { of capacity }\end{array}$

(*Emergency Power Generator Tanks only.)"

\section{REQUIREMENT SOURCE: WAC-173-360 Section 345(6)(c)}

"Monthly tank gauging. Only tanks that store fuel solely for use by emergency power generators with a nominal capacity of two thousand gallons or less may use monthly tank gauging as a method of release detection. Such tanks with nominal capacity of five hundred fifty-one to two thousand gallons shall also have an annual tank tightness test conducted in accordance with (d) of this subsection. Monthly tank gauging shall meet the following requirements:

(i) Inventory volume measurements for regulated substance inputs, withdrawals, and the amount still remaining in the tank are recorded whenever inputs or withdrawals occur; 
(ii) Tank liquid level measurements reconciled with inventory volume measurements are taken monthly at the beginning and ending of a period of at least twenty-one days, except when extreme snowfall or other travel obstructions occurring in remote locations and preventing access are specifically documented by the owner and operator;

(iii) Level measurements are based on an average of two consecutive readings at both the beginning and ending of the period (that is, four measurements shall be taken, two consecutive measurements at the beginning and two consecutive measurements at the end of the period);

(iv) The equipment used is capable of measuring the level of regulated substance in the tank over the full range of the tank's height to the nearest one-eighth of an inch or a corresponding amount of gallons;

(v) The measurement of any water level in the bottom of the tank is made to the nearest one-eighth of an inch at least once a month;

(vi) If the variation between beginning and ending measurements exceeds the monthly standard in the following table, a leak may be occurring and the requirements of WAC 173-360-360 through 173-360-375 shall be followed:

Nominal Tank Capacity Monthly Standard (average of four tests)

550 gallons or less

$551-1,000$ gallons

$1,001-2,000$ gallons
5 gallons

7 gallons

13 gallons"

\section{REQUIREMINT SOURCE: WAC-173-360 Section 345(6)(d)}

"Tank tightness testing. Tank Tightness testing (or another test of equivalent performance) shall be capable of detecting at least a 0.1 gallon per hour leak rate from any portion of the tank that routinely contains a regulated substance while accounting for the effects of thermal expansion or contraction of the regulated substance, vapor pockets, tank deformation, evaporation or condensation, and the location of the water table."

\section{REQUIREMENT SOURCE: WAC-173-360 Section 345(0)(e)}

"Automatic tank gauging. Equipment for automatic tank gauging that tests for the loss of regulated substance and conducts inventory control shall meet the following requirements:

(i) The automatic product level monitor test can detect at least a 0.2 gallon per hour leak rate from any portion of the tank that routinely contains a regulated substance; and

(ii) Daily inventory control (or another test of equivalent performance) is conducted in accordance with the requirements of (a) of this subsection."

\section{REQUIREMENT SOURCE: WAC-173-360 Section 345(6)(f)}

"Vapor monitoring. Testing or monitoring for vapors within the soil gas of the excavation zone shall meet the following requirements:

(i) The materials used as backfill are sufficiently porous (e.g., gravel, sand, crushed rock) to readily allow diffusion of vapors from releases into the excavation area; 
(ii) The stored regulated substance, or a tracer compound placed in the tank system, is sufficiently volatile (e.g., gasoline) to result in a vapor level that is detectable by the monitoring devices located in the excavation zone in the event of a release from the tank;

(iii) The measurement of vapors by the monitoring device is not rendered inoperative by the ground water, rainfall, or soil moisture or other known interferences so that a release could go undetected for more than thirty days;

(iv) The level of background contamination in the excavation zone will not interfere with the method used to detect releases from the tank;

(v) The vapor monitors are designed and operated to detect any significant increase in concentration above background of the regulated substance stored in the tank system, a component or components of that substance, or a tracer compound placed in the tank system;

(vi) In the UST excavation zone, the site is evaluated for its appropriateness for installation of vapor monitors to ensure compliance with the requirements of this subsection and to establish the number and positioning of monitoring wells that will detect releases within the excavation zone from any portion of the tank that routinely contains a regulated substance; and

(vii) Monitoring wells are clearly marked and secured to avoid unauthorized access and tampering.

Note: Monitoring wells must also comply with the minimum standards for construction, maintenance, and abandonment of wells specified in chapter 173-160 WAC."

\section{REQUIREMIENT SOURCE: WAC-173-360 Section 345(6)(g)}

"Ground water monitoring. Testing or monitoring for liquids on or in the ground water shall meet the following requirements:

(i) The regulated substance stored is immiscible in water and has a specific gravity of less than one;

(ii) Ground water is never more than twenty feet from the ground surface and the hydraulic conductivity of the soil(s) between the UST system and the monitoring wells or devices is not less than $0.01 \mathrm{~cm} / \mathrm{sec}$ (e.g., the soil should consist of gravels, coarse to medium sands, coarse silts or other permeable materials);

(iii) The slotted portion of the monitoring well casing shall be designed to prevent migration of natural soils or filter pack into the well and to allow entry of regulated substance on the water table into the well under both high and low ground-water conditions;

(iv) Monitoring wells shall be sealed from the ground surface to the top of the filter pack;

(v) Monitoring wells or devices intercept the excavation zone or are as close to it as is technically feasible;

(vi) The continuous monitoring devices or manual methods used can detect the presence of at least one-eighth of an inch of free product on top of the ground water in the monitoring wells;

(vii) Within and immediately below the UST system excavation zone, the site is evaluated for its appropriateness for installation of ground water monitors to ensure compliance with the requirements in $(\mathrm{g})(\mathrm{i})$ through $(\mathrm{v})$ of this subsection and to establish the number and 
positioning of monitoring wells or devices that will detect releases from any portion of the tank that routinely contains a regulated substance; and

(viii) Monitoring wells are clearly marked and secured to avoid unauthorized access and tampering.

Note: Monitoring wells must also comply with the minimum standards for construction, maintenance, and abandonment of wells specified in chapter 173-160 WAC."

\section{REQUIREMENT SOURCE: WAC-173-360 Section 345(6)(h)}

"Interstitial monitoring. Interstitial monitoring between the UST system and a secondary barrier immediately around or beneath it may be used, but only if the system is designed, constructed and installed to detect a leak from any portion of the tank that routinely contains a regulated substance and also meets one of the following requirements:

(i) For double-walled UST systems, the sampling or testing method can detect a release through the inner wall in any portion of the tank that routinely contains a regulated substance;

Note: The provisions outlined in the Steel Tank Institute's "Standard for Dual Wall Underground Storage Tanks" may be used as guidance for aspects of the design and construction of underground steel double-walled tanks.

(ii) For UST systems with a secondary barrier within the excavation zone, the sampling or testing method used can detect a release between the UST system and the secondary barrier;

(A) The secondary barrier around or beneath the UST system consists of artificially constructed material that is sufficiently thick and impermeable (at least $10^{\wedge}-6 \mathrm{~cm} / \mathrm{sec}$ for the regulated substance stored) to direct a release to the monitoring point and permit its detection;

(B) The barrier is compatible with the regulated substance stored so that a release from the UST system will not cause a deterioration of the barrier allowing a release to pass through undetected;

(C) For cathodically protected tanks, the secondary barrier shall be installed so that it does not interfere with the proper operation of the cathodic protection system;

(D) The ground water, soil moisture, or rainfall will not render the testing or sampling method used inoperative so that a release could go undetected for more than thirty days;

(E) The site is evaluated for its appropriateness for installation of interstitial monitors to ensure that the secondary barrier is always above the ground water and not in a twenty-five-year flood plain, unless the barrier and monitoring designs are for use under such conditions; and

(F) Monitoring wells are clearly marked and secured to avoid unauthorized access and tampering.

(iii) For tanks with an internally fitted liner, an automated device can detect a release between the inner wall of the tank and the liner, and the liner is compatible with the substance stored."

\section{REQUIREMENT SOURCE: WAC-173-360 Section 345(0)(j)}

"Other methods. Any other type of release detection method, or combination of methods, can be used if: 
(i) It can detect a 0.2 gallon per hour leak rate or a release of one hundred fifty gallons within a month with a probability of detection of 0.95 and a probability of false alarm of 0.05 ; or

(ii) The department or delegated agency may approve another method if the owner and operator can demonstrate that the method can detect a release as effectively as any of the methods allowed in (d) through (i) of this subsection. In comparing methods, the department or delegated agency shall consider the size of release that the method can detect and the frequency and reliability with which it can be detected. If the method is approved, the owner and operator shall comply with any conditions imposed by the department or delegated agency on its use to ensure the protection of human health and the environment."

\section{REQUIREMINT SOURCE: WAC-173-360 Section 350(1)}

"Any method of release detection for piping shall meet the performance requirements of this section, with any performance claims and their manner of determination described in writing by the equipment manufacturer or installer. In addition, methods used after December 22, 1990, except for methods permanently installed prior to date, shall be capable of detecting the leak rate or quantity specified for that method in subsection (3)(a) and (b) of this section and with a probability of detection of 0.95 and a probability of false alarm of 0.05 . (That is, under test conditions, a method will correctly detect at least ninety-five of one hundred actual releases, and will falsely indicate a release no more than five times in one hundred tests of nonleaking systems.)"

\section{REQUIREMENT SOURCE: WAC-173-360 Section 350(2)(b)}

"Suction piping. Underground piping that conveys regulated substances under suction shall either have a line tightness test conducted at least every three years and in accordance with subsection (3)(b) of this section, or use a monthly monitoring method conducted in accordance with subsection $(3)(c)$ of this section. No release detection is required for suction piping that is designed and constructed to meet the following standards:

(i) The below-grade piping operates at less than atmospheric pressure;

(ii) The below-grade piping is sloped so that the contents of the pipe will drain back into the storage tank if the suction is released;

(iii) Only one check valve is included in each suction line;

(iv) The check valve is located below and as close as practical to the suction pump; and

(v) A method is provided that allows compliance with subsection (2)(b)(ii) through (iv) of this section to be readily determined."

\section{REQUIREMENT SOURCE: WAC-173-360 Section 350(3)}

"Each method of release detection for piping used to meet the requirements of WAC 173-360-335 shall be conducted in accordance with the following:

(a) Automatic line leak detectors. Methods which alert the operator to the presence of a leak by restricting or shutting off the flow of regulated substances through piping or triggering an audible or visual alarm may be used only if they detect leaks of three gallons per hour at ten pounds per square inch line pressure within one hour. An annual test of the operation of the leak detector shall be conducted in accordance with the manufacturer's requirements. 
(b) Line tightness testing. A periodic test of piping may be conducted only if it can detect 0.1 gallon per hour leak rate at one and one-half times the operating pressure.

(c) Applicable tank methods. Any of the methods in WAC 173-360-345(6)(f) through (i) may be used if they are designed to detect a release from any portion of the underground piping that routinely contains regulated substances."

\section{REQUIREMENT SOURCE: WAC-173-360 Section 370(1)}

"System test. Owners and operators shall have a licensed tank services provider conduct tests (according to the requirements for tightness testing in WAC 173-360-345 (6)(d) and 173-360-350 (3)(b)) that determine whether a leak exists in any portions of the UST system that routinely contains a regulated substance, including the tank and the attached delivery piping, and in any connected tanks and piping that may or may not be in use. All such portions shall be tested either separately or together or in combinations thereof.

(a) Owners and operators shall have a licensed tank services provider repair, replace, upgrade, or close the UST system, and shall begin corrective action in accordance with WAC

173-360-399 if the test results for the system, tank, or delivery piping indicate that a leak exists.

(b) Further investigation is not required if the test results for the system, tank, and delivery piping do not indicate that a leak exists and if environmental contamination is not the basis for suspecting a release.

(c) Owners and operators shall conduct a site check in accordance with subsection (2) of this section if the test results for the system, tank, and delivery piping do not indicate that a leak exists but environmental contamination is the basis for suspecting a release."

\section{REQUIREMENT SOURCE: WAC-173-360 Section 370(2)}

"Site check. Owners and operators shall have a person registered by the department to perform site assessments, as specified in WAC 173-360-610, sample for the presence of a release. Such samples shall be taken, analyzed, and results reported to the department or delegated agency in accordance with the department's guidance document for site checks and site assessments, or as otherwise directed by the department or delegated agency, where contamination is most likely to be present at the UST site.

(a) If the site check results indicate that a release has occurred, owners and operators shall report to the department or delegated agency in accordance with WAC 173-360-372 and begin corrective action in accordance with WAC 173-360-399.

(b) If the site check results do not indicate that a release has occurred, further investigation is not required."

\section{REQUIREMENT SOURCE: WAC-173-360 Section 370(3)}

"Tank services providers who perform any of the tank services described in this section, and persons who perform site checks, shall certify that such services or site checks, as applicable, comply with the requirements of this section by submitting the appropriate checklist(s) to the department in accordance with WAC 173-360-630 (12)." 


\section{REQUIREMINT SOURCE: WAC-173-360 Section 380(1)}

"When an UST system is temporarily closed, owners and operators shall continue operation and maintenance of corrosion protection in accordance with WAC 173-360-320, and any release detection in accordance with WAC 173-360-330 through 173-360-355. WAC 173-360-360 through 173-360-375 and 173-360-399 shall be complied with if a release is suspected or confirmed. However, release detection is not required as long as the UST system is empty. The UST system is empty when all materials have been removed using commonly employed practices so that no more than 2.5 centimeters (one inch) of residue, or 0.3 percent by weight of the total capacity of the UST system, remain in the system."

\section{REQUIREMINT SOURCE: WAC-173-360 Section 380(2)}

"When an UST system is temporarily closed for three months or more, owners and operators shall also comply with the following requirements:

(a) Leave vent lines open and functioning; and

(b) Cap and secure all other lines, pumps, entryways, and ancillary equipment."

\section{REQUIREMINT SOURCE: WAC-173-360 Section 380(3)}

"Any UST system temporarily closed for three months or more shall be tightness tested by a licensed tank services provider in accordance with WAC 173-360-345 (6)(d) and 173-360-350 (3)(b) prior to being put back into service unless the system is subject to and in compliance with the release detection requirements of WAC 173-360-330."

\section{REQUIREMENT SOURCE: WAC-173-360 Section 380(4)}

"When an UST system is temporarily closed for more than twelve months, owners and operators shall have a licensed tank services provider permanently close the UST system if it does not either meet the performance standards in WAC 173-360-305 for new UST systems or the upgrading requirements in WAC 173-360-310 (2) and (3). Such UST systems shall be permanently closed in accordance with WAC 173-360-385 through 173-360-398 at the end of the twelve-month period unless the department or delegated agency provides an extension before expiration of the twelve-month temporary closure period. Owners and operators shall have a site assessment completed in accordance with WAC 173-360-390 before such an extension is applied for."

\section{REQUIREMENT SOURCE: WAC-173-360 Section 380(5)}

"Tank services providers who perform any of the tank services described in this section, and persons who perform site assessments, shall certify that such services and site assessments, as applicable, comply with the requirements of this chapter by submitting the appropriate checklist(s) to the department in accordance with WAC 173-360-630 (12)."

\section{REQUIREMENT SOURCE: WAC-173-360 Section 385(1)}

"At least thirty days before beginning either permanent closure or a change-in-service under subsections (2) and (3) of this section, or within another reasonable time period determined by the department or delegated agency, owners and operators shall notify the department or delegated agency in writing of their intent to permanently close or make the change-in-service, unless such action is in response to corrective action. The site assessment required under WAC 173-360-390 shall be performed after notifying the department or delegated agency but before completion of the permanent closure or a change-in-service." 


\section{REQUIREMENT SOURCE: WAC-173-360 Section 385(2)}

"Permanent closure shall be completed by a licensed tank services provider within sixty days after expiration of the thirty-day notice, unless a written request for an extension, explaining the reason for the request, is approved by the department or delegated agency. Any UST system not permanently closed by a compliance date that the UST system is subject to, shall be in compliance with the requirement associated with the compliance date, including the payment of fees. Any UST system not in compliance with any such requirement will be subject to the penalties described in WAC 173-360-170."

\section{REQUIREMENT SOURCE: WAC-173-360 Section 385(3)}

"To permanently close an UST system, the tank services provider shall empty and clean the tank by removing all liquids and accumulated sludges.

Note: Any sludges removed must also be designated and disposed of in accordance with chapter 173-303 WAC."

\section{REQUIREMENT SOURCE: WAC-173-360 Section 385(4)}

"All tanks taken out of service permanently shall also be either removed from the ground or filled with an inert solid material. All piping shall either be capped (except any vent lines) or removed from the ground."

\section{REQUIREMENT SOURCE: WAC-173-360 Section 385(6)}

"Owners and operators are responsible for submitting checklists for any of the tank services described in this section. Any active tank permits for the systems being closed shall be returned to the department within thirty days of closure activities."

\section{REQUIREMINT SOURCE: WAC-173-360 Section 390(1)}

"Before permanent closure or a change-in-service is completed, except as specified in subsections (2), (3), and (4) of this section, owners and operators shall have a person registered by the department to perform site assessments, as specified in WAC 173-360-610, sample for the presence of a release. Such samples shall be taken, analyzed, and the results reported to the department or delegated agency in accordance with the department's guidance document for site assessments, or as otherwise directed by the department or delegated agency, where contamination is most likely to be present at the UST site."

\section{REQUIREMENT SOURCE: WAC-173-360 Section 390(4)}

"If contaminated soils, contaminated ground water, or free product is discovered under subsection (1) of this section, or by any other manner, owners and operators shall report to the department or delegated agency in accordance with WAC 173-360-372 and take appropriate action in accordance with WAC 173-360-399."

\section{REQUIREMENT SOURCE: WAC-173-360 Section 390(5)}

"Persons who perform site assessments shall certify that such site assessments comply with the requirements of this section by submitting the appropriate checklist to the department in accordance with WAC 173-360-630 (12)." 


\section{REQUIREMENT SOURCE: WAC-173-360 Section 399}

"Corrective action requirements. Except as provided in WAC 173-360-375, upon confirmation of a release in accordance with WAC 173-360-370 or 173-360-390, or after a release from the UST system is identified in any other manner, owners and operators shall immediately undertake appropriate measures in accordance with chapter 173-340 WAC and/or this chapter, and any additional measures as directed by the department under chapter $90.48 \mathrm{RCW}$. Owners and operators shall also report such releases to the department or delegated agency within twenty-four hours in accordance with WAC 173-360-372."

\section{REQUIREMENT SOURCE: WAC-173-360(950131) Section 340(1)}

"Release detection at existing hazardous substance UST systems shall meet the requirements for petroleum UST systems in WAC 173-360-335. By December 22, 1998, all release detection requirements for new systems in subsection (2) of this section."

\section{REQUIREMENT SOURCE: WAC-173-360(950131) Section 340(2) Introduction}

"Release detection at new hazardous substance UST systems shall employ some method of release containment such as secondary containment systems, double-walled tanks, or external liners (e.g., in a pit or excavation). Such methods shall meet the following requirements: "

\section{REQUIREMINT SOURCE: WAC-173-360(950131) Section 340(2)(a)}

"Secondary containment systems shall be designed, constructed and installed to:

(i) Contain regulated substances released from the tank system until they are detected and removed;

(ii) Prevent precipitation and ground water from entering the external liner and prevent the release of regulated substances to the environment at any time during the operational life of the UST system; and

(iii) Be checked for evidence of a release at least every thirty days."

\section{REQUIREMENT SOURCE: WAC-173-360(950131) Section 340(2)(b)}

"Double-walled tanks shall be designed, constructed, and installed to:

(i) Contain a release from any portion of the inner tank within the outer wall; and

(ii) Detect the failure of the inner wall."

\section{REQUIREMENT SOURCE: WAC-173-360(950131) Section 340(2)(c)}

"External liners (including vaults) shall be designed, constructed, and installed to:

(i) Contain one hundred percent of the capacity of the largest tank within its boundary;

(ii) Prevent the interference of precipitation or groundwater intrusion with the ability to contain or detect a release of regulated substances; and

(iii) Surround the tank completely (i.e., it is capable of preventing lateral as well as vertical migration of regulated substances)." 


\section{REQUIREMENT SOURCE: WAC-173-360(950131) Section 340(2)(d)}

"Underground piping shall be equipped with secondary containment that satisfies the requirements of subsection (2)(a) of this section (e.g., trench liners, jacketing of double-walled pipe). In addition, underground piping that conveys regulated substances under pressure shall be equipped with an automatic line leak detector in accordance with WAC 173-360-350 (3)(a)."

\section{REQUIREMENT SOURCE: WAC-173-360(950131) Section 345( 6)(i)}

"Statistical inventory reconciliation. Statistical inventory reconciliation (SIR) shall meet the following requirements:

(i) Statistical inventory reconciliation must detect at least a 0.2 gallon per hour leak rate from any portion of the tank that routinely contains a regulated substance with a probability of detection of at least 0.95 and a probability of false alarm of no more than 0.05 ; and

(ii) Daily inventory control must be performed in accordance with the requirements of (a) of this subsection; and

(iii) Owners and operators must submit daily inventory records from at least the previous thirty days on a monthly basis to a SIR vendor whose statistical analysis method has been demonstrated to meet the performance standard of (i) of this subsection; and

(iv) The SIR vendor must perform an independent SIR analysis on the daily inventory records submitted and report the results to the owner or operator within fifteen days of receiving them; and

(v) If the results of a SIR analysis show a 0.2 gallon per hour or greater leak rate in any single month, from any portion of the tank that routinely contains a regulated substance with a probability of detection of at least 0.95 and a probability of false alarm of no more than 0.05 , it shall be determined to be a "fail. "If an owner or operator receives a "fail" for two consecutive months, the owner or operator shall have a tank tightness test conducted in accordance with (d) of this subsection within fifteen days of receiving the second "fail" from the SIR vendor."

\section{REQUIREMENT SOURCE: WAC-173-360(950131) Section 350( 2)(a)}

"Pressurized piping. Underground piping that conveys regulated substances under pressure shall:

(i) Be equipped with a automatic line leak detector conducted in accordance with subsection (3)(a) of this section; and

(ii) Have an annual line tightness test conducted by a certified UST supervisor in accordance with subsection (3)(b) of this section or have monthly monitoring conducted in accordance with subsection (3)(c) of this section."

\section{REQUIREMENT SOURCE: WAC-173-360(950131) Section 350( 3)(b)}

"Line tightness testing. A periodic test of piping may be conducted only if it can detect a 0.1 gallon per hour leak rate at one and one-half times the operating pressure, or if it can detect a leak rate equal to multiplying 0.1 gallon per hour by the square root of the value obtained by dividing the line pressure during testing by 1.5 times the operating pressure. Line tightness testing shall be conducted and results interpreted and reported in accordance with the 
department's guidance document for tightness testing, or as otherwise directed by the department or delegated agency."

\section{Ouality Assurance}

Author's Note: In accordance with the 5th Amendment to the Hanford Federal Facility Agreement and Consent Order (Tri-Party Agreement) Action Plan, Milestone Number M-45, all units located within the boundaries of Single Shell Tank Farms will be closed pursuant to WAC 173-303-610, including contaminated soil ancillary equipment previously identified as past practice units. Therefore, only citations from Section 6.5 of the TPA are cited.

\section{REQUIREMENT SOURCE: TPA Attachment 2, Section 6.5, Paragraph 1}

\section{"Quality Assurance}

The level of quality assurance and quality control $(\mathrm{QA} / \mathrm{QC})$ for the collection, preservation, transportation, and analysis of each sample which is required for implementation of this Agreement shall be dependent upon the data quality objectives for the sample. Such data quality objectives shall be specified in RCRA closure plans, the RCRA permit, and any other relevant plans that may be used to describe sampling and analyses at RCRA TSD units."

\section{REQUIREMENT SOURCE: TPA Attachment 2, Section 6.5, Paragraph 6}

"For analytical chemistry and radiological laboratories, the QA/QC plans must include the elements listed in "Guidance on Preparation of Laboratory Quality Assurance Plans" (as listed in Appendix F). DOE shall submit laboratory QA/QC plans to EPA and Ecology for review as secondary documents prior to use of that laboratory. In the event that DOE fails to demonstrate to the lead regulatory agency that data generated pursuant to this Agreement was obtained in accordance with the $Q A / Q C$ requirements of this section, including laboratory $\mathrm{QA} / \mathrm{QC}$ plans, DOE shall repeat sampling or analysis as required by the lead regulatory agency. Such action by the lead regulatory agency shall not preclude any other action which may be taken pursuant to this Agreement. For other data, Ecology or EPA may request DOE to provide $\mathrm{QA} / \mathrm{QC}$ documentation. Any such data that does not meet the $\mathrm{QA} / \mathrm{QC}$ standard required by this section shall be clearly flagged and noted to indicate this fact."

\section{ENVIRONMENTAL CONTROL STANDARDS}

Environmental control standards are media- and application-specific limits established for air emission sources, liquid effluent discharges, and waste management activities. Element 20.4 addresses water quality controls (Subelement 20.4.1), air quality controls (Subelement 20.4.2), and radiological effluent controls (Subelement 20.4.3) applicable to the Tank Farms.

\section{REQUIREMENT SOURCE: 40CFR355 Part 30(e)}

"Calculations of TPQs for solid and mixtures.

(1) If a container or storage vessel holds a mixture or solution of an extremely hazardous substance, then the concentration of extremely hazardous substance, in weight percent (greater than $1 \%$ ), shall be multiplied by the mass (in pounds) in the vessel to determine the actual quantity of extremely hazardous substance therein.

(2) (i) Extremely hazardous substances that are solids are subject to either of two threshold planning quantities as shown on Appendices A and B (i.e., 500/10,000 pounds). The lower quantity applies only if the solid exists in powdered form and has a particle size less than 100 microns; or is handled in solution or in molten form; or meets the criteria for a National Fire Protection Association (NFPA) rating of 2, 3 or 4 for reactivity. If the solid does not meet 
any of these criteria, it is subject to the upper $(10,000$ pound) threshold planning quantity as shown in Appendices A and B.

(ii) The 100 micron level may be determined by multiplying the weight percent of solid with a particle size less than 100 microns in a particular container by the quantity of solid in the container.

(iii) The amount of solid in solution may be determined by multiplying the weight percent of solid in the solution in a particular container by the quantity of solution in the container.

(iv) The amount of solid in molten form must be multiplied by 0.3 to determine whether the lower threshold planning quantity is met."

\section{REQUIREMIENT SOURCE: WAC-173-303(931208) Section 355(2)}

"(2) Appropriate and generally accepted computer models should be utilized to determine the impacts of a potential catastrophic air release due to fire, explosion, or other accidental releases of hazardous constituents. Evacuation plans prepared pursuant to WAC 173-303-350 (3)(d) shall include those effected persons and areas identified through these modelling efforts."

\section{Water Ouality}

Subelement 20.4.1 includes requirements and controls for the protection of groundwater quality. This section includes maximum concentration limits, alternative concentration limits, and requirements for BAT/AKART analyses.

\section{REQUIREMENT SOURCE: WAC-173-200(950131) Section 100(2)}

"No person shall engage in any activity that violates or causes the violation of this chapter."

\section{REQUIREMINT SOURCE: WAC-173-201A(950131) Section 040(1)}

"Toxic substances shall not be introduced above natural background levels in waters of the state which have the potential either singularly or cumulatively to adversely affect characteristic water uses, cause acute or chronic toxicity to the most sensitive biota dependent upon those waters, or adversely affect public health, as determined by the department."

\section{REQUIREMENT SOURCE: WAC-173-201A(950131) Section 160(3)(a)}

"Activities which generate nonpoint source pollution shall be conducted so as to comply with the water quality standards. The primary means to be used for requiring compliance with the standards shall be through best management practices required in waste discharge permits, rules, orders, and directives issued by the department for activities which generate nonpoint source pollution."

\section{REQUIREMENT SOURCE: WAC-173-201A(950131) Section 160(3)(b)}

"Best management practices shall be applied so that when all appropriate combinations of individual best management practices are utilized, violation of water quality criteria shall be prevented. If a discharger is applying all best management practices appropriate or required by the department and a violation of water quality criteria occurs, the discharger shall modify existing practices or apply further water pollution control measures, selected or approved by the department, to achieve compliance with water quality criteria. Best management practices 
established in permits, orders, rules, or directives of the department shall be reviewed and modified, as appropriate, so as to achieve compliance with water quality criteria."

\section{REQUIREMENT SOURCE: WAC-173-201A(950131) Section 160(3)(c)}

"Activities which contribute to nonpoint source pollution shall be conducted utilizing best management practice to prevent violation of water quality criteria. When applicable best management practices are not being implemented, the department may conclude individual activities are causing pollution in violation of RCW 90.48.080. In these situations, the department may pursue orders, directives, permits, or civil or criminal sanctions to gain compliance with the standards."

\section{REQUIREMENT SOURCE: WAC-173-201A(950131) Section 160(3)(d)}

"Activities which cause pollution of storm water shall be conducted so as to comply with the water quality standards. The primary means to be used for requiring compliance with the standards shall be through best management practices required in waste discharge permits, rules, orders, and directives issued by the department for activities which generate storm water pollution. The consideration and control procedures in (b) and (c) of this subsection apply to the control of pollutants in storm water."

\section{Air Ouality}

Subelement 20.4 .2 specifies the standards for emission of particulates, priority pollutants, and toxic chemicals to the atmosphere.

\section{REQUIREMENT SOURCE: WAC-173-400 Section 040 General}

"General standards for maximum emissions. All sources and emissions units are required to meet the emission standards of this chapter. Where an emission standard listed in another chapter is applicable to a specific emissions unit, such standard will take precedent over a general emission standard listed in this chapter. When two or more emissions units are connected to a common stack and the operator elects not to provide the means or facilities to sample emissions from the individual emissions units, and the relative contributions of the individual emissions units to the common discharge are not readily distinguishable, then the emissions of the common stack must meet the most restrictive standard of any of the connected emissions units. Further, all emissions units are required to use reasonably available control technology (RACT) which may be determined for some sources or source categories to be more stringent than the applicable emission limitations of any chapter of Title 173 WAC. Where current controls are determined to be less than RACT, ecology or the authority shall, as provided in section 8, chapter 252, Laws of 1993, define RACT for each source or source category and issue a rule or regulatory order requiring the installation of RACT."

\section{REQUIREMENT SOURCE: WAC-173-400 Section 040(1)}

"(1) Visible emissions. No person shall cause or permit the emission for more than three minutes, in any one hour, of an air contaminant from any emissions unit which at the emission point, or within a reasonable distance of the emission point, exceeds twenty percent opacity except:

(a) When the emissions occur due to soot blowing/grate cleaning and the operator can demonstrate that the emissions will not exceed twenty percent opacity for more than fifteen minutes in any eight consecutive hours. The intent of this provision is to permit the soot blowing and grate cleaning necessary to the operation of boiler facilities. This practice, except 
for testing and trouble shooting, is to be scheduled for the same approximate times each day and ecology or the authority be advised of the schedule.

(b) When the owner or operator of a source supplies valid data to show that the presence of uncombined water is the only reason for the opacity to exceed twenty percent.

(c) When two or more sources are connected to a common stack, ecology or the authority may allow or require the use of an alternate time period if it is more representative of normal operations.

(d) When an alternate opacity limit has been established per RCW 70.94 .331 (2)(c). "

\section{REQUIREMIENT SOURCE: WAC-173-400 Section 040(2)}

"Fallout. No person shall cause or permit the emission of particulate matter from any source to be deposited beyond the property under direct control of the owner(s) or operator(s) of the source in sufficient quantity to interfere unreasonably with the use and enjoyment of the property upon which the material is deposited."

\section{REQUIREMENT SOURCE: WAC-173-400 Section 040(3)}

"Fugitive emissions. The owner or operator of any emissions unit engaging in materials handling, construction, demolition or any other operation which is a source of fugitive emission:

(a) If located in an attainment area and not impacting any nonattainment area, shall take reasonable precautions to prevent the release of air contaminants from the operation.

(b) If the emissions unit has been identified as a significant contributor to the nonattainment status of a designated nonattainment area, shall be required to use reasonable and available control methods, which shall include any necessary changes in technology, process, or other control strategies to control emissions of the contaminants for which nonattainment has been designated."

\section{REQUIREMIENT SOURCE: WAC-173-400 Section 040(4)}

"Odors. Any person who shall cause or allow the generation of any odor from any source which may unreasonably interfere with any other property owner's use and enjoyment of his property must use recognized good practice and procedures to reduce these odors to a reasonable minimum."

\section{REQUIREMENT SOURCE: WAC-173-400 Section 040(5)}

"Emissions detrimental to persons or property. No person shall cause or permit the emission of any air contaminant from any source if it is detrimental to the health, safety, or welfare of any person, or causes damage to property or business."

\section{REQUIREMENT SOURCE: WAC-173-400 Section 040(7)}

"Concealment and masking. No person shall cause or permit the installation or use of any means which conceals or masks an emission of an air contaminant which would otherwise violate any provisions of this chapter." 


\section{REQUIREMINT SOURCE: WAC-173-400 Section 040(8)}

"Fugitive dust sources.

(a) The owner or operator of a source of fugitive dust shall take reasonable precautions to prevent fugitive dust from becoming airborne and shall maintain and operate the source to minimize emissions.

(b) The owner(s) or operator(s) of any existing source(s) of fugitive dust that has been identified as a significant contributor to a PM-10 nonattainment area shall be required to use reasonably available control technology to control emissions. Significance will be determined by the criteria found in WAC 173-400-113(3)."

\section{REQUIREMENT SOURCE: WAC-173-400(950131) Section 115(1)}

"Standards of performance for new sources. Title 40, Code of Federal Regulations, Part 60 (standards of performance for new sources), as in effect on January 1, 1993, is adopted by reference except for sections 60.5 (determination of construction or modification) and 60.6 (review of plans). The term "administrator" in 40 CFR Part 60 shall mean both the administrator of EPA and the director of ecology."

\section{Radiological Effluents}

Subelement 20.4 .3 primarily addresses limits for effluent monitoring and residual contamination to assure that external exposures are within established limits. Although DOE Order $5820.2 \mathrm{~A}$ is current, the exposure limits within the Order have become outdated.

Note: Requirement DOE 5820.2A Chapter III, Section 3.a(2), as located in subelement 16.8.2 in the Waste Management Functional Area document, is also applicable to this subelement.

\section{REQUIREMENT SOURCE: 40CFR61 Part 92}

"Standard. Emissions of radionuclides to the ambient air from Department of Energy facilities shall not exceed those amounts that would cause any member of the public to receive in any year an effective dose equivalent of $10 \mathrm{mrem} / \mathrm{yr}$."

\section{REQUIREMENT SOURCE: 40CFR61 Part 93(a)}

"To determine compliance with the standard, radionuclide emissions shall be determined and effective dose equivalent values to members of the public calculated using EPA approved sampling procedures, computer models CAP-88 or AIRDOS-PC, or other procedures for which EPA has granted prior approval. DOE facilities for which the maximally exposed individual lives within 3 kilometers of all sources of emissions in the facility, may use EPA's COMPLY model and associated procedures for determining dose for purpose of compliance."

\section{REQUIREMENT SOURCE: 40CFR61 Part 93(b)(1) and (2)}

"Radionuclide emission rates from point sources (stacks or vents) shall be measured in accordance with the following requirements or other procedures for which EPA has granted prior approval:

(1) Effluent flow rate measurements shall be made using the following methods:

(i) Reference Method 2 of Appendix A to part 60 shall be used to determine velocity and volumetric flow rates for stacks and large vents. 
(ii) Reference Method 2A of Appendix A to part 60 shall be used to measure flow rates through pipes and small vents.

(iii) The frequency of the flow rate measurements shall depend upon the variability of the effluent flow rate. For variable flow rates, continuous or frequent flow rate measurements shall be made. For relatively constant flow rates only periodic measurements are necessary.

(2) Radionuclides shall be directly monitored or extracted, collected and measured using the following methods:

(i) Reference Method 1 of Appendix A part 60 shall be used to select monitoring or sampling sites.

(ii) The effluent stream shall be directly monitored continuously with an in-line detector or representative samples of the effluent stream shall be withdrawn continuously from the sampling site following the guidance presented in ANSI N13.1-1969 "Guide to Sampling Airborne Radioactive Materials in Nuclear Facilities" (including the guidance presented in Appendix A of ANSI N13.1) (incorporated by reference-see 61.18). The requirements for continuous sampling are applicable to batch processes when the unit is operation. Periodic sampling (grab samples) may be used only with EPA's prior approval. Such approval may be granted in cases where continuous sampling is not practical and radionuclide emission rates are relatively constant. In such cases, grab samples shall be collected with sufficient frequency so as to provide a representative sample of the emissions.

(iii) Radionuclides shall be collected and measured using procedures based on the principles of measurement described on Appendix B, Method 114. Use of methods based on principles of measurement different from those described in Appendix B, Method 114 must have prior approval from the Administrator. EPA reserves the right to approve measurement procedures.

(iv) A quality assurance program shall be conducted that meets the performance requirements described in Appendix B, Method 114."

\section{REQUIREMIENT SOURCE: 40CFR61 Part 93(b)(3)}

"When it is impractical to measure the effluent flow rate at an existing source in accordance with the requirements of paragraph (b)(1) of this section or to monitor or sample an effluent stream at an existing source in accordance with the site selection and sample extraction requirements of paragraph $(b)(2)$ of this section, the facility owner or operator may use alternative effluent flow rate measurement procedures or site selection and sample extraction procedures provided that:

(i) It can be shown that the requirements of paragraph (b) (1) or (2) of this section are impractical for the effluent stream.

(ii) The alternative procedure will not significantly underestimạte the emissions.

(iii) The alternative procedure is fully documented.

(iv) The owner or operator has received prior approval from EPA."

\section{REQUIREMENT SOURCE: 40CFR61 Part 93(b)(4)}

"(i) Radionuclide emission measurements in conformance with the requirements of paragraph (b) of this section shall be made at all release points which have a potential to discharge radionuclides into the air in quantities which could cause an effective dose equivalent in excess 
of $1 \%$ of the standard. All radionuclides which could contribute greater than $10 \%$ of the potential effective dose equivalent for a release point shall be measured. With prior EPA approval, DOE may determine these emissions through alternative procedures. For other release points which have a potential to release radionuclides into the air, periodic confirmatory measurements shall be made to verify the low emissions.

(ii) To determine whether a release point is subject to the emission measurement requirements of paragraph (b) of this section, it is necessary to evaluate the potential for radionuclide emissions for that release point. In evaluating the potential of a release point to discharge radionuclides into the air for the purpose of this section, the estimated radionuclide release rates shall be based on the discharge of the effluent stream that would result if all pollution control equipment did not exist, but the facility operations were otherwise normal."

\section{REQUIREMENT SOURCE: DOE5400.5 Chapter II, Section 1(b)}

"b. Airborne Emissions Only, All DOE Sources of Radionuclides. To the extent required by the Clean Air Act, the exposure of members of the public to radioactive materials released to the atmosphere as a consequence of routine DOE activities shall not cause members of the public to receive, in a year, an effective dose equivalent greater than 10 mrem $(0.1 \mathrm{mSv})$. Exposures to, and releases of, radon-220, radon-222, and their respective decay products are subject to DOE limits (See Figure III-3 and paragraphs IV.4b and IV.6).

(1) Title 40 CFR Part 61. The public dose limits as outlined in paragraph II.1b are established by EPA regulation 40 CFR Part 61, Subpart H, under the authority of the Clean Air Act. These limits apply offsite where the members of the public reside or abide. Subparts Q and $T$ provide radon flux limits for DOE radium storage and disposal facilities (Chapter IV) and DOE inactive uranium mill tailings sites regulated under 40 CFR Part 192.

(2) AIRDOS/RADRISK Codes. To demonstrate compliance analytically with air emissions for the Clean Air Act Standards, doses to the individuals shall be evaluated using the version of AIRDOS/RADRISK known as CAP-88 or, when available and approved, AIRDOS-PC. Other computer codes or models, such as "Comply Code," which are specifically approved in accordance with 40 CFR Part 61, may also be used.

(3) Environmental Measurements. Compliance may also be demonstrated through environmental or effluent measurements using EPA-approved techniques. In this case, the doses estimated are to individuals in areas offsite, where they are assumed to reside at the point of maximum annual air concentration."

\section{REQUIREMENT SOURCE: DOE5400.5 Chapter II, Section 1.c(2)}

"Regulatory Requirements. DOE facilities and operations, in some instances, are subject to the regulatory requirements of the NRC and the EPA, e.g., 20 CFR Parts 60 and 72 and 40 CFR Parts 61, 191, and 192. It is Departmental policy that DOE facilities and operations will comply fully with the requirements of those and other applicable regulatory requirements. In addition, these same DOE facilities and operations shall comply with all applicable requirements in this Order unless they are duplicative or conflict with any of the other Federal regulatory requirements. The resolution of issues concerning duplicative or conflicting requirements will be conducted pursuant to the issue coordination provisions of DOE 5400.2A." 


\section{REQUIREMENT SOURCE: DOE5400.5 Chapter II, Section 6}

"Demonstration of Compliance with Dose Limits. Compliance with the dose limits of this Order shall be demonstrated by documentation of an appropriate combination of measurements and calculations to evaluate potential doses and the results of the evaluations."

\section{REQUIREMENT SOURCE: DOE5400.5 Chapter II, Section 6.a}

"Monitoring and Surveillance. General requirements for routine effluent monitoring are part of the environmental monitoring plan prescribed in DOE 5400.1. Specific requirements for radiological effluent monitoring and environmental surveillance and their schedule of implementation are prescribed in DOE Orders in the 5400 series, which deal with radiological effluent monitoring and environmental surveillance. The monitoring requirements are applicable to all DOE and DOE contractor operations that are subject to the standards and requirements of this Order."

\section{REQUIREMENT SOURCE: DOE5400.5 Chapter II, Section 6.b}

"Dose Evaluations. Doses to members of the public in the vicinity of DOE activities shall be evaluated and documented to demonstrate compliance with the dose limits of this Order and to assess exposures of the public from unplanned events. Collective doses to the public within 80 $\mathrm{km}$ of the site shall also be evaluated and documented at least annually.

(1) Modeling. Analytical models used for dose evaluations shall be appropriate for characteristics of emissions (e.g., gas, liquid, or particle; depositing or nondepositing; buoyant or non-buoyant); mode of release (e.g., stack or vent; crib or pond; surface water or sewer; continuous or intermittent); environmental transport medium (e.g., air or water); and exposure pathway (e.g., inhalation; ingestion of food, water, or milk; direct radiation). Information on dispersion (transport and diffusion) in the environment, demography, land use (including the location and number of dairy and slaughter animals), food supplies, and exposure pathways used in the dose calculations shall be appropriate to evaluate actual and potential doses in the environs of DOE facilities. Such information shall be updated as necessary to document significant changes that could affect dose evaluations. Dose evaluation models that are codified, approved, or accepted by regulatory or other authorities shall be used where appropriate, such as the AIRDOS/RADRISK codes for demonstrating compliance with 40 CFR Part 61, Subpart H.

(2) Dose Conversion Factors. Except as provided in paragraph II.6b(2)(d), tables of approved dose conversion factors in paragraphs II.6b(2)(a), (b), and (c), below, shall be used to evaluate doses unless otherwise legally required, e.g., use of AIRDOS/RADRISK codes pursuant to 40 CFR Part 61, Subpart H.

(a) Committed Dose Conversion Factors. Radionuclides taken into the body, generally by exposure modes whereby the radionuclide is ingested or inhaled, will continue to irradiate the body as long as they exist and are retained by the body. The dose delivered to a body over the lifetime of the individual from a single committed dose conversion factors shall be used, as appropriate, and are presented in EPA-520/1-88-020, Federal Guidance Report No. 11, "Limiting Values of Radionuclide Intake and Air Concentration and Dose Conversion Factors for Inhalation, Submersion, and Ingestion," and in DOE/EH-0071, "Internal Dose Conversion Factors for Calculation of Dose to the Public." These conversion factors are based upon the ICRP reference man model, and the committed dose is the dose integrated over an interval of 50 years.

(b) External Dose Conversion Factors. The doses from exposure to external radiation from radionuclide concentrations in air and in water that result from submersion or from exposure to 
contaminated plane surfaces shall be estimated, as appropriate, using the external dose conversion factors presented in EPA-520/1-88-020, Federal Guidance Report No. 11, "Limiting Values of Radionuclides Intake and Air Concentration and Dose Conversion Factors for Inhalation, Submersion, and Ingestion" and in DOE/EH-0070, "External Dose-Rate Conversion Factors for Calculation of Dose to the Public. ${ }^{n "}$

\section{REQUIREMINT SOURCE: DOE5400.5 Chapter II, Section 6.b(1)}

"Modeling. Analytical models used for dose evaluations shall be appropriate for characteristics of emissions (e.g., gas, liquid, or particle; depositing or non-depositing; buoyant or non-buoyant); mode of release (e.g., stack or vent; crib or pond; surface water or sewer; continuous or intermittent); environmental transport medium (e.g., air or water); and exposure pathway (e.g., inhalation; ingestion of food, water, or milk; direct radiation). Information on dispersion (transport and diffusion) in the environment, demography, land use (including the location and number of dairy and slaughter animals), food supplies, and exposure pathways used in the dose calculations shall be appropriate to evaluate actual and potential doses in the environs of DOE facilities. Such information shall be updated as necessary to document significant changes that could affect dose evaluations. Dose evaluation models that are codified, approved, or accepted by regulatory or other authorities shall be used where appropriate, such as the AIRDOS/RADRISK codes pursuant to 40 CFR Part 61, Subpart H."

\section{REQUIREMENT SOURCE: DOE5400.5 Chapter II, Section 6.b(2)}

"Dose Conversion Factors. Except as provided in Chapter II, 6.b.(2)(d), tables of approved dose conversion factors in Chapter II, 6.b.(2)(a), (b), and (c), below, shall be used to evaluate doses unless otherwise legally required, e.g., use of AIRDOS/RADRISK codes pursuant to 40 CFR Part 61, Subpart H. "

\section{REQUIREMENT SOURCE: DOE5400.5 Chapter II, Section 6.b(2)(a)}

"Committed Dose Conversion Factors. Radionuclides taken into the body, generally by exposure modes whereby the radionuclide is ingested or inhaled, will continue to irradiate the body as long as they exist and are retained by the body. The dose delivered to a body over the lifetime of the individual from a single committed dose conversion factors shall be used, as appropriate, and are presented in EPA-520/1-88-020, Federal Guidance Report No. 11, "Limiting Values of Radionuclide Intake and Air Concentration and Dose Conversion Factors for Inhalation, Submersion, and Ingestion," and in DOE/EH-0071, "Internal Dose Conversion Factors for Calculation of Dose to the Public." These conversion factors are based upon the ICRP reference man model, and the committed dose is the dose integrated over an interval of 50 years. "

\section{REQUIREMENT SOURCE: DOE5400.5 Chapter II, Section 6.b(2)(b)}

"External Dose Conversion Factors. The doses from exposure to external radiation from radionuclide concentrations in air and in water that result from submersion or from exposure to contaminated plane surfaces shall be estimated, as appropriate, using the external dose conversion factors presented in EPA-520/1-88-020, Federal Guidance Report No. 11, "Limiting Values of Radionuclides Intake and Air Concentration and Dose Conversion Factors for Inhalation, Submersion, and Ingestion," and in DOE/EH-0070, "External Dose-Rate Conversion Factors for Calculation of Dose to the Public" 


\section{REQUIREMENT SOURCE: DOE5400.5 Chapter II, Section 6.b(2)(c)}

"Derived Concentration Guides (DCG). DCG values are presented as reference values in Chapter III for each of three exposure modes: inhalation of air containing the radionuclide; submersion in a semi-infinite cloud of air containing the radionuclide; and ingestion of water containing the radionuclide. The DCG tables may be used to evaluate only the three exposure modes upon which they are based."

\section{REQUIREMENT SOURCE: DOE5400.5 Chapter II, Section 6.b(2)(d)}

"Other Methods and Alternatives. Methods and alternatives other than those discussed above and as prescribed in applicable regulations shall be submitted to EH-1 for approval. EH-1 may approve the alternative method, if appropriate."

\section{REQUIREMINT SOURCE: DOE5400.5 Chapter II, Section 6.b(3)(a)}

"Parametric Considerations

(a) Dose limits for members of the general public, from routine operation of a DOE activity, shall be expressed as a dose received by the individuals during the year (if, for example, the exposure is external to the body) or the committed dose received by the individual over a period of 50 years from radionuclides taken into the body during the year. The limits should not be interpreted as dose rates per se, especially not in the sense of instantaneous dose rates."

\section{REQUIREMINT SOURCE: DOE5400.5 Chapter II, Section 6.b(3)(b)}

"Doses calculated should be as realistic as practicable. Consequently, the individuals subject to the greatest exposure shall be identified, to the extent practicable, so that the highest dose might be determined."

\section{REQUIREMENT SOURCE: DOE5400.5 Chapter II, Section 6.b(3)(c)}

"Dose limits apply to actual or committed doses to real individuals. Consequently, all factors germane to dose determination should be applied. Alternatively, if available data are not sufficient to evaluate these factors of if they are too costly to determine, the assumed parametric values shall be sufficiently conservative so that it is unlikely that individuals would actually receive a dose that would exceed the dose calculated using the values assumed."

\section{REQUIREMENT SOURCE: DOE5400.5 Chapter II, Section 6.b(3)(d)}

"Parametric values used in performing dose calculations shall be recorded."

\section{REQUIREMENT SOURCE: DOE5400.5 Chapter II, Section 6.b(3)(e)}

"Collective public dose in the environs of a site with multiple emission points may be estimated using the assumption that all emissions occur from a single point centrally located on the site. Guidance on combining emission points is provided in EPA-450/477-001, "Guidelines for Air Quality Maintenance Planning and Analysis," Vol. 10, Revised: Procedures for Evaluating Air Quality Impact of New Stationary Sources."

\section{REQUIREMENT SOURCE: DOE5400.5 Chapter II, Section 6.b(3)(f)}

"The assumption of a single point of emission, as discussed in Il.6.b. (3)(e), may be used to calculate public dose for the maximally exposed individuals if the emission points are close to one another relative to the distance to the site boundary. Otherwise, the public dose to the 
maximally exposed individuals should be determined taking into consideration the actual locations of emissions on the site with respect to the offsite locations."

\section{REQUIREMENT SOURCE: DOE5400.5 Chapter II, Section 6.b, Paragraph 1}

"Dose Evaluations. Doses to members of the public in the vicinity of DOE activities shall be evaluated and documented to demonstrate compliance with the dose limits of this Order and to assess exposures of the public from unplanned events. Collective doses to the public within 80 $\mathrm{km}$ of the site shall also be evaluated and documented at least annually."

\section{REQUIREMENT SOURCE: DOE5400.5 Chapter IV, Section 4.a(1)}

"Hot Spots. If the average concentration in any surface or below-surface area less than or equal to $25 \mathrm{~m} 2$, exceeds the limit or guideline by a factor of $(100 / \mathrm{A})^{\wedge} 0.5$, [where $\mathrm{A}$ is the area (in square meters) of the region in which concentrations are elevated], limits for "hot-spots" shall also be developed and applied. Procedures for calculating these hot-spot limits, which depend on the extent of the elevated local concentrations, are given in DOE/CH-8901. In addition, reasonable efforts shall be made to remove any source of radionuclide that exceeds 30 times the appropriate limit for soil, irrespective of the average concentration in the soil."

\section{REQUIREMENT SOURCE: DOE5400.5 Chapter IV, Section 4.b}

"Airborne Radon Decay Products. Generic guidelines for concentrations of airborne radon decay products shall apply to existing occupied or habitable structures on private property that are intended for release without restriction; structures that will be demolished or buried are excluded. The applicable generic guideline (40 CFR Part 192) is: In any occupied or habitable building, the objective of remedial action shall be, and a reasonable effort shall be made to achieve, an annual average (or equivalent) radon decay product concentration (including background) not to exceed $0.02 \mathrm{WL}$. [A working level (WL) is any combination of short-lived radon decay products in $1 \mathrm{~L}$ of air that will result in the ultimate emission of $1.3 \mathrm{x}$ $105 \mathrm{MeV}$ of potential alpha energy.] In any case, the radon decay product concentration (including background) shall not exceed $0.03 \mathrm{WL}$. Remedial actions by DOE are not required in order to comply with this guideline when there is reasonable assurance that residual radioactive material is not the source of the radon concentration."

\section{REQUIREMENT SOURCE: DOE5400.5 Chapter IV, Section 4.c}

"External Gamma Radiation. The average level of gamma radiation inside a building or habitable structure on a site to be released without restrictions shall not exceed the background level by more than 20 micro $\mathrm{R} / \mathrm{h}$ and shall comply with the basic dose limit when an "appropriate-use" scenario is considered. This requirement shall not necessarily apply to structures scheduled for demolition or to buried foundations. External gamma radiation levels on open lands shall also comply with the basic limit and the ALARA process, considering appropriate-use scenarios for the area."

\section{REQUIREMENT SOURCE: IOES400.5 Chapter IV, Section 4.d}

"Surface Contamination. The generic surface contamination guidelines provided in Figure IV-1 are applicable to existing structures and equipment. These guidelines are generally consistent with standards of the NRC (NRC 1982) and functionally equivalent to Section 4, "Decontamination for Release for Unrestricted Use, " of Regulatory Guide 1.86, but apply to nonreactor facilities. These limits apply to both interior equipment and building components that are potentially salvageable or recoverable scrap. If a building is demolished, the guidelines in paragraph IV.6a are applicable to the resulting contamination in the ground." 


\section{REQUIREMIENT SOURCE: DOE5400.5 Chapter IV, Section 4.e}

"Residual Radionuclides in Air and Water. Residual concentrations of radionuclides in air and water shall be controlled to the required levels shown in paragraph II.1a and as required by other applicable Federal and/or State laws."

\section{REQUIREMENT SOURCE: WAC-246-247(940131) Section 040(3)}

"All new construction and significant modifications of emission units commenced after August 10, 1988 (the date this chapter originally became effective) shall utilize BARCT (see Appendix B)."

\section{REQUIREMENT SOURCE: WAC-246-247(940131) Section 040(4)}

"All existing emission units and nonsignificant modifications shall utilize ALARACT (see Appendix C)."

\section{REQUIREMENT SOURCE: WAC-246-247(940131) Section 040(0)}

"All emissions of radionuclides, including those due to emergency conditions resulting from startup, shutdown, maintenance activities, or process upsets are subject to the standards of this section and, therefore, subject to the enforcement actions of WAC 246-247-100."

\section{POLLUTION PREVENTION}

Element 20.5 includes requirements for Form $\mathrm{R}$ pollution prevention reporting; requirements for source reduction and recycling; requirements for waste minimization and material substitution; and requirements from the general Stormwater Permit. WAC 173-307 requirements for pollution prevention plans (except for facility specific training requirements) are voluntary and are complied with at the request of DOE-RL.

Tank Farms retains Part 1 of the state pollution prevention plan requirements in this subelement. Part 4 of the state pollution prevention plan, regarding employee training and employee involvement, is implemented through HGET. The Tank Farms also retains annual toxic chemical release reporting requirements; toxic chemical source reduction and recycling data reporting requirements; procurement requirements; and agency waste reduction goals.

Note: Requirements DOE 5820.2A Chapter III, Section 3.c(1), Section 3.c(3), and Section 3.c(4), as located in subelement 16.7 in the Waste Management Functional Area document, is also applicable to this subelement.

Note: Requirement DOE 5820.2A Chapter III, Section 3.c(2), as located in subelement 16.4.1 in the Waste Management Functional Area document, is also applicable to this subelement.

\section{REQUIREMENT SOURCE: 42USC13106 Section 6607}

"Source Reduction and Recycling Data Collection.

(a) Reporting Requirements.--Each owner or operator of a facility required to file an annual toxic chemical release form under section 313 of the Superfund Amendments and Reauthorization Act of 1986 ("SARA") for any toxic chemical shall include with each such annual filing a toxic chemical source reduction and recycling report for the preceding calendar year. The toxic chemical source reduction and recycling report shall cover each toxic chemical required to be reported in the annual toxic chemical release form filed by the owner or operator under section 313(c) of that Act. This section shall take effect with the annual 
report filed under section 313 for the first full calendar year beginning after the enactment of this subtitle.

(b) Items Included in Report.--The toxic chemical source reduction and recycling report required under subsection (a) shall set forth each of the following on a facility-by-facility basis for each toxic chemical:

(1) The quantity of the chemical entering any waste stream (or otherwise released into the environment) prior to recycling, treatment, or disposal during the calendar year for which the report is filed and the percentage change from the previous year. The quantity reported shall not include any amount reported under paragraph (7). When actual measurements of the quantity of a toxic chemical entering the waste streams are not readily available, reasonable estimates should be made on best engineering judgment.

(2) The amount of the chemical from the facility which is recycled (at the facility or elsewhere) during such calendar year, the percentage change from the previous year, and the process of recycling used.

(3) The source reduction practices used with respect to that chemical during such year at the facility. Such practices shall be reported in accordance with the following categories unless the Administrator finds other categories to be more appropriate.

(A) Equipment, technology, process, or procedure modifications.

(B) Reformulation or redesign of products.

(C) Substitution of raw materials.

(D) Improvement in management, training, inventory control, materials handling, or other general operational phases of industrial facilities.

(4) The amount expected to be reported under paragraph (1) and (2) for the two calendar years immediately following the calendar year for which the report is filed. Such amount shall be expressed as a percentage change from the amount reported in paragraphs (1) and (2).

(5) A ratio of production in the reporting year to production in the previous year. The ratio should be calculated to most closely reflect all activities involving the toxic chemical. In specific industrial classifications subject to this section, where a feedstock or some variable other than production is the primary influence on waste characteristics or volumes, the report may provide an index based on that primary variable for each toxic chemical. The Administrator is encouraged to develop production indexes to accommodate individual industries for use on a voluntary basis.

(6) The techniques which were used to identify source reduction opportunities. Techniques listed should include, but are not limited to, employee recommendations, external and internal audits, participative team management, and material balance audits. Each type of source reduction listed under paragraph (3) should be associated with the techniques or multiples of techniques used to identify the source reduction technique.

(7) The amount of any toxic chemical released into the environment which resulted from a catastrophic event, remedial action, or other one time event, and is not associated with production processes during the reporting year.

(8) The amount of the chemical from the facility which is treated (at the facility or elsewhere) during such calendar year and the percentage change from the previous year. For the first year of reporting under this subsection, comparison with the previous year is required only to the extent such information is available. 
(c) SARA Provisions.-- The provisions of sections 322, 325(c), and 326 of the Superfund Amendments and Reauthorization Act of 1986 shall apply to the reporting requirements of this section in the same manner as to the reports required under section 313 of that Act. The Administrator may modify the form required for purposes of reporting information under section 313 of that Act to the extent he deems necessary to include the additional information required under this section.

(d) Additional Optional Information.--Any person filing a report under this section for any year may include with the report additional information regarding source reduction, recycling, and other pollution control techniques in earlier years.

(e) Availability of Data.--Subject to section 322 of the Superfund Amendments and Reauthorization Act of 1986, the Administrator shall make data collected under this section publicly available in the same manner as the data collected under section 313 of the Superfund Amendments and Reauthorization Act of 1986."

\section{REQUIREMENT SOURCE: WAC-173-307 Section 030 WAC Plans Part (1)}

"(a) A written policy articulating management and corporate support for the plan and a commitment to implement planned activities and achieve established goals.

(b) The plan scope and objectives.

(c) A description of the facility type, a description of product(s) made and/or services provided, and a statement or listing of the current level(s) of production or service activity in units of measure appropriate to the industry or activity;

(d) A general overview of the processes used in production or service activities (a schematic drawing may be included);

(e) A statement providing, for the last calendar year, the total pounds of extremely hazardous waste and total pounds of dangerous waste reported on Form 4, Generator Annual Dangerous Waste Report, and, if applicable, the total pounds of toxic releases reported on Form $\mathbf{R}$ under SARA Title III, Section 313; and

(f) A description of current reduction, recycling, and treatment activities and documentation of hazardous substance use reduction and hazardous waste reduction efforts completed prior to the first plan due date specified in WAC 173-307-050. Clearly separate the explanations of reduction activities from recycling and other management activities.

\section{REQUIREMENT SOURCE: WAC-173-307 Section 030 WAC Plans Part (2)}

"Part two shall include an identification of hazardous substances used and hazardous wastes generated by the facility, a description of the facility processes, an identification of reduction, recycling, and treatment opportunities, an evaluation of those opportunities, a selection of proposed options, a policy to prevent shifting of risks, performance goals, and an implementation schedule. Specifically, Part two shall include:

(a) An identification of products containing hazardous substances used and hazardous wastes generated. This is to be based on actual usage and generation during the most recent calendar year for which records are available. This task can be accomplished by choosing one of two approaches. The approaches are identified as the "pounds approach" and the "percentage approach." Look at the following descriptions and requirements of each of these and determine which one you wish to use. 
(i) "Pounds approach."

This approach requires you to identify the types and amounts, in either weight or volume, of hazardous waste generated and products containing hazardous substances used up to these threshold levels:

(A) All dangerous waste streams five hundred pounds or greater, any smaller dangerous waste streams which individually represents ten percent or more of the total annual hazardous wastes, and all extremely hazardous waste streams subject to regulation by the department. If this combination equals less than ninety percent of the total hazardous wastes generated, then additional dangerous wastes generated at the facility shall be included until ninety percent of the total is reached; and

(B) Each product used which contains a total of fifty percent or more of any combination of hazardous substances if one thousand pounds or more was used; each product used which contains a total of between twenty-five percent and forty-nine percent of hazardous substances if four thousand pounds or more was used; and each product used which contains a total of between ten and twenty-four percent of hazardous substances if ten thousand pounds or more was used. Any product which contains less than ten percent of any hazardous substances need not be included in the list regardless of the amount of the product used.

(C) Office products and products which are used at the facility for nonprocess routine janitorial or grounds maintenance related activities may be excluded from this list.

(D) Hazardous substances used and hazardous wastes generated in laboratory research need not be listed.

Note: See Part two, (k) of this subsection for discussion on this issue.

\section{(ii) "Percentage approach."}

This approach requires you to identify the types and amounts, in either weight or volume, of hazardous waste generated and products containing hazardous substances used up to these threshold levels;

(A) All extremely hazardous waste and enough additional dangerous waste to reach ninety percent of all the hazardous waste generated; and

(B) Ninety percent of all the products used which contain hazardous substances. This selection of products should attempt to include those that contain the highest concentrations of hazardous substances and the most toxic hazardous substances.

(C) Office products and products which are used at the facility for nonprocess routine janitorial or grounds maintenance related activities may be excluded from this list.

(D) Hazardous substances used and hazardous wastes generated in laboratory research need not be listed.

Note: See Part two, (k) of this subsection for discussion on this issue.

(iii) Determinations of whether these quantities are met or exceeded for either approach shall be based on the best available information. This information may be included or referenced in the plan. Available information may include any or all of the following as necessary to determine quantities of hazardous substances contained in products; information available from material safety data sheets, information furnished upon request from manufacturers or 
suppliers of hazardous substances or products containing hazardous substances, information obtained from the department, and information otherwise known by the facility owner or operator.

An explanation of the procedures used to determine that the thresholds were met or exceeded must be included in this section of the plan.

(iv) The above thresholds shall only be used for plans required to be completed prior to September 2, 1996. Plans or plan updates completed from that date on must identify the types and amounts, in either weight or volume, of hazardous waste generated and hazardous substances used up to the following threshold levels;

(A) The "pounds approach" can only be used for identifying hazardous waste after September 2 , 1996. This approach cannot be used for products containing hazardous substances. The thresholds for hazardous waste are:

All dangerous waste streams five hundred pounds or greater, any smaller dangerous waste streams which individually represents ten percent or more of the total annual hazardous wastes, and all extremely hazardous waste streams subject to regulation by the department. If this combination equals less than ninety-five percent of the total hazardous wastes generated, then additional dangerous wastes generated at the facility shall be included until ninety-five percent of the total is reached.

(B) The "percentage approach" remains an optional approach for hazardous waste, but it is the only approach that can be used for products. The thresholds for this approach are:

All extremely hazardous waste and enough additional dangerous waste to reach ninety-five percent of all the hazardous waste generated; and Ninety-five percent of all the products used which contain hazardous substances.

(C) The exemptions in subitems (C) and (D) of item (ii) of this subdivision remain in effect.

(b) A detailed description of each process in the facility that generates hazardous waste or uses products containing hazardous substances as identified in the chosen approach in (a) of this subsection. This description may include a schematic drawing.

(c) For the hazardous waste and products containing hazardous substances identified in (a) of this subsection within each of the processes identified in (b) of this subsection, an identification, based on thorough research, of all reasonable opportunities for further hazardous substance use reduction, hazardous waste reduction, recycling, and treatment. Thorough research shall include, at a minimum, a review of literature commonly available to that industry or trade. The full range of potentially feasible opportunities is to be identified without regard to possible impediments to implementing the opportunities. In identifying opportunities, consideration shall be given to alternative approaches which, in the judgment of the facility management, satisfy the same demand for end products or services but use substantially less hazardous substances or result in the generation of substantially less hazardous waste;

(d) An evaluation of the identified opportunities. Opportunities shall be grouped by priority and evaluated according to these priorities. The priorities are, in descending order: Hazardous substance use and hazardous waste reduction; recycling; and, treatment. Opportunities of a lower priority shall be given consideration only after a determination is nade that the higher priority opportunities are inappropriate due to impediments to their implementation. Impediments that shall be considered acceptable include, but are not limited to: Adverse impacts on product quality, legal or contractual obligations, economic and 
technical practicality, safety considerations, and the creation of substantial new risks to human health or the environment.

Except with respect to the use and distribution of fertilizers or pesticides intended for commercial agricultural applications, the evaluation of hazardous waste reduction opportunities must include an evaluation of hazardous substance use reduction opportunities for those hazardous substances which subsequently result in hazardous waste streams as well as an evaluation of other opportunities for the reduction of hazardous waste.

The evaluation required under this subsection shall include an economic analysis, a technical evaluation, an identification of whether, and if so how, the identified opportunity would result in a shifting of risk(s) from one part of a process, environmental medium, or product to another and an identification of all impediments to implementing the opportunities. The economic analysis shall seek to identify the total costs associated with the current hazardous substance use and hazardous waste generation, management and disposal, compared with comparable costs associated with implementing the alternatives.

Evaluation of each opportunity may be considered complete when enough information is available to select or reject the opportunity for implementation. For opportunities rejected, the reason(s) for rejecting them shall be stated.

(e) A selection of opportunities to be implemented in accordance with the evaluation conducted in (d) of this subsection. For each selected opportunity, the process(es) it affects shall be identified, and estimates of the amount, by weight, of the reduction of hazardous substances or products containing hazardous substances and hazardous waste reduction which would be achieved through implementation shall be stated, as well as the amount of hazardous wastes recycled or treated as a result of implementation shall be included;

(f) A written policy stating that in implementing the selected options whenever technically and economically practicable, risks will not be shifted from one part of a process, environmental medium, or product to another;

(g) Specific performance goals in each of the following categories, expressed in numeric terms:

(i) Hazardous substances or products containing hazardous substances to be reduced or eliminated from use;

(ii) Hazardous wastes to be reduced or eliminated through hazardous waste reduction techniques;

(iii) Materials or hazardous wastes to be recycled; and

(iv) Hazardous wastes to be treated.

If the establishment of numeric performance goals is not practicable, the performance goals shall include a clearly stated list of objectives designed to lead to the establishment of numeric goals as soon as is practicable. Goals shall be set for a five-year period from the first reporting date (see (h) of this subsection regarding implementation activities that will take longer than five years);

(h) A five-year implementation schedule, which shall display planned implementation activities for each of the five calendar years following completion of the plan. Information to be provided shall include, but is not limited to, the opportunities (or phases of opportunities) being implemented and related milestones. Where complete implementation of a selected 
opportunity will take longer than five years, the schedule shall contain relevant milestones within a five-year period and an estimated date of completion. The schedule may be in table form and organized by opportunities within processes, if desired.

(i) A description of how those hazardous wastes that are not recycled or treated and the residues from recycling and treatment processes are managed may be included in the plan.

(j) Documentation of any research conducted in fulfilment of any of the above subdivisions of this subsection shall be available to the department upon request.

(k) For research laboratories, the plan may include, in lieu of all the detailed requirements of this subsection, a description of policies and procedures to be followed by laboratory personnel regarding the use of hazardous substances and the generation of hazardous wastes through laboratory research. These policies and procedures must be consistent with the waste reduction priorities as defined in this chapter."

\section{REQUIREMENT SOURCE: WAC-173-307 Section 030 WAC Plans Part (3)}

"Part three. Part three shall provide a financial description of the plan, which shall identify costs and benefits realized from implementing selected opportunities to the extent reasonably possible. Part three shall also include a description of accounting systems which will be used to identify hazardous substance use and hazardous waste management costs. Liability, compliance, and oversight costs must be components of these accounting systems."

\section{REQUIREMENT SOURCE: WAC-173-307 Section 030 WAC Plans Part (4)}

"Part four. Part four of the plan shall include a description of personnel training and employee involvement programs. Each facility require to write a plan is encouraged to advise its employees of the planning process and solicit comments or suggestions from its employees on hazardous substance use and waste reduction opportunities."

\section{REQUIREMENT SOURCE: WAC-173-307 Section 030 WAC Plans, Paragraph 1}

"Plan requirements. This section establishes the specific elements required to be included in a plan. The purpose of a plan is to require serious consideration of ways in which processes and procedures may be modified to reduce dependence upon hazardous substances and/or the generation of hazardous wastes. All plans must consider opportunities based on the following priorities: Hazardous substance use reduction and hazardous waste reduction, recycling, and treatment. The plans shall consist of the following parts $\langle(1)-(4)\rangle$ :"

\section{RECORDKEEPING, REPORTS AND NOTIFICATIONS}

Subelement 20.6.1 addresses immediate notification requirements and release reporting. Tank Farms defers discharge reporting requirements from the site-wide stormwater permit to the Company-level EP Functional Area Document.

\section{REQUIREMENT SOURCE: WAC-173-303(931208) Section 355(1)}

"Owners or operators shall coordinate preparedness and prevention planning and contingency planning efforts, conducted under WAC 173-303-340 and 173-303-350, with local emergency planning committees established pursuant to Title III of the 1986 Superfund Amendments and Reauthorization Act." 
Subelement 20.6.1 addresses immediate notification requirements and release reporting. Tank Farms defers discharge reporting requirements from the site-wide stormwater permit to the Company-level EP Functional Area Document.

\section{REQUIREMENT SOURCE: 40CFR355 Part 30(b)}

"Emergency planning notification. The owner or operator of a facility subject to this section shall provide notification to the Commission that it is a facility subject to emergency planning requirements of this Part. Such notification shall be provided: on or before May 17, 1987 or within sixty days after a facility first becomes subject to the requirements of this section, whichever is later.

\section{REQUIREMENT SOURCE: 40CFR355 Part 30(c)}

"Facility emergency coordinator. The owner or operator of a facility subject to this section shall designate a facility representative who will participate in the local emergency planning process as a facility emergency response coordinator. The owner or operator shall notify the local emergency planning committee of the facility representative on or before September 17, 1987 or 30 days after establishment of a local emergency planning committee, whichever is earlier.

\section{REQUIREMENT SOURCE: 40CFR355 Part 30(d)(1)}

"Provision of information.

(1) The owner or operator of a facility subject to this section shall inform the local emergency planning committee of any changes occurring at the facility which may be relevant to emergency planning."

\section{REQUIREMENT SOURCE: 40CFR355 Part 30(d)(2)}

"Upon request of the local emergency planning committee, the owner or operator of a facility subject to this section shall promptly provide to the committee any information necessary for development or implementation of the local emergency plan."

\section{REQUIREMENT SOURCE: 40CFR355 Part 40(b)(1)}

"Notice Requirements. The owner or operator of a facility subject to this section shall immediately notify the community emergency coordinator for the local emergency planning committee of any area likely to be affected by the release and the State emergency response commission of any State likely to be affected by the release. If there is no local emergency planning committee, notification shall be provided under this section to relevant local emergency response personnel."

\section{REQUIREMENT SOURCE: 40CFR355 Part 40(b)(2)}

"Emergency release notification. Notice requirements. The notice required under this section shall include the following to the extent known at the time of notice and so long as no delay in notice or emergency response results:

(i) The chemical name or identity of any substance involved in the release.

(ii) An indication of whether the substance is an extremely hazardous substance. 
(iii) An estimate of the quantity of any such substance that was released into the environment.

(iv) The time and duration of the release.

(v) The medium or media into which the release occurred.

(vi) Any known or anticipated acute or chronic health risks associated with the emergency and, where appropriate, advice regarding medical attention necessary for exposed individuals.

(vii) Proper precautions to take as a result of the release, including evacuation (unless such information is readily available to the community emergency coordination pursuant to the emergency plan).

(viii) The names and telephone number of the person or persons to be contacted for further information."

\section{REQUIREMENT SOURCE: 40CFR355 Part 40(b)(3)}

"As soon as practicable after a release which requires notice under (b)(1) of this section, such owner or operator shall provide a written follow-up emergency notice setting forth and updating the information required under paragraph (b)(2) of this section, and including additional information with respect to:

(i) Actions taken to respond to and contain the release,

(ii) Any known or anticipated acute or chronic health risks associated with the release, and,

(iii) Where appropriate, advice regarding medical attention necessary for exposed individuals."

\section{REQUIREMINT SOURCE: WAC-173-303(940523) Section 145(1)}

"Purpose and applicability. This section sets forth the requirements for any person responsible for a spill or discharge of a dangerous waste or hazardous substance into the environment, except when such release is otherwise permitted under state or federal law. For the purposes of complying with this section, a transporter who spills or discharges dangerous waste or hazardous substances during transportation will be considered the responsible person. This section shall apply when any dangerous waste or hazardous substance is intentionally or accidentally spilled or discharged into the environment (unless otherwise permitted) such that human health or the environment is threatened, regardless of the quantity of dangerous waste or hazardous substance."

\section{REQUIREMENT SOURCE: WAC-173-303(940523) Section 145(2)}

"Notification. Any person who is responsible for a spill or nonpermitted discharge shall immediately notify the individuals and authorities described for the following situations:

(a) For spills or discharges onto the ground or into groundwater or surface water, notify all local authorities in accordance with the local emergency plan. If necessary, check with the local emergency service coordinator and the fire department to determine all notification responsibilities under the local emergency plan. Also, notify the appropriate regional office of the department of ecology;

(b) For spills or discharges which result in emissions to the air, notify all local authorities in accordance with the local emergency plan. If necessary, check with the local emergency service coordinator and the fire department to determine all notification responsibilities under the local emergency plan. Also, in western Washington notify the local air pollution control 
authority, or in eastern Washington notify the appropriate regional office of the department of ecology."

\section{REQUIREMINT SOURCE: WAC-173-303(940523) Section 145(3)}

"Mitigation and control. The person responsible for a spill or nonpermitted discharge shall take appropriate immediate action to protect human health and the environment (e.g., diking to prevent contamination of state waters, shutting of open valves).

(a) In addition, the person responsible for a spill or discharge shall:

(i) Clean up all released dangerous wastes or hazardous substances, or take such actions as may be required or approved by federal, state, or local officials acting within the scope of their official responsibilities. This may include complete or partial removal of released dangerous wastes or hazardous substances as may be justified by the nature of the released dangerous wastes or hazardous substances, the human and environmental circumstances of the incident, and protection required by the Water Pollution Control Act, chapter $90.48 \mathrm{RCW}$;

(ii) Designate and treat, store or dispose of all soils, waters, or other materials contaminated by the spill or discharge in accordance with this chapter 173-303 WAC. The department may require testing in order to determine the amount or extent of contaminated materials, and the appropriate designation, treatment, storage, or disposal for any materials resulting from clean-up; and

(iii) If the property on which the spill or discharge occurred is not owned or controlled by the person responsible for the incident, restore the area impacted by the spill or discharge, and replenish resources (e.g., fish, plants) in a manner acceptable to the department.

(b) Where immediate removal or temporary storage of spilled or discharged dangerous wastes or hazardous substances is necessary to protect human health or the environment, the department may direct that removal be accomplished without a manifest, by transporters who do not have EPA/state identification numbers."

\section{REQUIREMENT SOURCE: WAC-173-303(940523) Section 145(4)}

"Nothing in WAC 173-303-145 shall eliminate any obligations to comply with reporting requirements which may exist in a permit or under other state or federal regulations."

\section{REQUIREMENT SOURCE: WAC-173-340 Section 300(2)}

\footnotetext{
"Release report. Any owner or operator who has information that a hazardous substance has been released to the environment at the owner or operator's facility and may be a threat to human health or the environment shall report such information to the department by June 1 , 1990 , or for discovery of releases after this date, within ninety days of discovery. Releases from underground storage tanks as described in the rules adopted under chapter $90.76 \mathrm{RCW}$ must be reported within twenty-four hours of release confirmation, in accordance with WAC 173-340-450. The extent known, the report shall include: The identification and location of the hazardous substance, circumstances of the release and the discovery, and any remedial actions planned, completed, or underway. All other persons are encouraged to report such information to the department."
} 


\section{REQUIREMENT SOURCE: WAC-246-247(940131) Section 080( 1)}

"The department reserves the right to inspect and audit all construction activities, equipment, operations, documents, data, and other records related to compliance with the requirements of this chapter. The department may require a demonstration of ALARACT at any time."

\section{REQUIREMENT SOURCE: WAC-246-247(940131) Section 080( 4)}

"Any report or application that contains proprietary or procurement-sensitive information shall be submitted to the department with those portions so designated. The department shall hold this information confidential, unless required to release the information pursuant to laws, regulations, or court order."

\section{REQUIREMENT SOURCE: WAC-246-247(940131) Section 080( 5)}

"The facility shall notify the department within twenty-four hours of any shutdown, or of any transient abnormal condition lasting more than four hours or other change in facility operations which, if allowed to persist, would result in emissions of radioactive material in excess of applicable standards or license requirements. If requested by the department, the facility shall submit a written report within ten days including known causes, corrective actions taken, and any preventive measures taken or planned to minimize or eliminate the chance of recurrence."

\section{REQUIREMINT SOURCE: WAC-246-247(940131) Section 080( 6)}

"The facility shall file a report of closure with the department whenever operations producing emissions of radioactive material are permanently ceased at any emission chapter. The closure report shall indicate whether, despite cessation of operations, there is still a potential for radioactive air emissions and a need for an active or passive ventilation system with emission control and/or monitoring devices. If decommissioning is planned and will constitute a modification, a NOC is required, as applicable, in accordance with WAC 246-247-060."

\section{REQUIREMENT SOURCE: WAC-246-247(940131) Section 080( 7)}

"The facility shall maintain a log for each emission unit that has received categorical approval under WAC 246-247-060(8). The log shall contain records of important operations parameters including the date, location, and duration of the release, measured or calculated radionuclide concentrations, the type of emissions (liquid, gaseous, solid) and the type of emission control and monitoring equipment."

\section{REQUIREMENT SOURCE: WAC-246-247(940131) Section 080( 9)}

"The facility shall ensure all emission units are fully accessible to department inspectors. In the event the hazard associated with accessibility to a unit require training and/or restrictions or requirements for entry, the facility owner and operator shall inform the department, prior to arrival, to those restrictions or requirements. The owner or operator shall be responsible for providing the necessary training escorts, and support services to allow the department to inspect the facility."

\section{REQUIREMINT SOURCE: WAC-246-247(940131) Section 080(11)}

"The facility shall respond in writing in a timely manner, or within a time limit set by the department. The inspection results which require the facility to implement corrective actions or any other actions so directed by the department." 


\section{Reporting Requirements}

Appropriate requirements for subelement 20.6.2 include those for groundwater reports, annual reporting, independent interim action reports, coordination with local emergency planning committees, and progress reports. Each of these reporting categories is applicable to Tank Farms, however, the requirements are implemented at the Site level. Source documents for these requirements include $40 \mathrm{CFR} 122$, DOE/EH0173T, DOE 5400.1, WAC 173-303, WAC 173-340, WAC 246-247, and the site-wide general stormwater permit.

\section{Underground Storage Tanks}

Subelement 20.6.3 includes requirements associated with reporting and notification of releases from underground diesel storage tanks (USTs). Status reports and investigations per WAC 173-340 and release reporting per WAC 173-360 will be applicable to any new USTs at Tank Farms.

Tank Farms retains requirements for initial response actions, interim actions, and reporting due to releases from USTs. Tank Farms defers requirements for follow-up action to the TWRS Emergency Management Functional Area Document.

\section{REQUIREMENT SOURCE: WAC-173-303 Section 360(1)}

"Emergency coordinator. At all times, there must be at least one employee either on the facility premises or on call with the responsibility for coordinating all emergency response measures. This emergency coordinator must be thoroughly familiar with all aspects of the facility's contingency plan, required by WAC 173-303-350(2), all operations and activities at the facility, the location and properties of all wastes handled, the location of all records within the facility, and the facility layout. In addition, this person must have the authority to commit the resources needed to carry out the contingency plan."

\section{REQUIREMENT SOURCE: WAC-173-303 Section 360(2)}

"Emergency procedures. The following procedures shall be implemented in the event of an emergency.

(a) Whenever there is an imminent or actual emergency situation, the emergency coordinator (or his designee when the emergency coordinator is on call) must immediately:

(i) Activate internal facility alarms or communication systems, where applicable, to notify all facility personnel; and

(ii) Notify appropriate state or local agencies with designated response roles if their help is needed.

(b) Whenever there is a release, fire, or explosion, the emergency coordinator must immediately identify the character, exact source, amount, and areal extent of any released materials.

(c) Concurrently, the emergency coordinator shall assess possible hazards to human health and the environment (considering direct, indirect, immediate, and long-term effects) that may result from the release, fire, or explosion.

(d) If the emergency coordinator determines that the facility has had a release, fire, or explosion which could threaten human health or the environment, he must report his findings as follows: 
(i) If his assessment indicates that evacuation of local areas may be advisable, he must immediately notify appropriate local authorities. He must be available to help appropriate officials decide whether local areas should be evacuated; and

(ii) He must immediately notify the department and either the government official designated as the on-scene coordinator, or the National Response Center (using their 24-hour toll free number (800) 424-8802).

(e) His assessment report must include:

(i) Name and telephone number of reporter;

(ii) Name and address of facility;

(iii) Time and type of incident (e.g., release, fire);

(iv) Name and quantity of material(s) involved, to the extent known;

(v) The extent of injuries, if any; and

(vi) The possible hazards to human health or the environment outside the facility.

(f) During an emergency, the emergency coordinator must take all reasonable measures necessary to ensure that fires, explosions, and releases do not occur, recur, or spread to other dangerous waste at the facility. These measures must include, where applicable, stopping processes and operations, collecting and containing released waste, and removing or isolating containers.

(g) If the facility stops operations in response to a fire, explosion, or release, the emergency coordinator must monitor for leaks, pressure buildup, gas generation, or ruptures in valves, pipes, or other equipment, wherever this is appropriate.

(h) Immediately after an emergency, the emergency coordinator must provide for treating, storing, or disposing of recovered waste, contaminated soil or surface water, or any other material that results from a release, fire, or explosion at the facility.

(i) The emergency coordinator must ensure that, in the affected area(s) of the facility:

(i) No waste that may be incompatible with the released material is treated, stored, or disposed of until cleanup procedures are completed; and

(ii) All emergency equipment listed in the contingency plan is cleaned and fit for its intended use before operations are resumed.

(j) The owner or operator must notify the department, and appropriate local authorities, that the facility is in compliance with (i) of this subsection before operations are resumed in the affected area(s) of the facility.

(k) The owner or operator must note in the operating record the time, date, and details of any incident that requires implementing the contingency plan. Within fifteen days after the incident, he must submit a written report on the incident to the department. The report must include:

(i) Name, address, and telephone number of the owner or operator;

(ii) Name, address, and telephone number of the facility;

(iii) Date, time, and type of incident (e.g., fire, explosion);

(iv) Name and quantity of material(s) involved; 
(v) The extent of injuries, if any;

(vi) An assessment of actual or potential hazards to human health or the environment, where this is applicable;

(vii) Estimated quantity and disposition of recovered material that resulted from the incident;

(viii) Cause of incident; and

(ix) Description of corrective action taken to prevent reoccurrence of the incident."

\section{REQUIREMINT SOURCE: WAC-173-303 Section 360(2)(a)}

"Whenever there is an imminent or actual emergency situation, the emergency coordinator (or his designee when the emergency coordinator is on call) must immediately:

(i) Activate internal facility alarms or communication systems, where applicable, to notify all facility personnel; and

(ii) Notify appropriate state or local agencies with designated response roles if their help is needed."

\section{REQUIREMENT SOURCE: WAC-173-303 Section 360(2)(b)}

"Whenever there is a release, fire, or explosion, the emergency coordinator must immediately identify the character, exact source, amount, and areal extent of any released materials."

\section{REQUIREMENT SOURCE: WAC-173-303 Section 360(2)(c)}

"Concurrently, the emergency coordinator shall assess possible hazards to human health and the environment (considering direct, indirect, immediate, and long-term effects) that may result from the release, fire, or explosion."

\section{REQUIREMENT SOURCE: WAC-173-303 Section 360(2)(d)}

"If the emergency coordinator determines that the facility has had a release, fire, or explosion which could threaten human health or the environment, he must report his findings as follows:

(i) If his assessment indicates that evacuation of local areas may be advisable, he must immediately notify appropriate local authorities. He must be available to help appropriate officials decide whether local areas should be evacuated; and

(ii) He must immediately notify the department and either the government official designated as the on-scene coordinator, or the National Response Center (using their 24-hour toll free number (800) 424-8802)."

\section{REQUIREMENT SOURCE: WAC-173-303 Section 360(2)(e)}

"His assessment report must include:

(i) Name and telephone number of reporter;

(ii) Name and address of facility;

(iii) Time and type of incident (e.g., release, fire);

(iv) Name and quantity of material(s) involved, to the extent known; 
(v) The extent of injuries, if any; and

(vi) The possible hazards to human health or the environment outside the facility."

\section{REQUIREMENT SOURCE: WAC-173-303 Section 360(2)(f)}

"During an emergency, the emergency coordinator must take all reasonable measures necessary to ensure that fires, explosions, and releases do not occur, recur, or spread to other dangerous waste at the facility. These measures must include, where applicable, stopping processes and operations, collecting and containing released waste, and removing or isolating containers."

\section{REQUIREMENT SOURCE: WAC-173-303 Section 360(2)(g)}

"If the facility stops operations in response to a fire, explosion, or release, the emergency coordinator must monitor for leaks, pressure buildup, gas generation, or ruptures in valves, pipes, or other equipment, wherever this is appropriate."

\section{REQUTREMIENT SOURCE: WAC-173-303 Section 360(2)(h)}

"Immediately after an emergency, the emergency coordinator must provide for treating, storing, or disposing of recovered waste, contaminated soil or surface water, or any other material that results from a release, fire, or explosion at the facility."

\section{REQUIREMENT SOURCE: WAC-173-303 Section 360(2)(i)}

"The emergency coordinator must ensure that, in the affected area(s) of the facility:

(i) No waste that may be incompatible with the released material is treated, stored, or disposed of until cleanup procedures are completed; and

(ii) All emergency equipment listed in the contingency plan is cleaned and fit for its intended use before operations are resumed."

\section{REQUIREMENT SOURCE: WAC-173-303 Section 360(2)(j)}

"The owner or operator must notify the department, and appropriate local authorities, that the facility is in compliance with 360 (2) (i) of this subsection before operations are resumed in the affected area(s) of the facility."

\section{REQUIREMENT SOURCE: WAC-173-303 Section 360(2)(k)}

"The owner or operator must note in the operating record the time, date, and details of any incident that requires implementing the contingency plan. Within fifteen days after the incident, he must submit a written report on the incident to the department. The report must include:

(i) Name, address, and telephone number of the owner or operator;

(ii) Name, address, and telephone number of the facility;

(iii) Date, time, and type of incident (e.g., fire, explosion);

(iv) Name and quantity of material(s) involved; 
(v) The extent of injuries, if any;

(vi) An assessment of actual or potential hazards to human health or the environment, where this is applicable;

(vii) Estimated quantity and disposition of recovered material that resulted from the incident;

(viii) Cause of incident; and

(ix) Description of corrective action taken to prevent reoccurrence of the incident. "

\section{REQUIREMENT SOURCE: WAC-173-340 Section 450(1)}

"Purpose. The purpose of this section is to set forth the requirements for addressing releases which may pose a threat to human health or the environment from USTs defined under chapter 90.76 RCW and rules adopted therein, including heating oil USTs of greater than 1,100 gallons capacity.

(a) Releases from USTs exempted under chapter $90.76 \mathrm{RCW}$ and rules adopted therein are still subject to all other requirements of this chapter.

(b) Unless the department requires otherwise, UST owners and UST operators shall comply with the requirements in this section after confirmation of an UST release which may pose a threat to human health or the environment."

\section{REQUIREMINT SOURCE: WAC-173-340 Section 450(2)}

"Initial response. Within twenty-four hours of the UST release, the UST owner or the UST operator shall perform the following actions:

(a) Report the UST release to the department and other authorities with jurisdiction, in accordance with rules adopted under chapter $90.76 \mathrm{RCW}$ and any other applicable law;

(b) Remove as much of the hazardous substance from the UST as is possible and necessary to prevent further release to the environment;

(c) Eliminate or reduce any fire, explosion or vapor hazards in such a way as to minimize any release of hazardous substances to surface water and ground water; and

(d) Visually inspect any aboveground releases or exposed belowground releases and prevent the hazardous substance from spreading into surrounding soils, ground water and surface water."

\section{REQUIREMENT SOURCE: WAC-173-340 Section 450(3)}

"Interim actions.

(a) As soon as possible but no later than twenty days following confirmation of an UST release, the UST owner or the UST operator shall perform the following interim actions:

(i) Continue to monitor and mitigate any additional fire and safety hazards posed by vapors or free product which may have migrated from the UST into structures in the vicinity of the site, such as sewers or basements;

(ii) Reduce the threat to human health and the environment posed by contaminated soils that are excavated or discovered as a result of investigation or cleanup activities. Treatment, 
storage and disposal of soils must be carried out in compliance with all applicable federal, state and local requirements;

(iii) Test for hazardous substances in the environment where they are most likely to be present. Such testing shall be done in accordance with a sampling and analysis plan prepared under WAC 173-340-820. The sample types, sample locations, and measurement methods shall be based on the nature of the stored substance, type of subsurface soils, depth to ground water and other factors as appropriate for identifying the presence and source of the release. If contaminated soil is found in contact with the ground water or soil contamination appears to extend below the lowest soil sampling depth, then testing shall include the installation of ground water monitoring wells to test for the presence of possible ground water contamination. Information gathered for the site check or closure site assessment conducted pursuant to rules adopted under chapter $90.76 \mathrm{RCW}$, which sufficiently characterizes the releases at the site, may be substituted for the testing required under this paragraph;

(iv) The testing performed under (a)(iii) of this subsection shall include, at a minimum, the following:

(A) Benzene, toluene, ethylbenzene, xylene, lead, and total petroleum hydrocarbons where leaded gasoline may be present;

(B) Benzene, toluene, ethylbenzene, xylene and total petroleum hydrocarbons where unleaded gasoline may be present;

(C) Total petroleum hydrocarbons and other appropriate indicator hazardous substances where any petroleum product other than gasoline may be present;

(D) The hazardous substance stored and any likely decomposition by-products where a hazardous substance other than petroleum may be present; and

(E) Any other tests required by the department; and

(v) Investigate for the presence of free product.

(b) Free product removal. At sites where investigations indicate free product is present, the UST owner or the UST operator shall conduct, as soon as possible after discovery, an interim action to remove the free product while continuing, as necessary, any other actions required under this section. To accomplish this the UST owner or UST operator shall:

(i) Conduct free product removal to the maximum extent practicable and in a manner which minimizes the spread of hazardous substances, by using recovery and disposal techniques appropriate to the hydrogeologic conditions at the site. The objective of free product removal system must be, at a minimum, to stop the free product migration;

(ii) Properly treat, discharge, or dispose of recovery by-products in compliance with all applicable local, state, and federal regulations and permits; and

(iii) Handle all flammable products safely to prevent fires and explosions."

\section{REQUIREMENT SOURCE: WAC-173-340 Section 450(4)}

"Reporting requirements. The following reports are required to be submitted to the department: 
(a) Status report. Within twenty days after an UST release, the UST owner or UST operator shall submit a status report to the department. The status report shall identify if known, the types, amounts, and locations of hazardous substances released, how the release occurred, evidence confirming the release, actions taken under subsections (2) and (3) of this section, any planned remedial actions, and any results of work done up to the time of the report. This report may be provided verbally to the department.

(b) Site characterization reports. Within ninety days after release confirmation, unless directed to do otherwise by the department, the UST owner or UST operator shall submit a report to the department about the site and nature of the release. This report shall be submitted to the department in writing and may be combined with the twenty-day status report, if the information required is available at that time. The site characterization report shall include, at a minimum, the following information:

(i) The information required for the status report under (a) of this subsection;

(ii) A site conditions map indicating approximate boundaries of the property, all areas where hazardous substances are known or suspected to be located, and sampling locations. This map may consist of a sketch of the site at a scale sufficient to illustrate this information;

(iii) Available data regarding surrounding populations, surface and ground water quality, use and approximate location of wells potentially affected by the release, subsurface soil conditions, depth to ground water, direction of ground water flow, proximity to and potential for affecting surface water, locations of sewers and other potential conduits for vapor or free product migration, surrounding land use, and proximity to sensitive environments;

(iv) Results of tests for hazardous substances performed under subsection (3)(a)(iii) and (iv) of this section;

(v) Results of the free product investigation required under subsection (3)(a)(v) of this section;

(vi) Results of all completed site investigations, interim actions and cleanup actions and a description of any remaining investigations, cleanup actions and compliance monitoring which are planned or underway; and

(vii) Information on the free product removal efforts at sites where investigations indicate free product is present. This shall include, at a minimum, the following information:

(A) Name of the person responsible for implementing the free product removal measures;

(B) The estimated quantity, type, and thickness of free product observed or measured in wells, boreholes and excavations;

(C) The type of free product recovery system used;

(D) The location of any on-site or off-site discharge during the recovery operation;

(E) The type of treatment applied to, and the effluent quality expected from, any discharge;

(F) The steps taken and planned to obtain necessary permits for any discharge;

(G) Disposition of recovered free product; and

(viii) Any other information required by the department." 


\section{REQUIREMINT SOURCE: WAC-173-340 Section 450(7)}

"Unless directed to do otherwise by the department, cleanup actions performed by UST owners or UST operators shall comply with cleanup standards, WAC 173-340-700 through 173-340-750 and the requirements for the selection of cleanup actions, WAC 173-340-360."

\section{REQUIREMINT SOURCE: WAC-173-340 Section 450(8)}

"Independent cleanup actions. In addition to work performed under subsections (2) through (5), and (7) of this section, UST owners or UST operators performing independent cleanup actions shall:

(a) Notify the department of their intention to begin cleanup. This can be included with other reports under this section;

(b) Comply with any conditions imposed by the department to assure adequate protection of human health and the environment; and

(c) Within ninety days of completion of the cleanup action, submit the results of all investigations, interim and cleanup actions and compliance monitoring not previously submitted to the department."

\section{REQUIREMENT SOURCE: WAC-173-360 Section 200(1)}

"Notice of intent to install a new UST system. Except in the circumstances defined in subsection (5) of this section, any owner who intends to install a new UST system shall submit a notice of such intent to the department or delegated agency at least thirty days prior to installing the UST system. Such notice shall meet the following requirements:

(a) The notice of intent shall be provided on the appropriate Washington state form, which is available from the department;

(b) Each UST system to be installed which is regulated under this chapter shall be reported;

(c) Owners may provide notice for more than one UST system using a single form, but UST systems to be installed at separate sites shall be reported on separate forms; and

(d) The completed form shall include all of the information required on the form."

\section{REQUIREMENT SOURCE: WAC-173-360 Section 200(2)}

"Notification of new UST systems in use. Within thirty days of bringing any newly installed UST system regulated under this chapter into use, the owner shall submit notice of such UST system to the department. This notice shall meet the following requirements:

(a) The notice shall be provided on the appropriate Washington state underground storage tank notification form, which is available from the department;

(b) Each tank regulated under this chapter shall be reported;

(c) Owners may provide notice for more than one tank using a single notification form, but owners who own tanks located at more than one site shall file a separate notification form for each site; 
(d) Notification required under this section shall include all of the information required on the form for each tank for which notice must be given; and

(e) Notification for tanks installed after December 22, 1988, shall also certify compliance with the following requirements:

(i) Corrosion protection of steel tanks and piping under WAC 173-360-305 (1) and (2);

(ii) Financial responsibility under WAC 173-360-400 through 173-360-499; and

(iii) Release detection under WAC 173-360-335 and 173-360-340."

\section{REQUIREMINT SOURCE: WAC-173-360 Section 200(3)}

"Installation checklist. All owners and operators of new UST systems shall ensure that a licensed installation supervisor certifies that the methods used to install the tanks and piping comply with the requirements in WAC 173-360-305 (4). Such certification shall be accomplished by completing an installation checklist, which is available from the department, as specified in WAC 173-360-305 (5)."

\section{REQUIREMINT SOURCE: WAC-173-360 Section 200(4)}

"Notification of existing UST systems. Owners of any existing UST system regulated under this chapter which has not previously been reported to the department shall provide notification regarding such UST system immediately, following the requirements of subsection (2) (a) through (e) of this section.

Note: Owners and operators of UST systems that were in the ground on or after May 8, 1986, unless taken out of operation on or before January 1, 1974, were required to notify the department in accordance with the Hazardous and Solid Waste Amendments of 1984, Public Law 98-616, on a form published by Washington state unless notice was given pursuant to section 103(c) of CERCLA."

\section{REQUIREMENT SOURCE: WAC-173-360 Section 200(5)}

"Emergency replacement of UST systems.

(a) An exception to the thirty-day notice requirement for new installations in subsection (1) of this section is allowed when an UST system is being replaced on an emergency basis due to a release from the system being replaced. An emergency shall be regarded as a newly discovered release from an UST system which is:

(i) In operation at the time of the release;

(ii) Located at an operating facility; and

(iii) Necessary for the normal operation of the facility.

(b) Under the circumstances described in (a) of this subsection, the notice of intent to install an UST system may be provided after the installation of the new system but no more than seven days after the installation is completed. The information which must be included in the notice of intent form is the same as in subsection (1) of this section. A site assessment meeting the requirements of WAC 173-360-390 shall be completed prior to installing a tank in the excavation pit of a tank being replaced and prior to installing new piping in the piping trench of piping being replaced."

\section{REQUIREMINT SOURCE: WAC-173-360 Section 200(6)}

"Changes to UST systems. Any changes in the information initially reported in the notification form submitted under subsection (2), (4) or (5) of this section, including temporary closure of 
an UST system that was initially reported as being in use, shall be reported to the department or delegated agency by submitting a new notification form within thirty days after such changes occur."

\section{REQUIREMENT SOURCE: WAC-173-360 Section 200(7)}

"Beginning October 24, 1988, any person who sells a new tank which is intended to be used as an underground storage tank, or an existing UST system or property including an existing UST system which is intended to be used as an UST system, shall notify the purchaser of such tank or UST system of the owner's notification obligations under this section."

\section{REQUIREMENT SOURCE: WAC-173-360 Section 210(1)}

"(1) Reporting. Owners and operators shall submit the information specified in (a) through (e) of this subsection to the department or delegated agency:

(a) Notification for all UST systems (WAC 173-360-200), which includes certification of installation for new UST systems (WAC 173-360-305(5));

(b) Reports of all suspected releases (WAC 173-360-360), confirmed releases (WAC 173-360-372), and spills and overfills (WAC 173-360-375);

(c) Reports required for corrective action under chapter 173-340 WAC;

(d) A notification before permanent closure or change-in-service (WAC 173-360-385); and

(e) The appropriate forms certificates of compliance, and evidence of financial responsibility (WAC 173-360-446).

(f) Checklists required for tank service activities, site checks, and site assessments shall be submitted by tank services providers or persons registered to perform site checks and site assessments, as applicable."

\section{REQUIREMENT SOURCE: WAC-173-360 Section 210(2)}

"(2) Recordkeeping. Owners and operators shall maintain the following information:

(a) Documentation of operation of corrosion protection equipment (WAC 173-360-320);

(b) Documentation of UST system repairs (WAC 173-360-325(7));

(c) Recent compliance with release detection requirements (WAC 173-360-355);

(d) N/A

(e) Corrective action records in accordance with chapter 173-340 WAC;"

\section{REQUIREMENT SOURCE: WAC-173-360 Section 210(3)}

"(3) Availability and maintenance of records. Owners and operators shall keep the records required either:

(a) At the UST site and immediately available for inspection by the department or delegated agency; or

(b) At a readily available alternative site and be provided for inspection to the department or delegated agency upon request." 


\section{REQUIREMENT SOURCE: WAC-173-360 Section 355}

"Release Detection Recordkeeping

All UST owners and operators shall maintain records demonstrating compliance with all applicable requirements of WAC 173-360-330 through 173-360-355. These records shall include the following:

(1) All written performance claims pertaining to any release detection system used, and the manner in which these claims have been justified or tested by the equipment manufacturer or installer, shall be maintained for five years, or for another reasonable period of time determined by the department or delegated agency, from the date of installation;

(2) The results of any sampling, testing, or monitoring shall be maintained for at least five years, or for another reasonable period of time determined by the department or delegaterd agency, except that the results of tank tightness testing conducted in accordance with WAC $173-360-345(6)$ (d) shall be retained until the next test is conducted; and

(3) Written documentation of all calibration, maintenance, and repair of release detection equipment permanently located on-site shall be maintained for at least five years after the servicing work is completed, or for another reasonable time period determined by the department or delegated agency. Any schedules of required calibration and maintenance provided by the release detection equipment manufacturer shall be retained for five years from the date of installation."

\section{REQUIREMINT SOURCE: WAC-173-360 Section 360}

"Reporting of Suspected Releases

Owners and Operators of UST systems shall report to the department or delegated agency within twenty-four hours, or another reasonable time period specified by the department or delegated agency, and follow the procedures in WAC 173-360-370 when any of the following conditions apply:

(1) Owners and operators or others discover released regulated substances at the UST site or in the surrounding area (including but not limited to the presence of free product or its constituents in soils, basements, sewer and utility lines, ground water, and/or surface water).

(2) Unusual operating conditions are observed by owners or operators (such as the erratic behavior of product dispensing equipment, the sudden loss of a regulated substance from the UST system, or an unexplained presence of water in the tank), unless system equipment is found to be defective but not leaking, and is immediately repaired or replaced; or

(3) Monitoring results from a release detection method required under WAC 173-360-355 and 173-360-340 indicate that a release may have occurred unless:

(b) The monitoring device is found to be defective, and is immediately repaired, recalibrated or replaced, and additional monitoring does not confirm the initial result; or

(c) In the case of inventory control, a second month of data does not confirm the initial result, except that owners and operators shall immediately investigate all larger-than-normal or reoccurring variations in inventory control results, and report such variations if they are unaccounted for, without waiting to obtain a second month of data." 


\section{REQUIREMENT SOURCE: WAC-173-360 Section 370(1)}

"System test. Owners and operators shall have a licensed tank services provider conduct tests (according to the requirements for tightness testing in WAC 173-360-345 (6)(d) and $173-360-350(3)(b))$ that determine whether a leak exists in any portions of the UST system that routinely contains a regulated substance, including the tank and the attached delivery piping, and in any connected tanks and piping that may or may not be in use. All such portions shall be tested either separately or together or in combinations thereof.

(a) Owners and operators shall have a licensed tank services provider repair, replace, upgrade, or close the UST system, and shall begin corrective action in accordance with WAC 173-360-399 if the test results for the system, tank, or delivery piping indicate that a leak exists.

(b) Further investigation is not required if the test results for the system, tank, and delivery piping do not indicate that a leak exists and if environmental contamination is not the basis for suspecting a release.

(c) Owners and operators shall conduct a site check in accordance with subsection (2) of this section if the test results for the system, tank, and delivery piping do not indicate that a leak exists but environmental contamination is the basis for suspecting a release."

\section{REQUIREMENT SOURCE: WAC-173-360 Section 370(2)}

"Site check. Owners and operators shall have a person registered by the department to perform site assessments, as specified in WAC 173-360-610, sample for the presence of a release. Such samples shall be taken, analyzed, and results reported to the department or delegated agency in accordance with the department's guidance document for site checks and site assessments, or as otherwise directed by the department or delegated agency, where contamination is most likely to be present at the UST site.

(a) If the site check results indicate that a release has occurred, owners and operators shall report to the department or delegated agency in accordance with WAC 173-360-372 and begin corrective action in accordance with WAC 173-360-399.

(b) If the site check results do not indicate that a release has occurred, further investigation is not required."

\section{REQUIREMENT SOURCE: WAC-173-360 Section 370(3)}

"Tank services providers who perform any of the tank services described in this section, and persons who perform site checks, shall certify that such services or site checks, as applicable, comply with the requirements of this section by submitting the appropriate checklist(s) to the department in accordance with WAC 173-360-630 (12)."

\section{REQUIREMINT SOURCE: WAC-173-360 Section 372}

"Reporting of confirmed releases. Owners and operators shall report all confirmed releases, including but not limited to those confirmed in accordance with WAC 173-360-370 and 173-360-390, and those required to be reported under WAC 173-360-375, to the department or delegated agency within twenty-four hours.

Note: Other federal, state, and local laws also require reporting, and in some cases cleanup, of confirmed releases." 


\section{REQUIREMENT SOURCE: WAC-173-360 Section 375(1)}

"Owners and operators of UST systems shall immediately contain and clean up any spill or overfill of petroleum or hazardous substances in accordance with subsections (2) and (3) of this section. Spills and overfills shall also be reported as follows:

(a) Owners and operators shall immediately report any spill or overfill of petroleum and the results of any related cleanup to the department or delegated agency if the spill or overfill comes in contact with soil, ground water, or surface water. Spills or overfills of petroleum which are above a de minimis amount but do not come in contact with soil, ground water, or surface water shall be reported within twenty-four hours. A de minimis amount of petroleum is any amount that immediately evaporates or that is specified by the department or delegated agency through guidance documents. Spills or overfills of petroleum which do not exceed a de minimis amount and do not come in contact with soil, ground water, or surface water are not required to be reported.

(b) Owners and operators shall immediately report any spill or overfill of a hazardous substance and the results of any related cleanup to the department or delegated agency if the spill or overfill comes in contact with soil, ground water, or surface water. Spills or overfills of hazardous substances which are above a de minimis amount but which do not come in contact with soil, ground water, or surface water shall also be reported immediately. A de minimis amount of a hazardous substance is any amount that is below the specified reportable quantity under CERCLA. Spills or overfills of hazardous substances which do not exceed a de minimis amount and do not come in contact with soil, ground water, or surface water are not required to be reported.

Note: A release of a hazardous substance equal to or in excess of its reportable quantity under CERCLA (40 CFR 302) must also be reported immediately to the National Response Center under sections 102 and 103 of CERCLA (40 CFR 302.6) and to the appropriate state and local authorities under Title III of the Superfund Amendments and Reauthorization Act of 1986 (40 CFR 355.40)."

\section{REQUIREMIENT SOURCE: WAC-173-360 Section 375(2)}

"Containment and cleanup shall include the following actions:

(a) Visually inspect and take immediate action to prevent any further release and/or spreading of the regulated substance into the environment, including surrounding soils, ground water, and surface water;

(b) Eliminate or minimize any fire, explosion, and vapor hazards, and absorb or otherwise contain all free product and provide for proper disposal of such product and any used absorbent materials in accordance with all applicable federal, state, and local requirements. Free product shall not be flushed into storm drains, catch basins, dry wells, monitoring wells, or other locations with a possible connection to surrounding soils, ground water, or surface water; and

(c) Provide for proper disposal of, or treat, any contaminated soils in accordance with all applicable federal, state, and local requirements."

\section{REQUIREMENT SOURCE: WAC-173-360 Section 375(3)}

"Owners and operators shall take appropriate action in accordance with WAC 173-360-399 in the following cases: 
(a) A spill or overfill of petroleum that results in a release to the environment of less than twenty-five gallons or another reasonable amount specified by the department or delegated agency, if cleanup is not or cannot be accomplished within twenty-four hours or another reasonable time period established by the department or delegated agency;

(b) A spill or overfill of petroleum that results in a release to the environment that exceeds twenty-five gallons or another reasonable amount specified by the department or delegated agency;

(c) A spill or overfill of petroleum, regardless of amount, that results in ground water contamination or causes a sheen on ground water or surface water, including such water in dry wells;

(d) A spill or overfill of a bazardous substance that results in a release to the environment that is less than the reportable quantity under CERCLA, if cleanup is not or cannot be accomplished within twenty-four hours or another reasonable time period established by the department or delegated agency; and

(e) A spill or overfill of a hazardous substance that results in a release to the environment that equals or exceeds its reportable quantity under CERCLA (40 CFR 302)."

\section{REQUIREMENT SOURCE: WAC-173-360 Section 390(1)}

"Before permanent closure or a change-in-service is completed, except as specified in subsections (2), (3), and (4) of this section, owners and operators shall have a person registered by the department to perform site assessments, as specified in WAC 173-360-610, sample for the presence of a release. Such samples shall be taken, analyzed, and the results reported to the department or delegated agency in accordance with the department's guidance document for site assessments, or as otherwise directed by the department or delegated agency, where contamination is most likely to be present at the UST site."

\section{REQUIREMENT SOURCE: WAC-173-360 Section 390(4)}

"If contaminated soils, contaminated ground water, or free product is discovered under subsection (1) of this section, or by any other manner, owners and operators shall report to the department or delegated agency in accordance with WAC 173-360-372 and take appropriate action in accordance with WAC 173-360-399."

\section{REQUIREMINT SOURCE: WAC-173-360 Section 390(5)}

"Persons who perform site assessments shall certify that such site assessments comply with the requirements of this section by submitting the appropriate checklist to the department in accordance with WAC 173-360-630 (12)."

\section{Records Management}

Subelement 20.6.4 includes facility recordkeeping requirements. Groundwater monitoring records, pertinent to Tank Farms, are maintained by the site organization performing the monitoring.

Given that the SST and DST systems are not regulated units as defined in WAC 173-303-040, they are not subject to the ground water monitoring requirements of WAC 173-303-645. 


\section{REQUIREMENT SOURCE: 40CFR61 Part 14(a)}

"Monitoring Requirements. Unless otherwise specified, this section applies to each monitoring system required under each subpart which requires monitoring."

\section{REQUIREMIENT SOURCE: 40CFR61 Part 14(b)}

"Each owner or operator shall maintain and operate each monitoring system as specified in the applicable subpart and in a manner consistent with good air pollution control practice for minimizing emissions. Any unavoidable breakdown or malfunction of the monitoring system should be repaired or adjusted as soon as practicable after its occurrence. The Administrator's determination of whether acceptable operating and maintenance procedures are being used will be based on information which may include, but not be limited to, review of operating and maintenance procedures, manufacturer recommendations and specifications, and inspection of the monitoring system."

\section{REQUIREMENT SOURCE: 40CFR61 Part 14(c)}

"When required by the applicable subpart, and at any other time the Administrator may require, the owner or operator of a source being monitored shall conduct a performance evaluation of the monitoring system and furnish the Administrator with a copy of a written report of the results within 60 days of the evaluation. Such a performance evaluation shall be conducted according to the applicable specifications and procedures described in the applicable subpart. The owner or operator of the source shall furnish the Administrator with written notification of the date of the performance evaluation at least 30 days before the evaluation is to begin."

\section{REQUIREMENT SOURCE: 40CFR61 Part 14(d)}

"When the effluents from a single source, or from two or more sources subject to the same emission standards, are combined before being released to the atmosphere, the owner or operator shall install a monitoring system on each effluent or on the combined effluent. If two or more sources are not subject to the same emission standards, the owner or operator shall install a separate monitoring system on each effluent, unless otherwise specified. If the applicable standard is a mass emission standard and the effluent from one source is released to the atmosphere through more than one point, the owner or operator shall install a monitoring system at each emission point unless the installation of fewer systems is approved by the Administrator."

\section{REQUIREMENT SOURCE: 40CFR61 Part 14(e)}

"The owner or operator of each monitoring system shall reduce the monitoring data as specified in each applicable subpart. Monitoring data recorded during periods of unavoidable monitoring system breakdowns, repairs, calibration checks, and zero and span adjustments shall not be included in any data average."

\section{REQUIREMENT SOURCE: 40CFR61 Part 14(f)}

"The owner or operator shall maintain records of monitoring data, monitoring system calibration checks, and the occurrence and duration of any period during which the monitoring system is malfunctioning or inoperative. These records shall be maintained at the source for a minimum of 2 years and made available, upon request, for inspection by the Administrator." 


\section{REQUIREMENT SOURCE: 40CFR61 Part 14(g)(1)}

"Monitoring shall be conducted as set forth in this section and the applicable subpart unless the Administrator--

(i) Specifies or approves the use of the specified monitoring requirements and procedures with minor changes in methodology; or

(ii) Approves the use of alternatives to any monitoring requirements or procedures."

\section{REQUIREMENT SOURCE: 40CFR61 Part 92}

"Standard. Emissions of radionuclides to the ambient air from Department of Energy facilities shall not exceed those amounts that would cause any member of the public to receive in any year an effective dose equivalent of $10 \mathrm{mrem} / \mathrm{yr}$."

\section{REQUIREMINT SOURCE: 40CFR61 Part 94}

\section{"Compliance and Reporting}

(a) Compliance with this standard shall be determined by calculating the highest effective dose equivalent to any member of the public at any off-site point where there is a residence, school, business or office. The owners or operators of each facility shall submit an annual report to both EPA headquarters and the appropriate regional office by June 30 which includes the results of the monitoring as recorded in DOE's Effluent Information System and the dose calculations required by 61.93 (a) for the previous calendar year.

(b) Items 1 - 8 only In addition to the requirements of paragraph (a) of this section, an annual report shall include the following information:

(1) The name and location of the facility.

(2) A list of the radioactive materials used at the facility.

(3) A description of the handling and processing that the radioactive materials undergo at the facility.

(4) A list of the stacks or vents or other points where radioactive materials are released to the atmosphere.

(5) A description of the effluent controls that are used on each stack, vent, or other release point and an estimate of the efficiency of each control device.

(6) Distances from the points of release to the nearest residence, school, business or office and the nearest farms producing vegetables, milk, and meat.

(7) The values used for all other user-supplied input parameters for the computer models (e.g. meteorological data) and the source of these data.

(8) A brief description of all construction and modifications which were completed in the calendar year for which the report is prepared, but for which the requirement to apply for approval to construct or modify was waived under 61.96 and associated documentation developed by DOE to support the waiver. EPA reserves the right to require that DOE send to EPA all the information that normally would be required in an application to construct or modify, following receipt of the description and supporting documentation." 


\section{REQUIREMENT SOURCE: 40CFR61 Part 95}

"Recordkeeping Requirements

All facilities must maintain records documenting the source of input parameters including the results of all measurements upon which they are based, the calculations and/or analytical methods used to derive values for input parameters, and the procedure used to determine effective dose equivalent. This documentation should be sufficient to allow an independent auditor to verify the accuracy of the determination made concerning the facility's compliance with the standard. These records must be kept at the site of the facility for at least five years and, upon request, be made available for inspection by the Administrator, or his authorized representative."

\section{REQUIREMENT SOURCE: WAC-173-303(940523) Section 380(1)}

"Operating record. The owner or operator of a facility shall keep a written operating record at his facility. The following information shall be recorded, as it becomes available, and maintained in the operating record until closure of the facility:

(a) A description of and the quantity of each dangerous waste received or managed on-site, and the method(s) and date(s) of its treatment, storage, or disposal at the facility as required by subsection (2) of this section, recordkeeping instructions;

(b) The location of each dangerous waste within the facility and the quantity at each location. For disposal facilities, the location and quantity of each dangerous waste must be recorded on a map or diagram of each cell or disposal area. For all facilities, this information must include cross-references to specific manifest document numbers, if the waste was accompanied by a manifest;

(c) Records and results of waste analyses required by WAC 173-303-300, General waste analysis;

(d) Summary reports and details of all incidents that require implementing the contingency plan, as specified in WAC $173-303-360(2)(\mathrm{k})$;

(e) Records and results of inspections as required by WAC 173-303-320 (2)(d), General inspection (except such information need be kept only for five years);

(f) Monitoring, testing, or analytical data, and corrective action where required by $40 \mathrm{CFR}$ Part 265 Subparts F through R for interim status facilities, and by WAC 173-303-630 through 173-303-680 for final status facilities;

(g) All closure and post-closure cost estimates required for the facility; and

(h) For off-site facilities, copies of notices to generators informing them that the facility has all appropriate permits, as required by WAC 173-303-290, Required notices. "

\section{REQUIREMENT SOURCE: WAC-173-303(940523) Section 380(2) Introduction}

"Recordkeeping instructions. This paragraph provides instructions for recording the portions of the operating record which are related to describing the types, quantities, and management of dangerous wastes at the facility. This information shall be kept in the operating record, as follows:" 


\section{REQUIREMENT SOURCE: WAC-173-303(940523) Section 380(2)(a)}

"Each dangerous waste received or managed shall be described by its common name and by its dangerous waste number(s) from WAC 173-303-080 through 173-303-104. Where a dangerous waste contains more than one process waste or waste constituent the waste description must include all applicable dangerous waste numbers. If the dangerous waste number is not listed then the waste description shall include the process which generated the waste; ${ }^{n}$

\section{REQUIREMINT SOURCE: WAC-173-303(940523) Section 380(2)(b)}

"The waste description shall include the waste's physical form (i.e., liquid, solid, sludge, or gas);"

\section{REQUIREMENT SOURCE: WAC-173-303(940523) Section 380(2)(c)}

"The weight, or volume and density, of the dangerous waste shall be recorded, using one of the units of measure specified in Table $1, \ldots$ "

\section{REQUIREMENT SOURCE: WAC-173-303(940523) Section 380(2)(d)}

"And, the date(s) and method(s) of management for each dangerous waste received or managed (treated, recycled, stored, or disposed of) shall be recorded, using the handling code(s) specified in Table $2, \ldots$...

\section{REQUIREMENT SOURCE: WAC-173-303(940523) Section 380(3) and (3)(a)}

"(3) Availability, retention and disposition of records.

(a) All facility records, including plans, required by this chapter must be furnished upon request, and made available at all reasonable times for inspection, by any officer, employee, or representative of the department who is designated by the director."

\section{REQUIREMENT SOURCE: WAC-173-303(940523) Section 380(3)(b)}

"The retention period for all facility records required under this chapter is extended automatically during the course of any unresolved enforcement action regarding the facility or as requested by the director."

\section{REQUIREMENT SOURCE: WAC-173-303(940523) Section 380(3)(c)}

"A copy of records of waste disposal locations and quantities under this section must be submitted to the United States EPA regional administrator, the department, and the local land use and planning authority upon closure of the facility."

\section{REQUIREMENT SOURCE: WAC-173-360 Section 398}

"Closure records. Owners and operators shall maintain records that demonstrate compliance with closure requirements under WAC 173-360-380 through 173-360-398. The results of the site assessment required in WAC 173-360-390 shall be maintained for at least five years after completion of permanent closure or change-in-service in one of the following ways:

(1) By the owners and operators who took the UST system out of service;

(2) By the current owners and operators of the UST system site; or 
(3) By mailing these records to the department or delegated agency if they cannot be maintained at the closed facility."

\section{REQUIREMENT SOURCE: WAC-173-400 Section 105}

"(1) the owner or operator of a stationary source listed in a source category of WAC 173-400-100 shall upon notification by the director, maintain records on the type and quantity of emissions from the source and other information deemed necessary by the director to determine whether the source is in compliance with applicable emission limitations and control measures."

\section{REQUIREMINT SOURCE: WAC-246-247(940131) Section 080( 3)}

"The facility shall annually submit to the department the information requirements adopted in subsection (2) of the section, as applicable, along with the following additional information, as applicable:

(a) The results of emission measurements for those emission units subject only to periodic confirmatory measurements;

(b) Wind rose or joint frequency table;

(c) Annual average ambient temperature;

(d) Annual average emission unit gas temperature, if available;

(e) Annual total rainfall;

(f) Annual average emission unit flow rate and total volume of air released during the calendar year.

If this additional information is available in another annual report, the facility may instead provide a copy of that report along with the information requirements in this subsection. Annual reports are due by June 30 for the previous calendar years's operations."

\section{REQUIREMIENT SOURCE: WAC-246-247(940131) Section 080( 8)}

"The facility shall maintain readily retrievable storage areas for all records and documents related to, and which may help establish compliance with, the requirements of the chapter. The facility shall keep these records available for department inspection for at least five years."

\section{REQUIREMENT SOURCE: WAC-246-247(940131) Section 080(10)}

"The facility shall make available, in a timely manner, all documents requested by the department for review. The facility shall allow the department to review documents in advance of an inspection. The facility shall allow access to classified documents by representatives of the department with the appropriate security clearance and demonstrable need-to-know."

\section{KEY INTERFACES}

This element describes key functional area interfaces including Waste Management, Emergency Management, Occupational Safety and Health, Quality Assurance, and Radiation 
Protection. These interfaces represent areas where there is the potential for overlap of requirements, and the need for review of more than one functional area to appreciate the total program in any one functional area.

\section{Waste Management}

The EP Functional Area provides for the development and implementation of programs for protection of the environment. This program provides oversight to the Waste Management Functional Area which focuses more narrowly on the identification, characterization, and management of dangerous wastes.

Section 20.2.3 of the EP Functional Area addresses the purpose and applicability of dangerous waste facility interim status requirements [WAC 173-303-400(1)-(2)]. The standards for interim status facilities [WAC 173-303-400(3)] are addressed in the Waste Management Functional Area.

DOE 5820.2A requirements are addressed in the Waste Management Functional Area. The EP Functional Area interfaces with Waste Management to assure releases from waste management units are within limits [e.g., DOE 5820.2A Chapter III, Section 3.a(2)]; and to assure waste reduction and waste minimization goals are obtained to meet pollution prevention requirements [e. g., DOE 5820.2A Chapter III, Section 3.c(1)-(4)].

Reporting related to dangerous waste facility activities is addressed by the Waste Management Functional Area [e.g., WAC 173-303-390(1)-(3)]. The Waste Management Functional Area addresses reporting due to releases of dangerous wastes, fires, explosions, and interim status groundwater monitoring data; unmanifested waste reports; and annual reports. The EP Functional Area interfaces with Waste Management to assure these reports are prepared correctly and submitted in a timely manner.

\section{Emergency Management}

The Emergency Management Functional Area defines the emergency planning, preparedness, and response activities which are required by the various permits and plans included in the EP Functional Area. The Emergency Management Functional Area focuses on the preparation for and response to catastrophic off-normal events whereas the EP Functional Area address spills and Releases.

\section{Occupational Safety and Health}

The Occupational Safety and Health Functional Area focuses on the programs and procedures for protection of workers and the public. These programs interface routinely with the EP programs to provide protection to workers responding to incidents or routine operating processes which have the potential to threaten the environment.

\section{Quality Assurance}

The Quality Assurance Functional Area and its requirements apply to all items, activities, and processes managed by Hanford facilities. The Quality Assurance Functional Area is integrated into the EP programs through management, performance, and assessment. 
$\underline{20.7 .5}$

20.8

$\underline{20.8 .1}$

\section{Radiation Protection}

The Radiation Protection Functional Area provides the control standards with which the EP programs must comply to provide protection to human health and the environment.

\section{REFERENCES}

\section{Requirement Source Documents}

40 CFR 61, National Emission Standards for Hazardous Air Pollutants, U.S. Environmental Protection Agency, amendments as of 07/15/94

40 CFR 129, Toxic Pollutant Effluent Standards, U.S. Environmental Protection Agency, amendments as of $07 / 01 / 91$

40 CFR 355, Emergency Planning and Notification, U.S. Environmental Protection Agency, amendments as of $10 / 12 / 94$

42 USC 7671, Clean Air Act, United States Code, Title 42 Part 7671, 11/15/90

42 USC 13106, Pollution Prevention Act of 1990, United States Code, Title 42 Part 13106, $11 / 05 / 90$

DOE 5400.1, General Environmental Protection Program, DOE Order 5400.1, U.S.

Department of Energy, 11/09/88

DOE 5400.5, Radiation Protection of the Public and Environment, DOE Order 5400.5, U.S. Department of Energy, 02/08/90

DOE 5484.1, Environmental Protection, Safety, and Health Protection Information Reporting Requirements, DOE Order 5484.1, U.S. Department of Energy, 02/24/81

DOE 5820.2A, Radioactive Waste Management, DOE Order 5820.2A, U.S. Department of Energy, 09/26/88

DOE/EHO173T, Environmental Regulatory Guide for Radiological Effluent Monitoring and Environmental Surveillance, U.S. Department of Energy, 01/91

EO 12088, Federal Compliance with Pollution Control Standards, Executive Order, 10/13/78

EO 12843, Procurement Requirements and Policies for Federal Agencies for Ozone-Depleting Substances, Executive Order, 04/21/93

EO 12873, Federal Acquisition, Recycling, and Waste Prevention, Executive Order, 10/20/93

FF-01, Permit for Radioactive Airborne Emission Sources, FF-01, Washington State

Department of Health, 11/19/93

BCCAA-REG1, General Regulation 1, Benton County Clean Air Authority, effective 10/07/93

RCRA-B(DW), Dangerous Waste Portion of the RCRA Permit for the Treatment, Storage and Disposal of Hazardous Waste, WA7890008967, Washington State Department of Ecology, 09/28/94 
RCRA-B(DW), HSWA Portion of the RCRA Permit for the Treatment, Storage, and Disposal of Hazardous Waste, WA7890008967, U.S. Environmental Protection Agency, 09/28/94

TPA, Hanford Federal Facility Agreement and Consent Order (Tri-Party Agreement [TPA]), U.S. Department of Energy, U.S. Environmental Protection Agency, Washington State Department of Ecology, 03/01/94

WAC 173-200, Water Quality Standards for Ground Waters of the State of Washington, WAC 173 Chapter 200, Washington State Department of Ecology, amendments as of 12/01/90

WAC 173-216, State Waste Discharge Permit Program, WAC Title 173 Chapter 216, Washington State Department of Ecology, amendments as of 10/23/93

WAC 173-218, Underground Injection Control Program, WAC Title 173, Chapter 218, Washington State Department of Ecology, amendments as of 03/30/84

WAC 173-240, Submission of Plans and Reports for Construction of Wastewater Facilities, WAC Title 173 Chapter 240, Washington State Department of Ecology, amendments as of $03 / 30 / 84$

WAC 173-303, Dangerous Waste Regulations, WAC Title 173 Chapter 303, Washington State Department of Ecology, amendments as of 06/23/94

WAC 173-304, Minimum Functional Standards for Solid Waste Handling, WAC Title 173 Chapter 304, Washington Department of Ecology, 11/05/88

WAC 173-307, Plans, WAC Title 173 Chapter 307, Washington State Department of Ecology, amendments as of 11/01/91

WAC 173-340, Cleanup Process, WAC Title 173 Chapter 340, Washington State Department of Ecology, amendments as of $12 / 25 / 93$

WAC 173-360, Underground Storage Tank Regulations, WAC Title 173 Chapter 360, Washington State Department of Ecology, amendments as of 01/31/94

WAC 173-400, General Regulations for Air Pollution Sources, WAC Title 173 Chapter 400, Washington State Department of Ecology, amendments as of 09/15/94

WAC 173-401, Operating Permit Regulations, WAC Title 173 Chapter 401, Washington State Department of Ecology, amendments as of 05/17/94

WAC 173-460, Controls for New Sources of Toxic Air Pollutants, WAC Title 173 Chapter 460, Washington State Department of Ecology, amendments as of 02/14/94

WAC 246-247, Radioactive Air Emissions, WAC Title 246 Chapter 247, Washington State Department of Health, amendments as of 01/31/94

WAC 246-272, On-Site Sewage Systems, WAC Title 245 Chapter 272, Washington State Department of Health, 03/09/94

WAR-00-00F, Authorization to Discharge Under the NEPDES for Stormwater Discharge Associated with Industrial Activities, Permit No. WAR-00-000F, U.S. Environmental Protection Agency, 09/09/92 
High Level Waste Storage

WHC-SD-MP-SRID-001

Tank Farms/242-A Evaporator

January 10, 1996

Standards/Requirements Identification Document

Rev. 0

20.0 Environmental Protection

Page 110 of 110

$\underline{20.8 .2}$

Reviewed Documents Not Used as Requirement Sources

The following documents were reviewed as requirement sources but were not used in the development of this S/RID:

None. 